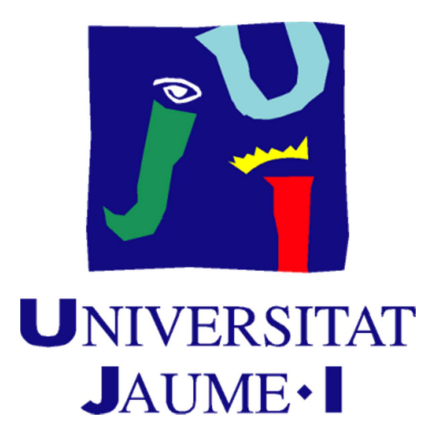

\title{
SÍNTESIS Y EVALUACIÓN BIOLÓGICA DE DERIVADOS DE COMBRETASTATINA Y DE AMINOCOMBRETASTATINA
}

\author{
UNIVERSITAT JAUME I \\ Escola Superior de Tecnologia i Ciències Experimentals \\ Departament de Química Inorgànica i Orgànica
}

Tesis Doctoral

Raül Agut Montoliu

Castellón de la Plana, 2017 

D. Juan Murga Clausell, Profesor Titular de Química Orgánica de la Universitat Jaume I, Jaume I y Da Eva Falomir Ventura, Profesora Titular de Química Orgánica de la Universitat Jaume I, hacen constar que:

D. Raül Agut Montoliu ha realizado bajo su dirección el trabajo que se recoge en esta memoria para optar al grado de Doctor.

Asimismo, autorizan la presentación del trabajo ante la Universitat Jaume I de Castelló para que se cumplan los trámites correspondientes.

Y para que así conste a los efectos legales presentamos dicha tesis y la firmamos en Castellón de la Plana en mayo de 2017.

Juan Murga Clausell

Eva Falomir Ventura 



\section{Agraïments}

La present Tesi Doctoral ha estat realitzada al Departament de Química Inorgànica i Orgànica de l'Escola Superior de Tecnologia i Ciències Experimentals de la Universitat Jaume I de Castelló de la Plana, sota la direcció del Dr. Juan Murga Clausell i de la Dra. Eva Falomir Ventura, als quals vull mostrar el meu agraïment per tota l'ajuda rebuda durant aquests anys i per haverme animat al principi a decidir-me a empendre aquest camí. Gràcies pels vostres consells i el vostre recolzament, no només en l'àmbit de la química, la biologia o la informàtica, sinó també en l'àmbit personal i esportiu.També vull manifestar la meua gratitut al Dr. Alberto Marco per la seua implicació i exigència en el treball $\mathrm{i}$ al Dr. Miguel Carda, per tota l'ajuda i els consells prestats, els ànims i l'interés en el treball ben fet, a més de les lliçons d'història o les experiències de ciclisme compartides a l'hora del café i per confiar en les meues previsions.

Vull fer extensiu el meu agraïment a la Generalitat Valenciana per la concesió de l'ajuda predoctoral VALi+d (ACIF/2013/099) que m'ha facilitat la realització d'aquest treball, al Ministeri d'Economia i Competitivitat pel projecte CTQ201452949-P, a la Generalitat Valenciana pel projecte PROMETEO/2013/027 i a la universitat Jaume I pel projecte PI-1B201575, gràcies als quals ha estat posible el finançament de tota la investigació duta a terme en aquesta Tesi Doctoral.

Gràcies a Cristian, Marc i José Miguel per tota l'ajuda prestada i la disposició mostrada en la caracterització dels productes a Serveis Centrals, així com a les tècniques de laboratori, Sílvia, Alicia i Imma, i als professors amb els quals he compartit docència, per l'ajuda a realizar de forma més profitosa i fàcil les tasques docents desenvolupades durant dos dels anys de la Tesi.

A tots els companys del grup. Als que em van acollir en un principi, César, Santi, Julián, Sandra, Conxín i Carme, moltes gràcies per resoldre tots els dubtes d'un principiant, aconseguir que poguera treballar autònomament i facilitar la 
meua integració al grup. Als que han compartit la major part del temps amb mi, Maria, Rosa, Steven, Pilar, Ana i Laura, moltes gràcies pels consells, els ànims i tots els moments d'alegria que hem viscut i han fet més agradable tota aquesta època. A les últimes incorporacions, Celia, Inés, Raquel i Alberto per entretindre'm i animar-me en el procés d'escritura i transmetre'm la vostra alegria i positivisme. A tots els estudiants de grau i màster que heu passat pel grup, en especial a Ana T. i Ana B. per la vostra ajuda i simpatia. A tots i totes, gràcies per fer més fàcil i entretingut el dia a dia.

Als companys de la planta 0 , per l'ajuda, els dinars compartits i les excursions realitzades.

També vull expressar l'agraïment als meus amics, alguns amb nocions per entendre el que he estat fent, altres amb no tantes, però que en tot cas heu sabut animar-me i escoltar-me quan ho he necessitat, heu sigut capaços de distraure el meu pensament en altres projectes i heu compartit el temps lliure amb mi.

Per suposat, he de donar les gràcies a la meua família, especialment als meus pares i el meu germà, per tots els ànims rebuts, per confiar amb mi i per haver suportat tot el mal humor durant els últims mesos.

A tots vosaltres, moltes gràcies. 


\section{Abreviaturas y acrónimos}

A-549 : células de adenocarcinoma de pulmón.

AcOEt : acetato de etilo.

$\mathrm{Ac}_{2} \mathrm{O}$ : anhídrido acético.

ADN : ácido desoxirribonucleico.

ADP : difosfato de adenosina.

AmCA-4 : aminocombretastatina.

$\mathrm{APCl}$ : ionización química a presión atmosférica.

app : señal con multiplicidad aparente.

ARN : ácido ribonucleico.

ATP : trifosfato de adenosina.

ATR : reflectancia total atenuada.

bFGF : factor de crecimiento de

fibroblastos básico.

br : banda o señal ancha.

$c$ : concentración.

CA-4 : combrestastatina A-4.

CrC : concentración crítica de tubulina.

CLSM : microscopio confocal láser de barrido.

d : doblete.

DCC : diciclohexilcarbodiimida.

dd : doble doblete.

$\mathrm{dq}$ : doble cuadruplete.

dqq : doble cuádruple cuadruplete.

$\mathrm{dt}$ : doble triplete.

DMAP : 4-N,N-dimetilaminopiridina.

DME : 1,2-dimetoxietano.

DMEM : Dulbecco's Modified Eagle Medium.

DMF : $N, N$-dimetilformamida.

DMSO : dimetilsulfóxido.

dNTP : desoxirribonucleótido trifosfato.

ECs : células endoteliales.

EDCI : 1-etil-3-(3-dimetilaminopropil)

carbodiimida.

EGF : factor de crecimiento epidérmico.

eq : equivalentes.

$\mathrm{Et}_{2} \mathrm{O}$ : dietiléter.

$\mathrm{Et}_{3} \mathrm{~N}$ : trietilamina.

$\mathrm{EtOH}$ : etanol.

FBS : suero fetal bovino.

FDA : food and drug administration.

FGF : factor de crecimiento de fibroblastos.

FITC : isocianato de fluoresceína.

Fmoc- $\mathrm{Cl}$ : cloruro de fluorenilmetoxicarbonilo.

GDP : bifosfato de guanosina .

GTP : trifosfato de guanosina .

HEK-293 : células embrionarias de riñón.

HIF-1 $\alpha$ : factor inducible de hipoxia.

HOBt : 1-hidroxibenzotriazol.
HR ESMS : espectroscopia de masas por electrospray de alta resolución.

hTERT : telomerasa transcriptasa inversa

humana.

hTR o TERC : componente ARN de la

telomerasa.

HT-29 : células de adenocarcinoma de colon.

$\mathrm{IC}_{50}$ : concentración de compuesto capaz de inhibir al 50\% la proliferación celular.

It 50 : tiempo necesario para alcanzar la mitad

de la polimerización de tubulina.

IR : infrarrojo.

IS : índice de selectividad.

$J$ : constante de acoplamiento.

$\mathrm{m}:$ multiplete.

MAP : proteínas asociadas a microtúbulos

MCAK : kinesina asociada al centrómero mitótico.

MCF-7 : células de adenocarcinoma de mama.

$\mathrm{MeOH}$ : metanol.

MMP : metaloproteinasas de la matriz

extracelular.

MTT : bromuro de 3-(4,5-dimetiltiazol-2-il)-

2,5-difeniltetrazolio.

PBS : tampón fosfato salino.

PCR : reacción en cadena de la polimerasa.

PDGF : factor de crecimiento derivado de

plaquetas.

p.f : punto de fusión.

PGF : factor de crecimiento placentario.

$\mathrm{PI}$ : yoduro de propidio.

$q$ : cuadruplete.

qd : cuádruple doblete.

Q-TOF :cuadrupolo-tiempo de vuelo.

quint : quintuplete.

$\mathrm{RMN}$ : resonancia magnética nuclear.

Rto : rendimiento.

$s$ : singulete.

SD : desviación estándar.

sext : sextuplete.

$\mathrm{t}$ : triplete.

$\mathrm{T}$ : temperatura.

temp. amb. : temperatura ambiente.

TGF- $\beta$ : factor transformador de

crecimiento beta.

TLC : cromatografía de capa fina.

TTL : tubulina-tirosina ligasa.

VEGF: factor de crecimiento endotelial

vascular.

VEGFR : receptores del VEGF. 



\section{Índice}

1. Introducción 1

1.1. El cáncer 1

1.2. Oncogenes 5

1.3. Metástasis 6

1.4. Estrategias terapéuticas 8

1.5. Dianas biológicas 9

1.6. Tubulina y microtúbulos 13

1.7. Compuestos antimitóticos 21

1.8. Combretastatinas 42

1.9. Angiogénesis $\quad 50$

1.10. Telomerasa 59

2. Objetivos $\quad 67$

3. Síntesis de derivados de combretastatina A-4 y de amino$\begin{array}{ll}\text { combretastatina } & 69\end{array}$

3.1. Síntesis de compuestos de la familia $1 \quad 69$

3.2. Síntesis de compuestos de la familia $2 \quad 71$

3.3. Síntesis de compuestos de la familia $3 \quad 74$

3.4. Parte experimental $\quad 75$

3.4.1. Técnicas generales $\quad 75$

3.4.2. Síntesis de combretastatina A-4 77

3.4.3. Síntesis de los compuestos de la familia $1 \quad 78$

3.4.3.a. Instalación del espaciador de acetato 78

3.4.3.b. Procedimento general para la esterificación de los

aminoácidos 79

3.4.3.c. Procedimento general para la reacción de amidación $\quad 80$

3.4.3.d. Datos físicos y espectroscópicos de los metilésteres de la familia $1 \quad 80$

3.4.3.e. Procedimiento experimental para la reacción de saponificación $\quad 89$

3.4.3.f. Datos físicos y espectroscópicos de los compuestos de la familia $1 \quad 89$

3.4.4. Síntesis de compuestos de la familia $2 \quad 98$ 
3.4.4.b. Procedimiento experimental para la N-Fmoc protección $\quad 100$ 3.4.4.c. Procedimiento experimental para la reacción de amidación con los aminoácidos $N$-Fmoc protegidos 100

3.4.4.d. Datos físicos y espectroscópicos de los compuestos de la familia $2 \mathrm{~N}$-Fmoc protegidos

3.4.4.e. Procedimiento experimental para la N-Fmoc desprotección 109

3.4.4.f. Datos físicos y espectroscópicos de los compuestos de la familia 2

3.4.5. Síntesis de compuestos de la familia 3

3.4.5.a. Procedimiento experimental para la $N$-acilación de la aminocombretastatina

3.4.5.b. Datos físicos y espectroscópicos de los compuestos de la familia 3

4. Evaluación biológica

4.a. Inhibición de la proliferación celular

4.b. Efecto sobre el ensamblaje de microtúbulos

4.c. Efecto sobre el ciclo celular

4.d. Efecto sobre la red de microtúbulos celulares

4.e. Efecto sobre la expresión de los genes VEGF, hTERT y c-Myc

4.1. Evaluación biológica de los compuestos de la familia 1

4.1.b. Efecto sobre el ensamblaje de microtúbulos

4.1.c. Efecto sobre el ciclo celular

4.1.d. Efecto sobre la red de microtúbulos celulares

4.1.e. Efecto sobre la expresión de los genes VEGF, hTERT y $c-M y c$

4.2. Evaluación biológica de los compuestos de la familia 2

4.2.b. Efecto sobre el ensamblaje de microtúbulos 


$$
\text { y } c-M y c
$$

4.3.g. Conclusión 158

4.3. Evaluación biológica de los compuestos de la familia $3 \quad 160$

4.3.a. Inhibición de la proliferación celular 160

4.3.b. Efecto sobre el ensamblaje de microtúbulos 162

4.3.c. Efecto sobre el ciclo celular 164

4.3.d. Efecto sobre la red de microtúbulos celulares 166

4.3.e. Efecto sobre la expresión de los genes VEGF, hTERT y C-Myc 167

$\begin{array}{ll}\text { 4.3.f. Conclusión } & 169\end{array}$

4.4. Parte experimental 171

4.4.a. Inhibición de la proliferación celular (ensayo MTT) 171

4.4.b. Efecto en el autoensamblaje in vitro de microtúbulos 172

4.4.c. Efecto sobre el ciclo celular 174

4.4.d. Efecto sobre la red de microtúbulos (inmunofluorescencia) 174

4.4.e. Determinación de la expresión génica de VEGF, hTERT

y c-Myc mediante qPCR 175

5. Resumen y conclusiones $\quad 177$

5.1. Actividad antiproliferativa $\quad 177$

5.2. Actividad antimitótica 180

5.3. Efecto sobre la expresión de los genes VEGF, hTERT y c-Myc 181

6. Espectros seleccionados 183 



\section{INTRODUCCIÓN}





\section{INTRODUCCIÓN}

La esperanza de vida de la población ha experimentado un crecimiento espectacular en los últimos cien años, sobre todo en algunos países como España. Así, la esperanza de vida en nuestro país era de 35.7 años en 1900, de 40 años en 1930, de 70 años en 1960 y de 77 años en 1990. ${ }^{1}$ En 2014, la esperanza de vida de la población española fue de 83 años. Este aumento espectacular en la esperanza de vida está asociado a múltiples factores, entre ellos el nivel socioeconómico de la población, pero sobre todo está íntimamente relacionado con las medidas de salud pública, que han conseguido controlar $y$, en algunos casos, erradicar muchas enfermedades, como algunas de origen bacteriano y viral. En la actualidad, el cáncer y las enfermedades cardiovasculares son la principal causa de mortalidad en los países desarrollados.

\subsection{El cáncer}

El cáncer no es una enfermedad unitaria sino que es el nombre con el que se designa a un conjunto de enfermedades caracterizadas por el crecimiento y la proliferación incontrolada de células mutadas. Estas células anómalas forman un tumor que puede ser benigno, si no invade el tejido cercano ni se disemina hacia otras partes del organismo, o maligno, si su proliferación le lleva a invadir otros tejidos u órganos. Por definición, el término cáncer se aplica a los tumores malignos.

Como se ha indicado anteriormente, el cáncer es una de las principales causas de muerte en todo el mundo. En la figura 1.1 se muestra el porcentaje de incidencia y mortalidad por tipo de cáncer en el año 2012 de la población mundial. Entre los distintos tipos de cáncer destacan, por su elevado nivel de incidencia, el de colon, pulmón, mama y próstata.

\footnotetext{
${ }^{1}$ Goerlich, F. J.; Pinilla, R. Esperanza de vida en España a lo largo del siglo XX. Fundación BBVA. 2006.
} 


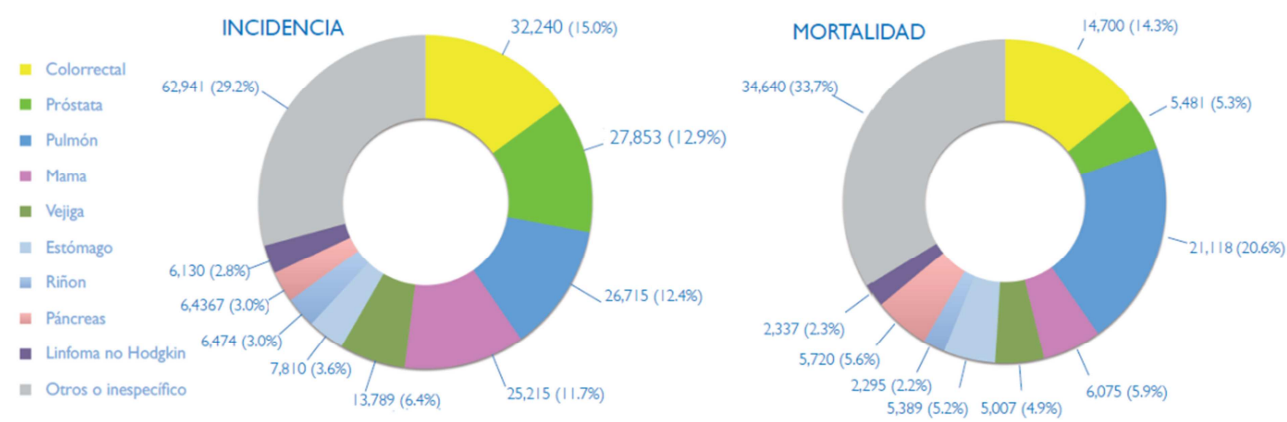

Figura.1.1. Epidemiología mundial del cáncer en $2012 .^{2}$

Se prevé que el número de defunciones anuales mundiales por cáncer seguirá aumentando y superará los 13.1 millones en $2030 .^{3}$

No es posible saber exactamente por qué una persona desarrolla cáncer y otra no, pero ciertos factores de riesgo pueden aumentar la probabilidad de que una persona tenga un cáncer. Estos factores de riesgo son los siguientes:

a) Edad. El cáncer puede tardar décadas en desarrollarse, lo que explica la elevada incidencia de esta enfermedad en personas mayores de 65 años.

b) Malos hábitos de consumo, como el alcoholismo o el tabaquismo.

c) Condiciones crónicas de salud, como la obesidad.

d) Condiciones medioambientales insalubres debidas a la presencia de determinados contaminantes atmosféricos o sustancias químicas nocivas (benceno, amianto, etc).

e) Radiaciones ionizantes (rayos X) y no ionizantes (radiación UV) y las radiaciones naturales que emite la propia corteza terrestre (radón).

f) Infecciones crónicas, como las provocadas por los virus de la hepatitis B y C y por los virus del papiloma humano, las cuales causan hasta un $20 \%$ de las muertes por cáncer en los países en vías de desarrollo y un $9 \%$ en los países desarrollados. $^{3}$

\footnotetext{
${ }^{2}$ Sociedad Española de Oncología Médica. http://www.seom.org

${ }^{3}$ http://www.nlm.nih.gov/medlineplus
} 
g) Factores hereditarios o predisposición genética al desarrollo de ciertos cánceres, que afecta entre el $5 \%$ y $10 \%$ de la población.

Según un reciente informe de la Sociedad Española de Oncología Médica (SEOM), en el año 2015 se diagnosticaron en España 247771 nuevos casos de cáncer, lo que supone un incremento de casi el 15\% respecto a los 215 534 que hubo en 2012, y mil más de lo esperado en la última proyección de la SEOM para 2020. ${ }^{4}$ En España, los tumores más frecuentemente diagnosticados en varones fueron los de próstata, colorrectal, pulmón, vejiga, estómago, hígado y linfoma no Hodgkin y en mujeres los de mama, colorrectal, útero, pulmón, vejiga, ovario, páncreas y estómago.

De acuerdo con la última información proporcionada por el Centro Nacional de Epidemiología del Instituto de Salud Carlos III, en España y en el año 2014, la causa más frecuente de muerte entre los varones fueron los tumores, que fueron responsables de 65014 fallecimientos, por delante de las enfermedades cardiovasculares, que ocasionaron 52907 fallecimientos y de las enfermedades respiratorias, con 24798 fallecimientos. En 2014 y en el sector poblacional femenino español, los tumores fueron la segunda causa de muerte (41020 fallecimientos en 2014), por detrás de las enfermedades cardiovasculares, que fueron responsables de 63546 muertes. En este año 2014, la tercera causa de muerte en mujeres en España fueron las enfermedades respiratorias (18 881 decesos). ${ }^{4}$

En el año 2015, y según los datos de la Red Española de Registros de Cáncer (REDECAN), una de cada tres muertes en varones y una de cada cinco en mujeres, se debieron a tumores malignos, lo que en términos globales significa que más de una de cada 4 muertes en España se debieron a distintos tipos de cáncer. ${ }^{4}$

http://www.seom.org/es/prensa/el-cancer-en-espanyacom/105941-las-cifras-del-cancer-enespana-2017 
Por otra parte, entre los años 2003-2012 y según datos del Instituto Nacional de Epidemiología, la mortalidad por tumores se redujo un $1.32 \%$ al año, pese a que se experimentó un aumento global de la incidencia de esta enfermedad. Esta mejora de la supervivencia de los pacientes oncológicos se debe a las acciones preventivas, las campañas de diagnóstico precoz y a los avances terapéuticos. Otras tendencias son, sin embargo, preocupantes, como el aumento de fallecimientos por cáncer de pulmón en mujeres (de $7.6 \mathrm{a}$ 11.6 por 100000 mujeres entre 2003-2012) lo que se achaca al aumento del consumo de tabaco en este sector poblacional. ${ }^{4}$

La supervivencia de los pacientes con cáncer en nuestro país es similar a la del resto de países de nuestro entorno situándose en un $53 \%$ a los 5 años. Los cánceres con mejores perspectivas de supervivencia son los de mama y colon, aunque otros cánceres, como el linfoma no Hodgkin, el cáncer colorrectal y el de próstata, también han experimentado un apreciable aumento en el porcentaje de supervivencia de los enfermos oncológicos. Los aumentos de la supervivencia en este tipo de cánceres están relacionados con los avances en los tratamientos oncológicos y con el diagnóstico precoz, ya que la supervivencia en los otros tumores continúa estancada. ${ }^{4}$

Hay que tener en cuenta que, de acuerdo con los datos publicados por la OMS en su Informe Mundial del Cáncer del año 2014, alrededor de 1/3 de las muertes por cáncer son debidas a causas evitables, como el tabaco, que es responsable de hasta un $33 \%$ de los tumores a nivel global, las infecciones, que son responsables de un $18 \%$ de los tumores, fundamentalmente en los países en vías de desarrollo, y el alcohol, que es responsable de hasta un $12 \%$ de los tumores en el mundo. ${ }^{4}$

Según el Global Cancer Observatory (GCO), de la International Agency for Research on Cancer (IARC), otra de las causas evitables del cáncer es la obesidad. La página web sobre obesidad y cáncer de la GCO 
(http://gco.iarc.fr/obesity/tools-pie) proporciona estimaciones del número de tumores atribuibles al exceso de peso corporal.

\subsection{Oncongenes}

Por lo general, una célula debe sufrir seis o más mutaciones genéticas antes de que se convierta en cancerosa. Heredar una copia defectuosa de un gen puede imposibilitar la reparación del ADN y facilitar la conversión de la célula portadora del gen defectuoso en célula tumoral. ${ }^{5}$ Los genes implicados en los procesos tumorales pueden agruparse en tres categorías. ${ }^{6}$

a) Protooncogenes, que son un grupo de genes que intervienen en la síntesis de proteínas implicadas en la transducción de señales intracelulares las cuales, a su vez, controlan los procesos de proliferación y diferenciación celular.

b) Oncogenes, que se originan a partir de los protooncogenes por cambios en la expresión o por cambios en la secuencia de codificación de éstos. El oncogén exhibe una actividad más intensa de lo normal, lo que incrementa la proliferación celular. Este incremento de la actividad origina proteínas cuya expresión y/o función está alterada, favoreciéndose el crecimiento celular y la invasión tumoral. Hasta la fecha se conocen más de 100 protooncogenes diferentes. Sin embargo, sólo un grupo limitado de ellos juega un papel esencial en el cáncer. Desde el punto de vista genético los oncogenes son dominantes, ya que basta la presencia de un solo alelo para predisponer a la célula a la transformación maligna. ${ }^{7}$

\footnotetext{
${ }^{5}$ Fidler, I. J. Nat. Rev. Cancer 2003, 3, 453-458.

${ }^{6} \mathrm{http}: / /$ www.cicancer.org

7 (a) M W Anderson, M. W.; Reynolds, S. H.; You, M.; R. M. Environ. Health Perspect. 1992, 98 : 13-24. (b) Hollstein, M.; Rice, K.; Greenblatt, M. S.; Soussi, T.; Fuchs, R.; Sorlie, T.; Hovig, E.; Smith-Sorensen, B.; Montesano, R.; Harris, C. C. Nucleic Acids Res. 1994, 22, 3551-3555. (c) Spandidos, D.; Anderson, M. L. M. J. Pathol. 1989, 157, 1-10. (d) Malumbres, M.; Barbacid, M. Nat. Rev. Cancer 2003, 3, 459-465. (e) Mascaux, C.; lannino, N.; Martin, B.; Paesmans, M.; et al. Br. J. Cancer 2006, 95, 131-139.
} 
c) Genes supresores de tumores. Esta clase de genes se encarga de controlar el ciclo celular evitando la proliferación celular descontrolada. A diferencia de los oncogenes, los genes supresores de tumores son recesivos, puesto que la presencia de un alelo normal es capaz de mantener los procesos de la célula. Para que la célula sana se transforme en cancerosa se deben acumular entre 4 y 6 mutaciones en el gen supresor. El gen más conocido de este grupo es el $p 53 .^{8}$ Este gen se traduce en proteínas encargadas de regular el ciclo celular ante un eventual daño del ADN. Así, cuando el ADN resulta dañado, el gen p53 se activa deteniendo el ciclo celular en la fase G1 y procediendo a la reparación del ADN. Si la reparación no es posible, el gen p53 induce la apoptosis de la célula. La alteración de la proteína codificada por p53 produce inestabilidad genómica. Las células que contienen esta alteración son incapaces de evitar la proliferación celular o de activar el proceso de apoptosis, provocándose en última instancia el proceso tumoral. ${ }^{9}$

Las alteraciones en los genes que controlan la proliferación y la diferenciación celular han demostrado ser el primer eslabón del proceso de malignización y, por tanto, constituyen dianas terapéuticas del máximo interés en los tratamientos contra el cáncer.

\subsection{Metástasis}

La metástasis se define como la propagación a distancia, por vía fundamentalmente linfática o sanguínea, de las células originarias del cáncer, con el consiguiente crecimiento de nuevos tumores en los lugares de destino de dicha metástasis. En la figura 1.2 se puede ver una representación del proceso de metástasis.

\footnotetext{
${ }^{8}$ Bai, L.; Zhu, W-G. J. Cancer Mol. 2006, 2, 141-153.

${ }^{9}$ (a) Hollstein, M.; Sidransky, D. E.; Vogelstein, B.; Harris, C. C. Science 1991, 253, 49-53. (b) El-Deiry, W. S.; Tokino, T.; Velculescu, V. E.; Levy, D. B.; et al. Cell 1993, 75, 817-825. (c) Vogelstein, B.; Lane, D.; Levine, A. J. Nature 2000, 408, 307-310. (d) Vogelstein, B.; Papadopoulos, N.; Velculescu, Victor, E.; et al. Science 2013, 339, 1546-1558.
} 


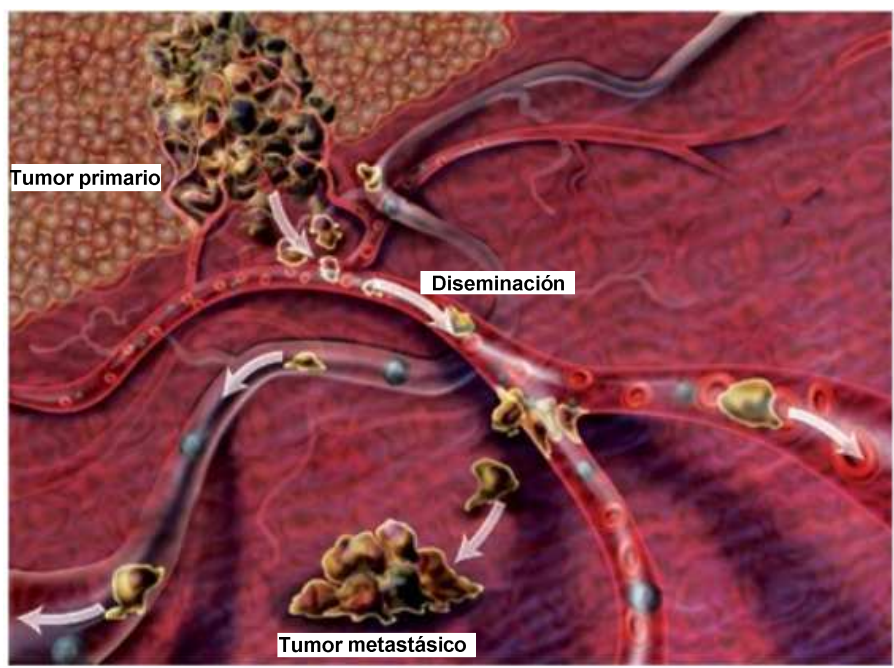

Figura 1.2. Representación de la metástasis tumoral. ${ }^{10}$

Las células poseen en su superficie unas moléculas de adhesión que les permiten unirse a otras células iguales. Estas moléculas de adhesión también les permiten unirse a la matriz extracelular, la cual está constituida por una red de proteínas insolubles que rellenan los espacios intersticiales entre las células y las mantienen unidas entre sí, evitando que éstas puedan quedar libres y migrar a otras partes del cuerpo. La migración de las células cancerosas se explica por la entrada de las mismas en la denominada transición epitelial-mesenquimal (EMT). En este proceso las células epiteliales pierden sus características y adquieren propiedades mesenquimales tales como la pérdida de adhesión celular, el aumento de su movilidad e invasividad y la resistencia a la apoptosis. ${ }^{11}$ Si una célula pierde su capacidad de adhesión a las células de su entorno se desencadena el proceso de apoptosis celular. $\mathrm{Si}$, a pesar de todo, la célula consigue penetrar en el torrente sanguíneo, el sistema inmunitario la detecta y la destruye para evitar que pueda establecerse en otra parte del organismo. Las células tumorales consiguen

\footnotetext{
${ }_{11}^{10}$ Imagen tomada de http://www.slideshare.net/csbrprasad/invasion-amp-metastasis-csbrp ${ }^{11}$ Franco-Chuaire, M. L.; Sánchez-Corredor, M. C.; Chuaire-Noack, L. Invest. Clin. 2013, 54, 186-205.
} 
evitar estos dos sistemas de control. Así, por un lado, las células tumorales tienen disminuida su capacidad de adhesión a las células del entorno y a la matriz extracelular, destruyéndola mediante la sobreexpresión y la segregación de enzimas denominadas MMPs (metaloproteinasas de la matriz extracelular). Por otro lado, la acción de las MMPs facilita la entrada de las células tumorales en el torrente sanguíneo al destruir la matriz extracelular de las células endoteliales de los vasos sanguíneos. ${ }^{12}$

Como consecuencia de la pérdida de moléculas de adhesión las células tumorales pierden su diferenciación y el sistema inmunitario no las puede detectar y destruir. Sin embargo, a pesar de no ser detectadas por el sistema inmunitario, se calcula que solo 1 de cada 10000 células cancerosas que penetran en el torrente sanguíneo llega a generar un tumor secundario. Las células cancerosas que logran superar las barreras inmunitarias viajan por el torrente sanguíneo a través de los capilares, se adhieren a la pared del vaso sanguíneo, la penetran (extravasación) e invaden el nuevo órgano formando un tumor secundario. La metástasis a través de los vasos sanguíneos se produce generalmente en zonas del organismo fuertemente vascularizadas, como pulmón, hígado o cerebro. La metástasis es la principal causa de mortalidad en la mayoría de los cánceres y constituye un grave problema en el tratamiento antineoplásico. ${ }^{13}$

\subsection{Estrategias terapéuticas}

En la lucha contra el cáncer se emplea la cirugía, la radioterapia, la quimioterapia y las terapias biológicas. La radioterapia y la quimioterapia ofrecen alternativas de tratamiento en aquellos casos en los que no es posible

\footnotetext{
${ }^{12}$ Angosto. M. C.; Álvarez-Gómez; J. A. An. R. Acad. Nac. Farm. 2010, 76, $59-84$

${ }^{13}$ Martin, T. A.; Ye. L.; Sanders, A. J.; J.; Jiang, W. G. Cancer invasion and metastasis: molecular and cellular perspective. Jandial, Rahul ed. Metastatic Cancer Clinical and Biological Perspectives, Austin, TX: Landes Bioscience, 2013, pp. 135-168. https://www.ncbi.nlm.nih.gov/books/NBK164700/
} 
la cirugía y también pueden ser utilizadas en combinación con cualquiera de las otras aproximaciones terapéuticas.

El problema de muchos tratamientos oncológicos es la falta de especificidad, ya que tanto la radiación como los agentes quimioterapéuticos afectan también a las células y tejidos sanos, pudiendo producir importantes efectos tóxicos o nocivos en los pacientes. ${ }^{14}$ La terapia biológica dirigida es una terapia mucho más específica que las anteriores. Dentro de este tipo de terapia se encuentra la inmunoterapia, las terapias hormonales, los inhibidores de transducción de señal, los moduladores de la expresión de genes, los inhibidores de la angiogénesis, los anticuerpos monoclonales, las vacunas contra el cáncer y la terapia génica. ${ }^{15}$

\subsection{Dianas biológicas}

La diana biológica puede definirse como el lugar del organismo en el que el fármaco ejerce su acción. Aunque el lugar de acción de los fármacos puede ser muy diverso, no lo es tanto la naturaleza química de la interacción del fármaco con su diana. Desde un punto de vista químico, las dianas se engloban en alguno de los siguientes tipos de biomoléculas: lípidos, proteínas o ácidos nucleicos. El diseño racional de nuevos fármacos requiere del conocimiento de estas dianas biológicas y del sitio de unión del fármaco a su diana, aunque en la actualidad aún es relativamente bajo el número de fármacos cuyo diseño se haya hecho en función de la estructura de su diana biológica. ${ }^{16}$

La unión fármaco-diana resulta tanto más fuerte cuanto más fuerte sea la interacción entre ambos, de lo que cabría deducir que los fármacos unidos a su diana mediante enlaces covalentes deberían ser los de mayor potencia terapéutica. Sin embargo, la mayoría de los fármacos interaccionan con su

\footnotetext{
${ }^{14} \mathrm{http}: / /$ cancer.stanford.edu/information/cancerTreatment/methods/chemotherapy.html

${ }^{15}$ Sandri, G.; Cestelli, V.; Mascia, M. T. J. Cancer Ther. 2013, 4, 460-465.

${ }^{16}$ López-Pérez, J. L.; Olmo-Fernández, E.; San Feliciano, A. Enf. Emerg. 2005, 7, 52-56.
} 
diana mediante fuerzas intermoleculares más o menos débiles, como las que ejercen las interacciones electrostáticas, los enlaces de hidrógeno y las interacciones de tipo van der Waals. ${ }^{17}$

En el caso del cáncer, un buen fármaco antitumoral sería aquel capaz de atacar muy selectivamente a las células tumorales, lo que se podría conseguir eligiendo como dianas biológicas aquellas biomoléculas no presentes en células sanas o presentes en una muy baja proporción.

En el año 2000, Hanahan y Weinberg publicaron un artículo titulado The Hallmarks of Cancer ${ }^{18}$ en el que proponían seis características que eran comunes a todas las células cancerosas. Estas características fueron ampliadas con otras cuatro adicionales en un artículo publicado por estos dos autores en el año 2011. ${ }^{19}$ Las diez características comunes a las células cancerosas son las siguientes:

1) Desregulación de los factores de crecimiento que provocan autoestimulación del crecimiento.

2) Resistencia a las señales de parada del crecimiento.

3) Resistencia a la apoptosis.

4) Capacidad de inducción de la angiogénesis.

5) Capacidad replicativa ilimitada.

6) Capacidad de invasión de los tejidos circundantes y metástasis.

7) Desregulación del metabolismo.

8) Capacidad de evasión al sistema inmunitario.

9) Anormalidades cromosómicas que provocan inestabilidad del ADN.

10) Inflamaciones crónicas locales.

Estas señas de identidad de las células cancerosas se representan en la figura 1.3.

\footnotetext{
${ }_{17}^{17}$ Patrick, G. L. An introduction to Medicinal Chemistry. $4^{\text {th }}$ Edition, 2009.

${ }^{18}$ Hanahan, D.; Weinberg, R. A. Cell 2000, 100, 57-70.

${ }^{19}$ Hanahan, D.; Weinberg, R. A. Cell 2011, 144, 646-674.
} 


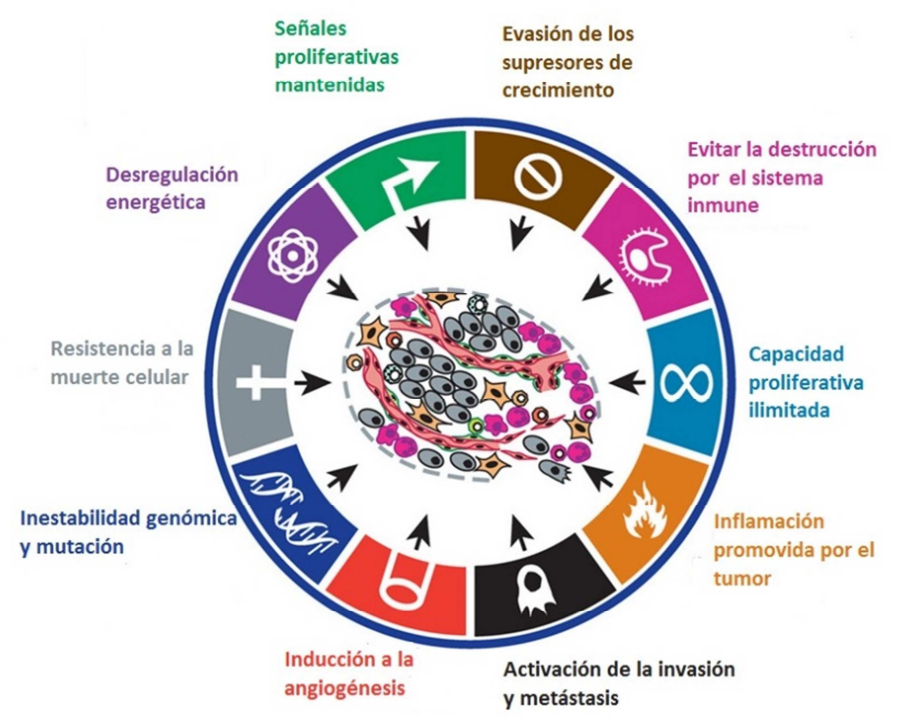

Figura 1.3. Señas de identidad de las células cancerosas.

La identificación de nuevas dianas se puede llevar a cabo mediante una combinación de técnicas de química médica, química biológica y proteómica, que permitan abordar el estudio de los sistemas biológicos de mayor complejidad. Muchas de las dianas biológicas son hormonas, genes, enzimas, proteínas receptoras de sustancias endógenas o canales iónicos que controlan el flujo de iones a través de las membranas celulares. De ahí que el conocimiento de las biomoléculas que estén implicadas en una determinada patología sea de suma importancia en el proceso de diseño de un nuevo fármaco.

La validación de una diana farmacológica puede realizarse abordando su estudio mediante técnicas de biología celular y molecular $y$, recientemente, con tecnologías genómicas y proteómicas, que han permitido a la industria farmacéutica descubrir un gran número de fármacos por medio del estudio de las relaciones existentes entre genes y enfermedades. ${ }^{20}$

${ }^{20}$ http://www.institutoroche.es 
El nivel más alto de la validación de una diana terapéutica se consigue cuando el fármaco, que se ha diseñado en función de esa diana, consigue revertir los síntomas asociados a una determinada enfermedad. Esto exige la recopilación de una gran cantidad de datos preclínicos y clínicos que permitan determinar la eficacia terapéutica del nuevo fármaco.

Hacia finales del siglo XIX, los productos naturales extraídos de las plantas $y$, más raramente, de animales formaban la base de la medicina terapéutica. Una gran parte de la actividad de muchas industrias farmacéuticas se ha enfocado a encontrar nuevos y mejores fármacos de fuentes naturales. En la segunda mitad de la década de los 90 se produjo un declive en el interés por los productos naturales, que representaron hasta esta fecha una fuente prioritaria de nuevos fármacos. ${ }^{21}$

La complejidad estructural de muchos productos naturales ha sido percibida como un obstáculo ya que su síntesis química y su derivatización pueden imponer un auténtico desafío. El enorme avance realizado en los últimos años en la biología molecular y la farmacología ha permitido reinvestigar viejas estructuras de productos naturales y encontrarles nuevas aplicaciones farmacológicas tales como inmunomoduladores, antibióticos, antitumorales, etc. Estos hallazgos han reactivado el estudio del mundo natural, del que sólo se han investigado alrededor de un $10 \%$ de las plantas. ${ }^{22}$ Es conveniente indicar que en el transcurso de los últimos veinte años el mar se ha convertido en una importantísima fuente de productos naturales biológicamente activos. ${ }^{23}$

\footnotetext{
${ }^{21}$ Para artículos relacionados con el renacimiento de los productos naturales como candidatos a fármacos véase: (a) Paterson, I.; Anderson, E. A. Science. 2005, 310, 451-453. (b) Chin, Y-W.; Balunas, M. J.; Chai, H, B.; Kinghorn, A. D. AAPS J. 2006; 8, E239-E253.

${ }_{22}$ Potier. P. Chem. Soc. Rev. 1992, 21, 113-119.

${ }^{23}$ (a) Jiménez, J. C.; Marfil, M.; Francesch, A. M.; Cuevas, C.; Alvarez, M.; Albericio, F. Investigación y ciencia 2007, 365, 75-83. (b) Blunt, J. W.; Copp, B. R.; Keyzers, R. A.; Munro M. H.; Prinsep, M. R. Nat. Prod. Rep. 2016, 33, 382-431.
} 


\subsection{Tubulina y microtúbulos}

Una de las señas de identidad de las células cancerosas es su capacidad replicativa ilimitada. El huso mitótico es la estructura subcelular que se forma en las células eucarióticas durante el proceso de división celular. El huso mitótico está compuesto por microtúbulos que, a su vez, están formados por tubulina. Muchos agentes quimioterapéuticos ejercen su efecto citotóxico actuando sobre los microtúbulos del huso mitótico.

La tubulina constituyente de los microtúbulos es una proteína heterodimérica formada por dos subunidades, enlazadas de forma no covalente, y denominadas $\alpha$ - y $\beta$-tubulina. Existe una tercera clase de tubulina, denominada $\gamma$-tubulina, que juega un papel clave en el proceso de nucleación de los microtúbulos. La secuencia aminoacídica de la tubulina se encuentra muy conservada y los genes que codifican la alfa, la beta y la gamma tubulina se encuentran en todas las células eucariotas. ${ }^{24}$

Las subunidades de alfa y beta tubulina contienen unos 450 aminoácidos. La diferencia más llamativa entre ambas reside en el denominado bucle S9S10, que en la subunidad alfa contiene ocho aminoácidos más que en la subunidad beta. Ambas subunidades llevan asociada una molécula de GTP. La de la subunidad alfa está anclada de manera fija y no es intercambiable, por lo que su sitio de unión se denomina sitio N (del inglés Nonexchangeable). En cambio, el GTP de la subunidad beta se puede hidrolizar a GDP e intercambiar posteriormente por GTP. Por esta razón, el sitio de unión del GTP en la subunidad beta se denomina sitio $\mathrm{E}$ (del inglés Exchangeable, véase la figura 1.4). ${ }^{25}$

\footnotetext{
${ }^{24}$ (a) Burns, R. G.; Surridge, C. FEBS Lett, 1990, 271, 1. (b) Ducki, S.; Mackenzie, G.; Greedy, B.; Armitage, S.; Fournier Dit Chabert, J.; Bennett E.; Nettles, J.; Snyder, J.; Lawrence, Nicholas J., Bioorg. Med. Chem. Lett. 2009, 17, 7711.

${ }^{25}$ Nogales, E.; Wolf, S. G.; Downing, K. H. Nature 1998, 391, 199-203. (b) Janke, C. J. Cell Biol. 2014, 206, 461-472.
} 


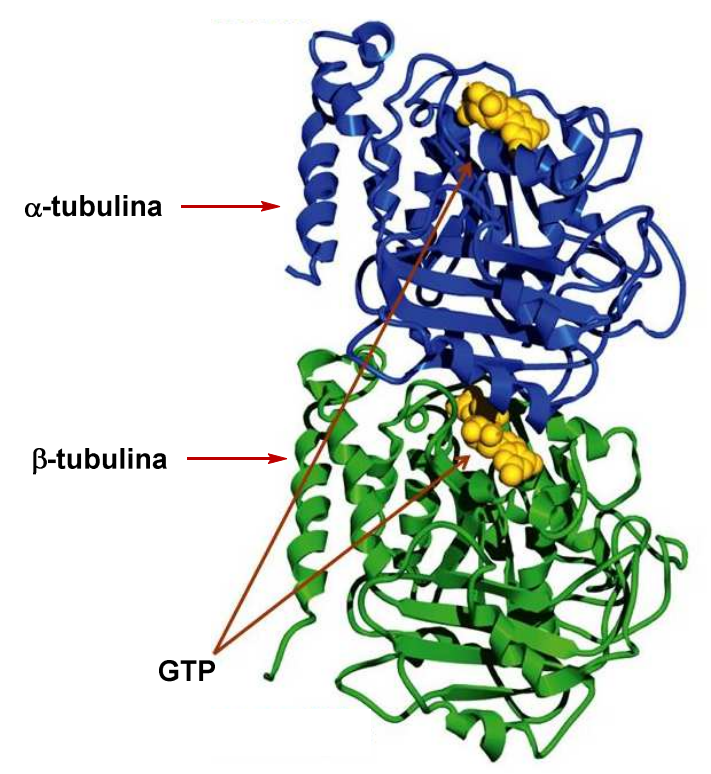

Figura 1.4. Representación del heterodímero de tubulina.

La polimerización de los heterodímeros de tubulina conduce progresivamente a la formación de unos protofilamentos. La unión de 13 protofilamentos genera los microtúbulos, que son tubos cilíndricos huecos con un diámetro de $25 \mathrm{~nm}$ y una longitud variable de 25-200 micras.

Un rasgo muy importante de los microtúbulos es su comportamiento dinámico, ya que son capaces de crecer aumentando su longitud añadiendo nuevos dímeros en los extremos del tubo. En uno de los extremos la polimerización es más rápida, por lo que es llamado polo positivo, o terminal (+) del microtúbulo, mientras que el otro extremo es denominado polo negativo, o terminal (-). El extremo (+) termina con subunidades de $\beta$-tubulina y el extremo (-) con subunidades de a-tubulina (véase la figura 1.5). Esta polaridad del microtúbulo tiene además su reflejo a nivel molecular y celular ya que los polos positivos apuntan y terminan en la periferia de la célula y los polos negativos hacia el centrosoma, que constituye el principal centro de organización de los microtúbulos en la célula. El extremo positivo del 
microtúbulo es el más activo en el proceso de ensamblaje y desensamblaje, mientras que el extremo negativo, que contiene subunidades alfa, es mucho menos activo y está además unido a unas proteínas denominadas proteínas organizadoras de los microtúbulos. ${ }^{26}$ Los contactos longitudinales a lo largo de los protofilamentos se establecen mediante interacciones polares hidrofóbicas.

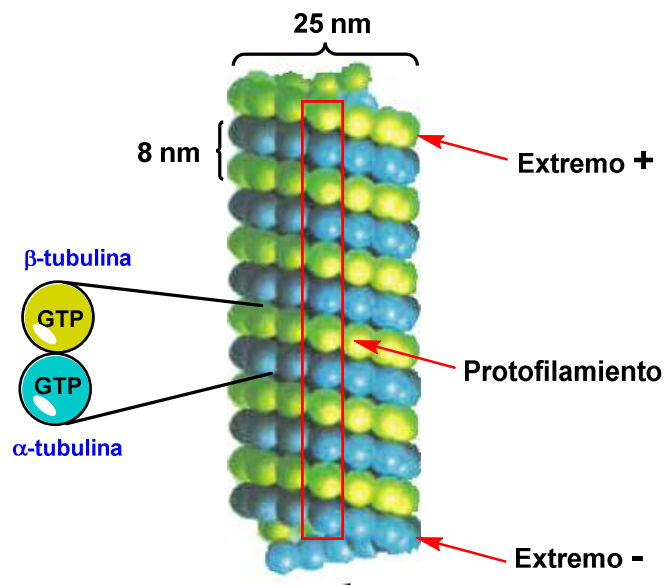

Figura 1.5. Estructura del microtúbulo.

Los microtúbulos son uno de los componentes esenciales del citoesqueleto, que es la estructura tridimensional dinámica que llena el citoplasma. Esta estructura actúa como un músculo y como un esqueleto para el movimiento y la estabilidad de la célula. Así, la polaridad de los filamentos microtubulares da origen a una superficie polarizada (direccional), repetida y regular en los heterodímeros de la tubulina, lo que proporciona un andamiaje que determina la forma celular, y constituye un conjunto de vías por donde se mueven distintos orgánulos celulares (mitocondrias, vesículas de secreción,

\footnotetext{
${ }^{26}$ (a) Nogales, E.; Wang, H.-W. Curr. Opin. Cell Biol. 2006, 18, 179-184. (b) Nogales, E.; Wang, H.-W. Curr. Opin. Struct. Biol. 2006, 16, 221-229. (c) Borisy, G.; Heald, R.; Howard, J.; Janke, C.; Musacchio, A.; Nogales, E. Nat. Rev. Mol. Cell Biol. 2016, 17, 322-328
} 
lisosomas) portados por diferentes proteínas motoras que caminan a lo largo de la superficie del microtúbulo. ${ }^{27}$

Los microtúbulos están sometidos a un proceso continuo de ensamblaje y desensamblaje que encuentra su explicación en dos fenómenos dinámicos intrínsecos:

a) El recambio rotatorio, denominado en inglés treadmilling, en el que tiene lugar, de forma concomitante, la adición de dímeros de tubulina en el terminal positivo y su liberación en el terminal negativo, permitiendo de esta forma mantener constante la longitud del microtúbulo. ${ }^{28}$ Este proceso, parecido a una cinta de transporte sin fin, tiene lugar durante la metafase y la anafase, en las que es esencial la transmisión de señales intracelulares desde el cinetocoro a los polos. ${ }^{29}$

b) La inestabilidad dinámica, fenómeno que provoca oscilaciones rápidas de alargamientos y acortamientos de los microtúbulos. El balance entre alargamiento y acortamiento depende de la hidrólisis de GTP a GDP y de la velocidad de adición de nuevos dímeros de tubulina al extremo positivo. ${ }^{30}$ Así, la unión de dímeros de tubulina (polimerización) induce la actividad GTPasa de la $\beta$-tubulina produciéndose la hidrólisis del GTP a GDP en esta subunidad. Se ha propuesto que un residuo de ácido glutámico de la $\alpha$-tubulina es el encargado de llevar a cabo la hidrólisis del GTP presente en la $\beta$-tubulina. El GTP enlazado a la $\alpha$-tubulina no se hidroliza a GDP, permaneciendo atrapado entre los dos monómeros alfa y beta.

La hidrólisis del GTP curva y desestabiliza el microtúbulo debido al cambio conformacional que experimenta la $\beta$-tubulina-GDP. Aunque en el proceso de polimerización prácticamente todo el GTP de la $\beta$-tubulina se ha hidrolizado a

${ }^{27}$ Chaudhuri, A.; Seetharamalu, P.; Schwarz, P.; Hausheer, F. H.; Ludueña, R. J. Mol. Biol. 2000, 303, 679-692.

${ }^{28}$ (a) Margolis, R. L.; Wilson, L. Cell 1978, 13, 1-8. (b) Margolis R. L.; Wilson, L. Bioessays 1998, 20, 830-836.

${ }^{29}$ McIntosh, J. R.; Grishchuk, E. L.; West, R. R. Annu. Rev. Cell. Dev. Biol. 2002, 18, 193-219.

${ }^{30}$ Mitchison, T.; Kirschner, M. Nature 1984, 312, 237-242. 
GDP, existe un tapón (cap) en el extremo positivo del microtúbulo que no ha hidrolizado el GTP. Mientras existan las unidades de GTP en los extremos del microtúbulo el polímero es estable. A medida que crece, el microtúbulo almacena energía y adquiere un estado meta-estable. La pérdida del tapón de $\beta$-tubulina-GTP provoca la despolimerización inmediata del microtúbulo, liberándose así la energía almacenada tras la hidrólisis del GTP (véase la figura 1.6). ${ }^{31}$ Por tanto, la hidrólisis de GTP en la $\beta$-tubulina modula la adición de nuevos dímeros y está implicada directamente en el proceso de mitosis. ${ }^{32}$

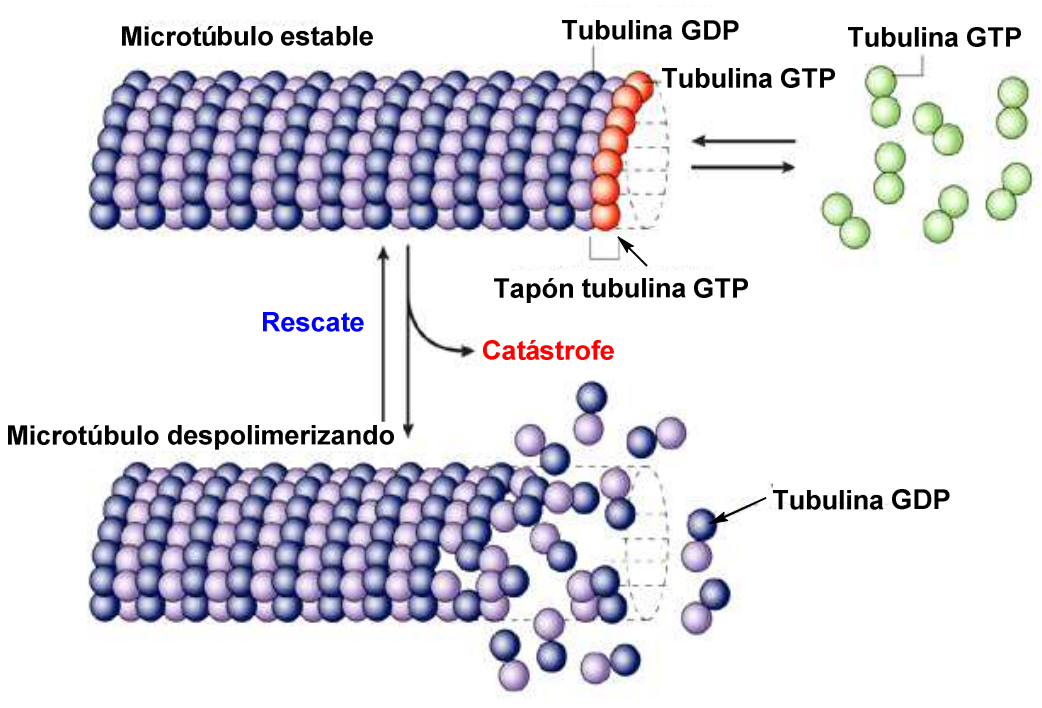

Figura 1.6. Dinámica de la polimerización de la tubulina.

El treadmilling y la inestabilidad dinámica no son mutuamente excluyentes $y$, a menudo, tienen lugar de manera simultánea. El grado en el cual una población de microtúbulos exhibe más o menos comportamiento de uno u otro tipo depende de las condiciones celulares. ${ }^{33}$

\footnotetext{
${ }^{31}$ Jordan, M. A.; Wilson, L. Nat. Rev. Cancer. 2004, 4, 253-265.

${ }^{32}$ Amos, L. A. Chem. Biol. 2004, 11, 745-747.

${ }^{33}$ Farrell, K. W.; Jordan, M. A.; Miller, H. P.; Wilson. L. J. Cell. Biol. 1987, 104, 1035-1046.
} 
La velocidad de crecimiento y contracción de los microtúbulos y la frecuencia de los procesos de despolimerización (catástrofe) y crecimiento (rescate) son las cuatro variables que describen la dinámica de los microtúbulos. ${ }^{34}$ Estos parámetros están regulados por factores estabilizantes, usualmente proteínas, que previenen la catástrofe y que o bien rescatan a los microtúbulos que se están despolimerizando, o bien disminuyen la velocidad de contracción de los mismos. También existen factores desestabilizantes que inducen la catástrofe, ya sea impidiendo el rescate, ya sea incrementando la contracción de los microtúbulos.

Las MAP, del inglés Microtubule Associated Proteins, son proteínas que se unen a la tubulina sin afectar al proceso de hidrólisis del GTP. Las MAP son proteínas reguladas por fosforilación, siendo la forma más fosforilada la que presenta menor capacidad de estabilización de los microtúbulos. ${ }^{35}$ De entre las MAP destacan la MAP1, MAP2, MAP4, tau, y DCX (doublecortina). ${ }^{36}$ Otro tipo de MAP, denominada +TIPS, se une al extremo positivo del microtúbulo en crecimiento y puede influenciar de manera importante el proceso de mitosis. ${ }^{37}$ Una de las proteínas +TIPS es la denominada EB1, del inglés EndBinding Protein 1, cuya sobreexpresión está relacionada con cáncer gástrico, con cáncer de células escamosas esofágicas y con cáncer hepatocelular. ${ }^{38} \mathrm{Se}$ ha demostrado que la sensibilidad de las células tumorales a los agentes que interaccionan con tubulina es dependiente de las MAP, lo que explica el papel

\footnotetext{
${ }^{34}$ Hyman, A. A.; Karsenti, E. Cell 1996, 84, 401-410.

35 (a) Drechsel, D. N.; Hyman, A. A.; Cobb, M. H.; Kirschner, M. W. Mol. Biol. Cell 1992, 3, $1141-$ 1154. (b) Trinczek, B.; Biernat, J.; Baumann, K.; Mandelkow, E. M.; Mandelkow, E. Mol. Biol. Cell 1995, 6, 1887-1902.

${ }^{36}$ Mandelkow, E.; Mandelkow, E. M. Cell Biol .1995, 7, 72-81.

37 (a) Schuyler, S. C.; Pellman, D. Cell 2001, 105, 421-424. (b) Gundersen, G. G.; Gomes, E. R.; Wen, Y. Curr. Opin. Cell. Biol. 2004, 16, 106-112.

38 (a) Fujii, K.; Kondo, T.; Yokoo, H.; Yamada, T.; Iwatsuki, K.; Hirohashi. S. Proteomics 2005, 5, 1411-1422. (b) Nishigaki, R:, Osaki, M.; Hiratsuka, M.; Toda. T.; Murakami, K.; Jeang, K. T.; Ito, H.; Inoue, T.; Oshimura. M. Proteomics 2005, 5, 3205-3213. (c) Wang, Y.; Zhou, X.; Zhu, H.; Liu, S.; Zhou, C.; Zhang, G.; Xue, L.; Lu, N.; Quan, L.; Bai, J.; Zhan, Q.; Xu. N. Oncogene 2005, 24, 6637-6645.
} 
que juegan las MAP en la resistencia de las células cancerosas a los agentes citostáticos. $^{39}$

Las proteínas desestabilizantes de los microtúbulos son kinesinas que cumplen un papel dual ya que por un lado promueven el proceso de catástrofe, que es dependiente de ATP y, por otro lado, participan en el secuestro de tubulina independiente de ATP. ${ }^{40}$ Las MCAK, del inglés Mitotic Centromere-Associated Kinesin, se unen a ambos extremos del microtúbulo, el positivo y el negativo, y muestran máxima afinidad por el microtúbulo curvado que está experimentando el proceso de acortamiento. Las MCAK promueven la disociación de los dímeros de tubulina del microtúbulo en el cinetocoro, de esta forma el microtúbulo se acorta y arrastra a los cromosomas durante la anafase. ${ }^{41}$

La estatmina es otra proteína reguladora de la estabilidad de los microtúbulos. Esta pequeña proteína, de tan solo $19 \mathrm{KDa}$ de peso molecular, está muy expresada en las células leucémicas e interacciona con los dímeros de la tubulina incrementando la velocidad del proceso de catástrofe. ${ }^{42} \mathrm{La}$ estatmina se une a dos moléculas de tubulina dimérica y forma un complejo ternario denominado complejo T2S (véase la figura 1.7). La tubulina unida a estatmina no es polimerizable y no se puede ensamblar en los microtúbulos. ${ }^{43}$ Mediante este mecanismo, la estatmina estimula el desensamblaje de los microtúbulos y regula indirectamente el ciclo celular.

\footnotetext{
${ }^{39}$ Bhat, K. M.; Setaluri, V. Clin. Cancer Res. 2007, 13, 2849-2854.

${ }^{40}$ Newton, C. N.; Wagenbach, M.; Ovechkina, Y.; Wordeman, L.; Wilson, L. FEBS Lett. 2004, 572, 80-84.

${ }^{41}$ Moores, C. A.; Yu, M.; Guo, J.; Beraud, C.; Sakowicz, R.; Milligan, R. A. Mol. Cell 2002, 9, 903-909.

42 Jourdain. L.; Curmi, P.; Sobel, A.; Pantaloni, D.; Carlier, M. F. Biochemistry 1997, 36, 1081710821.

${ }^{43}$ Steinmetz, M. O.; Kammerer, R. A.; Jahnke, W.; Goldie, K. N.; Lustig, A.; van Oostrum, J. EMBO J. 2000, 19, 572-580.
} 


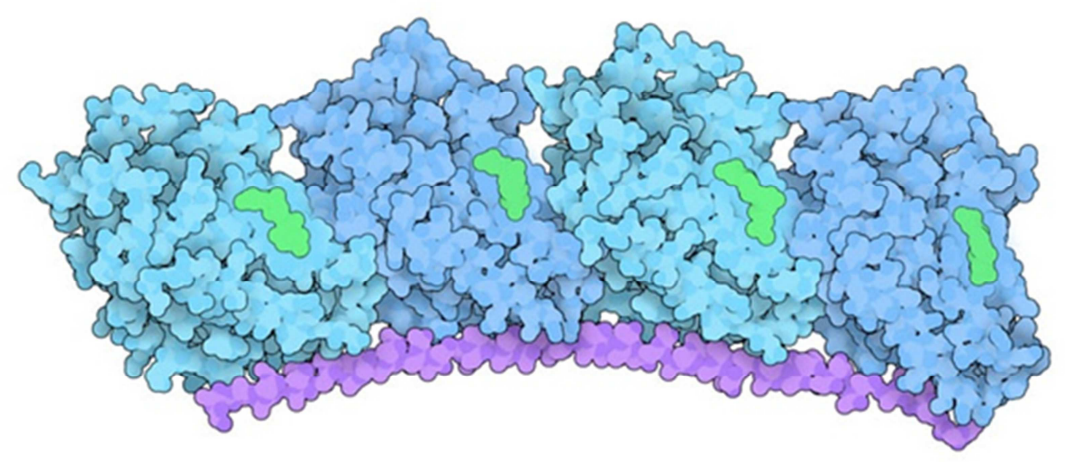

Figura 1.7. Complejo estatmina (en magenta) con tubulina. ${ }^{44}$

La acción de la estatmina está controlada por quinasas. Así, la fosforilación de cuatro residuos de serina en la estatmina provoca una unión más débil con los dímeros de tubulina, incrementándose la concentración de tubulina disponible en el citoplasma para el ensamblaje de los microtúbulos. Por tanto, para que la célula pueda ensamblar el huso mitótico es necesaria la fosforilación de la estatmina, de lo contrario se produce la detención del ciclo celular. La desfosforilación de la estatmina se produce en la citocinesis. La estatmina desfosforilada secuestra tubulina e impide que la célula vuelva entrar en el ciclo celular hasta que esté preparada para ello. ${ }^{45}$

La estatmina se clasifica como oncoproteína. Algunas mutaciones de estatmina impiden su unión a la tubulina favoreciéndose el ensamblaje continuo de microtúbulos y la formación constante del huso mitótico. En estas condiciones, la célula se replica sin control, produciéndose el característico crecimiento celular desregulado de las células cancerosas. ${ }^{46}$

\footnotetext{
${ }^{44}$ PDB $1 \mathrm{ffx}$.

45 (a) Manna, T.; Thrower, D.; Miller, H. P.; Curmi, P.; Wilson, L. J. Biol. Chem. 2006, 281, $2071-$ 2078. (b) Howell, B.; Deacon, H.; Cassimeris, L. J. Cell. Sci. 1999, 112, 3713-3722.

${ }^{46}$ Cassimeris, L. Curr. Opin. Cell Biol. 2002, 14, 18-24.
} 


\subsection{Compuestos antimitóticos}

Los compuestos que se unen a la tubulina pueden estabilizar o desestabilizar el proceso de formación de los microtúbulos, provocando en ambos casos la detención de la mitosis y la consiguiente muerte celular. Muchos fármacos antitumorales que tienen como diana biológica la tubulina ${ }^{47}$ son productos naturales o derivados de los mismos. ${ }^{48}$ La mayoría de estos fármacos interaccionan con la $\beta$-tubulina, ejerciendo su acción antitumoral bien mediante la estabilización de los microtúbulos, o bien mediante su desestabilización. Los compuestos conocidos que se unen a la $\alpha$-tubulina solo ejercen su acción farmacológica mediante desestabilización de los microtúbulos. $^{49}$

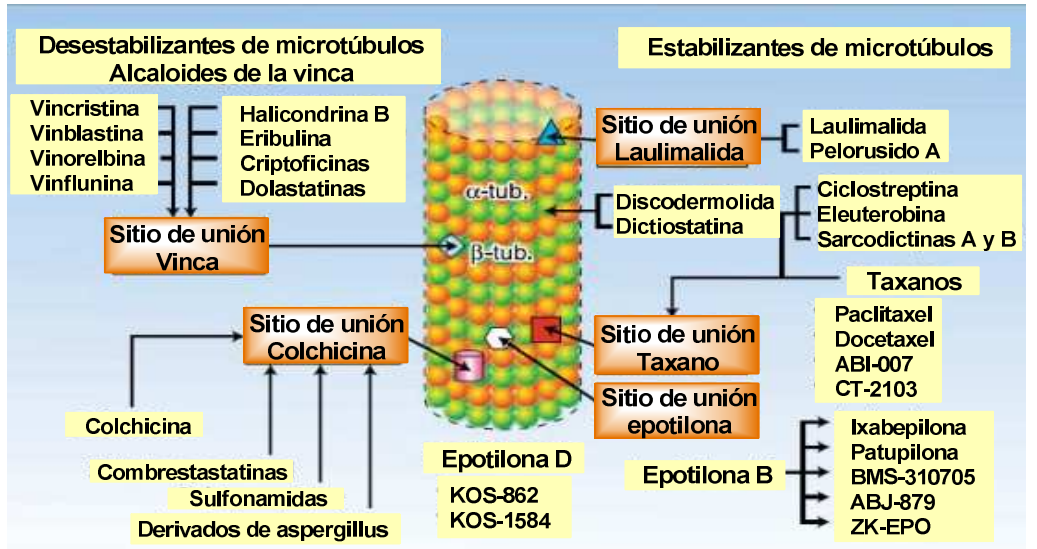

Figura 1.8. Representación de los sitios de unión a $\beta$-tubulina. ${ }^{50}$

\footnotetext{
${ }^{47}$ Mani, S.; Macapinlac, M. Jr.; Goel, S.; Verdier-Pinard, D.; Fojo, T.; Rothenberg, M.; Colevas, D. Anticancer Drugs 2004, 15, 553-558.

${ }^{48}$ (a) Jordan, M. A.; Wilson, L. Nat. Rev. Cancer 2004, 4, 253-265. (b) Altmann, K.-H., Gertsch, J. Nat. Prod. Rep. 2007, 24, 327-357. (b) Kingston, D. F. I. J. Org. Chem. 2008, 73, 3975-3984. (c) Kingston, D. G. I. J. Nat. Prod. 2009, 72, 507-515. (d) Dumontet, C.; Jordan, M. A. Nat. Rev. Drug Discov. 2010, 9, 790-803. (e) Stanton, R. A.; Gernert, K. M.; Nettles, J. H.; Aneja, R. Med. Res. Rev. 2011 31, 443-481. (f) Mukhtar, E.; Adhami, V. M.; Mukhtar, H. Mol. Cancer Ther. 2014, 13, 275-284. (g) van Vuuren, R. J.; Visagie, M. H.; Theron, A. E.; Joubert, A. M. Cancer Chemother. Pharmacol. 2015, 76, 1101-1112.

${ }^{49}$ (a) Sánchez-Pedregal, V. M.; Griesinger, C. Top. Curr. Chem. 2009, 286, 151-208. (b) Nettles, J. H.; Downing, K. H. Top. Curr. Chem. 2009, 286, 209-257. (c) Botta, M.; Forli, S.; Magnani, M.; Manetti, F. Top. Curr. Chem. 2009, 286, 279-328. (d) Dumontet, C.; Jordan, M. A. Nat Rev Drug Discov. 2010, 9, 790-803.

${ }^{50}$ Figura modificada de la referencia $49 a$.
} 
Los sitios de unión de los compuestos antimitóticos a la $\beta$-tubulina se describen gráficamente en la figura $1.8 .^{51}$ La colchicina, alcaloide extraído de la planta Colchicum autumnale, es un agente destabilizante de los microtúbulos. Se une a la $\beta$-tubulina cerca del GTP de la subunidad de $\alpha$ tubulina (véase la figura 1.9). ${ }^{52}$ La colchicina interacciona con la tubulina libre y forma complejos tubulina-colchicina (T-C). La velocidad de formación de estos complejos es lenta respecto a la velocidad de formación de microtúbulos, pero una vez formados estos complejos copolimerizan en los extremos de los microtúbulos. La unión reversible de los complejos T-C en el extremo del microtúbulo bloquea su crecimiento. ${ }^{53}$

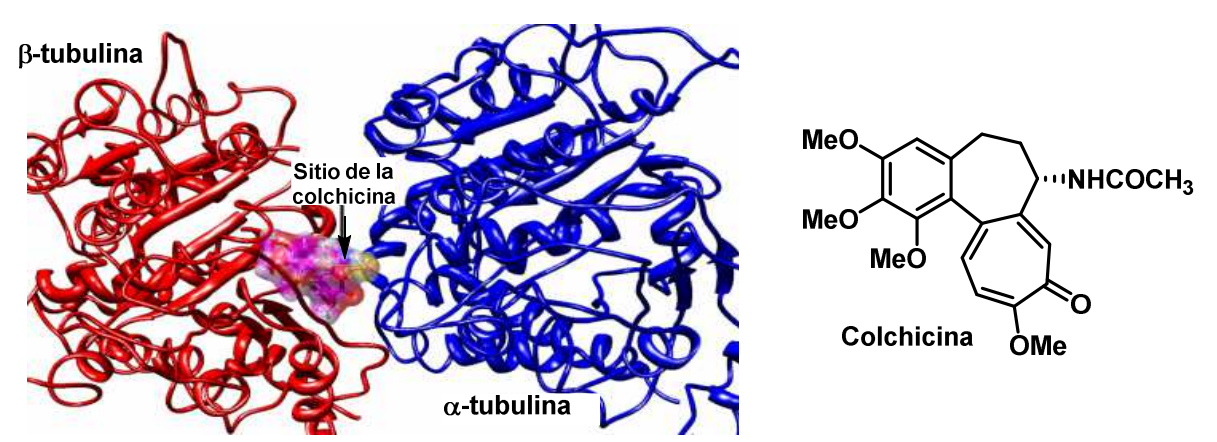

Figura 1.9. Sitio de unión de la colchicina. ${ }^{54}$

Otros compuestos antimitóticos de origen natural que se unen a la tubulina en el sitio de colchicina se indican en la figura 1.10. Estos compuestos son las combretastatinas, una clase de fenoles estilbénicos aislados de Combretum caffrum; la podofilotoxina, un alcaloide lignánico extraído de las raíces y los rizomas de especies de Podophyllum; la estaganacina, una lactona obtenida del extracto alcohólico de Steganataenia araliacea Hochest, la curacina A, obtenida de la bacteria Lyngbya majuscula y el 2-metoxiestradiol, un

\footnotetext{
${ }^{51}$ (a) Morris, P. G.; Fornier, M. N. Clin. Cancer Res. 2008, 14, 7167-7172. (b) Lu, Y.; Xiao, J. M.; Li, W.; Miller, D. D. Pharm Res. 2012, 29, 2943-2971.

${ }_{52}$ Ravelli, R.; Gigant, B.; Curmi, P.; Jourdain, I.; Lachkar, S.; Sobel, A. Nature 2004, 428, $198-$ 202.

${ }_{53}^{53}$ Keates, R. A.; Mason, G. B., Can. J. Biochem. 1981, 59, 361-370.

54 Imagen tomada de http://teleomechanist.blogspot.com.es/2008/09/memetic-algorithmsconvergence-and-pre.html
} 
metabolito endógeno formado por la acción del citocromo hepático P450 mediante hidroxilación del $\beta$-estradiol y 2-O-metilación vía catecol Ometiltransferasa.<smiles>COc1cc(/C=C\c2cc(OC)c(OC)c(OC)c2)cc(O)c1OC</smiles>

Combretastatina A-4<smiles>C=CCC(CC/C(C)=C/C=C/CC/C=C/[C@H]1CSC([C@@H]2C[C@H]2C)=N1)OC</smiles>

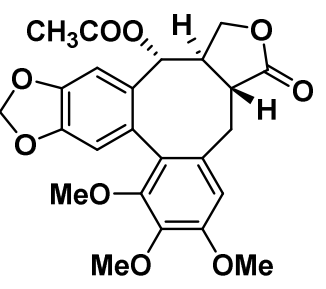

Esteganacina<smiles>COc1cc2c(cc1O)[C@@H]1CC[C@]3(C)[C@@H](O)CC[C@H]3[C@@H]1CCc1cc(O)c(O)cc1-2</smiles><smiles>COc1cc(O)cc(C(=O)c2cc(OC)c(OC)c(OC)c2)c1</smiles>

estradiol<smiles>COc1cc([C@H]2C(C#N)=C(N)Oc3c2ccc(N)c3N)cc(Br)c1OC</smiles><smiles>COc1ccc(S(=O)(=O)Nc2cccnc2Nc2ccc(O)cc2)cc1</smiles><smiles>CC(=O)Nc1nc2ccc(Sc3ccc(NC(=O)C(C)N)cc3)cc2[nH]1</smiles><smiles>CCCC(Nc1ccnc(-c2ccc(NC(=O)NCC)c(OC)c2)n1)c1cccnc1</smiles><smiles></smiles>

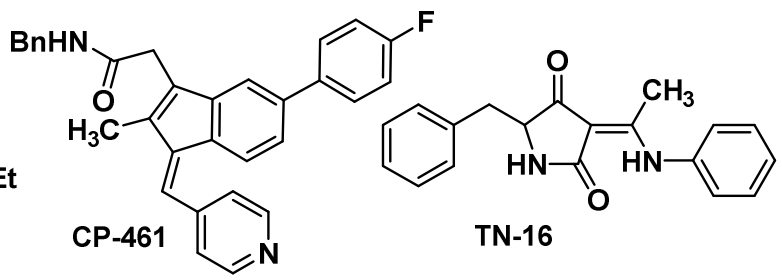

Figura 1.10. Estructuras de compuestos que se unen al sitio colchicina. 
En la figura 1.10 también se indican las estructuras de compuestos antimitóticos de origen sintético que se unen a la tubulina en el sitio de colchicina, tales como la fenstatina; la indibulina, un agente antimitótico oralmente activo contra varios tumores humanos, incluyendo los resistentes a taxanos; la crolibulina, un compuesto sintético de tipo 4-aril-4H-cromeno; la denibulina, que contiene una función de tipo carbamato de benzimidazol; el nocodazol; la sulfonamida ABT-751 y los compuestos CYT-997, Cl-980, MPC6827, CP-461 y TN-16. ${ }^{55}$

Los alcaloides de la vinca se unen a la tubulina en el denominado sitio vinca. Entre esta clase de compuestos cabe mencionar a la vinblastina y a la vincristina, aisladas de la planta Catharanthus roseus o vinca de Madagascar, y a los derivados semisintéticos vindesina $\left(\right.$ Enison $^{\circledR}$ ) y vinorelbina $\left(\right.$ Navelbine $\left.{ }^{\circledR}\right) .{ }^{56}$
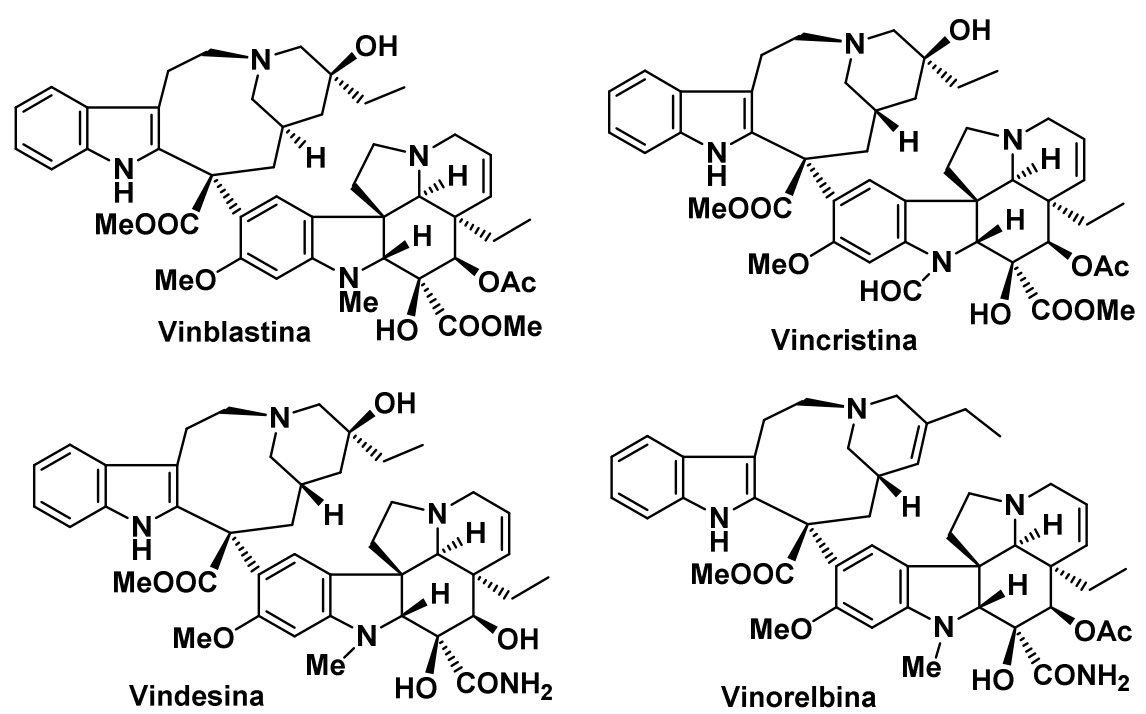

Figura 1.11. Estructuras de alcaloides de la vinca y derivados.

\footnotetext{
${ }^{55}$ Lu, Y.; Chen, J.; Xiao, M.; Li, W.; Miller, D. D. Pharm Res. 2012; 29, 2943-2971.

${ }^{56}$ (a) Johnson, I. S.; Armstrong, J. G.; Gorman, M.; Burnett J. P. Cancer Res. 1963, 23, 13901427. (b) Noble, R. L. Biochem. Cell Biol. 1990, 68, 1344-1351. (c) Kruczynski, A.; Hill, B. T. Crit. Rev. Oncol. Hematol. 2001, 40, 159-173. (d) Moudi, M.; Go, R.; Yien, C. Y. S.; Nazre, M. Int J. Prev. Med. 2013, 4, 1231-1235.
} 
La tubulina es muy difícil de estudiar mediante cristalografía debido a su tendencia a agregarse y formar microtúbulos. La estatmina ha resultado muy útil en los estudios cristalográficos de la tubulina porque los complejos estatmina-tubulina son relativamente fáciles de cristalizar. En la figura $1.12 \mathrm{se}$ puede observar un complejo estatmina (magenta) con dos heterodímeros de tubulina (en colores azul y cian) que llevan asociados una molécula de colchicina (amarillo) y una de vinblastina (rojo). ${ }^{57}$ La vinblastina (en rojo) se coloca como una cuña en la interfaz entre la alfa y la beta-tubulina.

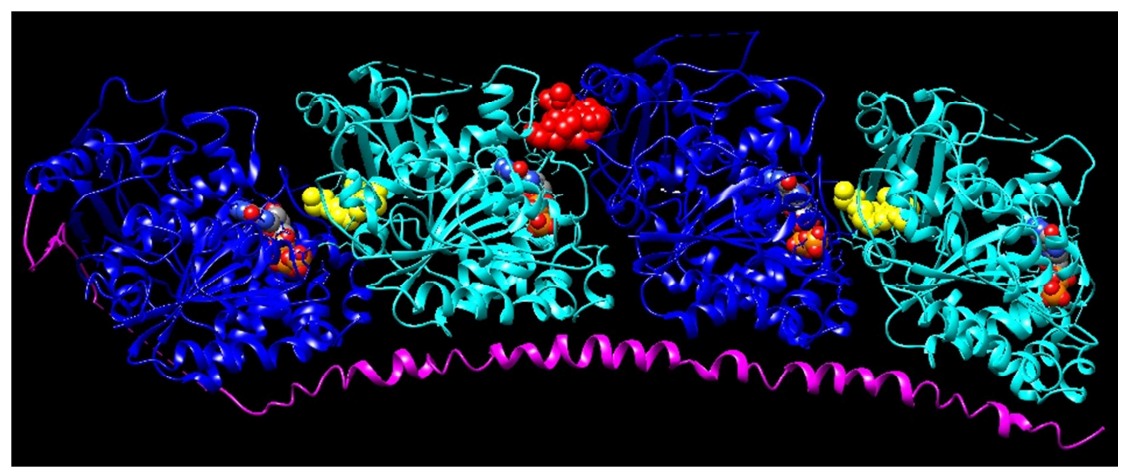

Figura 1.12. Complejo estatmina-tubulina con colchicina (amarillo) y vinblastina (rojo). ${ }^{58}$

La unión de los alcaloides de la vinca a la tubulina es rápida y reversible. Esta unión disminuye la tasa de treadmilling e impide el normal ensamblaje del huso mitótico. Como resultado se rebaja la tensión que ejercen los cinetocoros sobre los cromosomas, la mitosis se retrasa en metafase y los cromosomas se quedan pegados en el ecuador del huso mitótico, incapaces de viajar hacia los polos del huso. La señal del ciclo celular que permite progresar desde metafase a anafase se bloquea y la célula entra en apoptosis. ${ }^{59}$

${ }^{57}$ Gigant, B.; Wang, C.; Ravelli, R. B.; Roussi, F.; Steinmetz, M. O.; Curmi, P. A.; Sobel, A., Knossow, M. Nature 2005, 435: 519-522.

${ }^{58}$ PDB $1 z 2 b$.

59 (a) Himes, R. H. Pharmacol. Ther.1991, 51, 257-267. (b) Jordan, M. A.; Thrower, D.; Wilson, L. Cancer Res. 1991, 51, 2212-2222. (c) Donoso, R. J.; Jordan, M. A.; Farrell, K. W.; et al. Biochemistry 1993, 32, 1285-1293. 
La vinblastina se administra en el tratamiento de la enfermedad de Hodgkin, el linfoma no-Hodgkin, el cáncer testicular, de mama, pulmonar, de cabeza y cuello, de vejiga y en el coriocarcinoma. ${ }^{60}$ La vincristina se emplea en el tratamiento de la leucemia aguda, sarcoma de Ewing, mieloma múltiple, cáncer de tiroides y tumores cerebrales. ${ }^{61}$

Otros productos naturales ejercen su acción antimitótica, al igual que los alcaloides de la vinca, mediante desestabilización de los microtúbulos. En la figura 1.13 se indican las estructuras de algunos de estos compuestos, como la fomopsina A, aislada del hongo Phomopsis leptostromiformis, las ustiloxinas, aisladas del hongo Ustilaginoidea virens, y de las cuales se dibuja la estructura de la ustiloxina $D$ en la figura 1.13, y la criptoficina, aislada de la cianobacteria Nostoc sp. ${ }^{62}$

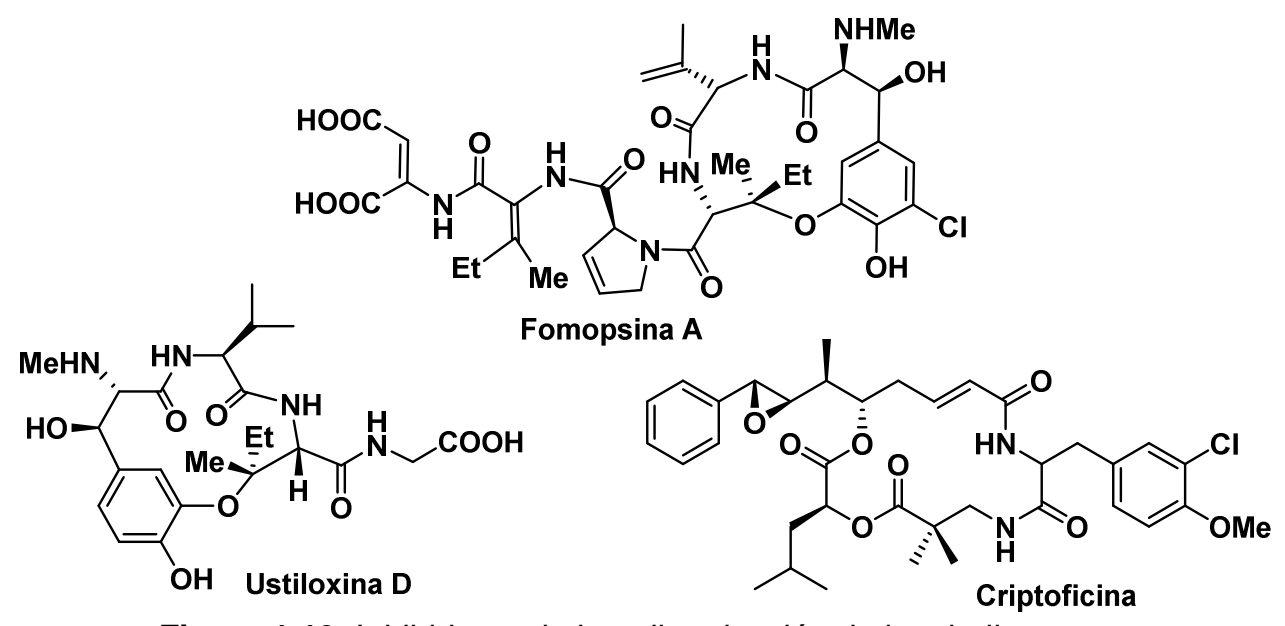

Figura 1.13. Inhibidores de la polimerización de la tubulina.

${ }^{60}$ (a) Klement, G.; Baruchel, S.; Rak, J.; Man, S.; Clark, K.; Hicklin, D. J.; Bohlen, P.; Kerbel, R. S. J. Clin. Invest. 2000, 105, R15-24. (b) Bates, D. J. P.; Salerni, B. L.; Lowrey C. H.; Eastman. A. Cancer. Biol. Ther. 2011, 12, 314-325.

${ }^{61}$ (a) Gidding, C. E.; Kellie, S. J.; Kamps, W. A.; et al. Crit. Rev. Oncol. Hematol. 1999, 29, $267-$ 287. (b) Groth-Pedersen, L; Stampe Ostenfeld, M. S.; Høyer- Hansen, M.; Nylandsted, J.; Jäättelä, M. Cancer Res. 2007, 67, 2217-2225.

62 (a) Li, Y.; Kobayashi; H.; Tokiwa, Y.; Hashimoto, Y.; Iwasaki, S. Biochem Pharmacol. 1992, 22, 219-224. (b) Ludueña, R. F.; Roach, M. C.; Prasad, V.; Banerjee, M.; Koiso, Y.; Li, Y.; Iwasaki, S. Biochem. Pharmacol. 1994, 47, 1593-1599. (c) Li, Y.; Koiso, Y.; Kobayashi, H.; Hashimoto, Y.; Iwasaki, S. Biochem. Pharmacol. 1995, 49, 1367-1372. (d) Shin, C.; Teicher, B.

A. Curr. Pharmaceutical Design 2001, 13, 1259-1276. 
Los compuestos dibujados en la figura 1.14 son compuestos antimitóticos aislados de organismos marinos. Las espongistatinas, de las cuales se representa en la figura 1.14 la espongistatina 1 , se han aislado de la esponja marina Hyrtios altum. La espongiastatinas son potentes inhibidores de la polimerización de la tubulina. ${ }^{63}$

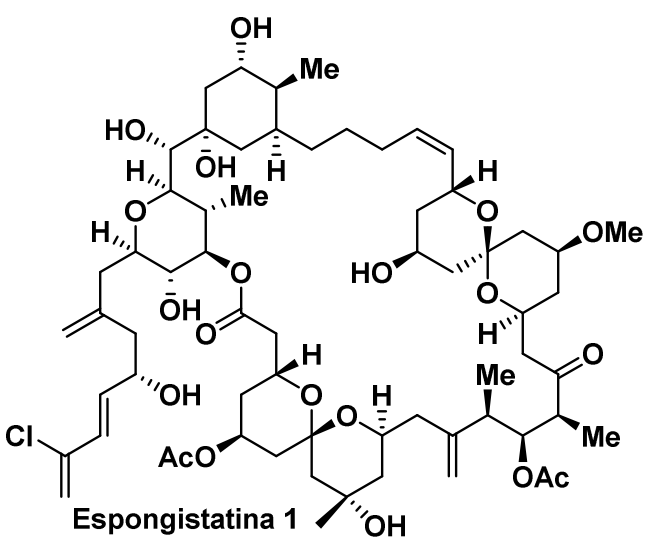

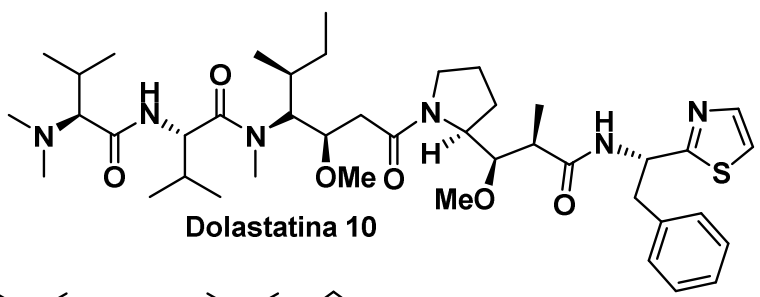<smiles>COC1=CC(=O)N(C(=O)C2OC(=O)C3C(CCN3C(=O)C3CCCN3C(=O)C(C(C)C)N(C)C(=O)[C@H](NC(=O)C(C(C)C)N(C)C)C(C)C)C(C)C2c2ccccc2OC)C1C</smiles>

Figura 1.14. Antimitóticos aislados de organismos marinos.

Las dolastatinas 10 y 15 se han aislado del molusco gasterópodo Dollabella auricularia y de la cianobacteria marina Symploca sp. VP642. Estos compuestos se han mostrado activos en líneas celulares de cáncer de mama y de hígado. ${ }^{64} \mathrm{Su}$ acción antimitótica se basa en la interrupción de la

63 (a) Hamel E. Pharmacol Ther. 1992, 55, 31-51. Bai, R.; Taylor, G. F.; Cichacz, Z. A.; Herald, C. L.; Kepler, J. A.; Pettit, G. R.; Hamel, E. Biochemistry 1995, 34, 9714-9721.

${ }^{64}$ Perez, E. A.; Hillman, D. W.; Fishkin, P. A.; Krook, J. E.; et al. Invest. New Drugs. 2005, 23, 257-261. 
polimerización de los microtúbulos, lo que provoca apoptosis y fosforilación de $\mathrm{Bcl}-2^{65}$ en diversas líneas celulares tumorales. Estos dos compuestos inhiben de manera no competitiva la unión de la vincristina a la tubulina. ${ }^{66}$

La halicondrina $B$, cuya estructura en dibuja en figura 1.15 , se ha aislado de la esponja marina Halichondria okadai. La halicondrina $B$ se une a los microtúbulos e inhibe la polimerización de la tubulina. ${ }^{67}$ La eribulina (Halaven ${ }^{\mathrm{TM}}$ ) es un análogo sintético de la halicondrina $B$, estructuralmente más simple, que se emplea en el tratamiento del cáncer de mama metastásico. $^{68}$

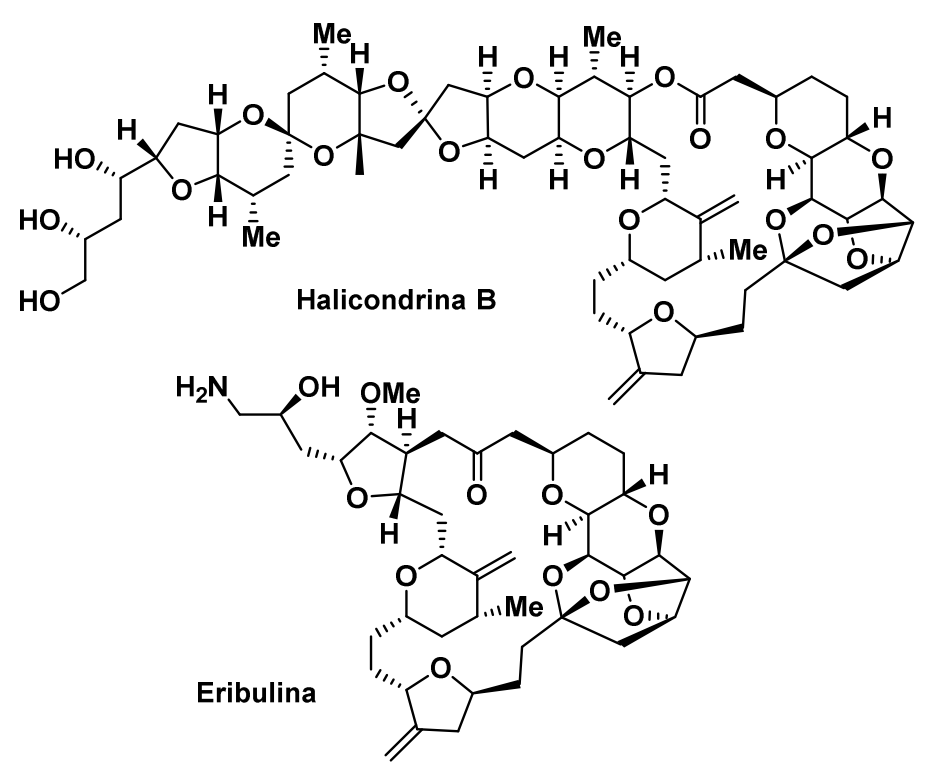

Figura 1.15. Estructuras de la halicondrina $B$ y de la eribulina.

La rhizoxina se ha aislado del hongo Rhizopus chinensis y la maytansina, se ha aislado de la planta Maytenus ovatus. Estos dos compuestos también exhiben una potente acción antimitótica mediante inhibición de la

\footnotetext{
${ }^{65}$ Las proteínas $\mathrm{Bcl}-2$ son proteínas citoplasmáticas que juegan un papel clave en la regulación de la apoptosis.

${ }^{66}$ Amador, M. L.; Jimeno, J.; Paz-Ares, L.; Cortes-Funes, H.; M. Hidalgo. Ann. Oncol. 2003, 14, 1607-1615.

${ }^{67}$ Bai, R.; Nguyen, T. L.; Burnett, J. C.; Atasoylu, O.; et al. J. Chem. Inf. Model. 2011, 51, 13931404.

${ }^{68}$ Cortes, J.; O'Shaughnessy, J.; Loesch, D.; Blum, J. L. Lancet 2011, 377, 914-923.
} 
polimerización de la tubulina ${ }^{69}$ La maytansina se administra conjugada con un anticuerpo en el tratamiento del cáncer de mama avanzado. ${ }^{70}$

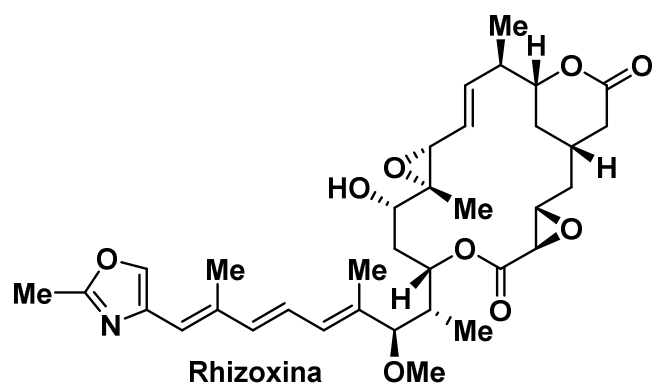

Figura 1.16. Estructuras de la rhizoxina y de la maytansina.

Mediante el análisis de la estructura cristalina de alta resolución de los complejos tubulina-maytansina y de un complejo de tubulina con una variante de rhizoxina se ha demostrado que la rhizoxina y la maytansina se unen a la $\beta$-tubulina en un sitio diferente al sitio de los alcaloides de la vinca, como se puede observar en la figura $1.17 .^{71}$

69 Takahashi, M.; Iwasaki, S.; Kobayashi, H.; Okuda, S.; Murai, T.; Sato, Y. Biochim. Biophys. Acta 1987, 926, 215-223. (b) Tolcher, A. W.; Aylesworth, C.; Rizzo, J.; Izbicka, E.; et al. Ann. Oncol. 2000, 11, 333-338. (c) Lopus, M.; Oroudjev, E.; Wilson, L.; Wilhelm, S.; Widdison, W.; Chari, R.; Jordan, M. A. Mol. Cancer Ther. 2010, 9, 2689-2699.

${ }^{70}$ (a) Luduena, R. F.; Anderson, W. H.; Prasad, V.; Jordan, M. A.; et al. Ann. N. Y. Acad. Sci. 1986, 466, 718-732 (b) Tassone, P.; Gozzini, A.; Goldmacher, V.; Shammas, M. A.; et al. Cancer Res. 2004, 64, 4629-4636. (c) Dybdal-Hargreaves, N. F.; Risinger, A. L.; Mooberry, S. L. Clin. Cancer Res. 2015, 21, 2445-2452.

${ }^{71}$ Prota, A. E.; Bargsten, K.; Diaz, J. F.; Mars, M.; Cuevas, C.; Liniger, M.; Neuhaus, C.; Andreu, J. M.; Altmann, K. H.; Steinmetz, M. O. Proc. Natl. Acad. Sci. USA 2014, 111, 13817-13821. 


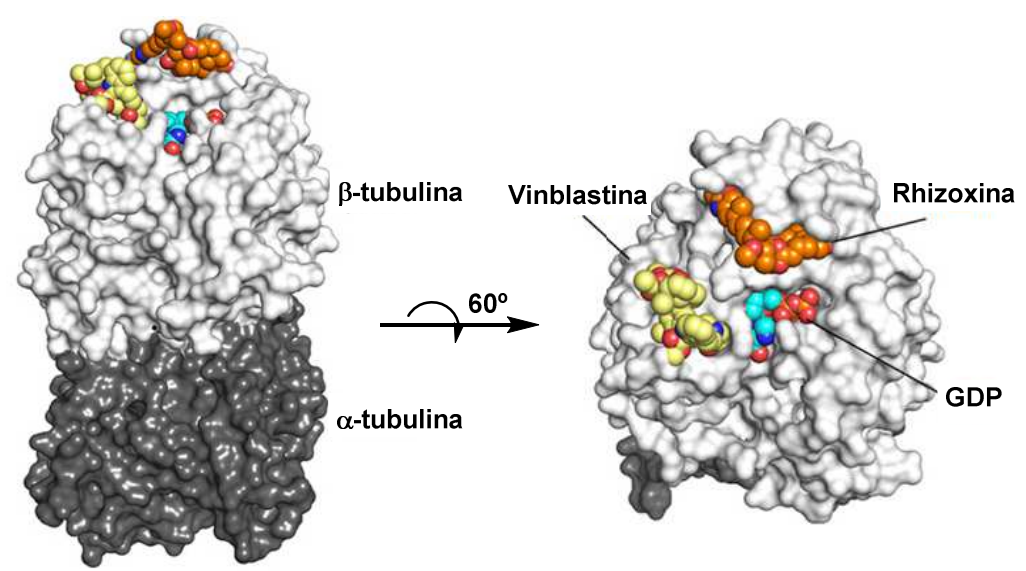

Figura 1.17. Sitios de unión de rhizoxina y de vinblastina a tubulina. ${ }^{72}$

Los diferentes sitios de unión de vinblastina y de la rhizoxina a la tubulina explican su diferente mecanismo de acción en el proceso de desestabilización de los microtúbulos. Así, la vinblastina se une al microtúbulo en la interfaz entre la $\alpha$ - y la $\beta$-tubulina, inhibiendo la transición conformacional curvadarecta que se requiere para la construcción del microtúbulo y/o favoreciendo la formación de oligómeros anulares curvos, no compatibles con la estructura recta de los microtúbulos. Por el contrario, la rhizoxina se une a la $\beta$-tubulina en un sitio que está implicado en la formación de contactos longitudinales entre los protofilamentos. El efecto desestabilizador de los microtúbulos por la rhizoxina se lleva a cabo mediante unión al extremo (+), lo que impide la adición de nuevos dímeros de tubulina o mediante la formación complejos con la tubulina en disolución que son incapaces de polimerizar y formar los microtúbulos.

Los taxanos, entre los que destacan el paclitaxel $\left(\right.$ Taxol $\left.^{\circledR}\right)$, metabolito aislado de la corteza del Taxus brevifolia ${ }^{73}$ y su análogo semisintético el docetaxel (Taxotere ${ }^{\circledR}$ ), son compuestos estabilizantes de los microtúbulos. ${ }^{74}$

\footnotetext{
${ }_{72}^{72}$ Figura tomada de la referencia 71.

${ }^{73}$ (a) Cragg, C.; Boyd, M.; Cardelina II, J.; Newman, D.; Snader, K.; McCloud, T. Ethnobotany and drug discovery: the experience of the US National Cancer Institute. Ethnobotany and search
} 


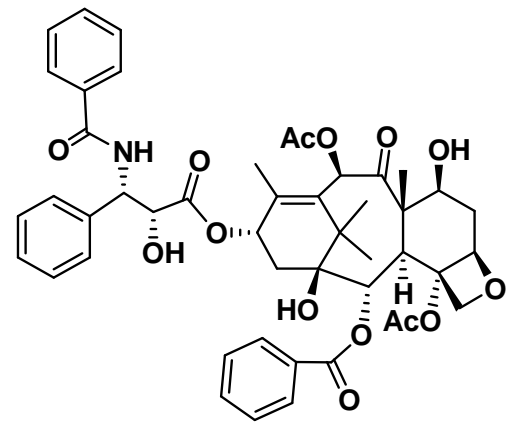

Paclitaxel (Taxol®)

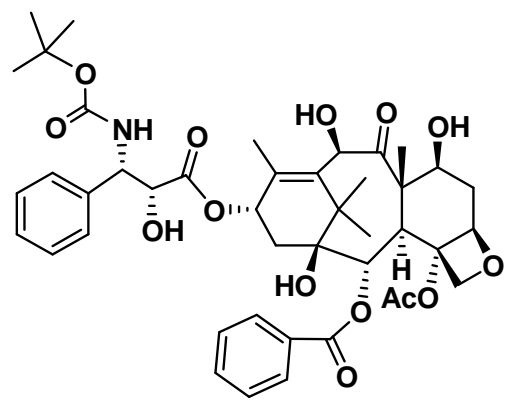

Docetaxel (Taxotere $\left.{ }^{\circledR}\right)$

Figura 1.18. Estructuras del paclitaxel y del docetaxel.

El paclitaxel se une con baja afinidad a la tubulina soluble pero se une con alta afinidad a la subunidad de $\beta$-tubulina en la parte interior del tubo que forma el microtúbulo. ${ }^{75}$ El paclitaxel accede al sitio de unión mediante difusión a través de pequeñas aperturas en la pared del microtúbulo. ${ }^{76}$ En la figura 1.19 se representa un heterodímero de tubulina ( $\alpha$-tubulina en azul y $\beta$-tubulina en cian) unido a paclitaxel (en magenta).

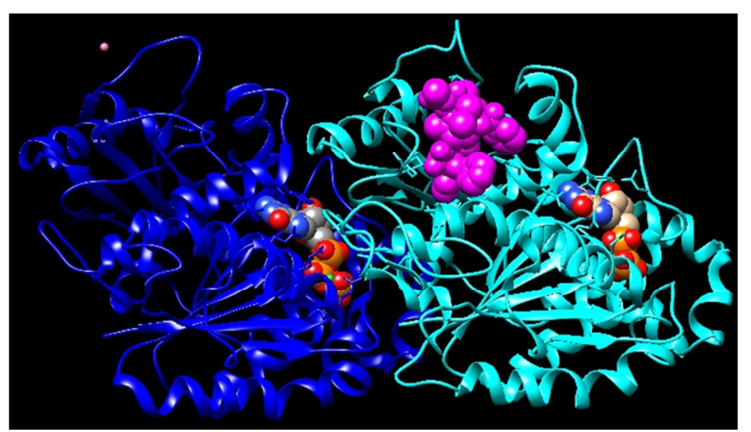

Figura 1.19. Sitio de unión del paclitaxel (magenta) a la tubulina. ${ }^{77}$

for new drugs. Wiley \& Sons. 1994, 178. (b) Vega-Ávila, E.; Velasco-Lezama, R.; JiménezEstrada, M. Bioquímia 2006, 31, 97-111. (c) Nirmala, M. J.; Samundeeswari, A.; Sankar, P. D. Res. Plant. Biol. 2011, 13, 1-14.

${ }^{74}$ (a) Dewick, P. M. Medicinal Natural Products, John Wiley and Sons, 2ํㅡ. Ed., 2002. (b) Bioactive Natural Products (Attaur-Rahman, Ed.), Elsevier, 2007. (c) Chen, J. et al. Mini-Rev. Med. Chem. 2009, 9, 1174-1190.

${ }^{75}$ Nogales, E.; Wolf, S. G.; Khan, I. A.; Luduena, R. F.; Downing, K. A. Nature 1995, 375, 424427.

${ }^{76}$ Nogales, E. Annu. Rev. Biophys. Biomol. Struct. 2001, 30, 397-420.

77 PDB 1jff. 
Por cada molécula de tubulina hay un sitio de unión de paclitaxel y la capacidad de éste para incrementar la polimerización se asocia con una estequiometría 1:1 paclitaxel-tubulina en los microtúbulos. Por tanto, si un microtúbulo consiste en la unión de 10000 moléculas de tubulina, el incremento de la polimerización requiere la unión de $\sim 5000$ moléculas de paclitaxel. El elevado número de moléculas de paclitaxel que se necesitan para incrementar la polimerización contrasta con el escaso número de moléculas de paclitaxel que hacen falta para estabilizar la dinámica de los microtúbulos. Por ejemplo, basta una sola molécula de paclitaxel, por cientos de moléculas de tubulina del microtúbulo, para reducir la velocidad de alargamiento del microtúbulo en un $\sim 50 \%{ }^{78}$ El paclitaxel provoca el bloqueo de la mitosis, así por ejemplo en células HeLa, la mitosis se bloquea en metafase/anafase con una concentración $8 \mathrm{nM}$ de paclitaxel. ${ }^{79}$ La supresión de la dinámica de los microtúbulos por los taxanos impide el paso del ciclo celular desde metafase a anafase y provoca la entrada de las células en apoptosis. ${ }^{80}$

La unión del paclitaxel a la $\beta$-tubulina estabiliza el microtúbulo incrementándose el proceso de polimerización al inducir un cambio conformacional en la tubulina. ${ }^{81}$ En la figura 1.20 se representa el proceso de estabilización de los microtúbulos como consecuencia de la unión del paclitaxel a la $\beta$-tubulina.

\footnotetext{
${ }_{79}^{78}$ Derry, W. B.; Wilson, L.; Jordan, M. A. Biochemistry 1995, 34, 2203-2211.

79 Jordan, M. A.; Toso, R. J.; Thrower, D.; Wilson, L. Proc. Natl Acad. Sci. USA 1993, 90, $9552-$ 9556.

80 (a) Kelling, J.; Sullivan, K.; Wilson, L.; Jordan, M. A. Cancer Res. 2003, 63, 2794-2801. (b) Fu, Y.; Li, S.; Zu, Y.; Yang, G.; Yang, Z.; Luo, M.; Jiang, S.; Wink, M.; Efferth, T. Curr. Med. Chem. 2009, 16, 3966-3985.

${ }^{81}$ Alushin, G. M.; Lanser, G. C.; Kellogg, E. H.; Zhang, R.; Baker, D.; Nogales, E. Cell 2014, 157, 1117-1129.
} 


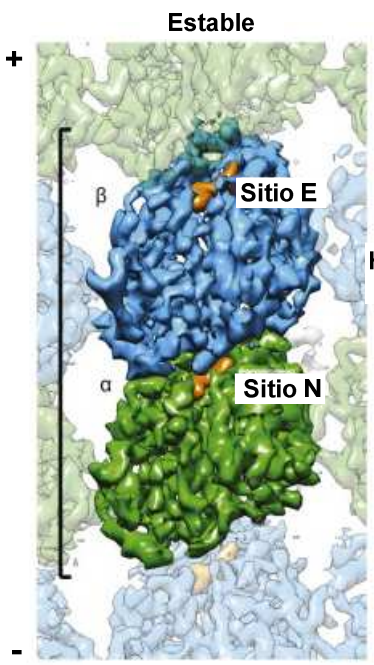

Estado GTP

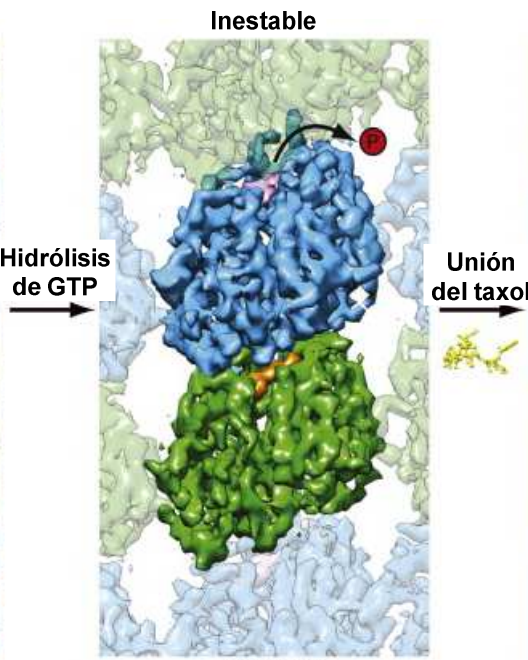

Estado GDP

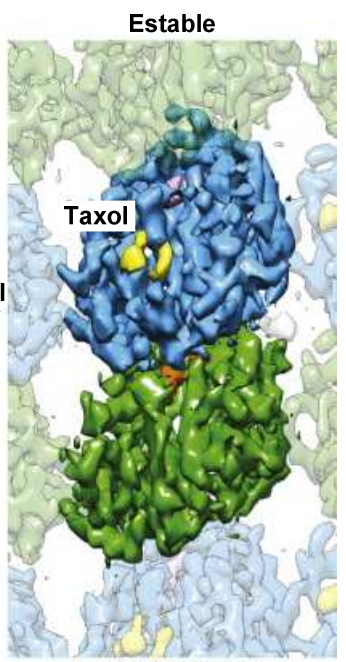

Estado GDP-taxol

Figura 1.20. Estabilización del microtúbulo por unión del taxol. ${ }^{82}$

El mecanismo de estabilización del microtúbulo por la unión del paclitaxel se ha explicado recientemente. ${ }^{81}$ Así, se ha demostrado que la hidrólisis de GTP y la liberación del fosfato conduce a una compactación del sitio $\mathrm{E}$ y a una reordenación de la subunidad de a-tubulina. Esta reordenación provoca una tensión en el microtúbulo que desestabiliza su estructura. La unión del taxol a la $\beta$-tubulina revierte la compactación del sitio $E$, restaurando la estructura estable del microtúbulo, tal y como se representa en la figura $1.21{ }^{83}$

\footnotetext{
${ }^{82}$ Figura tomada de la referencia 81.

${ }^{83}$ Figura modificada de la referencia 81.
} 


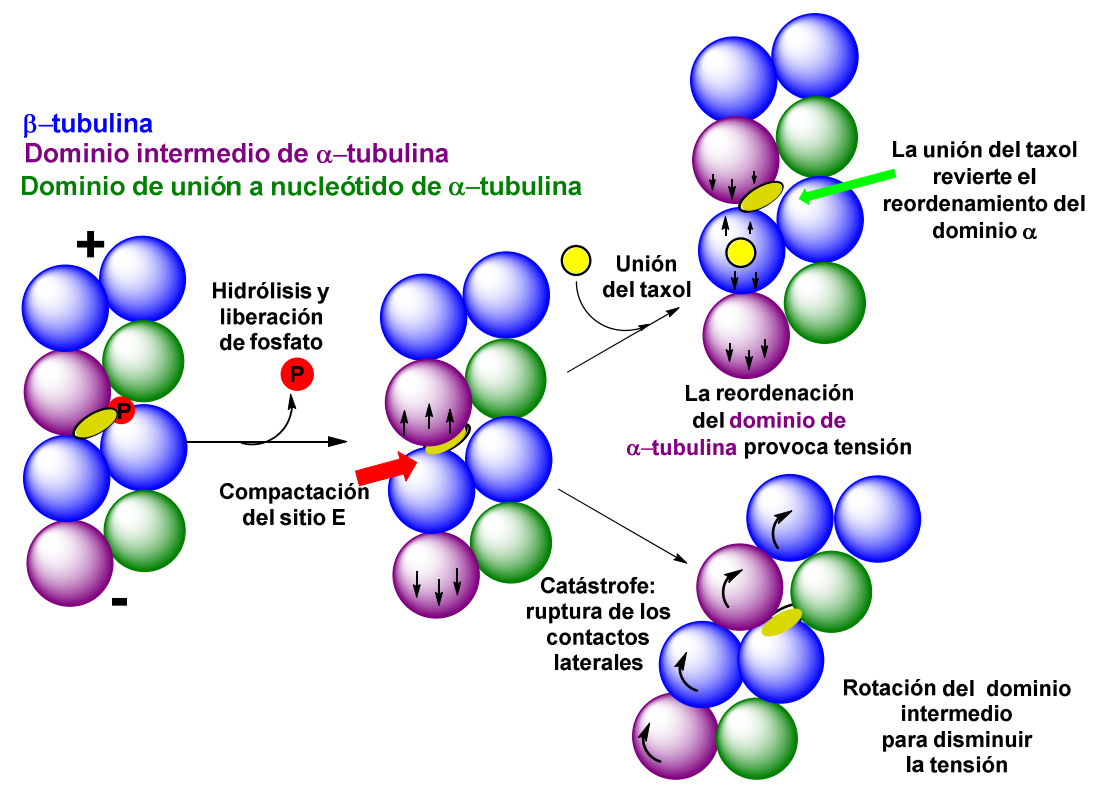

Figura 1.21. Representación esquemática de la acción estabilizante del taxol.

El paclitaxel y el docetaxel se emplean en el tratamiento del cáncer de mama y del cáncer no microcítico de pulmón. El paclitaxel está indicado también en el tratamiento del carcinoma avanzado de ovario, mientras que el docetaxel se emplea también contra el cáncer de próstata metastático independiente de andrógenos, el adenocarcinoma gástrico y el carcinoma de células escamosas de cuello y cabeza localmente avanzado. Cabe destacar que, unido a las ventajas que le aporta la mayor solubilidad en agua con respecto al paclitaxel, aunque ambos son bastante insolubles, el docetaxel se muestra más activo que su predecesor natural en el tratamiento de ciertos tipos de cáncer. ${ }^{84}$

84 (a) Slichenmyer, W. J.; Von Hoff, D. D. Anticancer Drugs 1991, 519-530. (b) Jones, S. E.; Erban, J.; Overmoyer, B.; Budd, G. T.; Hutchins, L.; Lower, E.; Laufman, L.; Sundaram, S.; Urba, W. J.; Pritchard, K. I.; Mennel, R.; Richards, D.; Olsen, S.; Meyers, M. L.; Ravdin. P. M. J. Clin. Oncol. 2005, 23, 5542-5551. (c) Montero, A.; Fossella, F.; Hortobagyi, G.; Valero, V. Lancet Oncol. 2005, 6, 229-239. (d) Marupudi, N. I.; Han, J. E.; Li, K. W.; Renard, V. M.; Tyler, B. M.; Brem, H. Expert Opin Drug Saf. 2007, 6, 609-621. (e) Weaver, B. A. Mol. Biol. Cell. 2014, 25, 2677-2681. 
En la figura 1.22 se indican las estructuras de las epotilonas A-F junto con la de un azaanálogo sintético denominado ixabepilona. Las epotilonas se han aislado de los extractos de la bacteria Gram-negativa Sorangium cellulosum. ${ }^{85}$ Las epotilonas favorecen la polimerización de los microtúbulos y suprimen la dinámica de los microtúbulos mediante un mecanismo similar al de los taxanos. ${ }^{86}$ Esta acción provoca la parada del ciclo celular en fase G2/M. ${ }^{87}$.

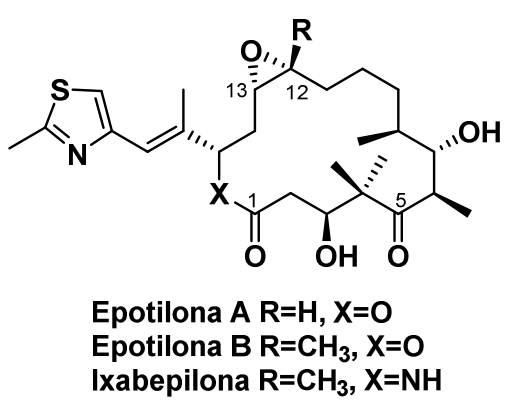

Figura 1.22. Estructuras de las epotilonas $A-F$ y de la ixabepilona.

Algunos autores afirman que las epotilonas y los taxanos poseen un farmacóforo común para su unión a los microtúbulos, ${ }^{88}$ pero la unión a la tubulina de compuestos con estructuras químicas tan diferentes más bien apunta a la existencia de un bolsillo de unión promiscuo que acepta la unión de moléculas muy disímiles. Así, estudios sobre la levadura de Saccharomyces cerevisiae han demostrado que los microtúbulos de dicho organismo son estabilizados por epotilonas pero no por el paclitaxel, muy probablemente como resultado de las diferencias en las interacciones que enlazan a estos fármacos. ${ }^{89}$

\footnotetext{
${ }^{85}$ (a) Hoefle, G.; Bedorf, N.; Gerth, K.; Reichenback, H. Patent DE 4138042, 1993. (b) Gerth, K.; Bedorf, N.; Hoefle, G.; et al. J. Antibiot. 1996, 49, 560 -563.

${ }^{86}$ Kowalski, R. J.; Giannakakou P.; Hamel, E. J. Biol. Chem. 1997, 272, 2534-2541.

87 (a) Bollag, D. M.; McQueney, P. A.; Zhu, J.; et al. Cancer Res. 1995, 55, 2325-2333. (b) Goodin, S.; Kane, M. P.; Rubin, E. H. J. Clin. Oncol. 2004, 22, 2015-2025.

${ }^{88}$ (a) Ojima, I.; Chakravarty, S.; Inoue, T.; et al. Proc. Natl. Acad. Sci. USA 1999, 96, 42564261. (b) Giannakakou, P.; Gussio, R.; Nogales, E.; et al. Proc. Natl. Acad. Sci. USA 2000, 97, 2904-2909.

${ }^{89}$ Bode, C. J.; Gupta, M. L. Jr.; Reiff, E. A.; et al. Biochemistry 2002, 41, 3870-3874.
} 
La estructura del complejo epotilona A/tubulina se ha determinado mediante cristalografía electrónica. ${ }^{90} \mathrm{La}$ molécula de epotilona $A$, más pequeña que la de taxol, ocupa la mitad del sitio de unión del taxol en la cavidad de la $\beta$-tubulina (véase la figura 1.23). Además, la cavidad se ajusta al sustrato reorientando las cadenas laterales de los aminoácidos, a fin de optimizar las interacciones con la epotilona, un proceso conocido como ajuste inducido. Las interacciones de la epotilona $A$ con la $\beta$-tubulina difieren apreciablemente de las que establece el taxol con esta proteína, ya que con la excepción del enlace de hidrógeno entre 7-OH y Arg-282, no existen otras interacciones de grupos homólogos del taxol y de la epotilona $A$ con la $\beta$ tubulina.
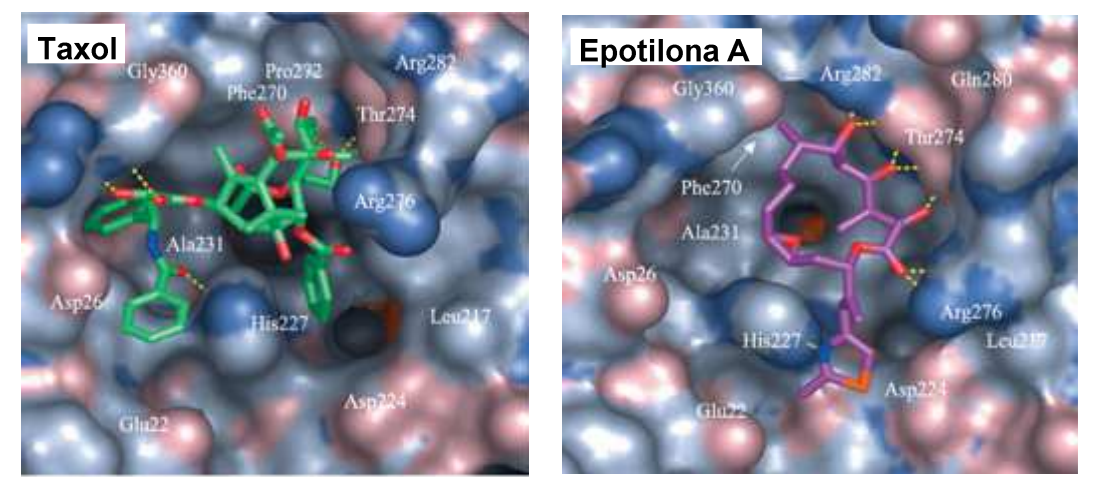

Figura 1.23. Colocación del taxol y de la epotilona $A$ en la $\beta$-tubulina. ${ }^{91}$

Las modificaciones estructurales en las epotilonas afectan a su actividad biológica. Así, la presencia del grupo metilo en la posición C-12 de la epotilona $B$ hace que ésta sea dos veces más activa que la epotilona $A$ en la inducción de la polimerización in vitro de la tubulina. ${ }^{92}$ Sin embargo, la presencia del anillo oxiránico no es vital para la unión de la epotilona al microtúbulo, pues la

\footnotetext{
${ }^{90}$ (a) Heinz, D. W.; Schubert, W-D.; Höfle, G. Angew. Chem. Int. Ed. 2005, 44, 1298-1301. (b) Véase también Ranade, A. R.; Higgins, L.; Markowski, T. W.; Glaser, N.; Kashin, D.; Bai, R.; Hong, K. H.; Hamel, E.; Höfle, G.; Georg, G. I. J. Med. Chem. 2016, 59, 3499-3514.

${ }^{91}$ Figura tomada de la referencia $90 \mathrm{a}$.

92 Nicolaou, K. C.; Winssinger, N.; Pastor, J.; et al. Nature 1997, 387, 268-272.
} 
epotilona $D$, que carece del anillo oxiránico, ha demostrado tener in vitro mayor capacidad estabilizante de los microtúbulos que la epotilona A o la B. ${ }^{93}$

La ixabepilona es un azaanálogo de la epotilona $B$ y ha recibido la aprobación de la FDA para el tratamiento del cáncer de mama metastático resistente a antraciclinas, a taxanos y a capecitabina. ${ }^{94}$

Al contrario que el paclitaxel, las epotilonas conservan su actividad contra células resistentes que expresan la glicoproteína-P. ${ }^{95}$ Otra ventaja de las epotilonas, en comparación con los taxanos, es que aquéllas son capaces de atravesar la barrera hematoencefálica, por lo que se podrían emplear en el tratamiento de tumores cerebrales. ${ }^{96}$

La laulimalida, aislada de esponjas marinas del océano Pacífico, ${ }^{97}$ y la pelorusida A, aislada de la esponja marina Mycale hentscheli, recolectada en Nueva Zelanda, son dos macrólidas que han mostrado una potente acción antiproliferativa en cultivos celulares y efectos inhibitorios del crecimiento tumoral en ratones. ${ }^{98}$

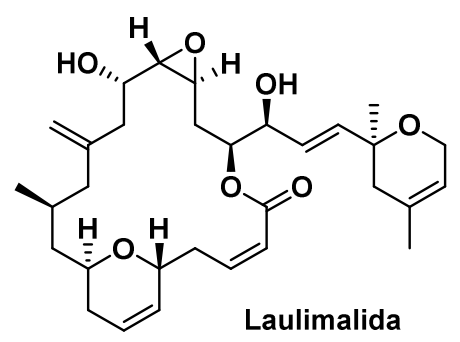

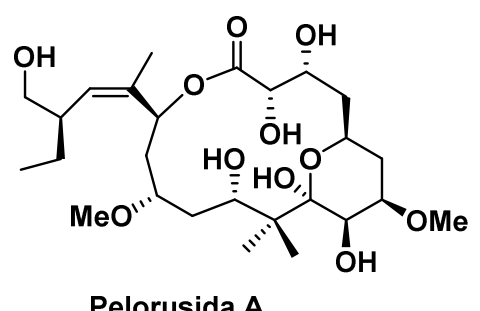

Figura 1.24. Estructuras de la laulimalida y de la pelorusida A.

La pelorusida A y la laulimalida ejercen su acción antimitótica mediante estabilización de los microtúbulos. La pelorusida A compite con la laulimalida

${ }^{93}$ Chou, T. C.; Zhang, X. G.; Balog, A.; et al. Proc. Natl. Acad. Sci. USA 1998, 95, 9642-9647.

94 Lerzo, G. L.; Lee, R. K.; Thomas, E. S. et al. J. Clin. Oncol. 2007, 25, 152. (b) Pivot, X. B.; Lee, R. K.; Thomas, E. S.; et al. J. Clin. Oncol. 2007, 25, 221. (c) Vahdat, L. T. Cancers 2010, 2, $1-19$.

${ }_{95}$ Fojo, T.; Menefee, M. Ann. Oncol. 2007, 18 (Suppl 5), v3 -8.

${ }^{96}$ Hoffmann, J.; Fichtner, I.; Lemm, M.; Lienau, P.; et al. Neuro. Oncol. 2009, 11,158-166.

97 (a) Quiñoa, E.; Kakou, Y.; Crews, P. J. Org. Chem. 1988, 53, 3642-3644. (b) Corley, D. G.; Herb, R.; Moore, R. E.; Sheuer, P. J.; Paul, V. J. J. Org. Chem. 1988, 53, 3644-3646.

${ }_{98}$ Kanakkanthara, A. Northcote, P. T.; Miller, J. H. Nat. Prod. Rep. 2016, 33, 549-561. 
por el mismo sitio de unión, ${ }^{99}$ pero el sitio de unión de estos compuestos es diferente del sitio que ocupan los taxanos y las epotilonas en la $\beta$-tubulina. ${ }^{100}$ En contraste con el sitio taxano, que se encuentra en el interior del microtúbulo, el sitio laulimalida/pelorusida $A$ se encuentra en la parte exterior del microtúbulo. Mediante el empleo de cristalografía de rayos $X$ se ha demostrado que la laulimalida y la pelorusida $A$ se unen a un sitio no taxano único en la $\beta$-tubulina y estabilizan a los microtúbulos mediante un aumento de las interacciones entre los protofilamentos. Así, la unión de estas macrólidas a la tubulina estabiliza alostéricamente el denominado bucle $\mathrm{M}$ del sitio taxano, que es el que establece los contactos laterales en los protofilamentos del microtúbulo. ${ }^{101}$ En la parte izquierda de la figura 1.25 se aprecia la laulimalida unida a la $\beta$-tubulina y en amarillo el bucle M. Esta unión estabiliza a este bucle y permite establecer contactos estabilizantes entre protofilamentos adyacentes. La unión de estas macrólidas a la tubulina también incrementa las interacciones laterales con la hélice $\mathrm{H} 3$ del protofilamento vecinal, tal y como se puede observar en la parte derecha de la figura 1.25. Este aumento de las interacciones con los protofilamentos vecinos explican el efecto promotor sobre el ensamblaje y la estabilidad de los microtúbulos que ejercen la laulimalida y la pelorusida $A$.

\footnotetext{
${ }_{99}$ Gaitanos, T. N.; Buey, R. M.; Díaz, J. F.; Northcote, P. T.; Teesdale-Spittle, P.; Andreu, J. M.; Miller, J. H. Cancer Res. 2004, 64, 5063-5067.

100 (a) Pryor, D. E.; O’Brate, A.; Bilcer, G.; Díaz. J. F.; et al. Biochemistry 2002, 41, 9109-9115. (b) Bennett, M. J.; Barakat, K.; Huzil, J. T.; Tuszynski, J.; Schriemer, D. C. Chem. Biol. 2010, 30, 725-734.

${ }^{101}$ Prota, A. E.; Bargsten, K.; Northcote, P. T.; Marsh, M.; Altmann, K-H.; Miller, J. H.; Diaz, J. F.; Steinmetz, M. O. Angew. Chem. Int. Ed. 2014, 53, 1621-1625.
} 

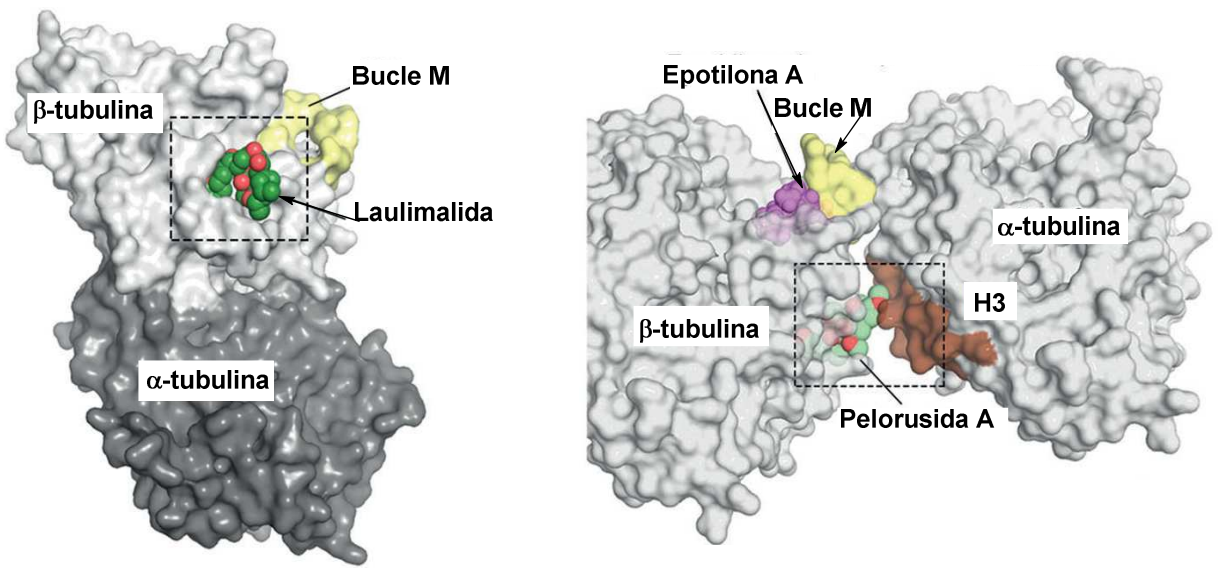

Figura 1.25. Unión de la laulimalida y de la pelorusida A a la tubulina. ${ }^{102}$

La dictiostatina y la discodermolida también son agentes estabilizantes de los microtúbulos, aunque su sitio de unión es diferente del sitio taxano. ${ }^{103}$

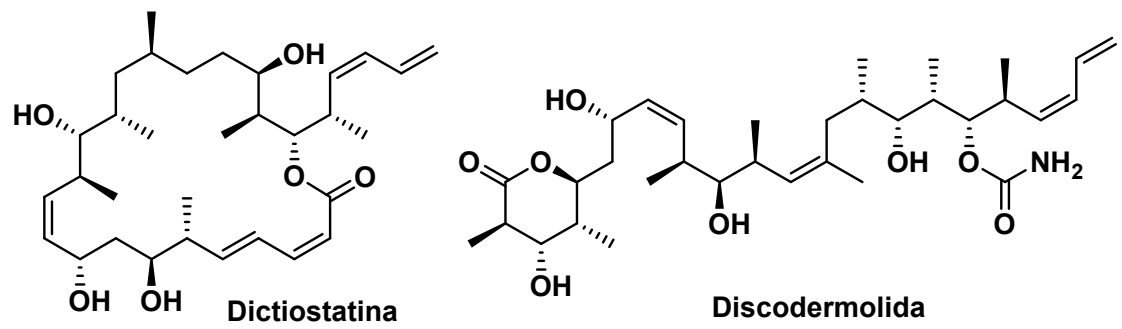

Figura 1.26. Estructuras de otras macrólidas estabilizantes de microtúbulos.

La dictiostatina se aisló en 1994 de esponjas del océano Índico. La mínima cantidad obtenida ( $1.35 \mathrm{mg}$ a partir de $400 \mathrm{~kg}$ de esponja húmeda), impidió llevar a cabo estudios biológicos en profundidad, aunque se pudieron determinar las potentes propiedades antitumorales de este compuesto. ${ }^{104}$ Casi una década después (2003), Wright y colaboradores aislaron la dictiostatina

\footnotetext{
102 Figura tomada de la referencia 101.

103 Madiraju, C.; Edler, M. C.; Hamel, E.; Raccor, B. S.; et al. Biochemistry 2005, 44, 1505315063.

${ }^{104}$ Pettit, G. R.; Cichacz, Z. A.; Gao, F.; Boyd, M. R.; Schmidt, J. M. J. Chem. Soc., Chem. Commun. 1994, 1111-1112.
} 
de esponjas de la familia corallistidae, que fueron recolectadas frente a la costa de Jamaica empleando un submarino tripulado. ${ }^{105}$

La dictiostatina muestra una potente actividad antimitótica contra líneas celulares resistentes a múltiples fármacos. La dictiostatina estabiliza los microtúbulos y acumula células en fase G2/M provocando la muerte celular por apoptosis. ${ }^{106}$

La discodermolida, aislada en 1990 de la esponja Discodermia dissoluta, es también un agente estabilizante de los microtúbulos. ${ }^{107} \mathrm{Su}$ acción estabilizante es mucho más potente que la del taxol. ${ }^{108}$

El número de compuestos que ejercen acción antimitótica mediante unión a la $\beta$-tubulina es relativalente elevado. Por el contrario, el número de compuestos antimitóticos que se unen a la $\alpha$-tubulina es mucho menor. Entre estos compuestos destaca la pironetina, un metabolito secundario aislado de Streptomyces $s p$. NK-10958 y de cultivos de fermentación de Streptomyces prunicolor PA-48153. ${ }^{109}$

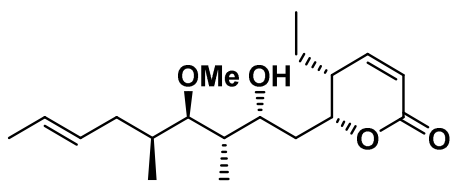

Pironetina

Figura 1.27. Estructura de la pironetina.

Recientemente se ha determinado el sitio de unión de la pironetina a la $\alpha$ tubulina mediante resolución de la estructura cristalina de un complejo

105 Isbrucker, R. A.; Cummins, J.; Pomponi, S. A.; Longley, R. E.; Wright, A. E. Biochem. Pharmacol. 2003, 66, 75-82.

${ }^{106}$ Kowalski, R. J.; Giannakakou, P.; Gunesekera, S. P.; Longley, R. E.; Day, B. W.; Hamel, E. Mol. Pharmacol. 1997, 52, 613-622.

107 Gunasekera, S. P.; Gunasekera, M.; Longley, R. E.; Schulte, G. K. J. Org. Chem. 1990, 55, $4912-4915$.

108 ter Haar, E.; Kowalski, R. J.; Hamel, E.; Lin, C. M.; Longley, R. E.: Gunasekera, S. P.; Rosenkranz, H. S.; and Day, B. W. Biochemistry 1996, 35, 243-250.

${ }^{109}$ (a) Kobayashi, S.; Tsuchiya, K.; Harada, T.; Nishide, M.; Kurokawa, T.; Nakagawa, T.; Shimada, N.; Kobayashi, K. J. Antibiot. 1994, 47, 697-702. (b) Kobayashi, S.; Tsuchiya, K.; Kurokawa, T.; Nakagawa, T.; Shimada, N.; litaka, Y. J. Antibiot. 1994, 47, 703-707. 
tubulina-pironetina. ${ }^{110}$ En la figura 1.28 se representa la estructura del complejo cuaternario que forma la pironetina enlazada a dos heterodímeros de tubulina, que, a su vez, están estabilizados por unión a la tubulina-tirosina ligasa (TTL) y a la proteína RB3 de tipo estatmina. ${ }^{111 \mathrm{~b}}$

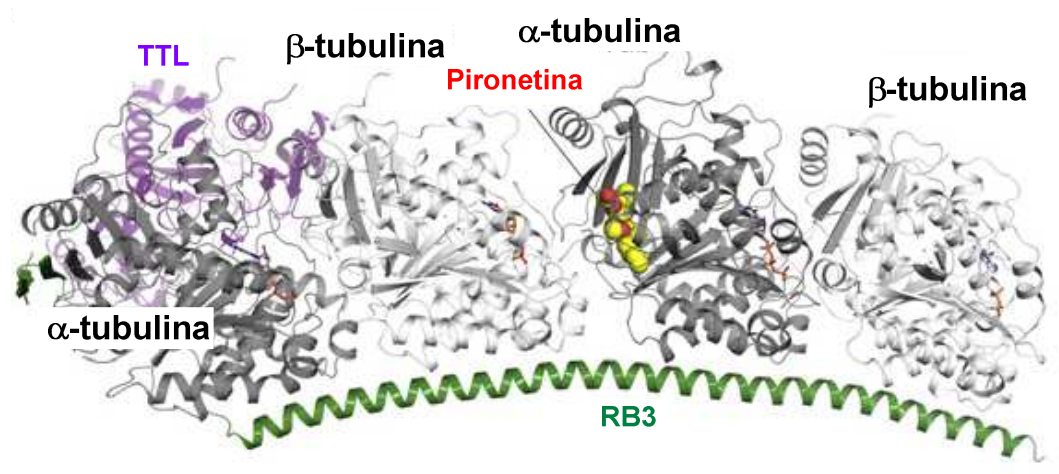

Figura 1.28. Complejo tubulina-pironetina. ${ }^{111}$

Estos análisis han permitido demostrar que la pironetina se une covalentemente a $\alpha$-tubulina mediante adición tipo Michael de la Cys-315 al sistema de lactona conjugada, tal y como se puede observar en la figura 1.29. ${ }^{110 a}$

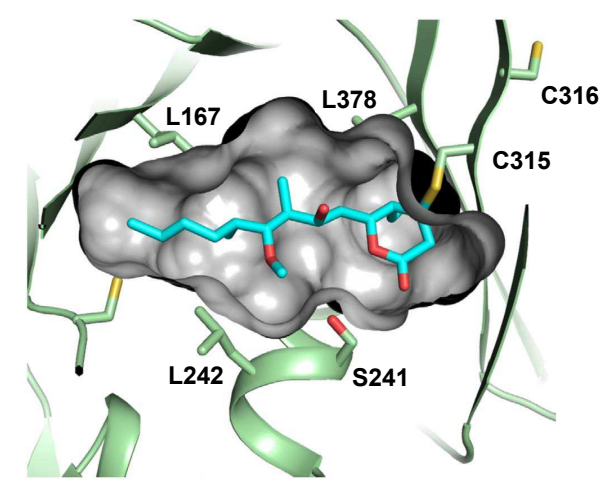

Figura 1.29. Unión covalente de la pironetina a Cys-315 de $\alpha$-tubulina. ${ }^{112}$

\footnotetext{
${ }^{110}$ (a) Yang, J.; Wang, Y.; Wang, T.; Jiang, J.; et al. Nat. Commun. 2016, 7, 12103. (b) Prota, E. A.; Setter, J.; Waight, A. B.; Bargsten, K.; Murga, J.; Diaz, J. F.; Steinmetz, M. O. J. Mol. Biol. 2016, 428, 2981-2988.

${ }_{111}$ Figura tomada de la referencia $111 \mathrm{~b}$.

${ }^{112}$ Figura tomada de la referencia 111a.
} 
La unión de la pironetina a la $\alpha$-tubulina perturba el bucle T7 y la hélice H8, dos elementos esenciales en el establecimiento de contactos entre los protofilamentos, lo que explica la acción desestabilizante que la pironetina ejerce sobre los microtúbulos.

\subsection{Combretastatinas}

Las combretastatinas son productos naturales que exhiben variadas propiedades biológicas entre las cuales cabe destacar su acción antimitótica y antiangiogénica. Las combretastatinas A-1, A-2 y A-3 fueron aisladas en 1987 de la corteza del árbol Combretum caffrum en el Sur de África e India por Pettit y colaboradores. ${ }^{113}$ La combretastatina A-4 fue aislada por estos mismos autores en 1989. ${ }^{114}$ Las estructuras de la combretastatinas A-1, A-2, A-3 y A-4 se indican en la figura 1.30 .<smiles>COc1cc(/C=C\c2ccc(OC)c(O)c2O)cc(OC)c1O</smiles><smiles>COc1ccc(/C=C\c2cc(O)c(OC)c(OC)c2)cc1O</smiles>

Combretastatina A-3<smiles>COc1ccc(/C=C\c2cc(OC)c3c(c2)OCO3)cc1O</smiles>

Combretastatina A-2<smiles>COc1ccc(/C=C\c2ccc(OC)c(OC)c2)cc1OC</smiles>

Combretastatina A-4

Figura 1.30. Estructuras de combrestastatinas $\mathrm{A}$.

De Combretum caffrum también se han aislado otras combretastatinas como la (-)-combretastatina, la combretastatina B-1 (un dihidroestilbeno) y la combretastatina C-1 (una fenantrenona, véase la figura 1.31).

${ }^{113}$ (a) Pettit, G. R.; Cragg, G. M.; Singh, S. B. J. Nat. Prod. 1987, 50, 386-391. (b) Pettit, G. R.; Singh, S. B. Can. J. Chem. 1987, 65, 2390-2396.

${ }_{114}$ Pettit, G. R.; Singh, S. B.; Hamel, E.; Lin, C. M.; Alberts, D. S.; Garcia-Kendall, D. Experientia 1989, 45, 209-211. 
<smiles>COc1ccc(C[C@H](O)c2cc(OC)c(OC)c(OC)c2)cc1O</smiles>

(-)-Combretastatina<smiles>COc1ccc(CCc2cc(OC)c(OC)c(OC)c2)c(O)c1O</smiles>

Combretastatina B-1<smiles>COC1=C(OC)C(=O)c2c(ccc3cc(O)c(OC)cc23)C1=O</smiles>

Combretastatina C-1

Figura 1.31. Estructuras de otros combretastatinas.

Las combretastatinas D-1 y D-2 también se han aislado de Combretum caffrum ${ }^{115}$ pero su estructura difiere de las anteriores combretastatinas ya que aquéllas contienen un anillo macrolactónico biarílico en su estructura (véase la figura 1.32). Un compuesto relacionado, denominado combretastatina D-4, ha sido aislado de Getonia floribunda (Combretaceae). ${ }^{116}$<smiles>O=C(CCc1ccc(O)c(Oc2ccc(C3CO3)cc2)c1)OCC1CO1</smiles>

Combretastatina D-1<smiles>O=C1C=Cc2ccc(cc2)Oc2cc(ccc2O)CC1</smiles>

Combretastatina D-2<smiles>O=C(O)CCc1ccc(O)c(Oc2ccc(CCCOC(=O)O)cc2)c1</smiles>

Combretastatina D-4

Figura 1.32. Estructuras de combretastatinas D.

Las combretastatinas inducen muerte celular al enlazarse selectivamente a la tubulina deteniendo el ciclo celular en los estados de transición de meta a anafase. ${ }^{117}$

La combretastatina A-4 es el agente antitumoral más potente de la familia de las combretastatinas. Además de su acción antimitótica, la combretastatina A-4 provoca cambios en el citoesqueleto y por lo tanto en la morfología de las células endoteliales. Estos cambios explican la actividad antiangiogénica de la

115 (a) Pettit, G. R.; Singh, S. B.; Niven, M. L. J. Am. Chem. Soc. 1988, 110, 8539-8540. (b) Singh, S. B.; Pettit, G. R. J. Org. Chem. 1990, 55, 2797-2800.

116 Vongvanich, N.; Kittakoop, P.; Charoenchai, P.; Intamas, S.; Danwisetkanjana, K.; Thebtaranonth, Y. Planta Med. 2005, 71, 191-193. Para una síntesis de combretastatinas D véase Harras, M.; Milius, W.; Aitken, R. A.; Schobert, R. J. Org. Chem. 2017, 82, 579-587.

117 Fürst, R.; Zupkó, I.; Berényi, A.; Ecker, G.; Rinner, U. Bioorg. Med. Chem. Lett. 2009, 19, 6948-6951. 
combretastatina A-4 al aumentar la permeabilidad vascular y provocar la disrupción del flujo sanguíneo del tumor, lo que lleva a su necrosis isquémica. ${ }^{118}$

La combretastatina A-4 es de todas las combretastatinas la que muestra mayor inhibición del ensamblaje de los microtúbulos. ${ }^{119}$ Estudios de relación estructura-actividad han demostrado que el sistema de cis-estilbeno de la combretastatina A-4 coloca a los dos anillos aromáticos con una inclinación entre ellos de $50^{\circ}-60^{\circ}$ y que esta inclinación juega un papel clave en la unión al sitio de la colchicina en la tubulina. ${ }^{120}$ El anillo trimetoxifenílico (anillo A) de la combretastatina A-4 es clave en su capacidad citotóxica y su actividad inhibidora de polimerización de tubulina. Se ha demostrado que las sustituciones en este anillo dan lugar a compuestos con menor actividad (véase la figura 1.33). ${ }^{121}$

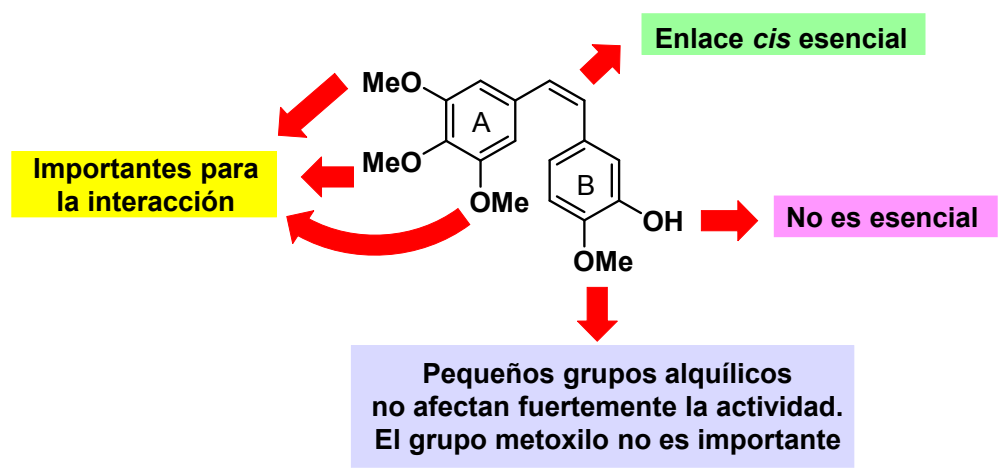

Figura 1.33. Relaciones estructura-actividad en la combretastatina A-4.

Las modificaciones funcionales en el anillo $B$ de la combretastatina A-4 ejercen menos influencia en su actividad biológica. Por ejemplo, el cambio del

118 (a) Hori, K.; Saito, S.; Kubota K. Br J Cancer 2002, 86, 1604-1614. (b) West, C. M. L.; Price, P. Anti-Cancer Drugs 2004, 3, 179-187. (c) Kim, T. J., Ravoori, M., Landen, C. N:, Kamat, A. A.; et al. Cancer Res. 2007, 67, 9337-9345.(d) Cai, S. X. Recent Pat. Anticancer Drug Discov. 2007, 2, 79-101.

${ }_{119}$ Lin, C. M.; Ho, H. H.; Pettit, G. R.; Hamel, E. Biochemistry 1989, 28, 6984-6991.

120 Woods, J. A.; Hadfield, J. A.; Pettit, G. R.; Fox, B. W.; McGown, A. T. Br. J. Cancer, 1995, 71, 705-711.

${ }^{121}$ (a) Gaukroger, K.; Hadfield, J.; Lawrence, N.J.; Nolan, S.; McGown, A. T. Org. Biomol. Chem. 2003, 1, 3033-3037. (b) Álvarez-Lozano. Antimitóticos relacionados con combretastatinas y fenstatinas. Tesis Doctoral. 2009. Universidad de Salamanca. 
grupo metoxilo del anillo B no genera compuestos más activos. La sustitución del grupo hidroxilo del anillo B por un bromo mantiene la potencia antimitótica y la introducción de grupos amino la aumenta, a la vez que se mejora la solubilidad en agua. ${ }^{122}$ La sustitución del anillo B por anillos de menos de 6 miembros conlleva una pérdida de actividad. Sin embargo, su reemplazo por sistemas bicíclicos no provoca disminución de la actividad. ${ }^{123}$

La configuración cis del doble enlace es clave en la actividad de las combretastatinas. Se ha demostrado que los isómeros trans no causan inhibición de la polimerización de la tubulina en ensayos in vitro. Es conveniente indicar la fácil isomerización que experimentan las combretastatinas al más estable isómero trans durante su almacenamiento, su administración o su disolución en disolventes próticos. ${ }^{124}$

Muy recientemente Steinmetz y colaboradores han confirmado, mediante resolución de la estructura cristalina de un complejo tubulina-combretastatina A4, que el sitio de unión de la combretastatina A-4 a la $\beta$-tubulina es el sitio de colchicina. $^{125}$ En la figura 1.34 se representa la estructura del complejo cuaternario que forma la combretastatina A-4 enlazada a dos heterodímeros de tubulina, que, a su vez, están estabilizados por unión a la tubulina-tirosina ligasa (TTL) y a la proteína RB3 similar a estatmina.

\footnotetext{
122 Tron, G.; Pirali, T.; Sorba, G.; Pagliai, F.; Busacca, S.; Genazzani, A. J. Med. Chem. 2006, 49, 3033-3044.

${ }^{123}$ Maya, A. B.; Pérez-Melero, C.; Mateo, C.; Alonso, D.; Fernández, J. L.; Gajate, C.; Mollinde, F.; Pélaez, R.; Caballero, E.; Medarde, M. J. Med. Chem. 2005, 48, 556-558.

${ }_{124}$ Schobert, R.; Effenberg-Neidnicht, K.; Biersack, B. Int. J. Clin. Pharmacol. Ther. 2011, 49, 71.

125 Gaspari, R.; Prota, A. E.; Bargsten, K.; Cavalli, A.; Steinmetz, M. O. Chem 2017, 2, 102-113.
} 


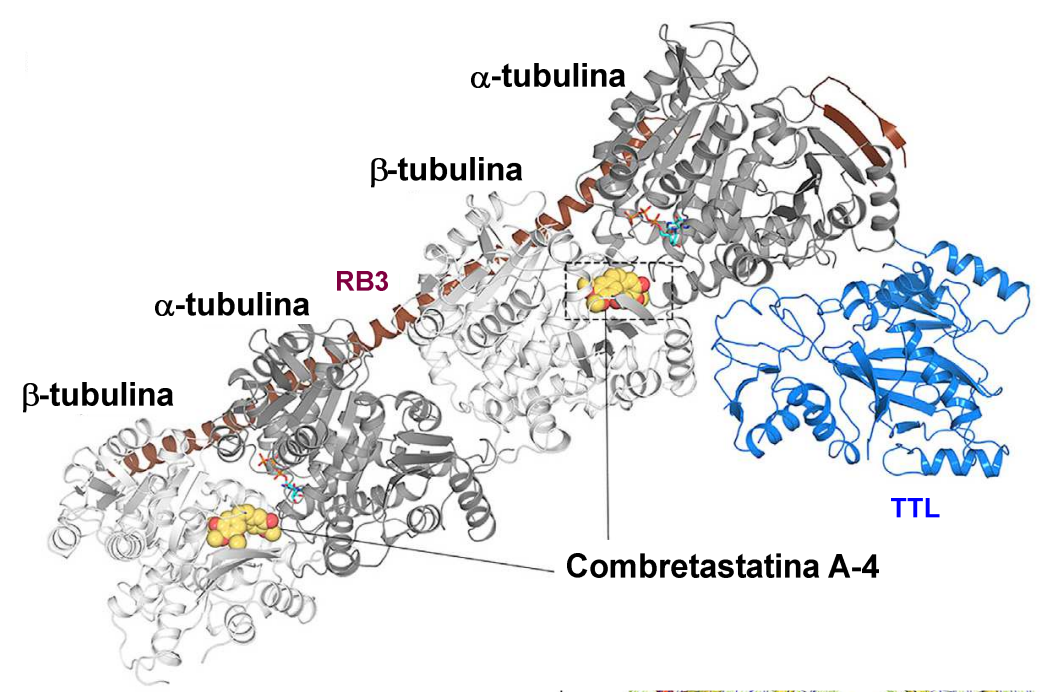

Figura 1.34. Complejo tubulina-combretastatina A-4. ${ }^{126}$

Los dímeros de tubulina en los microtúbulos asumen una estructura recta mientras que la estructura curvada es característica de la tubulina libre. La combretastatina A-4 inhibe la transición estructural curvada-recta impidiendo que el bucle bT7 adopte la conformación característica de la tubulina recta.

En contraposición con la combretastatina A-4, cuyo doble enlace tiene configuración cis, el isómero trans apenas muestra actividad antimitótica. Steinmetz y colaboradores han demostrado, mediante cálculos computacionales, que la menor afinidad del isómero trans por la tubulina se debe a su incapacidad para adaptarse completamente al sitio de la colchicina. $^{125}$

La actividad biológica de CA-4, unida a su inestabilidad configuracional, explican el desarrollo de estrategias sintéticas conducentes a la preparación de análogos más estables. ${ }^{127}$ Se han sintetizado y evaluado una gran variedad

\footnotetext{
${ }_{126}^{126}$ Figura tomada de la referencia 125.

127 (a) Nam, N. H. Curr Med Chem. 2003, 10, 1697-1672. (b) Chaudhary, A.; Pandeya, S. N.; Kumar, P.; Sharma, P. P.; Gupta, S.; Soni, N.; Verma, K. K.; Bhardwaj, G. Mini Rev. Med. Chem. 2007, 7, 1186-205.
} 
de análogos de combretastatina A-4 rígidos capaces de mantener la posición relativa cis entre los dos anillos aromáticos.

En la figura 1.35 se dibujan las estructuras de algunos de estos análogos que contienen anillos heterocíclicos de dioxolano, oxazol, oxadiazol, triazol, tiofeno, imidazol, oxazolidinona, piridina y anillos carbocíclicos de ciclopentanona y ciclopropano.
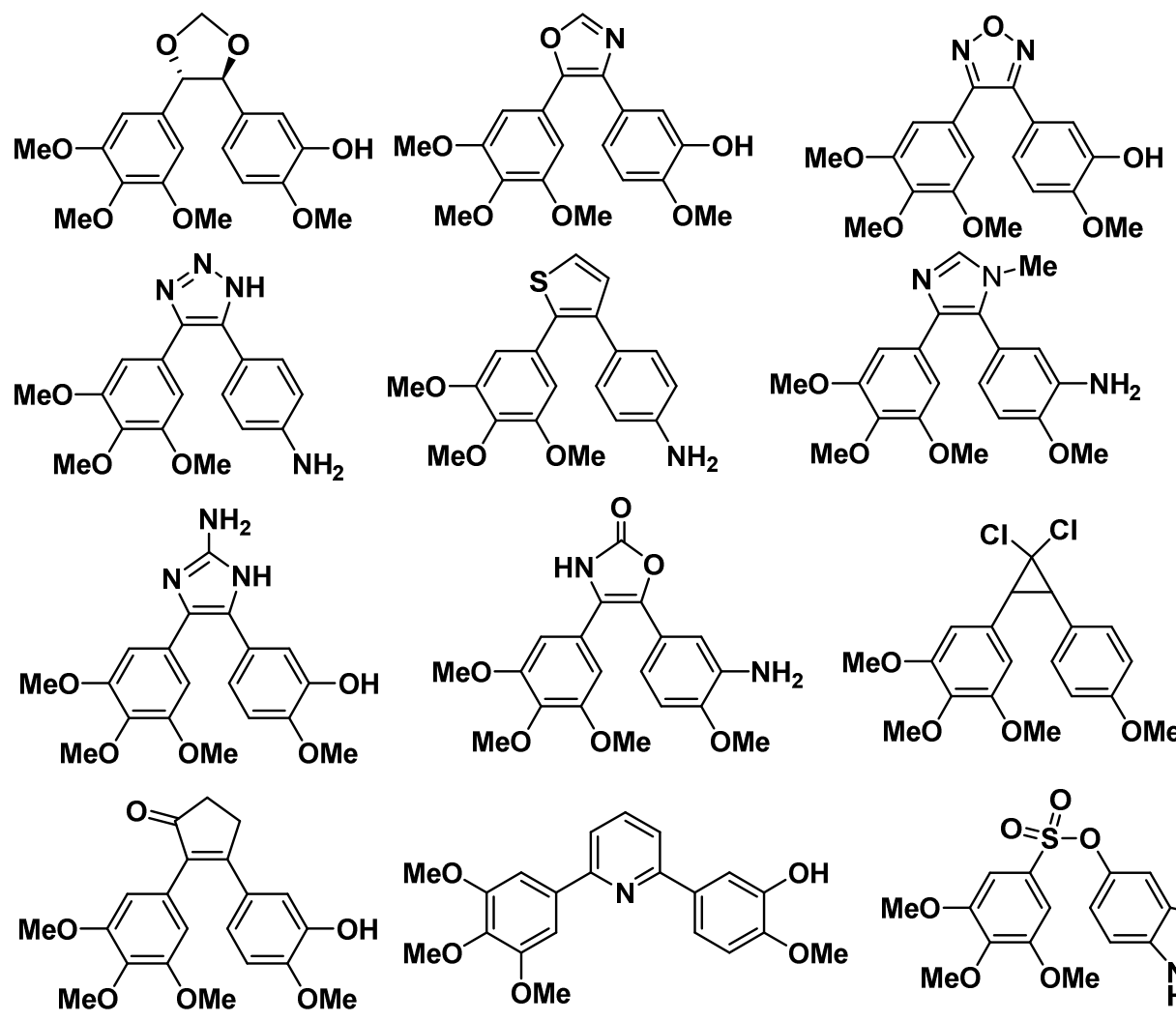<smiles>COc1ccc(-c2cccc(-c3cc(OC)c(OC)c(OC)c3)n2)cc1O</smiles><smiles>COc1ccc(C2C(c3cc(OC)c(OC)c(OC)c3)C2(Cl)Cl)cc1</smiles><smiles>COc1ccc(C(=O)c2cc(OC)c(OC)c(OC)c2)cc1O</smiles><smiles>COc1ccc(OCc2cc(OC)c(OC)c(OC)c2)cc1C=O</smiles><smiles>COc1ccc(/C=C(/C#N)c2cc(OC)c(OC)c(OC)c2)cc1O</smiles>

Figura 1.35. Estructuras de análogos de combretastatina A-4. 
La geometría $Z$ de la combretastatina A-4 también se puede mantener mediante la introducción de grupos funcionales de tipo cetona, éter, nitrilo o sulfonato (véase la figura 1.35). ${ }^{128}$

La combretastatina A-4 muestra una potente actividad citotóxica frente a varias líneas celulares de cáncer humano incluyendo algunas multirresistentes. ${ }^{129}$ Sin embargo, la combretastatina A-4 no muestra actividad antitumoral in vivo contra cáncer murino. ${ }^{130}$ Dado que la combretastatina A-4 es altamente lipófila y su solubilidad acuosa es limitada, su falta de eficacia in vivo se achaca a su deficiente farmacocinética. Por ello, se ha sintetizado el éster de fosfato denominado CA4P que se encuentra actualmente en ensayos clínicos de fase II en Estados Unidos y Reino Unido para el tratamiento del cáncer en pacientes con tumores sólidos. ${ }^{131}$

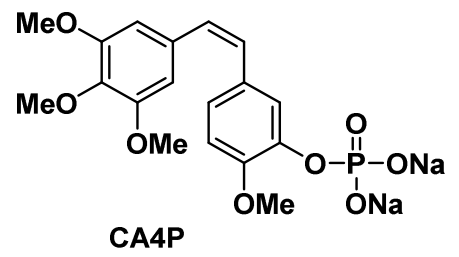

Figura 1.36. Estructura de CA4P.

La combretastatina A-4 y CA4P incrementan la permeabilidad e inhiben la migración de las células endoteliales bloqueando la formación de tubos capilares al romperse el ciclo de señalización, lo que conduce al colapso vascular y a la necrosis del tumor. ${ }^{132} \mathrm{CA} 4 \mathrm{P}$ ha despertado un gran interés por

${ }^{128}$ Véase Chaudhary, V.; Venghateri, J. B.; Dhaked, H. P. S.; Bhoyar, A. S.; Guchhait, S. K.; Panda, D. J. Med. Chem. 2016, 59, 3439-3451, y referencias allí citadas.

${ }^{129}$ (a) McGown, A. T.; Fox, B. W. Cancer Chemother. Pharmacol. 1990, 26, 79-81. (b) El-Zayat, A. A. E.; Degen, D.; Drabek, S.; Clark, G. M.; Pettit, G. R.; Von Hoff, D. D. Anti-Cancer Drugs 1993, 4, 19-25.

130 Dorr, R. T.; Dvorakova, K.; Snead, K.; Alberts, D. S.; Salmon, S. E.; Pettit, G. R. Invest. New Drugs 1996, 14, 131-137.

${ }_{131}$ (a) https://www.clinicaltrials.gov/ct2/show/NCT01305213?term=Zybrestat\&rank=1 (b) https://www.clinicaltrials.gov/ct2/show/NCT00653939?term=Zybrestat\&rank=4 (c) Srivastava, V.; Singh, N.A.; Kumar, J. K.; Gupta M. M.; Khanuja, S. Bioorg. Med. Chem. 2005, 13, 5892-5908.

(a) Griggs, J.; Metcalfe, J. C.; Hesketh, R. Lancet Oncol. 2001, 2, 82-87. (a) Rustin J.S.;

Galbraith, S.; Anderson, H.; Stratford, M.; Folkes, L.; Sena, L.; Gumbrell, L.; Price, P. J. Clin. 
sus efectos citotóxicos frente a una variedad de células cancerígenas, entre las que cabe incluir a las multirresistentes. ${ }^{133}$

En 1998, K. Ohsumi y colaboradores prepararon una serie de azaderivados de combretastatina y evaluaron sus efectos en el proceso de polimerización de la tubulina y su citotoxicidad en el adenocarcinoma murino Colon 26. Entre los compuestos sintetizados y evaluados se encontraba la aminocombretastatina (véase la figura 1.37). Este compuesto mostró un $\mathrm{IC}_{50}$ de $5.1 \mathrm{nM}$ en la línea tumoral anteriormente indicada. ${ }^{134}$

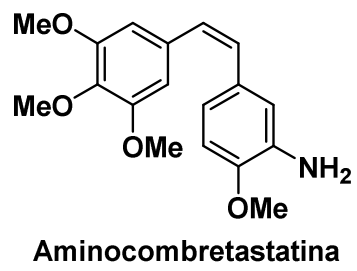

Figura 1.37. Estructura de la aminocombretastatina.

En 1999, K. Ohsumi y colaboradores prepararon los derivados aminoacídicos de la aminocombretastatina que se indican en la figura 1.38. Estos compuestos mostraron valores de citotoxicidad en el rango nanomolar en el adenocarcinoma murino Colon 26 , siendo los más activos los derivados de glicina, L-alanina y L-valina con valores de 2.8, 7.4 y $4.7 \mathrm{nM}$, respectivamente. El derivado de serina mostró un valor de $27.2 \mathrm{nM}$, sin embargo este compuesto fue el más activo en la actividad antitumoral en ratones con un valor de $82 \%$ de IR en dosis de $80 \mathrm{mg} / \mathrm{kg}^{135}$

Oncol. 2003, 21, 2815-2822. (b) Vincent, L.; Kermani, P.; Young L.M.; Cheng, J.; Zhang, F.; Shido, K. J. Clin. Invest. 2005, 115, 2992-3006.

${ }_{133}$ (a) Hamel, E.; Lin, C. M. Biochem. Pharmacol. 1983, 32, 3863. (b) McGown, A. T.; Fox, B.W., Anti-Cancer Drug Des. 1989, 3, 249-254. (c) Lin, C. M.; Shing, S. B.; Chu, P. S.; Dempcy, R. O.; Schimdt, J. M.; Pettit, G. R.; Hamel, E. Mol. Pharmacol. 1988, 34, 200-208.

${ }_{134}$ Ohsumi, K.; Nakagawa, R.; Fukuda, Y.; Hatanaka, T.; et al. J. Med. Chem. 1998, 41, $3022-$ 3032

${ }^{135}$ Ohsumi, K.; Hatanaka, T.; Nakagawa, R.; Fukuda, Y.; et al. Anti-cancer Drug Des. 1999, 14, 539-548. 


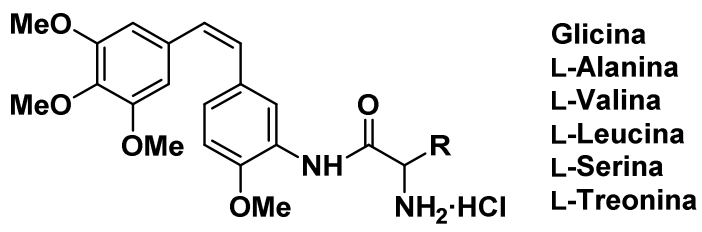

Figura 1.38. Derivados aminoacídicos de la aminocombretastatina.

El derivado de aminocombretastatina denominado ombrabulina (véase la figura 1.39), se encuentra actualmente en ensayos clínicos fase III para el tratamiento de un determinado tipo de sarcoma y cáncer de ovario. ${ }^{136}$<smiles>COc1ccc(/C=C\c2cc(OC)c(OC)c(OC)c2)cc1NC(=O)[C@H](N)CO</smiles>

Figura 1.39. Estructura de la ombrabulina.

\subsection{Angiogénesis}

La angiogénesis se define como el proceso de formación de nuevos vasos sanguíneos a partir de los vasos vasculares ya existentes. La angiogénesis comprende la migración, crecimiento y diferenciación de las células endoteliales que forman el revestimiento interno de los vasos sanguíneos. El proceso angiogénico está controlado por un delicado balance entre activadores e inhibidores. Los primeros activan la reparación de vasos sanguíneos dañados y la formación de vasos sanguíneos nuevos. Los segundos bloquean el proceso de formación de nuevos vasos sanguíneos (véase la figura 1.40).

\footnotetext{
${ }^{136}$ (a) Nihei, Y.; Suga, Y.; Morinaga, Y.; Ohishi, K. Jpn. J. Cancer Res. 1999, 90, 1016-1025. (b) Hori, K.; Saito, S.; Kubota, K. Brit. J. Cancer 2002, 86, 1604-1614. (c) https://www.clinicaltrials.gov/ct2/show/NCT01332656?term=AVE8062\&rank=11 https://www.clinicaltrials.gov/ct2/show/NCT01193595?term=AVE8062\&rank=4 https://www.clinicaltrials.gov/ct2/show/NCT01293630?term=AVE8062\&rank=10 


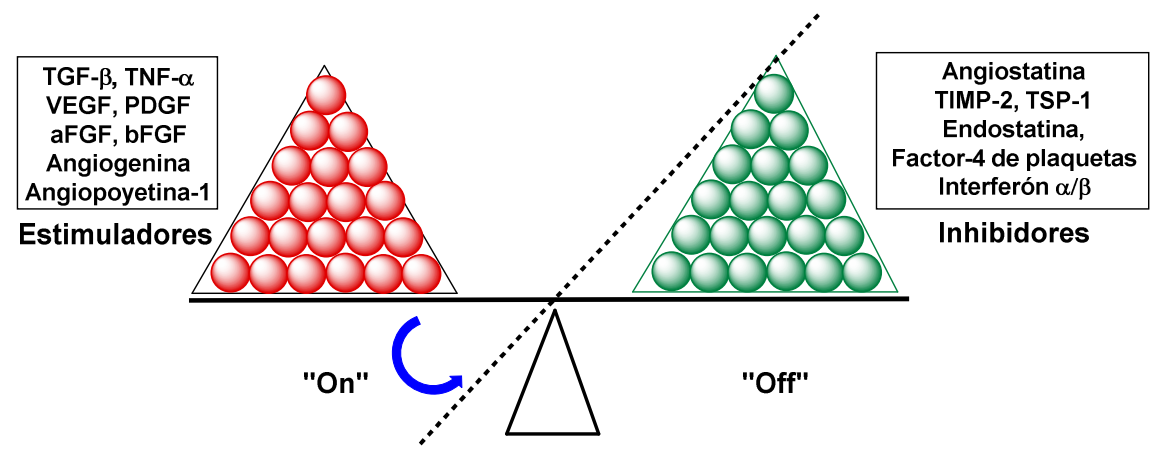

Figura 1.40. Representación del proceso on-off de la angiogenésis.

En la figura anterior se representa un modelo de activación-desactivación (on-off) de la angiogénesis. Entre los factores que estimulan la angiogénesis están el TGF- $\beta 1$ (Transforming Factor Growth beta-1), el TNF- $\alpha$ (Tumor Necrosis Factor alpha), el VEGF (Vascular Endothelial Growth Factor), el PDGF (Platelet Derived Growth Factor), el aFGF (Acidic Fibroblast Growth Factor), el bFGF (Basic Fibroblast Growth Factor), la angiogenina y la angiopoyetina-1. Entre los factores inhibidores de la angiogénesis se encuentran la angiostatina, el TIMP-1 (Tissue inhibitor of metalloproteinases1), el TSP-1 (Thrombospondin-1), la endostatina, el factor-4 de plaquetas y los interferones $\alpha$ y $\beta$.

Normalmente, los efectos estimulantes e inhibidores están equilibrados, de modo que los vasos sanguíneos se forman solamente cuando y donde sean necesarios. Se pueden distinguir dos tipos de angiogénesis: ${ }^{137}$

a) La angiogénesis fisiológica/normal. Este proceso tiene lugar durante la embriogénesis y continúa después del nacimiento en el desarrollo temprano post-natal, aportando el oxígeno y los nutrientes requeridos por los órganos en crecimiento, proporcionando señales promotoras morfológicas y siendo

\footnotetext{
${ }^{137}$ Martínez-Ezquerro, J. D.; Herrera, L. A. Cancerología 2006, 1, 83-88.
} 
fundamental para la formación del hueso endocondral ${ }^{138}$ y en el crecimiento del esqueleto.

b) La angiogénesis patológica/anormal. Este proceso se produce cuando se alcanza y se sobrepasa el umbral entre los estimuladores e inhibidores angiogénicos. La angiogénesis patológica se puede clasificar en dos tipos:

b1) La angiogénesis activada, en la que dominan los niveles de moléculas proangiogénicas. Este tipo de angiogénesis está asociada, muy frecuentemente a enfermedades malignas, además de estar implicada en la obesidad, el asma, la diabetes, la cirrosis, la esclerosis múltiple, la endometriosis, el SIDA, las infecciones bacterianas y las enfermedades autoinmunes.

b2) La angiogénesis inhibida, en la que dominan los niveles de moléculas antiangiogénicas. Este proceso está asociado al mal funcionamiento de células endoteliales (ECs) e impide la revascularización, la cicatrización y la regeneración de los vasos sanguíneos.

La mayoría de los tumores persisten durante largos periodos de tiempo, meses e incluso años, en un estado avascular aquiescente. En esta fase el tumor está formado por unos millones de células. Cuando un subgrupo de éstas cambia a fenotipo angiogénico, por alteración del equilibrio entre estimuladores e inhibidores, el tumor comienza a crecer rápidamente. ${ }^{139} \mathrm{La}$ angiogénesis tumoral provoca un crecimiento rápido de los vasos sanguíneos, los cuales presentan una vasculatura diferente a la habitual y una arquitectura con muchos huecos entre los nuevos vasos sanguíneos. ${ }^{140} \mathrm{La}$ inadecuada formación de los vasos sanguíneos también provoca fugas que dan lugar a elevaciones de la presión intersticial tumoral, provocando hemorragias y edemas. Cuando el tumor crece más de 1-2 mm de diámetro, las células

\footnotetext{
${ }^{138}$ El hueso endocondral es el que se forma en los fetos a partir de tejido cartilaginoso. El término endocondral significa que la osificación se realiza desde el interior del cartílago hacia el exterior.

${ }_{139}$ Madhusudan, S.; Harris, A. L. Curr. Opin. Pharmacol. 2002, 2, 403-414.

${ }^{140}$ Baluk, P.; Hashizume, H.; McDonald, M. C. Curr. Opin. Genet. Dev. 2005, 15, 102-111.
} 
centrales quedan muy lejos de los vasos sanguíneos existentes y no reciben los nutrientes necesarios para sobrevivir, lo que provoca que el tumor se encuentre en condiciones de hipoxia. ${ }^{141}$ Esta falta de oxígeno activa el factor inducible de hipoxia (HIF-1 $\alpha$ ), ${ }^{142}$ que sobreexpresa diversos factores proangiogénicos, como el VEGF. ${ }^{143}$ Esta proteína, que fue identificada en 1989 por Ferrara y Henzel como el principal factor involucrado en la angiogénesis, ${ }^{144}$ estimula la migración de células endoteliales hacia zonas del tumor con hipoxia, activando la cascada de señalización de la angiogénesis. ${ }^{145}$

EI VEGF es una proteína homodimérica unida mediante puentes disulfuro. La familia del VEGF incluye al VEGF-A, VEGF-B, VEGF-C, VEGF-D, VEGF-E, VEGF-F y PGF (del inglés Placental Growth Factor). De esta familia, el más estudiado es el VEGF-A, que es denominado simplemente como VEGF.

Las distintas isoformas del VEGF-A incrementan la permeabilidad vascular, estimulan la proliferación y la migración de las células endoteliales, proveen a dichas células con señales de supervivencia y anti-senescencia, y fomentan la neuroprotección en los desórdenes isquémicos. Se han descrito seis isoformas humanas de VEGF-A con un número diferente de aminoácidos (VEGF 121, 145, 165, 183, 189 y 206) generados como resultado del procesamiento alternativo del ARNm. ${ }^{146}$

El VEGF-121 es responsable del aumento de la permeabilidad vascular mientras que el VEGF-165 es un importante estimulador de la proliferación de células endoteliales. Estas dos isoformas de VEGF son las más abundantes.

\footnotetext{
${ }^{141}$ Folkman, J. Curr. Mol. Med. 2003, 3, 643-651.

142 (a) Kachs, G. U.; Patterson, A. V. et al. Nat. Med. 1997, 3, 515-520. (b) Fruehauf, J. P.; Meyskens, F. L. Jr. Clin. Cancer. Res. 2007, 13, 789-794.

${ }_{143}$ (a) Mazure, N. M.; Chen, E. Y.; Laderote, K. R.; Giaccia, A. J. Blood 1997, 90, 3322-3331. (b) Folkman, J. Semin. Oncol. 2002, 29, 15-18. (c) Beppu, K.; Nakamura, K.; Linehan, W. M.; Rapisarda, A.; Thiele, C. J. Cancer Res. 2005, 65, 4775-4781.

${ }_{144}$ (a) Ferrara, N.; Henzel, W. J. Biochem. Biophys. Res. Commun. 1989, 161, 851. (b) Kim, K. J.; Li, B.; Winer, J.; Armanini, M.; Gillet, N.; Phillips, H. S.: Ferrara, N. Nature 1993, 362, 841.

${ }_{145}$ (a) Darland, D. C.; D'Amore, P. A. J. Clin. Invest. 1999, 103, 157-158. (b) Neufeld, G.; Cohen, T.; Gengrinovitch, S.; Poltorak, Z. FASEB J. 1999, 13, 9-22.

${ }^{146}$ Park, J. E.; Keller, G. A.; N. Mol. Biol. Cell. 1993, 4, 1317-1326.
} 
Todas las isoformas de VEGF comparten la misma parte $\mathrm{N}$-terminal y seis residuos C-terminales. El dominio de unión al receptor del VEGF comparte mucha homología con el factor de crecimiento derivado de plaquetas (PDGF). La expresión de VEGF está mediada por receptores de tipo tirosina-quinasa denominados VEGFR que se localizan en la superficie de las células endoteliales vasculares y en la superficie de células derivadas de la médula ósea.

En la figura 1.41 se esquematizan los diferentes VEGF y su relación con los receptores a ellos asociados (VEGFR).

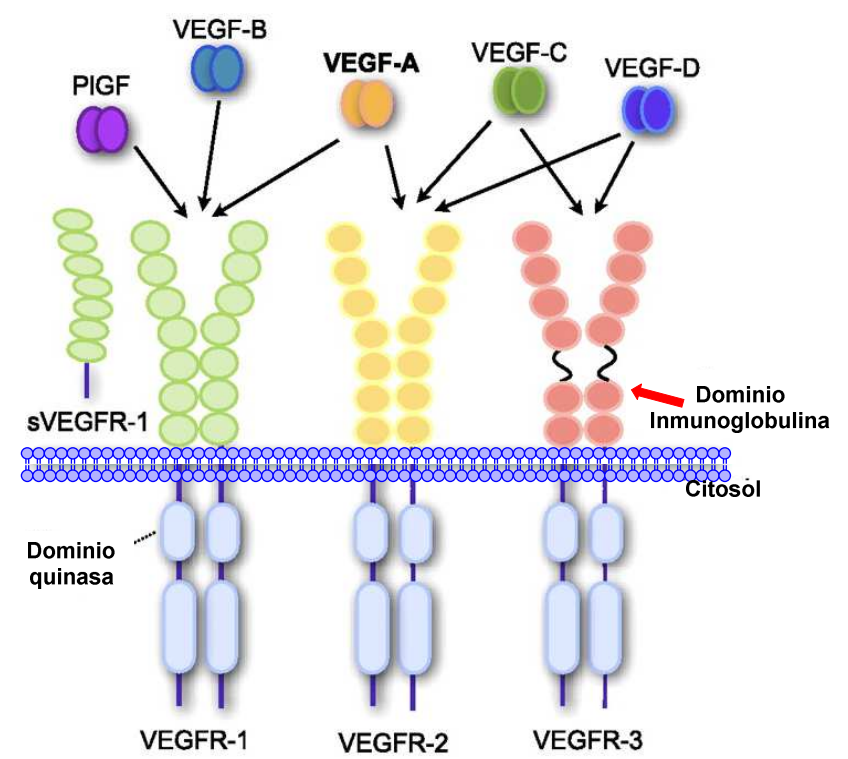

Figura 1.41. Familia de proteínas del VEGF y sus receptores asociados.

EI VEGF-A emplea sitios de unión simétricos en cada polo del dímero para unirse tanto al VEGFR-1 como al VEGFR-2 y puede inducir heterodímeros entre estos dos receptores. ${ }^{147}$

EI VEGF-B se une al receptor VEGFR-1 modulando la actividad de VEGFA en células endoteliales durante el desarrollo embrionario y durante la

${ }_{147}$ Veikkola, T.; Karkkainen, M.; Cleasson-Welsh, L.; Alitalo, K. Cancer Res. 2000, 60, 203-212.

(b) Dvorak H. F. Thromb Haemost. 2005, 3, 1835-1842. 
angiogénesis patológica. El VEGF-B se expresa en tumores humanos tanto benignos como malignos. ${ }^{148}$

El VEGF-C y el VEGF-D se unen a VEGFR-2 en células endoteliales de vasos sanguíneos. Estos miembros de la familia VEGF se unen a su receptor VEGFR-3 en los tejidos linfáticos promoviendo el desarrollo de vasos linfáticos. El VEGF-C se expresa significativamente en tumores como los de mama, cérvix, colon, próstata, pulmón y estómago, siendo una potente diana anticancerígena. ${ }^{149}$ La expresión de VEFG-D se correlaciona con metátesis de ganglios linfáticos en el cáncer colorrectal, en el cáncer de pulmón y en los carcinomas de ovario. ${ }^{150}$

EI VEGF-E fue descubierto en el genoma del parapoxivirus Orf (cepa NZ7), un virus de cadena lineal doble de ADN que causa dermatitis pustular contagiosa en ovejas, cabras y ocasionalmente en seres humanos. EI VEGF-E se une y activa específicamente al VEGFR-2 resultando en un efecto mitogénico y en actividad de permeabilidad vascular similar al producido por el VEGF-A. ${ }^{151}$ No se ha caracterizado del todo la función del VEGF-F.

La interacción del VEGF con sus receptores induce una cascada de señalización intracelular que favorece la supervivencia de las células endoteliales activando su proliferación, migración, diferenciación, y transformación, aportando oxígeno e incrementando la permeabilidad vascular.

La expresión del VEGF se aumenta mediante estímulos tales como hipoxia/isquemia principalmente mediante el factor inducible de hipoxia 1. Por otro lado, el gen supresor del ciclo celular p53 juega un papel importante en la

\footnotetext{
${ }_{148}$ Partanen, T. A.; Paavonen, K. Microsc. Res. Tech. 2001, 55, 108-121.

149 (a) Siegfried, G.; Basak, A.; Cromlish, J. A. J. Clin. Invest. 2003, 111, 1723-1722. (b) Su, J. L.; Yang, P. C.; Shih J. Y. Cancer Cell 2006, 9, 209-223. (c) Shida, A.; Fujioka, S.; Kobayashi, K. $J$ Clin. Onc. 2006, 11, 38-43.

150 (a) Achen, M. G.; Williams, R. A.; Minekus, M. P. J. Pathol. 2001, 193, 147-154. (b) Funaki, H.; Nishimura, G.; Harada, S. Oncology 2003, 64, 416-422. (c) Niki, T.; lba, S.; Tokunou, M.; Yamada, T.; Matsuno, Y.; Hirohashi, S. Clin. Cancer Res. 2000, 6, 2431-2439.

${ }^{151}$ Shibuya, M. Cell Struct. Funct. 2001, 26, 25-35.
} 
inhibición de la angiogénesis y en la expresión del VEGF. La proteína producida por el gen $p 53$ es la principal inductora de la apoptosis y participa en la secreción de la trombospondina-1, una glicoproteína endógena que inhibe la angiogénesis. Las mutaciones que inactivan al gen p53 estimulan la proliferación celular y ocasionan un incremento en la expresión de VEGF. ${ }^{152}$

El efecto de los VEGF está mediado por los receptores VEGFR-1, VEGFR2 y VEGFR-3 todos con actividad tirosina-quinasa. El bevacizumab (Avastin®) es un anticuerpo monoclonal anti-VEGF que se emplea en el tratamiento del cáncer de colon, mama, cáncer de pulmón no microcítico, cáncer de riñón avanzado o metastásico. ${ }^{153}$ El bevacizumab se une al VEGF-A evitando su unión los receptores endoteliales VEGFR-1 y VEGFR-2 (véase la figura 1.42). ${ }^{154}$

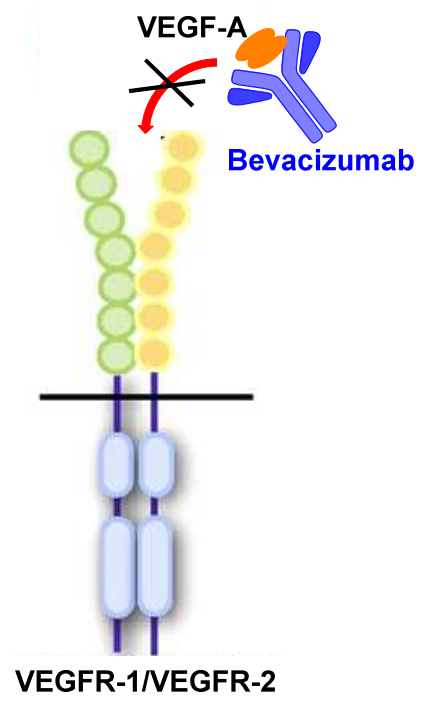

Figura 1.42. Unión de VEGF-A al bevacizumab.

152 (a) Lee, M.; Hwang, J.T.; Lee, H.J.; Jung, S.N.; Kang, I.; Chi, S.G.; Kim S.S.; Ha, J., Biol Chem 2003, 278, 39653-39361. (b) Dameron, K.M.; Volpert, O.V.; Tainsky M. A.; Bouck, N. Science 1994, 265, 1582-1584.

153 European Medicines Agency, documento EMA/487898/2016.

154 (a) Hurwitz, H.; Fehrenbacher, L.; Novotny, W.; Cartwright, T.; Hainsworth, J.; Heim, W.; Berlin, J.; Baron, A.; Griffing, S.; Holmgren, E.; Ferrara, N.; Fyfe, G.; Rogers, B.; Ross, R.; Kabbinavar, F. N. Engl. J. Med. 2004, 350, 2335-2342. (b) Cao, Y. Exp. Cell Res. 2010, 316, 1304-1308. 
Otras estrategias antitumorales, que también dirigen su foco de acción a la inhibición de la angiogénesis, se centran en la administración de pequeñas moléculas que bloquean la actividad tirosina-quinasa de los receptores VEGFR. Algunos de estos inhibidores son el sorafenib (Nevaxar®), el sunitinib (Sutent $\left.{ }^{\circledR}\right)$, el vatalanib, el vandetanib (Caprelsa $\left.{ }^{\circledR}\right)$, el pazopanib (Votrient $\left.{ }^{\circledR}\right)$, el gefitinib (Iressa ${ }^{\circledR}$ ), el erlotinib (Tarceva $\left.{ }^{\circledR}\right)$, el regorafenib (Stivarga ${ }^{\circledR}$ ) y el cabozantinib (Cabometyx®) (véase la figura 1.43).<smiles>NC(=O)c1cc(Oc2ccc(NC(=O)Nc3ccc(Cl)c(C(F)(F)F)c3)cc2)ccn1</smiles><smiles>CCN(CC)CCNC(=O)c1c(C)[nH]c(/C=C2\C(=O)Nc3ccccc32)c1C</smiles><smiles>Clc1ccc(Cc2nnc(Cc3ccncc3)c3ccccc23)cc1</smiles><smiles>COc1cc2c(Nc3ccc(Br)cc3F)ncnc2cc1OCC1CCN(C)CC1</smiles><smiles>C#Cc1cccc(Nc2ncnc3cc(OCCOC)c(OCCOC)cc23)c1</smiles>

Figura 1.43. Inhibidores del dominio tirosina-quinasa de VEGFR. 
Los inhibidores representados en la figura anterior se emplean en el tratamiento de distintos tipos de cáncer. ${ }^{155}$ Una de las diferencias entre los fármacos anteriores y los anticuerpos monoclonales es que aquéllos presentan disponibilidad oral mientras que éstos sólo pueden utilizarse por vía intravenosa.

El empleo como monoterapia de fármacos antiangiogénicos detiene el crecimiento tumoral durante un cierto período de tiempo al impedir el aporte a gran escala de oxígeno y nutrientes al tumor. Sin embargo, no se consigue evitar el crecimiento del tumor a largo plazo, ni mucho menos su muerte o desaparición. Así, los resultados obtenidos en los ensayos clínicos indican que el mayor éxito de las terapias antiangiogénicas tiene lugar cuando se combina con la quimioterapia tradicional mediante una actuación simultánea sobre las células tumorales y las endoteliales. ${ }^{156}$

Los tratamientos antiangiogénicos deben resolver algunas importantes cuestiones, como la diferente respuesta de los pacientes a la misma terapia antiangiogénica, ${ }^{157}$ la relación respuesta-coste del fármaco, ${ }^{158}$ la resistencia evasiva que ofrecen algunos fármacos antiangiogénicos, que son a menudo muy efectivos en el primer estadio del tratamiento, pero provocan resistencia

155 (a) Kim, S.; Yazici, Y. D.; Calzada, G.; Wang, Z. Y.; et al. Mol. Cancer Ther. 2007 6, 17851792. (b) Roskoski, R. Jr. Biochem. Biophys. Res. Commun. 2007, 356, 323-328. (c) Dragovich T.; Laheru, D.; Dayyani, F.; Bolejack, V.; et al. Cancer Chemother. Pharmacol. 2014, 74, 379387. (d) Zhou, Y.; Zhang, Y.; Zou, H.; N. Sci. Rep. 2015, 5, 8629. (e) Lang, J. M.; Harrison, M. R. Clin. Med. Insights Oncol. 2010, 4, 95-105. (f) Choi, H.; Chang, J.; Shin, H-J.; et al. Thoracic Cancer 2015, 6, 224-226. (g) Wilhelm, S. M.; Dumas, J.; Adnane, L.; Lynch, M.; et al. Int. J. Cancer. 2011, 129, 245-255. (h) Atkins, M.; Jones, C.A.; Kirkpatrick, P. Nat. Rev. Drug Discov. 2006, 5, 279-280. (i) Reguart, N.; Cardona, A. F.; Rosell, R. Cancer Manag. Res. 2010, 2, 143156. (j) Lendvai, N.; Yee, A. J.; Tsakos, I.; Alexander, A.; et al. Blood 2016, 127, 2355-2356. ${ }^{156}$ Carmeliet, P.; Jain, R. K. Nature 2000, 407, 249-257.

157 (a) Garassino, M.C.; Hollander, L.; Torri. N. Engl. J. Med. 2007, 356, 1373-1375. (b) Haines, I.E.; Miklos, G. L. N. Engl. J. Med. 2008, 358, 1637-1638. (c) Plotkin, S.R.; StemmerRachamimov, A.O.; Barker, F. G.; Halpin, C.; Padera, T. P.; Tyrell, A.; Sorensen, A.G.; Jain, R. K.; di Tomaso, E. Engl. J. Med. 2009, 361, 358-367. (d) Kerbel, R. S. Engl. J. Med. 2008, 358, $2039-2049$.

${ }_{158}$ (a) Jain, R. K.; Duda, D. G.; Willet, C. G.; Sahani, D. V.; Zhu, A. X.; Loeffler, J. S.; Batchelor, T. T.; Sorensen, A. G. Nat. Rev. Clin. Oncol. 2009, 6, 327-328. (b) Cao, Y.; Zhong, W.; Sun, Y. Semin. Cancer Biol. 2009, 19, 338-343. 
cuando se prolonga el tratamiento, ${ }^{159}$ y los efectos secundarios entre los que destacan las incidencias cardiovasculares. ${ }^{160}$

Las terapias antiangiogénicas se administran en combinación con quimioterapia. Según el mecanismo de angiogénesis del tumor, los inhibidores angiogénicos deben ser suministrados a los pacientes con cáncer durante el resto de su vida, ya que una interrupción del tratamiento puede acelerar la revascularización y la reaparición del tumor. ${ }^{161}$

Algunos agentes antimitóticos son también antiangiogénicos. Esta particularidad, que se ha observado tanto en aquellos que se unen al dominio vinca como en los que se unen a los sitios de taxol o colchicina, es muy interesante desde el punto de vista oncológico ya que la formación de tumores va asociada al fenómeno de metástasis, el cual está directamente relacionado con la capacidad del tumor para formar nuevos vasos sanguíneos. ${ }^{162}$

\subsection{Telomerasa}

Los telómeros son regiones de ADN no codificante, altamente repetitivas, situadas en los extremos de los cromosomas y cuya función principal es la de proteger a éstos frente a la degradación que tiene lugar, de forma natural, después de cada ciclo de replicación. ${ }^{163}$ Los telómeros están formados por un tramo de secuencias de doble hebra, formada por repeticiones en tándem, y por un tramo final corto no codificante de cadena sencilla rico en residuos de guanina, con una longitud de 30-110 nucleótidos. En los vertebrados, los telómeros están formados por repeticiones en tándem de un hexámero de

\footnotetext{
${ }_{159}$ Cao Y. Semin. Cancer Biol. 2009, 19, 338-343.

${ }^{160}$ Verheul, H. M. W.; Pinedo, H. M. Nat. Rev. Cancer 2007, 7, 475-485.

161 (a) Folkman, J. Nat. Rev. Drug Discov. 2007, 6, 273-286. (b) Ebos, J. M.; Lee, C. R.; Christensen, J. G.; Mutsaers, A. J.; Kerbel, R.S. Proc. Natl. Acad. Sci. U. S. A. 2007, 104, 17069-17074. (c) Mancuso, M. R.; Davis, R.; Norberg, S. M.; O`Brien, S.; Sennino, B.; Nakahara, T.; Yao, V. J.; Inai, T.; Brooks, P.; Freimark, B.; Shalinsky, D. R.; Hu-Lowe, D. D.; McDonald, D. M. J. Clin. Invest. 2006, 116, 2610-2621.

${ }_{162}$ Schwartz, L. S. Clin. Cancer Res. 2009, 15, 2594-2601.

163 (a) Blackburn, E. H. Nature 1991, 350, 569-573. (b) Greider, C. W.; Blackburn. E. H. Cell, 1985, 43, 405-413. (c) Kirkpatrick, K. L.; Mokbel. K. Eur. J. Surg. Oncol. 2001, 27, 754-760.
} 
nucleótidos 5'-(TTAGGG)n-3' y de una serie de proteínas asociadas. ${ }^{164} \mathrm{El}$ número de repeticiones es específico de cada especie y varía en función de la vida de la célula. Los telómeros humanos contienen aproximadamente de 500 a 2000 repeticiones, lo que viene a ser de 3000 a 12000 pares de bases. ${ }^{165}$

En la figura 1.44 se puede ver una representación de una región telomérica ubicada en el extremo del ADN.

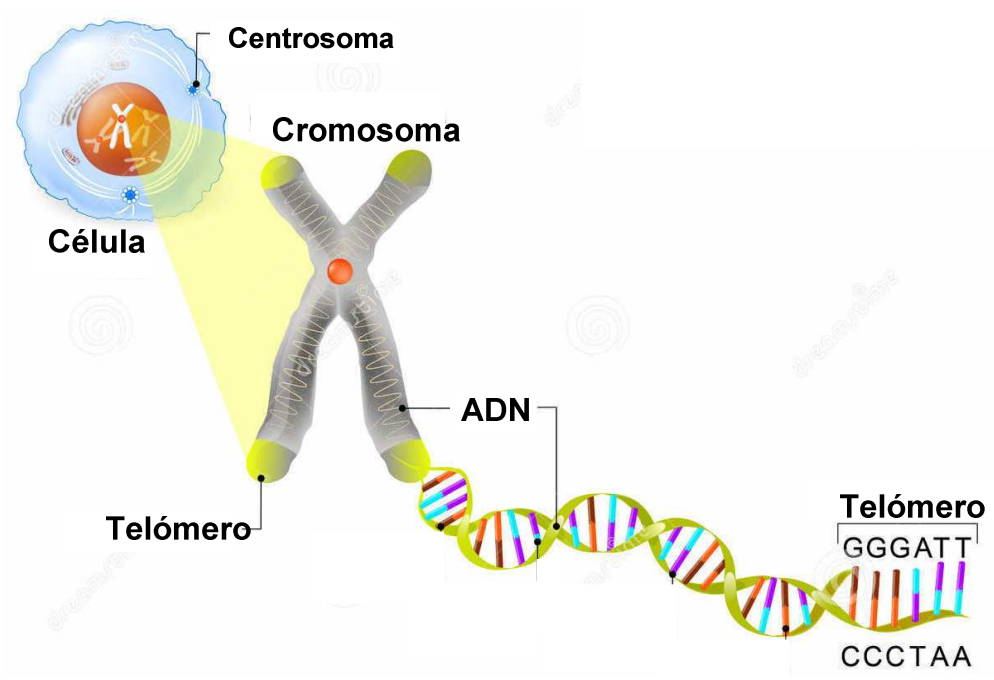

Figura 1.44. Representación de un telómero.

La telomerasa es una ribonucleoproteína que se encarga de la adición de desoxirribonucleótidos en los extremos de los telómeros, manteniendo así una longitud telomérica estable a lo largo de la historia replicativa de determinados tipos celulares. ${ }^{166}$ El mantenimiento de la longitud telomérica, en consecuencia, requiere un delicado equilibrio entre acortamiento y alargamiento. Si el acortamiento es excesivo se producen síntomas asociados al envejecimiento prematuro. Por el contrario, si la actividad de la telomerasa es aberrante se puede favorecer la inmortalidad de las células malignas.

\footnotetext{
164 (a) Moyzis, R. K.; Buckingham, J. M.; Cram, L. S.; Dani, M.; Deaven, L. L.; Jones, M. D.; Meyne, J.; Ratliff, R. L.; Wu, J. R. Proc. Natl. Acad. Sci. USA 1988, 85, 6622-6626. (b) Cheng, J. L.; Smith, C. L.; Cantor, C. R. Nucleic Acid Res. 1989, 17, 61109-61127.

${ }_{165}$ McElligott, R.; Wellinger, R. J. EMBO J. 1997, 16, 3705-3714.

${ }^{166}$ Collins, K.; Mitchell, J. R. Oncogene 2002, 21, 564-579.
} 
La telomerasa fue descubierta por E. Blackburn y C. Grieder en 1985 en el protozoo Tetrahymena. ${ }^{167}$ La telomerasa está formada por tres componentes:

a) Componente ribonucleotídico, denominado TER, de Telomerase RNA, que contiene la porción de $A R N$ de la telomerasa. La longitud del componente TER depende de las especies, y puede contener entre 146 a 1544 nucleótidos. La secuencia molde del telómero suele tener una longitud de entre 9 y 28 nucleótidos y también es característica de cada especie.

b) Componente proteico, denominado TERT, de Telomerase Reverse Transcriptase, que es la parte de la enzima que contiene la capacidad transcriptasa inversa encargada de la transcripción de la parte TER en ADN.

c) La proteína diskerina (Dkc1) que se encarga del ensamblaje entre TERT y TER.

La telomerasa es reprimida en las células somáticas maduras después del nacimiento. En cada ciclo replicativo los telómeros se acortan a causa del problema intrínseco de la replicación de los extremos de las secuencias de ADN lineales. ${ }^{168}$ Así, durante el proceso de replicación celular no se copia toda la secuencia del cromosoma, perdiéndose en cada replicación entre 50-100 pares de bases. Este fenómeno, conocido como problema de la replicación, se debe al modo de acción de la ADN-polimerasa, ya que esta enzima siempre requiere de un cebador de ARN de unos 8-12 nucleótidos que proporcione el extremo 5' de la nueva hebra y siempre lee el ADN en sentido 3' $\rightarrow 5$ ', sintetizando las nuevas hebras en sentido $5^{\prime} \rightarrow 3$ '. Así, la ADN-polimerasa se mueve ininterrumpidamente desde el origen de la replicación hasta el final del cromosoma cuando la hebra molde es la $3^{\prime} \rightarrow 5^{\prime}$. Sin embargo, cuando la hebra molde es la $5^{\prime} \rightarrow 3$ ' su replicación debe ser forzosamente discontinua, originándose pequeños fragmentos de $A D N$ que crecen en sentido $5^{\prime} \rightarrow 3^{\prime}$ y

\footnotetext{
${ }^{167}$ Greider, C. W.; Blackburn, E. H. Cell 1985, 43, 405. Los científicos Elizabeth H. Blackburn, Carol W. Greider, junto con Jack W. Szostak, fueron galardonados con el Premio Nobel en Fisiología o Medicina, del año 2009, por descubrir la protección de los cromosomas por los telómeros y la acción de la enzima telomerasa.

${ }_{168}$ de Lange, T. Science 2009, 326, 948-952.
} 
que más tarde se enlazan para generar una hebra continua. Esto provoca que el extremo 5' de la hebra retardada se vaya acortando progresivamente en cada replicación, por lo que los telómeros sufren una pérdida neta de 50-100 pares de bases en cada ciclo celular. ${ }^{169}$ La telomerasa utiliza su componente ARN como molde para alargar los extremos 3' de las cadenas sencillas teloméricas. ${ }^{170}$ Esta región molde es complementaria del ADN telomérico y está formada por 11 nucleótidos de secuencia 5'-CUAACCCUAAC-3' (véase la figura 1.45). ${ }^{171}$ La telomerasa agrega secuencias repetitivas en el extremo $3^{\prime}$. Luego, una ADN polimerasa sintetiza las nuevas secuencias complementarias, impidiendo así el acortamiento telomérico.

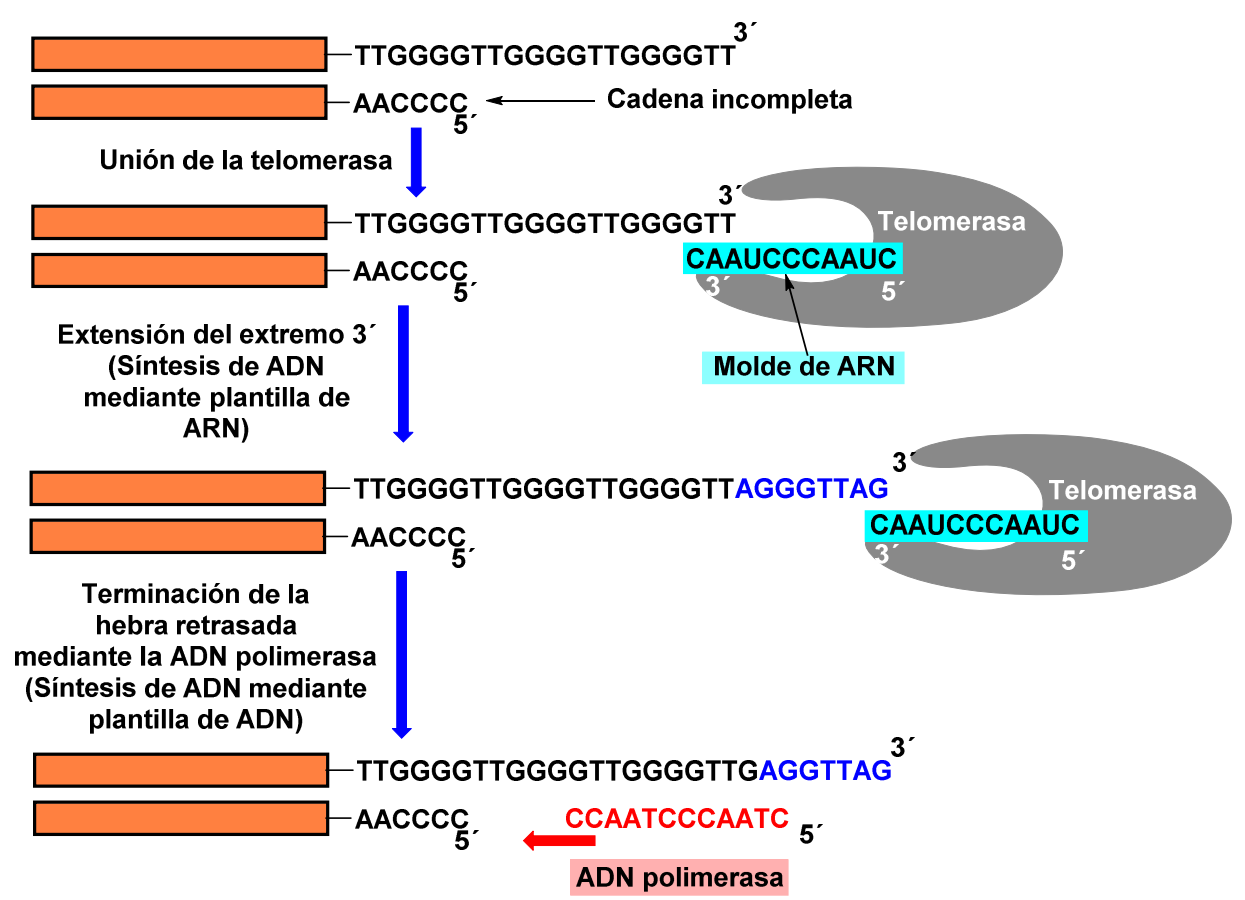

Figura 1.45. Representación de la reconstrucción del telómero por la telomerasa.

La expresión de la telomerasa en los mamíferos está restringida a ciertas etapas tempranas del desarrollo embrionario. En los organismos adultos la

\footnotetext{
${ }^{169}$ Watson, J. D. Nat. New Biol. 1972, 239, 197-201.

170 Collins, K.; Mitchell, J. R. Oncogene 2002, 21, 564-579.

171 Gavory, G.; Farrow, M.; Balasubramanian, S. Nucleic Acids Res. 2002, 30, 4470-4480.
} 
telomerasa está activada en determinados compartimentos de las células madre adultas y en algunos linajes celulares altamente proliferativos, como los linfocitos, los queratinocitos o las células germinales. ${ }^{172}$ Como las células sanas no expresan la enzima telomerasa, los telómeros se van acortando después de cada proceso de división celular. Debido a que los telómeros son secuencias no codificantes de nucleótidos, su acortamiento inicial no produce daños en el código genético. Sin embargo, el telómero desaparece después de muchas divisiones celulares y las siguientes divisiones comienzan a provocar el acortamiento de regiones codificantes, lo que conlleva pérdida de información genética. Cuando se llega a este punto se produce la muerte de la célula por senescencia. En muchas células cancerosas la telomerasa está sobreexpresada, lo que explica que este tipo de células no alcancen nunca la senescencia, de ahí el término de inmortales con el que se designa a menudo a las células cancerosas. ${ }^{173}$

La actividad telomerasa constituye el principal mecanismo regulador de la longitud telomérica, si bien en ciertos tipos de cánceres, como el osteosarcoma o el glioma multiforme, se dan unos mecanismos alternativos de alargamiento telomérico que funcionan en ausencia de la telomerasa. ${ }^{174}$

El acortamiento telomérico hace que la mayor parte de las células de nuestro organismo tengan una vida limitada. ${ }^{175}$ La longitud telomérica es una de las principales barreras contra la proliferación incontrolada. De hecho, el $90 \%$ de los procesos tumorales experimentan en algún momento una reactivación anómala de la telomerasa. ${ }^{176}$ Estos datos ponen de manifiesto la

\footnotetext{
172 (a) Liu, K.; Hodes, R. J.; Weng, N-p. J. Immunol. 2001, 166, 4826-4830. (b) Sprague, D. L.; Phillips, S. L.; Mitchell, C. J.; Berger, K. L.; et al. Virology 2002, 301, 247-354. (c) Bekaerta, S.; Derradji, H.; Baatout, S. Develop. Biol. 2004, 274, 15-30.

${ }_{173}$ Blasco, M. A. Nat. Rev. Genet. 2005, 6, 611-622.

174 Lundblad, V.; Blackburn, E. H. Cell 1993, 73, 347-360.

${ }^{175}$ Callaway, E. Nature 2010, doi:10.1038/news.2010.635

${ }^{176}$ Kim, N. W.; Piatyszek, M. A.; Prowse, K. R.; Harley, C. B.; et al. Science 1994, 266, $2011-$ 2015.
} 
dependencia entre la adquisición de un potencial replicativo ilimitado y la capacidad tumorigénica de las células. ${ }^{177}$

La actividad aberrante de la telomerasa explica la necesidad de buscar inhibidores de esta enzima que puedan actuar de forma localizada y controlada para prevenir la aparición y el desarrollo tumoral, sin incidir negativamente en la longevidad ni en la homeostasis tisular. Se ha demostrado que los ratones deficientes en telomerasa muestran resistencia al cáncer, validando a la telomerasa como una prometedora diana en terapias antitumorales. ${ }^{178}$

La actividad de la telomerasa parece que se debe a la sobreexpresión de la proteína hTERT, por lo que se puede deducir que esta proteína es el factor limitante para el ensamblaje del complejo enzimático activo que forma la telomerasa. La expresión de hTERT tiene lugar, principalmente, a nivel transcripcional aunque, también se ha observado que existe un control posttraduccional de dicha proteína. La regulación transcripcional de hTERT está controlada esencialmente por los factores de transcripción c-Myc y sp1. ${ }^{179}$

El factor de transcripción c-Myc es una proteína codificada por el oncogen C-Myc. ${ }^{180}$ La proteína está implicada en una amplia red de señalización celular por lo que influye en la progresión del ciclo celular, el metabolismo celular, la angiogénesis, la adherencia celular, la reparación del ADN, la apoptosis y la diferenciación celular. ${ }^{181}$

\footnotetext{
${ }^{177}$ La mera reactivación de la telomerasa no constituye un evento transformante per se, véase: Hahn, W. C.; Counter C. M.: Lundberg, A. S.; Beijersbergen, R. L., Brooks M. V.; Weinberg R. A. Nature 1999, 400, 464-468.

${ }_{178}$ (a) Blasco, M. A.; Funk, W.; Villaponteau, B.; Greider, C. W. Science 1995, 269, 1267-1270.

(b) Blasco, M. A.; Lee, H.-W.; Hande, P.; Samper, E.; Lansdorp, P.; DePinho, R. A.; Greider, C. W. Cell 1997, 91, 25-34. (c) González-Suárez, E.; Samper, E.; Flores, J. M.; Blasco, M. A. Nat. Genet. 2000, 26, 114-117.

${ }_{179}$ Wang, J.; Xie, L. Y.; Allan, S.; Beach, D.; Hannon, G. Genes Dev. 1998, 12, 1769-1774.

${ }^{180}$ El gen regulador $c-M y c$ fue descubierto mediante su homología con el gen transformante del virus de la mielocitomatosis aviar MC29 $(v-M y c)$, véase: Vennstrom, B.; Sheiness, D.; Zabielski, J.; Bishop, J. M. J. Virol. 1982, 42, 773-779.

${ }_{181}$ Eilers, M.; Eisenman, R. N. Genes Dev. 2008, 22, 2755-2766.
} 


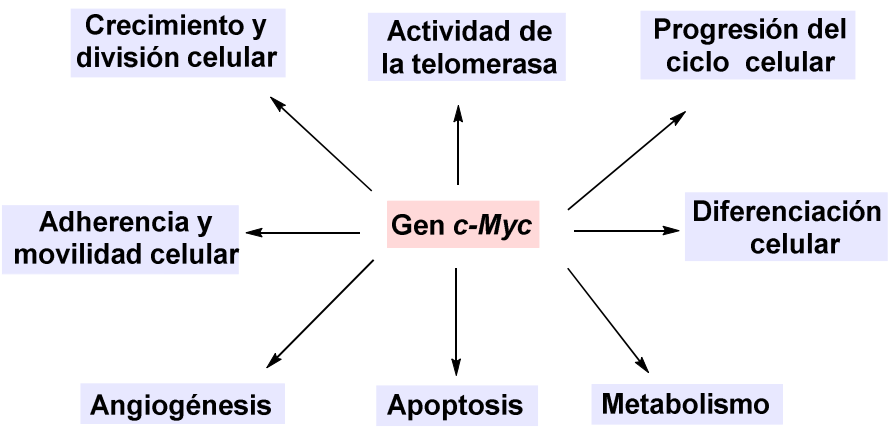

Figura 1.46. Funciones celulares en las que participa el gen $c-M y c$.

El gen $c-M y c$ se encuentra alterado en un gran número de tumores sólidos, leucemias y linfomas. Las alteraciones de $c-M y c$ encontradas con mayor frecuencia en células cancerosas son las amplificaciones, translocaciones, mutaciones y reordenamientos cromosómicos que involucran el locus de este gen y conducen a la desregulación de su expresión en diversas neoplasias humanas. El gen $c-M y c$ se encuentra alterado en muchos cánceres de mama, pulmón, ovario y próstata, así como en leucemias y linfomas, mientras que la pérdida de su regulación es común en el cáncer de colon, en tumores ginecológicos y en el melanoma. ${ }^{182}$

182 (a) Wang, J.: Xie, L. Y.; Allan, S.; Beach, D.; Hannon, G. Genes Dev. 1998, 12, 1769-1774. (b) Danga, C. V.; Donnell, K. A. O.; Zeller, K. I.; Nguyena, T.; Osthus, R. C.; Li, F. Semin. Cancer Biol. 2006, 16, 253-264. (b) Ospina Pérez, M.; Muñetón Peña, C. M. latreia 2011, 24, 389-401. 

2. OBJETIVOS 



\section{OBJETIVOS}

Como se ha explicado en el apartado de introducción, la combretastatina A-4 (CA-4) exhibe propiedades antimitóticas, las cuales se deben a su unión al sitio de la colchicina en la tubulina, y también antiangiogénicas. Por otro lado, la aminocombretastatina y algunos derivados aminoacídicos de la misma también exhiben potentes actividades citotóxicas y antitumorales. Por ello, los objetivos de esta Tesis se enfocan a la síntesis y evaluación biológica de derivados de combretastatina y de aminocombretastatina.

1) Parte de síntesis. En esta parte de la Tesis se explicará la preparación de tres familias de compuestos cuyas estructuras generales se indican a continuación:<smiles>[R]C(NC(=O)COc1cc(/C=C\c2cc(OC)c(OC)c(OC)c2)ccc1OC)C(=O)O</smiles><smiles>[R]C(N)C(=O)Nc1cc(/C=C\c2cc(OC)c(OC)c(OC)c2)ccc1OC</smiles><smiles>[R]C(=O)Nc1cc(/C=C\c2cc(OC)c(OC)c(OC)c2)ccc1OC</smiles>

Figura 2.1. Estructuras generales de los compuestos sintetizados en esta Tesis.

Los compuestos de la familia 1 se pueden considerar híbridos de CA-4 y aminoácidos unidos mediante un espaciador de ácido acético.

Los compuestos de la familias 2 y 3 son derivados $N$-acilados de la aminocombretastatina (AmCA-4). La familia 2 está constituida por derivados obtenidos por acilación de la AmCA-4 con aminoácidos. La familia 3 la componen derivados acilados de AmCA-4 obtenidos mediante acilación con ácidos carboxílicos que contienen cadenas hidrocarbonadas de variada longitud. 
2) Parte de evaluación biológica. En esta parte de la Tesis se evaluará la actividad biológica de los compuestos sintéticos centrada en:

a) la actividad antiproliferativa de los derivados frente a diferentes líneas celulares, tanto tumorales como no tumorales.

b) la interacción de los derivados sintéticos con la tubulina.

c) el efecto de los derivados sobre la inhibición de los genes hTERT y c-Myc implicados en la activación de la polimerasa y el gen VEGF implicado en la angiogénesis. 


\section{SÍNTESIS DE DERIVADOS DE COMBRETASTATINA A-4 Y DE AMINOCOMBRETASTATINA}





\section{SÍNTESIS DE DERIVADOS DE COMBRETASTATINA A-4 Y DE AMINOCOMBRETASTATINA}

\subsection{Síntesis de los compuestos de la familia 1}

La preparación de los derivados de la familia 1 requirió en primer lugar la síntesis de combretastatina A-4 (CA-4). Este compuesto es un producto natural que se encuentra comercialmente accesible, aunque a un precio muy elevado. Por ejemplo, la compañia Aldrich lo vende en presentación de $5 \mathrm{mg}$ por un importe de $93.6 €$ o en presentación de $25 \mathrm{mg}$ por un importe de 346.5 $€$. $^{183}$ Debido a su elevado precio, la combretastatina A-4 se preparó siguiendo el procedimiento de Gaukroger y colaboradores, que transcurre con excelente estereocontrol $Z / E$, sin el empleo de grupos protectores y en tan solo dos etapas de reacción. ${ }^{184}$ La síntesis se inició con la condensación de Perkin entre el ácido 2-(3,4,5-trimetoxifenil)acético 1 y la isovainillina 2 (véase el esquema 3.1). La reacción se llevó a cabo mediante calentamiento a reflujo durante 3 horas y en presencia de anhídrido acético y trietilamina. La adición de $\mathrm{HCl}$ y el procesado de la reacción proporcionó, después de la cristalización de etanol, el ácido 3 de configuración E. Este compuesto se convirtió en CA-4 mediante descarboxilación con cobre a reflujo en presencia de quinolina (véase el esquema 3.1).

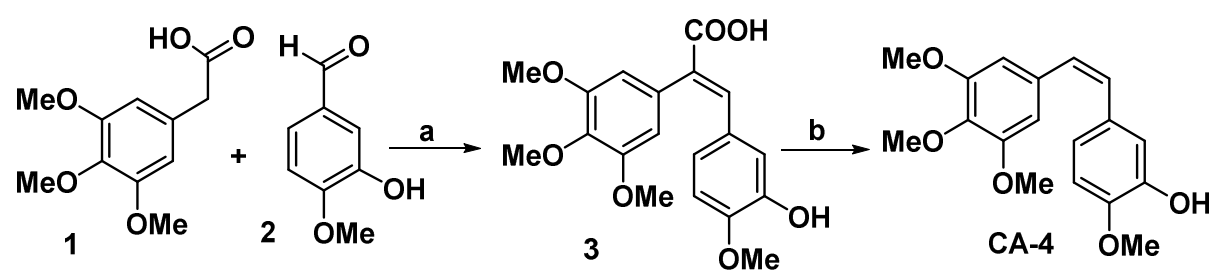

Esquema 3.1

Reactivos y condiciones: (a) $\mathrm{Ac}_{2} \mathrm{O}, \mathrm{Et}_{3} \mathrm{~N}$, reflujo, $3 \mathrm{~h}$, después $\mathrm{HCl}$ conc. $56 \%$; (b) $\mathrm{Cu}$, quinolina, reflujo, $3 \mathrm{~h}, 83 \%$ (Z/E 98:2).

\footnotetext{
${ }^{183} \mathrm{http}: / /$ www.sigmaaldrich.com/catalog/product/sigma/c7744?lang=es\&region=ES ${ }^{184}$ Gaukroger, K; Hadfield, J. A.; Hepworth, L. A; Lawrence, N. L; McGown, A.T. J. Org. Chem. 2001, 66, 8135-8138.
} 
Los compuestos de la família 1 se obtuvieron mediante la secuencia sintética indicada en el esquema 3.2. Así, CA-4 se convirtió en el compuesto 4 mediante reacción con bromoacetato de etilo en presencia de $\mathrm{K}_{2} \mathrm{CO}_{3}$. La saponificación de 4 condujo al ácido 5 .

Por otro lado, a partir de una serie de L-aminoácidos se obtuvieron los correspondientes metilésteres, en su forma de clorhidrato, por reacción con cloruro de tionilo en metanol. ${ }^{185} \mathrm{La}$ amidación del ácido 5 con los Laminoésteres se llevó a cabo en presencia de EDCI y $\operatorname{DMAP}^{186}$ y condujo a los productos 3.1-3.9. La saponificación de estos compuestos proporcionó los derivados de la familia 1 (véase el esquema 3.2).

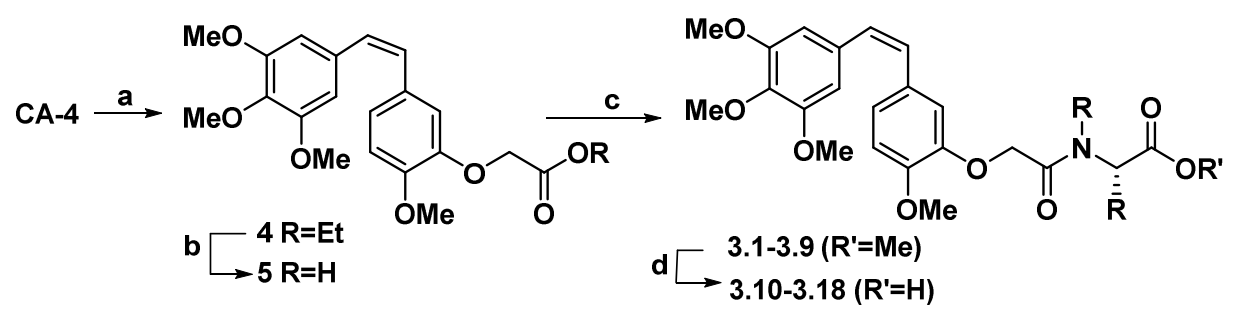

Esquema 3.2

Reactivos y condiciones: (a) $\mathrm{K}_{2} \mathrm{CO}_{3}$, DMF, temp. amb., $1 \mathrm{~h}$., luego adición de $\mathrm{BrCH}_{2} \mathrm{COEt}$, temp. amb., 24 h, 94\% (b) $\mathrm{NaOH}$, EtOH, temp. amb., 1 h, $91 \%$. (c) Laminoéster, EDCl.HCl, DMAP, DMF, $0^{\circ} \mathrm{C}, 2 \mathrm{~h}$ y temp. amb., 2 h. (d) $\mathrm{LiOH}, \mathrm{MeOH} / \mathrm{H}_{2} \mathrm{O}$, temp. amb., $1 \mathrm{~h}$.

En la figura 3.1 se indican las estructuras de los compuestos 3.1-3.9 y 3.10-3.18 obtenidos.

\footnotetext{
${ }^{185}$ Aitali, M.; Allaoud, S.; Karim, A.; Meliet, C.; Mortreux, A. Tetrahedron: Asymmetry, 2000, 11, 1367-1374

${ }^{186}$ Iwaszkiewicz-Grzes, D.; Cholewinski, G.; Kot-Wasik, A.; Trzonkowski, P.; Dzierzbicka, K. Eur. J. Med. Chem, 2013, 863-871.
} 
<smiles>[R]C(C(=O)OC)N([R])C(=O)COc1cc(/C=C\c2cc(OC)c(OC)c(OC)c2)ccc1OC</smiles>

$3.1 \mathrm{R}=\mathrm{R}^{\prime}=\mathrm{H}(68 \%)$

$3.2 \mathrm{R}=\mathrm{CH}\left(\mathrm{CH}_{3}\right)_{2}, \mathrm{R}^{\prime}=\mathrm{H}(72 \%)$

$3.3 \mathrm{R}=\mathrm{CH}_{2} \mathrm{CH}\left(\mathrm{CH}_{3}\right)_{2}, \mathrm{R}^{\prime}=\mathrm{H}(79 \%)$

$3.4 \mathrm{R}=\mathrm{CH}_{2} \mathrm{C}_{6} \mathrm{H}_{5}, \mathrm{R}^{\prime}=\mathrm{H}(80 \%)$

$3.5 \mathrm{R}=\mathrm{R}^{\prime}=\left(\mathrm{CH}_{2}\right)_{3}(74 \%)$

$3.6 \mathrm{R}=\mathrm{CH}_{2}(\mathrm{OH}), \mathrm{R}^{\prime}=\mathrm{H}(97 \%)$

$3.7 \mathrm{R}=\mathrm{CH}(\mathrm{OH}) \mathrm{CH}_{3}, \mathrm{R}^{\prime}=\mathrm{H}(70 \%)$

$3.8 \mathrm{R}=\mathrm{CH}_{2} \mathrm{pC}_{6} \mathrm{H}_{4}-\mathrm{OH}, \mathrm{R}^{\prime}=\mathrm{H}(84 \%)$

$3.9 \mathrm{R}=\left(\mathrm{CH}_{2}\right)_{2} \mathrm{SCH}_{3}, \mathrm{R}^{\prime}=\mathrm{H}(66 \%)$<smiles>[R]C(C(=O)O)N([R])C(=O)COc1cc(/C=C\c2cc(OC)c(OC)c(OC)c2)ccc1OC</smiles>

$3.10 \quad R=R^{\prime}=H(71 \%)$

$3.11 \mathrm{R}=\mathrm{CH}\left(\mathrm{CH}_{3}\right)_{2}, \mathrm{R}^{\prime}=\mathrm{H}(46 \%)$

$3.12 \mathrm{R}=\mathrm{CH}_{2} \mathrm{CH}\left(\mathrm{CH}_{3}\right)_{2}, \mathrm{R}^{\prime}=\mathrm{H}(52 \%)$

$3.13 \mathrm{R}=\mathrm{CH}_{2} \mathrm{C}_{6} \mathrm{H}_{5}, \mathrm{R}^{\prime}=\mathrm{H}(87 \%)$

$3.14 \mathrm{R}=\mathrm{R}^{\prime}=\left(\mathrm{CH}_{2}\right)_{3}(89 \%)$

$3.15 \mathrm{R}=\mathrm{CH}_{2}(\mathrm{OH}), \mathrm{R}^{\prime}=\mathrm{H}(67 \%)$

$3.16 \mathrm{R}=\mathrm{CH}(\mathrm{OH}) \mathrm{CH}_{3}, \mathrm{R}^{\prime}=\mathrm{H}(68 \%)$

$3.17 \mathrm{R}=\mathrm{CH}_{2} \mathrm{pC}_{6} \mathrm{H}_{4}-\mathrm{OH}, \mathrm{R}^{\prime}=\mathrm{H}(97 \%)$

$3.18 \mathrm{R}=\left(\mathrm{CH}_{2}\right)_{2} \mathrm{SCH}_{3}, \mathrm{R}^{\prime}=\mathrm{H}(66 \%)$

Figura 3.1. Estructuras de los compuestos 3.1-3.9 y 3.10-3.18.

Los derivados de la familia 1 con D-aminoácidos se obtuvieron de forma similar (véase el esquema 3.3).

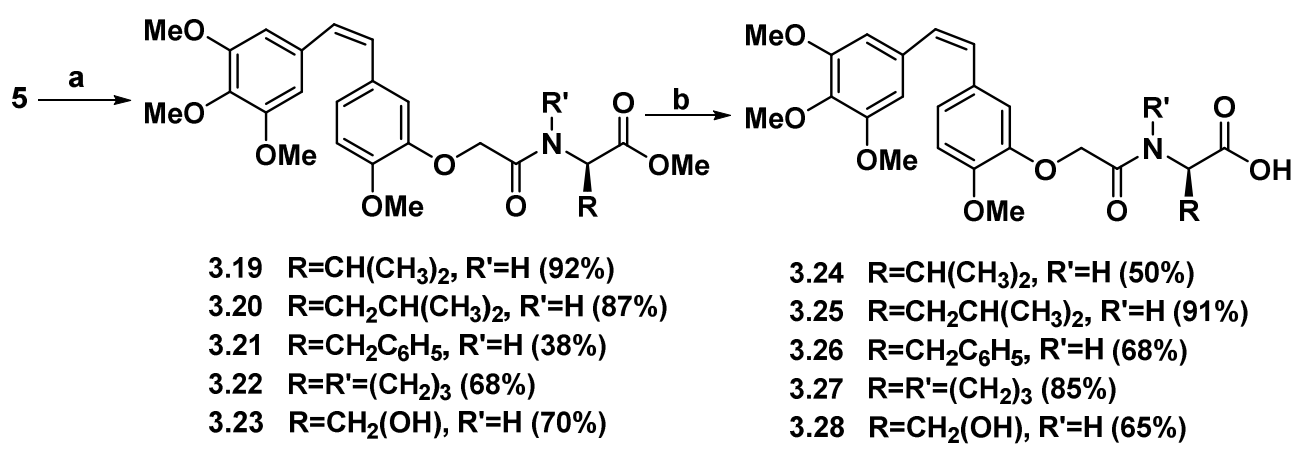

Esquema 3.3

Reactivos y condiciones: (a) D-aminoéster, EDCl. $\mathrm{HCl}$, DMAP, DMF, $0^{\circ} \mathrm{C}, 2 \mathrm{~h}$ y temp. amb., 2 h. (b) $\mathrm{LiOH}, \cdot \mathrm{MeOH} / \mathrm{H}_{2} \mathrm{O}$, temp. amb., 1 h.

\subsection{Síntesis de los compuestos de la familia 2}

La preparación de los derivados de la familia 2 requirió, en primer lugar, la síntesis de aminocombretastatina (AmCA-4). La síntesis se indica en el esquema 3.4 y se inició con la condensación de Perkin entre el ácido 2-(3,4,5trimetoxifenil)acético $\mathbf{1}$ y el 4 -metoxi-3-nitrobenzaldehido 6 mediante calentamiento a reflujo, durante 3 horas, en presencia de anhídrido acético y trietilamina. La adición de $\mathrm{HCl}$ y el procesado de la reacción proporcionó, 
después de la cristalización de etanol, el ácido 7 de configuración $E$. La descarboxilación de 7 con cobre a reflujo de quinolina condujo al compuesto 8 el cual, por reducción del grupo nitro con zinc en ácido acético, proporcionó la AmCA-4. ${ }^{187}$

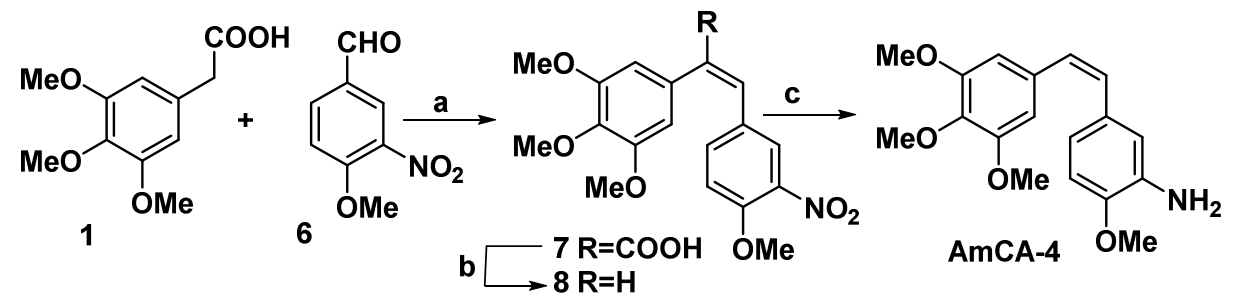

\section{Esquema 3.4}

Reactivos y condiciones: (a) $\mathrm{Ac}_{2} \mathrm{O}, \mathrm{Et}_{3} \mathrm{~N}$, reflujo, $3 \mathrm{~h}$, después $\mathrm{HCl}$ conc. 49\%; (b) $\mathrm{Cu}$, quinolina, reflujo, $3 \mathrm{~h}, 37 \%$ (Z/E 98:2). (c) $\mathrm{Zn}, \mathrm{AcOH}$, temp. amb., 4 h, 87\%.

Los compuestos de la familia 2 se obtuvieron mediante la secuencia sintética indicada en el esquema 3.5. Para ello, AmCA-4 se sometió a reacción de $\mathrm{N}$-acilación con una serie de L-aminoácidos $\mathrm{N}$-Fmoc-protegidos (véase la parte experimental para el proceso de protección). La reacción de acilación entre los L- $\alpha$-aminoácidos protegidos y AmCA-4 se llevó a cabo utilizando DMF como disolvente y en presencia de DCC y $\mathrm{HOBt}^{188}$ lo que condujo a los compuestos 3.29-3.37. Dichos compuestos se sometieron a $N$ desprotección mediante reacción con KF en presencia de 18-corona- $6^{189}$ lo que proporcionó los $N$ - $\alpha$-aminoacil derivados de aminocombretastatina 3.383.46 (véase el esquema 3.5).

\footnotetext{
${ }^{187}$ Ying-Qian, L.; Xiao-Jing, L.; Chun-Yan, Z.; Xiang, N.; Jing, T.; Morris-Natschke, S.L.; Zhi-Jun, Z.; Xiao-Ming, Y.; Liu, Y.; Lin-Hai, L.; Xing-Wen, Z.; Kuo-Hsiung, L. Bioorg. Med. Chem., 2013, $21,1248-1256$.

${ }_{188}$ Monk, K.A.; Siles, R.; Hadimani, B. M.; Mugabe, B.E.; Ackley, J.F.; Studerus, S.W.; Edvarsen, K.; Trawick, M. L.; Garner, C. M.; Rhodes, M. R, Pettit, G. R.; Pinney, K.G. Bioorg. Med. Chem. 2006, 14, 3231-3244.

${ }^{189}$ Kuduk, S.D.; Schwarz, J.B.; Chen, X.T.; Glunz, P.W.; Sames, D.; Ragupathi, G.; Livingston, P.O.; Danishefsky, S. J., J. Am. Chem. Soc. 1998, 120, 12474-12485
} 


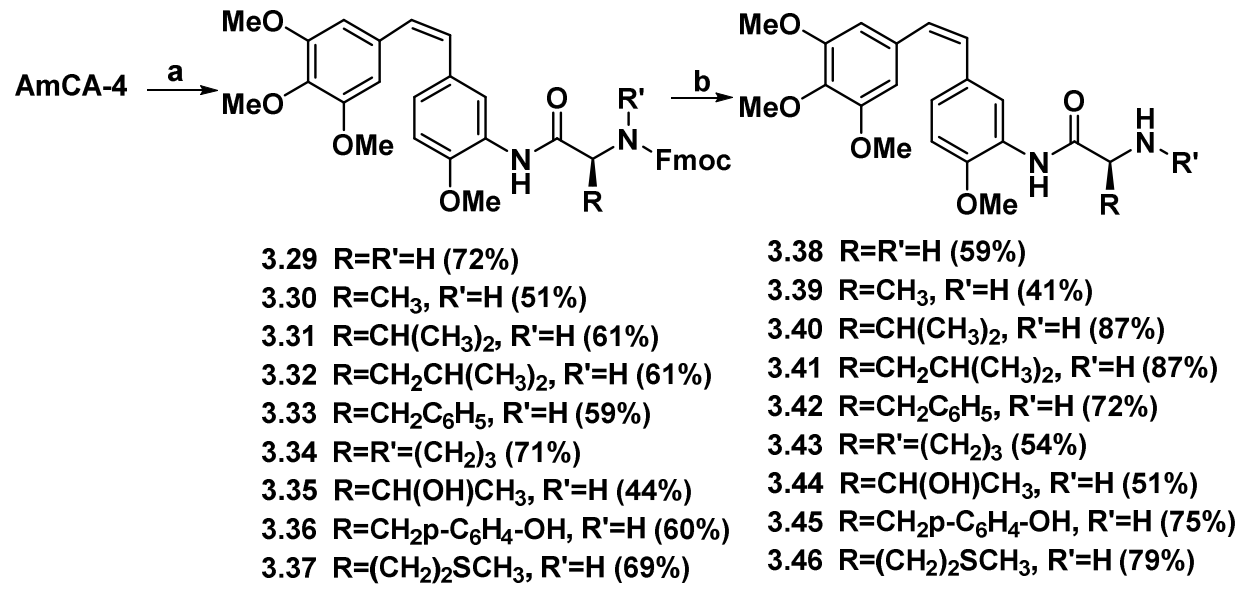

\section{Esquema 3.5}

Reactivos y condiciones: (a) DCC, HOBt, DMF, temp. amb., 16h. (b) KF, 18-corona6, DMF, temp. amb., $4 \mathrm{~h}$.

Los derivados con aminoácidos de la serie $D$ se obtuvieron de forma similar (véase el esquema 3.6).

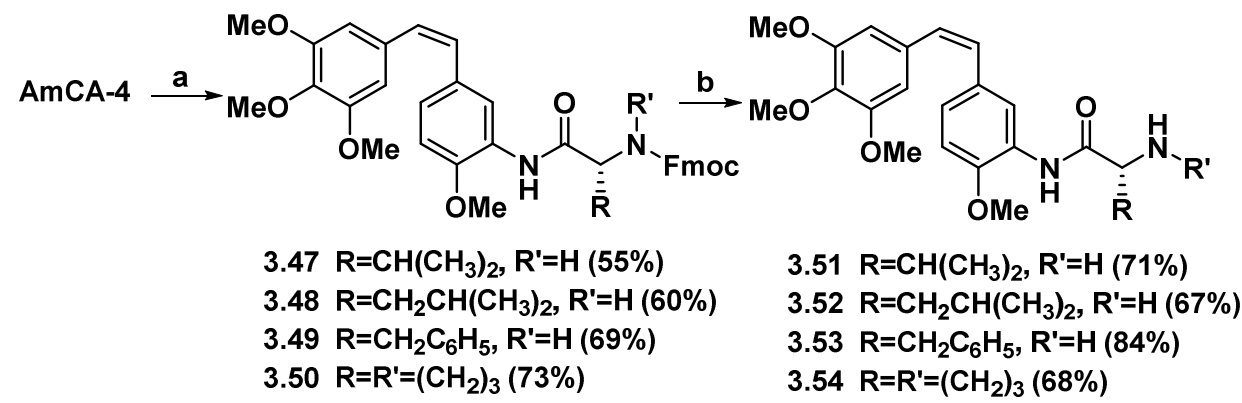

\section{Esquema 3.6}

Reactivos y condiciones: (a) DCC, HOBt, DMF, temp. amb., 16h. (b) KF, 18-corona6, DMF, temp. amb., $4 \mathrm{~h}$. 


\subsection{Síntesis de los compuestos de la familia 3}

La compuestos de la familia 3 se obtuvieron mediante $\mathrm{N}$-acilación de AmCA-4 con diversos ácidos alifáticos de cadena líneal, tal y como se indica en el esquema 3.7.

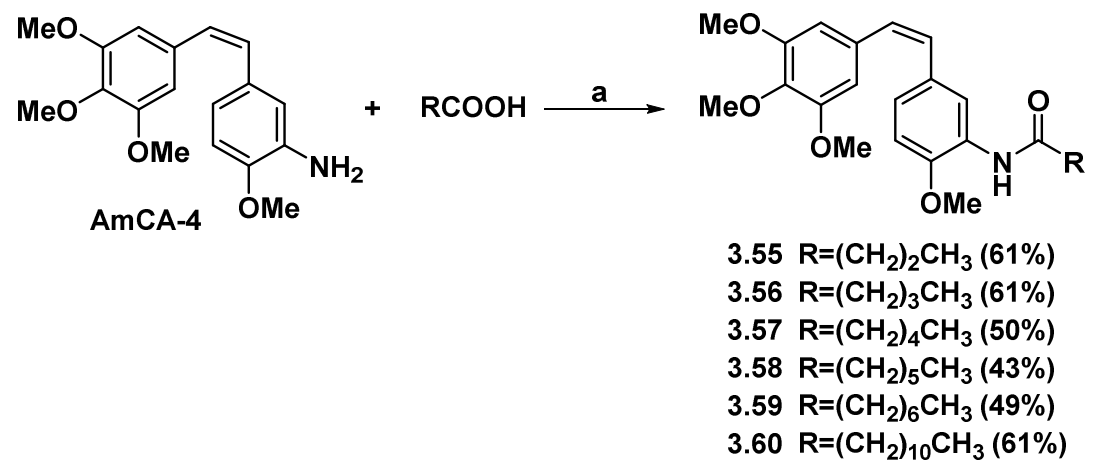

Esquema 3.7

Reactivos y condiciones: $\mathrm{EDCl} \cdot \mathrm{HCl}, \mathrm{DMAP}, \mathrm{DMF}, 0^{\circ} \mathrm{C}, 2 \mathrm{~h}$, luego temp. amb., $2 \mathrm{~h}$. 


\subsection{Parte experimental}

\subsubsection{Técnicas generales}

Los espectros de RMN fueron registrados en espectrómetro Varian Unity de 500 (frecuencias aproximadas de operación, $500 \mathrm{MHz}$ para ${ }^{1} \mathrm{H} ; 125 \mathrm{MHz}$ para $\left.{ }^{13} \mathrm{C}\right)$. La naturaleza de las señales de carbono $\left(\mathrm{C}, \mathrm{CH}, \mathrm{CH}_{2}, \mathrm{CH}_{3}\right)$ y las asignaciones de las todas las señales se han llevado a cabo mediante correlaciones heteronucleares bidimensionales (COSY y HSQC). LoS espectros se midieron en disolución de $\mathrm{CDCl}_{3}, \mathrm{CD}_{3} \mathrm{OD}$ y DMSO- $d_{6}$. Los desplazamientos químicos $(\delta)$ están indicados en ppm usando como referencia las señales residuales de los disolventes. Para el ${ }^{1} \mathrm{H}$, se referencia $\delta=7.27$ ppm para el $\mathrm{CDCl}_{3}, \delta=3.31 \mathrm{ppm}$ para el $\mathrm{CD}_{3} \mathrm{OD}$ y $\delta=2.50 \mathrm{ppm}$ para el DMSO- $d_{6}$. Para el ${ }^{13} \mathrm{C}$, se referencia $\delta=77.0 \mathrm{ppm}$ para el $\mathrm{CDCl}_{3}, \delta=49.0 \mathrm{ppm}$ para el $\mathrm{CD}_{3} \mathrm{OD}$ y $\delta=39.5 \mathrm{ppm}$ para el $\mathrm{DMSO}-d_{6}$. En el caso de las multiplicidades en el ${ }^{1} \mathrm{H}-\mathrm{RMN}$ se ha usado $s$ cuando se trata de un singulete, $d$ para doblete, $t$ para triplete, $q$ para cuadruplete, quint para quintuplete, sext para sextuplete, $m$ para multiplete, $b r$ cuando se trata de una señal ancha y app cuando se trata de una señal con multiplicidad aparente.

Los espectros de IR se obtuvieron mediante el uso de pastillas de $\mathrm{KBr}$ para muestras líquidas o mediante el uso de ATR para muestras sólidas en un espectrómetro Jasco FT/IR-6200, abarcando la región 4000-600 cm-1. Sólo se indican las bandas más importantes $(\mathrm{C}=\mathrm{O}, \mathrm{O}-\mathrm{H}, \mathrm{N}-\mathrm{H})$

Los espectros de masas se midieron en un espectrómetro de masas QTOF (Waters, Manchester, UK) con fuente de ionización combinada electrospray y APCI con diseño Z-spray; la tensión capilar de $3.5 \mathrm{KV}$ se utilizó en el sentido positivo y la tensión de cono se estableció en $20 \mathrm{~V}$.

Los puntos de fusión fueron medidos en un aparato de punto de fusión digital SMP10 (Stuart Scientific) y no fueron corregidos.

Para la cromatografía de capa fina (TLC) se utilizaron cromatofolios de gel de sílice de Merck 5554. 
Los reactivos disponibles comercialmente se emplearon sin tratamiento previo, directamente de las casas comerciales Sigma-Aldrich, Fluka, Scharlab o Acros. La trietilamina se destilo sobre hidróxido potásico. La DMF se destiló y se guardó sobre tamices de $3 \AA ̊$.

Los reactivos sensibles al aire se utilizaron bajo atmósfera de nitrógeno evitando en todo momento el contacto con el aire y humedad.

Todos los derivados han sido sintetizados protegiéndolos de la luz. 


\subsubsection{Síntesis de combretastatina A-4}

a) Síntesis del ácido (E)-3-(3-hidroxi-4-metoxifenil)-2-(3,4,5-trimetoxifenil) acrílico 3.

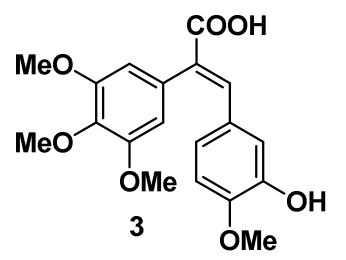

A una mezcla de 1 (10 mmol, 1 eq.) y 2 (20 mmol, 2.0 eq.) en $\mathrm{Ac}_{2} \mathrm{O}$ (12 $\mathrm{mL}$ ) se le añadió $\mathrm{Et}_{3} \mathrm{~N}(5 \mathrm{~mL})$ y se calentó a reflujo durante $3 \mathrm{~h}$. Acabado este tiempo, se acidificó la mezcla de reacción con $\mathrm{HCl}$ concentrado $(6 \mathrm{~mL})$ formándose un precipitado que se filtró a vacío. El sólido obtenido se recristalizó de $\mathrm{EtOH}$.

Rto. $=56 \%$. Sólido amarillo.

$\mathbf{R M N}^{1} \mathbf{H}\left(500 \mathrm{MHz}, \mathrm{CDCl}_{3}\right) \delta 7.58(1 \mathrm{H}, \mathrm{s}), 6.80(1 \mathrm{H}, \mathrm{d}, J=8.3 \mathrm{~Hz}), 6.61(1 \mathrm{H}$, $\mathrm{dd}, J=8.3,1.9 \mathrm{~Hz}), 6.54(1 \mathrm{H}, \mathrm{d}, J=1.9 \mathrm{~Hz}), 6.44(2 \mathrm{H}, \mathrm{s}), 3.74(3 \mathrm{H}, \mathrm{s}), 3.72$ $(3 \mathrm{H}, \mathrm{s}), 3.68(6 \mathrm{H}, \mathrm{s})$.

RMN ${ }^{13} \mathbf{C}\left(125 \mathrm{MHz}, \mathrm{CDCl}_{3}\right) \delta 169.0(\mathrm{CO}) ; 153.5,149.2,146.2,139.5,137.3$, 132.5, 130.7 (C); 127.4, 123.4, 117.5, 111.8, $107.0(\mathrm{CH}) ; 60.5,56.3,55.8$ $\left(\mathrm{CH}_{3}\right)$.

b) Síntesis de (Z)-2-metoxi-5-(3,4,5-trimetoxiestiril)fenol (CA-4)

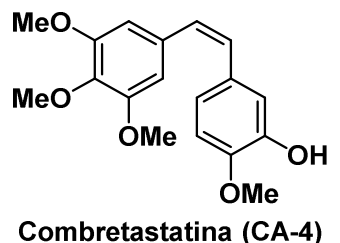

A una suspensión de $\mathrm{Cu}(31.2 \mathrm{mmol}, 5.2$ eq.) en quinolina $(23.5 \mathrm{~mL})$ se le adicionó el ácido 3 (6 mmol, 1 eq.) y la mezcla resultante se calentó a reflujo durante $3 \mathrm{~h}$. A continuación se enfrió la reacción, se adicionó $\mathrm{Et}_{2} \mathrm{O}(100 \mathrm{~mL})$ y el Cu se filtró a través de celite. El filtrado se lavó con $\mathrm{HCl} 1 \mathrm{M}$ y la fase acuosa se extrajo con $\mathrm{Et}_{2} \mathrm{O}$. Los extractos orgánicos reunidos se lavaron con una disolución acuosa saturada de $\mathrm{NaHCO}_{3}$ y luego se secaron con $\mathrm{Na}_{2} \mathrm{SO}_{4}$. Después de filtrar, el disolvente se eliminó a presión reducida. El residuo resultante se cromatografió sobre gel de sílice con Hexano-AcOEt (7:3). 
Rto. $=83 \%$. Sólido rosado como mezcla de isómeros Z/E 98:2.

RMN ${ }^{1} \mathbf{H}\left(500 \mathrm{MHz}, \mathrm{CDCl}_{3}\right) \delta 6.93(1 \mathrm{H}, \mathrm{d}, J=1.9 \mathrm{~Hz}), 6.82(1 \mathrm{H}, \mathrm{dd}, J=8.3,1.9$ $\mathrm{Hz}), 6.74(1 \mathrm{H}, \mathrm{d}, J=8.3 \mathrm{~Hz}), 6.54(2 \mathrm{H}, \mathrm{s}), 6.46(1 \mathrm{H}, \mathrm{d}, J=12.4 \mathrm{~Hz}), 6.42(1 \mathrm{H}$, d, $J=12.4 \mathrm{~Hz}),(5.52(1 \mathrm{H}, \mathrm{br} \mathrm{s}, \mathrm{OH}), 3.86(3 \mathrm{H}, \mathrm{s}), 3.85(3 \mathrm{H}, \mathrm{s}), 3.70(6 \mathrm{H}, \mathrm{s})$.

RMN ${ }^{13} \mathbf{C}\left(125 \mathrm{MHz}, \mathrm{CDCl}_{3}\right): \delta 152.8(x 2), 145.7,145.2,137.2,132.6,130.6$

$(\mathrm{C}) ; 129.4,128.9,121.0,115.0,110.3,106.1(x 2)(\mathrm{CH}) ; 60.8,55.8(x 3)\left(\mathrm{CH}_{3}\right)$.

\subsubsection{Síntesis de los compuestos de la familia 1}

\subsection{3.a. Instalación del espaciador de acetato}

Síntesis de (Z)-2-(2-metoxi-5-(3,4,5-trimetoxiestiril)fenoxi)acetato de etilo

4.<smiles>CCOC(=O)COc1cc(/C=C\c2cc(OC)c(OC)c(OC)c2)cc(OC)c1OC</smiles>

A una disolución de combretastatina A-4 (0.5 mmol, 1 eq.) en DMF anhidro (12 mL) se le añadió, bajo atmósfera de $\mathrm{N}_{2}$, añadió $\mathrm{K}_{2} \mathrm{CO}_{3}(1 \mathrm{mmol}, 2$ eq.). Luego se agitó durante una hora y se adicionó bromoacetato de etilo (0.75 mmol, 1.5 eq.). La mezcla resultante se agitó a temperatura ambiente durante $24 \mathrm{~h}$ protegida de la luz. A continuación, la mezcla se vertió sobre una disolución acuosa saturada de $\mathrm{NH}_{4} \mathrm{Cl}$ y se extrajo con $\mathrm{Et}_{2} \mathrm{O}(3 \times 20 \mathrm{~mL})$. Los extractos orgánicos reunidos se secaron sobre $\mathrm{MgSO}_{4}$ anhidro. Después de filtrar y eliminar el disolvente a presión reducida, el residuo resultante se cromatografió sobre gel de sílice con hexano-AcOEt (7:3).

Rto. $=94 \%$. Sólido blanco. p. $f=70-72^{\circ} \mathrm{C}$.

IR: $\boldsymbol{V}_{\max } 1755 \mathrm{~cm}^{-1}(\mathrm{br}, \mathrm{C}=\mathrm{O})$.

RMN ${ }^{1} \mathbf{H}\left(500 \mathrm{MHz}, \mathrm{CDCl}_{3}\right) \delta 6.90(1 \mathrm{H}, \mathrm{dd}, J=8.3,2 \mathrm{~Hz}), 6.78(1 \mathrm{H}, \mathrm{d}, J=8.3$ $\mathrm{Hz}), 6.74(1 \mathrm{H}, \mathrm{d}, J=2 \mathrm{~Hz}), 6.47(2 \mathrm{H}, \mathrm{s}), 6.46(1 \mathrm{H}, \mathrm{d}, J=12.2 \mathrm{~Hz}), 6.42(1 \mathrm{H}, \mathrm{d}$, $J=12.2 \mathrm{~Hz}), 4.48(2 \mathrm{H}, \mathrm{s}), 4.18(2 \mathrm{H}, \mathrm{q}, J=7.3 \mathrm{~Hz}), 3.84(3 \mathrm{H}, \mathrm{s}), 3.82(3 \mathrm{H}, \mathrm{s})$, $3.69(6 \mathrm{H}, \mathrm{s}), 1.23(3 \mathrm{H}, \mathrm{t}, J=7.3 \mathrm{~Hz})$.

RMN ${ }^{13} \mathbf{C}\left(125 \mathrm{MHz}, \mathrm{CDCl}_{3}\right) \delta 168.5(\mathrm{CO}) ; 152.9(\mathrm{x} 2), 148.7,146.8,137.1$, 132.6, $129.8(\mathrm{C}) ; 129.3,129.1,123.2,114.6,111.6,106.0$ (x 2) $(\mathrm{CH}) ; 66.1$, $61.1\left(\mathrm{CH}_{2}\right) ; 60.7,55.9,55.8(\times 2), 14.0\left(\mathrm{CH}_{3}\right)$.

HR ESMS : $m / z 425.1576(\mathrm{M}+\mathrm{Na})^{+}$. Calculado para $\mathrm{C}_{22} \mathrm{H}_{26} \mathrm{NaO}_{7 .} 425.1576$. 
Síntesis del ácido (Z)-2-(2-metoxi-5-(3,4,5-trimetoxiestiril)fenoxi)acético 5.<smiles>COc1cc(/C=C\c2cc(OC)c(OC)c(OCC(=O)O)c2)cc(OC)c1OC</smiles>

A una disolución del éster 4 ( $0.5 \mathrm{mmol}, 1$ eq.) en $\mathrm{EtOH}(25 \mathrm{~mL})$ se le adicionó una disolución de $\mathrm{NaOH}\left(10 \mathrm{mmol}, 20\right.$ eq.) en $\mathrm{H}_{2} \mathrm{O}(2.6 \mathrm{~mL})$. La mezcla se mantuvo en agitación durante una hora protegida de la luz. Transcurrido este tiempo se eliminó el EtOH a presión reducida, se acidificó el residuo con $\mathrm{HCl} 2 \mathrm{M}$ y se extrajo con $\mathrm{CH}_{2} \mathrm{Cl}_{2}(3 \times 30 \mathrm{~mL})$. Los extractos orgánicos reunidos se secaron sobre $\mathrm{MgSO}_{4}$ anhidro. Después de filtrar y eliminar el disolvente a presión reducida, el residuo resultante se recristalizó sobre una mezcla hexano-AcOEt (8:2).

Rto. $=91 \%$. Sólido blanco. p. $f=109-111^{\circ} \mathrm{C}$.

IR: $\boldsymbol{v}_{\max }$ 3500-3200 (br, OH), $1742(\mathrm{br}, \mathrm{C}=\mathrm{O}) \mathrm{cm}^{-1}$.

$\mathbf{R M N}^{1} \mathbf{H}\left(500 \mathrm{MHz}, \mathrm{CDCl}_{3}\right) \delta 8.10(1 \mathrm{H}, \mathrm{br} \mathrm{s}, \mathrm{OH}), 6.93(1 \mathrm{H}, \mathrm{dd}, J=8.3,2 \mathrm{~Hz})$, $6.79(1 \mathrm{H}, \mathrm{d}, J=8.3 \mathrm{~Hz}), 6.78(1 \mathrm{H}, \mathrm{d}, J=2 \mathrm{~Hz}), 6.47(2 \mathrm{H}, \mathrm{s}), 6.45(2 \mathrm{H}, \mathrm{s}), 4.52$ $(2 \mathrm{H}, \mathrm{s}), 3.85(3 \mathrm{H}, \mathrm{s}), 3.83(3 \mathrm{H}, \mathrm{s}), 3.69(6 \mathrm{H}, \mathrm{s})$.

RMN ${ }^{13} \mathbf{C}\left(125 \mathrm{MHz}, \mathrm{CDCl}_{3}\right) \delta 172.0$ (CO); 152.9 (x 2), 148.7, 146.6, 137.1, 132.7, 130.0 (C); 129.2, 129.1, 123.8, 115.2, 111.7, 106.0 (x 2) (CH); 66.3 $\left(\mathrm{CH}_{2}\right) ; 60.8,55.9(\times 2), 55.8\left(\mathrm{CH}_{3}\right)$.

HR ESMS : $m / z 373.1284(\mathrm{M}-\mathrm{H})^{\circ}$. Calculado para $\mathrm{C}_{20} \mathrm{H}_{21} \mathrm{O}_{7 .} 373.1287$.

\subsection{3.b. Procedimento general para la esterificación de los aminoácidos}

A una disolución del aminoácido ( $5 \mathrm{mmol}, 1$ eq.) en $\mathrm{CH}_{3} \mathrm{OH}(12.5 \mathrm{~mL})$ se le añadió lentamente, bajo atmósfera de nitrógeno y $0^{\circ} \mathrm{C}, \mathrm{SOCl}_{2}(12.5 \mathrm{mmol}, 2.5$ eq.). La mezcla de reacción se dejó agitando a temperatura ambiente durante 2 horas. Transcurrido este tiempo, la mezcla de reacción se calentó hasta llegar a reflujo durante 1.5 h. Seguidamente se eliminó el $\mathrm{MeOH}$ a presión reducida y se recristalizó el clorhidrato del éster obtenido mediente una mezcla hexano: AcOEt (7:3) obteniéndose el correspondiente clorhidrato del aminoéster. 


\subsection{3.c. Procedimento general para la reacción de amidación}

A una disolución del ácido 5 (0.5 mmol, 1 eq) en DMF anhidro $(10 \mathrm{~mL})$ se le añadió DMAP (1.14 mmol, 2.28 eq.) y el clorhidrato del aminoéster (0.57 mmol, 1.14 eq.). La mezcla de reacción se protegió de la luz, se enfrió a $0^{\circ} \mathrm{C}$ y se añadió, bajo atmósfera de $\mathrm{N}_{2}$, EDCl. $\mathrm{HCl}(0.55 \mathrm{mmol}, 1.1$ eq. $)$. La mezcla resultante se agitó durante 2 horas a $0^{\circ} \mathrm{C}$. Seguidamente, la mezcla se llevó a temperatura ambiente y se dejó reaccionando durante 2 horas. A continuación, la mezcla se vertió sobre una disolución acuosa saturada de $\mathrm{NH}_{4} \mathrm{Cl}$ y se extrajo con AcOEt $(3 \times 20 \mathrm{~mL}$ ). Los extractos orgánicos reunidos se lavaron con $\mathrm{H}_{2} \mathrm{O}$ y salmuera y se secaron sobre $\mathrm{MgSO}_{4}$ anhidro. Después de filtrar y eliminar el disolvente a presión reducida, el residuo resultante se cromatografió sobre gel de sílice con hexano-AcOEt (6:4) obteniéndose los derivados correspondientes.

\subsection{3.d. Datos físicos y espectroscópicos de los metilésteres de la familia} 1

(Z)-(2-(2-metoxi-5-(3,4,5-trimetoxiestiril)fenoxi)acetil)glicinato de metilo 3.1.

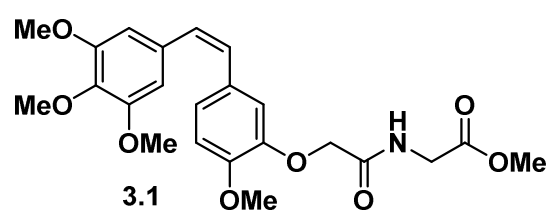

Rto. $=68 \%$. Sólido blanco. p. $f=103-105^{\circ} \mathrm{C}$.

IR: $\boldsymbol{v}_{\max } 3400(\mathrm{br}, \mathrm{NH}), 1751,1683(\mathrm{C}=\mathrm{O}) \mathrm{cm}^{-1}$.

$\mathbf{R M N}^{1} \mathbf{H}\left(500 \mathrm{MHz}, \mathrm{CDCl}_{3}\right) \delta 7.45(1 \mathrm{H}, \mathrm{br} \mathrm{s}, \mathrm{NH}), 6.96(1 \mathrm{H}, \mathrm{dd}, J=8.3,2 \mathrm{~Hz})$, $6.85(1 \mathrm{H}, \mathrm{d}, J=2 \mathrm{~Hz}), 6.80(1 \mathrm{H}, \mathrm{d}, J=8.3 \mathrm{~Hz}), 6.48(2 \mathrm{H}, \mathrm{s}), 6.46(2 \mathrm{H}, \mathrm{s}), 4.43$ $(2 \mathrm{H}, \mathrm{s}), 4.11(2 \mathrm{H}, \mathrm{d}, J=6 \mathrm{~Hz}), 3.87(3 \mathrm{H}, \mathrm{s}), 3.84(3 \mathrm{H}, \mathrm{s}), 3.76(3 \mathrm{H}, \mathrm{s}), 3.69$ $(6 \mathrm{H}, \mathrm{s})$.

RMN ${ }^{13} \mathbf{C}\left(125 \mathrm{MHz}, \mathrm{CDCl}_{3}\right) \delta$ 169.7, 168.7 (CO); 153.0 (x 2), 148.9, 146.7, $137.4,132.5,130.3(\mathrm{C}) ; 129.5,128.9,124.0,116.5,111.7,106.0(\mathrm{x} \mathrm{2})(\mathrm{CH})$; 69.4, $40.7\left(\mathrm{CH}_{2}\right) ; 60.9,55.9(\times 2), 55.8,52.3\left(\mathrm{CH}_{3}\right)$.

HR ESMS : $m / z 468.1634(\mathrm{M}+\mathrm{Na})^{+}$. Calculado para $\mathrm{C}_{23} \mathrm{H}_{27} \mathrm{NNaO}_{8 .} 468.1634$. 
(Z)-(2-(2-metoxi-5-(3,4,5-trimetoxiestiril)fenoxi)acetil)-L-valinato de metilo 3.2.

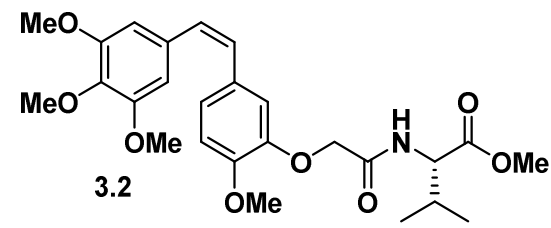

Rto. $=72 \%$. Aceite amarillento.

$[\alpha]_{\mathrm{D}} 11.8\left(\mathrm{c} 1.1, \mathrm{CHCl}_{3}\right)$.

IR: $\boldsymbol{v}_{\max } 3350(\mathrm{br}, \mathrm{NH}), 1742,1686(\mathrm{C}=\mathrm{O}) \mathrm{cm}^{-1}$.

RMN ${ }^{1} \mathbf{H}\left(500 \mathrm{MHz}, \mathrm{CDCl}_{3}\right) \delta 7.50(1 \mathrm{H}$, br d, $J \sim 9 \mathrm{~Hz}, \mathrm{NH}), 6.98(1 \mathrm{H}, \mathrm{dd}, J=$ 8.3, $2 \mathrm{~Hz}), 6.87(1 \mathrm{H}, \mathrm{d}, J=2 \mathrm{~Hz}), 6.80(1 \mathrm{H}, \mathrm{d}, J=8.3 \mathrm{~Hz}), 6.49(2 \mathrm{H}, \mathrm{s}), 6.47$ (2H, app s), $4.59(1 \mathrm{H}, \mathrm{dd}, J=9,5 \mathrm{~Hz}), 4.46(1 \mathrm{H}, \mathrm{d}, J=15 \mathrm{~Hz}), 4.43(1 \mathrm{H}, \mathrm{d}, J=$ $15 \mathrm{~Hz}), 3.87(3 \mathrm{H}, \mathrm{s}), 3.85(3 \mathrm{H}, \mathrm{s}), 3.73(3 \mathrm{H}, \mathrm{s}), 3.70(6 \mathrm{H}, \mathrm{s}), 2.20(1 \mathrm{H}, \mathrm{m}), 0.94$ $(3 \mathrm{H}, \mathrm{d}, J=7 \mathrm{~Hz}), 0.91(3 \mathrm{H}, \mathrm{d}, J=7 \mathrm{~Hz})$.

RMN ${ }^{13} \mathbf{C}\left(125 \mathrm{MHz}, \mathrm{CDCl}_{3}\right) \delta 171.8,168.5$ (CO); 153.0 (x 2), 149.0, 146.9, 137.4, 132.5, 130.4 (C); 129.5, 128.9, 124.0, 116.8, 111.6, 106.0 (x 2), 56.6, $31.2(\mathrm{CH}) ; 69.8\left(\mathrm{CH}_{2}\right) ; 60.9,55.9(\mathrm{x} 2), 55.8,52.0,18.8,17.6\left(\mathrm{CH}_{3}\right)$.

HR ESMS : m/z $510.2099(\mathrm{M}+\mathrm{Na})^{+}$. Calculado para $\mathrm{C}_{26} \mathrm{H}_{33} \mathrm{NNaO}_{8 .} 510.2104$.

(Z)-(2-(2-metoxi-5-(3,4,5-trimetoxiestiril)fenoxi)acetil)-L-leucinato de metilo 3.3 .

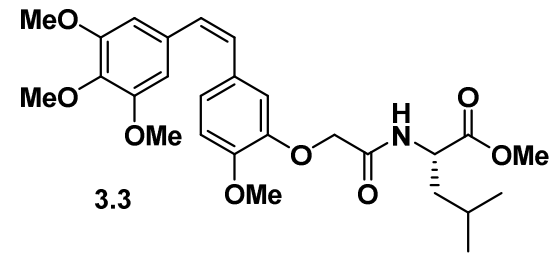

Rto. $=79 \%$. Sólido blanco. p. $f=85-87^{\circ} \mathrm{C}$.

$[\alpha]_{\mathrm{D}} 1.7\left(\mathrm{c} 1.2, \mathrm{CHCl}_{3}\right)$.

IR: $\boldsymbol{v}_{\max } 3350(\mathrm{br}, \mathrm{NH}), 1744,1684(\mathrm{C}=\mathrm{O}) \mathrm{cm}^{-1}$.

RMN ${ }^{1} \mathbf{H}\left(500 \mathrm{MHz}, \mathrm{CDCl}_{3}\right) \delta 7.40(1 \mathrm{H}, \mathrm{br} \mathrm{d}, J \sim 8.5 \mathrm{~Hz}, \mathrm{NH}), 6.98(1 \mathrm{H}, \mathrm{dd}, J=$ 8.3, $2 \mathrm{~Hz}), 6.86(1 \mathrm{H}, \mathrm{d}, J=2 \mathrm{~Hz}), 6.80(1 \mathrm{H}, \mathrm{d}, J=8.3 \mathrm{~Hz}), 6.49(2 \mathrm{H}, \mathrm{s}), 6.47$ (2H, app s), $4.68(1 \mathrm{H}, \mathrm{m}), 4.43(1 \mathrm{H}, \mathrm{d}, J=15 \mathrm{~Hz}), 4.41(1 \mathrm{H}, \mathrm{d}, J=15 \mathrm{~Hz}), 3.87$ $(3 \mathrm{H}, \mathrm{s}), 3.85(3 \mathrm{H}, \mathrm{s}), 3.73(3 \mathrm{H}, \mathrm{s}), 3.70(6 \mathrm{H}, \mathrm{s}), 1.75-1.55(3 \mathrm{H}, \mathrm{br} \mathrm{m}), 0.94(3 \mathrm{H}$, d, $J=7 \mathrm{~Hz}), 0.93(3 \mathrm{H}, \mathrm{d}, J=7 \mathrm{~Hz})$. 
RMN ${ }^{13} \mathbf{C}\left(125 \mathrm{MHz}, \mathrm{CDCl}_{3}\right) \delta 172.8,168.4(\mathrm{CO}) ; 153.0$ (x 2), 149.0, 146.9, 137.4, 132.5, $130.4(\mathrm{C}) ; 129.6,128.9,124.0,117.0,111.6,106.0$ (x 2), 50.3, $24.8(\mathrm{CH}) ; 69.8,41.5\left(\mathrm{CH}_{2}\right) ; 60.9,55.9(\times 2), 55.8,52.2,22.8,21.8\left(\mathrm{CH}_{3}\right)$.

HR ESMS : $m / z 524.2250(\mathrm{M}+\mathrm{Na})^{+}$. Calculado para $\mathrm{C}_{27} \mathrm{H}_{35} \mathrm{NNaO}_{8}$ 524.2260.

(Z)-(2-(2-metoxi-5-(3,4,5-trimetoxiestiril)fenoxi)acetil)-L-fenilalaninato de metilo 3.4 .

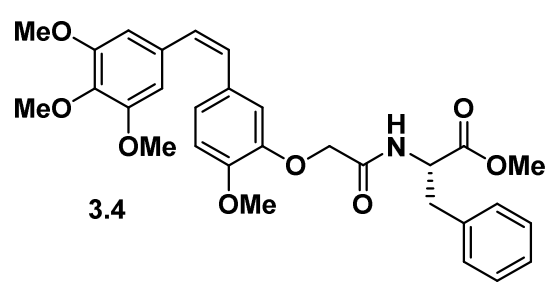

Rto. $=80 \%$. Aceite amarillento.

[a] 24.7 (c 1.0, $\left.\mathrm{CHCl}_{3}\right)$.

IR: $\boldsymbol{v}_{\max } 3400,3340(\mathrm{br}, \mathrm{NH}), 1745,1682(\mathrm{C}=\mathrm{O}) \mathrm{cm}^{-1}$.

$\mathbf{R M N}^{1} \mathbf{H}\left(500 \mathrm{MHz}, \mathrm{CDCl}_{3}\right) \delta 7.55(1 \mathrm{H}$, br d, J $8 \mathrm{~Hz}, \mathrm{NH}), 7.25-7.20(3 \mathrm{H}, \mathrm{m})$, $7.08(2 \mathrm{H}, \mathrm{m}), 6.98(1 \mathrm{H}, \mathrm{dd}, J=8.3,2 \mathrm{~Hz}), 6.83(1 \mathrm{H}, \mathrm{d}, J=2 \mathrm{~Hz}), 6.77(1 \mathrm{H}, \mathrm{d}, J$ $=8.3 \mathrm{~Hz}), 6.49(2 \mathrm{H}, \mathrm{s}), 6.47(2 \mathrm{H}$, sistema $\mathrm{AB}$ degenerado, $J \sim 12 \mathrm{~Hz}), 4.94$ $(1 \mathrm{H}, \mathrm{dt}, J=8,6.5 \mathrm{~Hz}), 4.42(1 \mathrm{H}, \mathrm{d}, J=15 \mathrm{~Hz}), 4.38(1 \mathrm{H}, \mathrm{d}, J=15 \mathrm{~Hz}), 3.85$ $(3 \mathrm{H}, \mathrm{s}), 3.73(3 \mathrm{H}, \mathrm{s}), 3.71(3 \mathrm{H}, \mathrm{s}), 3.69(6 \mathrm{H}, \mathrm{s}), 3.12(2 \mathrm{H}, \mathrm{m})$.

RMN ${ }^{13} \mathbf{C}\left(125 \mathrm{MHz}, \mathrm{CDCl}_{3}\right) \delta 171.4,168.3$ (CO); 153.0 (x 2), 149.1, 146.9, 137.4, 135.8, 132.6, 130.3 (C); 129.5, 129.2 (x 2), 128.9, 128.5 (x 2), 127.0, 124.1, 116.9, 111.7, 106.0 (x 2), $52.8(\mathrm{CH}) ; 69.8,38.1\left(\mathrm{CH}_{2}\right) ; 60.9,56.0(\mathrm{x} \mathrm{2})$, $55.7,52.2\left(\mathrm{CH}_{3}\right)$.

HR ESMS : $m / z 558.2100(\mathrm{M}+\mathrm{Na})^{+}$. Calculado para $\mathrm{C}_{30} \mathrm{H}_{33} \mathrm{NNaO}_{8 .}$ 558.2104.

(Z)-(2-(2-metoxi-5-(3,4,5-trimetoxiestiril)fenoxi)acetil)-L-prolinato de metilo 3.5.

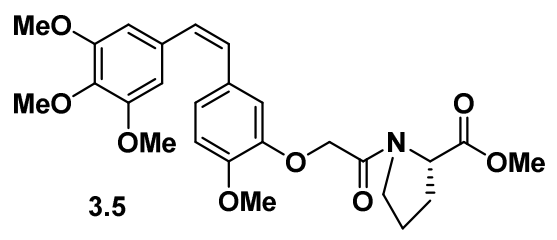

Rto. $=74 \%$. Aceite amarillento.

$[\alpha]_{\mathrm{D}}-41.9\left(\mathrm{c} 1.1, \mathrm{CHCl}_{3}\right)$.

IR: $\boldsymbol{v}_{\max } 1742,1671(\mathrm{C}=\mathrm{O}) \mathrm{cm}^{-1}$. 
RMN ${ }^{1} \mathbf{H}\left(500 \mathrm{MHz}, \mathrm{CDCl}_{3}\right) \delta 6.90(1 \mathrm{H}, \mathrm{dd}, J=8.3,2 \mathrm{~Hz}), 6.80(1 \mathrm{H}, \mathrm{d}, J=2$ $\mathrm{Hz}), 6.76(1 \mathrm{H}, \mathrm{d}, J=8.3 \mathrm{~Hz}), 6.50(2 \mathrm{H}, \mathrm{s}), 6.48(1 \mathrm{H}, \mathrm{d}, J=12 \mathrm{~Hz}), 6.43(1 \mathrm{H}, \mathrm{d}$, $J=12 \mathrm{~Hz}), 4.52(2 \mathrm{H}, \mathrm{s}), 4.49(1 \mathrm{H}, \mathrm{m}), 3.83(3 \mathrm{H}, \mathrm{s}), 3.82(3 \mathrm{H}, \mathrm{s}), 3.71(6 \mathrm{H}, \mathrm{s})$, $3.68(3 \mathrm{H}, \mathrm{s}), 3.60-3.50(2 \mathrm{H}, \mathrm{m}), 2.20-1.90(4 \mathrm{H}, \mathrm{br} \mathrm{m})$.

RMN ${ }^{13} \mathbf{C}\left(125 \mathrm{MHz}, \mathrm{CDCl}_{3}\right) \delta 172.3,166.4$ (CO); 152.9 (x 2), 148.7, 147.0, 137.1, 132.9, 129.8 (C); 129.5, 128.8, 123.1, 114.7, 111.6, 106.0 (x 2), 59.1 $(\mathrm{CH}) ; 67.9,46.1$, 28.6, $24.9\left(\mathrm{CH}_{2}\right)$; 60.8, $55.9(\mathrm{x} 2)$, 55.8, $52.1\left(\mathrm{CH}_{3}\right)$.

HR ESMS : $m / z 508.1945(\mathrm{M}+\mathrm{Na})^{+}$. Calculado para $\mathrm{C}_{26} \mathrm{H}_{31} \mathrm{NNaO}_{8}$ 508.1947.

(Z)-(2-(2-metoxi-5-(3,4,5-trimetoxiestiril)fenoxi)acetil)-L-serinato de metilo 3.6.

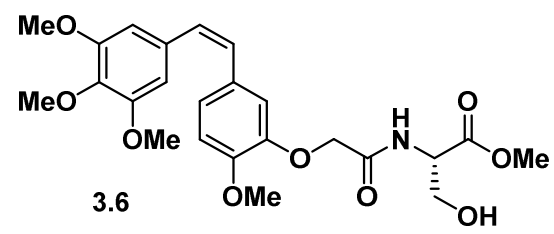

Rto. $=97 \%$. Sólido blanco. p. $f=65-67^{\circ} \mathrm{C}$.

$[\alpha]_{\mathrm{D}} 14.4\left(c 1.0, \mathrm{CHCl}_{3}\right)$.

IR: $\boldsymbol{v}_{\max } 3500-3300(\mathrm{br}, \mathrm{OH}, \mathrm{NH}), 1748,1676(\mathrm{C}=\mathrm{O}) \mathrm{cm}^{-1}$.

RMN ${ }^{1} \mathbf{H}\left(500 \mathrm{MHz}, \mathrm{CDCl}_{3}\right) \delta 7.90(1 \mathrm{H}$, br d, J $7.5 \mathrm{~Hz}, \mathrm{NH}), 6.96(1 \mathrm{H}, \mathrm{dd}, J=$ 8.3, $2 \mathrm{~Hz}), 6.86(1 \mathrm{H}, \mathrm{d}, J=2 \mathrm{~Hz}), 6.80(1 \mathrm{H}, \mathrm{d}, J=8.3 \mathrm{~Hz}), 6.48(2 \mathrm{H}, \mathrm{s}), 6.46$ $(2 \mathrm{H}$, app s), $4.71(1 \mathrm{H}, \mathrm{m}), 4.43(2 \mathrm{H}, \mathrm{s}), 4.00(1 \mathrm{H}, \mathrm{dd}, J=11.2,4 \mathrm{~Hz}), 3.91(1 \mathrm{H}$, $\mathrm{dd}, J=11.2,3.5 \mathrm{~Hz}), 3.86(3 \mathrm{H}, \mathrm{s}), 3.84(3 \mathrm{H}, \mathrm{s}), 3.79(3 \mathrm{H}, \mathrm{s}), 3.70(6 \mathrm{H}, \mathrm{s}), 2.70$ $(1 \mathrm{H}$, br s, OH).

RMN ${ }^{13} \mathbf{C}\left(125 \mathrm{MHz}, \mathrm{CDCl}_{3}\right) \delta 170.4,169.0$ (CO); 153.0 (x 2), 149.1, 146.9, 137.3, 132.6, 130.4 (C); 129.6, 128.9, 124.2, 117.0, 111.8, 106.0 (x 2), 54.3 $(\mathrm{CH}) ; 69.8,63.2\left(\mathrm{CH}_{2}\right) ; 60.9,55.9(\times 3), 52.6\left(\mathrm{CH}_{3}\right)$.

HR ESMS : $m / z 498.1743(\mathrm{M}+\mathrm{Na})^{+}$. Calculado para $\mathrm{C}_{24} \mathrm{H}_{29} \mathrm{NNaO}_{9} 498.1740$. 
(Z)-(2-(2-metoxi-5-(3,4,5-trimetoxiestiril)fenoxi)acetil)-L-treoninato de metilo 3.7 .

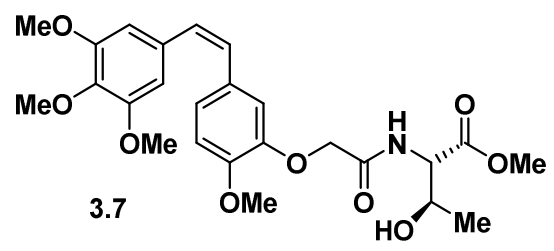

Rto. $=70 \%$. Aceite amarillento.

$[\alpha]_{\mathrm{D}} 2.2\left(c 1.0, \mathrm{CHCl}_{3}\right)$.

IR: $\boldsymbol{v}_{\max }$ 3500-3300 (br, OH, NH), 1748, $1671(\mathrm{C}=\mathrm{O}) \mathrm{cm}^{-1}$.

$\mathbf{R M N}^{1} \mathbf{H}\left(500 \mathrm{MHz}, \mathrm{CDCl}_{3}\right) \delta 7.75(1 \mathrm{H}, \mathrm{br} \mathrm{d}, J \sim 9 \mathrm{~Hz}, \mathrm{NH}), 6.98(1 \mathrm{H}, \mathrm{dd}, J=$ 8.3, $2 \mathrm{~Hz}), 6.89(1 \mathrm{H}, \mathrm{d}, J=2 \mathrm{~Hz}), 6.80(1 \mathrm{H}, \mathrm{d}, J=8.3 \mathrm{~Hz}), 6.49(2 \mathrm{H}, \mathrm{s}), 6.46$ (2H, app s), $4.64(1 \mathrm{H}, \mathrm{dd}, J=9,2.5 \mathrm{~Hz}), 4.49(2 \mathrm{H}, \mathrm{s}), 4.37(1 \mathrm{H}, \mathrm{br}$ qd, $J \sim 6.5$, $2.5 \mathrm{~Hz}), 3.86(3 \mathrm{H}, \mathrm{s}), 3.84(3 \mathrm{H}, \mathrm{s}), 3.75(3 \mathrm{H}, \mathrm{s}), 3.70(6 \mathrm{H}, \mathrm{s}), 2.30(1 \mathrm{H}, \mathrm{br} \mathrm{s}$, $\mathrm{OH}), 1.18(3 \mathrm{H}, \mathrm{d}, J=6.5 \mathrm{~Hz})$.

RMN ${ }^{13} \mathbf{C}\left(125 \mathrm{MHz}, \mathrm{CDCl}_{3}\right) \delta 170.9,169.3$ (CO); 153.0 (x 2), 149.2, 147.1, 137.3, 132.6, 130.4 (C); 129.6, 128.9, 124.2, 117.3, 111.8, 106.0 (x 2), 67.9, $56.8(\mathrm{CH}) ; 70.1\left(\mathrm{CH}_{2}\right) ; 60.9,56.0(\times 3), 52.5,19.8^{*}\left(\mathrm{CH}_{3}\right)$.

HR ESMS : $m / z 512.1895(\mathrm{M}+\mathrm{Na})^{+}$. Calculado para $\mathrm{C}_{25} \mathrm{H}_{31} \mathrm{NNaO}_{9}$. 512.1897. Las señales marcadas con * aparecen bajas y anchas.

\section{(Z)-(2-(2-metoxi-5-(3,4,5-trimetoxiestiril)fenoxi)acetil)-L-tirosinato de} metilo 3.8 .

Rto. $=84 \%$. Aceite amarillento.

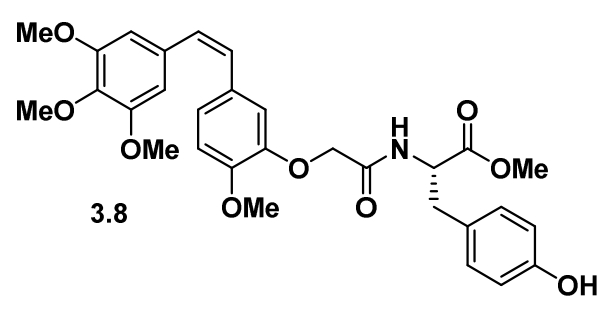

$[\alpha]_{D} 40.0\left(c 1.0, \mathrm{CHCl}_{3}\right)$.

IR: $\boldsymbol{v}_{\max } 3400,3340(\mathrm{br}, \mathrm{OH}, \mathrm{NH}), 1746,1666(\mathrm{C}=\mathrm{O}) \mathrm{cm}^{-1}$.

$\mathbf{R M N}^{1} \mathbf{H}\left(500 \mathrm{MHz}, \mathrm{CDCl}_{3}\right) \delta 7.45(1 \mathrm{H}, \mathrm{br} \mathrm{d}, J \sim 8 \mathrm{~Hz}, \mathrm{NH}), 6.98(1 \mathrm{H}, \mathrm{dd}, J=$ 8.3, $2 \mathrm{~Hz}), 6.90(2 \mathrm{H}$, app d, $J=8.3 \mathrm{~Hz}), 6.86(1 \mathrm{H}, \mathrm{d}, J=2 \mathrm{~Hz}), 6.79(1 \mathrm{H}, \mathrm{d}, J=$ $8.3 \mathrm{~Hz}), 6.65(2 \mathrm{H}$, app d, J = 8.3 Hz), $6.50(2 \mathrm{H}, \mathrm{s}), 6.47(2 \mathrm{H}$, app s), $5.80(1 \mathrm{H}$, br s, OH), $4.90(1 \mathrm{H}, \mathrm{dt}, J=8,6 \mathrm{~Hz}), 4.43(1 \mathrm{H}, \mathrm{d}, J=15 \mathrm{~Hz}), 4.35(1 \mathrm{H}, \mathrm{d}, J=15$ 
$\mathrm{Hz}), 3.86(3 \mathrm{H}, \mathrm{s}), 3.77(3 \mathrm{H}, \mathrm{s}), 3.71(3 \mathrm{H}, \mathrm{s}), 3.69(6 \mathrm{H}, \mathrm{s}), 3.08(1 \mathrm{H}, \mathrm{dd}, J=14$, $6 \mathrm{~Hz}), 3.02(1 \mathrm{H}, \mathrm{dd}, J=14,6 \mathrm{~Hz})$.

RMN ${ }^{13} \mathbf{C}\left(125 \mathrm{MHz}, \mathrm{CDCl}_{3}\right) \delta 171.5,168.6$ (CO); 155.4, 153.0 (x 2), 149.2, 146.7, 137.2, 132.7 (x 2), 126.8 (C); 130.2 (x 2), 129.4, 128.9, 124.2, 117.4, 115.4 (x 2), 111.7, 106.1 (x 2), $53.0(\mathrm{CH}) ; 69.8,37.3\left(\mathrm{CH}_{2}\right) ; 60.9,56.0(\mathrm{x} \mathrm{2})$, 55.7, $52.2\left(\mathrm{CH}_{3}\right)$.

HR ESMS : $m / z 574.2058(\mathrm{M}+\mathrm{Na})^{+}$. Calculado para $\mathrm{C}_{30} \mathrm{H}_{33} \mathrm{NNaO}_{9}$. 574.2053.

(Z)-(2-(2-metoxi-5-(3,4,5-trimetoxiestiril)fenoxi)acetil)-L-metioninato de metilo 3.9 .

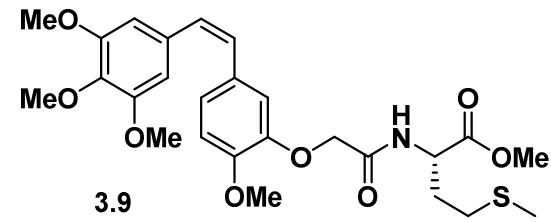

Rto. $=66 \%$. Sólido blanco. p. $f=77-79^{\circ} \mathrm{C}$.

$[\alpha]_{\mathrm{D}} 24.9\left(c 1.0, \mathrm{CHCl}_{3}\right)$.

IR: $\boldsymbol{v}_{\max } 3350(\mathrm{br}, \mathrm{NH}), 1741,1683(\mathrm{C}=\mathrm{O}) \mathrm{cm}^{-1}$.

RMN ${ }^{1} \mathbf{H}\left(500 \mathrm{MHz}, \mathrm{CDCl}_{3}\right) \delta 7.60(1 \mathrm{H}, \mathrm{br} \mathrm{d}, J \sim 8 \mathrm{~Hz}, \mathrm{NH}), 6.98(1 \mathrm{H}, \mathrm{dd}, J=$ 8.3, $2 \mathrm{~Hz}), 6.87(1 \mathrm{H}, \mathrm{d}, J=2 \mathrm{~Hz}), 6.81(1 \mathrm{H}, \mathrm{d}, J=8.3 \mathrm{~Hz}), 6.49(2 \mathrm{H}, \mathrm{s}), 6.47$ $(2 \mathrm{H}$, sistema $A B$ degenerado, $J \sim 12 \mathrm{~Hz}), 4.78(1 \mathrm{H}, \mathrm{dt}, J=8,6 \mathrm{~Hz}), 4.45(1 \mathrm{H}$, d, $J=15 \mathrm{~Hz}), 4.43(1 \mathrm{H}, \mathrm{d}, J=15 \mathrm{~Hz}), 3.88(3 \mathrm{H}, \mathrm{s}), 3.85(3 \mathrm{H}, \mathrm{s}), 3.76(3 \mathrm{H}, \mathrm{s})$, $3.71(6 \mathrm{H}, \mathrm{s}), 2.50-2.45(2 \mathrm{H}, \mathrm{m}), 2.20(1 \mathrm{H}, \mathrm{m}), 2.08(3 \mathrm{H}, \mathrm{s}), 2.02(1 \mathrm{H}, \mathrm{m})$.

RMN ${ }^{13} \mathbf{C}\left(125 \mathrm{MHz}, \mathrm{CDCl}_{3}\right) \delta 171.7,168.4$ (CO); 153.0 (x 2), 149.0, 146.8, 137.3, 132.5, 130.3 (C); 129.5, 128.8, 124.1, 116.9, 111.6, 106.0 (x 2), 50.9 $(\mathrm{CH})$; 69.7, 31.7, $29.7\left(\mathrm{CH}_{2}\right) ;$ 60.9, 55.9 (x 2), 55.8, 52.4, $15.3\left(\mathrm{CH}_{3}\right)$.

HR ESMS : $m / z 542.1832(\mathrm{M}+\mathrm{Na})^{+}$. Calculado para $\mathrm{C}_{26} \mathrm{H}_{33} \mathrm{NNaO}_{8} \mathrm{~S}$. 542.1825. 
(Z)-(2-(2-metoxi-5-(3,4,5-trimetoxiestiril)fenoxi)acetil)-D-valinato de metilo 3.19 .

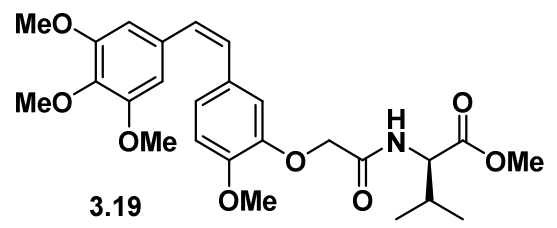

Rto. $=92 \%$. Aceite amarillento.

$[\alpha]_{D}-11.5\left(c 1.1, \mathrm{CHCl}_{3}\right)$.

IR: $\boldsymbol{v}_{\max } 3350(\mathrm{br}, \mathrm{NH}), 1742,1686(\mathrm{C}=\mathrm{O}) \mathrm{cm}^{-1}$.

$\mathbf{R M N}^{1} \mathbf{H}\left(500 \mathrm{MHz}, \mathrm{CDCl}_{3}\right) \delta 7.50(1 \mathrm{H}, \mathrm{br} \mathrm{d}, J \sim 9 \mathrm{~Hz}, \mathrm{NH}), 6.98(1 \mathrm{H}, \mathrm{dd}, J=$ 8.3, $2 \mathrm{~Hz}), 6.87(1 \mathrm{H}, \mathrm{d}, J=2 \mathrm{~Hz}), 6.80(1 \mathrm{H}, \mathrm{d}, J=8.3 \mathrm{~Hz}), 6.49(2 \mathrm{H}, \mathrm{s}), 6.47$ (2H, app s), $4.59(1 \mathrm{H}, \mathrm{dd}, J=9,5 \mathrm{~Hz}), 4.46(1 \mathrm{H}, \mathrm{d}, J=15 \mathrm{~Hz}), 4.43(1 \mathrm{H}, \mathrm{d}, J=$ $15 \mathrm{~Hz}), 3.87(3 \mathrm{H}, \mathrm{s}), 3.85(3 \mathrm{H}, \mathrm{s}), 3.73(3 \mathrm{H}, \mathrm{s}), 3.70(6 \mathrm{H}, \mathrm{s}), 2.20(1 \mathrm{H}, \mathrm{m}), 0.94$ $(3 \mathrm{H}, \mathrm{d}, J=7 \mathrm{~Hz}), 0.91(3 \mathrm{H}, \mathrm{d}, J=7 \mathrm{~Hz})$.

RMN ${ }^{13} \mathbf{C}\left(125 \mathrm{MHz}, \mathrm{CDCl}_{3}\right) \delta 171.8,168.5$ (CO); 153.0 (x 2), 149.0, 146.9, 137.4, 132.5, 130.4 (C); 129.5, 128.9, 124.0, 116.8, 111.6, 106.0 (x 2), 56.6, $31.2(\mathrm{CH}) ; 69.8\left(\mathrm{CH}_{2}\right) ; 60.9,55.9(\times 2), 55.8,52.0,18.8,17.6\left(\mathrm{CH}_{3}\right)$.

HR ESMS : $m / z 510.2099(\mathrm{M}+\mathrm{Na})^{+}$. Calculado para $\mathrm{C}_{26} \mathrm{H}_{33} \mathrm{NNaO}_{8}$ 510.2104.

(Z)-(2-(2-metoxi-5-(3,4,5-trimetoxiestiril)fenoxi)acetil)-D-leucinato de metilo 3.20 .

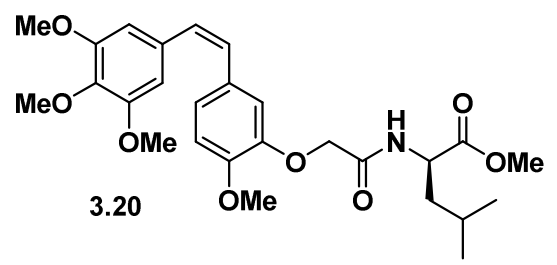

Rto. $=87 \%$. Sólido blanco. p. $f=85-87^{\circ} \mathrm{C}$.

$[\alpha]_{\mathrm{D}}-1.4\left(c 1.2, \mathrm{CHCl}_{3}\right)$.

IR: $\boldsymbol{v}_{\max } 3350(\mathrm{br}, \mathrm{NH}), 1744,1684(\mathrm{C}=\mathrm{O}) \mathrm{cm}^{-1}$.

RMN ${ }^{1} \mathbf{H}\left(500 \mathrm{MHz}, \mathrm{CDCl}_{3}\right) \delta 7.40(1 \mathrm{H}, \mathrm{br} \mathrm{d}, J \sim 8.5 \mathrm{~Hz}, \mathrm{NH}), 6.98(1 \mathrm{H}, \mathrm{dd}, J=$ 8.3, $2 \mathrm{~Hz}), 6.86(1 \mathrm{H}, \mathrm{d}, J=2 \mathrm{~Hz}), 6.80(1 \mathrm{H}, \mathrm{d}, J=8.3 \mathrm{~Hz}), 6.49(2 \mathrm{H}, \mathrm{s}), 6.47$ (2H, app s), $4.68(1 \mathrm{H}, \mathrm{m}), 4.43(1 \mathrm{H}, \mathrm{d}, J=15 \mathrm{~Hz}), 4.41(1 \mathrm{H}, \mathrm{d}, J=15 \mathrm{~Hz}), 3.87$ $(3 \mathrm{H}, \mathrm{s}), 3.85(3 \mathrm{H}, \mathrm{s}), 3.73(3 \mathrm{H}, \mathrm{s}), 3.70(6 \mathrm{H}, \mathrm{s}), 1.75-1.55(3 \mathrm{H}, \mathrm{br} \mathrm{m}), 0.94(3 \mathrm{H}$, d, $J=7 \mathrm{~Hz}), 0.93(3 \mathrm{H}, \mathrm{d}, J=7 \mathrm{~Hz})$. 
RMN ${ }^{13} \mathbf{C}\left(125 \mathrm{MHz}, \mathrm{CDCl}_{3}\right) \delta 172.8,168.4(\mathrm{CO}) ; 153.0$ (x 2), 149.0, 146.9, 137.4, 132.5, 130.4 (C); 129.6, 128.9, 124.0, 117.0, 111.6, 106.0 (x 2), 50.3, $24.8(\mathrm{CH}) ; 69.8,41.5\left(\mathrm{CH}_{2}\right)$; 60.9, $55.9(\times 2), 55.8,52.2,22.8,21.8\left(\mathrm{CH}_{3}\right)$.

HR ESMS : $m / z 524.2250(\mathrm{M}+\mathrm{Na})^{+}$. Calculado para $\mathrm{C}_{27} \mathrm{H}_{35} \mathrm{NNaO}_{8 .} 524.2260$.

(Z)-(2-(2-metoxi-5-(3,4,5-trimetoxiestiril)fenoxi)acetil)-D-fenilalaninato de metilo 3.21 .

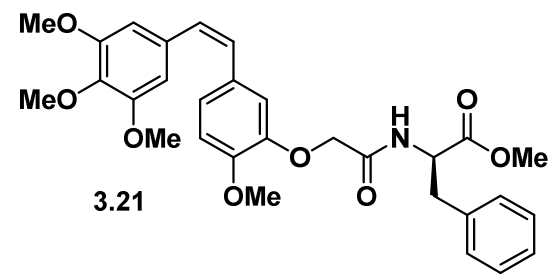

Rto. $=38 \%$. Aceite amarillento.

[a] $-25.3\left(c 1.0, \mathrm{CHCl}_{3}\right)$.

IR: $\boldsymbol{v}_{\max } 3400,3340(\mathrm{br}, \mathrm{NH}), 1745,1682(\mathrm{C}=\mathrm{O}) \mathrm{cm}^{-1}$.

RMN ${ }^{1} \mathbf{H}\left(500 \mathrm{MHz}, \mathrm{CDCl}_{3}\right) \delta 7.55(1 \mathrm{H}, \mathrm{br} \mathrm{d}, J \sim 8 \mathrm{~Hz}, \mathrm{NH}), 7.25-7.20(3 \mathrm{H}, \mathrm{m})$, $7.08(2 \mathrm{H}, \mathrm{m}), 6.98(1 \mathrm{H}, \mathrm{dd}, J=8.3,2 \mathrm{~Hz}), 6.83(1 \mathrm{H}, \mathrm{d}, J=2 \mathrm{~Hz}), 6.77(1 \mathrm{H}, \mathrm{d}, J$ $=8.3 \mathrm{~Hz}), 6.49(2 \mathrm{H}, \mathrm{s}), 6.47(2 \mathrm{H}$, sistema $\mathrm{AB}$ degenerado, $J \sim 12 \mathrm{~Hz}), 4.94$ $(1 \mathrm{H}, \mathrm{dt}, J=8,6.5 \mathrm{~Hz}), 4.42(1 \mathrm{H}, \mathrm{d}, J=15 \mathrm{~Hz}), 4.38(1 \mathrm{H}, \mathrm{d}, J=15 \mathrm{~Hz}), 3.85$ $(3 \mathrm{H}, \mathrm{s}), 3.73(3 \mathrm{H}, \mathrm{s}), 3.71(3 \mathrm{H}, \mathrm{s}), 3.69(6 \mathrm{H}, \mathrm{s}), 3.12(2 \mathrm{H}, \mathrm{m})$.

RMN ${ }^{13} \mathbf{C}\left(125 \mathrm{MHz}, \mathrm{CDCl}_{3}\right) \delta 171.4,168.3(\mathrm{CO}) ; 153.0$ (x 2), 149.1, 146.9, 137.4, 135.8, 132.6, 130.3 (C); 129.5, 129.2 (x 2), 128.9, 128.5 (x 2), 127.0, 124.1, 116.9, 111.7, 106.0 (x 2), $52.8(\mathrm{CH}) ; 69.8,38.1\left(\mathrm{CH}_{2}\right) ; 60.9,56.0$ (x 2), 55.7, $52.2\left(\mathrm{CH}_{3}\right)$.

HR ESMS : $m / z 558.2100(\mathrm{M}+\mathrm{Na})^{+}$. Calculado para $\mathrm{C}_{30} \mathrm{H}_{33} \mathrm{NNaO}_{8}$ 558.2104.

(Z)-(2-(2-metoxi-5-(3,4,5-trimetoxiestiril)fenoxi)acetil)-D-prolinato de metilo 3.22 .

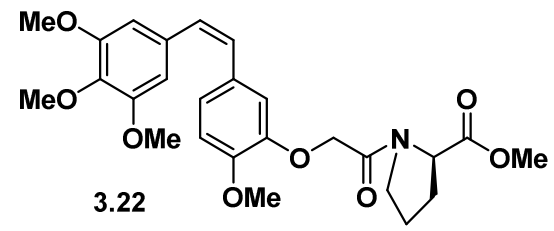

Rto. $=68 \%$. Aceite amarillento.

$[\alpha]_{\mathrm{D}} 36.9$ (c 1.1, $\left.\mathrm{CHCl}_{3}\right)$.

IR: $\boldsymbol{V}_{\max } 1742,1671(\mathrm{C}=\mathrm{O}) \mathrm{cm}^{-1}$. 
RMN ${ }^{1} \mathbf{H}\left(500 \mathrm{MHz}, \mathrm{CDCl}_{3}\right) \delta 6.90(1 \mathrm{H}, \mathrm{dd}, J=8.3,2 \mathrm{~Hz}), 6.80(1 \mathrm{H}, \mathrm{d}, J=2$ $\mathrm{Hz}), 6.76(1 \mathrm{H}, \mathrm{d}, J=8.3 \mathrm{~Hz}), 6.50(2 \mathrm{H}, \mathrm{s}), 6.48(1 \mathrm{H}, \mathrm{d}, J=12 \mathrm{~Hz}), 6.43(1 \mathrm{H}, \mathrm{d}$, $J=12 \mathrm{~Hz}), 4.52(2 \mathrm{H}, \mathrm{s}), 4.49(1 \mathrm{H}, \mathrm{m}), 3.83(3 \mathrm{H}, \mathrm{s}), 3.82(3 \mathrm{H}, \mathrm{s}), 3.71(6 \mathrm{H}, \mathrm{s})$, $3.68(3 \mathrm{H}, \mathrm{s}), 3.60-3.50(2 \mathrm{H}, \mathrm{m}), 2.20-1.90(4 \mathrm{H}, \mathrm{br} \mathrm{m})$.

RMN ${ }^{13} \mathbf{C}\left(125 \mathrm{MHz}, \mathrm{CDCl}_{3}\right) \delta 172.3,166.4(\mathrm{CO}) ; 152.9$ (x 2), 148.7, 147.0, 137.1, 132.9, 129.8 (C); 129.5, 128.8, 123.1, 114.7, 111.6, 106.0 (x 2), 59.1 $(\mathrm{CH}) ; 67.9,46.1$, 28.6, $24.9\left(\mathrm{CH}_{2}\right) ; 60.8,55.9(\times 2), 55.8,52.1\left(\mathrm{CH}_{3}\right)$.

HR ESMS : $m / z 508.1945(\mathrm{M}+\mathrm{Na})^{+}$. Calculado para $\mathrm{C}_{26} \mathrm{H}_{31} \mathrm{NNaO}_{8}$ 508.1947.

(Z)-(2-(2-metoxi-5-(3,4,5-trimetoxiestiril)fenoxi)acetil)-D-serinato de metilo 3.22 .

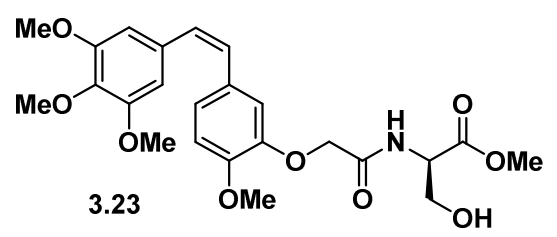

Rto. $=70 \%$. Solido blanco. p. $f=83-85^{\circ} \mathrm{C}$.

$[\alpha]_{\mathrm{D}}-16.4\left(\mathrm{c} 1.0, \mathrm{CHCl}_{3}\right)$.

IR: $\boldsymbol{v}_{\max }$ 3500-3300 (br, OH, NH), 1748, $1676(\mathrm{C}=\mathrm{O}) \mathrm{cm}^{-1}$.

RMN ${ }^{1} \mathbf{H}\left(500 \mathrm{MHz}, \mathrm{CDCl}_{3}\right) \delta 7.90(1 \mathrm{H}, \mathrm{br} \mathrm{d}, J \sim 7.5 \mathrm{~Hz}, \mathrm{NH}), 6.96(1 \mathrm{H}, \mathrm{dd}, J=$ 8.3, $2 \mathrm{~Hz}), 6.86(1 \mathrm{H}, \mathrm{d}, J=2 \mathrm{~Hz}), 6.80(1 \mathrm{H}, \mathrm{d}, J=8.3 \mathrm{~Hz}), 6.48(2 \mathrm{H}, \mathrm{s}), 6.46$ (2H, app s), $4.71(1 \mathrm{H}, \mathrm{m}), 4.43(2 \mathrm{H}, \mathrm{s}), 4.00(1 \mathrm{H}, \mathrm{dd}, J=11.2,4 \mathrm{~Hz}), 3.91(1 \mathrm{H}$, $\mathrm{dd}, J=11.2,3.5 \mathrm{~Hz}), 3.86(3 \mathrm{H}, \mathrm{s}), 3.84(3 \mathrm{H}, \mathrm{s}), 3.79(3 \mathrm{H}, \mathrm{s}), 3.70(6 \mathrm{H}, \mathrm{s}), 2.70$ $(1 \mathrm{H}, \mathrm{br} \mathrm{s}, \mathrm{OH})$.

RMN ${ }^{13} \mathbf{C}\left(125 \mathrm{MHz}, \mathrm{CDCl}_{3}\right) \delta$ 170.4, 169.0 (CO); 153.0 (x 2), 149.1, 146.9, 137.3, 132.6, 130.4 (C); 129.6, 128.9, 124.2, 117.0, 111.8, 106.0 (x 2), 54.3 $(\mathrm{CH}) ; 69.8,63.2\left(\mathrm{CH}_{2}\right) ; 60.9,55.9(\times 3), 52.6\left(\mathrm{CH}_{3}\right)$.

HR ESMS : $m / z 498.1743(\mathrm{M}+\mathrm{Na})^{+}$. Calculado para $\mathrm{C}_{24} \mathrm{H}_{29} \mathrm{NNaO}_{9} 498.1740$. 


\subsection{3.e. Procedimiento experimental para la reacción de saponificación}

Los derivados anteriormente sintetizados $(0.15 \mathrm{mmol}, 1$ eq.) se disolvieron en $\mathrm{MeOH}(2.2 \mathrm{~mL})$ y luego se les adicionó una disolución de $\mathrm{LiOH} \cdot \mathrm{H}_{2} \mathrm{O}(0.45$ mmol, 3 eq.) en $\mathrm{H}_{2} \mathrm{O}(2.2 \mathrm{~mL})$. La mezcla se agitó durante una hora protegida de la luz. Transcurrido este tiempo la mezcla se vertió sobre $\mathrm{H}_{2} \mathrm{O}$ y se lavó con $\mathrm{Et}_{2} \mathrm{O}$. La fase acuosa resultante se acidificó con $\mathrm{HCl} 2 \mathrm{M}$ y se extrajo con AcOEt $(3 \times 30 \mathrm{~mL})$. Los extractos orgánicos reunidos se secaron sobre $\mathrm{MgSO}_{4}$ anhidro. Después de filtrar y eliminar el disolvente a presión reducida se obtuvieron los compuestos correspondientes.

\subsection{3.f. Datos físicos y espectroscópicos de los compuestos de la familia} 1

(Z)-(2-(2-metoxi-5-(3,4,5-trimetoxiestiril)fenoxi)acetil)-glicina 3.10.<smiles>COc1ccc(/C=C\c2cc(OC)c(OC)c(OC)c2)cc1OCC(=O)NCC(=O)O</smiles>

Rto. $=71 \%$. Sólido blanco. p. $f=137-139^{\circ} \mathrm{C}$.

IR: $\boldsymbol{v}_{\max } 3500-3200(\mathrm{br}, \mathrm{OH}, \mathrm{NH}), 1735,1655(\mathrm{C}=\mathrm{O}) \mathrm{cm}^{-1}$.

RMN ${ }^{1} \mathbf{H}\left(500 \mathrm{MHz}, \mathrm{CD}_{3} \mathrm{OD}\right) \delta 6.94(1 \mathrm{H}, \mathrm{dd}, J=8.3,2 \mathrm{~Hz}), 6.92(1 \mathrm{H}, \mathrm{d}, J=8.3$ $\mathrm{Hz}), 6.90(1 \mathrm{H}, \mathrm{d}, J=2 \mathrm{~Hz}), 6.52(2 \mathrm{H}, \mathrm{s}), 6.51(1 \mathrm{H}, \mathrm{d}, J=12.2 \mathrm{~Hz}), 6.48(1 \mathrm{H}, \mathrm{d}$, $J=12.2 \mathrm{~Hz}), 4.38(2 \mathrm{H}, \mathrm{s}), 3.99(2 \mathrm{H}, \mathrm{s}), 3.85(3 \mathrm{H}, \mathrm{s}), 3.75(3 \mathrm{H}, \mathrm{s}), 3.65(6 \mathrm{H}, \mathrm{s})$ (las señales de $\mathrm{NH}, \mathrm{OH}$ no se detectan, quizás puedan estar solapadas con la señal de agua a $4.80 \mathrm{ppm})$.

RMN ${ }^{13} \mathbf{C}\left(125 \mathrm{MHz}, \mathrm{CD}_{3} \mathrm{OD}\right) \delta 172.5,171.5$ (CO); 154.3 (x 2), 150.6, 148.4, 138.4, 134.5, 131.8 (C); 130.5, 130.4, 125.1, 118.0, 113.3, 107.5 (x 2) (CH); 70.4, $41.5\left(\mathrm{CH}_{2}\right) ; 61.2,56.5(\times 3), 55.8\left(\mathrm{CH}_{3}\right)$.

HR ESMS : $m / z 454.1477(\mathrm{M}+\mathrm{Na})^{+}$. Calculado para $\mathrm{C}_{22} \mathrm{H}_{25} \mathrm{NNaO}_{8} 454.1478$. 
(Z)-(2-(2-metoxi-5-(3,4,5-trimetoxiestiril)fenoxi)acetil)-L-valina 3.11.

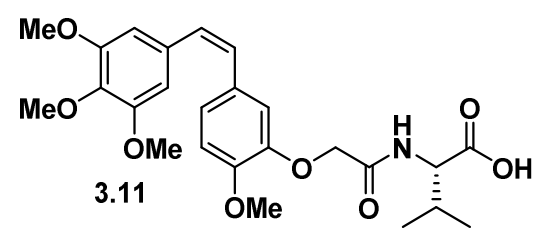

Rto. $=46 \%$. Sólido blanco. p. $f=71-73^{\circ} \mathrm{C}$.

[a] $14.0\left(c 1.0, \mathrm{CHCl}_{3}\right)$.

IR: $\boldsymbol{v}_{\max }$ 3500-3200 (br, OH, NH), 1736, $1677(\mathrm{C}=\mathrm{O}) \mathrm{cm}^{-1}$.

$\mathbf{R M N}^{1} \mathbf{H}\left(500 \mathrm{MHz}, \mathrm{CD}_{3} \mathrm{OD}\right) \delta 6.95-6.90(3 \mathrm{H}, \mathrm{m}), 6.52(2 \mathrm{H}, \mathrm{s}), 6.50(1 \mathrm{H}, \mathrm{d}, J=$ $12.2 \mathrm{~Hz}), 6.47(1 \mathrm{H}, \mathrm{d}, J=12.2 \mathrm{~Hz}), 4.40(3 \mathrm{H}, \mathrm{br} \mathrm{s}), 3.84(3 \mathrm{H}, \mathrm{s}), 3.74(3 \mathrm{H}, \mathrm{s})$, $3.64(6 \mathrm{H}, \mathrm{s}), 2.20(1 \mathrm{H}, \mathrm{m}), 0.94(3 \mathrm{H}, \mathrm{d}, J=6.5 \mathrm{~Hz}), 0.92(3 \mathrm{H}, \mathrm{d}, J=6.5 \mathrm{~Hz})$ (las señales de $\mathrm{NH}, \mathrm{OH}$ no se detectan, quizás puedan estar solapadas con la señal de agua a $4.80 \mathrm{ppm})$.

RMN ${ }^{13} \mathbf{C}\left(125 \mathrm{MHz}, \mathrm{CD}_{3} \mathrm{OD}\right) \delta 174.5^{*}, 170.9$ (CO); 154.3 (x 2), 150.5, 148.5, 138.5, 134.4, 131.9 (C); 130.6, 130.3, 125.2, 118.1, 113.2, 107.5 (x 2), 58.5, $32.1(\mathrm{CH}) ; 70.6\left(\mathrm{CH}_{2}\right) ; 61.2,56.5,56.4(\times 2), 19.5,18.0\left(\mathrm{CH}_{3}\right)$.

HR ESMS : $m / z 496.1945(\mathrm{M}+\mathrm{Na})^{+}$. Calculado para $\mathrm{C}_{25} \mathrm{H}_{31} \mathrm{NNaO}_{8} 496.1945$.

La señal marcada con * aparece baja y ancha.

\section{(Z)-(2-(2-metoxi-5-(3,4,5-trimetoxiestiril)fenoxi)acetil)-L-leucina 3.12.}

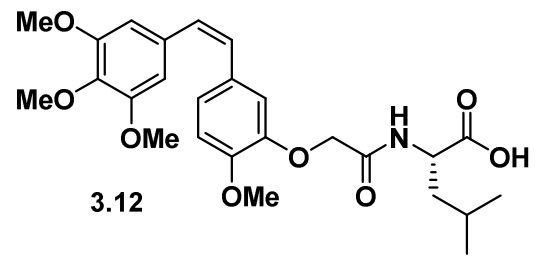

Rto. $=52 \%$. Sólido blanco. p. $\mathrm{f}=108-110^{\circ} \mathrm{C}$.

$[\alpha]_{\mathrm{D}} 1.0\left(\mathrm{c} 1.0, \mathrm{CHCl}_{3}\right)$.

IR: $\boldsymbol{v}_{\max } 3500-3200(\mathrm{br}, \mathrm{OH}, \mathrm{NH}), 1735,1672(\mathrm{C}=\mathrm{O}) \mathrm{cm}^{-1}$.

RMN ${ }^{1} \mathbf{H}\left(500 \mathrm{MHz}, \mathrm{CD}_{3} \mathrm{OD}\right) 6.95(1 \mathrm{H}, \mathrm{dd}, J=8.3,2 \mathrm{~Hz}), 6.92(1 \mathrm{H}, \mathrm{d}, J=8.3$ $\mathrm{Hz}), 6.90(1 \mathrm{H}, \mathrm{d}, J=2 \mathrm{~Hz}), 6.52(2 \mathrm{H}, \mathrm{s}), 6.50(1 \mathrm{H}, \mathrm{d}, J=12.2 \mathrm{~Hz}), 6.47(1 \mathrm{H}, \mathrm{d}$, $J=12.2 \mathrm{~Hz}), 4.53(1 \mathrm{H}, \mathrm{dd}, J=9,5 \mathrm{~Hz}), 4.41(1 \mathrm{H}, \mathrm{d}, J=15.5 \mathrm{~Hz}), 4.37(1 \mathrm{H}, \mathrm{d}$, $J=15.5 \mathrm{~Hz}), 3.86(3 \mathrm{H}, \mathrm{s}), 3.75(3 \mathrm{H}, \mathrm{s}), 3.66(6 \mathrm{H}, \mathrm{s}), 1.75-1.60(3 \mathrm{H}, \mathrm{br} \mathrm{m}), 0.93$ $(3 \mathrm{H}, \mathrm{d}, J=6.5 \mathrm{~Hz}), 0.91(3 \mathrm{H}, \mathrm{d}, J=6.5 \mathrm{~Hz}$ ) (las señales de $\mathrm{NH}, \mathrm{OH}$ no se detectan, quizás puedan estar solapadas con la señal de agua a 4.80 ppm). 
RMN ${ }^{13} \mathbf{C}\left(125 \mathrm{MHz}, \mathrm{CD}_{3} \mathrm{OD}\right) \delta 175.3,171.0$ (CO); 154.3 (x 2), 150.5, 148.5, 138.5, 134.4, 132.0 (C); 130.6, 130.3, 125.1, 118.1, 113.3, 107.5 (x 2), 51.6, $26.0(\mathrm{CH}) ; 70.6,41.9\left(\mathrm{CH}_{2}\right) ; 61.2,56.5,56.4(x)$ 2), 23.3, $22.0\left(\mathrm{CH}_{3}\right)$.

HR ESMS : $m / z 510.2103(\mathrm{M}+\mathrm{Na})^{+}$. Calculado para $\mathrm{C}_{26} \mathrm{H}_{33} \mathrm{NNaO}_{8} 510.2104$.

(Z)-(2-(2-metoxi-5-(3,4,5-trimetoxiestiril)fenoxi)acetil)-L-fenilalanina 3.13.

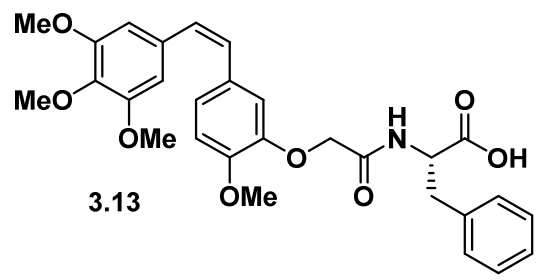

Rto. $=87 \%$. Aceite amarillento.

$[\alpha]_{\mathrm{D}} 22.6\left(c 1.1, \mathrm{CHCl}_{3}\right)$.

IR: $\boldsymbol{v}_{\max } 3500-3200(\mathrm{br}, \mathrm{OH}, \mathrm{NH}), 1741,1675(\mathrm{C}=\mathrm{O}) \mathrm{cm}^{-1}$.

RMN ${ }^{1} \mathbf{H}\left(500 \mathrm{MHz}, \mathrm{CD}_{3} \mathrm{OD}\right) \delta$ 7.20-7.16 $(3 \mathrm{H}, \mathrm{m}), 7.14-7.10(2 \mathrm{H}, \mathrm{m}), 6.93(1 \mathrm{H}$, $\mathrm{dd}, J=8.3,2 \mathrm{~Hz}), 6.85(1 \mathrm{H}, \mathrm{d}, J=8.3 \mathrm{~Hz}), 6.83(1 \mathrm{H}, \mathrm{d}, J=2 \mathrm{~Hz}), 6.51(2 \mathrm{H}, \mathrm{s})$, $6.47(2 \mathrm{H}$, app s), $4.76(1 \mathrm{H}, \mathrm{dd}, J=7.3,5.3 \mathrm{~Hz}), 4.33(1 \mathrm{H}, \mathrm{d}, J=15 \mathrm{~Hz}), 4.26$ $(1 \mathrm{H}, \mathrm{d}, J=15 \mathrm{~Hz}), 3.73(3 \mathrm{H}, \mathrm{s}), 3.69(3 \mathrm{H}, \mathrm{s}), 3.61(6 \mathrm{H}, \mathrm{s}), 3.18(1 \mathrm{H}, \mathrm{dd}, J=14$, $5.3 \mathrm{~Hz}$ ), $3.04(1 \mathrm{H}, \mathrm{dd}, J=14,7.3 \mathrm{~Hz}$ ) (las señales de $\mathrm{NH}, \mathrm{OH}$ no se detectan, quizás puedan estar solapadas con la señal de agua a 4.80 ppm).

RMN ${ }^{13} \mathbf{C}\left(125 \mathrm{MHz}, \mathrm{CD}_{3} \mathrm{OD}\right) \delta$ 173.7, 170.7 (CO); 154.3 (x 2), 150.5, 148.5, 138.4, 137.7, 134.4, 131.8 (C); 130.5, 130.4 (x 2), 130.3, 129.5 (x 2), 127.9, 125.3, 118.2, 113.2, 107.5 (x 2), $54.3(\mathrm{CH}) ; 70.6,38.4\left(\mathrm{CH}_{2}\right) ; 61.2,56.5(x 2)$, $56.4\left(\mathrm{CH}_{3}\right)$.

HR ESMS : $m / z 520.1973(\mathrm{M}-\mathrm{H})^{-}$. Calculado para $\mathrm{C}_{29} \mathrm{H}_{30} \mathrm{NO}_{8} 520.1971$.

(Z)-(2-(2-metoxi-5-(3,4,5-trimetoxiestiril)fenoxi)acetil)-L-prolina 3.14.

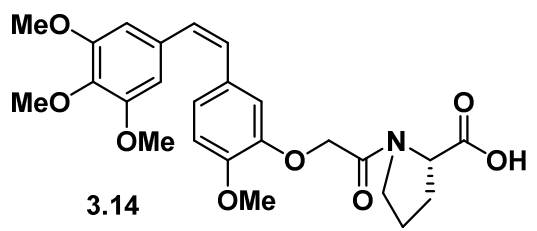

Rto. $=89 \%$. Sólido blanco. p. $f=66-68^{\circ} \mathrm{C}$.

$[\alpha]_{D}-39.8\left(c 1.1, \mathrm{CHCl}_{3}\right)$.

IR: $\boldsymbol{v}_{\max }$ 3500-3200 (br, OH, NH), 1749, $1669(\mathrm{C}=\mathrm{O}) \mathrm{cm}^{-1}$. 
$\mathbf{R M N}^{1} \mathbf{H}\left(500 \mathrm{MHz}, \mathrm{CD}_{3} \mathrm{OD}\right) \delta 6.90-6.80(3 \mathrm{H}, \mathrm{m}), 6.53(2 \mathrm{H}, \mathrm{s}), 6.48(1 \mathrm{H}, \mathrm{d}, J=$ $12.2 \mathrm{~Hz}), 6.44(1 \mathrm{H}, \mathrm{d}, J=12.2 \mathrm{~Hz}), 4.51(2 \mathrm{H}, \mathrm{s}), 4.45(1 \mathrm{H}, \mathrm{m}), 3.80(3 \mathrm{H}, \mathrm{s})$, $3.74(3 \mathrm{H}, \mathrm{s}), 3.65(6 \mathrm{H}, \mathrm{s}), 3.50-3.40(2 \mathrm{H}, \mathrm{br} \mathrm{m}), 2.25-2.15(1 \mathrm{H}, \mathrm{m}), 2.00-1.85$ $(2 \mathrm{H}, \mathrm{br} \mathrm{m})$ (las señales de $\mathrm{NH}, \mathrm{OH}$ no se detectan, quizás puedan estar solapadas con la señal de agua a $4.80 \mathrm{ppm}$ ).

RMN ${ }^{13} \mathbf{C}\left(125 \mathrm{MHz}, \mathrm{CD}_{3} \mathrm{OD}\right) \delta 175.2,169.0$ (CO); 154.2 (x 2), 150.5, 148.5, 138.3, 134.6, 131.4 (C); 130.6, 130.1, 124.5, 116.3, 113.3, 107.4 (x 2), 60.4 $(\mathrm{CH})$; 68.6, 47.1, 29.8, $25.7\left(\mathrm{CH}_{2}\right) ; 61.2,56.5,56.4$ (x 2) $\left(\mathrm{CH}_{3}\right)$.

HR ESMS : $m / z 470.1818(\mathrm{M}-\mathrm{H})^{-}$. Calculado para $\mathrm{C}_{25} \mathrm{H}_{28} \mathrm{NO}_{8 .} 470.1815$.

(Z)-(2-(2-metoxi-5-(3,4,5-trimetoxiestiril)fenoxi)acetil)-L-serina 3.15.

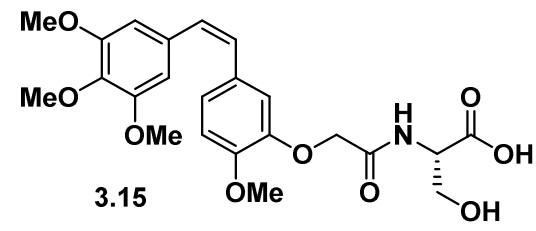

Rto. $=65 \%$. Sólido blanco. p. $f=125-128^{\circ} \mathrm{C}$.

$[\alpha]_{\mathrm{D}}-9.8\left(\mathrm{c} 1.0, \mathrm{CHCl}_{3}\right)$.

IR: $\boldsymbol{v}_{\max } 3500-3200(\mathrm{br}, \mathrm{OH}, \mathrm{NH}), 1740,1664(\mathrm{C}=\mathrm{O}) \mathrm{cm}^{-1}$.

RMN ${ }^{1} \mathbf{H}\left(500 \mathrm{MHz}, \mathrm{CD}_{3} \mathrm{OD}\right) \delta 6.94(1 \mathrm{H}, \mathrm{dd}, J=8.3,2 \mathrm{~Hz}), 6.92(1 \mathrm{H}, \mathrm{d}, J=2$ $\mathrm{Hz}), 6.91(1 \mathrm{H}, \mathrm{d}, J=8.3 \mathrm{~Hz}), 6.52(2 \mathrm{H}, \mathrm{s}), 6.51(1 \mathrm{H}, \mathrm{d}, J=12 \mathrm{~Hz}), 6.47(1 \mathrm{H}, \mathrm{d}$, $J=12 \mathrm{~Hz}), 4.51(1 \mathrm{H}, \mathrm{br} \mathrm{t}, J \sim 4 \mathrm{~Hz}), 4.41(1 \mathrm{H}, \mathrm{d}, J=15 \mathrm{~Hz}), 4.37(1 \mathrm{H}, \mathrm{d}, J=15$ $\mathrm{Hz}), 3.98(1 \mathrm{H}, \mathrm{dd}, J=11.2,4 \mathrm{~Hz}), 3.85(1 \mathrm{H}, \mathrm{dd}$, solapado), $3.84(3 \mathrm{H}, \mathrm{s}), 3.74$ $(3 \mathrm{H}, \mathrm{s}), 3.65(6 \mathrm{H}, \mathrm{s})$ (las señales de $\mathrm{NH}, \mathrm{OH}$ no se detectan, quizás puedan estar solapadas con la señal de agua a $4.80 \mathrm{ppm})$.

RMN ${ }^{13} \mathbf{C}\left(125 \mathrm{MHz}, \mathrm{CD}_{3} \mathrm{OD}\right) \delta 173.3^{*}, 171.0$ (CO); 154.3 (x 2), 150.7, 148.5, $138.4,134.4,131.8(\mathrm{C}) ; 130.5,130.3,125.2,118.3,113.2,107.5$ (x 2), 55.8* $(\mathrm{CH}) ; 70.7,62.9\left(\mathrm{CH}_{2}\right) ; 61.2,56.5(\times 3)\left(\mathrm{CH}_{3}\right)$.

HR ESMS : $m / z 484.1584(\mathrm{M}+\mathrm{Na})^{+}$. Calculado para $\mathrm{C}_{23} \mathrm{H}_{27} \mathrm{NNaO}_{9} 484.1577$. Las señales marcadas con * aparecen bajas y anchas. 
(Z)-(2-(2-metoxi-5-(3,4,5-trimetoxiestiril)fenoxi)acetil)-L-treonina 3.16.

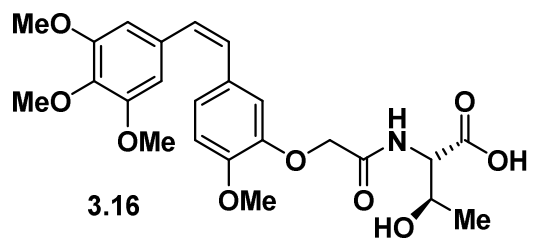

Rto. $=68 \%$. Aceite amarillento.

$[\alpha]_{\mathrm{D}} 5.2\left(c 1.1, \mathrm{CHCl}_{3}\right)$.

IR: $\boldsymbol{v}_{\max } 3500-3200(\mathrm{br}, \mathrm{OH}, \mathrm{NH}), 1739,1664(\mathrm{C}=\mathrm{O}) \mathrm{cm}^{-1}$.

RMN ${ }^{1} \mathbf{H}\left(500 \mathrm{MHz}, \mathrm{CD}_{3} \mathrm{OD}\right) \delta 6.94(1 \mathrm{H}, \mathrm{dd}, J=8.3,2 \mathrm{~Hz}), 6.92(1 \mathrm{H}, \mathrm{d}, J=2$ $\mathrm{Hz}), 6.90(1 \mathrm{H}, \mathrm{d}, J=8.3 \mathrm{~Hz}), 6.52(2 \mathrm{H}, \mathrm{s}), 6.49(1 \mathrm{H}, \mathrm{d}, J=12.2 \mathrm{~Hz}), 6.47(1 \mathrm{H}$, $\mathrm{d}, J=12.2 \mathrm{~Hz}), 4.46(1 \mathrm{H}, \mathrm{br} d, J \sim 3 \mathrm{~Hz}), 4.45(1 \mathrm{H}, \mathrm{d}, J=15 \mathrm{~Hz}), 4.40(1 \mathrm{H}, \mathrm{d}, J$ $=15 \mathrm{~Hz}), 4.37(1 \mathrm{H}, \mathrm{qd}, J=7,3 \mathrm{~Hz}), 3.84(3 \mathrm{H}, \mathrm{s}), 3.74(3 \mathrm{H}, \mathrm{s}), 3.64(6 \mathrm{H}, \mathrm{s})$, $1.16(3 \mathrm{H}, \mathrm{d}, J=7 \mathrm{~Hz}$ ) (las señales de $\mathrm{NH}, \mathrm{OH}$ no se detectan, quizás puedan estar solapadas con la señal de agua a $4.80 \mathrm{ppm}$ ).

RMN ${ }^{13} \mathbf{C}\left(125 \mathrm{MHz}, \mathrm{CD}_{3} \mathrm{OD}\right) \delta 173.4^{*}, 171.5$ (CO); 154.3 (x 2), 150.7, 148.5, 138.4, 134.4, $131.7(\mathrm{C})$; 130.5, 130.3, 125.3, 118.4, 113.2, 107.5 (x 2), 68.3, $58.6(\mathrm{CH}) ; 70.8\left(\mathrm{CH}_{2}\right) ; 61.2,56.6,56.5(\times 2), 20.5\left(\mathrm{CH}_{3}\right)$.

HR ESMS : $m / z 474.1766(\mathrm{M}-\mathrm{H})^{-}$. Calculado para $\mathrm{C}_{24} \mathrm{H}_{28} \mathrm{NO}_{9} 474.1764$.

Las señales marcadas con * aparecen bajas y anchas.

(Z)-(2-(2-metoxi-5-(3,4,5-trimetoxiestiril)fenoxi)acetil)-L-tirosina 3.17.

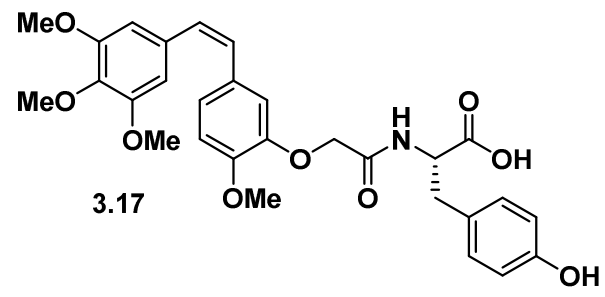

Rto. $=97 \%$. Sólido blanco. p.f $=71-73^{\circ} \mathrm{C}$.

$[\alpha]_{\mathrm{D}} 31.5\left(c 1.0, \mathrm{CHCl}_{3}\right)$.

IR: $\boldsymbol{v}_{\max }$ 3500-3200 (br, OH, NH), 1735, $1662(\mathrm{C}=\mathrm{O}) \mathrm{cm}^{-1}$.

RMN ${ }^{1} \mathbf{H}\left(500 \mathrm{MHz}, \mathrm{CD}_{3} \mathrm{OD}\right) \delta$ 6.95-6.90 $(3 \mathrm{H}, \mathrm{m}), 6.86(1 \mathrm{H}, \mathrm{d}, J=8.3 \mathrm{~Hz}), 6.83$ $(1 \mathrm{H}, \mathrm{d}, J=2 \mathrm{~Hz}), 6.63(2 \mathrm{H}, \mathrm{d}, J=8.4 \mathrm{~Hz}), 6.51(2 \mathrm{H}, \mathrm{s}), 6.48(2 \mathrm{H}$, app s$), 4.68$ $(1 \mathrm{H}, \mathrm{dd}, J=7,5.3 \mathrm{~Hz}), 4.34(1 \mathrm{H}, \mathrm{d}, J=15 \mathrm{~Hz}), 4.26(1 \mathrm{H}, \mathrm{d}, J=15 \mathrm{~Hz}), 3.74$ $(3 \mathrm{H}, \mathrm{s}), 3.72(3 \mathrm{H}, \mathrm{s}), 3.62(6 \mathrm{H}, \mathrm{s}), 3.08(1 \mathrm{H}, \mathrm{dd}, J=14,5.3 \mathrm{~Hz}), 2.96(1 \mathrm{H}, \mathrm{dd}, J$ 
$=14,7 \mathrm{~Hz}$ ) (las señales de $\mathrm{NH}, \mathrm{OH}$ no se detectan, quizás puedan estar solapadas con la señal de agua a $4.80 \mathrm{ppm})$.

RMN ${ }^{13} \mathbf{C}\left(125 \mathrm{MHz}, \mathrm{CD}_{3} \mathrm{OD}\right) \delta 174.5^{*}, 170.7$ (CO); 157.3, 154.3 (x 2), 150.5, 148.4, 138.4, 134.5, 131.8, 128.4 (C); 131.4 (x 2), 130.5, 130.3, 125.3, 118.1, 116.2 (x 2), 113.2, $107.5(x 2), 54.8^{*}(\mathrm{CH}) ; 70.6,37.7\left(\mathrm{CH}_{2}\right) ; 61.2,56.5$ (x 2), $56.4\left(\mathrm{CH}_{3}\right)$.

HR ESMS: $m / z 536.1918(\mathrm{M}-\mathrm{H})^{-}$. Calculado para $\mathrm{C}_{29} \mathrm{H}_{30} \mathrm{NO}_{9} 536.1921$.

Las señales marcadas con * aparecen bajas y anchas.

(Z)-(2-(2-metoxi-5-(3,4,5-trimetoxiestiril)fenoxi)acetil)-L-metionina 3.18.

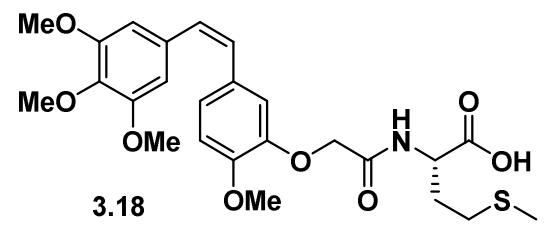

Rto. $=76 \%$. Sólido blanco. p. $f=103-105^{\circ} \mathrm{C}$.

$[\alpha]_{\mathrm{D}} 17.0\left(\mathrm{c} 1.1, \mathrm{CHCl}_{3}\right)$.

IR: $\boldsymbol{v}_{\max }$ 3500-3200 (br, OH, NH), 1735, $1678(\mathrm{C}=\mathrm{O}) \mathrm{cm}^{-1}$.

$\mathbf{R M N}^{1} \mathbf{H}\left(500 \mathrm{MHz}, \mathrm{CD}_{3} \mathrm{OD}\right) \delta 6.94(1 \mathrm{H}, \mathrm{dd}, J=8.3,2 \mathrm{~Hz}), 6.92(1 \mathrm{H}, \mathrm{d}, J=2$ $\mathrm{Hz}), 6.90(1 \mathrm{H}, \mathrm{d}, J=8.3 \mathrm{~Hz}), 6.52(2 \mathrm{H}, \mathrm{s}), 6.50(1 \mathrm{H}, \mathrm{d}, J=12.2 \mathrm{~Hz}), 6.48(1 \mathrm{H}$, $\mathrm{d}, J=12.2 \mathrm{~Hz}), 4.63(1 \mathrm{H}, \mathrm{dd}, J=8.3,5 \mathrm{~Hz}), 4.41(1 \mathrm{H}, \mathrm{d}, J=15 \mathrm{~Hz}), 4.38(1 \mathrm{H}$, $\mathrm{d}, J=15 \mathrm{~Hz}), 3.85(3 \mathrm{H}, \mathrm{s}), 3.74(3 \mathrm{H}, \mathrm{s}), 3.65(6 \mathrm{H}, \mathrm{s}), 2.50-2.40(2 \mathrm{H}, \mathrm{br} \mathrm{m})$, 2.20-2.15 $(1 \mathrm{H}, \mathrm{m}), 2.05(3 \mathrm{H}, \mathrm{s}), 2.05-1.95(1 \mathrm{H}, \mathrm{m})$ (las señales de $\mathrm{NH}, \mathrm{OH}$ no se detectan, quizás puedan estar solapadas con la señal de agua a 4.80 ppm). RMN ${ }^{13} \mathbf{C}\left(125 \mathrm{MHz}, \mathrm{CD}_{3} \mathrm{OD}\right) \delta 174.3,171.1$ (CO); 154.3 (x 2), 150.5, 148.5, $138.4,134.4,131.9$ (C); 130.6, 130.3, 125.2, 118.1, 113.3, 107.5 (x 2), 52.3 $(\mathrm{CH}) ; 70.6,32.2,31.0\left(\mathrm{CH}_{2}\right) ; 61.2,56.6,56.5(\times 2), 15.2\left(\mathrm{CH}_{3}\right)$.

HR ESMS : $m / z 528.1676(\mathrm{M}+\mathrm{Na})^{+}$. Calculado para $\mathrm{C}_{25} \mathrm{H}_{31} \mathrm{NNaO}_{8} \mathrm{~S}$. 528.1668. 
(Z)-(2-(2-metoxi-5-(3,4,5-trimetoxiestiril)fenoxi)acetil)-D-valina 3.24.

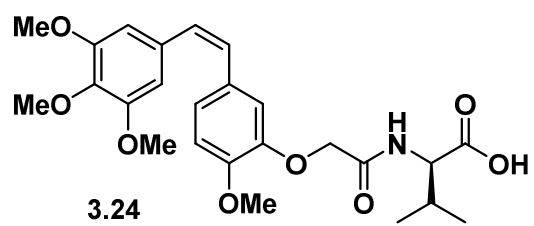

Rto. $=50 \%$. Sólido blanco. p. $f=71-73^{\circ} \mathrm{C}$

$[\alpha]_{\mathrm{D}}-14.6\left(\mathrm{c} 1.0, \mathrm{CHCl}_{3}\right)$.

IR: $\boldsymbol{v}_{\max }$ 3500-3200 (br, OH, NH), 1736, $1677(\mathrm{C}=\mathrm{O}) \mathrm{cm}^{-1}$.

RMN ${ }^{1} \mathrm{H}\left(500 \mathrm{MHz}, \mathrm{CD}_{3} \mathrm{OD}\right) \delta$ 6.95-6.90 $(3 \mathrm{H}, \mathrm{m}), 6.52(2 \mathrm{H}, \mathrm{s}), 6.50(1 \mathrm{H}, \mathrm{d}, J=$ $12.2 \mathrm{~Hz}), 6.47(1 \mathrm{H}, \mathrm{d}, J=12.2 \mathrm{~Hz}), 4.40(3 \mathrm{H}, \mathrm{br} \mathrm{s}), 3.84(3 \mathrm{H}, \mathrm{s}), 3.74(3 \mathrm{H}, \mathrm{s})$, $3.64(6 \mathrm{H}, \mathrm{s}), 2.20(1 \mathrm{H}, \mathrm{m}), 0.94(3 \mathrm{H}, \mathrm{d}, J=6.5 \mathrm{~Hz}), 0.92(3 \mathrm{H}, \mathrm{d}, J=6.5 \mathrm{~Hz})$ (las señales de $\mathrm{NH}, \mathrm{OH}$ no se detectan, quizás puedan estar solapadas con la señal de agua a $4.80 \mathrm{ppm})$.

RMN ${ }^{13} \mathbf{C}\left(125 \mathrm{MHz}, \mathrm{CD}_{3} \mathrm{OD}\right) \delta 174.5^{\star}, 170.9$ (CO); 154.3 (x 2), 150.5, 148.5, 138.5, 134.4, 131.9 (C); 130.6, 130.3, 125.2, 118.1, 113.2, 107.5 (x 2), 58.5, $32.1(\mathrm{CH}) ; 70.6\left(\mathrm{CH}_{2}\right)$; 61.2, 56.5, $56.4(\times 2), 19.5,18.0\left(\mathrm{CH}_{3}\right)$.

HR ESMS : $m / z 496.1945(\mathrm{M}+\mathrm{Na})^{+}$. Calculado para $\mathrm{C}_{25} \mathrm{H}_{31} \mathrm{NNaO}_{8} 496.1945$.

La señal marcada con * aparece baja y ancha.

(Z)-(2-(2-metoxi-5-(3,4,5-trimetoxiestiril)fenoxi)acetil)-D-leucina 3.25.

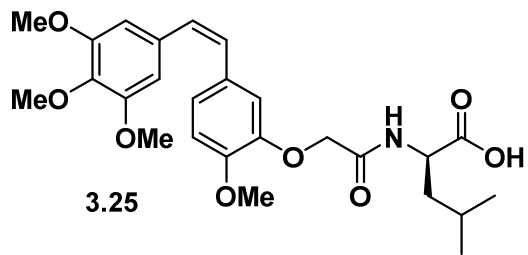

Rto. $=91 \%$. Sólido blanco cristalino. p. $f=105-107^{\circ} \mathrm{C}$.

$[\alpha]_{\mathrm{D}}-0.9\left(c 1.0, \mathrm{CHCl}_{3}\right)$.

IR: $\boldsymbol{v}_{\max } 3500-3200(\mathrm{br}, \mathrm{OH}, \mathrm{NH}), 1735,1672(\mathrm{C}=\mathrm{O}) \mathrm{cm}^{-1}$.

RMN ${ }^{1} \mathbf{H}\left(500 \mathrm{MHz}, \mathrm{CD}_{3} \mathrm{OD}\right) 6.95(1 \mathrm{H}, \mathrm{dd}, J=8.3,2 \mathrm{~Hz}), 6.92(1 \mathrm{H}, \mathrm{d}, J=8.3$ $\mathrm{Hz}), 6.90(1 \mathrm{H}, \mathrm{d}, J=2 \mathrm{~Hz}), 6.52(2 \mathrm{H}, \mathrm{s}), 6.50(1 \mathrm{H}, \mathrm{d}, J=12.2 \mathrm{~Hz}), 6.47(1 \mathrm{H}, \mathrm{d}$, $J=12.2 \mathrm{~Hz}), 4.53(1 \mathrm{H}, \mathrm{dd}, J=9,5 \mathrm{~Hz}), 4.41(1 \mathrm{H}, \mathrm{d}, J=15.5 \mathrm{~Hz}), 4.37(1 \mathrm{H}, \mathrm{d}$, $J=15.5 \mathrm{~Hz}), 3.86(3 \mathrm{H}, \mathrm{s}), 3.75(3 \mathrm{H}, \mathrm{s}), 3.66(6 \mathrm{H}, \mathrm{s}), 1.75-1.60(3 \mathrm{H}, \mathrm{br} \mathrm{m}), 0.93$ $(3 \mathrm{H}, \mathrm{d}, J=6.5 \mathrm{~Hz}), 0.91(3 \mathrm{H}, \mathrm{d}, J=6.5 \mathrm{~Hz})$ (las señales de $\mathrm{NH}, \mathrm{OH}$ no se detectan, quizás puedan estar solapadas con la señal de agua a 4.80 ppm). 
RMN ${ }^{13} \mathbf{C}\left(125 \mathrm{MHz}, \mathrm{CD}_{3} \mathrm{OD}\right) \delta$ 175.3, 171.0 (CO); 154.3 (x 2), 150.5, 148.5, 138.5, 134.4, $132.0(\mathrm{C}) ; 130.6,130.3,125.1,118.1,113.3,107.5(x 2), 51.6$, $26.0(\mathrm{CH}) ; 70.6,41.9\left(\mathrm{CH}_{2}\right) ; 61.2,56.5,56.4(\times 2), 23.3,22.0\left(\mathrm{CH}_{3}\right)$.

HR ESMS : $m / z 510.2103(\mathrm{M}+\mathrm{Na})^{+}$. Calculado para $\mathrm{C}_{26} \mathrm{H}_{33} \mathrm{NNaO}_{8} 510.2104$.

(Z)-(2-(2-metoxi-5-(3,4,5-trimetoxiestiril)fenoxi)acetil)-D-fenilalanina 3.26.

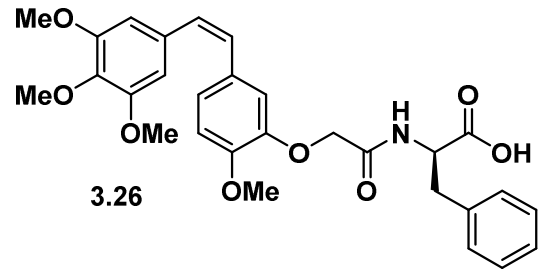

Rto. $=68 \%$. Aceite amarillento.

$[\alpha]_{\mathrm{D}}-22.8\left(c 1.1, \mathrm{CHCl}_{3}\right)$.

IR: $\boldsymbol{v}_{\max }$ 3500-3200 (br, OH, NH), 1741, $1675(\mathrm{C}=\mathrm{O}) \mathrm{cm}^{-1}$.

RMN ${ }^{1} \mathbf{H}\left(500 \mathrm{MHz}, \mathrm{CD}_{3} \mathrm{OD}\right) \delta$ 7.20-7.16 $(3 \mathrm{H}, \mathrm{m}), 7.14-7.10(2 \mathrm{H}, \mathrm{m}), 6.93(1 \mathrm{H}$, $\mathrm{dd}, J=8.3,2 \mathrm{~Hz}), 6.85(1 \mathrm{H}, \mathrm{d}, J=8.3 \mathrm{~Hz}), 6.83(1 \mathrm{H}, \mathrm{d}, J=2 \mathrm{~Hz}), 6.51(2 \mathrm{H}, \mathrm{s})$, $6.47(2 \mathrm{H}$, app s), $4.76(1 \mathrm{H}, \mathrm{dd}, J=7.3,5.3 \mathrm{~Hz}), 4.33(1 \mathrm{H}, \mathrm{d}, J=15 \mathrm{~Hz}), 4.26$ $(1 \mathrm{H}, \mathrm{d}, J=15 \mathrm{~Hz}), 3.73(3 \mathrm{H}, \mathrm{s}), 3.69(3 \mathrm{H}, \mathrm{s}), 3.61(6 \mathrm{H}, \mathrm{s}), 3.18(1 \mathrm{H}, \mathrm{dd}, J=14$, $5.3 \mathrm{~Hz}$ ), $3.04(1 \mathrm{H}, \mathrm{dd}, J=14,7.3 \mathrm{~Hz}$ ) (las señales de $\mathrm{NH}, \mathrm{OH}$ no se detectan, quizás puedan estar solapadas con la señal de agua a $4.80 \mathrm{ppm})$.

RMN ${ }^{13} \mathbf{C}\left(125 \mathrm{MHz}, \mathrm{CD}_{3} \mathrm{OD}\right) \delta$ 173.7, 170.7 (CO); 154.3 (x 2), 150.5, 148.5, 138.4, 137.7, 134.4, 131.8 (C); 130.5, 130.4 (x 2), 130.3, 129.5 (x 2), 127.9, 125.3, 118.2, 113.2, 107.5 (x 2), $54.3(\mathrm{CH}) ; 70.6,38.4\left(\mathrm{CH}_{2}\right) ; 61.2,56.5(x 2)$, $56.4\left(\mathrm{CH}_{3}\right)$.

HR ESMS : $m / z 520.1973(\mathrm{M}-\mathrm{H})^{-}$. Calculado para $\mathrm{C}_{29} \mathrm{H}_{30} \mathrm{NO}_{8} 520.1971$.

(Z)-(2-(2-metoxi-5-(3,4,5-trimetoxiestiril)fenoxi)acetil)-D-prolina 3.27.

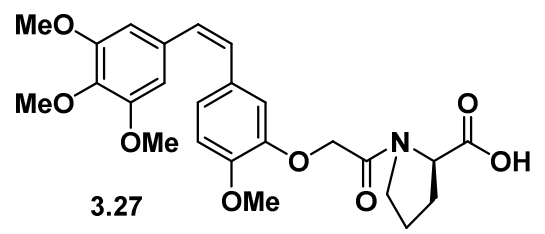

Rto. $=85 \%$. Sólido blanco. p.f $=67-69^{\circ} \mathrm{C}$.

$[\alpha]_{\mathrm{D}} 46.4\left(c 1.1, \mathrm{CHCl}_{3}\right)$.

IR: $\boldsymbol{v}_{\max } 3500-3200(\mathrm{br}, \mathrm{OH}, \mathrm{NH}), 1749,1669(\mathrm{C}=\mathrm{O}) \mathrm{cm}^{-1}$. 
RMN ${ }^{1} \mathbf{H}\left(500 \mathrm{MHz}, \mathrm{CD}_{3} \mathrm{OD}\right) \delta$ 6.90-6.80 (3H, m), $6.53(2 \mathrm{H}, \mathrm{s}), 6.48(1 \mathrm{H}, \mathrm{d}, J=$ $12.2 \mathrm{~Hz}), 6.44(1 \mathrm{H}, \mathrm{d}, J=12.2 \mathrm{~Hz}), 4.51(2 \mathrm{H}, \mathrm{s}), 4.45(1 \mathrm{H}, \mathrm{m}), 3.80(3 \mathrm{H}, \mathrm{s})$, $3.74(3 \mathrm{H}, \mathrm{s}), 3.65(6 \mathrm{H}, \mathrm{s}), 3.50-3.40(2 \mathrm{H}, \mathrm{br} \mathrm{m}), 2.25-2.15(1 \mathrm{H}, \mathrm{m}), 2.00-1.85$ $(2 \mathrm{H}$, br m) (las señales de $\mathrm{NH}, \mathrm{OH}$ no se detectan, quizás puedan estar solapadas con la señal de agua a $4.80 \mathrm{ppm}$ ).

RMN ${ }^{13} \mathbf{C}\left(125 \mathrm{MHz}, \mathrm{CD}_{3} \mathrm{OD}\right) \delta 175.2,169.0$ (CO); 154.2 (x 2), 150.5, 148.5, 138.3, 134.6, 131.4 (C); 130.6, 130.1, 124.5, 116.3, 113.3, 107.4 (x 2), 60.4 $(\mathrm{CH})$; 68.6, 47.1, 29.8, $25.7\left(\mathrm{CH}_{2}\right)$; 61.2, 56.5, 56.4 (x 2) $\left(\mathrm{CH}_{3}\right)$.

HR ESMS : $m / z 470.1818(\mathrm{M}-\mathrm{H})^{-}$. Calculado para $\mathrm{C}_{25} \mathrm{H}_{28} \mathrm{NO}_{8 .} 470.1815$.

(Z)-(2-(2-metoxi-5-(3,4,5-trimetoxiestiril)fenoxi)acetil)-D-serina 3.28.

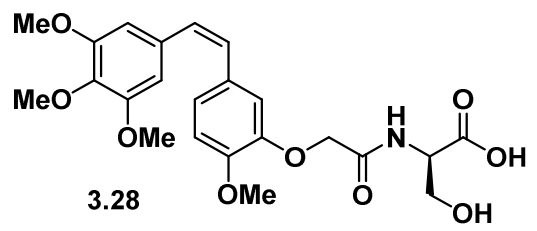

Rto. $=67 \%$. Sólido blanco. p. $f=135-137^{\circ} \mathrm{C}$.

$[\alpha]_{\mathrm{D}} 12.2\left(c 1.1, \mathrm{CHCl}_{3}\right)$.

IR: $\boldsymbol{v}_{\max } 3500-3200(\mathrm{br}, \mathrm{OH}, \mathrm{NH}), 1740,1664(\mathrm{C}=\mathrm{O}) \mathrm{cm}^{-1}$.

RMN ${ }^{1} \mathbf{H}\left(500 \mathrm{MHz}, \mathrm{CD}_{3} \mathrm{OD}\right) \delta 6.94(1 \mathrm{H}, \mathrm{dd}, J=8.3,2 \mathrm{~Hz}), 6.92(1 \mathrm{H}, \mathrm{d}, J=2$ $\mathrm{Hz}), 6.91(1 \mathrm{H}, \mathrm{d}, J=8.3 \mathrm{~Hz}), 6.52(2 \mathrm{H}, \mathrm{s}), 6.51(1 \mathrm{H}, \mathrm{d}, J=12 \mathrm{~Hz}), 6.47(1 \mathrm{H}, \mathrm{d}$, $J=12 \mathrm{~Hz}), 4.51(1 \mathrm{H}, \mathrm{br} \mathrm{t}, J \sim 4 \mathrm{~Hz}), 4.41(1 \mathrm{H}, \mathrm{d}, J=15 \mathrm{~Hz}), 4.37(1 \mathrm{H}, \mathrm{d}, J=15$ $\mathrm{Hz}), 3.98(1 \mathrm{H}, \mathrm{dd}, J=11.2,4 \mathrm{~Hz}), 3.85(1 \mathrm{H}, \mathrm{dd}$, solapado), $3.84(3 \mathrm{H}, \mathrm{s}), 3.74$ $(3 \mathrm{H}, \mathrm{s}), 3.65(6 \mathrm{H}, \mathrm{s})$ (las señales de $\mathrm{NH}, \mathrm{OH}$ no se detectan, quizás puedan estar solapadas con la señal de agua a $4.80 \mathrm{ppm}$ ).

RMN ${ }^{13} \mathbf{C}\left(125 \mathrm{MHz}, \mathrm{CD}_{3} \mathrm{OD}\right) \delta 173.3^{*}, 171.0$ (CO); 154.3 (x 2), 150.7, 148.5, 138.4, 134.4, $131.8(\mathrm{C}) ; 130.5,130.3,125.2,118.3,113.2,107.5$ (x 2), 55.8* $(\mathrm{CH}) ; 70.7,62.9\left(\mathrm{CH}_{2}\right) ; 61.2,56.5(\times 3)\left(\mathrm{CH}_{3}\right)$.

HR ESMS : $m / z 484.1584(\mathrm{M}+\mathrm{Na})^{+}$. Calculado para $\mathrm{C}_{23} \mathrm{H}_{27} \mathrm{NNaO}_{9} 484.1577$.

Las señales marcadas con * aparecen bajas y anchas. 


\subsubsection{Síntesis de compuestos de la familia 2}

\subsection{4.a. Síntesis de aminocombretastatina}

a) Síntesis del ácido (E)-3-(4-metoxi-3-nitrofenil)-2-(3,4,5-trimetoxifenil)acrílico 7.

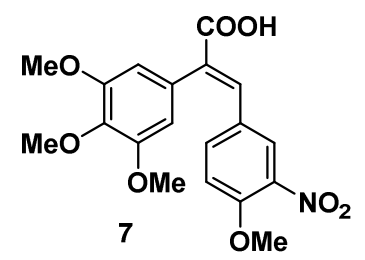

A una mezcla de 1 (10 mmol, 1 eq.) y 6 (20 mmol, 2.0 eq.) en $\mathrm{Ac}_{2} \mathrm{O}$ (12 $\mathrm{mL})$ se le añadió $\mathrm{Et}_{3} \mathrm{~N}(5 \mathrm{~mL})$ y se calentó a reflujo durante $3 \mathrm{~h}$. Acabado este tiempo se acidificó la mezcla de reacción con $\mathrm{HCl}$ concentrado $(6 \mathrm{~mL}$ ) formándose un precipitado que se filtró a vacío. El sólido obtenido se recristalizó de EtOH.

Rto. $=49 \%$. Sólido amarillo cristalino. p. $f=229-231^{\circ} \mathrm{C}$.

RMN ${ }^{1} \mathbf{H}\left(500 \mathrm{MHz}\right.$, DMSO- $\left.d_{6}\right) \delta 12.71(1 \mathrm{H}, \mathrm{br} \mathrm{s}, \mathrm{COOH}), 7.71(1 \mathrm{H}, \mathrm{s}), 7.54$ $(1 \mathrm{H}, \mathrm{s}), 7.41(1 \mathrm{H}, \mathrm{d}, J=8.3 \mathrm{~Hz}), 7.26(1 \mathrm{H}, \mathrm{d}, J=8.5 \mathrm{~Hz}), 6.48(2 \mathrm{H}, \mathrm{s}), 3.89$ $(3 \mathrm{H}, \mathrm{s}), 3.71(3 \mathrm{H}, \mathrm{s}), 3.69(6 \mathrm{H}, \mathrm{s})$.

RMN ${ }^{13} \mathbf{C}\left(125 \mathrm{MHz}\right.$, DMSO- $\left.d_{6}\right) \delta 168.4(\mathrm{CO}) ; 153.9(\mathrm{x} 2), 152.7,139.2,137.9$, 134.0, 131.7, $127.3(\mathrm{C}) ; 136.7,136.6,126.9,114.7,107.0(\mathrm{x} 2)(\mathrm{CH}) ; 60.6$, 57.3, $55.7(\times 2)\left(\mathrm{CH}_{3}\right)$.

HR ESMS : $m / z 388.1031(\mathrm{M}-\mathrm{H})^{-}$. Calculado para $\mathrm{C}_{19} \mathrm{H}_{18} \mathrm{NO}_{8}, 388.1032$.

\section{b) Síntesis de (Z)-1,2,3-trimetoxi-5-(4-metoxi-3-nitroestiril)benceno 8.}

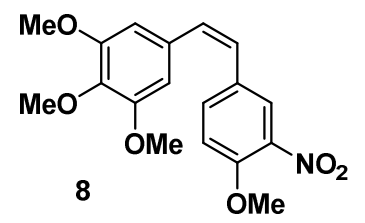

A una suspensión de Cu (26 mmol, 5.2 eq.) en quinolina (19.6 mL) se le adicionó el ácido 7 ( $5 \mathrm{mmol}, 1$ eq.) y la mezcla resultante se calentó a reflujo durante $3 \mathrm{~h}$. A continuación se enfrió la reacción, se adicionó $\mathrm{Et}_{2} \mathrm{O}(100 \mathrm{~mL})$ y el Cu se filtró a través de celite. El filtrado se lavó con $\mathrm{HCl} 1 \mathrm{M}$ y la fase acuosa se extrajo con $\mathrm{Et}_{2} \mathrm{O}$. Los extractos orgánicos reunidos se lavaron con una disolución acuosa saturada de $\mathrm{NaHCO}_{3}$ y luego se secaron con $\mathrm{Na}_{2} \mathrm{SO}_{4}$. 
Después de filtrar, el disolvente se eliminó a presión reducida. El residuo resultante se cromatografió sobre gel de sílice con Hexano-AcOEt (7:3).

Rto. $=37 \%$. Sólido amarillo. p. $f=121-123^{\circ} \mathrm{C}$.

IR: $\boldsymbol{V}_{\max }$ No se observan $\mathrm{C}=\mathrm{O}$ ni $\mathrm{N}-\mathrm{H}$.

RMN ${ }^{1} \mathbf{H}\left(500 \mathrm{MHz}, \mathrm{CDCl}_{3}\right) \delta 7.80(1 \mathrm{H}, \mathrm{d}, J=2 \mathrm{~Hz}), 7.43(1 \mathrm{H}, \mathrm{dd}, J=8.8,2$ $\mathrm{Hz}), 6.95(1 \mathrm{H}, \mathrm{d}, J=8.3 \mathrm{~Hz}), 6.59(1 \mathrm{H}, \mathrm{d}, J=12.2 \mathrm{~Hz}), 6.48(2 \mathrm{H}, \mathrm{s}), 6.45(1 \mathrm{H}$, d, $J=12.2 \mathrm{~Hz}), 3.94(3 \mathrm{H}, \mathrm{s}), 3.86(3 \mathrm{H}, \mathrm{s}), 3.72(6 \mathrm{H}, \mathrm{s})$.

RMN ${ }^{13} \mathbf{C}\left(125 \mathrm{MHz}, \mathrm{CDCl}_{3}\right) \delta 153.2(\mathrm{x} 2), 151.6,139.4,137.7,131.7,129.7$ (C); 134.5, 131.2, 126.8, 125.8, 113.0, 105.9 (x2) (CH); 60.6, 56.5, 56.0 (x2) $\left(\mathrm{CH}_{3}\right)$.

HR ESMS : $m / z 368.1109(\mathrm{M}+\mathrm{Na})^{+}$. Calculado para $\mathrm{C}_{18} \mathrm{H}_{19} \mathrm{NNaO}_{6}$ 368.1110.

c) Síntesis de (Z)-2-metoxi-5-(3,4,5-trimetoxiestiril)anilina (aminocombretastatina)

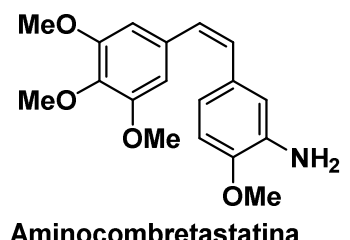

A una disolución del compuesto 8 (1.85 mmol, 1 eq.) en ácido acético $(60.1 \mathrm{~mL})$ se le adicionó zinc en polvo (260 mmol, 141 eq.) y la mezcla resultante se mantuvo en agitación a temperatura ambiente durante $6 \mathrm{~h}$. A continuación, la mezcla de reacción se filtró a vacío sobre Celite. El filtrado se neutralizó con $\mathrm{NaHCO}_{3}$ y la fase acuosa se extrajo con AcOEt. Los extractos orgánicos reunidos se secaron con $\mathrm{Na}_{2} \mathrm{SO}_{4}$. Después de filtrar, el disolvente se eliminó en el rotavapor. El residuo resultante se cromatografió sobre gel de sílice con Hexano-AcOEt (7:3).

Rto. $=87 \%$. Aceite anaranjado.

IR: $\boldsymbol{v}_{\max } 3471-3370 \mathrm{~cm}^{-1}(\mathrm{~N}-\mathrm{H})$.

RMN ${ }^{1} \mathbf{H}\left(500 \mathrm{MHz}, \mathrm{CDCl}_{3}\right) \delta 6.70(2 \mathrm{H}$, app d , $J=10.8 \mathrm{~Hz}), 6.69(1 \mathrm{H}, \mathrm{s}), 6.48$ $(2 \mathrm{H}, \mathrm{s}), 6.46(1 \mathrm{H}, \mathrm{d}, J=12.2 \mathrm{~Hz}), 6.38(1 \mathrm{H}, \mathrm{d}, J=12.2 \mathrm{~Hz}), 3.85(3 \mathrm{H}, \mathrm{s}), 3.84$ $(3 \mathrm{H}, \mathrm{s}), 3.71(6 \mathrm{H}, \mathrm{s})$.

RMN ${ }^{13} \mathbf{C}\left(125 \mathrm{MHz}, \mathrm{CDCl}_{3}\right) \delta 153.2(\mathrm{x} 2), 151.6,139.4,137.7,134.0,131.7$ (C); 130.0, 128.4, 119.5, 115.2, 110.1, 106.1 (x2) (CH); 60.9, 55.9, 55.5 (x2) $\left(\mathrm{CH}_{3}\right)$. 
HR ESMS : $m / z 316.1547(\mathrm{M}+\mathrm{H})^{+}$. Calculado para $\mathrm{C}_{18} \mathrm{H}_{22} \mathrm{NO}_{4.316 .1549 .}$

\subsection{4.b. Procedimiento experimental para N-Fmoc protección}

El aminoácido ( $3.33 \mathrm{mmol}, 1$ eq.) se disolvió en $\mathrm{Na}_{2} \mathrm{CO}_{3}$ al $10 \%$ en agua ( 7 $\mathrm{mL}$ ) a temperatura ambiente. Seguidamente se enfrió dicha disolución hasta $0^{\circ} \mathrm{C}$ y se le añadió, lentamente y bajo atmósfera de $\mathrm{N}_{2}$, una disolución de Fmoc-Cl (3.33 mmol, 1 eq.) en dioxano ( $6 \mathrm{~mL})$. La mezcla de reacción agitó a temperatura ambiente durante 4 horas. Luego la mezcla de reacción se vertió sobre agua y se extrajo con éter $(3 \times 75 \mathrm{~mL})$. La fase acuosa resultante se acidificó hasta $\mathrm{pH}=2$ con $\mathrm{HCl} 2 \mathrm{M}$ y se extrajo con AcOEt $(3 \times 50 \mathrm{~mL})$. Los extractos orgánicos reunidos se lavaron con salmuera y se secaron sobre $\mathrm{MgSO}_{4}$ anhidro. Después de filtrar y eliminar el disolvente a presión reducida, el residuo resultante se recristalizó de hexano: AcOEt (8:2) obteniéndose el aminoácido protegido deseado.

\subsection{4.c. Procedimiento experimental para la reacción de amidación con los aminoácidos $\mathrm{N}$-Fmoc protegidos}

A una disolución de la aminocombretastatina (0.394 mmol, 1 eq) en DMF anhidro (1.3 $\mathrm{mL})$ se le añadió DCC $(0.472 \mathrm{mmol}, 1.2$ eq.), el aminoácido $\mathrm{N}$ Fmoc protegido $(0.472 \mathrm{mmol}, 1.2 \mathrm{eq})$ y $\mathrm{HOBt} \cdot \mathrm{H}_{2} \mathrm{O}(0.472 \mathrm{mmol}, 1.2 \mathrm{eq})$. La mezcla de reacción se agitó bajo atmósfera de $\mathrm{N}_{2}$ durante 16 horas. Seguidamente se filtró y el filtrado se vertió sobre una disolución saturada de $\mathrm{NH}_{4} \mathrm{Cl}$ y luego se extrajo con AcOEt $(3 \times 15 \mathrm{~mL})$. Los extractos orgánicos reunidos se lavaron 2 veces con agua y con salmuera y se secaron sobre $\mathrm{MgSO}_{4}$ anhidro. Después de filtrar y eliminar el disolvente a presión reducida, el residuo resultante se cromatografió sobre gel de sílice con hexano-AcOEt $(6: 4)$. 
3.4.4.d. Datos físicos y espectroscópicos de los compuestos de la familia $2 \mathrm{~N}$-Fmoc protegidos

(Z)-(2-((2-metoxi-5-(3,4,5-trimetoxiestiril)fenil)amino)-2-oxoetil)carbamato de (9H-fluoren-9-il)metilo 3.29 .

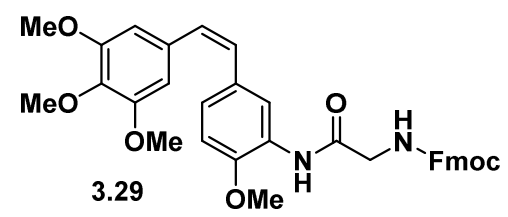

Rto. $=72 \%$. Sólido blanco. p. $f=78-80^{\circ} \mathrm{C}$.

IR: $\boldsymbol{v}_{\max } 3400,3300$ (br NH), 1727, $1686(\mathrm{C}=\mathrm{O}) \mathrm{cm}^{-1}$.

$\mathbf{R M N}^{1} \mathbf{H}\left(500 \mathrm{MHz}, \mathrm{CDCl}_{3}\right) \delta 8.30(1 \mathrm{H}, \mathrm{br} \mathrm{s}), 8.14(1 \mathrm{H}, \mathrm{br} \mathrm{s}, \mathrm{NH}), 7.77(2 \mathrm{H}, \mathrm{d}, \mathrm{J}$ $\sim 7.5 \mathrm{~Hz}), 7.62(2 \mathrm{H}, \mathrm{br} \mathrm{d}, \mathrm{J} \sim 7 \mathrm{~Hz}), 7.40(2 \mathrm{H}, \mathrm{br} \mathrm{t}, \mathrm{J} \sim 7 \mathrm{~Hz}), 7.32(2 \mathrm{H}, \mathrm{m})$, $7.02(1 \mathrm{H}, \mathrm{d}, \mathrm{J} \sim 8.3 \mathrm{~Hz}), 6.71(1 \mathrm{H}, \mathrm{d}, \mathrm{J}=8.8 \mathrm{~Hz}), 6.53(1 \mathrm{H}, \mathrm{d}, \mathrm{J}=12.2 \mathrm{~Hz})$, $6.52(2 \mathrm{H}, \mathrm{s}), 6.45(1 \mathrm{H}, \mathrm{d}, \mathrm{J}=12.2 \mathrm{~Hz}), 5.60(1 \mathrm{H}, \mathrm{br} \mathrm{s}, \mathrm{NH}), 4.46(2 \mathrm{H}, \mathrm{d}, \mathrm{J}=7.3$ $\mathrm{Hz}), 4.26(1 \mathrm{H}, \mathrm{t}, \mathrm{J}=7.3 \mathrm{~Hz}), 4.04(2 \mathrm{H}, \mathrm{br} \mathrm{s}), 3.85(3 \mathrm{H}, \mathrm{s}), 3.79(3 \mathrm{H}, \mathrm{s}), 3.69$ $(6 \mathrm{H}, \mathrm{s})$.

RMN ${ }^{13} \mathbf{C}\left(125 \mathrm{MHz}, \mathrm{CDCl}_{3}\right) \delta 166.6,156.6^{*}(\mathrm{CO}) ; 152.8$ (x 2), 147.1, 143.7 (x2), 141.3 (x 2), 137.1, 132.8, 130.2, 126.7 (C); 129.5, 129.3, 127.7 (x 2), 127.1 (x 2), 125.0 (x 2), 124.7, 120.8, 120.0 (x 2), 109.6, 106.1 (x 2), 47.1 $(\mathrm{CH}) ; 67.4,45.4^{*}\left(\mathrm{CH}_{2}\right) ; 60.8,55.9(\times 2), 55.8\left(\mathrm{CH}_{3}\right)$.

HR ESMS : $m / z 617.2262(\mathrm{M}+\mathrm{Na})^{+}$. Calculado para $\mathrm{C}_{35} \mathrm{H}_{34} \mathrm{~N}_{2} \mathrm{NaO}_{7 .} 617.2264$. Las señales marcadas con * aparecen bajas y anchas.

(Z)-(2-((2-metoxi-5-(3,4,5-trimetoxiestiril)fenil)amino)-1-oxopropan-2-il) carbamato de (9H-fluoren-9-il)metilo 3.30.

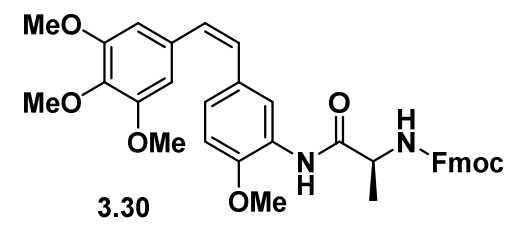

Rto. $=51 \%$. Sólido blanco. p. $f=143-145^{\circ} \mathrm{C}$.

[a] $-29.2\left(c 1.0, \mathrm{CHCl}_{3}\right)$.

IR: $\boldsymbol{v}_{\max } 3400,3300(\mathrm{br} \mathrm{NH}), 1701,1686(\mathrm{C}=\mathrm{O}) \mathrm{cm}^{-1}$. 
$\mathbf{R M N}^{1} \mathbf{H}\left(500 \mathrm{MHz}, \mathrm{CDCl}_{3}\right) \delta 8.33(1 \mathrm{H}$, br d, J $1.5 \mathrm{~Hz}), 8.25(1 \mathrm{H}$, br s, NH), $7.77(2 \mathrm{H}, \mathrm{d}, \mathrm{J} \sim 7.8 \mathrm{~Hz}), 7.60(2 \mathrm{H}, \mathrm{br} \mathrm{d}, \mathrm{J} \sim 7 \mathrm{~Hz}), 7.40(2 \mathrm{H}, \mathrm{br} \mathrm{t}, \mathrm{J} \sim 7 \mathrm{~Hz})$, $7.31(2 \mathrm{H}, \mathrm{m}), 7.02(1 \mathrm{H}, \mathrm{dd}, \mathrm{J}=8.3,1.5 \mathrm{~Hz}), 6.71(1 \mathrm{H}, \mathrm{d}, \mathrm{J}=8.8 \mathrm{~Hz}), 6.52(2 \mathrm{H}$, s), $6.51(1 \mathrm{H}, \mathrm{d}, \mathrm{J}=12.2 \mathrm{~Hz}), 6.45(1 \mathrm{H}, \mathrm{d}, \mathrm{J}=12.2 \mathrm{~Hz}), 5.40(1 \mathrm{H}, \mathrm{br} \mathrm{s}, \mathrm{NH})$, 4.50-4.40 $(3 \mathrm{H}, \mathrm{m}), 4.25(1 \mathrm{H}, \mathrm{t}, \mathrm{J}=7 \mathrm{~Hz}), 3.85(3 \mathrm{H}, \mathrm{s}), 3.80(3 \mathrm{H}, \mathrm{s}), 3.70(6 \mathrm{H}$, s), $1.49(3 \mathrm{H}, \mathrm{d}, \mathrm{J}=7.3 \mathrm{~Hz})$.

RMN ${ }^{13} \mathbf{C}\left(125 \mathrm{MHz}, \mathrm{CDCl}_{3}\right) \delta 170.1,156.0^{*}(\mathrm{CO}) ; 152.8(\mathrm{x} 2), 147.1,143.7$ (x 2), 141.3 (x 2), 137.1, 132.8, 130.1, 126.9 (C); 129.5, 129.2, 127.7 (x 2), 127.1 (x 2), 125.0 (x 2), 124.7, 120.8, 120.0 (x 2), 109.6, 106.1 (x 2), 51.5*, 47.1 $(\mathrm{CH}) ; 67.1\left(\mathrm{CH}_{2}\right) ; 60.8,55.9(\times 2), 55.8,18.6\left(\mathrm{CH}_{3}\right)$.

HR ESMS : $m / z 609.2600(\mathrm{M}+\mathrm{H})^{+}$. Calculado para $\mathrm{C}_{36} \mathrm{H}_{37} \mathrm{~N}_{2} \mathrm{O}_{7}$. 609.2607.

Las señales marcadas con * aparecen bajas y anchas.

(Z)-(2-((2-metoxi-5-(3,4,5-trimetoxiestiril)fenil)amino)-3-metil-1-oxobutan2-il)carbamato de (9H-fluoren-9-il)metilo 3.31 .

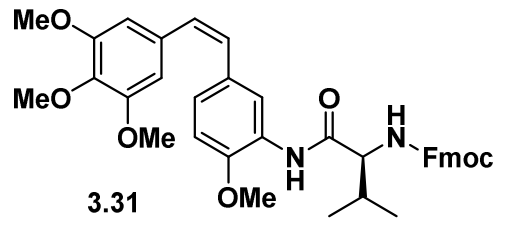

Rto. $=61 \%$. Sólido blanco. p.f $=176-178^{\circ} \mathrm{C}$.

$[\alpha]_{\mathrm{D}}-35.3\left(c 1.0, \mathrm{CHCl}_{3}\right)$.

IR: $\boldsymbol{v}_{\max } 3400,3300(\mathrm{br} \mathrm{NH}), 1714,1683(\mathrm{C}=\mathrm{O}) \mathrm{cm}^{-1}$.

$\mathbf{R M N}^{1} \mathbf{H}\left(500 \mathrm{MHz}, \mathrm{CDCl}_{3}\right) \delta 8.34(1 \mathrm{H}$, br d , J $1.5 \mathrm{~Hz}), 8.00(1 \mathrm{H}$, br s, NH), $7.77(2 \mathrm{H}, \mathrm{d}, \mathrm{J} \sim 7.5 \mathrm{~Hz}), 7.60(2 \mathrm{H}, \mathrm{br} \mathrm{d}, \mathrm{J} \sim 6 \mathrm{~Hz}), 7.40(2 \mathrm{H}, \mathrm{br}$ t, J $~ 7 \mathrm{~Hz})$, $7.32(2 \mathrm{H}, \mathrm{m}), 7.03(1 \mathrm{H}, \mathrm{dd}, \mathrm{J}=8.3,2 \mathrm{~Hz}), 6.72(1 \mathrm{H}, \mathrm{d}, \mathrm{J}=8.3 \mathrm{~Hz}), 6.53(2 \mathrm{H}$, s), $6.51(1 \mathrm{H}, \mathrm{d}, \mathrm{J}=12.2 \mathrm{~Hz}), 6.46(1 \mathrm{H}, \mathrm{d}, \mathrm{J}=12.2 \mathrm{~Hz}), 5.45(1 \mathrm{H}, \mathrm{br} \mathrm{s}, \mathrm{NH})$, 4.50-4.40 (2H, m), $4.24(1 \mathrm{H}, \mathrm{t}, \mathrm{J}=7 \mathrm{~Hz}), 4.14(1 \mathrm{H}, \mathrm{m}), 3.85(3 \mathrm{H}, \mathrm{s}), 3.83(3 \mathrm{H}$, br s), $3.70(6 \mathrm{H}, \mathrm{s}), 2.22(1 \mathrm{H}, \mathrm{dqq}, \mathrm{J}=7,7,7 \mathrm{~Hz}), 1.02(6 \mathrm{H}$, app t, J $7.5 \mathrm{~Hz})$.

RMN ${ }^{13} \mathbf{C}\left(125 \mathrm{MHz}, \mathrm{CDCl}_{3}\right) \delta 169.2,156.4(\mathrm{CO}) ; 152.8$ (x 2), 147.2, 143.7 (x 2), 141.2 (x 2), 137.1, 132.7, 130.1, 126.7 (C); 129.5, 129.2, 127.6 (x 2), 127.0 (x 2), 124.9 (x 2), 124.7, 120.8, 119.8 (x 2), 109.6, 106.0 (x 2), 61.3, 47.1, 31.2 $(\mathrm{CH})$; $67.1\left(\mathrm{CH}_{2}\right)$; 60.8, $55.9(\mathrm{x} 2)$, 55.8, 19.1, $17.8\left(\mathrm{CH}_{3}\right)$.

HR ESMS : $m / z 659.2725(\mathrm{M}+\mathrm{Na})^{+}$. Calculado para $\mathrm{C}_{38} \mathrm{H}_{40} \mathrm{~N}_{2} \mathrm{NaO}_{7}$ 659.2733. 
(Z)-(2-((2-metoxi-5-(3,4,5-trimetoxiestiril)fenil)amino)-4-metil-1-oxo-pentan-2-il)carbamato de (9H-fluoren-9-il)metilo 3.32.

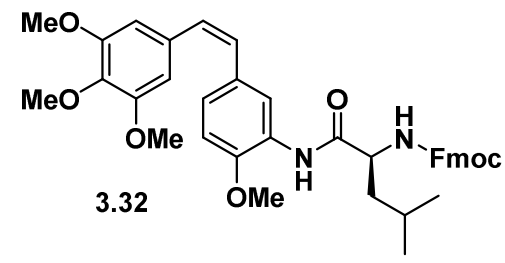

Rto. $=61 \%$. Sólido blanco. p. $f=72-74^{\circ} \mathrm{C}$.

$[\alpha]_{\mathrm{D}}-34.3\left(\mathrm{c} 1.0, \mathrm{CHCl}_{3}\right)$.

IR: $\boldsymbol{v}_{\max } 3400,3320(\mathrm{br} \mathrm{NH}), 1701,1685(\mathrm{C}=\mathrm{O}) \mathrm{cm}^{-1}$.

RMN ${ }^{1} \mathbf{H}\left(500 \mathrm{MHz}, \mathrm{CDCl}_{3}\right) \delta 8.34(1 \mathrm{H}, \mathrm{br} \mathrm{d}, J \sim 1.5 \mathrm{~Hz}), 8.20(1 \mathrm{H}, \mathrm{br} \mathrm{s}, \mathrm{NH})$, $7.77(2 \mathrm{H}$, br d, $J \sim 7 \mathrm{~Hz}), 7.60(2 \mathrm{H}$, br d, $J \sim 7 \mathrm{~Hz}), 7.40(2 \mathrm{H}$, br t, $J \sim 7 \mathrm{~Hz})$, $7.31(2 \mathrm{H}, \mathrm{m}), 7.02(1 \mathrm{H}, \mathrm{dd}, J=8.3,1.5 \mathrm{~Hz}), 6.70(1 \mathrm{H}, \mathrm{d}, J=8.3 \mathrm{~Hz}), 6.53(2 \mathrm{H}$, s), $6.51(1 \mathrm{H}, \mathrm{d}, J=12.2 \mathrm{~Hz}), 6.45(1 \mathrm{H}, \mathrm{d}, J=12.2 \mathrm{~Hz}), 5.25(1 \mathrm{H}, \mathrm{br} \mathrm{s}, \mathrm{NH})$, $4.44(2 \mathrm{H}, \mathrm{d}, J=7 \mathrm{~Hz}), 4.34(1 \mathrm{H}, \mathrm{m}), 4.24(1 \mathrm{H}, \mathrm{t}, J=7 \mathrm{~Hz}), 3.84(3 \mathrm{H}, \mathrm{s}), 3.81$ $(3 \mathrm{H}, \mathrm{br} \mathrm{s}), 3.69(6 \mathrm{H}, \mathrm{s}), 1.80-1.70(2 \mathrm{H}, \mathrm{m}), 1.60(1 \mathrm{H}, \mathrm{m}), 0.99(6 \mathrm{H}, \mathrm{br} \mathrm{d}, J \sim 7$ $\mathrm{Hz}$ ).

RMN ${ }^{13} \mathbf{C}\left(125 \mathrm{MHz}, \mathrm{CDCl}_{3}\right) \delta 170.1,156.2(\mathrm{CO}) ; 152.8$ (x 2), 147.2, $143.7(\mathrm{x}$ 2), 141.2 (x 2), 137.1, 132.7, 130.1, 126.9 (C); 129.5, 129.2, 127.6 (x 2), 127.0 (x 2), 124.9 (x 2), 124.6, 120.9, 119.8 (x 2), 109.6, 106.0 (x 2), 54.5, 47.1, 22.1 $(\mathrm{CH})$; 67.1, $41.6\left(\mathrm{CH}_{2}\right)$, 60.8, 55.9 (x 2), 55.8, 24.7, $22.8\left(\mathrm{CH}_{3}\right)$.

HR ESMS : $m / z 673.2886(\mathrm{M}+\mathrm{Na})^{+}$. Calculado para $\mathrm{C}_{39} \mathrm{H}_{42} \mathrm{~N}_{2} \mathrm{NaO}_{7} 673.2890$

(Z)-(2-((2-metoxi-5-(3,4,5-trimetoxiestiril)fenil)amino)-1-oxo-3-fenilpropan2-il)carbamato de (9H-fluoren-9-il)metilo 3.33.

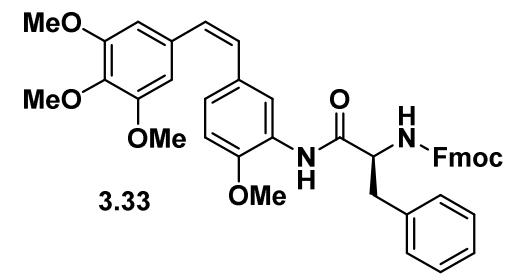

Rto. $=59 \%$. Sólido blanco. p. $f=78-80^{\circ} \mathrm{C}$.

$[\alpha]_{D}-25.0\left(c 1.0, \mathrm{CHCl}_{3}\right)$.

IR: $\boldsymbol{v}_{\max } 3400,3300(\mathrm{br} \mathrm{NH}), 1701,1684(\mathrm{C}=\mathrm{O}) \mathrm{cm}^{-1}$. 
$\mathbf{R M N}^{1} \mathbf{H}\left(500 \mathrm{MHz}, \mathrm{CDCl}_{3}\right) \delta 8.32(1 \mathrm{H}, \mathrm{br} \mathrm{d}, J \sim 1.5 \mathrm{~Hz}), 7.95(1 \mathrm{H}, \mathrm{br} \mathrm{s}, \mathrm{NH})$, $7.77(2 \mathrm{H}$, br d, $J \sim 7.3 \mathrm{~Hz}), 7.56(2 \mathrm{H}$, app t, $J \sim 7 \mathrm{~Hz}), 7.40(2 \mathrm{H}$, br t, $J \sim 7.3$ $\mathrm{Hz}), 7.35-7.20(7 \mathrm{H}, \mathrm{br} \mathrm{m}), 7.01(1 \mathrm{H}, \mathrm{dd}, J=8.8,1.5 \mathrm{~Hz}), 6.66(1 \mathrm{H}, \mathrm{d}, J=8.8$ $\mathrm{Hz}), 6.53(2 \mathrm{H}, \mathrm{s}), 6.52(1 \mathrm{H}, \mathrm{d}, J=12.2 \mathrm{~Hz}), 6.47(1 \mathrm{H}, \mathrm{d}, J=12.2 \mathrm{~Hz}), 5.60(1 \mathrm{H}$, br s, NH), $4.60(1 \mathrm{H}$, br s), 4.50-4.35 $(2 \mathrm{H}, \mathrm{m}), 4.22(1 \mathrm{H}, \mathrm{t}, J=7 \mathrm{~Hz}), 3.86(3 \mathrm{H}$, s), $3.70(6 \mathrm{H}$, br s), $3.68(3 \mathrm{H}, \mathrm{s}), 3.25-3.10(2 \mathrm{H}, \mathrm{br} \mathrm{m})$.

RMN ${ }^{13} \mathbf{C}\left(125 \mathrm{MHz}, \mathrm{CDCl}_{3}\right) \delta 168.6,155.9^{*}(\mathrm{CO}) ; 152.8$ (x 2), 147.5, 143.7, 143.6, 141.2 (x 2), 137.1, 136.2* $132.7,130.1,126.6^{*}$ (C); 129.5, 129.3 (x 3), 129.2, 128.7 (x 2), 127.7 (x 2), 127.0 (x 2), 125.0 (x 2), 124.7, 120.8, 120.0 (x 2), 109.5, 106.1 (x 2), 57.1 ${ }^{*}, 47.1(\mathrm{CH}) ; 67.2,38.7\left(\mathrm{CH}_{2}\right), 60.8,55.9(x 2), 55.8$ $\left(\mathrm{CH}_{3}\right)$.

HR ESMS : $m / z 685.2906(\mathrm{M}+\mathrm{H})^{+}$. Calculado para $\mathrm{C}_{42} \mathrm{H}_{41} \mathrm{~N}_{2} \mathrm{O}_{7}$. 685.2914.

Las señales marcadas con * aparecen bajas y anchas.

(Z)-(2-((2-metoxi-5-(3,4,5-trimetoxiestiril)fenil)carbamoil)pirrolidin-1carboxilato de (9H-fluoren-9-il)metilo 3.34.

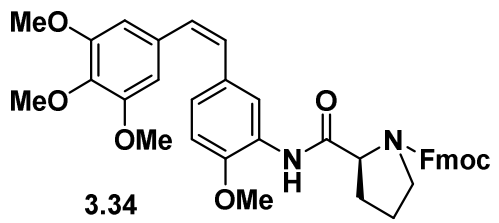

Rto. $=71 \%$. Sólido blanco. p. $f=70-72 \stackrel{\circ}{ } \mathrm{C}$.

$[\alpha]_{\mathrm{D}}-73.3\left(\mathrm{c} 1.0, \mathrm{CHCl}_{3}\right)$.

IR: $\boldsymbol{v}_{\max } 3400,3300(\mathrm{br} \mathrm{NH}), 1700(\mathrm{br} \mathrm{C}=\mathrm{O}) \mathrm{cm}^{-1}$.

RMN ${ }^{1} \mathbf{H}\left(500 \mathrm{MHz}, \mathrm{CDCl}_{3}\right) \delta 8.90(1 \mathrm{H}, \mathrm{br} \mathrm{s}, \mathrm{NH}), 8.38(1 \mathrm{H}, \mathrm{br} \mathrm{s}), 7.80-7.20$ $(8 \mathrm{H}, \mathrm{br} \mathrm{m}), 7.10-7.00(1 \mathrm{H}, \mathrm{br} \mathrm{m}), 6.67(1 \mathrm{H}, \mathrm{d}, J=8.3 \mathrm{~Hz}), 6.55(2 \mathrm{H}, \mathrm{s}), 6.55-$ $6.40(2 \mathrm{H}, \mathrm{br} \mathrm{m}), 4.60-4.40(4 \mathrm{H}, \mathrm{br} \mathrm{m}), 3.85(6 \mathrm{H}, \mathrm{s}), 3.73(3 \mathrm{H}, \mathrm{br} \mathrm{s}), 3.68(3 \mathrm{H}$, s), 3.65-3.60 (2H, br m), 2.45-2.00 (4H, br m).

RMN ${ }^{13} \mathbf{C}\left(125 \mathrm{MHz}, \mathrm{CDCl}_{3}\right) \delta 169.4^{*}, 156.0^{*}$ (CO); 152.8 (x 2), 147.2, 143.7 (x 2), 141.2 (x 2), 137.2, 132.8, 130.0, 126.9* (C); 129.6, 129.0, 127.7 (x 2), 127.0 (x 2), 124.9 (x 2), 124.4* $120.9^{*}, 119.9$ (x 2), 109.6*, 106.1 (x 2), 61.5*, $47.2(\mathrm{CH}) ; 67.9^{\star}, 31.2^{*}, 28.4^{\star}, 24.5^{\star}\left(\mathrm{CH}_{2}\right) ; 60.8,55.8(\times 2), 55.7\left(\mathrm{CH}_{3}\right)$.

HR ESMS : $m / z 657.2582(\mathrm{M}+\mathrm{Na})^{+}$. Calculado para $\mathrm{C}_{38} \mathrm{H}_{38} \mathrm{~N}_{2} \mathrm{NaO}_{7}$ 657.2578.

Las señales marcadas con * aparecen bajas y anchas. 
((2S,3S)-3-hidroxi-1-((2-metoxi-5-((Z)-3,4,5-trimetoxiestiril)fenil)amino)-1oxobutan-2-il)carbamato de (9H-fluoren-9-il)metilo 3.35 .

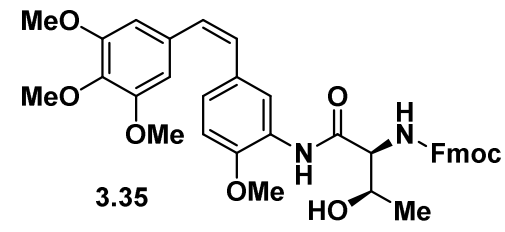

Rto. $=44 \%$. Sólido blanco. p. $f=145-147^{\circ} \mathrm{C}$.

$[\alpha]_{\mathrm{D}}-51.5\left(\mathrm{c} 1.0, \mathrm{CHCl}_{3}\right)$.

IR: $\boldsymbol{v}_{\max } 3400,3300(\mathrm{br}, \mathrm{OH}, \mathrm{NH}), 1701,1684(\mathrm{C}=\mathrm{O}) \mathrm{cm}^{-1}$.

RMN ${ }^{1} \mathbf{H}\left(500 \mathrm{MHz}, \mathrm{CDCl}_{3}\right) \delta 8.80(1 \mathrm{H}, \mathrm{br} \mathrm{s}, \mathrm{NH}), 8.29(1 \mathrm{H}, \mathrm{br} \mathrm{s}), 7.76(2 \mathrm{H}, \mathrm{br}$ d, $J \sim 7.3 \mathrm{~Hz}), 7.60(2 \mathrm{H}, \mathrm{br} d, J \sim 7.3 \mathrm{~Hz}), 7.40(2 \mathrm{H}, \mathrm{m}), 7.30(2 \mathrm{H}, \mathrm{m}), 7.02(1 \mathrm{H}$, dd, $J=8.3,1.5 \mathrm{~Hz}), 6.69(1 \mathrm{H}, \mathrm{d}, J=8.8 \mathrm{~Hz}), 6.53(2 \mathrm{H}, \mathrm{s}), 6.50(1 \mathrm{H}, \mathrm{d}, J=12.2$ $\mathrm{Hz}), 6.45(1 \mathrm{H}, \mathrm{d}, J=12.2 \mathrm{~Hz}), 6.00(1 \mathrm{H}, \mathrm{br} d, J \sim 7 \mathrm{~Hz}, \mathrm{NH}), 4.50-4.40(3 \mathrm{H}, \mathrm{m})$, $4.32(1 \mathrm{H}, \mathrm{br} d, J \sim 7 \mathrm{~Hz}), 4.25(1 \mathrm{H}, \mathrm{t}, J=7 \mathrm{~Hz}), 3.85(3 \mathrm{H}, \mathrm{s}), 3.74(3 \mathrm{H}, \mathrm{br} \mathrm{s})$, $3.69(6 \mathrm{H}, \mathrm{s}), 3.45(1 \mathrm{H}, \mathrm{br} \mathrm{s}, \mathrm{OH}) .1 .23(3 \mathrm{H}, \mathrm{br} \mathrm{d}, J \sim 6.5 \mathrm{~Hz})$.

RMN ${ }^{13} \mathbf{C}\left(125 \mathrm{MHz}, \mathrm{CDCl}_{3}\right) \delta$ 168.7, 156.9 (CO); 152.8 (x 2), 147.5, 143.6 (x 2), 141.2 (x 2), 137.1, 132.7, 130.0, 126.7 (C); 129.5, 129.2, 127.7 (x 2), 127.0 (x 2), 125.0 (x 2), 124.9, 121.1, 119.9 (x 2), 109.7, 106.1 (x 2), 66.7, 59.4, 47.1 $(\mathrm{CH}) ; 67.4\left(\mathrm{CH}_{2}\right) ; 60.8,55.9(\times 2), 55.8,18.2\left(\mathrm{CH}_{3}\right)$.

HR ESMS : $m / z 661.2521(\mathrm{M}+\mathrm{Na})^{+}$. Calculado para $\mathrm{C}_{37} \mathrm{H}_{38} \mathrm{~N}_{2} \mathrm{NaO}_{8 .} 661.2526$.

(S,Z)-(3-(4-hidroxifenil)-1-((2-metoxi-5-(3,4,5-trimetoxiestiril)fenil)amino)-1oxopropan-2-il)carbamato de (9H-fluoren-9-il)metilo 3.35 .

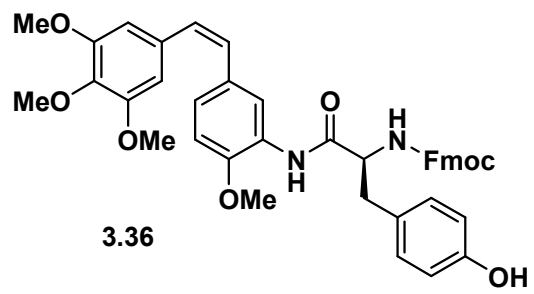

Rto. $=60 \%$. Sólido blanco. p. $f=94-96^{\circ} \mathrm{C}$.

$[\alpha]_{\mathrm{D}}-25.3\left(\mathrm{c} 1.0, \mathrm{CHCl}_{3}\right)$.

IR: $\boldsymbol{v}_{\max } 3400,3300(\mathrm{br}, \mathrm{OH}, \mathrm{NH}), 1700(\mathrm{br}, \mathrm{C}=\mathrm{O}) \mathrm{cm}^{-1}$. 
RMN ${ }^{1} \mathbf{H}\left(500 \mathrm{MHz}, \mathrm{CDCl}_{3}\right) \delta 8.20(1 \mathrm{H}$, br s), $7.85(1 \mathrm{H}$, br s, NH), $7.77(2 \mathrm{H}$, br d, $J \sim 7.3 \mathrm{~Hz}), 7.57(2 \mathrm{H}$, br d, $J \sim 4 \mathrm{~Hz}), 7.40(2 \mathrm{H}$, br t, $J \sim 6.5 \mathrm{~Hz}), 7.30(2 \mathrm{H}$, $\mathrm{m}), 7.01(3 \mathrm{H}, \mathrm{m}), 6.68(3 \mathrm{H}, \mathrm{m}), 6.54(1 \mathrm{H}, \mathrm{d}, J=12.2 \mathrm{~Hz}), 6.49(2 \mathrm{H}, \mathrm{s}), 6.46$ $(1 \mathrm{H}, \mathrm{d}, J=12.2 \mathrm{~Hz}), 5.75(1 \mathrm{H}, \mathrm{br} \mathrm{s}, \mathrm{NH}), 5.50(1 \mathrm{H}, \mathrm{br} \mathrm{s}, \mathrm{OH}), 4.55-4.35(3 \mathrm{H}$, m), $4.22(1 \mathrm{H}, \mathrm{t}, J=6.5 \mathrm{~Hz}), 3.86(3 \mathrm{H}, \mathrm{s}), 3.78(3 \mathrm{H}, \mathrm{s}), 3.65(6 \mathrm{H}, \mathrm{br} \mathrm{s}), 3.14(1 \mathrm{H}$, $\mathrm{m}), 2.98(1 \mathrm{H}, \mathrm{m})$.

RMN ${ }^{13} \mathbf{C}\left(125 \mathrm{MHz}, \mathrm{CDCl}_{3}\right) \delta 168.9,156.0^{*}(\mathrm{CO}) ; 155.3,152.8$ (x 2), 147.3, 143.6, 143.5, 141.2 (x 2), 136.8, 132.8, 130.0, 126.4, 120.9* (C); 130.3 (x 2), 129.6, 129.2, 127.7 (x 3), 127.0 (x 2), 124.9 (x 2), 124.7, 119.9 (x 2), $115.6(x$ 2), 109.6, 106.1 (x 2), 57.3* $47.1(\mathrm{CH}) ; 67.2^{*}, 37.9\left(\mathrm{CH}_{2}\right) ; 60.8,55.8(x 2), 55.7$ $\left(\mathrm{CH}_{3}\right)$.

HR ESMS : $m / z 723.2676(\mathrm{M}+\mathrm{Na})^{+}$. Calculado para $\mathrm{C}_{42} \mathrm{H}_{40} \mathrm{~N}_{2} \mathrm{NaO}_{7} .723 .2682$.

Las señales marcadas con * aparecen bajas y anchas.

(S,Z)-(1-((2-metoxi-5-(3,4,5-trimetoxiestiril)fenil)amino)-4-(metiltio)-1oxobutan-2-il)carbamato de (9H-fluoren-9-il)metilo 3.37 .

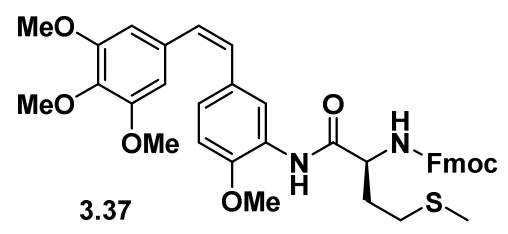

Rto. $=69 \%$. Sólido blanco. p. $f=71-73^{\circ} \mathrm{C}$.

$[\alpha]_{\mathrm{D}}-23.3\left(c 1.0, \mathrm{CHCl}_{3}\right)$.

IR: $\boldsymbol{v}_{\max } 3400,3320(\mathrm{br}, \mathrm{NH}), 1700,1686(\mathrm{br}, \mathrm{C}=\mathrm{O}) \mathrm{cm}^{-1}$.

$\mathbf{R M N}^{1} \mathbf{H}\left(500 \mathrm{MHz}, \mathrm{CDCl}_{3}\right) \delta 8.40(1 \mathrm{H}, \mathrm{br} \mathrm{s}, \mathrm{NH}), 8.32(1 \mathrm{H}, \mathrm{d}, J=1.5 \mathrm{~Hz}), 7.76$ $(2 \mathrm{H}, \mathrm{d}, J=7.8 \mathrm{~Hz}), 7.60(2 \mathrm{H}, \mathrm{d}, J=7.4 \mathrm{~Hz}), 7.38(2 \mathrm{H}, \mathrm{brt}, J \sim 7 \mathrm{~Hz}), 7.30(2 \mathrm{H}$, $\mathrm{m}), 7.03(1 \mathrm{H}, \mathrm{dd}, J=8.3,1.5 \mathrm{~Hz}), 6.70(1 \mathrm{H}, \mathrm{d}, J=8.3 \mathrm{~Hz}), 6.54(2 \mathrm{H}, \mathrm{s}), 6.51$ $(1 \mathrm{H}, \mathrm{d}, J=12.2 \mathrm{~Hz}), 6.45(1 \mathrm{H}, \mathrm{d}, J=12.2 \mathrm{~Hz}), 5.80(1 \mathrm{H}, \mathrm{br} d, J \sim 7 \mathrm{~Hz}, \mathrm{NH})$, $4.57(1 \mathrm{H}, \mathrm{m}), 4.44(2 \mathrm{H}, \mathrm{d}, J=7 \mathrm{~Hz}), 4.23(1 \mathrm{H}, \mathrm{t}, J=7 \mathrm{~Hz}), 3.85(3 \mathrm{H}, \mathrm{s}), 3.78$ $(3 \mathrm{H}, \mathrm{br} \mathrm{s}), 3.69(6 \mathrm{H}, \mathrm{s}), 2.70-2.55(2 \mathrm{H}, \mathrm{br} \mathrm{m}), 2.20-2.15(1 \mathrm{H}, \mathrm{m}), 2.12(3 \mathrm{H}, \mathrm{br}$ s), 2.10-2.05 (1H, m).

RMN ${ }^{13} \mathbf{C}\left(125 \mathrm{MHz}, \mathrm{CDCl}_{3}\right) \delta 169.0,156.0^{*}(\mathrm{CO}) ; 152.8$ (x 2), 147.3, 143.7, 143.6, 141.2 (x 2), 137.2, 132.8, 130.1, 126.7* (C); 129.5, 129.2, 127.7 (x 2), 127.0 (x 2), 124.9 (x 2), 124.8, 121.0*, 119.9 (x 2), 109.6, 106.1 (x 2), 54.6*, $47.1(\mathrm{CH}) ; 67.1^{*}, 31.6,30.1\left(\mathrm{CH}_{2}\right) ; 60.8,55.8(x 2), 55.7,15.1\left(\mathrm{CH}_{3}\right)$. 
HR ESMS : $m / z 691.2460(\mathrm{M}+\mathrm{Na})^{+}$. Calculado para $\mathrm{C}_{38} \mathrm{H}_{40} \mathrm{~N}_{2} \mathrm{NaO}_{7} \mathrm{~S}$. 691.2454. Las señales marcadas con * aparecen bajas y anchas.

( $R, Z)$-(1-((2-metoxi-5-(3,4,5-trimetoxiestiril)fenil)amino)-3-metil-1-oxobutan-2-il)carbamato de (9H-fluoren-9-il)metilo 3.47 .

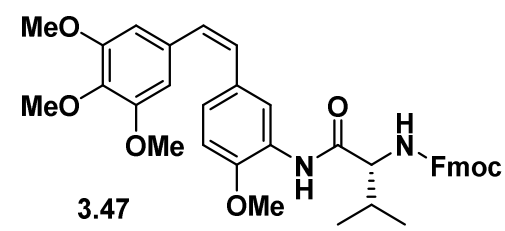

Rto. $=55 \%$. Sólido blanco. p. $f=176-178^{\circ} \mathrm{C}$.

$[\alpha]_{\mathrm{D}}+36\left(c 1.0, \mathrm{CHCl}_{3}\right)$.

IR: $\boldsymbol{v}_{\max } 3400,3300(\mathrm{br}, \mathrm{NH}), 1714,1683(\mathrm{C}=\mathrm{O}) \mathrm{cm}^{-1}$.

RMN ${ }^{1} \mathbf{H}\left(500 \mathrm{MHz}, \mathrm{CDCl}_{3}\right) \delta 8.34(1 \mathrm{H}$, br d , J $1.5 \mathrm{~Hz}), 8.00(1 \mathrm{H}$, br s, NH), $7.77(2 \mathrm{H}, \mathrm{d}, \mathrm{J} \sim 7.5 \mathrm{~Hz}), 7.60(2 \mathrm{H}, \mathrm{br} \mathrm{d}, \mathrm{J} \sim 6 \mathrm{~Hz}), 7.40(2 \mathrm{H}, \mathrm{br} \mathrm{t}, \mathrm{J} \sim 7 \mathrm{~Hz})$, $7.32(2 \mathrm{H}, \mathrm{m}), 7.03(1 \mathrm{H}, \mathrm{dd}, \mathrm{J}=8.3,2 \mathrm{~Hz}), 6.72(1 \mathrm{H}, \mathrm{d}, \mathrm{J}=8.3 \mathrm{~Hz}), 6.53(2 \mathrm{H}, \mathrm{s})$, $6.51(1 \mathrm{H}, \mathrm{d}, \mathrm{J}=12.2 \mathrm{~Hz}), 6.46(1 \mathrm{H}, \mathrm{d}, \mathrm{J}=12.2 \mathrm{~Hz}), 5.45(1 \mathrm{H}, \mathrm{br} \mathrm{s}, \mathrm{NH}), 4.50-$ $4.40(2 \mathrm{H}, \mathrm{m}), 4.24(1 \mathrm{H}, \mathrm{t}, \mathrm{J}=7 \mathrm{~Hz}), 4.14(1 \mathrm{H}, \mathrm{m}), 3.85(3 \mathrm{H}, \mathrm{s}), 3.83(3 \mathrm{H}, \mathrm{br} \mathrm{s})$, $3.70(6 \mathrm{H}, \mathrm{s}), 2.22(1 \mathrm{H}, \mathrm{dqq}, \mathrm{J}=7,7,7 \mathrm{~Hz}), 1.02(6 \mathrm{H}$, app t, J $7.5 \mathrm{~Hz})$.

RMN ${ }^{13} \mathbf{C}\left(125 \mathrm{MHz}, \mathrm{CDCl}_{3}\right) \delta 169.2,156.4(\mathrm{CO}) ; 152.8(\mathrm{x} 2), 147.2,143.7(\mathrm{x}$ 2), 141.2 (x 2), 137.1, 132.7, 130.1, 126.7 (C); 129.5, 129.2, 127.6 (x 2), 127.0 (x 2), 124.9 (x 2), 124.7, 120.8, 119.8 (x 2), 109.6, 106.0 (x 2), 61.3, 47.1, 31.2 $(\mathrm{CH}) ; 67.1\left(\mathrm{CH}_{2}\right) ; 60.8,55.9(\times 2), 55.8,19.1,17.8\left(\mathrm{CH}_{3}\right)$.

HR ESMS : $m / z 659.2725(\mathrm{M}+\mathrm{Na})^{+}$. Calculado para $\mathrm{C}_{38} \mathrm{H}_{40} \mathrm{~N}_{2} \mathrm{NaO}_{7} 659.2733$.

(R,Z)-(1-((2-metoxi-5-(3,4,5-trimetoxiestiril)fenil)amino)-4-metil-1-oxopentan-2-il)carbamato de (9H-fluoren-9-il)metilo 3.48 .

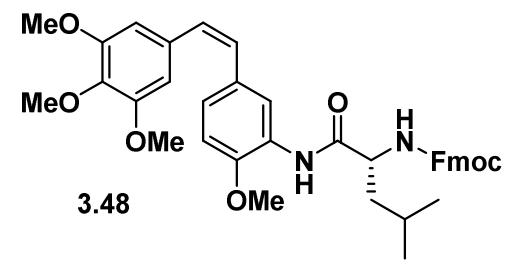

Rto. $=60 \%$. Sólido blanco. p. $\mathrm{f}=72-74^{\circ} \mathrm{C}$.

$[\alpha]_{\mathrm{D}}+34.0\left(\right.$ c $\left.0.9, \mathrm{CHCl}_{3}\right)$. 
IR: $\boldsymbol{v}_{\max } 3400,3320(\mathrm{br} \mathrm{NH}), 1701,1685(\mathrm{C}=\mathrm{O}) \mathrm{cm}^{-1}$.

RMN ${ }^{1} \mathbf{H}\left(500 \mathrm{MHz}, \mathrm{CDCl}_{3}\right) \delta 8.34(1 \mathrm{H}, \mathrm{br} \mathrm{d}, J \sim 1.5 \mathrm{~Hz}), 8.20(1 \mathrm{H}, \mathrm{br} \mathrm{s}, \mathrm{NH})$, $7.77(2 \mathrm{H}, \mathrm{br} \mathrm{d}, J \sim 7 \mathrm{~Hz}), 7.60(2 \mathrm{H}, \mathrm{br} \mathrm{d}, J \sim 7 \mathrm{~Hz}), 7.40(2 \mathrm{H}, \mathrm{brt}, J \sim 7 \mathrm{~Hz})$, $7.31(2 \mathrm{H}, \mathrm{m}), 7.02(1 \mathrm{H}, \mathrm{dd}, J=8.3,1.5 \mathrm{~Hz}), 6.70(1 \mathrm{H}, \mathrm{d}, J=8.3 \mathrm{~Hz}), 6.53(2 \mathrm{H}$, s), $6.51(1 \mathrm{H}, \mathrm{d}, J=12.2 \mathrm{~Hz}), 6.45(1 \mathrm{H}, \mathrm{d}, J=12.2 \mathrm{~Hz}), 5.25(1 \mathrm{H}, \mathrm{br} \mathrm{s}, \mathrm{NH})$, $4.44(2 \mathrm{H}, \mathrm{d}, J=7 \mathrm{~Hz}), 4.34(1 \mathrm{H}, \mathrm{m}), 4.24(1 \mathrm{H}, \mathrm{t}, J=7 \mathrm{~Hz}), 3.84(3 \mathrm{H}, \mathrm{s}), 3.81$ $(3 \mathrm{H}, \mathrm{br} \mathrm{s}), 3.69(6 \mathrm{H}, \mathrm{s}), 1.80-1.70(2 \mathrm{H}, \mathrm{m}), 1.60(1 \mathrm{H}, \mathrm{m}), 0.99(6 \mathrm{H}, \mathrm{br} \mathrm{d}, J \sim 7$ $\mathrm{Hz})$.

RMN ${ }^{13} \mathbf{C}\left(125 \mathrm{MHz}, \mathrm{CDCl}_{3}\right) \delta 170.1,156.2(\mathrm{CO}) ; 152.8(\mathrm{x} 2), 147.2,143.7$ (x 2), 141.2 (x 2), 137.1, 132.7, 130.1, 126.9 (C); 129.5, 129.2, 127.6 (x 2), 127.0 (x 2), 124.9 (x 2), 124.6, 120.9, 119.8 (x 2), 109.6, 106.0 (x 2), 54.5, 47.1, 22.1 $(\mathrm{CH}) ; 67.1,41.6\left(\mathrm{CH}_{2}\right), 60.8,55.9(x 2), 55.8,24.7,22.8\left(\mathrm{CH}_{3}\right)$.

HR ESMS : $m / z 673.2886(\mathrm{M}+\mathrm{Na})^{+}$. Calculado para $\mathrm{C}_{39} \mathrm{H}_{42} \mathrm{~N}_{2} \mathrm{NaO}_{7} 673.2890$.

( $R, Z)$-(1-((2-metoxi-5-(3,4,5-trimetoxiestiril)fenil)amino)-4-metil-1-oxo-fenilpropan-2-il)carbamato de (9H-fluoren-9-il)metilo 3.49.

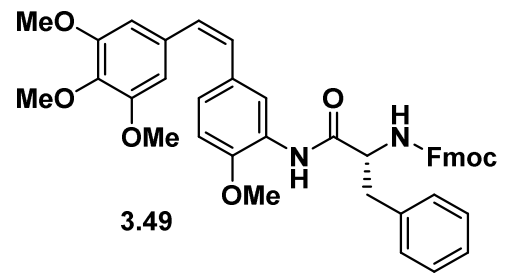

Rto. $=69 \%$. Sólido blanco. p. $f=76-78^{\circ} \mathrm{C}$.

$[\alpha]_{\mathrm{D}}+24.0\left(\mathrm{c} 1.0, \mathrm{CHCl}_{3}\right)$.

IR: $\boldsymbol{v}_{\max } 3400,3300(\mathrm{br}, \mathrm{NH}), 1701,1684(\mathrm{C}=\mathrm{O}) \mathrm{cm}^{-1}$.

$\mathbf{R M N}^{1} \mathbf{H}\left(500 \mathrm{MHz}, \mathrm{CDCl}_{3}\right) \delta 8.32(1 \mathrm{H}$, br d, $J \sim 1.5 \mathrm{~Hz}), 7.95(1 \mathrm{H}$, br s, NH), $7.77(2 \mathrm{H}$, br d, $J \sim 7.3 \mathrm{~Hz}), 7.56(2 \mathrm{H}$, app t, $J \sim 7 \mathrm{~Hz}), 7.40(2 \mathrm{H}, \mathrm{br} \mathrm{t}, J \sim 7.3$ $\mathrm{Hz}), 7.35-7.20(7 \mathrm{H}, \mathrm{br} \mathrm{m}), 7.01(1 \mathrm{H}, \mathrm{dd}, J=8.8,1.5 \mathrm{~Hz}), 6.66(1 \mathrm{H}, \mathrm{d}, J=8.8$ $\mathrm{Hz}), 6.53(2 \mathrm{H}, \mathrm{s}), 6.52(1 \mathrm{H}, \mathrm{d}, J=12.2 \mathrm{~Hz}), 6.47(1 \mathrm{H}, \mathrm{d}, J=12.2 \mathrm{~Hz}), 5.60(1 \mathrm{H}$, br s, NH), $4.60(1 \mathrm{H}$, br s), 4.50-4.35 $(2 \mathrm{H}, \mathrm{m}), 4.22(1 \mathrm{H}, \mathrm{t}, J=7 \mathrm{~Hz}), 3.86(3 \mathrm{H}$, s), $3.70(6 \mathrm{H}, \mathrm{br} \mathrm{s}), 3.68(3 \mathrm{H}, \mathrm{s}), 3.25-3.10(2 \mathrm{H}, \mathrm{br} \mathrm{m})$.

RMN ${ }^{13} \mathbf{C}\left(125 \mathrm{MHz}, \mathrm{CDCl}_{3}\right) \delta 168.6,155.9^{*}(\mathrm{CO}) ; 152.8$ (x 2), 147.5, 143.7, 143.6, 141.2 (x 2), 137.1, 136.2* $132.7,130.1,126.6^{*}(\mathrm{C})$; 129.5, 129.3 (x 3), 129.2, 128.7 (x 2), 127.7 (x 2), 127.0 (x 2), 125.0 (x 2), 124.7, 120.8, 120.0 (x 2), 109.5, 106.1 (x 2), 57.1* $47.1(\mathrm{CH}) ; 67.2,38.7\left(\mathrm{CH}_{2}\right), 60.8,55.9(x)$ 2), 55.8 $\left(\mathrm{CH}_{3}\right)$. 
HR ESMS : $m / z 685.2906(\mathrm{M}+\mathrm{H})^{+}$. Calculado para $\mathrm{C}_{42} \mathrm{H}_{41} \mathrm{~N}_{2} \mathrm{O}_{7}$ 685.2914.

Las señales marcadas con * aparecen bajas y anchas.

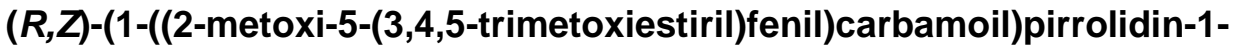
carboxilato de (9H-fluoren-9-il)metilo 3.50 .

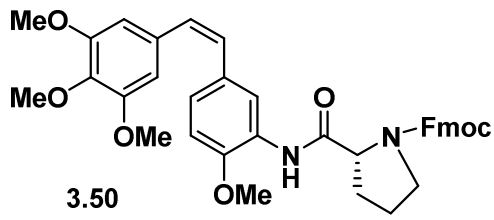

Rto. $=73 \%$. Sólido blanco. p. $\mathrm{f}=69-71^{\circ} \mathrm{C}$.

$[\alpha]_{\mathrm{D}}+73.2\left(c 0.95, \mathrm{CHCl}_{3}\right)$.

IR: $\boldsymbol{v}_{\max } 3400,3300(\mathrm{br}, \mathrm{NH}), 1700(\mathrm{br}, \mathrm{C}=\mathrm{O}) \mathrm{cm}^{-1}$.

RMN ${ }^{1} \mathbf{H}\left(500 \mathrm{MHz}, \mathrm{CDCl}_{3}\right) \delta 8.90(1 \mathrm{H}$, br s, NH), $8.38(1 \mathrm{H}$, br s), 7.80-7.20 $(8 \mathrm{H}, \mathrm{br} \mathrm{m}), 7.10-7.00(1 \mathrm{H}, \mathrm{br} \mathrm{m}), 6.67(1 \mathrm{H}, \mathrm{d}, J=8.3 \mathrm{~Hz}), 6.55(2 \mathrm{H}, \mathrm{s}), 6.55-$ $6.40(2 \mathrm{H}, \mathrm{br} \mathrm{m}), 4.60-4.40(4 \mathrm{H}, \mathrm{br} \mathrm{m}), 3.85(6 \mathrm{H}, \mathrm{s}), 3.73(3 \mathrm{H}, \mathrm{br} \mathrm{s}), 3.68(3 \mathrm{H}$, s), 3.65-3.60 (2H, br m), 2.45-2.00 (4H, br m).

RMN ${ }^{13} \mathbf{C}\left(125 \mathrm{MHz}, \mathrm{CDCl}_{3}\right) \delta 169.4^{*}, 156.0^{*}$ (CO); 152.8 (x 2), 147.2, 143.7 (x 2), 141.2 (x 2), 137.2, 132.8, 130.0, 126.9* (C); 129.6, 129.0, 127.7 (x 2), 127.0 (x 2), 124.9 (x 2), 124.4* 120.9*, 119.9 (x 2), 109.6*, 106.1 (x 2), 61.5*, 47.2 (CH); 67.9*, 31.2*, 28.4*, 24.5* $\left(\mathrm{CH}_{2}\right) ; 60.8,55.8(x 2), 55.7\left(\mathrm{CH}_{3}\right)$.

HR ESMS : $m / z 657.2582(\mathrm{M}+\mathrm{Na})^{+}$. Calculado para $\mathrm{C}_{38} \mathrm{H}_{38} \mathrm{~N}_{2} \mathrm{NaO}_{7} 657.2578$.

Las señales marcadas con * aparecen bajas y anchas.

\subsection{4.e. Procedimiento experimental para la $N$-Fmoc desprotección}

A una disolución del compuesto $(0.15 \mathrm{mmol}, 1$ eq.) en DMF anhidro (5.5 $\mathrm{mL}$ ) se le añadió $\mathrm{KF}$ anhidro ( $1.5 \mathrm{mmol}, 10 \mathrm{eq})$ y 18-corona-6 $(0.015 \mathrm{mmol}, 0.1$ eq.). La mezcla resultante se agitó a temperatura ambiente bajo atmósfera de $\mathrm{N}_{2}$ durante 4 horas. Pasado este tiempo, la mezcla de reacción se vertió sobre una disolución acuosa saturada $\mathrm{NH}_{4} \mathrm{Cl}$ y se extrajo con AcOEt $(3 \times 25 \mathrm{~mL})$. Los extractos orgánicos reunidos se lavaron secuencialmente con agua (x 2) y con salmuera y se secaron sobre $\mathrm{MgSO}_{4}$ anhidro. Luego se eliminó el disolvente a presión reducida y el residuo resultante se cromatografió sobre gel de sílice con AcOEt. 
3.4.4.f. Datos físicos y espectroscópicos de los compuestos de la familia 2

(Z)-2-amino- $N$-(2-metoxi-5-(3,4,5-trimetoxiestiril)fenil)acetamida 3.38.

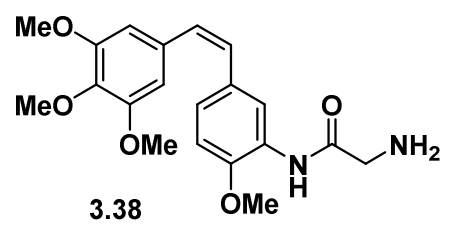

Rto. $=59 \%$. Aceite blanquecino.

IR: $\boldsymbol{v}_{\max } 3400,3300\left(\mathrm{br}, \mathrm{NH}, \mathrm{NH}_{2}\right), 1683(\mathrm{br}, \mathrm{C}=\mathrm{O}) \mathrm{cm}^{-1}$.

$\mathbf{R M N}^{1} \mathbf{H}\left(500 \mathrm{MHz}, \mathrm{CDCl}_{3}\right) 9.60(1 \mathrm{H}$, br s, NH), $8.37(1 \mathrm{H}, \mathrm{br} \mathrm{s}), 7.00(1 \mathrm{H}, \mathrm{dd}, J$ $=8.3,1.5 \mathrm{~Hz}), 6.73(1 \mathrm{H}, \mathrm{d}, J=8.3 \mathrm{~Hz}), 6.54(1 \mathrm{H}, \mathrm{d}, J=12.2 \mathrm{~Hz}), 6.52(2 \mathrm{H}, \mathrm{s})$, $6.44(1 \mathrm{H}, \mathrm{d}, J=12.2 \mathrm{~Hz}), 3.87(3 \mathrm{H}, \mathrm{s}), 3.83(3 \mathrm{H}, \mathrm{s}), 3.68(6 \mathrm{H}, \mathrm{s}), 3.50(2 \mathrm{H}, \mathrm{br}$ s), $2.00\left(2 \mathrm{H}\right.$, br s, $\left.\mathrm{NH}_{2}\right)$.

RMN ${ }^{13} \mathbf{C}\left(125 \mathrm{MHz}, \mathrm{CDCl}_{3}\right) \delta 170.5$ (CO); 152.8 (x 2), 147.5, 137.1, 132.8, $130.1,127.2$ (C); 129.8, 129.0, 124.2, 120.6, 109.6, 106.1 (x 2) (CH); 45.5 $\left(\mathrm{CH}_{2}\right) ; 60.8,55.9(\times 2), 55.8\left(\mathrm{CH}_{3}\right)$.

HR ESMS : $m / z 373.1769(\mathrm{M}+\mathrm{H})^{+}$. Calculado para $\mathrm{C}_{20} \mathrm{H}_{25} \mathrm{~N}_{2} \mathrm{O}_{5}$. 373.1763.

(Z)-2-amino-N-(2-metoxi-5-(3,4,5-trimetoxiestiril)fenil)propanamida 3.39.

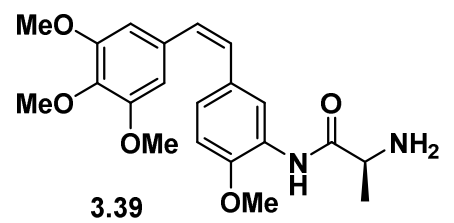

Rto. $=41 \%$. Aceite blanquecino.

$[\alpha]_{D}-7.6\left(c 1.0, \mathrm{CHCl}_{3}\right)$.

IR: $\boldsymbol{v}_{\max } 3300\left(\mathrm{br}, \mathrm{NH}, \mathrm{NH}_{2}\right), 1685(\mathrm{br}, \mathrm{C}=\mathrm{O}) \mathrm{cm}^{-1}$.

$\mathbf{R M N}^{1} \mathbf{H}\left(500 \mathrm{MHz}, \mathrm{CDCl}_{3}\right) \delta 9.75(1 \mathrm{H}, \mathrm{br} \mathrm{s}, \mathrm{NH}), 8.42(1 \mathrm{H}, \mathrm{d}, J=2 \mathrm{~Hz}), 7.00$ $(1 \mathrm{H}, \mathrm{dd}, J=8.8,2 \mathrm{~Hz}), 6.72(1 \mathrm{H}, \mathrm{d}, J=8.8 \mathrm{~Hz}), 6.54(1 \mathrm{H}, \mathrm{d}, J=12.2 \mathrm{~Hz}), 6.53$ $(2 \mathrm{H}, \mathrm{s}), 6.43(1 \mathrm{H}, \mathrm{d}, J=12.2 \mathrm{~Hz}), 3.87(3 \mathrm{H}, \mathrm{s}), 3.84(3 \mathrm{H}, \mathrm{s}), 3.69(6 \mathrm{H}, \mathrm{s}), 3.65$ $(1 \mathrm{H}, \mathrm{q}, J=7 \mathrm{~Hz}), 1.80\left(2 \mathrm{H}\right.$, br s, $\left.\mathrm{NH}_{2}\right), 1.43(3 \mathrm{H}, \mathrm{d}, J=7 \mathrm{~Hz})$. 
RMN ${ }^{13} \mathbf{C}\left(125 \mathrm{MHz}, \mathrm{CDCl}_{3}\right) \delta 173.6$ (CO); 152.8 (x 2), 147.5, 137.1, 132.9, $130.1,127.3(\mathrm{C}) ; 129.9,129.0,124.2,120.5,109.6,106.1$ (x 2), $51.6(\mathrm{CH})$; $60.8,55.9(\times 2), 55.8,21.7\left(\mathrm{CH}_{3}\right)$.

HR ESMS : $m / z 387.1925(\mathrm{M}+\mathrm{H})^{+}$. Calculado para $\mathrm{C}_{21} \mathrm{H}_{27} \mathrm{~N}_{2} \mathrm{O}_{5} .387 .1920$.

(S,Z)-2-amino-N-(2-metoxi-5-(3,4,5-trimetoxiestiril)fenil)-3-metilbutanamida 3.40.

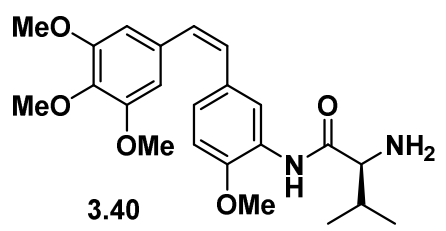

Rto. $=87 \%$. Aceite blanquecino.

[a] $-34.4\left(c 0.7, \mathrm{CHCl}_{3}\right)$.

IR: $\boldsymbol{v}_{\max } 3400,3300\left(\mathrm{br}, \mathrm{NH}, \mathrm{NH}_{2}\right), 1682(\mathrm{C}=\mathrm{O}) \mathrm{cm}^{-1}$.

RMN ${ }^{1} \mathbf{H}\left(500 \mathrm{MHz}, \mathrm{CDCl}_{3}\right) \delta 9.75(1 \mathrm{H}, \mathrm{br} \mathrm{s}, \mathrm{NH}), 8.42(1 \mathrm{H}, \mathrm{d}, J=2 \mathrm{~Hz}), 6.99$ $(1 \mathrm{H}, \mathrm{dd}, J=8.3,2 \mathrm{~Hz}), 6.72(1 \mathrm{H}, \mathrm{d}, J=8.3 \mathrm{~Hz}), 6.53(2 \mathrm{H}, \mathrm{s}), 6.52(1 \mathrm{H}, \mathrm{d}, J=$ $12.2 \mathrm{~Hz}), 6.42(1 \mathrm{H}, \mathrm{d}, J=12.2 \mathrm{~Hz}), 3.86(3 \mathrm{H}, \mathrm{s}), 3.83(3 \mathrm{H}, \mathrm{s}), 3.68(6 \mathrm{H}, \mathrm{s})$, $3.36(1 \mathrm{H}, \mathrm{d}, J=4 \mathrm{~Hz}), 2.39(1 \mathrm{H}, \mathrm{m}), 1.55\left(2 \mathrm{H}\right.$, br s, $\left.\mathrm{NH}_{2}\right), 1.03(3 \mathrm{H}, \mathrm{d}, J=6.8$ $\mathrm{Hz}), 0.87(3 \mathrm{H}, \mathrm{d}, J=6.8 \mathrm{~Hz})$.

RMN ${ }^{13} \mathbf{C}\left(125 \mathrm{MHz}, \mathrm{CDCl}_{3}\right) \delta 172.4$ (CO); 152.8 (x 2), 147.5, 137.1, 132.9, $130.1,127.3$ (C); 129.8, 128.9, 124.1, 120.5, 109.6, 106.1 (x 2), 60.8, 30.9 $(\mathrm{CH}) ; 60.9,55.9$ (x 2), 55.8, 19.7, $16.1\left(\mathrm{CH}_{3}\right)$.

HR ESMS : $m / z 415.2235(\mathrm{M}+\mathrm{Na})^{+}$. Calculado para $\mathrm{C}_{23} \mathrm{H}_{31} \mathrm{~N}_{2} \mathrm{O}_{5} 415.2233$.

(S,Z)-2-amino- $N$-(2-metoxi-5-(3,4,5-trimetoxiestiril)fenil)-4-metilpentanamida 3.41.

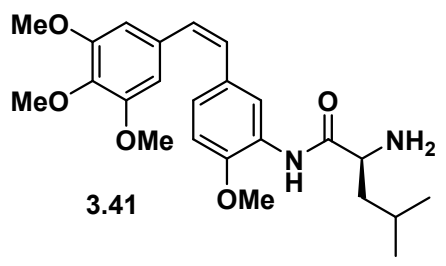

Rto. $=87 \%$. Aceite blanquecino.

$[\alpha]_{\mathrm{D}}-19.7\left(\mathrm{c} 1.0, \mathrm{CHCl}_{3}\right)$.

IR: $\boldsymbol{v}_{\max } 3400,3300\left(\mathrm{br}, \mathrm{NH}, \mathrm{NH}_{2}\right), 1684(\mathrm{C}=\mathrm{O}) \mathrm{cm}^{-1}$. 
$\mathbf{R M N}^{1} \mathbf{H}\left(500 \mathrm{MHz}, \mathrm{CDCl}_{3}\right) \delta 9.80(1 \mathrm{H}, \mathrm{br} \mathrm{s}, \mathrm{NH}), 8.41(1 \mathrm{H}, \mathrm{d}, J=2 \mathrm{~Hz}), 6.99$ $(1 \mathrm{H}, \mathrm{dd}, J=8.3,2 \mathrm{~Hz}), 6.72(1 \mathrm{H}, \mathrm{d}, J=8.3 \mathrm{~Hz}), 6.53(2 \mathrm{H}, \mathrm{s}), 6.52(1 \mathrm{H}, \mathrm{d}, J=$ $12.2 \mathrm{~Hz}), 6.43(1 \mathrm{H}, \mathrm{d}, J=12.2 \mathrm{~Hz}), 3.87(3 \mathrm{H}, \mathrm{s}), 3.83(3 \mathrm{H}, \mathrm{s}), 3.68(6 \mathrm{H}, \mathrm{s})$, $3.51(1 \mathrm{H}, \mathrm{br} d d, J \sim 9.5,3 \mathrm{~Hz}), 1.85-1.75(2 \mathrm{H}, \mathrm{m}), 1.60\left(2 \mathrm{H}, \mathrm{br} \mathrm{s}, \mathrm{NH}_{2}\right), 1.44$ $(1 \mathrm{H}, \mathrm{m}), 0.99(3 \mathrm{H}, \mathrm{d}, J=6.5 \mathrm{~Hz}), 0.97(3 \mathrm{H}, \mathrm{d}, J=6.5 \mathrm{~Hz})$.

RMN ${ }^{13} \mathbf{C}\left(125 \mathrm{MHz}, \mathrm{CDCl}_{3}\right) \delta 173.5$ (CO); 152.8 (x 2), 147.5, 137.1, 132.9, $130.1,127.4$ (C); 129.9, 128.9, 124.0, 120.5, 109.5, 106.1 (x 2), 54.4, 25.0 $(\mathrm{CH}) ; 44.1\left(\mathrm{CH}_{2}\right) ; 60.8,55.9(\times 2), 55.8,23.3,21.4\left(\mathrm{CH}_{3}\right)$.

HR ESMS : $m / z 429.2390(\mathrm{M}+\mathrm{H})^{+}$. Calculado para $\mathrm{C}_{24} \mathrm{H}_{33} \mathrm{~N}_{2} \mathrm{O}_{5} 429.2389$.

(S,Z)-2-amino-N-(2-metoxi-5-(3,4,5-trimetoxiestiril)fenil)-4-fenilpropanamida 3.42 .

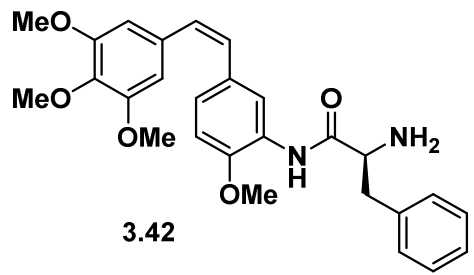

Rto. $=72 \%$. Sólido blanco. p.f $=40-42^{\circ} \mathrm{C}$.

$[\alpha]_{\mathrm{D}}-60.0\left(c \mathrm{0} .9, \mathrm{CHCl}_{3}\right)$.

IR: $\boldsymbol{v}_{\max } 3300\left(\mathrm{br}, \mathrm{NH}, \mathrm{NH}_{2}\right), 1683(\mathrm{C}=\mathrm{O}) \mathrm{cm}^{-1}$.

$\mathbf{R M N}^{1} \mathbf{H}\left(500 \mathrm{MHz}, \mathrm{CDCl}_{3}\right) \delta 9.80(1 \mathrm{H}$, br s, NH), $8.45(1 \mathrm{H}, \mathrm{d}, J=2 \mathrm{~Hz}), 7.35-$ $7.25(5 \mathrm{H}, \mathrm{br} \mathrm{m}), 7.01(1 \mathrm{H}, \mathrm{dd}, J=8.3,1.5 \mathrm{~Hz}), 6.72(1 \mathrm{H}, \mathrm{d}, J=8.3 \mathrm{~Hz}), 6.55$ $(1 \mathrm{H}, \mathrm{d}, J=12.2 \mathrm{~Hz}), 6.54(2 \mathrm{H}, \mathrm{s}), 6.45(1 \mathrm{H}, \mathrm{d}, J=12.2 \mathrm{~Hz}), 3.85(6 \mathrm{H}, \mathrm{s}), 3.72$ $(1 \mathrm{H}, \mathrm{m}), 3.70(6 \mathrm{H}, \mathrm{s}), 3.38(1 \mathrm{H}, \mathrm{dd}, J=13.5,3.5 \mathrm{~Hz}), 2.78(1 \mathrm{H}, \mathrm{dd}, J=13.5$, $9.8 \mathrm{~Hz}), 1.55\left(2 \mathrm{H}, \mathrm{br} \mathrm{s}, \mathrm{NH}_{2}\right)$.

RMN ${ }^{13} \mathbf{C}\left(125 \mathrm{MHz}, \mathrm{CDCl}_{3}\right) \delta 172.2$ (CO); 152.8 (x 2), 147.6, 137.9, 137.1, 132.9, 130.1, 126.8 (C); 129.8, 129.2 (x 3), 129.0, 128.7 (x 2), 124.2, 120.5, 109.5, 106.1 (x 2), $57.3(\mathrm{CH}) ; 40.8\left(\mathrm{CH}_{2}\right) ; 60.8,55.9(x 2), 55.8\left(\mathrm{CH}_{3}\right)$.

HR ESMS : $m / z 463.2229(\mathrm{M}+\mathrm{Na})^{+}$. Calculado para $\mathrm{C}_{27} \mathrm{H}_{31} \mathrm{~N}_{2} \mathrm{O}_{5} .463 .2233$. 
(S,Z)-2-amino- $\mathrm{N}$-(2-metoxi-5-(3,4,5-trimetoxiestiril)fenil)pirrolidin-2carboxamida 3.43 .

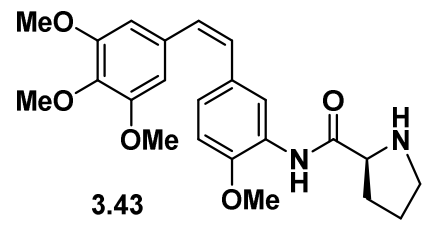

Rto. $=54 \%$. Aceite blanquecino.

$[\alpha]_{D}-34.1\left(c 1.0, \mathrm{CHCl}_{3}\right)$.

IR: $\boldsymbol{v}_{\max } 3300(\mathrm{br}, \mathrm{NH}), 1684(\mathrm{C}=\mathrm{O}) \mathrm{cm}^{-1}$.

RMN ${ }^{1} \mathbf{H}\left(500 \mathrm{MHz}, \mathrm{CDCl}_{3}\right) \delta 10.0(1 \mathrm{H}, \mathrm{br} \mathrm{s}, \mathrm{NH}), 8.39(1 \mathrm{H}, \mathrm{d}, J=2 \mathrm{~Hz}), 7.00$ $(1 \mathrm{H}, \mathrm{dd}, J=8.3,2 \mathrm{~Hz}), 6.71(1 \mathrm{H}, \mathrm{d}, J=8.3 \mathrm{~Hz}), 6.53(2 \mathrm{H}, \mathrm{s}), 6.52(1 \mathrm{H}, \mathrm{d}, J=$ $12.2 \mathrm{~Hz}), 6.43(1 \mathrm{H}, \mathrm{d}, J=12.2 \mathrm{~Hz}), 3.88(1 \mathrm{H}, \mathrm{m}), 3.86(3 \mathrm{H}, \mathrm{s}), 3.84(3 \mathrm{H}, \mathrm{s})$, $3.69(6 \mathrm{H}, \mathrm{s}), 3.10(1 \mathrm{H}, \mathrm{m}), 3.02(1 \mathrm{H}, \mathrm{m}), 2.20(2 \mathrm{H}, \mathrm{m}), 2.05(1 \mathrm{H}, \mathrm{m}), 1.80-1.75$ $(2 \mathrm{H}, \mathrm{m})$.

RMN ${ }^{13} \mathrm{C}\left(125 \mathrm{MHz}, \mathrm{CDCl}_{3}\right) \delta 173.1$ (CO); 152.8 (x 2), 147.6, 137.1, 132.8, $130.1,127.3(\mathrm{C})$; 129.8, 128.9, 124.1, 120.5, 109.6, 106.1 (x 2), $61.4(\mathrm{CH})$; 47.3, 30.8, $26.2\left(\mathrm{CH}_{2}\right)$; 60.8, $55.9(\times 2)$, $55.8\left(\mathrm{CH}_{3}\right)$.

HR ESMS : $m / z 413.2070(\mathrm{M}+\mathrm{H})^{+}$. Calculado para $\mathrm{C}_{23} \mathrm{H}_{29} \mathrm{~N}_{2} \mathrm{O}_{5}$. 413.2076.

(2S,3R)-2-amino-3-hidroxi- $N$-(2-metoxi-5-((Z)-(3,4,5-trimetoxiestiril)fenil)butanamida 3.44 .

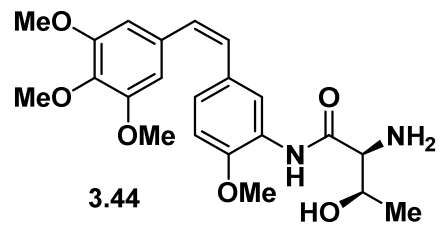

Rto. $=51 \%$. Aceite blanquecino.

$[\alpha]_{\mathrm{D}}-8.2\left(\mathrm{c} 0.7, \mathrm{CHCl}_{3}\right)$.

IR: $\boldsymbol{v}_{\max } 3450,3300\left(\mathrm{br}, \mathrm{OH}, \mathrm{NH}, \mathrm{NH}_{2}\right), 1683(\mathrm{C}=\mathrm{O}) \mathrm{cm}^{-1}$.

RMN ${ }^{1} \mathbf{H}\left(500 \mathrm{MHz}, \mathrm{CDCl}_{3}\right) \delta 9.85(1 \mathrm{H}, \mathrm{br} \mathrm{s}, \mathrm{NH}), 8.37(1 \mathrm{H}, \mathrm{d}, J=2 \mathrm{~Hz}), 7.01$ $(1 \mathrm{H}, \mathrm{dd}, J=8.3,2 \mathrm{~Hz}), 6.72(1 \mathrm{H}, \mathrm{d}, J=8.3 \mathrm{~Hz}), 6.52(2 \mathrm{H}, \mathrm{s}), 6.51(1 \mathrm{H}, \mathrm{d}, J=$ $12.2 \mathrm{~Hz}), 6.43(1 \mathrm{H}, \mathrm{d}, J=12.2 \mathrm{~Hz}), 4.40(1 \mathrm{H}, \mathrm{qd}, J=6.5,2.5 \mathrm{~Hz}), 3.86(3 \mathrm{H}, \mathrm{s})$, $3.84(3 \mathrm{H}, \mathrm{s}), 3.69(6 \mathrm{H}, \mathrm{s}), 3.35(1 \mathrm{H}, \mathrm{br} \mathrm{d}, J \sim 2.5 \mathrm{~Hz}), 2.10\left(3 \mathrm{H}, \mathrm{br} \mathrm{s}, \mathrm{OH}, \mathrm{NH}_{2}\right)$, $1.25(3 \mathrm{H}, \mathrm{d}, J=6.5 \mathrm{~Hz})$. 
RMN ${ }^{13} \mathbf{C}\left(125 \mathrm{MHz}, \mathrm{CDCl}_{3}\right) \delta 171.7$ (CO); 152.8 (x 2), 147.6, 137.1, 132.8, $130.1,127.0$ (C); 129.7, 129.0, 124.5, 120.6, 109.6, 106.1 (x 2), 67.8, 60.4 $(\mathrm{CH}) ; 60.9,55.9(\times 2), 55.8,19.0\left(\mathrm{CH}_{3}\right)$.

HR ESMS : $m / z 417.2024(\mathrm{M}+\mathrm{H})^{+}$. Calculado para $\mathrm{C}_{22} \mathrm{H}_{29} \mathrm{~N}_{2} \mathrm{O}_{6}$ 4 417.2026.

(S,Z)-2-amino-3-(4-hidroxifenil)- $N$-(2-metoxi-5-(3,4,5-trimetoxiestiril)fenil)propanamida 3.45 .

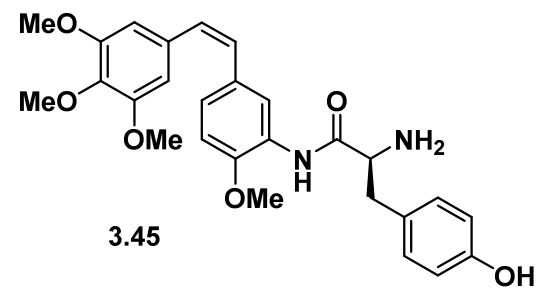

Rto. $=75 \%$. Sólido blanco. p. $f=63-65^{\circ} \mathrm{C}$.

$\left.[\alpha]_{D}-61.1(c) 0.9, \mathrm{CHCl}_{3}\right)$.

IR: $\boldsymbol{v}_{\max } 3400,3300\left(\mathrm{br}, \mathrm{OH}, \mathrm{NH}, \mathrm{NH}_{2}\right), 1682(\mathrm{C}=\mathrm{O}) \mathrm{cm}^{-1}$.

RMN ${ }^{1} \mathbf{H}\left(500 \mathrm{MHz}, \mathrm{CDCl}_{3}\right) \delta 9.70(1 \mathrm{H}, \mathrm{br} \mathrm{s}, \mathrm{NH}), 8.37(1 \mathrm{H}, \mathrm{d}, J=2 \mathrm{~Hz}), 7.07$ $(2 \mathrm{H}, \mathrm{d}, J=8.2 \mathrm{~Hz}), 7.01(1 \mathrm{H}, \mathrm{dd}, J=8.3,2 \mathrm{~Hz}), 6.75(2 \mathrm{H}, \mathrm{d}, J=8.2 \mathrm{~Hz}), 6.72$ $(1 \mathrm{H}, \mathrm{d}, J=8.3 \mathrm{~Hz}), 6.56(1 \mathrm{H}, \mathrm{d}, J=12.2 \mathrm{~Hz}), 6.52(2 \mathrm{H}, \mathrm{s}), 6.45(1 \mathrm{H}, \mathrm{d}, J=$ $12.2 \mathrm{~Hz}), 3.85(3 \mathrm{H}, \mathrm{s}), 3.84(3 \mathrm{H}, \mathrm{s}), 3.68(1 \mathrm{H}, \mathrm{m}), 3.66(6 \mathrm{H}, \mathrm{s}), 3.17(1 \mathrm{H}, \mathrm{dd}, J$ $=13.5,3.5 \mathrm{~Hz}$ ), $2.82\left(1 \mathrm{H}, \mathrm{dd}, J=13.5,8.8 \mathrm{~Hz}\right.$ ) (las señales de $\mathrm{OH} / \mathrm{NH}_{2}$ no se aprecian).

RMN ${ }^{13} \mathbf{C}\left(125 \mathrm{MHz}, \mathrm{CDCl}_{3}\right) \delta 172.7$ (CO); 155.3, 152.8 (x 2), 147.7, 136.9, 132.9, 130.1, 128.6, 126.9 (C); 130.3 (x 2), 129.8, 129.1, 124.4, 120.7, 115.7 (x 2), 109.7, 106.1 (x 2), $57.3(\mathrm{CH}) ; 40.0\left(\mathrm{CH}_{2}\right) ; 60.9,55.9(x)$ 2), $55.8\left(\mathrm{CH}_{3}\right)$.

HR ESMS : $m / z 479.2187(\mathrm{M}+\mathrm{Na})^{+}$. Calculado para $\mathrm{C}_{27} \mathrm{H}_{31} \mathrm{~N}_{2} \mathrm{O}_{6}$. 479.2182.

(S,Z)-2-amino- $N$-(2-metoxi-5-(3,4,5-trimetoxiestiril)fenil)-4-(metiltio)butanamida 3.46 .

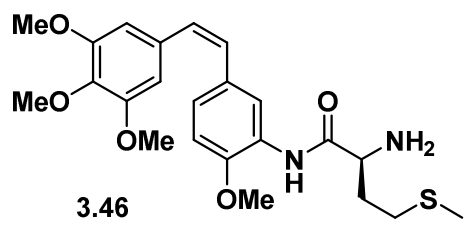

Rto. $=79 \%$. Aceite blanquecino.

$[\alpha]_{D}-15.5\left(c 0.7, \mathrm{CHCl}_{3}\right)$. 
IR: $\boldsymbol{v}_{\max } 3300\left(\mathrm{br}, \mathrm{NH}, \mathrm{NH}_{2}\right), 1683(\mathrm{C}=\mathrm{O}) \mathrm{cm}^{-1}$.

RMN ${ }^{1} \mathbf{H}\left(500 \mathrm{MHz}, \mathrm{CDCl}_{3}\right) \delta 9.75(1 \mathrm{H}, \mathrm{br} \mathrm{s}, \mathrm{NH}), 8.38(1 \mathrm{H}, \mathrm{d}, J=2 \mathrm{~Hz}), 7.00$ $(1 \mathrm{H}, \mathrm{dd}, J=8.3,2 \mathrm{~Hz}), 6.71(1 \mathrm{H}, \mathrm{d}, J=8.3 \mathrm{~Hz}), 6.52(1 \mathrm{H}, \mathrm{d}, J=12.2 \mathrm{~Hz}), 6.51$ $(2 \mathrm{H}, \mathrm{s}), 6.42(1 \mathrm{H}, \mathrm{d}, J=12.2 \mathrm{~Hz}), 3.85(3 \mathrm{H}, \mathrm{s}), 3.83(3 \mathrm{H}, \mathrm{s}), 3.66(6 \mathrm{H}, \mathrm{s}), 3.64$ $(1 \mathrm{H}, \mathrm{dd}, J=8.3,4.5 \mathrm{~Hz}), 2.65(2 \mathrm{H}, \mathrm{m}), 2.26(1 \mathrm{H}, \mathrm{m}), 2.11(3 \mathrm{H}, \mathrm{s}), 1.84(1 \mathrm{H}$, $\mathrm{m}), 1.65\left(2 \mathrm{H}, \mathrm{br} \mathrm{s}, \mathrm{NH}_{2}\right)$.

RMN ${ }^{13} \mathbf{C}\left(125 \mathrm{MHz}, \mathrm{CDCl}_{3}\right) \delta 172.5$ (CO); 152.8 (x 2), 147.5, 137.0, 132.8, $130.1,127.2(\mathrm{C}) ; 129.7,129.0,124.2,120.5,109.5,106.1$ (x 2), $55.0(\mathrm{CH})$; 34.0, $30.6\left(\mathrm{CH}_{2}\right)$; 60.8, 55.9 (x 2), 55.8, $15.2\left(\mathrm{CH}_{3}\right)$.

HR ESMS : $m / z 447.1954(\mathrm{M}+\mathrm{H})^{+}$. Calculado para $\mathrm{C}_{23} \mathrm{H}_{31} \mathrm{~N}_{2} \mathrm{O}_{5} \mathrm{~S}$. 447.1954.

(R,Z)-2-amino-N-(2-metoxi-5-(3,4,5-trimetoxiestiril)fenil)-3-metilbutanamida 3.51 .

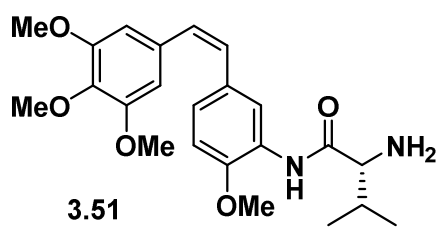

Rto. $=71 \%$. Aceite blanquecino.

[a] $30.8\left(c 0.9, \mathrm{CHCl}_{3}\right)$.

IR: $\boldsymbol{v}_{\max } 3400,3300\left(\mathrm{br}, \mathrm{NH}, \mathrm{NH}_{2}\right), 1682(\mathrm{C}=\mathrm{O}) \mathrm{cm}^{-1}$.

RMN ${ }^{1} \mathbf{H}\left(500 \mathrm{MHz}, \mathrm{CDCl}_{3}\right) \delta 9.75(1 \mathrm{H}, \mathrm{br} \mathrm{s}, \mathrm{NH}), 8.42(1 \mathrm{H}, \mathrm{d}, J=2 \mathrm{~Hz}), 6.99$ $(1 \mathrm{H}, \mathrm{dd}, J=8.3,2 \mathrm{~Hz}), 6.72(1 \mathrm{H}, \mathrm{d}, J=8.3 \mathrm{~Hz}), 6.53(2 \mathrm{H}, \mathrm{s}), 6.52(1 \mathrm{H}, \mathrm{d}, J=$ $12.2 \mathrm{~Hz}), 6.42(1 \mathrm{H}, \mathrm{d}, J=12.2 \mathrm{~Hz}), 3.86(3 \mathrm{H}, \mathrm{s}), 3.83(3 \mathrm{H}, \mathrm{s}), 3.68(6 \mathrm{H}, \mathrm{s})$, $3.36(1 \mathrm{H}, \mathrm{d}, J=4 \mathrm{~Hz}), 2.39(1 \mathrm{H}, \mathrm{m}), 1.55\left(2 \mathrm{H}, \mathrm{br} \mathrm{s}, \mathrm{NH}_{2}\right), 1.03(3 \mathrm{H}, \mathrm{d}, J=6.8$ $\mathrm{Hz}), 0.87(3 \mathrm{H}, \mathrm{d}, J=6.8 \mathrm{~Hz})$.

RMN ${ }^{13} \mathbf{C}\left(125 \mathrm{MHz}, \mathrm{CDCl}_{3}\right) \delta 172.4(\mathrm{CO}) ; 152.8$ (x 2), 147.5, 137.1, 132.9, $130.1,127.3$ (C); 129.8, 128.9, 124.1, 120.5, 109.6, 106.1 (x 2), 60.8, 30.9 $(\mathrm{CH}) ; 60.9,55.9$ (x 2), 55.8, 19.7, $16.1\left(\mathrm{CH}_{3}\right)$.

HR ESMS : $m / z 415.2235(\mathrm{M}+\mathrm{Na})^{+}$. Calculado para $\mathrm{C}_{23} \mathrm{H}_{31} \mathrm{~N}_{2} \mathrm{O}_{5}$ 415.2233. 
( $R, Z)$-2-amino- $N$-(2-metoxi-5-(3,4,5-trimetoxiestiril)fenil)-3-metilpentanamida 3.52 .

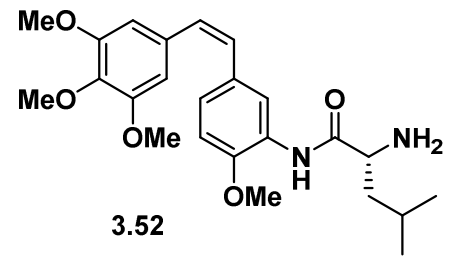

Rto. $=67 \%$. Aceite blanquecino.

$[\alpha]_{\mathrm{D}} 19.8\left(c \mathrm{c} 0.9, \mathrm{CHCl}_{3}\right)$.

IR: $\boldsymbol{v}_{\max } 3400,3300\left(\mathrm{br}, \mathrm{NH}, \mathrm{NH}_{2}\right), 1684(\mathrm{C}=\mathrm{O}) \mathrm{cm}^{-1}$.

$\mathbf{R M N}^{1} \mathbf{H}\left(500 \mathrm{MHz}, \mathrm{CDCl}_{3}\right) \delta 9.80(1 \mathrm{H}$, br s, NH), $8.41(1 \mathrm{H}, \mathrm{d}, J=2 \mathrm{~Hz}), 6.99$ $(1 \mathrm{H}, \mathrm{dd}, J=8.3,2 \mathrm{~Hz}), 6.72(1 \mathrm{H}, \mathrm{d}, J=8.3 \mathrm{~Hz}), 6.53(2 \mathrm{H}, \mathrm{s}), 6.52(1 \mathrm{H}, \mathrm{d}, J=$ $12.2 \mathrm{~Hz}), 6.43(1 \mathrm{H}, \mathrm{d}, J=12.2 \mathrm{~Hz}), 3.87(3 \mathrm{H}, \mathrm{s}), 3.83(3 \mathrm{H}, \mathrm{s}), 3.68(6 \mathrm{H}, \mathrm{s})$, $3.51(1 \mathrm{H}, \mathrm{br} d d, J \sim 9.5,3 \mathrm{~Hz}), 1.85-1.75(2 \mathrm{H}, \mathrm{m}), 1.60\left(2 \mathrm{H}, \mathrm{br} \mathrm{s}, \mathrm{NH}_{2}\right), 1.44$ $(1 \mathrm{H}, \mathrm{m}), 0.99(3 \mathrm{H}, \mathrm{d}, J=6.5 \mathrm{~Hz}), 0.97(3 \mathrm{H}, \mathrm{d}, J=6.5 \mathrm{~Hz})$.

RMN ${ }^{13} \mathbf{C}\left(125 \mathrm{MHz}, \mathrm{CDCl}_{3}\right) \delta 173.5$ (CO); 152.8 (x 2), 147.5, 137.1, 132.9, 130.1, $127.4(\mathrm{C}) ; 129.9,128.9,124.0,120.5,109.5,106.1$ (x 2), 54.4, 25.0 $(\mathrm{CH}) ; 44.1\left(\mathrm{CH}_{2}\right) ; 60.8,55.9(\times 2), 55.8,23.3,21.4\left(\mathrm{CH}_{3}\right)$.

HR ESMS : $m / z 429.2390(\mathrm{M}+\mathrm{H})^{+}$. Calculado para $\mathrm{C}_{24} \mathrm{H}_{33} \mathrm{~N}_{2} \mathrm{O}_{5 .} 429.2389$.

( $R, Z)$-2-amino- $N$-(2-metoxi-5-(3,4,5-trimetoxiestiril)fenil)-3-fenilpropanamida 3.53 .

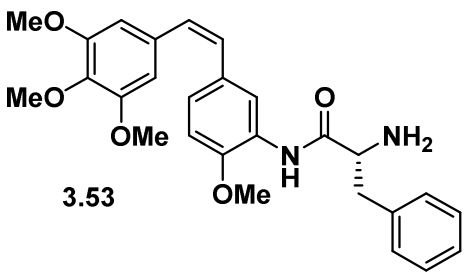

Rto. $=84 \%$. Sólido blanco. p. $f=40-42^{\circ} \mathrm{C}$.

$[\alpha]_{\mathrm{D}} 72.1\left(c 1.0, \mathrm{CHCl}_{3}\right)$.

IR: $\boldsymbol{v}_{\max } 3300\left(\mathrm{br}, \mathrm{NH}, \mathrm{NH}_{2}\right), 1683(\mathrm{C}=\mathrm{O}) \mathrm{cm}^{-1}$.

RMN ${ }^{1} \mathbf{H}\left(500 \mathrm{MHz}, \mathrm{CDCl}_{3}\right) \delta 9.80(1 \mathrm{H}, \mathrm{br} \mathrm{s}, \mathrm{NH}), 8.45(1 \mathrm{H}, \mathrm{d}, J=2 \mathrm{~Hz}), 7.35-$ $7.25(5 \mathrm{H}, \mathrm{br} \mathrm{m}), 7.01(1 \mathrm{H}, \mathrm{dd}, J=8.3,1.5 \mathrm{~Hz}), 6.72(1 \mathrm{H}, \mathrm{d}, J=8.3 \mathrm{~Hz}), 6.55$ $(1 \mathrm{H}, \mathrm{d}, J=12.2 \mathrm{~Hz}), 6.54(2 \mathrm{H}, \mathrm{s}), 6.45(1 \mathrm{H}, \mathrm{d}, J=12.2 \mathrm{~Hz}), 3.85(6 \mathrm{H}, \mathrm{s}), 3.72$ 
$(1 \mathrm{H}, \mathrm{m}), 3.70(6 \mathrm{H}, \mathrm{s}), 3.38(1 \mathrm{H}, \mathrm{dd}, J=13.5,3.5 \mathrm{~Hz}), 2.78(1 \mathrm{H}, \mathrm{dd}, J=13.5$, $9.8 \mathrm{~Hz}), 1.55\left(2 \mathrm{H}\right.$, br s, $\left.\mathrm{NH}_{2}\right)$.

RMN ${ }^{13} \mathbf{C}\left(125 \mathrm{MHz}, \mathrm{CDCl}_{3}\right) \delta 172.2$ (CO); 152.8 (x 2), 147.6, 137.9, 137.1, 132.9, 130.1, 126.8 (C); 129.8, 129.2 (x 3), 129.0, 128.7 (x 2), 124.2, 120.5, 109.5, 106.1 (x 2), $57.3(\mathrm{CH}) ; 40.8\left(\mathrm{CH}_{2}\right) ; 60.8,55.9(\mathrm{x} 2), 55.8\left(\mathrm{CH}_{3}\right)$.

HR ESMS : $m / z 463.2229(\mathrm{M}+\mathrm{Na})^{+}$. Calculado para $\mathrm{C}_{27} \mathrm{H}_{31} \mathrm{~N}_{2} \mathrm{O}_{5} 463.2233$.

( $R, Z)$-2-amino-N-(2-metoxi-5-(3,4,5-trimetoxiestiril)fenil)pirrolidin-2carboxamida 3.54 .

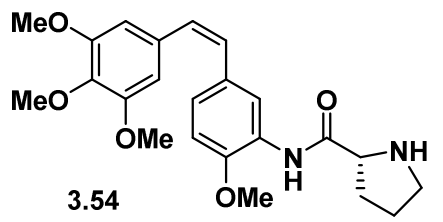

Rto. $=68 \%$. Aceite blanquecino.

$[\alpha]_{\mathrm{D}} 32\left(c 1.0, \mathrm{CHCl}_{3}\right)$.

IR: $\boldsymbol{v}_{\max } 3300(\mathrm{br}, \mathrm{NH}), 1684(\mathrm{C}=\mathrm{O}) \mathrm{cm}^{-1}$.

RMN ${ }^{1} \mathbf{H}\left(500 \mathrm{MHz}, \mathrm{CDCl}_{3}\right) \delta 10.0(1 \mathrm{H}, \mathrm{br} \mathrm{s}, \mathrm{NH}), 8.39(1 \mathrm{H}, \mathrm{d}, J=2 \mathrm{~Hz}), 7.00$ $(1 \mathrm{H}, \mathrm{dd}, J=8.3,2 \mathrm{~Hz}), 6.71(1 \mathrm{H}, \mathrm{d}, J=8.3 \mathrm{~Hz}), 6.53(2 \mathrm{H}, \mathrm{s}), 6.52(1 \mathrm{H}, \mathrm{d}, J=$ $12.2 \mathrm{~Hz}), 6.43(1 \mathrm{H}, \mathrm{d}, J=12.2 \mathrm{~Hz}), 3.88(1 \mathrm{H}, \mathrm{m}), 3.86(3 \mathrm{H}, \mathrm{s}), 3.84(3 \mathrm{H}, \mathrm{s})$, $3.69(6 \mathrm{H}, \mathrm{s}), 3.10(1 \mathrm{H}, \mathrm{m}), 3.02(1 \mathrm{H}, \mathrm{m}), 2.20(2 \mathrm{H}, \mathrm{m}), 2.05(1 \mathrm{H}, \mathrm{m}), 1.80-1.75$ $(2 \mathrm{H}, \mathrm{m})$.

RMN ${ }^{13} \mathrm{C}\left(125 \mathrm{MHz}, \mathrm{CDCl}_{3}\right) \delta 173.1$ (CO); 152.8 (x 2), 147.6, 137.1, 132.8, $130.1,127.3(\mathrm{C})$; 129.8, 128.9, 124.1, 120.5, 109.6, 106.1 (x 2), $61.4(\mathrm{CH})$; 47.3, 30.8, 26.2 $\left(\mathrm{CH}_{2}\right) ; 60.8,55.9(\times 2), 55.8\left(\mathrm{CH}_{3}\right)$.

HR ESMS : $m / z 413.2070(\mathrm{M}+\mathrm{H})^{+}$. Calculado para $\mathrm{C}_{23} \mathrm{H}_{29} \mathrm{~N}_{2} \mathrm{O}_{5} .413 .2076$.

\subsubsection{Síntesis de compuestos de la familia 3}

\subsection{5.a. Procedimiento general para la $N$-acilación de la aminocombretastatina.}

A una disolución de aminocombretastatina $(0.5 \mathrm{mmol}, 1$ eq.) en DMF anhidro $(10 \mathrm{~mL})$ se le añadió $\operatorname{DMAP}(1.14 \mathrm{mmol}, 2.28$ eq.) y el ácido carboxílico ( $1 \mathrm{mmol}, 2$ eq.). La mezcla de reacción se protegió de la luz, se enfrió a $0^{\circ} \mathrm{C}$ y luego, bajo atmósfera de $\mathrm{N}_{2}$, se le añadió $\mathrm{EDCl} \cdot \mathrm{HCl}(0.55 \mathrm{mmol}$, 1.1 eq.) y se agitó durante 2 horas más a $0^{\circ} \mathrm{C}$. Seguidamente, la mezcla se llevó a temperatura ambiente y se dejó reaccionando durante 2 horas más. $A$ 
continuación, se vertió la mezcla sobre una disolución acuosa saturada de $\mathrm{NH}_{4} \mathrm{Cl}$ y posteriormente se extrajo con AcOEt $(3 \times 20 \mathrm{~mL})$. Los extractos orgánicos reunidos se lavaron con $\mathrm{H}_{2} \mathrm{O}$ y salmuera y se secaron sobre $\mathrm{MgSO}_{4}$ anhidro. Después de filtrar y eliminar el disolvente a presión reducida, el residuo resultante se cromatografió sobre gel de sílice con hexano-AcOEt $(6: 4)$.

3.4.5.b. Datos físicos y espectroscópicos de los compuestos de la familia 3

(Z)-N-(2-metoxi-5-(3,4,5-trimetoxiestiril)fenil)butiramida 3.55 .

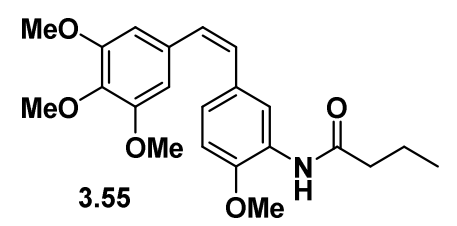

Rto. $=61 \%$. Aceite incoloro.

IR $\boldsymbol{v}_{\max } 3420,3340(\mathrm{br}, \mathrm{NH}), 1684(\mathrm{C}=\mathrm{O}) \mathrm{cm}^{-1}$.

$\mathbf{R M N}^{1} \mathbf{H}\left(500 \mathrm{MHz}, \mathrm{CDCl}_{3}\right) 8.36(1 \mathrm{H}, \mathrm{s}), 7.70(1 \mathrm{H}, \mathrm{br} \mathrm{s}, \mathrm{NH}) .6 .97(1 \mathrm{H}, \mathrm{dd}, J=$ 8.3, $2 \mathrm{~Hz}), 6.70(1 \mathrm{H}, \mathrm{d}, J=8.3 \mathrm{~Hz}), 6.50(2 \mathrm{H}, \mathrm{s}), 6.49(1 \mathrm{H}, \mathrm{d}, J=12.2 \mathrm{~Hz}), 6.42$ $(1 \mathrm{H}, \mathrm{d}, J=12.2 \mathrm{~Hz}), 3.83(3 \mathrm{H}, \mathrm{s}), 3.82(3 \mathrm{H}, \mathrm{s}), 3.67(6 \mathrm{H}, \mathrm{s}), 2.34(2 \mathrm{H}, t, J=7.5$ $\mathrm{Hz}), 1.74(2 \mathrm{H}$, app sext, $J=7.5 \mathrm{~Hz}), 0.99(3 \mathrm{H}, t, J=7.5 \mathrm{~Hz})$

RMN ${ }^{13} \mathbf{C}\left(125 \mathrm{MHz}, \mathrm{CDCl}_{3}\right) \delta 170.9$ (CO); 152.7 (x2), 146.7, 137.0, 132.7, $130.1,127.5(\mathrm{C}) ; 129.7,129.0,123.9,120.7,109.4,106.1(\mathrm{x} 2)(\mathrm{CH}) ; 39.8,18.9$ $\left(\mathrm{CH}_{2}\right) ; 60.7,55.8(\mathrm{x} 2), 55.7,13.6\left(\mathrm{CH}_{3}\right)$.

HR ESMS : $m / z 408.1786(\mathrm{M}+\mathrm{Na})^{+}$. Calculado para $\mathrm{C}_{22} \mathrm{H}_{27} \mathrm{NNaO}_{5}, 408.1787$.

(Z)-N-(2-metoxi-5-(3,4,5-trimetoxiestiril)fenil)pentanamida 3.56 .

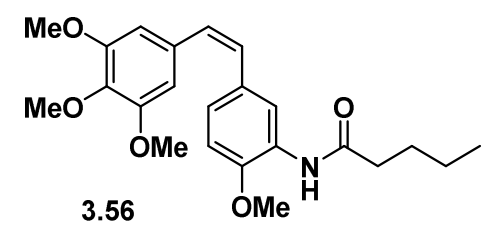

Rto. $=61 \%$. Aceite incoloro.

IR: $\boldsymbol{v}_{\max } 3420,3340(\mathrm{br}, \mathrm{NH}), 1684(\mathrm{C}=\mathrm{O}) \mathrm{cm}^{-1}$.

$\mathbf{R M N}^{1} \mathbf{H}\left(500 \mathrm{MHz}, \mathrm{CDCl}_{3}\right) \delta 8.36(1 \mathrm{H}, \mathrm{s}), 7.70(1 \mathrm{H}$, br s, NH). $6.98(1 \mathrm{H}, \mathrm{dd}, J$ $=8.3,2 \mathrm{~Hz}), 6.70(1 \mathrm{H}, \mathrm{d}, J=8.3 \mathrm{~Hz}), 6.51(2 \mathrm{H}, \mathrm{s}), 6.50(1 \mathrm{H}, \mathrm{d}, J=12.2 \mathrm{~Hz})$, 
$6.42(1 \mathrm{H}, \mathrm{d}, J=12.2 \mathrm{~Hz}), 3.85(3 \mathrm{H}, \mathrm{s}), 3.83(3 \mathrm{H}, \mathrm{s}), 3.68(6 \mathrm{H}, \mathrm{s}), 2.37(2 \mathrm{H}, t, J$ $=7.5 \mathrm{~Hz}), 1.70(2 \mathrm{H}$, app quint, $J=7.5 \mathrm{~Hz}), 1.41(2 \mathrm{H}$, app sext, $J=7.5 \mathrm{~Hz})$, $0.95(3 \mathrm{H}, t, J=7.5 \mathrm{~Hz})$

RMN ${ }^{13} \mathbf{C}\left(125 \mathrm{MHz}, \mathrm{CDCl}_{3}\right) \delta 171.1$ (CO); 152.8 (x2), 146.7, 137.1, 132.8, $130.1,127.5(\mathrm{C}) ; 129.7,129.0,123.9,120.7,109.4,106.1(\mathrm{x} 2)(\mathrm{CH}) ; 37.7$, 27.6, $22.3\left(\mathrm{CH}_{2}\right)$; 60.8, $55.8(\mathrm{x} 2)$, 55.7, $13.7\left(\mathrm{CH}_{3}\right)$.

HR ESMS : $m / z 422.1943(\mathrm{M}+\mathrm{Na})^{+}$. Calculado para $\mathrm{C}_{23} \mathrm{H}_{29} \mathrm{NNaO}_{5}, 422.1943$.

(Z)-N-(2-metoxi-5-(3,4,5-trimetoxiestiril)fenil)hexanamida 3.57.

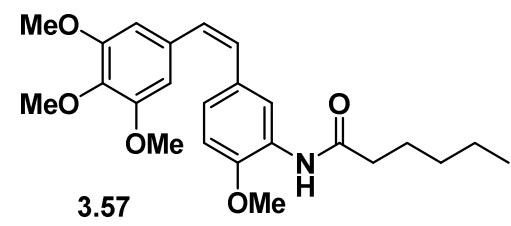

Rto. $=51 \%$. Aceite incoloro.

IR: $\boldsymbol{v}_{\max } 3420,3350(\mathrm{br}, \mathrm{NH}), 1684(\mathrm{C}=\mathrm{O}) \mathrm{cm}^{-1}$.

RMN ${ }^{1} \mathbf{H}\left(500 \mathrm{MHz}, \mathrm{CDCl}_{3}\right) \delta 8.37(1 \mathrm{H}, \mathrm{s}), 7.70(1 \mathrm{H}, \mathrm{br} \mathrm{s}, \mathrm{NH}) .6 .98(1 \mathrm{H}, \mathrm{dd}, J$ $=8.3,2 \mathrm{~Hz}), 6.70(1 \mathrm{H}, \mathrm{d}, J=8.3 \mathrm{~Hz}), 6.51(2 \mathrm{H}, \mathrm{s}), 6.50(1 \mathrm{H}, \mathrm{d}, J=12.2 \mathrm{~Hz})$, $6.43(1 \mathrm{H}, \mathrm{d}, J=12.2 \mathrm{~Hz}), 3.85(3 \mathrm{H}, \mathrm{s}), 3.84(3 \mathrm{H}, \mathrm{s}), 3.69(6 \mathrm{H}, \mathrm{s}), 2.37(2 \mathrm{H}, t, J$ $=7.5 \mathrm{~Hz}), 1.72(2 \mathrm{H}$, app quint, $J=7.5 \mathrm{~Hz}), 1.36(4 \mathrm{H}, \mathrm{m}), 0.92(3 \mathrm{H}, t, J=7.2$ $\mathrm{Hz})$

RMN ${ }^{13} \mathbf{C}\left(125 \mathrm{MHz}, \mathrm{CDCl}_{3}\right) \delta 171.1$ (CO); 152.8 (x2), 146.7, 137.1, 132.8, $130.1,127.5(\mathrm{C}) ; 129.8,129.0,123.9,120.7,109.4,106.1(\mathrm{x} 2)(\mathrm{CH}) ; 37.9$, 31.3, 25.2, $22.4\left(\mathrm{CH}_{2}\right) ; 60.8,55.8(\mathrm{x} 2), 55.7,13.8\left(\mathrm{CH}_{3}\right)$.

HR ESMS : $m / z 436.2104(\mathrm{M}+\mathrm{Na})^{+}$. Calculado para $\mathrm{C}_{24} \mathrm{H}_{31} \mathrm{NNaO}_{5}, 436.2100$.

(Z)-N-(2-metoxi-5-(3,4,5-trimetoxiestiril)fenil)heptanamida 3.58.

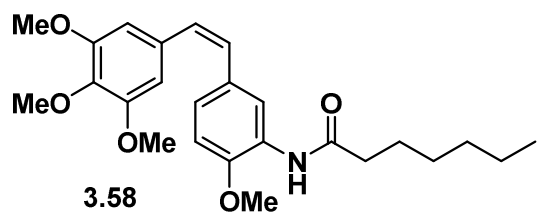

Rto. $=43 \%$. Aceite incoloro.

IR: $\boldsymbol{v}_{\max } 3420,3350(\mathrm{br}, \mathrm{NH}), 1684 \mathrm{~cm}^{-1}(\mathrm{C}=\mathrm{O}) \mathrm{cm}^{-1}$.

RMN ${ }^{1} \mathbf{H}\left(500 \mathrm{MHz}, \mathrm{CDCl}_{3}\right) \delta 8.36(1 \mathrm{H}, \mathrm{s}), 7.70(1 \mathrm{H}, \mathrm{br} \mathrm{s}, \mathrm{NH}) .6 .98(1 \mathrm{H}, \mathrm{dd}, J$ $=8.8,2 \mathrm{~Hz}), 6.70(1 \mathrm{H}, \mathrm{d}, J=8.8 \mathrm{~Hz}), 6.52(2 \mathrm{H}, \mathrm{s}), 6.51(1 \mathrm{H}, \mathrm{d}, J=12.2 \mathrm{~Hz})$, 
$6.43(1 \mathrm{H}, \mathrm{d}, J=12.2 \mathrm{~Hz}), 3.85(3 \mathrm{H}, \mathrm{s}), 3.84(3 \mathrm{H}, \mathrm{s}), 3.69(6 \mathrm{H}, \mathrm{s}), 2.37(2 \mathrm{H}, t, J$ $=7.5 \mathrm{~Hz}), 1.70(2 \mathrm{H}$, app quint, $J=7.5 \mathrm{~Hz}), 1.40-1.25(6 \mathrm{H}, \mathrm{br} \mathrm{m}), 0.90(3 \mathrm{H}, t, J$ $=7.2 \mathrm{~Hz})$

RMN ${ }^{13} \mathbf{C}\left(125 \mathrm{MHz}, \mathrm{CDCl}_{3}\right) \delta 171.1$ (CO); $152.8(\mathrm{x} 2), 146.7,137.1,132.8$, 130.2, $127.5(\mathrm{C}) ; 129.7,129.0,123.9,120.8,109.4,106.1(\mathrm{x} 2)(\mathrm{CH}) ; 38.0$, 31.5, 28.8, 25.5, $22.4\left(\mathrm{CH}_{2}\right) ;$ 60.8, $55.8(\mathrm{x} 2)$, 55.7, $14.0\left(\mathrm{CH}_{3}\right)$.

HR ESMS : $m / z 450.2263(\mathrm{M}+\mathrm{Na})^{+}$. Calculado para $\mathrm{C}_{25} \mathrm{H}_{33} \mathrm{NNaO}_{5}, 450.2256$.

(Z)-N-(2-metoxi-5-(3,4,5-trimetoxiestiril)fenil)octanamida 3.59.

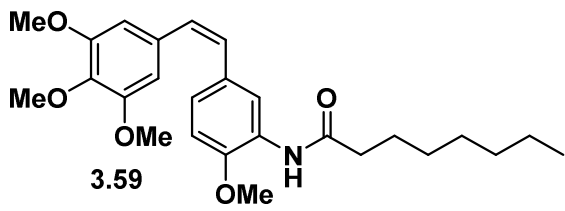

Rto. $=49 \%$. Aceite incoloro.

IR: $\boldsymbol{v}_{\max } 3420,3350(\mathrm{br}, \mathrm{NH}), 1684(\mathrm{C}=\mathrm{O}) \mathrm{cm}^{-1}$.

RMN ${ }^{1} \mathbf{H}\left(500 \mathrm{MHz}, \mathrm{CDCl}_{3}\right) \delta 8.36(1 \mathrm{H}, \mathrm{s}), 7.70(1 \mathrm{H}, \mathrm{br}$ s, NH). $6.98(1 \mathrm{H}, \mathrm{dd}, J$ $=8.8,2 \mathrm{~Hz}), 6.70(1 \mathrm{H}, \mathrm{d}, J=8.8 \mathrm{~Hz}), 6.52(2 \mathrm{H}, \mathrm{s}), 6.51(1 \mathrm{H}, \mathrm{d}, J=12.2 \mathrm{~Hz})$, $6.43(1 \mathrm{H}, \mathrm{d}, J=12.2 \mathrm{~Hz}), 3.85(3 \mathrm{H}, \mathrm{s}), 3.84(3 \mathrm{H}, \mathrm{s}), 3.69(6 \mathrm{H}, \mathrm{s}), 2.37(2 \mathrm{H}, t, J$ $=7.5 \mathrm{~Hz}), 1.71(2 \mathrm{H}$, app quint, $J=7.5 \mathrm{~Hz}), 1.40-1.25(8 \mathrm{H}, \mathrm{br} \mathrm{m}), 0.89(3 \mathrm{H}, t, J$ $=7 \mathrm{~Hz}$ )

RMN ${ }^{13} \mathbf{C}\left(125 \mathrm{MHz}, \mathrm{CDCl}_{3}\right) \delta 171.1(\mathrm{CO}) ; 152.8(\mathrm{x} 2), 146.7,137.1,132.8$, 130.2, $127.5(\mathrm{C})$; 129.7, 129.0, 123.9, 120.8, 109.4, 106.1 (x2) (CH); 38.0, 31.6, 29.1, 29.0, 25.5, $22.5\left(\mathrm{CH}_{2}\right)$; 60.8, $55.8(\mathrm{x} 2)$, 55.7, $14.0\left(\mathrm{CH}_{3}\right)$.

HR ESMS : $m / z 464.2410(\mathrm{M}+\mathrm{Na})^{+}$. Calculado para $\mathrm{C}_{26} \mathrm{H}_{35} \mathrm{NNaO}_{5}, 464.2413$.

(Z)-N-(2-metoxi-5-(3,4,5-trimetoxiestiril)fenil)dodecanamida 3.60 .

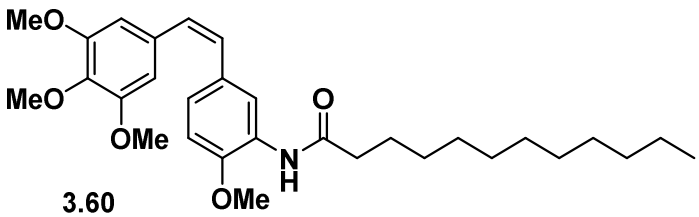

Rto. $=61 \%$. Sólido blanco. p. $f=58-60^{\circ} \mathrm{C}$.

IR $\boldsymbol{v}_{\max } 3427-3350(\mathrm{NH}), 1685(\mathrm{C}=\mathrm{O}) \mathrm{cm}^{-1}$.

RMN ${ }^{1} \mathbf{H}\left(500 \mathrm{MHz}, \mathrm{CDCl}_{3}\right) \delta 8.36(1 \mathrm{H}, \mathrm{s}), 7.70(1 \mathrm{H}, \mathrm{br} \mathrm{s}, \mathrm{NH}) .6 .98(1 \mathrm{H}, \mathrm{dd}, J$ $=8.8,2 \mathrm{~Hz}), 6.70(1 \mathrm{H}, \mathrm{d}, J=8.8 \mathrm{~Hz}), 6.52(2 \mathrm{H}, \mathrm{s}), 6.51(1 \mathrm{H}, \mathrm{d}, J=12.2 \mathrm{~Hz})$, 
$6.43(1 \mathrm{H}, \mathrm{d}, J=12.2 \mathrm{~Hz}), 3.85(3 \mathrm{H}, \mathrm{s}), 3.84(3 \mathrm{H}, \mathrm{s}), 3.68(6 \mathrm{H}, \mathrm{s}), 2.37(2 \mathrm{H}, t, J$ $=7.5 \mathrm{~Hz}), 1.71(2 \mathrm{H}$, app quint, $J=7.5 \mathrm{~Hz}), 1.40-1.25(16 \mathrm{H}, \mathrm{br} \mathrm{m}), 0.88(3 \mathrm{H}, t, J$ $=7 \mathrm{~Hz})$

RMN ${ }^{13} \mathbf{C}\left(125 \mathrm{MHz}, \mathrm{CDCl}_{3}\right) \delta 171.1$ (CO); 152.8 (x2), 146.7, 137.1, 132.8, $130.2,127.5$ (C); 129.7, 129.0, 123.9, 120.8, 109.4, 106.1 (x2) (CH); 38.0, 31.8, 29.6, 29.5, 29.4, 29.3 (x2), 29.2, 25.5, $22.6\left(\mathrm{CH}_{2}\right) ;$ 60.8, 55.8 (x2), 55.7, $14.0\left(\mathrm{CH}_{3}\right)$.

HR ESMS : $m / z 520.3046(\mathrm{M}+\mathrm{Na})^{+}$. Calculado para $\mathrm{C}_{30} \mathrm{H}_{43} \mathrm{NNaO}_{5}, 520.3039$. 

4. EVALUACIÓN BIOLÓGICA 



\section{EVALUACIÓN BIOLÓGICA}

Los análogos sintéticos han sido evaluados biológicamente por lo que hace a su:

1. Inhibición de la proliferación celular

2. Efecto sobre el ensamblaje de microtúbulos

3. Efecto sobre el ciclo celular

4. Efecto sobre la red de microtúbulos celulares

5. Inhibición de la expresión de los genes VEGF, hTERT y c-Myc

Los estudios sobre el ensamblaje de microtúbulos de los compuestos de la familia 3 y parte de los de la familia 2 se realizaron en los laboratorios del grupo del Dr. Fernando Díaz, en colaboración con el Dr. Fernando Josa, en el Centro de Investigaciones Biológicas (CIB, CSIC-Madrid).

El resto de ensayos biológicos, junto con los estudios sobre el ensamblaje de microtúbulos de los compuestos de la familia 1 y del resto de la familia 2 , se realizaron en los laboratorios del grupo de Síntesis Orgánica, en el departamento de Química Inorgánica y Orgánica de la Universitat Jaume I de Castellón.

En este capítulo se van a explicar, en primer lugar, los ensayos realizados, a continuación se van a detallar los resultados familia por familia y, finalmente, se van a exponer los procedimientos experimentales mediante los cuales se han realizado los ensayos. 


\section{4.a. Inhibición de la proliferación celular}

La capacidad de inhibición de la proliferación celular se determinó a través del valor de $\mathrm{IC}_{50}$, que se define como la concentración de compuesto a la cual éste es capaz de inhibir la proliferación celular al 50\%. Este valor se calculó para todos los compuestos en las líneas celulares tumorales humanas HT-29 (adenocarcinoma de colon), MCF-7 (adenocarcinoma de mama) y A-549 (adenocarcinoma de pulmón) y en la línea celular no tumoral HEK-293 (células embrionarias de riñón). También se calcularon los índices de selectividad (IS) que permiten evaluar el margen de seguridad terapéutico de cada derivado respecto de cada línea celular. Los IS se calcularon dividiendo los valores de $\mathrm{IC}_{50}$ de la línea no tumoral HEK-293 entre los valores de $\mathrm{IC}_{50}$ de la línea celular correspondiente.

La determinación del $\mathrm{IC}_{50}$ se llevó a cabo mediante el ensayo colorimétrico de MTT (bromuro de 3-(4,5-dimetiltiazol-2-il)-2,5-difeniltetrazolio). El fundamento de este ensayo es la reducción del MTT, de color amarillo, a formazán, sólido de color morado insoluble en disolución acuosa, que lleva a cabo la enzima mitocondrial succinato-deshidrogenasa en las células vivas (véase el esquema 4.A). ${ }^{190}$ La cantidad de células vivas es proporcional a la cantidad de formazán producido, por lo que este método permite medir la proliferación celular en presencia de los compuestos a evaluar.

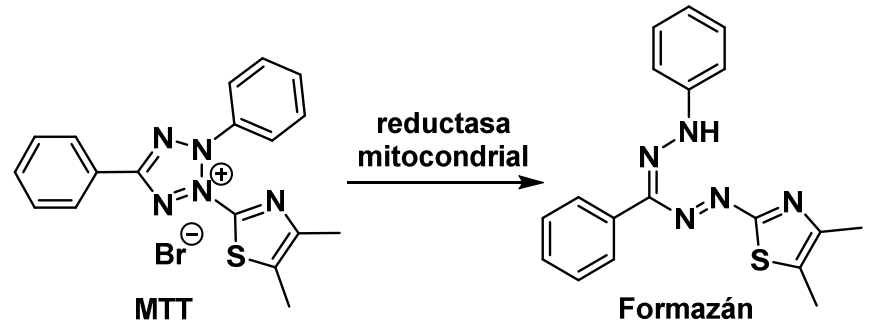

Esquema 4.A. Reducción del MTT a formazán.

190 a) Mosmann, T. J. Immunol. Methods 1983, 65, 55-63. b) Denizot, F.; Lang, R. J. Immunol. Methods 1986, 89, 271-277. 
El formazán absorbe radiación entre 450-600 nm por lo que se puede medir su absorbancia mediante un colorímetro o lector de microplacas. Una vez obtenidas las absorbancias de cada pocillo, se calcula el valor de $\mathrm{IC}_{50}$ con el programa GraphPad Prism 4, que ajusta los resultados de las distintas concentraciones de un compuesto a una representación sinusoidal, cuyo punto de inflexión corresponde al valor de $\mathrm{IC}_{50}$.

Los valores de $I_{50}$ y de IS sirvieron para seleccionar los compuestos a evaluar en el resto de ensayos biológicos. Así, se seleccionaron de cada familia los compuestos con valores de IS superiores a 1 y/o un bajo valor de $\mathrm{IC}_{50}$ en la línea HT-29. Los valores de $\mathrm{IC}_{50}$ también sirvieron de referencia para decidir las concentraciones de compuestos a emplear en el resto de ensayos. Todos los valores de $\mathrm{IC}_{50}$ vienen expresados por la media de $\mathrm{IC}_{50} \pm \mathrm{SD}$ (tres valores experimentales como mínimo).

\section{4.b. Efecto sobre el ensamblaje de microtúbulos}

Durante el proceso de ensamblaje de microtúbulos se pueden distinguir tres fases denominadas de nucleación, elongación y meseta. En la fase de nucleación, la tubulina aparece en forma de dímeros individuales y empieza a condensarse formando oligómeros. A continuación, en la fase de elongación, las subunidades de tubulina se van añadiendo a ambos lados del microtúbulo provocando un rápido crecimiento del mismo. En la fase de meseta, el microtúbulo entra en equilibrio dinámico manteniéndose constante la longitud del microtúbulo, ya que el número de unidades de tubulina que se van añadiendo es igual al número de unidades de tubulina que se van eliminando. En este momento, la concentración de tubulina que permanece en disolución se conoce como concentración crítica $(\mathrm{CrC})$, que se define como la concentración mínima necesaria para que se produzca el ensamblaje reversible de los microtúbulos. Esta concentración no es fija, sino que depende de muchas variables, como el pH, la temperatura o la concentración de los compuestos presentes en la disolución. Si éstos estabilizan los 
microtúbulos, la concentración crítica será menor que en la prueba de control ( $\sin$ compuesto añadido), puesto que en la fase de meseta habrá menor número de unidades de tubulina en disolución. Por el contrario, si están presentes compuestos que desestabilizan los microtúbulos, la $\mathrm{CrC}$ será mayor que la medida en la prueba de control.

Como los microtúbulos no son solubles en agua, se puede observar el efecto de los compuestos en el proceso de polimerización por turbidimetria, y la absorbancia medida será proporcional a la cantidad de polímero formado. Por otra parte, la representación de las cinéticas de polimerización permite determinar el efecto de los compuestos en el retraso de la polimerización mediante el valor de $\mathrm{It}_{50}$, que se define como el tiempo transcurrido hasta alcanzar el $50 \%$ de la polimerización. Este valor se calcula con el programa GraphPad Prism 4, que ajusta los resultados de las distintas concentraciones de un compuesto a una representación sinusoidal. El $I_{50}$ corresponde al punto de inflexión de la representación.

\section{4.c. Efecto sobre el ciclo celular}

Los estudios sobre el ciclo celular permiten evaluar la distribución celular en función del compuesto añadido, así como observar y cuantificar la parada de las células en fase G2/M. Estos estudios se llevaron a cabo en la línea A549 mediante la técnica de citometría de flujo.

El citómetro de flujo permite contar células y clasificarlas según sus características morfológicas. Las células suspendidas en un fluido atraviesan un fino tubo transparente sobre el que incide un rayo de luz láser. La luz transmitida y dispersada al pasar a través del tubo se recoge por medio de unos dispositivos de detección permitiendo discernir el tamaño y la complejidad de las células. Generalmente, se utilizan fluoróferos como etiquetas para el marcado fluorescente. 
Para el análisis del ciclo celular mediante citometría se utilizó yoduro de propidio (PI). Este compuesto se intercala en el ADN y aporta información sobre la distribución de las células en las diferentes fases del ciclo en función de la cantidad de ADN que éstas contengan. Sin embargo, la técnica no permite diferenciar entre las fases $\mathrm{G} 2$ y mitosis puesto que el contenido en ADN de las células en estas dos fases es el mismo.

Los datos recogidos se representan en un histograma que muestra las variaciones en el contenido de ADN frente al número de células analizadas, tal y como se indica en la figura 4.A.

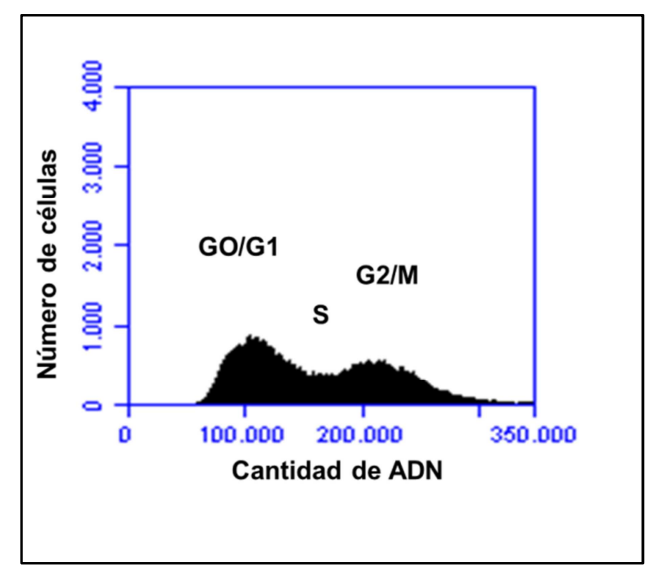

Figura 4.A. Histograma de ciclo celular

En el histograma se pueden distinguir tres fases:

1) Fase de reposo y presíntesis $G 0 / G 1$, en la cual la célula tiene contenido diploide de ADN fijo correspondiente a 23 pares de cromosomas.

2) Fase de síntesis, en la cual la célula sintetiza material genético hasta duplicar el ADN.

3) Fase G2/M, en la que se mantiene el material genético duplicado respecto a la fase $\mathrm{G} 0 / \mathrm{G} 1$. 
Los compuestos que actúan frente tubulina acumulan células en la fase G2/M.

Todas las medidas de ciclo celular de esta Tesis se llevaron a cabo con el citómetro de flujo BD Accuri ${ }^{\mathrm{TM}} \mathrm{C} 6$.

\section{4.d. Efecto sobre la red de microtubulos celulares}

El efecto de los compuestos sobre la red de microtúbulos celulares se observó mediante ensayos de inmunofluorescencia. Esta técnica utiliza un marcador fluorescente, que en esta Tesis fue el isocianato de fluoresceína (FITC), unido a un anticuerpo que reconoce a la $\alpha$-tubulina. El anticuerpo marcado se incorpora a las células tratadas y luego éstas son irradiadas con una fuente de luz de onda corta (ultravioleta o azul) seleccionada mediante un monocromador. La molécula marcadora o sonda fluorescente emite luz a una longitud de onda más larga (verde para FITC) y puede ser observada por medio de un microscopio de fluorescencia.

La inmunofluorescencia se estudió sobre células A-549 y las imágenes del citoesqueleto se tomaron con un microscopio confocal de barrido por láser (CLSM) Leica SP5.

\section{4.e. Efecto sobre la expresión de los genes VEGF, hTERT y c-Myc}

Una forma indirecta de evaluar la expresión de un gen es mediante la medida del ARNm que éste ha expresado. Este ácido nucleico se transcribe a ADN mediante la acción de una transcriptasa inversa y el ADN formado se amplifica mediante la reacción en cadena de la polimerasa (PCR en sus siglas en inglés). Existen dos tipos de PCR, la PCR convencional, en la cual se evalúa la expresión de genes de forma cualitativa y la qPCR (real-time Polymerase Chain Reaction o quantitative Polymerase Chain Reaction), que determina la expresión de genes de manera cuantitativa. En esta tesis se ha utilizado la técnica qPCR para la determinación de la expresión génica. Las 
células utilizadas en este ensayo fueron las HT-29 y como cebadores se usaron secuencias comercialmente accesibles para la amplificación de los genes VEGF, hTERT y c-Myc, así como $\beta$-actina como gen endógeno.

La técnica PCR o reacción en cadena de la polimerasa está basada en la amplificación de una región específica de cualquier tipo de ADN, mediante el uso de cebadores o primers, generando de miles a millones de copias de dicha secuencia. Presenta numerosas aplicaciones dentro del campo de la biología molecular, entre ellas se encuentra la amplificación de determinados genes para evaluar su grado de expresión. ${ }^{191}$

Los componentes básicos para llevar a cabo la amplificación son: ${ }^{192}$

- El ADN de muestra o molde que contiene la región de ADN a amplificar.

- La ADN polimerasa, enzima encargada de sintetizar nuevas hebras de ADN complementario de la secuencia específica.

- Cebadores, que son pequeños fragmentos de una sola hebra de ADN que contienen la secuencia complementaria a las regiones iniciales y finales que se quiere amplificar. Se necesitan 2 cebadores, uno con el oligonucleótido complementario al inicio de la secuencia (forward) y otro con el oligonucleótido complementario a la secuencia de bases final (reverse), que actúan como límites de la región de ADN que va a ser amplificada.

- Oligonucleótidos conocidos como dNTPs (deoxynucleotide triphosphates) que son los bloques de construcción a partir de los cuales la ADN polimerasa sintetiza una nueva hebra de ADN.

${ }_{191}$ Mullis, K. B.; Faloona, F. A. Methods Enzymol. 1987, 155, 335-350.

192 (a) Alberts, B.; Bray, D.; Hopkin, K.; Johnson, A.; Lewis, J.; Raff, M.; Roberts, K.; Walter, P. Essential Cell Biology. Garland Science, Taylor \& Francis Group. 2009. (b) Müller-Sterl, W. Bioquímica: Fundamentos para Medicina y Ciencias de la Vida. Editorial Reverté, S. A. 2008. 
La PCR se lleva a cabo mediante un termociclador que se encarga de realizar repeticiones de ciclos de calentamiento y enfriamiento. Un ciclo de replicación se compone de tres etapas:

1) Desnaturalización del $A D N$, mediante calentamiento alrededor de los 95드. lo que provoca la separación de las hebras del ADN.

2) Hibridación de los cebadores con la hebra sencilla de ADN, mediante enfriamiento a $40-68^{\circ} \mathrm{C}$.

3) Elongación de la cadena, mediante calentamiento a $72^{\circ} \mathrm{C}$, que es la temperatura óptima para que actúe la ADN polimerasa.

Una vez alcanzados los $72^{\circ} \mathrm{C}$, la polimerasa sintetiza la cadena complementaria de ADN añadiendo los dNTPs en sentido $5^{\prime} \rightarrow 3^{\prime}$. A continuación, el ciclo vuelve a comenzar (véase la figura 4.B). Normalmente se necesitan entre 20-40 ciclos para que el ADN pueda ser detectado y cuantificado. ${ }^{193}$

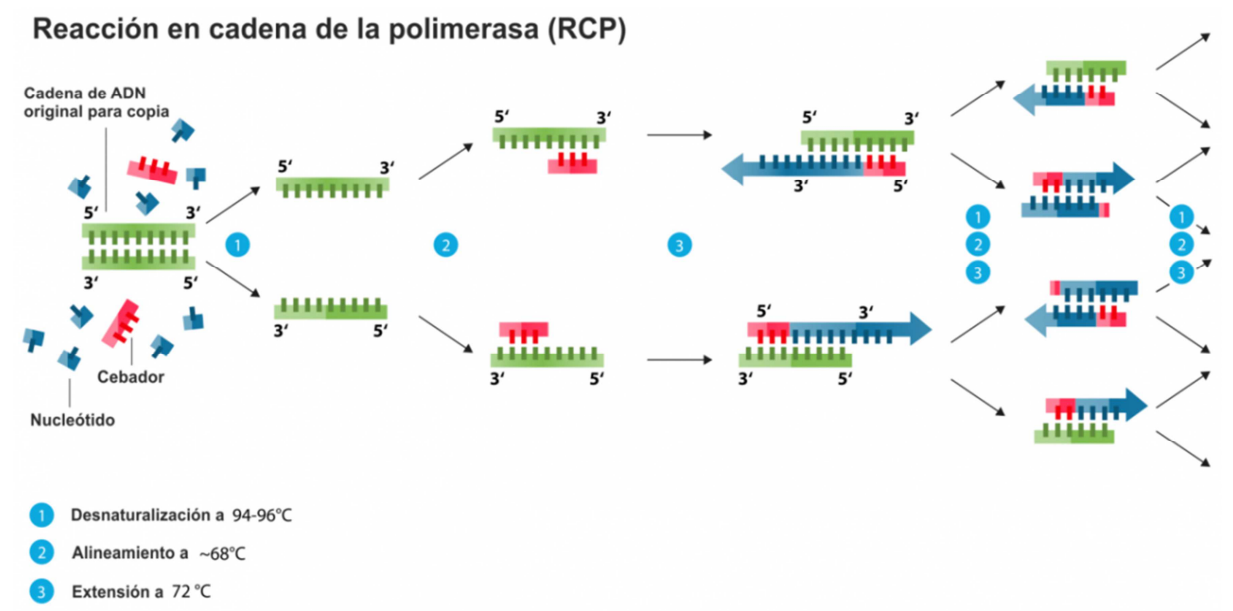

Figura 4.B. Reacción de la PCR. ${ }^{194}$

\footnotetext{
193 White, B.A. PCR protocols: current methods and applications. In: Methods in molecular biology. Humana Press. 1993.

194 Imagen tomada de http://www.jotdown.es/2014/09/la-deuda-de-la-genetica-con-thomas-dbrock/pcr/
} 
La PCR cuantitativa o qPCR en tiempo real es una variación de la PCR estándar en la que, simultáneamente, se amplifica y cuantifica el ADN de la muestra. Para ello, además de los componentes mencionados anteriormente, también se necesita la adición de una sonda fluorescente compuesta por un oligonucleótido de unión específica al ADN diana. En nuestros ensayos se ha empleado la sonda TaqMan, marcada con un fluoróforo donador (reporter) en el extremo $5^{\prime}$ que emite fluorescencia al ser excitado y un aceptor (quencher) en el extremo 3' que absorbe la fluorescencia liberada por el donador. Durante cada amplificación el fluoróforo es liberado y el termociclador es capaz de medir la fluorescencia que se corresponde con el nivel de amplificación del gen (véase la figura 4.C). ${ }^{195}$

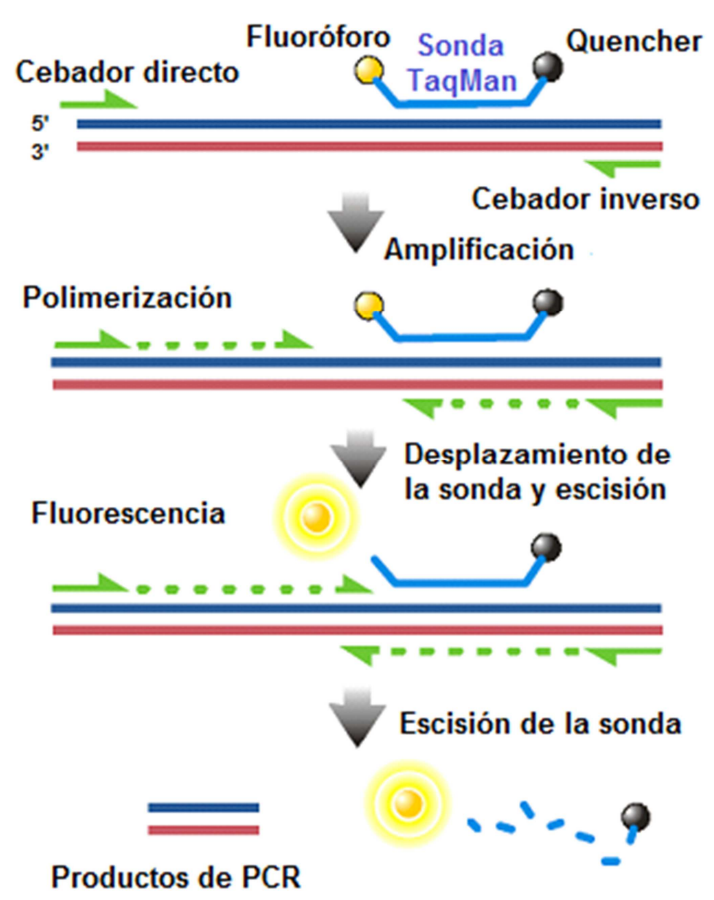

Figura 4.C. Fundamentos de la sonda TaqMan.

195 (a) Lie, Y.S.; Petropoulos, C. J. Curr. Opin. Biotechnol. 1998, 9, 43-48. (b) Heid, C. A.; Stevens, J.; Livak, K. J.; Williams, P. M. Genome Res. 1996, 6, 986-994. 
Los datos de fluorescencia se representan en una curva similar a la de la figura 4.D, en dónde se pueden distinguir varias fases. La primera es una línea base debido a que el equipo no es capaz de detectar la fluorescencia emitida. La segunda es una fase exponencial en la cual el equipo ya es capaz de detectar la fluorescencia. Por último, el equipo llega a su máximo de saturación que se conoce como fase meseta o plateau. ${ }^{196}$

Para el análisis de esta curva se traza un umbral de fluorescencia límite. La interpolación entre la línea umbral y la curva de fluorescencia se denomina $\mathrm{C}_{\mathrm{T}}$ (treshold cycle) y es el valor que se utiliza para cuantificar la expresión génica. El valor de $\mathrm{C}_{\mathrm{T}}$ es inversamente proporcional a la cantidad de ADN presente en la muestra. ${ }^{197}$

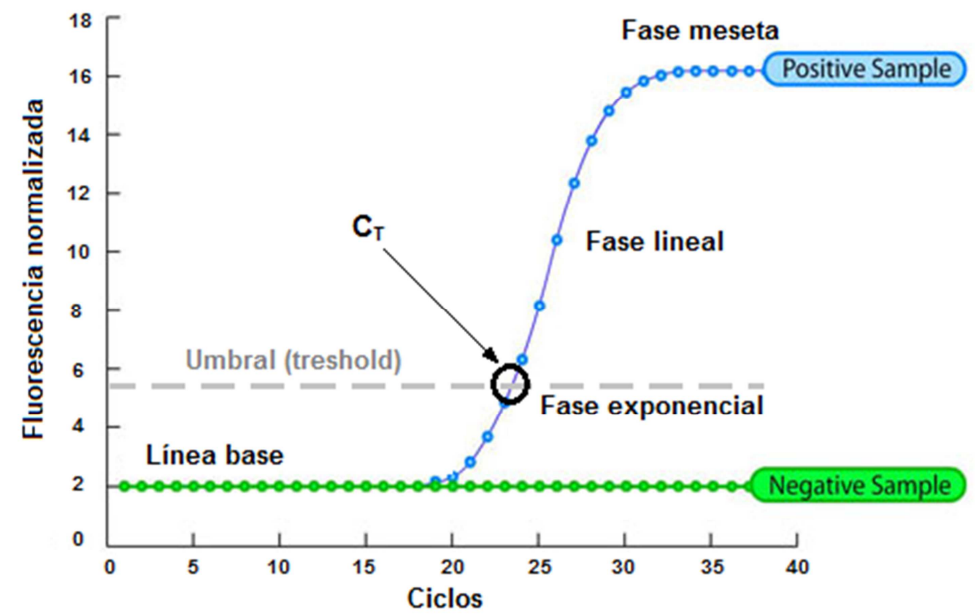

Figura 4.D. Curva de amplificación obtenida mediante PCR cuantitativa.

Para realizar los cálculos de ADN es necesario calcular la eficiencia (E) de los cebadores de cada gen mediante una curva de calibración en la que se representa el logaritmo de la concentración inicial de ADN frente a $C_{T}$. La

\footnotetext{
${ }^{196}$ Walker, N. J. J. Biochem. Molecular Toxicology 2001, 15, 121-127.

${ }^{197}$ Larionov, A.; Krause, A.; Miller, W. BMC bioinformatics 2005, 6, 62-78.
} 
eficiencia se determina a partir de la pendiente de la curva de calibrado siguiendo la ecuación:

$$
E=10^{[-1 / \text { pendiente }]}-1
$$

Si la eficiencia alcanza su máximo teórico 1 (100\%) significa que el número de copias de ADN se ha duplicado en cada ciclo. Sin embargo esto no siempre sucede y en algunas ocasiones se generan menos copias de lo esperado, factor que se debe tener en cuenta al realizar los cálculos posteriores.

El cálculo de los valores de expresión de los genes se realiza por cuantificación relativa, comparando una muestra tratada con producto con respecto a una muestra control (sin tratar) para un mismo gen y relacionando la cantidad de ADN del gen diana con respecto a la cantidad de ADN del gen endógeno para la misma muestra. Para ello, se emplea la diferencia en valores de $\mathrm{C}_{\mathrm{T}}{ }^{198}$

1) Normalización del gen específico al gen endógeno:

$$
\Delta \mathbf{C}_{\mathrm{T}}=\mathrm{C}_{\mathrm{T} \text { (gen diana) }}-\mathrm{C}_{\mathrm{T}} \text { (gen endógeno) }
$$

2) Normalizacion de la muestra tratada a la muestra control:

$$
\Delta \Delta \mathbf{C}_{\mathrm{T}}=\Delta \mathrm{C}_{\mathrm{T} \text { (muestra tratada) }}-\Delta \mathrm{C}_{\mathrm{T} \text { (control) }}
$$

En el caso que los dos genes tengan eficiencias similares y cercanas al $100 \%$, se calcula las veces que se expresa el gen específico cuando las células son tratadas respecto al control $(R Q)$, mediante la siguiente ecuación:

$$
R Q=2^{-\Delta \Delta C T}
$$

Sin embargo, si la eficiencia del gen diana y la del gen endógeno no es la misma, el valor de RQ se calcula según la siguiente ecuación matemática: ${ }^{199}$

\footnotetext{
198 Bustin, S.A.; Benes, V.; Garson, J.A.; Hellemans, J.; Huggett, J.; Kubista, M.; Mueller, R.; Nolan, T.; Pfaffl, M. W. Shipley, G. L.; Vandesompele, J.; Wittwer, C. T., MIQE guideless for QPCR. Clinical Chem. 2009, 611-622.

199 StepOne Plus Real Time PCR System User Training. Applied Biosystems by Life Technologies.
} 


$$
\begin{aligned}
& \mathrm{R} \\
& \mathrm{c}
\end{aligned}=\frac{\text { muestra normalizada }}{\text { control normalizado }}=\frac{\frac{A D N_{\text {gen diana muestra }}}{A D N_{\text {gen endógeno muestra }}}}{\frac{A D N_{\text {gen diana control }}}{A D N_{\text {gen endógeno control }}}}
$$

donde la cantidad de ADN se obtiene de extrapolar el valor de $\mathrm{C}_{\mathrm{T}}$ en la recta de calibrado realizada para el cálculo de la eficiencia del gen diana:

$$
\begin{gathered}
C_{T}=a \log (A D N)+b \\
A D N=10^{\frac{C_{T^{-b}}}{a}}
\end{gathered}
$$




\subsection{Evaluación biológica de los compuestos de la familia 1}

\section{1.a. Inhibición de la proliferación celular}

La inhibición de la proliferación celular de los compuestos de la familia 1 se calculó midiendo los valores de $\mathrm{IC}_{50}$ en las líneas celulares tumorales HT29, MCF-7 y A-549 y en la línea celular no tumoral HEK-293. Dichos valores de $\mathrm{IC}_{50}$ se obtuvieron mediante ensayo con MTT después de 48 horas de incubación. En la Tabla 4.1.1 se presentan los resultados obtenidos junto con los índices de selectividad $I_{A}, I_{B}$ e $I_{C}$, que se obtienen dividiendo el valor de $\mathrm{IC}_{50}$ de la línea no tumoral HEK-293 entre los valores de $\mathrm{IC}_{50}$ de las líneas celulares tumorales HT-29, MCF-7 y A-549, respectivamente. Cuanto mayor sea el índice de selectividad, mayor será el margen de seguridad terapéutica. El valor de CA-4 se presenta como compuesto de referencia.

Tabla 4.1.1. Valores de $\mathrm{IC}_{50}(\mu \mathrm{M})$ e índices de selectividad

\begin{tabular}{|c|c|c|c|c|c|c|c|}
\hline \multirow{2}{*}{ Comp. } & \multicolumn{4}{|c|}{$\mathrm{IC}_{50} \pm \mathrm{SD}(\mu \mathrm{M})$} & \multicolumn{3}{|c|}{$\begin{array}{l}\text { Índices de } \\
\text { selectividad }\end{array}$} \\
\hline & HT-29 & MCF-7 & A-549 & HEK-293 & $I_{A}$ & $I_{B}$ & ISc \\
\hline CA-4 & $4.2 \pm 0.5$ & $1.0 \pm 0.2$ & $0.428 \pm 0.004$ & $25 \pm 3$ & 5.9 & 25 & 58 \\
\hline 4 & $7 \pm 4$ & $8 \pm 4$ & $9 \pm 1$ & $3.6 \pm 0.5$ & 0.5 & 0.4 & 0.4 \\
\hline 5 & $33 \pm 6$ & $11 \pm 5$ & $38 \pm 5$ & $12 \pm 5$ & 0.4 & 1.1 & 0.3 \\
\hline 3.1 (Gly-OMe) & $12 \pm 2$ & $8 \pm 2$ & $26 \pm 2$ & $9 \pm 1$ & 0.7 & 1.1 & 0.3 \\
\hline 3.2 (L-Val-OMe) & $24 \pm 4$ & $12 \pm 6$ & $24 \pm 1$ & $5 \pm 2$ & 0.2 & 0.4 & 0.2 \\
\hline 3.3 (L-Leu-OMe) & $29 \pm 6$ & $19 \pm 6$ & $8 \pm 1$ & $9 \pm 2$ & 0.3 & 0.5 & 1.1 \\
\hline 3.4 (L-Phe-OMe) & $28 \pm 7$ & $8 \pm 2$ & $9 \pm 2$ & $4 \pm 1$ & 0.14 & 0.5 & 0.4 \\
\hline 3.5 (L-Pro-OMe) & $48 \pm 5$ & $24 \pm 2$ & $50 \pm 10$ & $20 \pm 1$ & 0.4 & 0.8 & 0.4 \\
\hline 3.6 (L-Ser-OMe) & $9 \pm 3$ & $7 \pm 3$ & $18 \pm 4$ & $7 \pm 2$ & 0.8 & 1.0 & 0.4 \\
\hline 3.7 (L-Thr-OMe) & $18 \pm 7$ & $12 \pm 4$ & $19 \pm 1$ & $14 \pm 2$ & 0.8 & 1.2 & 0.7 \\
\hline 3.8 (L-Tyr-OMe) & $16 \pm 5$ & $12 \pm 4$ & $18 \pm 1$ & $10 \pm 2$ & 0.6 & 0.8 & 0.6 \\
\hline 3.9 (L-Met-OMe) & $16 \pm 7$ & $10 \pm 3$ & $10 \pm 2$ & $8 \pm 1$ & 0.5 & 0.8 & 0.9 \\
\hline 3.10 (Gly) & $5 \pm 1$ & $6 \pm 1$ & $24 \pm 4$ & $5 \pm 1$ & 0.9 & 0.8 & 0.2 \\
\hline 3.11 (L-Val) & $12 \pm 5$ & $7 \pm 1$ & $17 \pm 2$ & $4 \pm 1$ & 0.4 & 0.6 & 0.3 \\
\hline 3.12 (L-Leu) & $15 \pm 5$ & $16 \pm 6$ & $14 \pm 2$ & $9 \pm 2$ & 0.6 & 0.6 & 0.6 \\
\hline 3.13 (L-Phe) & $54 \pm 9$ & $45 \pm 4$ & $100 \pm 20$ & $47 \pm 3$ & 0.9 & 1.0 & 0.5 \\
\hline 3.14 (L-Pro) & $26 \pm 13$ & $83 \pm 16$ & $110 \pm 10$ & $45 \pm 16$ & 1.7 & 0.5 & 0.4 \\
\hline
\end{tabular}




\begin{tabular}{|c|c|c|c|c|c|c|c|}
\hline $\mathbf{3 . 1 5}$ (L-Ser) & $39 \pm 16$ & $27 \pm 9$ & $36 \pm 4$ & $17 \pm 1$ & 0.4 & 0.6 & 0.5 \\
\hline $\mathbf{3 . 1 6}$ (L-Thr) & $34 \pm 11$ & $40 \pm 9$ & $41 \pm 3$ & $23 \pm 9$ & 0.7 & 0.6 & 0.6 \\
\hline $\mathbf{3 . 1 7}$ (L-Tyr) & $55 \pm 5$ & $43 \pm 7$ & $30 \pm 7$ & $33 \pm 1$ & 0.6 & 0.8 & 1.1 \\
\hline $\mathbf{3 . 1 8}$ (L-Met) & $32 \pm 6$ & $13 \pm 2$ & $>300$ & $40 \pm 4$ & 1.3 & 3.1 & $<0.1$ \\
\hline $\mathbf{3 . 1 9}$ (D-Val-OMe) & $27 \pm 7$ & $9 \pm 3$ & $5 \pm 1$ & $3.9 \pm 0.6$ & 0.1 & 0.4 & 0.8 \\
\hline $\mathbf{3 . 2 0}$ (D-Leu-OMe) & $26 \pm 1$ & $16 \pm 3$ & $22 \pm 3$ & $13 \pm 3$ & 0.5 & 0.8 & 0.6 \\
\hline $\mathbf{3 . 2 1}$ (D-Phe-OMe) & $12 \pm 4$ & $6 \pm 1$ & $10 \pm 3$ & $3.7 \pm 1.6$ & 0.3 & 0.7 & 0.4 \\
\hline $\mathbf{3 . 2 2}$ (D-Pro-OMe) & 50 & $10 \pm 4$ & $15 \pm 1$ & $5.7 \pm 0.8$ & 0.1 & 0.6 & 0.4 \\
\hline $\mathbf{3 . 2 3}$ (D-Ser-OMe) & $11 \pm 2$ & $7 \pm 2$ & $28 \pm 1$ & $9 \pm 3$ & 0.8 & 1.3 & 0.3 \\
\hline $\mathbf{3 . 2 4}$ (D-Val) & $45 \pm 5$ & $46 \pm 3$ & $54 \pm 7$ & $39 \pm 6$ & 0.9 & 0.8 & 0.7 \\
\hline $\mathbf{3 . 2 5}$ (D-Leu) & $47 \pm 9$ & $25 \pm 2$ & $68 \pm 1$ & $49 \pm 12$ & 1.0 & 2.0 & 0.7 \\
\hline $\mathbf{3 . 2 6}$ (D-Phe) & $27 \pm 5$ & $43 \pm 3$ & $60 \pm 4$ & $46 \pm 6$ & 1.7 & 1.1 & 0.8 \\
\hline $\mathbf{3 . 2 7}$ (D-Pro) & $50 \pm 11$ & $55 \pm 13$ & $95 \pm 14$ & $53 \pm 9$ & 1.1 & 1.0 & 0.6 \\
\hline $\mathbf{3 . 2 8}$ (D-Ser) & $13 \pm 1$ & $12 \pm 1$ & $>150$ & $14 \pm 4$ & 1.1 & 1.2 & $<0.09$ \\
\hline
\end{tabular}

Todos los derivados de esta familia muestran una actividad antiproliferativa en el rango micromolar, con valores semejantes a los del producto natural CA4. Para la línea celular HT-29 los compuestos más activos son $4(7 \mu \mathrm{M}), 3.6$ (L-Ser-OMe) $(9 \mu \mathrm{M})$ y 3.10 (Gly) $(5 \mu \mathrm{M})$, aunque sus índices de selectividad son inferiores a 1. Por el contrario, los compuestos 3.14 (L-Pro), 3.18 (L-Met), 3.25 (D-Leu), 3.26 (D-Phe), 3.27 (D-Pro) y $\mathbf{3 . 2 8}$ (D-Ser) muestran valores de IS superiores a la unidad, aunque no llegan a alcanzar los altos índices de CA-4. En la línea MCF-7 los compuestos 3.6 (L-Ser-OMe) (7 $\mu \mathrm{M})$, 3.10 (Gly) $(6 \mu \mathrm{M})$, 3.11 (L-Val) $(7 \mu \mathrm{M})$ y $\mathbf{3 . 2 3}$ (D-Ser-OMe) $(7 \mu \mathrm{M})$ son los más activos, siendo los índices de selectividad de $\mathbf{3 . 6}$ y $\mathbf{3 . 2 3}$ superiores a 1. En la línea A-549 los valores de $\mathrm{IC}_{50}$ son, en general, comparables a los de las otras líneas celulares, siendo los compuestos 4, 3.3 (L-Leu-OMe), 3.4 (L-Phe-OMe), 3.9 (LMet-OMe) y 3.19 (D-Val-OMe), con valores de $\mathrm{IC}_{50}$ inferiores a $10 \mu \mathrm{M}$, los más activos. En esta línea celular, los compuestos 3.3 (L-Leu-OMe) y 3.17 (L-Tyr) exhiben valores de IS superiores a 1. 
Para los compuestos de esta familia se ha comprobado el cumplimiento de "la regla de los cinco" de Lipinski ${ }^{200}$ que permite predecir si será posible o no la administración oral de un principio activo. Las condiciones propuestas por Lipinski que debe cumplir un principio activo son: que presente un logP inferior a 5 , un peso molecular inferior a 500 , menos de 5 grupos donadores de enlaces de hidrógeno $(\mathrm{OH}+\mathrm{NH})$ y menos de 10 grupos aceptores de enlaces de hidrógeno $(\mathrm{N}+\mathrm{O})$. Este modelo predictivo es ampliamente aceptado como un buen sistema para la selección de moléculas con potencial actividad terapéutica. En el estudio llevado a cabo por Lipinski ${ }^{200 a}$ sobre el grupo de compuestos que se encontraba en fase clínica II se observó que la gran mayoría de los mismos cumplían al menos 3 de las cuatro condiciones propuestas. Así, alrededor de un $40 \%$ de los compuestos analizados cumplía tres de las condiciones mientras que únicamente alrededor de un $20 \%$ incumplía dos de las condiciones. Por tanto, el incumplimiento de dos de las condiciones propuestas por Lipinski implica una posible baja absorción o permeabilidad. Asimismo, hay que destacar que la quinta recomendación de Lipinski indica que las cuatro condiciones anteriores no deben tenerse en cuenta en el caso de compuestos que sean sustratos para transportadores biológicos, por lo que los productos naturales podrían ser eximidos de estas recomendaciones. ${ }^{201}$

En la tabla 4.1.2 se muestran los valores obtenidos para los compuestos de la familia 1. ${ }^{202}$ En la tabla se observan varios derivados que incumplen una o dos de las condiciones formuladas por Lipinski. Algunos de los compuestos o bien sobrepasan el límite en el peso molecular, como 3.3 (L-Leu-OMe), 3.4 (L-Phe-OMe), 3.9 (L-Met-OMe), 3.13 (L-Phe), 3.18 (L-Met), 3.20 (D-Leu-OMe), 3.21 (D-Phe-OMe) y 3.26 (D-Phe), o bien llegan al número máximo de grupos

\footnotetext{
200 Lipinski, C.A.; Lombardo, F.; Dominy, B.W.; Feeney, P.J. Advanced Drug Delivery Reviews 2001, 46, 3-26. (b) C. A. Lipinski, Drug Discovery Today: Technol. 2004, 1, 337-341. 201 Jiménez, C. An. Quím. 2013, 109, 134-141.

202 El valor de logP se ha calculado mediante el programa ChemBioDraw Ultra 14.0
} 
aceptores de enlaces de hidrógeno recomendados, como 3.6 (L-Ser-OMe), 3.7 (L-Thr-OMe), 3.15 (L-Ser), 3.16 (L-Thr), 3.23 (D-Ser-OMe) y 3.28 (D-Ser). Únicamente los derivados 3.8 (L-Tyr-OMe) y 3.17 (L-Tyr) incumplen dos condiciones y, por tanto, violarían las reglas de Lipinski.

Tabla 4.1.2. Comprobación de la regla de Lipinski

\begin{tabular}{|c|c|c|c|c|c|}
\hline Compuesto & $\log P$ & PM g/mol & $\mathrm{OH}+\mathrm{NH}$ & $\mathrm{N}+\mathrm{O}$ & No cumple \\
\hline CA-4 & 3.33 & 316.35 & 1 & 5 & - \\
\hline 4 & 3.46 & 402.44 & 0 & 7 & - \\
\hline 5 & 2.86 & 374.39 & 1 & 7 & - \\
\hline 3.1 (Gly-OMe) & 1.97 & 445.47 & 1 & 9 & - \\
\hline 3.2 (L-Val-OMe) & 3.35 & 487.55 & 1 & 9 & - \\
\hline 3.3 (L-Leu-OMe) & 3.7 & 501.58 & 1 & 9 & 1 \\
\hline 3.4 (L-Phe-OMe) & 4.14 & 535.39 & 1 & 9 & 1 \\
\hline 3.5 (L-Pro-OMe) & 2.68 & 485.53 & 0 & 9 & - \\
\hline 3.6 (L-Ser-OMe) & 1.51 & 475.49 & 2 & 10 & 1 \\
\hline 3.7 (L-Thr-OMe) & 1.93 & 489.52 & 2 & 10 & 1 \\
\hline 3.8 (L-Tyr-OMe) & 3.75 & 551.59 & 2 & 10 & 2 \\
\hline 3.9 (L-Met-OMe) & 2.8 & 519.61 & 1 & 9 & 1 \\
\hline 3.10 (Gly) & 1.71 & 431.44 & 2 & 9 & - \\
\hline 3.11 (L-Val) & 3.09 & 473.52 & 2 & 9 & - \\
\hline 3.12 (L-Leu) & 3.44 & 487.55 & 2 & 9 & - \\
\hline 3.13 (L-Phe) & 3.88 & 521.57 & 2 & 9 & 1 \\
\hline 3.14 (L-Pro) & 2.42 & 471.51 & 1 & 9 & - \\
\hline 3.15 (L-Ser) & 1.35 & 461.47 & 3 & 10 & 1 \\
\hline 3.16 (L-Thr) & 1.67 & 475.49 & 3 & 10 & 1 \\
\hline 3.17 (L-Tyr) & 3.49 & 537.57 & 3 & 10 & 2 \\
\hline 3.18 (L-Met) & 2.54 & 505.58 & 2 & 9 & 1 \\
\hline 3.19 (D-Val-OMe) & 3.35 & 487.55 & 1 & 9 & - \\
\hline 3.20 (D-Leu-OMe) & 3.7 & 501.58 & 1 & 9 & 1 \\
\hline 3.21 (D-Phe-OMe) & 4.14 & 535.39 & 1 & 9 & 1 \\
\hline 3.22 (D-Pro-OMe) & 2.68 & 485.53 & 0 & 9 & - \\
\hline 3.23 (D-Ser-OMe) & 1.51 & 475.49 & 2 & 10 & 1 \\
\hline 3.24 (D-Val) & 3.09 & 473.52 & 2 & 9 & - \\
\hline 3.25 (D-Leu) & 3.44 & 487.55 & 2 & 9 & - \\
\hline 3.26 (D-Phe) & 3.88 & 521.57 & 2 & 9 & 1 \\
\hline
\end{tabular}




\begin{tabular}{|l|l|l|l|l|l|}
\hline $\mathbf{3 . 2 7}$ (D-Pro) & 2.42 & 471.51 & 1 & 9 & - \\
\hline $\mathbf{3 . 2 8}$ (D-Ser) & 1.35 & 461.47 & 3 & 10 & 1 \\
\hline
\end{tabular}

\section{1.b. Efecto sobre el ensamblaje de microtúbulos}

El efecto sobre el autoensamblaje de la tubulina se determinó mediante la medida de la concentración crítica $(\mathrm{CrC})$. Todos los derivados se ensayaron a una concentración de $27.5 \mu \mathrm{M}$ en un tampón de ensamblaje de glicerol (GAB) y GTP, al cual se le añadió tubulina a una concentración de $25 \mu \mathrm{M}$. En la tabla 4.1.3 se muestran los resultados y se comparan con los obtenidos en ausencia de ligando (control) y en presencia de CA-4 como compuesto patrón

Tabla 4.1.3. Valores de $\mathrm{CrC}$

\begin{tabular}{|c|c|}
\hline Comp. & CrC $(\mu \mathrm{M})$ \\
\hline Contr. & $7.9 \pm 1.2$ \\
\hline CA-4 & $21.5 \pm 0.8$ \\
\hline $\mathbf{4}$ & $13.6 \pm 0.3$ \\
\hline $\mathbf{5}$ & $12.0 \pm 0.7$ \\
\hline $\mathbf{3 . 1}$ (Gly-OMe) & $9.52 \pm 0.05$ \\
\hline 3.2 (L-Val-OMe) & $11.7 \pm 2.3$ \\
\hline 3.3 (L-Leu-OMe) & $9.4 \pm 1.4$ \\
\hline 3.4 (L-Phe-OMe) & $13.20 \pm 0.06$ \\
\hline 3.5 (L-Pro-OMe) & $10.4 \pm 2.0$ \\
\hline 3.6 (L-Ser-OMe) & $13.00 \pm 0.10$ \\
\hline 3.7 (L-Thr-OMe) & $10 \pm 3$ \\
\hline
\end{tabular}

\begin{tabular}{|c|c|}
\hline Comp. & CrC $(\boldsymbol{\mu M})$ \\
\hline $\mathbf{3 . 8}$ (L-Tyr-OMe) & $13.26 \pm 0.19$ \\
\hline $\mathbf{3 . 9}$ (L-Met-OMe) & $8.06 \pm 0.04$ \\
\hline $\mathbf{3 . 1 0}$ (Gly) & $9.3 \pm 0.4$ \\
\hline $\mathbf{3 . 1 1}$ (L-Val) & $9.3 \pm 0.3$ \\
\hline $\mathbf{3 . 1 2}$ (L-Leu) & $8 \pm 3$ \\
\hline $\mathbf{3 . 1 3}$ (L-Phe) & $11.4 \pm 0.7$ \\
\hline $\mathbf{3 . 1 4}$ (L-Pro) & $9.2 \pm 0.5$ \\
\hline $\mathbf{3 . 1 5}$ (L-Ser) & $7.9 \pm 1.6$ \\
\hline $\mathbf{3 . 1 6}$ (L-Thr) & $10.1 \pm 1.8$ \\
\hline $\mathbf{3 . 1 7}$ (L-Tyr) & $8.5 \pm 2.0$ \\
\hline $\mathbf{3 . 1 8}$ (L-Met) & $8.6 \pm 0.4$ \\
\hline
\end{tabular}

\begin{tabular}{|c|c|}
\hline Comp. & $\mathrm{CrC}(\boldsymbol{M M})$ \\
\hline 3.19 (D-Val-OMe) & $13.31 \pm 0.01$ \\
\hline 3.20 (D-Leu-OMe) & $13.2 \pm 0.5$ \\
\hline 3.21 (D-Phe-OMe) & $13.1 \pm 0.8$ \\
\hline $\mathbf{3 . 2 2}$ (D-Pro-OMe) & $9 \pm 3$ \\
\hline $\mathbf{3 . 2 3}$ (D-Ser-OMe) & $9.2 \pm 0.9$ \\
\hline $\mathbf{3 . 2 4}$ (D-Val) & $9.4 \pm 1.3$ \\
\hline $\mathbf{3 . 2 5}$ (D-Leu) & $11 \pm 3$ \\
\hline $\mathbf{3 . 2 6}$ (D-Phe) & $9.2 \pm 0.4$ \\
\hline $\mathbf{3 . 2 7}$ (D-Pro) & $10 \pm 3$ \\
\hline $\mathbf{3 . 2 8}$ (D-Ser) & $9.25 \pm 0.16$ \\
\hline
\end{tabular}

Al contrario de lo que cabría esperar, ya que los derivados provienen de CA-4, que es un potente desestabilizador de microtúbulos, la mayor parte de los derivados de la familia 1 no exhiben diferencias demasiado significativas respecto del control. Los mayores valores de $\mathrm{CrC}$ los consiguen los compuestos 4, 3.4 (L-Phe-OMe), 3.6 (L-Ser-OMe), 3.8 (L-Tyr-OMe), 3.19 (DVal-OMe), 3.20 (D-Leu-OMe) y 3.21 (D-Phe-OMe) (alrededor de $13 \mu \mathrm{M}$ ), muy lejos del valor de CA-4 que es de $21.5 \mu \mathrm{M}$. Por otro lado, el tiempo necesario 
para que comience la polimerización de la tubulina, en presencia de los compuestos de la familia 1, es similar al del control. De todo ello, se puede concluir que los compuestos de la familia 1 no inhiben in vitro el proceso de polimerización de la tubulina.

\section{1.c. Efecto sobre el ciclo celular}

Los efectos de algunos de los derivados de la familia 1 sobre el ciclo celular se evaluaron en células A-549. Los derivados se seleccionaron después de observar la morfología celular, descartándose los compuestos que no mostraban una gran concentración de células paradas en mitosis, que son aquellas que se caracterizan por tener una forma redondeada y por estar ligeramente despegadas de la base inferior de la placa. En los histogramas indicados en la figura 4.1 .2 se puede apreciar que la muestra control prácticamente no presenta células acumuladas en fase G2/M mientras que para CA-4 se observa una mayoría de células en G2/M (60\%). Los compuestos 4, 3.4 (L-Phe-OMe), 3.6 (L-Ser-OMe), 3.7 (L-Thr-OMe), 3.8 (L-TyrOMe), 3.11 (L-Val), 3.12 (L-Leu) y 3.22 (D-Pro-OMe) acumulan entre un 50$70 \%$ de células en fase $\mathrm{G} 2 / \mathrm{M}$, igualando o incluso mejorando los resultados obtenidos para CA-4 (60\%), aunque hay que hacer constar que estos compuestos ejercen su acción a unas concentraciones entre 1000-1500 veces superiores a las de CA-4. 


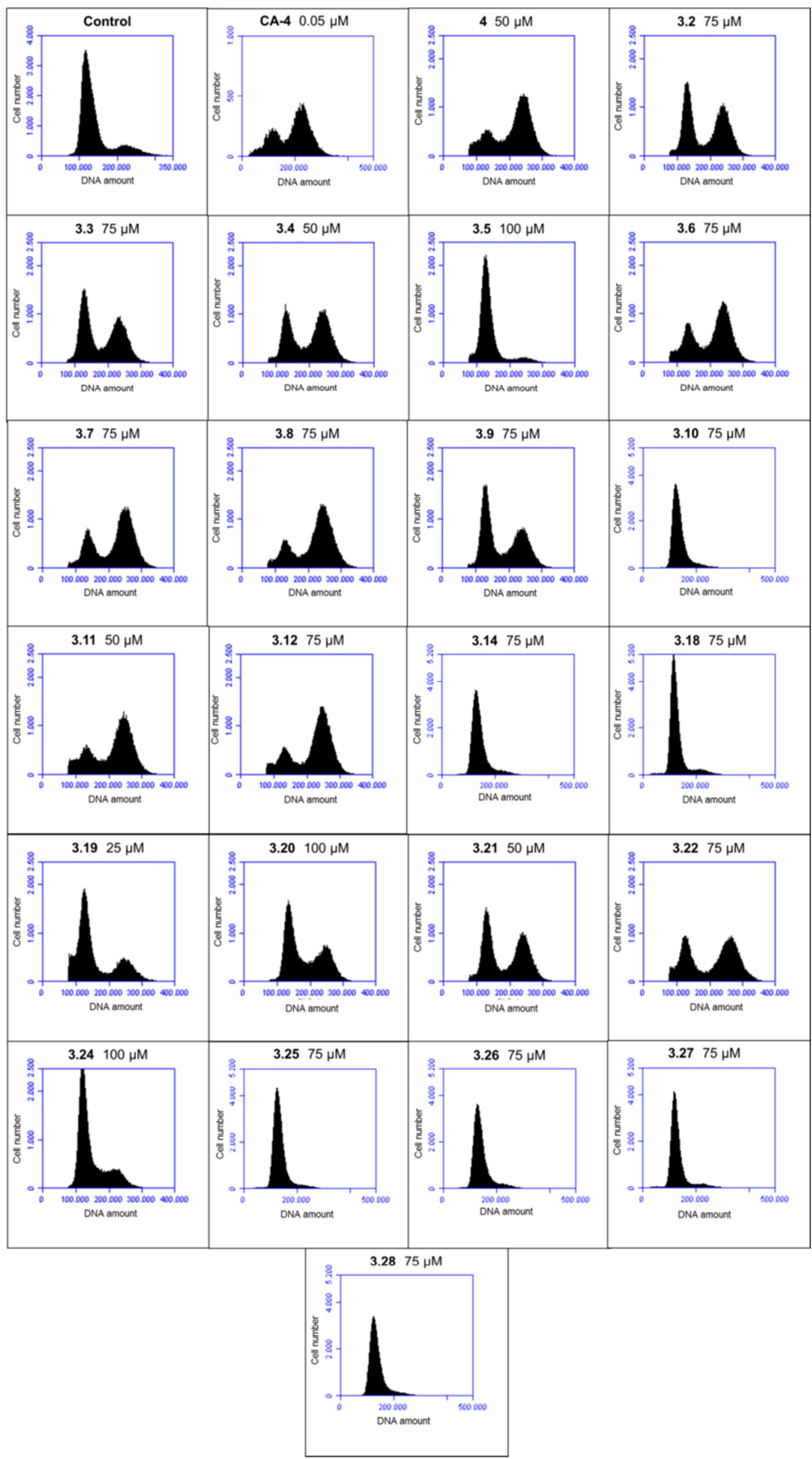

Figura 4.1.2. Histogramas del ciclo celular de CA-4 y compuestos seleccionados de la familia 1. 
Los resultados del ciclo celular se presentan en la tabla 4.1.4 en forma numérica, así como las concentraciones de ligando a las que se realizó el ensayo.

Tabla 4.1.4. Distribución del ciclo celular

\begin{tabular}{|c|c|c|c|c|}
\hline Compuesto & Conc. $(\mu M)$ & G0/G1 & s & G2/M \\
\hline Control & - & $75 \pm 4$ & $11 \pm 2$ & $14 \pm 2$ \\
\hline CA-4 & 0.05 & $25 \pm 1$ & $15 \pm 1$ & $60 \pm 2$ \\
\hline 4 & 50 & $23 \pm 5$ & $22 \pm 4$ & $55 \pm 8$ \\
\hline 3.2 (L-Val-OMe) & 75 & $42 \pm 3$ & $14 \pm 4$ & $44 \pm 1$ \\
\hline 3.3 (L-Leu-OMe) & 75 & $45 \pm 6$ & $19 \pm 2$ & $36 \pm 4$ \\
\hline 3.4 (L-Phe-OMe) & 50 & $33 \pm 4$ & $16 \pm 5$ & $51 \pm 2$ \\
\hline 3.5 (L-Pro-OMe) & 100 & $77 \pm 2$ & $16 \pm 2$ & $7 \pm 1$ \\
\hline 3.6 (L-Ser-OMe) & 75 & $30 \pm 9$ & $17 \pm 6$ & $53 \pm 3$ \\
\hline 3.7 (L-Thr-OMe) & 75 & $25 \pm 5$ & $18 \pm 1$ & $57 \pm 6$ \\
\hline 3.8 (L-Tyr-OMe) & 75 & $17 \pm 2$ & $18 \pm 1$ & $65 \pm 1$ \\
\hline 3.9 (L-Met-OMe) & 75 & $47 \pm 4$ & $17 \pm 3$ & $36 \pm 1$ \\
\hline 3.10 (Gly) & 75 & 68 & 12 & 20 \\
\hline 3.11 (L-Val) & 50 & $17 \pm 2$ & $16 \pm 3$ & $67 \pm 4$ \\
\hline 3.12 (L-Leu) & 75 & $22 \pm 6$ & $15 \pm 2$ & $63 \pm 5$ \\
\hline 3.14 (L-Pro) & 75 & 72 & 12 & 16 \\
\hline 3.18 (L-Met) & 75 & 76 & 11 & 13 \\
\hline 3.19 (D-Val-OMe) & 25 & $53 \pm 8$ & $16 \pm 2$ & $31 \pm 7$ \\
\hline 3.20 (D-Leu-OMe) & 100 & $43 \pm 4$ & $23 \pm 4$ & $34 \pm 1$ \\
\hline 3.21 (D-Phe-OMe) & 50 & $38 \pm 2$ & $19 \pm 2$ & $43 \pm 1$ \\
\hline 3.22 (D-Pro-OMe) & 75 & $36 \pm 4$ & $14 \pm 3$ & $50 \pm 1$ \\
\hline 3.24 (D-Val) & 100 & $67 \pm 2$ & $20 \pm 2$ & $13 \pm 1$ \\
\hline 3.25 (D-Leu) & 75 & $85 \pm 1$ & $3 \pm 2$ & $12 \pm 1$ \\
\hline 3.26 (D-Phe) & 75 & $74 \pm 3$ & $11 \pm 6$ & $14 \pm 2$ \\
\hline 3.27 (D-Pro) & 75 & 71 & 14 & 15 \\
\hline 3.28 (D-Ser) & 75 & 64 & 18 & 18 \\
\hline
\end{tabular}

Los derivados 3.2 (L-Val-OMe), 3.3 (L-Leu-OMe), 3.4 (L-Phe-OMe), 3.9 (LMet-OMe), 3.21 (D-Phe-OMe) y 3.22 (D-Pro-OMe) igualan la acción de CA-4, pero también cuando se emplean a concentraciones entre 1000-1500 veces superiores a las del producto natural. A su vez, los compuestos 3.5 (L-Pro- 
OMe), 3.10 (Gly), 3.14 (L-Pro), 3.18 (L-Met), 3.24 (D-Val), 3.25 (D-Leu), 3.26 (D-Phe), 3.27 (D-Pro) y 3.28 (D-Ser) no ejercen ningún efecto significativo sobre las células.

\section{1.d. Efecto sobre la red de microtúbulos celulares}

El efecto sobre la red de microtúbulos celulares se estudió con los compuestos 4, 3.7 (L-Thr-OMe), 3.8 (L-Tyr-OMe), 3.11 (L-Val) y 3.12 (L-Leu), que eran los que acumulaban más células en la fase G2/M. Así, se incubaron células A-549 durante $24 \mathrm{~h}$ en presencia de los compuestos anteriores y de CA-4 en las concentraciones indicadas en la figura 4.1.2. Como se puede ver en las imágenes, CA-4 (panel B) despolimeriza en gran medida los microtúbulos a una concentración de $50 \mathrm{nM}$. Asimismo, los derivados 4 (C) (50 $\mu \mathrm{M}), 3.7$ (L-Thr-OMe) (D) $(75 \mu \mathrm{M}), 3.8$ (L-Tyr-OMe) (E) (75 $\mu \mathrm{M}), 3.11$ (L-Val) (F) $(50 \mu \mathrm{M})$ y $3.12(\mathrm{~L}-\mathrm{Leu})(\mathrm{G})(50 \mu \mathrm{M})$ producen desorganización en el huso mitótico en todos los casos estudiados, aunque dicho efecto es ejercido a concentraciones mucho mayores que en el caso del producto natural CA-4.
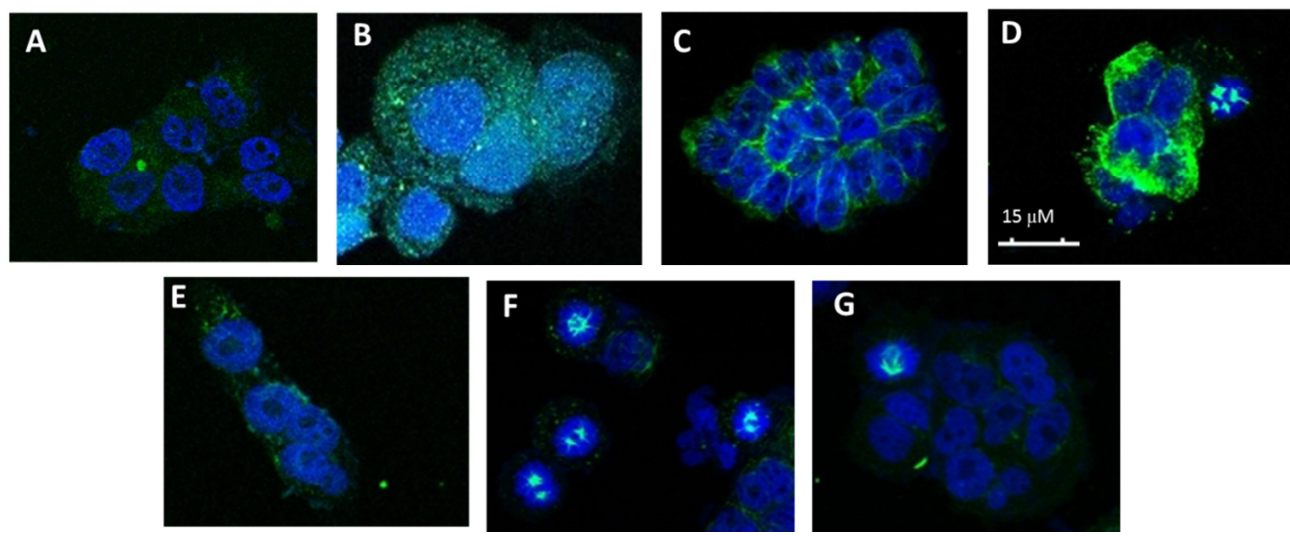

Figura 4.1.2. Efectos sobre la red de microtúbulos celulares. (A) DMSO, (B) $50 \mathrm{nM}$ de CA-4, (C) $50 \mu \mathrm{M}$ de 4, (D) $75 \mu \mathrm{M}$ de 3.7 (L-Thr-OMe), (E) $75 \mu \mathrm{M}$ de 3.8 (L-Tyr-OMe), (F) $50 \mu \mathrm{M}$ de 3.11 (L-Val) y (G) $75 \mu \mathrm{M}$ de 3.12 (L-Leu). 


\section{1.e. Efecto sobre la expresión de los genes VEGF, hTERT y c-Myc}

El efecto sobre la expresión de los genes VEGF, hTERT y $c-M y c$ se ha estudiado para todos los derivados que muestran índices de selectividad en la línea celular HT-29 superior a 0.9. Los derivados estudiados, junto con las concentraciones a los que se han probado, son: 3.10 (Gly) $(5 \mu \mathrm{M}), \mathbf{3 . 1 4}$ (L-Pro) $(25 \mu \mathrm{M}), 3.18$ (L-Met) $(25 \mu \mathrm{M}), 3.25$ (D-Leu) (25 $\mu \mathrm{M}), 3.26$ (D-Phe) $(25 \mu \mathrm{M})$, 3.27 (D-Pro) $(25 \mu \mathrm{M})$ y 3.28 (D-Ser) $(10 \mu \mathrm{M})$. La expresión de los genes se determinó mediante la metodología RT-qPCR, tal y como se describe en la Sección Experimental. Los resultados se presentan en la figura 4.1.3 que muestra el porcentaje de expresión de cada gen después de $48 \mathrm{~h}$ de incubación en presencia de DMSO (control), CA-4 y cada uno de los derivados.
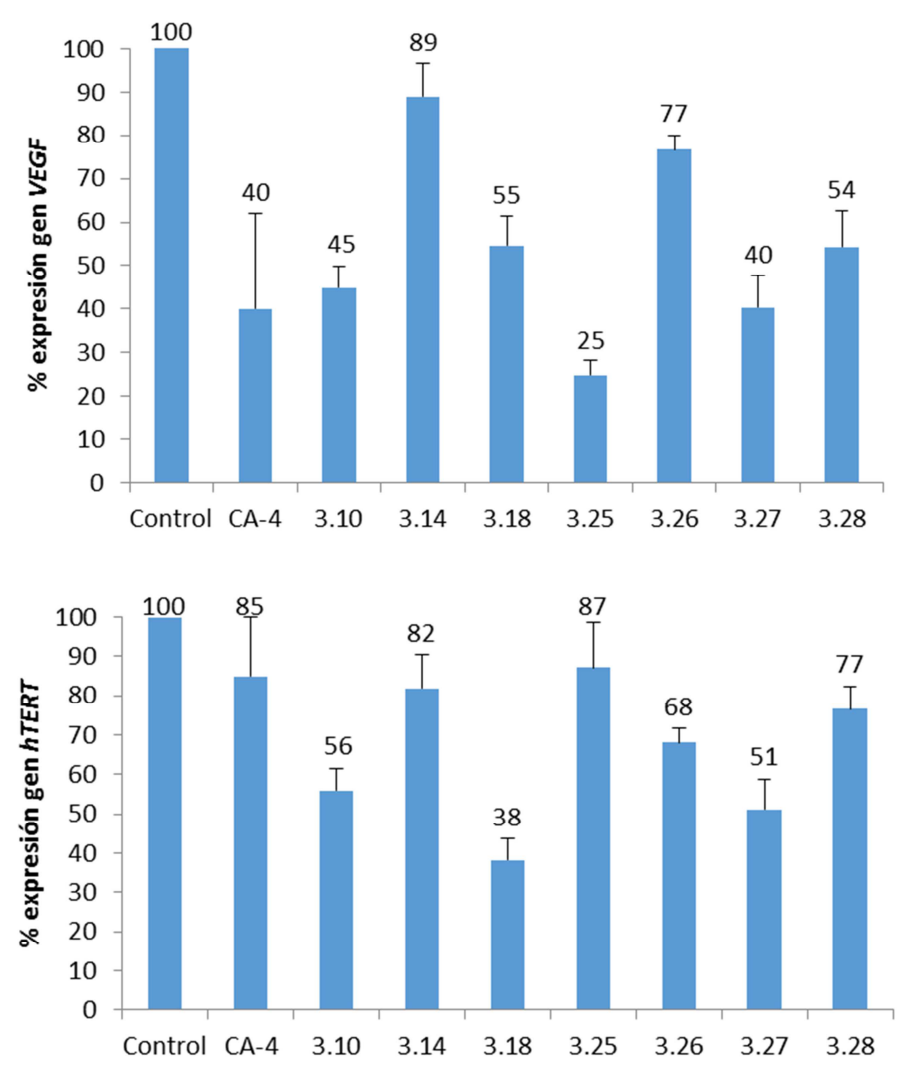


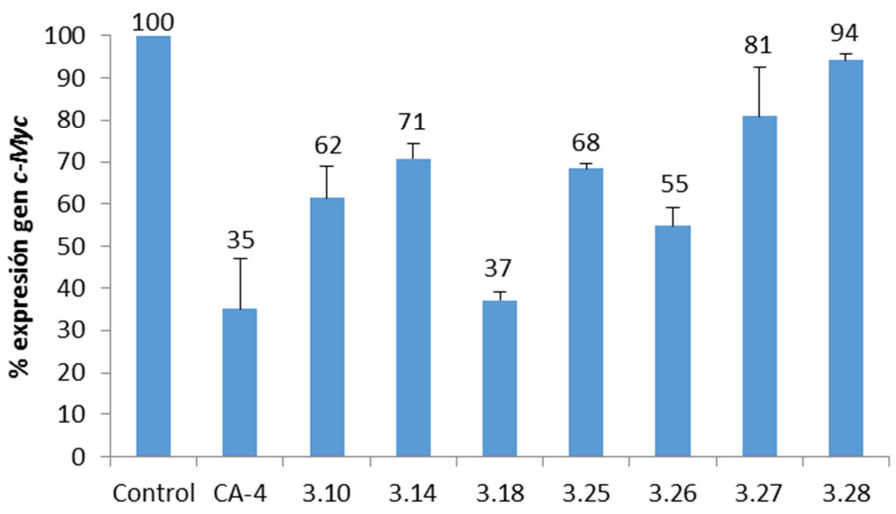

Figura 4.1.3. Porcentajes de expresión de genes.

Algunos derivados se muestran bastante activos en la inhibición de la expresión del gen VEGF, como los compuestos 3.25 (D-Leu) y 3.27 (D-Pro), que son capaces de igualar (3.27 40\%) e incluso mejorar (3.25 25\%) la inhibición que se consigue con CA-4 (40\%).

En el caso del gen $h T E R T$, casi todos los derivados logran porcentajes de inhibición mejores que CA-4, aunque es necesario mencionar que este compuesto sólo logra reducir la expresión del gen hasta el $85 \%$. El derivado 3.18 (L-Met) es el más activo, al expresar únicamente el $38 \%$ respecto al control.

En el caso del gen $c-M y c$, ninguno de los derivados mejora la capacidad inhibidora de CA-4, que expresa sólo el 35\% este gen. No obstante, 3.18 (LMet) es capaz de regular negativamente la expresión del gen $c-M y c$ en un porcentaje del $37 \%$.

En términos generales, 3.18 (L-Met) se podría considerar como el derivado más activo de la familia, ya que reduce la expresión de los tres genes estudiados entre el $37-55 \%$. 


\section{1.f. Conclusión}

En resumen, se puede destacar que los derivados de CA-4 con aminoácidos presentan actividades antiproliferativas en el rango micromolar, y con valores bastante semejantes en todas las líneas celulares estudiadas. Estos valores no difieren apreciablemente de los que presenta el producto natural CA-4. En cuanto a los índices de selectividad, algunos derivados logran valores superiores a 1. En la línea HT-29, este es el caso de 3.14 (LPro), 3.18 (L-Met) y 3.25-3.28 (D-Leu, D-Phe, D-Pro, D-Ser), mientras que en la línea MCF-7 5, 3.1 (Gly-OMe), 3.6 (L-Ser-OMe), 3.7 (L-Thr-OMe), 3.13 (LPhe), 3.23 (D-Ser-OMe), 3.25 (D-Val), 3.26 (D-Phe) y 3.28 (D-Ser) son los presentan IS superior a 1 , aunque en ningún caso se alcanzan los IS tan elevados que exhibe CA-4.

Ninguno de los derivados, a diferencia de CA-4, inhiben la polimerización in vitro de tubulina, ya que no presentan desviaciones significativas de su $\mathrm{CrC}$ respecto del control ni retrasan el inicio del proceso de polimerización.

En relación con el ciclo celular, los derivados 4, 3.6 (L-Ser-OMe), 3.7 (LThr-OMe), 3.8 (L-Tyr-OMe), 3.11 (L-Val) y 3.12 (L-Leu) ejercen una acción comparable a CA-4, acumulando un elevado porcentaje de células en fase G2/M, aunque este efecto lo consiguen a concentraciones entre 1000-1500 veces superiores a las de CA-4. Otros derivados, como 3.5 (L-Pro-OMe), 3.10 (Gly), 3.14 (L-Pro), 3.18 (L-Met), 3.24-3.28 (D-Val, D-Leu, D-Phe, D-Pro y DSer), no ejercen efecto alguno, observándose en los histogramas una distribución prácticamente idéntica a la de la muestra control. Los compuestos que ejercen efecto sobre el ciclo celular también son capaces de despolimerizar mayoritariamente la red de microtúbulos a la concentración ensayada.

Respecto a la inhibición de la expresión génica, los compuestos ensayados presentan mayor actividad frente a los genes VEGF y hTERT que frente al $c-M y c$, mejorando en algunos casos la actividad de CA-4. El 
compuesto con mejor actividad antigénica global es 3.18 (L-Met), capaz de reducir la expresión de los tres genes hasta un 37-55\%.

\subsection{Evaluación biológica de los compuestos de la familia 2}

\section{2.a. Inhibición de la proliferación celular}

Para todos los compuestos de la familia 2 se determinó la inhibición de la proliferación celular sobre las líneas celulares tumorales HT-29, MCF-7 y A549 y sobre la línea celular no tumoral HEK-293, mediante la medida de sus valores de $I_{50}$. Dichos valores de $I_{50}$ se obtuvieron mediante ensayo con MTT después de 48 horas de incubación. En la Tabla 4.2.1 se presentan los resultados obtenidos junto con los índices de selectividad.

Tabla 4.2.1. Valores de $I_{50}(\mathrm{nM})$ e índices de selectividad

\begin{tabular}{|c|c|c|c|c|c|c|c|}
\hline \multirow{2}{*}{ Comp. } & \multicolumn{4}{|c|}{$\mathrm{IC}_{50} \pm \mathrm{SD}(\mathrm{nM})$} & \multicolumn{3}{|c|}{$\begin{array}{l}\text { Índices de } \\
\text { selectividad }\end{array}$} \\
\hline & HT-29 & MCF-7 & A-549 & HEK-293 & $I_{\mathrm{A}}$ & $\mathrm{IS}_{\mathrm{B}}$ & ISc \\
\hline CA-4 & $4200 \pm 500$ & $1000 \pm 200$ & $428 \pm 4$ & $25000 \pm 3000$ & 5.9 & 25 & 60 \\
\hline AmCA-4 & $22 \pm 1$ & $8 \pm 1$ & $117 \pm 7$ & $7 \pm 1$ & 0.3 & 0.9 & 0.06 \\
\hline 3.29 (Fmoc-Gly) & $7 \pm 4$ & $4.8 \pm 0.5$ & $186 \pm 11$ & $3.5 \pm 1.9$ & 0.5 & 0.7 & 0.02 \\
\hline 3.30 (Fmoc-L-Ala) & $1.1 \pm 0.4$ & $1.9 \pm 0.8$ & $242 \pm 13$ & $1.5 \pm 0.6$ & 1.4 & 0.8 & 0.01 \\
\hline 3.31 (Fmoc-L-Val) & $130 \pm 40$ & $100 \pm 50$ & $870 \pm 60$ & $60 \pm 20$ & 0.5 & 0.6 & 0.07 \\
\hline 3.32 (Fmoc-L-Leu) & $23 \pm 10$ & $9 \pm 2$ & $490 \pm 13$ & $14 \pm 3$ & 0.6 & 1.6 & 0.03 \\
\hline 3.33 (Fmoc-L-Phe) & $8 \pm 3$ & $14 \pm 4$ & $270 \pm 50$ & $2.3 \pm 2$ & 0.3 & 0.2 & 0.01 \\
\hline 3.34 (Fmoc-L-Pro) & $320 \pm 140$ & $58 \pm 12$ & $1330 \pm 90$ & $130 \pm 30$ & 0.4 & 2.2 & 0.1 \\
\hline 3.35 (Fmoc-L-Thr) & $9 \pm 3$ & $25 \pm 12$ & $422 \pm 8$ & $13 \pm 2$ & 1.4 & 0.5 & 0.03 \\
\hline 3.36 (Fmoc-L-Tyr) & $18 \pm 5$ & $12 \pm 2$ & $8900 \pm 1200$ & $16 \pm 2$ & 0.9 & 1.3 & 0.01 \\
\hline 3.37 (Fmoc-L-Met) & $33 \pm 20$ & $5.1 \pm 0.3$ & $407 \pm 23$ & $8 \pm 4$ & 0.2 & 1.6 & 0.02 \\
\hline 3.38 (Gly) & $10 \pm 2$ & $9 \pm 4$ & $400 \pm 70$ & $10 \pm 2$ & 1.0 & 1.1 & 0.02 \\
\hline 3.39 (L-Ala) & $3.0 \pm 0.3$ & $4.8 \pm 0.5$ & $611 \pm 16$ & $4.0 \pm 0.1$ & 1.3 & 0.8 & 0.01 \\
\hline 3.40 (L-Val) & $13.3 \pm 0.5$ & $13 \pm 2$ & $490 \pm 100$ & $7.6 \pm 0.3$ & 0.6 & 0.6 & 0.02 \\
\hline 3.41 (L-Leu) & $1.8 \pm 0.4$ & $1.8 \pm 1.2$ & $167 \pm 23$ & $1.7 \pm 0.8$ & 0.9 & 0.9 & 0.01 \\
\hline 3.42 (L-Phe) & $4.4 \pm 2.5$ & $2.3 \pm 1.5$ & $141 \pm 3$ & $3.5 \pm 1.9$ & 0.8 & 1.5 & 0.02 \\
\hline 3.43 (L-Pro) & $700 \pm 200$ & $3100 \pm 600$ & $1200 \pm 300$ & $2400 \pm 1400$ & 3.4 & 0.8 & 2.0 \\
\hline 3.44 (L-Thr) & $8 \pm 2$ & $12 \pm 1$ & $410 \pm 40$ & $14 \pm 3$ & 1.8 & 1.1 & 0.03 \\
\hline 3.45 (L-Tyr) & $2.2 \pm 1.2$ & $4.9 \pm 0.2$ & $206 \pm 20$ & $2.7 \pm 1.4$ & 1.2 & 0.5 & 0.01 \\
\hline
\end{tabular}




\begin{tabular}{|c|c|c|c|c|c|c|c|}
\hline 3.46 (L-Met) & $4.9 \pm 0.1$ & $3.4 \pm 1.2$ & $90 \pm 30$ & $3.7 \pm 0.3$ & 0.7 & 1.1 & 0.04 \\
\hline 3.47 (Fmoc-D-Val) & $5500 \pm 700$ & $4800 \pm 500$ & $7340 \pm 230$ & $5100 \pm 700$ & 0.9 & 1.1 & 0.7 \\
\hline $\mathbf{3 . 4 8}$ (Fmoc-D-Leu) & $44000 \pm 6000$ & $3100 \pm 500$ & $48000 \pm 3000$ & $2400 \pm 400$ & 0.05 & 0.8 & 0.05 \\
\hline 3.49 (Fmoc-D-Phe) & $13000 \pm 5000$ & $4500 \pm 1700$ & $18500 \pm 1700$ & $11200 \pm 1500$ & 0.9 & 2.5 & 0.6 \\
\hline $\mathbf{3 . 5 0}$ (Fmoc-D-Pro) & $5300 \pm 300$ & $5300 \pm 1100$ & $12800 \pm 800$ & $3100 \pm 1100$ & 0.6 & 0.6 & 0.2 \\
\hline 3.51 (D-Val) & $4800 \pm 600$ & $4700 \pm 700$ & $9900 \pm 1300$ & $2400 \pm 300$ & 0.5 & 0.5 & 0.2 \\
\hline 3.52 (D-Leu) & $1050 \pm 140$ & $2000 \pm 900$ & $157 \pm 7$ & $430 \pm 40$ & 0.4 & 0.2 & 2.7 \\
\hline 3.53 (D-Phe) & $3900 \pm 800$ & $2000 \pm 800$ & $2900 \pm 500$ & $3500 \pm 900$ & 0.9 & 1.8 & 1.2 \\
\hline 3.54 (D-Pro) & $4400 \pm 1900$ & $600 \pm 140$ & $7030 \pm 220$ & $3000 \pm 600$ & 0.7 & 5.0 & 0.4 \\
\hline
\end{tabular}

Los derivados de esta familia muestran importantes diferencias en la actividad antiproliferativa, que depende de la configuración del aminoácido. Así, los que incorporan aminoácidos de la serie $L$ presentan valores de $\mathrm{IC}_{50}$ en el rango nanomolar, del mismo orden de magnitud, en general, que la AmCA-4 y mucho más activos que el producto natural CA-4. Destacan los compuestos 3.30 (Fmoc-L-Ala), 3.39 (L-Ala), 3.41 (L-Leu), 3.42 (L-Phe), 3.45 (L-Tyr) y 3.46 (L-Met) con valores de $\mathrm{IC}_{50}$ inferiores a $5 \mathrm{nM}$ en las líneas celulares $\mathrm{HT}$-29, MCF-7 y HEK-293. Los menos activos de la serie $L$ son los que contienen el aminoácido prolina (3.34 y 3.43). En cuanto a los índices de selectividad, los valores más altos se consiguen en la línea celular HT-29 para los derivados 3.30 (Fmoc-L-Ala), 3.35 (Fmoc-L-Thr), 3.39 (L-Ala), 3.43 (L-Pro), 3.44 (L-Thr) y 3.45 (L-Tyr), con valores superiores a 1, mayores que los de AmCA-4 pero inferiores a los de CA-4. Para la línea celular A-549 los valores de $\mathrm{IC}_{50}$ se sitúan un par de órdenes de magnitud por encima de los obtenidos en las otras dos líneas celulares tumorales, con índices de selectividad en esta línea celular semejantes a los de AmCA-4. Por otra parte, los derivados de la serie $\mathrm{D}, \mathbf{3 . 4 7 - 3 . 5 4}$, presentan valores de $\mathrm{IC}_{50}$ en el rango micromolar, por tanto con actividad similar a la de de CA-4 o incluso menor. Únicamente 3.52 (D-Leu) exhibe actividad antiproliferativa en el rango nanomolar alto en A-549 y un alto IS (2.7). 
Para los compuestos de este grupo se ha comprobado el cumplimiento de "la regla de los cinco" de Lipinski. En la tabla 4.2.2 se muestran los valores obtenidos.

Tabla 4.2.2. Comprobación de la regla de Lipinski

\begin{tabular}{|c|c|c|c|c|c|}
\hline Compuesto & $\log P$ & PM g/mol & $\mathrm{OH}+\mathrm{NH}$ & $\mathrm{N}+\mathrm{O}$ & No cumple \\
\hline CA-4 & 3.33 & 316.35 & 1 & 5 & - \\
\hline AmCA-4 & 2.92 & 315.37 & 1 & 5 & - \\
\hline 3.29 (Fmoc-Gly) & 5.3 & 594.66 & 2 & 9 & 2 \\
\hline 3.30 (Fmoc-L-Ala) & 5.8 & 608.69 & 2 & 9 & 2 \\
\hline 3.31 (Fmoc-L-Val) & 6.68 & 636.75 & 2 & 9 & 2 \\
\hline 3.32 (Fmoc-L-Leu) & 7.03 & 650.77 & 2 & 9 & 2 \\
\hline 3.33 (Fmoc-L-Phe) & 7.47 & 684.79 & 2 & 9 & 2 \\
\hline 3.34 (Fmoc-L-Pro) & 6.01 & 634.73 & 1 & 9 & 2 \\
\hline 3.35 (Fmoc-L-Thr) & 5.26 & 638.72 & 3 & 10 & 3 \\
\hline 3.36 (Fmoc-L-Tyr) & 7.08 & 700.79 & 3 & 10 & 3 \\
\hline 3.37 (Fmoc-L-Met) & 6.13 & 669.81 & 2 & 9 & 2 \\
\hline 3.38 (Gly) & 1.55 & 372.42 & 2 & 7 & - \\
\hline 3.39 (L-Ala) & 2.04 & 386.45 & 2 & 7 & - \\
\hline 3.40 (L-Val) & 2.92 & 414.50 & 2 & 7 & - \\
\hline 3.41 (L-Leu) & 3.27 & 428.53 & 2 & 7 & - \\
\hline 3.42 (L-Phe) & 3.71 & 462.55 & 2 & 7 & - \\
\hline 3.43 (L-Pro) & 2.54 & 412.49 & 2 & 7 & - \\
\hline 3.44 (L-Thr) & 1.5 & 416.47 & 3 & 8 & - \\
\hline 3.45 (L-Tyr) & 3.32 & 478.55 & 3 & 8 & - \\
\hline 3.46 (L-Met) & 2.37 & 446.56 & 2 & 7 & - \\
\hline 3.47 (Fmoc-D-Val) & 6.68 & 636.75 & 2 & 9 & 2 \\
\hline 3.48 (Fmoc-D-Leu) & 7.03 & 650.77 & 2 & 9 & 2 \\
\hline 3.49 (Fmoc-D-Phe) & 7.47 & 684.79 & 2 & 9 & 2 \\
\hline 3.50 (Fmoc-D-Pro) & 6.01 & 634.73 & 1 & 9 & 2 \\
\hline 3.51 (D-Val) & 2.92 & 414.50 & 2 & 7 & - \\
\hline 3.52 (D-Leu) & 3.27 & 428.53 & 2 & 7 & - \\
\hline 3.53 (D-Phe) & 3.71 & 462.55 & 2 & 7 & - \\
\hline 3.54 (D-Pro) & 2.54 & 412.49 & 2 & 7 & - \\
\hline
\end{tabular}


A diferencia de los compuestos de la familia 1, en este caso son varios los compuestos que incumplen dos o más condiciones. De este modo, los derivados protegidos 3.29-3.37 y 3.47-3.50 incumplen tanto el valor logP, que debe ser inferior a 5, como la condición referente al peso molecular, que debe ser inferior a $500 \mathrm{~g} / \mathrm{mol}$. Estos incumplimientos se deben a la presencia del grupo protector Fmoc, muy voluminoso y lipofílico, lo que resta hidrofilia a estos derivados. Cabe mencionar también que los derivados 3.35 y 3.36, los cuales llevan incorporados residuos de treonina y tirosina, respectivamente, y están protegidos con Fmoc, llegan además al límite de 10 aceptores de enlaces de hidrógeno. El resto de compuestos 3.38-3.46 y 3.51-5.54 cumple todos los requerimientos de Lipinski.

\section{2.b. Efecto sobre el ensamblaje de los microtúbulos}

El ensamblaje de los microtúbulos se ensayó a una concentración de 27.5 $\mu \mathrm{M}$ de ligando en un tampón de ensamblaje de glicerol (GAB) y GTP al que se le añadió tubulina en concentración de $25 \mu \mathrm{M}$. En la tabla 4.2 .3 se muestran los resultados obtenidos y se comparan con los obtenidos en ausencia de ligando (control) y en presencia de CA-4 y AmCA-4 como compuestos patrón.

Tabla 4.2.3. Valores de $\mathrm{CrC}$

\begin{tabular}{|c|c|}
\hline Comp. & CrC $(\mu \mathrm{M})$ \\
\hline Control & $7.9 \pm 1.2$ \\
\hline CA-4 & $21.5 \pm 0.8$ \\
\hline AmCA-4 & $23 \pm 3$ \\
\hline 3.29 (Fmoc-Gly) & $11 \pm 4$ \\
\hline 3.30 (Fmoc-L-Ala) & $9.4 \pm 0.3$ \\
\hline 3.31 (Fmoc-L-Val) & $6.9 \pm 0.3$ \\
\hline 3.32 (Fmoc-L-Leu) & $9.9 \pm 0.8$ \\
\hline 3.33 (Fmoc-L-Phe) & $8.1 \pm 1.6$ \\
\hline 3.34 (Fmoc-L-Pro) & $6.0 \pm 0.5$ \\
\hline 3.35 (Fmoc-L-Thr) & $12.0 \pm 0.3$ \\
\hline
\end{tabular}

\begin{tabular}{|c|c|}
\hline Comp. & $\operatorname{CrC}(\mu \mathrm{M})$ \\
\hline $\mathbf{3 . 3 6}$ (Fmoc-L-Tyr) & $10.1 \pm 1.1$ \\
\hline $\mathbf{3 . 3 7}$ (Fmoc-L-Met) & $7.1 \pm 0.4$ \\
\hline $\mathbf{3 . 3 8}$ (Gly) & $10.2 \pm 1.8$ \\
\hline $\mathbf{3 . 3 9}$ (L-Ala) & $13.9 \pm 1.5$ \\
\hline $\mathbf{3 . 4 0}$ (L-Val) & $9.3 \pm 0.5$ \\
\hline $\mathbf{3 . 4 1}$ (L-Leu) & $8.3 \pm 0.3$ \\
\hline $\mathbf{3 . 4 2}$ (L-Phe) & $9.1 \pm 0.9$ \\
\hline $\mathbf{3 . 4 3}$ (L-Pro) & $8.4 \pm 0.1$ \\
\hline $\mathbf{3 . 4 4}$ (L-Thr) & $12.3 \pm 0.6$ \\
\hline $\mathbf{3 . 4 5}$ (L-Tyr) & $7.7 \pm 0.8$ \\
\hline
\end{tabular}

\begin{tabular}{|c|c|}
\hline Comp. & $\mathrm{CrC}(\boldsymbol{\mu M})$ \\
\hline $\mathbf{3 . 4 6}$ (L-Met) & $8.5 \pm 1.2$ \\
\hline $\mathbf{3 . 4 7}$ (Fmoc-D-Val) & $8.9 \pm 1.5$ \\
\hline $\mathbf{3 . 4 8}$ (Fmoc-D-Leu) & $6.5 \pm 0.7$ \\
\hline $\mathbf{3 . 4 9}$ (Fmoc-D-Phe) & $6.6 \pm 0.2$ \\
\hline $\mathbf{3 . 5 0}$ (Fmoc-D-Pro) & $11.4 \pm 0.2$ \\
\hline $\mathbf{3 . 5 1}$ (D-Val) & $12.8 \pm 0.3$ \\
\hline $\mathbf{3 . 5 2}$ (D-Leu) & $7.0 \pm 0.5$ \\
\hline $\mathbf{3 . 5 3}$ (D-Phe) & $7.7 \pm 2.1$ \\
\hline $\mathbf{3 . 5 4}$ (D-Pro) & $8.7 \pm 1.2$ \\
\hline \multicolumn{2}{|l}{} \\
\end{tabular}


La mayor parte de los derivados no presentan valores de $\mathrm{CrC}$ significativamente distintos al valor medido en el control. Cabe destacar que los compuestos 3.29 (Fmoc-Gly), 3.35 (Fmoc-L-Thr), 3.38 (Gly), 3.39 (L-Ala), 3.44 (L-Thr), 3.50 (Fmoc-D-Pro) y 3.51 (D-Val) presentan valores de $\mathrm{CrC}$ de entre 10-14 $\mu \mathrm{M}$, superiores a los del control aunque muy inferiores a los de los compuestos de referencia CA-4 y AmCA-4.

El estudio del proceso de polimerización de la tubulina mediante turbidimetría se midió a $350 \mathrm{~nm}$ y $37^{\circ} \mathrm{C}$ y se muestra en la figura 4.2.1 para los compuestos 3.29 (Fmoc-Gly), 3.35 (Fmoc-L-Thr), 3.38 (Gly), 3.39 (L-Ala), 3.44 (L-Thr), 3.50 (Fmoc-D-Pro) y 3.51 (D-Val), que tenían un mayor valor de CrC. En la figura también se incluyen las curvas de polimerización en presencia de CA-4 y AmCA-4 y de paclitaxel, que es un estabilizador de microtúbulos.

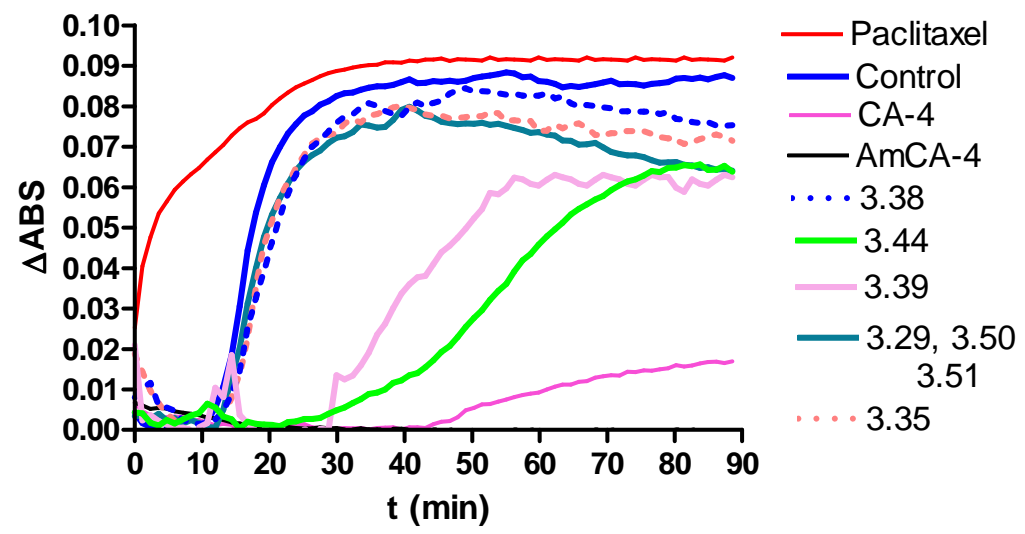

Figura 4.2.1. Cinética de polimerización de tubulina.

En la figura anterior se puede observar la casi nula absorbancia que se mide en presencia de CA-4 y AmCA-4, lo que es indicativo de la inhibición del proceso de polimerización que provocan estos dos compuestos (la línea correspondiente a AmCA-4 aparece en la parte inferior de la figura, solapada con el eje de abcisas). Por otro lado, se puede ver la elevada absorbancia que se mide en el proceso de polimerización cuando éste se lleva a cabo en presencia del paclitaxel, que es un agente favorecedor de la polimerización. 
En este caso la fase de meseta se alcanza 30 minutos después del comienzo del proceso.

Los derivados sintéticos no ejercen efectos significativos. Solamente los derivados 3.39 (L-Ala) y 3.44 (L-Thr) son capaces de retrasar el proceso de polimerización.

Los valores de $\mathrm{It}_{50}$, que indican el tiempo transcurrido hasta alcanzarse el $50 \%$ en la polimerización, se dan en la tabla 4.2.4.

Tabla 4.2.4. Valores de $\mathrm{It}_{50}$

\begin{tabular}{|c|c|}
\hline Compuesto & It $_{50}(\mathrm{~min})$ \\
\hline Control & $16.6 \pm 1.0$ \\
\hline $\mathbf{3 . 2 9}$ (Fmoc-Gly) & $16 \pm 3$ \\
\hline $\mathbf{3 . 3 5}$ (Fmoc-L-Thr) & $19.2 \pm 0.3$ \\
\hline $\mathbf{3 . 3 8}$ (Gly) & $18.5 \pm 2.1$ \\
\hline $\mathbf{3 . 3 9}$ (L-Ala) & $48 \pm 5$ \\
\hline $\mathbf{3 . 4 4}$ (L-Thr) & $65 \pm 7$ \\
\hline $\mathbf{3 . 5 0}$ (Fmoc-D-Pro) & $16.5 \pm 0.3$ \\
\hline $\mathbf{3 . 5 1}$ (D-Val) & $17.1 \pm 1.3$ \\
\hline
\end{tabular}

Con el control (ausencia de ligando) y con la mayoría de derivados, se alcanza el 50\% de la polimerización entre los 16-20 minutos. Sin embargo, con el derivado 3.39 (L-Ala) el proceso sufre una demora de casi 50 minutos, mientras que para el derivado 3.44 (L-Thr) el retraso es de 65 minutos, por lo que se podría clasificar a estos dos compuestos como inhibidores parciales del proceso de polimerización.

\section{2.c. Efecto sobre el ciclo celular}

Los efectos de algunos de derivados sobre el ciclo celular se evaluaron en células A-549. Los derivados se seleccionaron después de observar la morfología celular, realizándose el ensayo solo en aquellos compuestos en los que se detectaron células paradas en mitosis, es decir, células redondeadas y ligeramente despegadas de la base inferior de la placa. También se estudió el 
compuesto 3.51 (D-Val), que ejercía un menor efecto antimitótico, con el fin de comparar su efecto con los del resto de derivados. En los histogramas que se indican en la figura 4.2.2, se puede apreciar que la muestra control prácticamente no presenta células acumuladas en fase G2/M mientras que para AmCA-4 se observa una mayoría de células en G2/M, situación similar a la que se había observado anteriormente para CA-4.

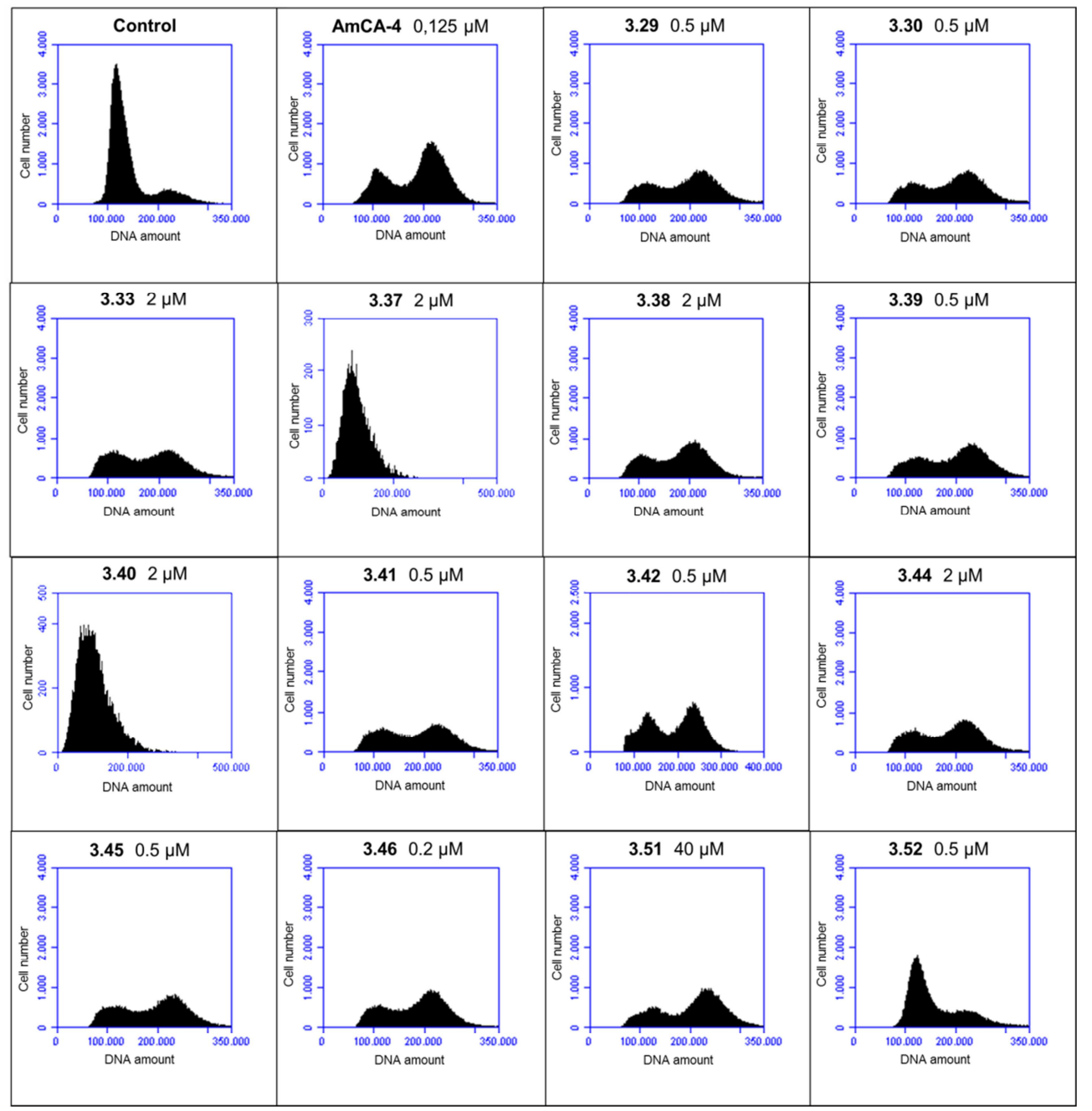

Figura 4.2.2 Histogramas del ciclo celular de CA-4 y compuestos seleccionados de la familia 2. 
Los derivados 3.29 (Fmoc-Gly), 3.30 (Fmoc-L-Ala), 3.38 (Gly), 3.39 (L-Ala), 3.45 (L-Tyr), 3.46 (L-Met) y 3.51 (D-Val) son capaces de acumular más del $50 \%$ de las células en fase $\mathrm{G} 2 / \mathrm{M}$, valores semejantes a los que presentan $\mathrm{CA}$ 4 y AmCA-4 y muy superiores a los que presenta el control (14\%), si bien a concentraciones superiores a las de este compuesto. Los derivados $\mathbf{3 . 3 7}$ (Fmoc-L-Met), 3.40 (L-Val) y $\mathbf{3 . 5 2}$ (D-Leu) no acumulan significativamente células en G2/M y el resto de derivados de la familia se encuentran en una situación intermedia entre las comentadas anteriormente.

Los resultados se presentan en la tabla 4.2.5 en forma numérica, así como las concentraciones de ligando a las que se realizó el ensayo.

Tabla 4.2.5. Distribución del ciclo celular en la familia 2

\begin{tabular}{|c|c|c|c|c|}
\hline Compuesto & Conc. $(\mu \mathrm{M})$ & G0/G1 & S & G2/M \\
\hline Control & - & $75 \pm 4$ & $11 \pm 2$ & $14 \pm 2$ \\
\hline CA-4 & 0.05 & $25 \pm 1$ & $15 \pm 1$ & $60 \pm 2$ \\
\hline AmCA-4 & 0.125 & $26 \pm 1$ & $15 \pm 2$ & $59 \pm 2$ \\
\hline 3.29 (Fmoc-Gly) & 0.5 & $28 \pm 1$ & $18 \pm 2$ & $54 \pm 1$ \\
\hline 3.30 (Fmoc-L-Ala) & 0.5 & $28 \pm 1$ & $19 \pm 2$ & $53 \pm 2$ \\
\hline 3.33 (Fmoc-L-Phe) & 2 & $34 \pm 2$ & $20 \pm 1$ & $46 \pm 3$ \\
\hline 3.37 (Fmoc-L-Met) & 2 & $72 \pm 2$ & $18 \pm 1$ & $10 \pm 3$ \\
\hline 3.38 (Gly) & 2 & $32 \pm 5$ & $22 \pm 2$ & $46 \pm 4$ \\
\hline 3.39 (L-Ala) & 3 & $28 \pm 1$ & $14 \pm 4$ & $58 \pm 5$ \\
\hline 3.40 (L-Val) & 2 & $65 \pm 2$ & $20 \pm 1$ & $15 \pm 2$ \\
\hline 3.41 (L-Leu) & 0.5 & $35 \pm 1$ & $17 \pm 2$ & $48 \pm 1$ \\
\hline 3.42 (L-Phe) & 0.5 & $46 \pm 2$ & $28 \pm 11$ & $26 \pm 10$ \\
\hline 3.44 (L-Thr) & 2 & $31 \pm 1$ & $18 \pm 1$ & $51 \pm 2$ \\
\hline 3.45 (L-Tyr) & 0.5 & $30 \pm 2$ & $18 \pm 1$ & $52 \pm 3$ \\
\hline 3.46 (L-Met) & 0.2 & $30 \pm 1$ & $19 \pm 1$ & $51 \pm 2$ \\
\hline 3.51 (D-Val) & 40 & $26 \pm 2$ & $14 \pm 1$ & $60 \pm 1$ \\
\hline 3.52 (D-Leu) & 0.5 & $63 \pm 4$ & $16 \pm 3$ & $22 \pm 2$ \\
\hline
\end{tabular}




\section{2.d. Efecto sobre la red de microtúbulos celulares}

El efecto de algunos de los derivados la familia 2 sobre la red de microtúbulos celulares se estudió sobre células A-549. Los compuestos seleccionados fueron 3.29 (Fmoc-Gly) $(0.5 \mu \mathrm{M})$, 3.38 (Gly) $(2 \mu \mathrm{M})$, 3.39 (L-Ala) (3 $\mu \mathrm{M})$ y 3.51 (D-Val) $(40 \mu \mathrm{M})$, que eran los que ejercían más efecto sobre el ciclo celular, y también el compuesto 3.42 (L-Phe) $(0.5 \mu \mathrm{M})$, que se escogió por presentar un bajo $\mathrm{IC}_{50}$ y el derivado 3.52 (D-Leu) $(0.5 \mu \mathrm{M})$, que se eligió como compuesto de referencia porque no destaca por su actividad antiproliferativa, ni por su acción sobre el ensamblaje de microtúbulos ni en el ciclo celular.

En la figura 4.2.2 se puede ver como AmCA-4 (panel B) despolimeriza en gran medida los microtúbulos a una concentración de $50 \mathrm{nM}$. Por otra parte, los derivados 3.29 (Fmoc-Gly) (C), 3.38 (Gly) (D), 3.39 (L-Ala) (E) y 3.51 (DVal) (G), que acumulan células en fase $G 2 / M$, provocan también la despolimerización casi total de la red de microtúbulos, aunque en concentraciones superiores a AmCA-4. Los derivados 3.42 (L-Phe) (F) y $\mathbf{3 . 5 2}$ (D-Leu) $(\mathrm{H})$ se muestran mucho menos activos, aunque se puede observar cierta afectación en la red de microtúbulos.
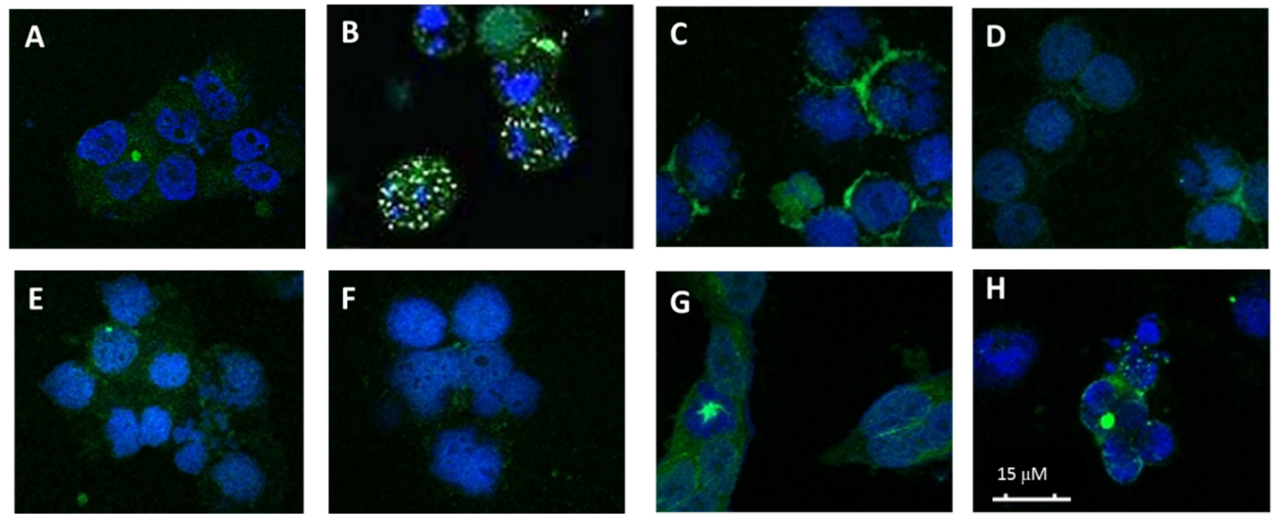

Figura 4.2.2. Efectos sobre la red de microtúbulos celulares. (A) DMSO, (B) $50 \mathrm{nM}$ AmCA-4, (C) $0.5 \mu \mathrm{M}$ de 3.29 (Fmoc-Gly), (D) $2 \mu \mathrm{M}$ de 3.38 (Gly), (E) $3 \mu \mathrm{M}$ de 3.39 (LAla), (F) $0.5 \mu \mathrm{M}$ de 3.42 (L-Phe), (G) $40 \mu \mathrm{M}$ de 3.51 (D-Val) y (H) $0.5 \mu \mathrm{M}$ de 3.52 (DLeu). 


\section{2.e. Efecto sobre la expresión de genes VEGF, hTERT y c-Myc}

El efecto sobre la expresión de los genes VEGF, hTERT y $c-M y c$ se ha estudiado sobre los derivados que muestran $\mathrm{IC}_{50}$ en el rango nanomolar bajo en la línea celular HT-29 (compuestos 3.30, 3.35, 3.39, 3.44 y 3.45) y/o cuyo índice de selectividad respecto a esta línea celular es mayor de 1 (3.29, 3.31, 3.32, 3.43, 3.36-3.38, 3.40-3.42 y 3.46). En la tabla 4.2 .6 se muestran las concentraciones a las cuales se ha medido el efecto de los compuestos. En todos los casos la concentración elegida para un compuesto determinado es similar o ligeramente inferior a su valor de $\mathrm{IC}_{50}$.

Tabla 4.2.6. Concentraciones empleadas

\begin{tabular}{|c|c|}
\hline Compuesto & Conc. (nM) \\
\hline CA-4 & $15(\mu \mathrm{M})$ \\
\hline AmCA-4 & 15 \\
\hline $\mathbf{3 . 2 9}$ (Fmoc-Gly) & 7 \\
\hline $\mathbf{3 . 3 0}$ (Fmoc-L-Ala) & 1.5 \\
\hline $\mathbf{3 . 3 1}$ (Fmoc-L-Val) & 4 \\
\hline $\mathbf{3 . 3 2}$ (Fmoc-L-Leu) & 15 \\
\hline $\mathbf{3 . 3 3}$ (Fmoc-L-Phe) & 2 \\
\hline $\mathbf{3 . 3 5}$ (Fmoc-L-Thr) & 7 \\
\hline $\mathbf{3 . 3 6}$ (Fmoc-L-Tyr) & 15 \\
\hline
\end{tabular}

\begin{tabular}{|c|c|}
\hline Compuesto & Conc. (nM) \\
\hline $\mathbf{3 . 3 7}$ (Fmoc-L-Met) & 30 \\
\hline $\mathbf{3 . 3 8}$ (Gly) & 7 \\
\hline $\mathbf{3 . 3 9}$ (L-Ala) & 3 \\
\hline $\mathbf{3 . 4 0}$ (L-Val) & 10 \\
\hline $\mathbf{3 . 4 1}$ (L-Leu) & 1.5 \\
\hline $\mathbf{3 . 4 2}$ (L-Phe) & 4 \\
\hline $\mathbf{3 . 4 4}$ (L-Thr) & 7 \\
\hline $\mathbf{3 . 4 5}$ (L-Tyr) & 3 \\
\hline $\mathbf{3 . 4 6}$ (L-Met) & 4 \\
\hline
\end{tabular}

La expresión de los genes se determinó mediante la metodología RTqPCR, tal y como se describe en la Sección Experimental. Los resultados se presentan en la figura 4.2.3 que muestra el porcentaje de expresión de cada gen después de $48 \mathrm{~h}$ de incubación en presencia de DMSO (control), de CA-4, de AmCA-4 y de cada uno de los derivados.

Por lo que respecta a la expresión del gen VEGF, la mitad de los compuestos sintéticos presentan porcentajes de expresión inferiores al $40 \%$, valores inferiores a los de CA-4 y AmCA-4. Los porcentajes más destacados 
son los de 3.30 (Fmoc-L-Ala) (25\%), 3.31 (Fmoc-L-Val) (23\%), 3.33 (Fmoc-LPhe) (16\%), 3.38 (Gly) (24\%) y 3.44 (L-Thr) (15\%).
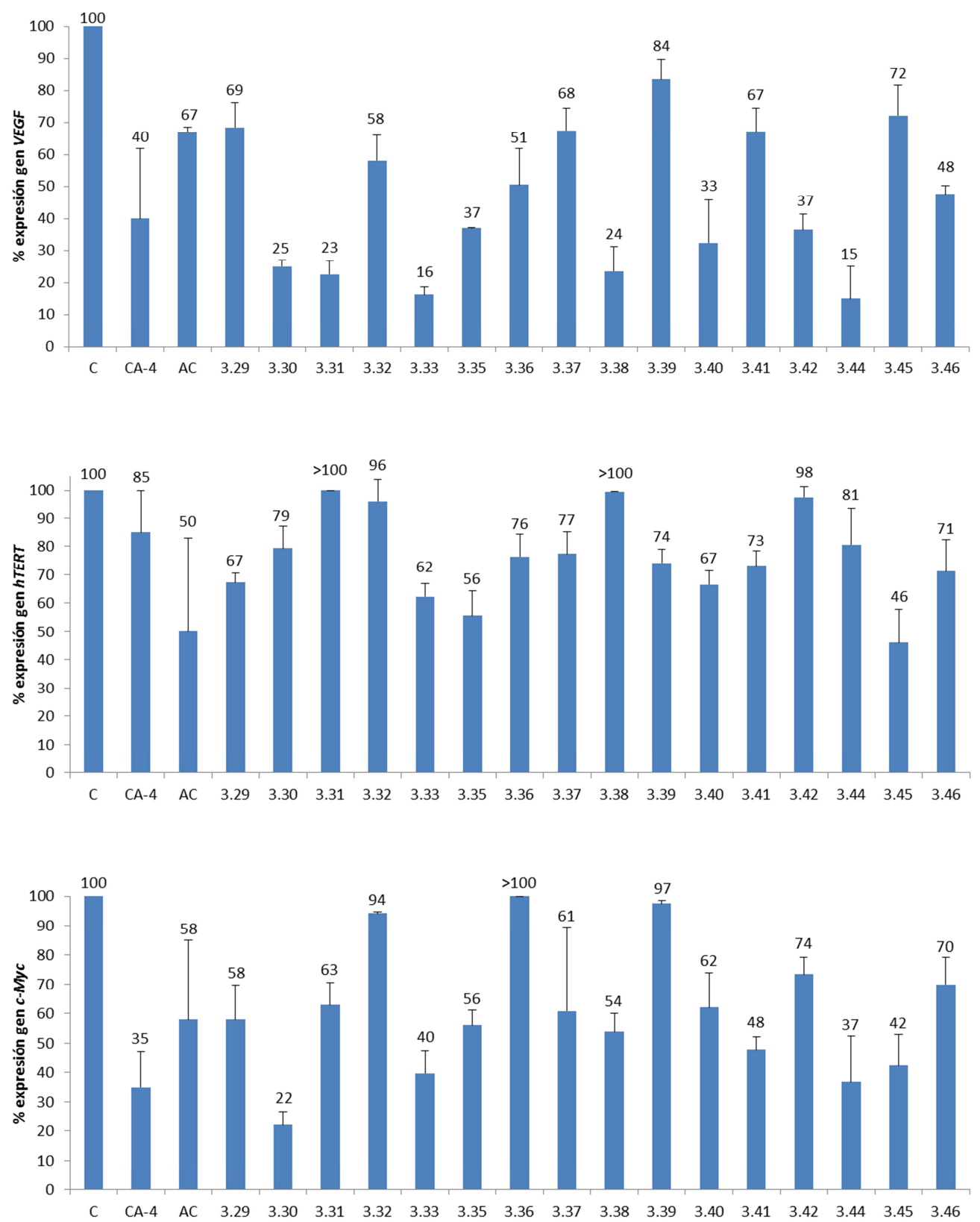

Figura 4.2.3. Porcentajes de expresión de genes. 
En relación a la expresión del gen $h T E R T$, los derivados de la familia 2 no se muestran tan activos como en el caso del gen VEGF. El compuesto más destacado es 3.45 (L-Tyr) (46\%), que mejora los porcentajes tanto de CA-4 como de AmCA-4, mientras que los derivados 3.29 (Fmoc-Gly), 3.33 (Fmoc-LPhe), 3.35 (Fmoc-L-Thr) y $\mathbf{3 . 4 0}$ (L-Val), con porcentajes de expresión inferiores al 70\% són más activos que CA-4 y se encuentran al mismo nivel que AmCA4.

Para el gen $c-M y c$, la mayor parte de derivados ejercen un efecto bastante destacado, especialmente 3.30 (Fmoc-L-Ala), que reduce la expresión hasta el $22 \%$, y se muestra más activo que los compuestos de referencia CA-4 y AmCA-4. También merecen ser destacados los compuestos 3.33 (Fmoc-LPhe) (40\%), 3.41 (L-Leu) (48\%), 3.44 (L-Thr) (37\%) y 3.45 (L-Tyr) (42\%), que consiguen disminuir a la mitad la expresión del gen c-Myc.

El compuesto más destacable en la inhibición de la expresión de genes es 3.33 (Fmoc-L-Phe), que se muestra muy activo en la inhibición de los tres genes estudiados.

\section{2.f. Conclusión}

Los derivados de AmCA-4 con aminoácidos presentan actividades antiproliferativas muy diferentes según sea la configuración del aminoácido que incorporan en su estructura. Los derivados con aminoácidos de la serie $L$ presentan valores de $\mathrm{IC}_{50}$ en el rango nanomolar para las líneas celulares $\mathrm{HT}$ 29, MCF-7 y HEK-293, mientras que para la línea celular A-549 los valores son de un par de órdenes de magnitud superiores. Así, los derivados 3.30 (Fmoc-L-Ala), 3.39 (L-Ala), 3.41 (L-Leu), 3.42 (L-Phe), 3.45 (L-Tyr) y 3.46 (LMet) presentan valores inferiores a $5 \mathrm{nM}$ para las tres líneas celulares. Además, para la línea celular HT-29, los derivados 3.30 (Fmoc-L-Ala), 3.35 (Fmoc-L-Thr), 3.39 (L-Ala), 3.43 (L-Pro), 3.44 (L-Thr) y 3.45 (L-Tyr) muestran

índices de selectividad superiores a 1 . Por otro lado, los derivados con 
aminoácidos de la serie D muestran actividades antiproliferativas para todas las líneas celulares en el intervalo micromolar.

En cuanto a la capacidad de inhibición de la polimerización in vitro de tubulina, ningún derivado de la familia 2 alcanza los valores de AmCA-4 o CA4. Solo los compuestos 3.39 (L-Ala) y 3.44 (L-Thr) consiguen retrasar apreciablemente el proceso de polimerización, con lo cual podrían ser considerados como inhibidores parciales del proceso de polimerización.

La mayor parte de los derivados estudiados afectan al desarrollo normal del ciclo celular y son capaces de acumular células en fase $\mathrm{G} 2 / \mathrm{M}$, aunque los derivados 3.37 (Fmoc-L-Met), $\mathbf{3 . 4 0}$ (L-Val) y $\mathbf{3 . 5 2}$ (D-Leu) no producen cambios significativos respecto del control. Los derivados que acumulan células en fase G2/M también despolimerizan casi totalmente la red de microtúbulos como se aprecia en los ensayos de immunofluorescencia.

Respecto a la inhibición de la expresión génica, la mitad de los derivados con $\mathrm{IC}_{50}$ más bajo reducen la expresión de VEGF hasta más del $40 \%$, destacando los derivados 3.30 (Fmoc-L-Ala) (25\%), 3.31 (Fmoc-L-Val) (23\%), 3.33 (Fmoc-L-Phe) (16\%), 3.38 (Gly) (24\%) y 3.44 (L-Thr) (15\%). Sobre hTERT la actividad es menor y se muestran muy activos frente a $c-M y c$, destacando 3.30 (Fmoc-L-Ala) (22\%). El más activo de todos los derivados es el 3.33 (Fmoc-L-Phe), muy activo frente a los tres genes. 


\subsection{Evaluación biológica de los compuestos de la familia 3}

\section{3.a. Inhibición de la proliferación celular}

La inhibición de la proliferación celular de los compuestos $\mathbf{3 . 5 5 - 3 . 6 0}$ se estableció mediante la medida de sus valores $\mathrm{IC}_{50}$ en las líneas celulares tumorales HT-29, MCF-7 y A-549 y en la línea celular no tumoral HEK-293. Los valores de $\mathrm{IC}_{50}$ se obtuvieron mediante el ensayo con MTT después de 48 horas de incubación.Los resultados se presentan en la Tabla 4.3.1 junto con los índices de selectividad IS.

Tabla 4.3.1. Valores de $\mathrm{IC}_{50}(\mathrm{nM})$ e índices de selectividad

\begin{tabular}{|c|c|c|c|c|c|c|c|}
\hline \multirow{2}{*}{ Comp. } & \multicolumn{4}{|c|}{ IC $_{50 \pm S D}$ (nM) } & \multicolumn{3}{|c|}{$\begin{array}{c}\text { Índices de } \\
\text { selectividad }\end{array}$} \\
\cline { 2 - 8 } & HT-29 & MCF-7 & A-549 & HEK-293 & IS $_{\text {A }}$ & IS $_{\text {B }}$ & IS $_{C}$ \\
\hline CA-4 & $4200 \pm 500$ & $1000 \pm 200$ & $428 \pm 4$ & $25000 \pm 3000$ & 5.9 & 25 & 60 \\
\hline AmCA-4 & $22.0 \pm 0.7$ & $8.0 \pm 0.9$ & $117 \pm 7$ & $7.1 \pm 1.0$ & 0.3 & 0.9 & 0.06 \\
\hline $\mathbf{3 . 5 5}$ (But) & $230 \pm 30$ & $800 \pm 200$ & $510 \pm 90$ & $450 \pm 50$ & 2.0 & 0.6 & 0.9 \\
\hline $\mathbf{3 . 5 6}$ (Pent) & $14 \pm 5$ & $210 \pm 70$ & $280 \pm 2$ & $44 \pm 15$ & 3.1 & 0.2 & 0.1 \\
\hline $\mathbf{3 . 5 7}$ (Hex) & $36.8 \pm 0.2$ & $69 \pm 4$ & $560 \pm 90$ & $73 \pm 6$ & 2.0 & 1.1 & 0.1 \\
\hline $\mathbf{3 . 5 8}$ (Hept) & $18 \pm 7$ & $220 \pm 90$ & $980 \pm 80$ & $80 \pm 20$ & 4.4 & 0.4 & 0.08 \\
\hline $\mathbf{3 . 5 9}$ (Oct) & $590 \pm 110$ & $4900 \pm 1500$ & $1800 \pm 400$ & $1140 \pm 130$ & 1.9 & 0.2 & 0.6 \\
\hline $\mathbf{3 . 6 0}$ (Dod) & $3700 \pm 600$ & $8600 \pm 300$ & $8100 \pm 1200$ & $3200 \pm 1300$ & 0.9 & 0.4 & 0.4 \\
\hline
\end{tabular}

Todos los derivados exhiben su mayor actividad antiproliferativa en la línea celular HT-29. En esta línea los valores de $I_{50}$ oscilan desde valores micromolares bajos (compuestos 3.55 (But), 3.59 (Oct) y 3.60 (Dod)) hasta valores nanomolares (compuestos 3.56 (Pent), 3.57 (Hex) y 3.58 (Hept)), los cuales superan al valor mostrado por el producto natural CA-4, que en HT-29 exhibe actividad antiproliferativa en el rango micromolar bajo. De hecho, todos los derivados sintéticos mejoran el valor de $\mathrm{IC}_{50}$ de $\mathrm{CA}-4$ en las líneas celulares HT-29 y HEK-293. En la línea celular MCF-7, AmCA-4 y los derivados 3.55-3.58 (But-Hept) se muestran más activos que CA-4, mientras que en la línea celular A-549 sólo AmCA-4 y el compuesto 3.56 (Pent) exhiben mayor actividad antiproliferativa que el producto natural CA-4. En términos 
generales, el compuesto 3.56, que contiene una cadena de pentanoílo, es el derivado más activo en cuanto a la inhibición de la proliferación celular. Con respecto a los índices de selectividad, los valores más altos se consiguen con los derivados 3.55-3.59 (Pent-Oct) en la línea celular HT-29 (valores de IS entre 1.9-4.4) en la que se supera claramente el IS de AmCA-4 (0.3). No obstante, excepto en la línea HT-29, los valores IS de los derivados sintéticos son, en prácticamente todos los casos, inferiores a 1, con cifras similares a las mostradas por AmCA-4 y lejos de los altos valores de IS que exhibe el producto natural CA-4.

Para los compuestos de este grupo también se ha comprobado el cumplimiento de "la regla de los cinco" de Lipinski. En la tabla 4.3.2 se muestran los valores obtenidos.

Tabla 4.3.2. Comprobación de la regla de Lipinski

\begin{tabular}{|c|c|c|c|c|c|}
\hline Comp. & logP & PM & OH+NH & N+O & No cumple \\
\hline AmCA-4 & 2.92 & 315.37 & 1 & 5 & 0 \\
\hline $\mathbf{3 . 5 5}$ (But) & 3.7 & 385.46 & 1 & 6 & 0 \\
\hline $\mathbf{3 . 5 6}$ (Pent) & 4.12 & 399.49 & 1 & 6 & 0 \\
\hline $\mathbf{3 . 5 7}$ (Hex) & 4.53 & 413.51 & 1 & 6 & 0 \\
\hline $\mathbf{3 . 5 8}$ (Hept) & 4.95 & 427.54 & 1 & 6 & 0 \\
\hline $\mathbf{3 . 5 9}$ (Oct) & 5.37 & 441.25 & 1 & 6 & 1 \\
\hline $\mathbf{3 . 6 0}$ (Dod) & 7.04 & 497.68 & 1 & 6 & 1 \\
\hline
\end{tabular}

En la tabla anterior se puede apreciar que todos los compuestos podrían ser buenos candidatos según las reglas de Lipinski, ya que únicamente los derivados 3.59 (Oct) y $\mathbf{3 . 6 0}$ (Dod) incumplen una de las condiciones de Lipinski al presentar valores de logP superiores a 5 . Estos dos compuestos también son los que menos inhiben la proliferación celular. 


\section{3.b. Efecto sobre el ensamblaje de los microtúbulos}

La CrC se midió en un tampón de ensamblaje de glicerol (GAB) y GTP de concentración de $27.5 \mu \mathrm{M}$ al que se le añadió tubulina a una concentración de $25 \mu \mathrm{M}$. Los resultados se muestran en la tabla 4.3 .3 y se comparan con los obtenidos en ausencia de ligando (control) y en presencia de CA-4 y AmCA-4.

Tabla 4.3.3. Valores de $\mathrm{CrC}$

\begin{tabular}{|c|c|}
\hline Compuesto & CrC $(\mu \mathrm{M})$ \\
\hline Control & $7.9 \pm 1.2$ \\
\hline CA-4 & $21.5 \pm 0.8$ \\
\hline AmCA-4 & $23 \pm 3$ \\
\hline $\mathbf{3 . 5 5}$ (But) & $23.4 \pm 0.9$ \\
\hline $\mathbf{3 . 5 6}$ (Pent) & $18 \pm 5$ \\
\hline $\mathbf{3 . 5 7}$ (Hex) & $21 \pm 6$ \\
\hline $\mathbf{3 . 5 8}$ (Hept) & $11.7 \pm 1.9$ \\
\hline $\mathbf{3 . 5 9}$ (Oct) & $11.6 \pm 1.7$ \\
\hline $\mathbf{3 . 6 0}$ (Dod) & $8.72 \pm 0.03$ \\
\hline
\end{tabular}

Todos los compuestos ensayados incrementan el valor de $\mathrm{CrC}$ en relación con el valor medido en el control (ausencia de ligando). Los compuestos 3.553.57 (But-Hex), que contienen las cadenas acilo más cortas, muestran valores de $\mathrm{CrC}$ similares a los de CA-4 y AmCA-4, mientras que los compuestos 3.583.60 (Hept-Dod) presentan valores de $\mathrm{CrC}$ inferiores.

La figura 4.3.1 muestra los efectos de los ligandos sobre el proceso de polimerización in vitro de tubulina estudiado por turbidimetría a $350 \mathrm{~nm}$ y a $37^{\circ} \mathrm{C}$. A modo de comparación, la figura también incluye la curva de polimerización en presencia de paclitaxel, un estabilizador de microtúbulos. 


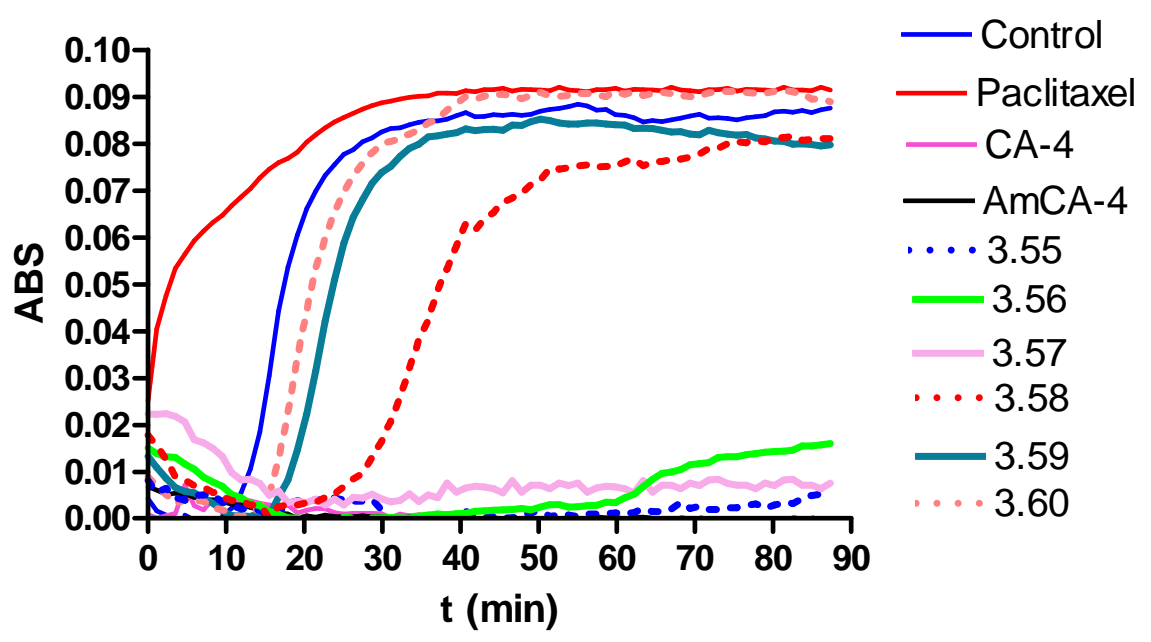

Figura 4.3.1. Cinética de polimerización de tubulina

En la figura anterior se puede apreciar que CA-4 y AmCA-4 suprimen completamente la formación de microtúbulos (sus líneas correspondientes aparecen en la parte inferior de la figura, solapadas con el eje de abcisas). Por otro lado, la curva de polimerización en presencia del paclitaxel, un agente estabilizador de microtúbulos, muestra que la fase de meseta (estado estable) se alcanza 30 minutos después del comienzo del ensamblaje.

Los compuestos 3.55-3.60 son derivados de CA-4, por lo que se esperaba que inhibieran la formación de microtúbulos. De hecho, los compuestos 3.553.57 (But-Hex) inhiben la formación de microtúbulos de manera similar a CA-4 y AmCA-4. El compuesto 3.58 (Hept) retrasa el inicio de la polimerización durante aproximadamente 20 minutos, mientras que los compuestos 3.59 (Oct) y 3.60 (Dod) demoran la polimerización durante aproximadamente 5 minutos. Con el fin de cuantificar el retraso en la polimerización observado para los derivados 3.58-3.60 (Hept-Dod), se calcularon los valores de It $_{50}$, que se presentan en la tabla 4.3.4. 
Tabla 4.3.4. Valores de $\mathrm{It}_{50}$

\begin{tabular}{|c|c|}
\hline Compuesto & It $_{50}(\mathrm{~min})$ \\
\hline Control & $16.6 \pm 1.0$ \\
\hline $\mathbf{3 . 5 8}$ (Hept) & $38 \pm 3$ \\
\hline $\mathbf{3 . 5 9}$ (Oct) & $23.06 \pm 0.15$ \\
\hline $\mathbf{3 . 6 0}$ (Dod) & $20.83 \pm 0.19$ \\
\hline
\end{tabular}

Se puede deducir de la tabla 4.3.4 que los derivados $3.58-3.60$ retrasan el proceso de polimerización en comparación con el control, de modo que estos compuestos pueden considerarse como inhibidores parciales del proceso de polimerización.

\section{3.c. Efecto sobre el ciclo celular}

Los efectos de los derivados sintéticos en el ciclo celular se evaluaron en células A549. Las células se incubaron durante $20 \mathrm{~h}$ en presencia de CA-4, AmCA-4 y los compuestos 3.55-3.60. El contenido de ADN se midió por citometría de flujo (véase la sección experimental). En la figura 4.3.2 se indican los histogramas del ciclo celular de los compuestos de la famila 3, los del control (ausencia de ligando) y los de AmCA-4. El histograma del control contiene a la mayor parte de las células en la fase G0/G1, con relativamente pocas células en la fase $S$ y en la fase G2/M. El histograma de AmCA-4 muestra una situación contraria, puesto que la mayor parte de las células se han acumulado en la fase G2/M, que es la acción que cabe esperar de un compuesto antimitótico. La forma del histograma de los compuestos 3.55-3.58 (But-Hept) es similar al de AmCA-4, aunque se aprecia una menor acumulación de células en G2/M con 3.55-3.58 (But-Hept). Por otro lado, el histograma de 3.59-3.60 (Oct-Dod) muestra una situación intermedia entre la del control y la de los otros compuestos de la familia 3. 


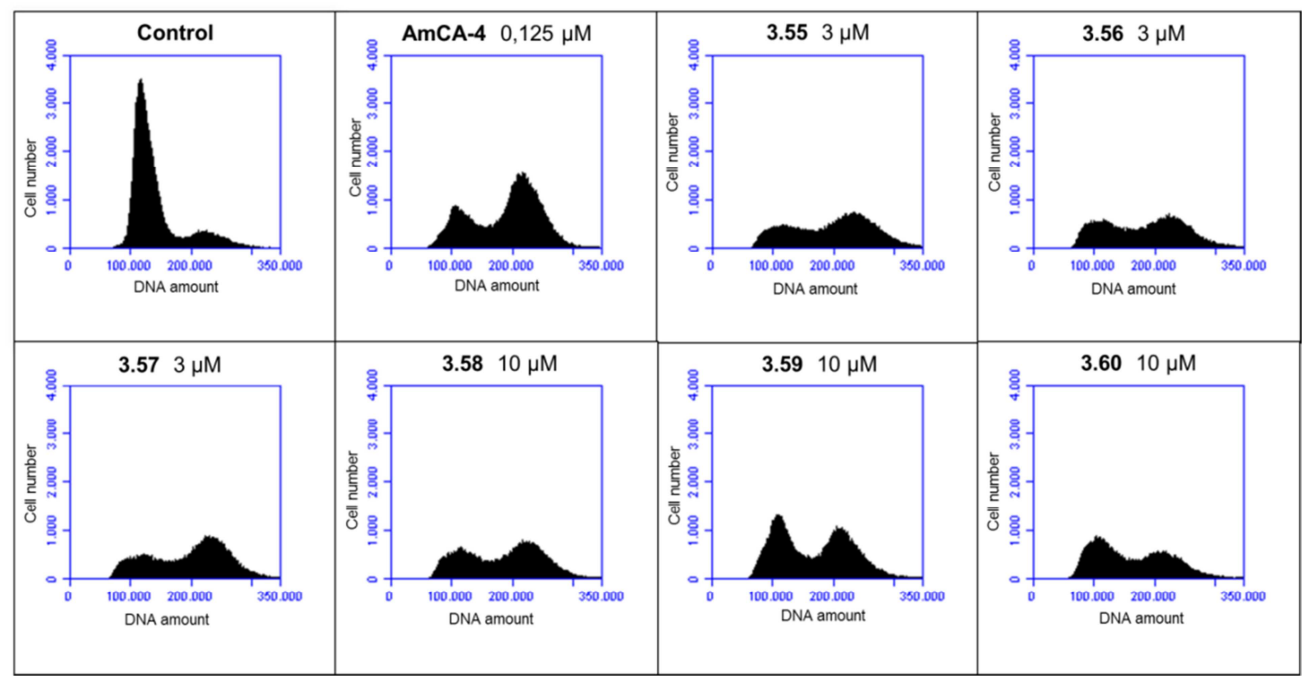

Figura 4.3.2 Histogramas del ciclo celular sobre células A-549 tratadas con AmCA-4 y con los compuestos $3.55,3.56,3.57,3.58,3.59$ y 3.60 .

Los resultados de ciclo celular en forma numérica en la tabla 4.3.5. CA-4 y AmCA-4 provocan una extensa acumulación de células en la fase G2/M a una concentración de 50 y 125 nM (60\% y 59\%, respectivamente). Los derivados 3.55-3.58 (But-Hept) acumulan células en proporciones entre 47-56\%, similares a las de CA-4 y AmCA-4, aunque en el caso de los derivados sintéticos las concentraciones empleadas eran 3-10 $\mu \mathrm{M}$, por tanto 12-40 veces mayores a las de AmCA-4 y 60-200 veces mayores a las de CA-4. Los compuestos 3.59 (Oct) y $\mathbf{3 . 6 0}$ (Dod), que incorporan las cadenas de acilo más largas, son los menos activos en la acumulación de células en la fase G2/M, sin embargo, son capaces de acumular entre $30-40 \%$ de las células en fase G2/M (el control acumula sólo 14\% en esta fase). 
Tabla 4.3.5. Distribución de células en el ciclo celular

\begin{tabular}{|c|c|c|c|c|}
\hline Compuesto & Conc. $(\mu \mathrm{M})$ & G0/G1 & S & G2/M \\
\hline Control & - & $75 \pm 4$ & $11 \pm 2$ & $14 \pm 2$ \\
\hline CA-4 & 0.05 & $25 \pm 1$ & $15 \pm 1$ & $60 \pm 2$ \\
\hline AmCA-4 & 0.125 & $26 \pm 1$ & $15 \pm 2$ & $59 \pm 2$ \\
\hline 3.55 (But) & 3 & $29 \pm 1$ & $18 \pm 1$ & $53 \pm 2$ \\
\hline 3.56 (Pent) & 3 & $34 \pm 2$ & $19 \pm 1$ & $47 \pm 2$ \\
\hline 3.57 (Hex) & 3 & $27 \pm 1$ & $18 \pm 2$ & $56 \pm 2$ \\
\hline 3.58 (Hept) & 10 & $33 \pm 2$ & $17 \pm 1$ & $50 \pm 2$ \\
\hline 3.59 (Oct) & 10 & $45 \pm 4$ & $17 \pm 2$ & $38 \pm 5$ \\
\hline 3.60 (Dod) & 10 & $48 \pm 6$ & $19 \pm 1$ & $33 \pm 5$ \\
\hline
\end{tabular}

\section{3.d. Efecto sobre la red de microtúbulos celulares}

También se han estudiado los efectos de los compuestos 3.55-3.60 sobre el citoesqueleto celular. En este caso, las células A-549 se incubaron durante $24 \mathrm{~h}$ en presencia de AmCA-4 y los compuestos 3.55-3.60 y en ausencia de ligando (véase la figura 4.3.2). AmCA-4 (B) despolimeriza casi completamente los microtúbulos celulares a una concentración de $125 \mathrm{nM}$. Entre los derivados sinteticos, los compuestos 3.55 (But) (C), $\mathbf{3 . 5 6}$ (Pent) (D) y $\mathbf{3 . 5 7}$ (Hex) (E) son lo que muestran el mayor efecto ya que provocan la despolimerizaron prácticamente completa de la red de microtúbulos a una concentración de 3 $\mu \mathrm{M}$. Los compuestos 3.58 (Hept) (F), 3.59 (Oct) (G) y 3.60 (Dod) (H) eran menos activos, aunque producían un efecto notable en la red de microtúbulos a una concentración de $10 \mu \mathrm{M}$. 

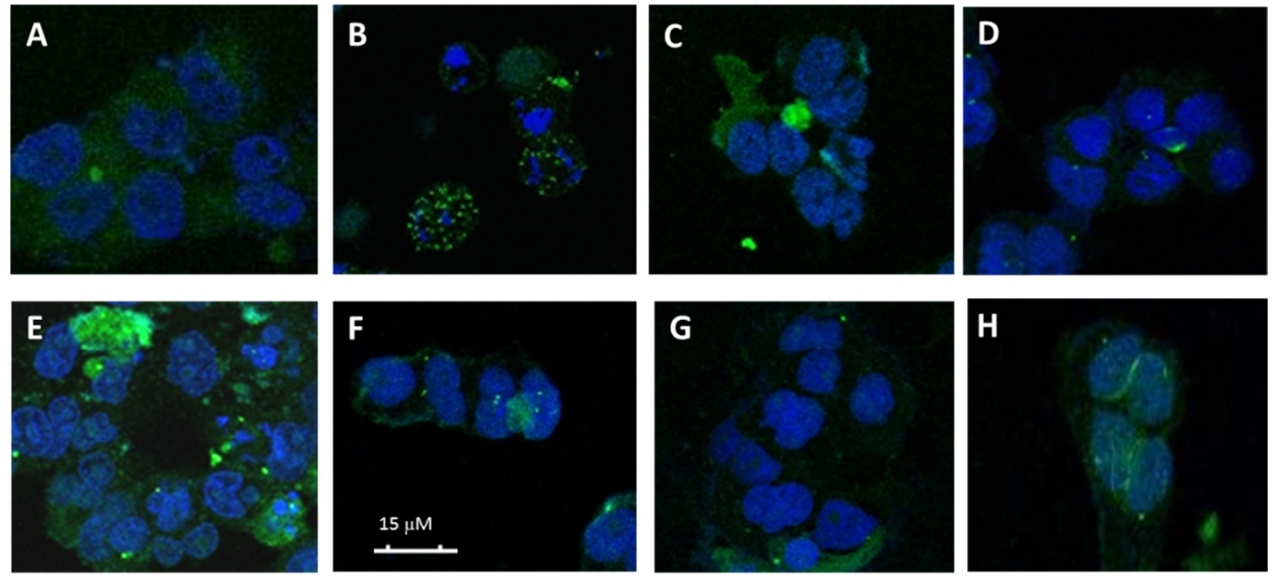

Figura 4.3.2. Efecto sobre la red de microtúbulos celulares. (A) DMSO, (B) $125 \mathrm{nM}$ AmCA-4, (C) $3 \mu \mathrm{M}$ de 3.55 (But), (D) $3 \mu \mathrm{M}$ de 3.56 (Pent), (E) $3 \mu \mathrm{M}$ de 3.57 (Hex), (F) $10 \mu \mathrm{M}$ de 3.58 (Hept), (G) $10 \mu \mathrm{M}$ de 3.59 (Oct) y (H) $10 \mu \mathrm{M}$ de 3.60 (Dod).

\section{3.e. Efecto sobre la expresión de genes VEGF, hTERT y c-Myc}

El efecto sobre la expresión de los genes VEGF, hTERT y c-Myc se ha estudiado en todos los derivados excepto en el compuesto 3.60 (Dod), que es el que muestra menor actividad anti-proliferativa y valores de SI menores a 1. Así, las células HT-29 se trataron durante 48 horas con el compuesto correspondiente a concentraciones similares o ligeramente menores que su $\mathrm{IC}_{50}$ (3.55 (But) a $200 \mathrm{nM}, 3.56$ (Pent) a $15 \mathrm{nM}, 3.57$ (Hex) a $40 \mathrm{nM}, 3.58$ (Hept) a $15 \mathrm{nM}$ y 3.59 (Oct) a $400 \mathrm{nM}$ ). La expresión de los genes se determinó mediante RT-qPCR, como se describe en la Sección Experimental. Los resultados se representan en la figura 4.3.3, que muestra el porcentaje de expresión génica después de 48 h de incubación en presencia de DMSO (experimento de control) y en presencia de cada uno de los compuestos investigados. Todos los valores se estandarizaron (100\%) en relación al (DMSO) y a la $\beta$-actina. 

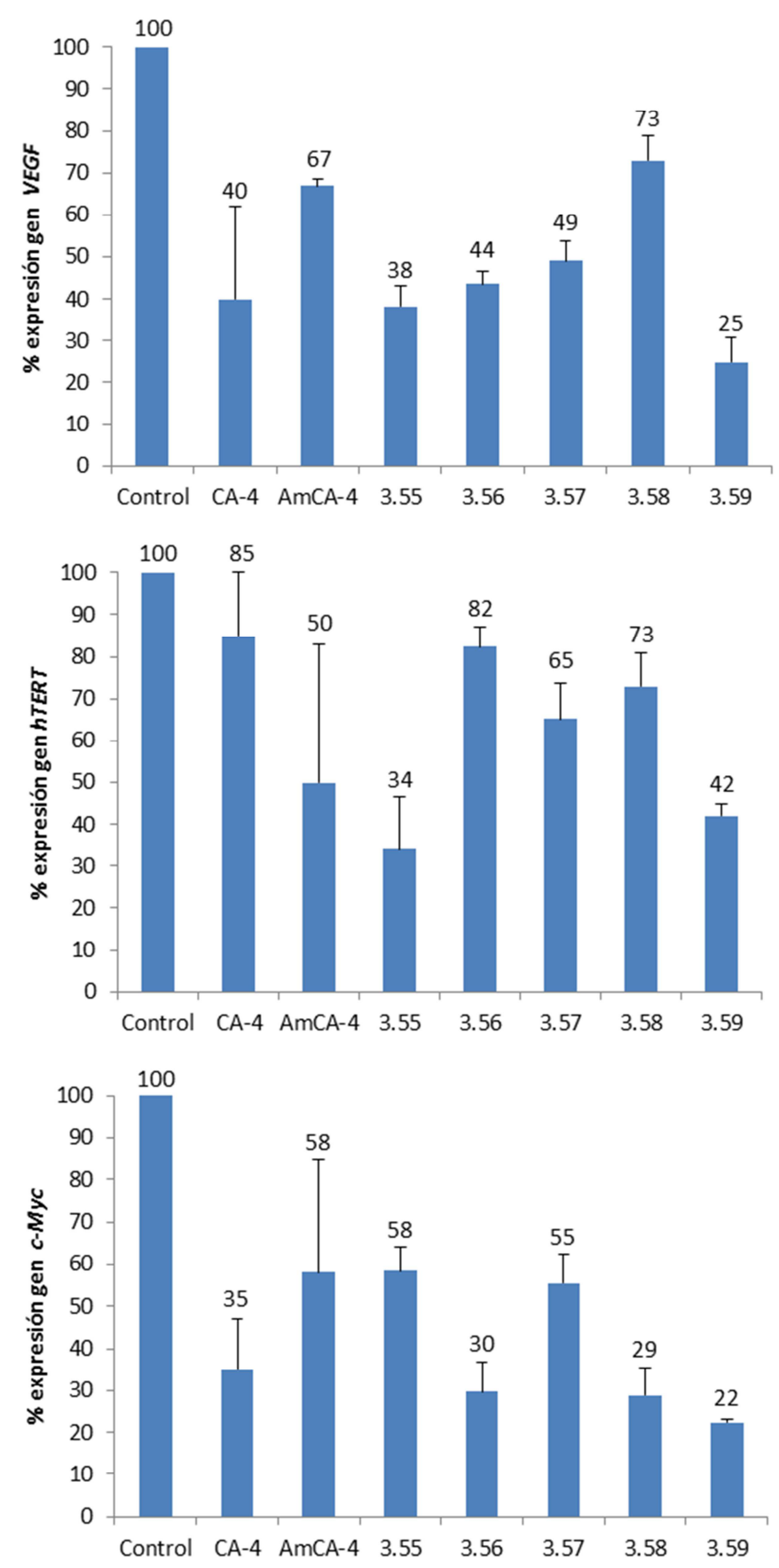

Figura 4.3.3. Porcentajes de expresión de genes. 
En relación con la expresión del gen $V E G F$, los compuestos que muestran mayores porcentajes de inhibición son 3.55-3.57 (But-Hex) (38\%, 44\% y 49\%, respectivamente) y $\mathbf{3 . 5 9}$ (Oct) (25\%), cuyos valores son similares a los de CA4 (40\%) pero inferiores a los obtenidos por AmCA-4 (67\%). El compuesto 3.59 (Oct) se muestra particularmente activo ya que regula negativamente la expresión génica de VEGF hasta el 25\%, una cifra considerablemente inferior a la de CA-4.

En cuanto a la expresión génica de $h T E R T$, sólo los compuestos 3.55 (But) (34\%) y 3.59 (Oct) (42\%) son capaces de regular negativamente la expresión del gen $h T E R T$ en porcentajes inferiores a los de CA-4 (85\%) y AmCA-4 (50\%).

El mayor efecto inhibitorio sobre la expresión del gen $c-M y c$ lo exhiben los compuestos 3.56 (Pent), 3.58 (Hept) y 3.59 (Oct) (30\%, 29\% y 22\%, respectivamente), regulando negativamente la expresión de este gen en valores similares a los de CA-4 (35\%), pero logrando valores mucho más bajos a los mostrados por AmCA-4, que regula la expresión de este gen al $58 \%$.

\section{3.f. Conclusión}

Como conclusión cabe decir que los derivados $N$-acilados muestran actividades antiproliferativas que van desde valores micromolares bajos a nanomolares bajos. Particularmente activos son los derivados 3.56 (Pent) y 3.58 (Hept) en células HT-29 en las que superan con mucho la actividad de CA-4. Con respecto a los índices de selectividad, los valores más altos los consiguen los derivados 3.56-3.59 (Hex-Oct) en la línea celular HT-29 en los que superan claramente el SI de AmCA-4. En las líneas celulares MCF-7 y A549 , los valores SI de los derivados sintéticos son, en prácticamente todos los casos, menores que 1, con valores similares a los mostrados por AmCA-4 y lejos de los altos valores SI mostrados por CA-4. Los compuestos 3.55-3.57 
(But-Hex) inhiben la polimerización de tubulina in vitro de manera similar a la CA-4 y AmCA-4, mientras que los compuestos 3.58-3.60 (Hept-Dod) pueden ser considerados como inhibidores parciales del proceso de polimerización de la tubulina. Todos los derivados son capaces de acumular células en la fase G2/M aunque de nuevo los compuestos con las cadenas acilo más largas (3.59 (Oct) y 3.60 (Dod)) son los menos activos en esta acción particular. Todos los compuestos evaluados despolimerizan extensivamente la red de microtúbulos a la concentración ensayada. En cuanto a la inhibición de la expresión génica, el compuesto 3.59 (Oct), que no se muestra muy activo en las actividades antes mencionadas, es, sin embargo, el que combina la mayor regulación negativa sobre los tres genes estudiados. 


\subsection{Parte experimental}

\section{4.a. Inhibición de la proliferación celular (ensayo MTT)}

El medio de cultivo se obtuvo de Gibco (Grand Island, NY). El suero fetal bovino (FBS) provenía de Harlan-Seralab (Belton, U.K). Los suplementos y otros reactivos no especificados en esta sección se obtuvieron de Sigma Chemical Co. (St. Louis, MO). El material plástico para cultivos celulares se adquirió de Thermo Scientific BioLite.

Las células de adenocarcinoma de colon humano HT-29, de adenocarcinoma de mama MCF-7, de adenocarcinoma de pulmón A-549 y las células embrionarias de riñón humano HEK-293 se cultivaron en un medio de cultivo compuesto por DMEM (Dulbecco's Modified Eagle's Medium) que contiene glucosa (1 $\mathrm{g} / \mathrm{L})$, glutamina $(2 \mathrm{mM})$, penicilina $(50 \mathrm{IU} / \mathrm{mL})$, estreptomicina $(50 \mu \mathrm{g} / \mathrm{mL})$ y anfotericina $B(1.25 \mu \mathrm{g} / \mathrm{mL})$ y está suplementado con un $10 \%$ de FBS.

Todos los derivados que han sido evaluados se disolvieron en DMSO hasta una concentración de $10 \mathrm{mM}$ y se almacenaron a $-20^{\circ} \mathrm{C}$ hasta su uso.

La evaluación de la capacidad antiproliferativa de los derivados sintetizados se realizó con células HT-29, MCF-7, A-549 y HEK-293 mediante el ensayo MTT. ${ }^{203}$ Se sembraron 5000 células por pocillo en placas de 96 pocillos con un volumen de $80 \mu \mathrm{L}$ de medio de cultivo y se dejaron incubando durante 24 horas.

Por otra parte, a partir de la disolución inicial de $10 \mathrm{mM}$ se realizaron diferentes diluciones seriadas desde concentración 500 a $0 \mu \mathrm{M}$ de cada producto, usando medio de cultivo para realizar las diluciones $y$ conservándolas a $4^{\circ} \mathrm{C}$ hasta su uso.

\footnotetext{
${ }^{203}$ a) Yang, C.; Barasoain, I.; Li, X.; Matesanz, R.; Liu, R.; Sharom, F. J.; Yin, D. L.; Díaz, J. F.; Fang, W. S. Chem. Med. Chem. 2007, 2, 691-701. b) Rodriguez-Nieto, S.; Medina, M. A.; Quesada, A. R. Anticancer Res. 2001, 21, 3457-3460.
} 
Pasadas las 24 horas de incubación de las células, se añadió a cada pocillo $20 \mu \mathrm{L}$ de cada una de las diluciones de los distintos compuestos a ensayar y se dejaron incubar durante 2 días a $37^{\circ} \mathrm{C}$ y $5 \%$ de $\mathrm{CO}_{2}$ en atmósfera húmeda.

Posteriormente, se añadió a cada pocillo $10 \mu \mathrm{L}$ de MTT ( $5 \mathrm{mg} / \mathrm{mL}$ en PBS) y se incubaron durante 3 horas a $37^{\circ} \mathrm{C}$. Seguidamente, se eliminó el medio de cultivo, los cristales de formazán formado se disolvieron en $100 \mu \mathrm{L}$ de DMSO y se midió la absorbancia a 492 nm y a $630 \mathrm{~nm}$ mediante un espectrofotómetro, resultando la diferencia, el valor de absorbancia debido al formazan formado durante el ensayo. Todas las medidas se efectuaron como mínimo por triplicado y los valores de $\mathrm{IC}_{50}$ (concentración necesaria para inhibir a la mitad la proliferación celular) se determinaron gráficamente haciendo uso de GraphPad Prism 4.

\section{4.b. Efecto en el autoensamblaje in vitro de microtúbulos}

Los ensayos se realizaron con tubulina liofilizada suministrada por el grupo del Dr. Fernando Díaz del Centro de Investigaciones Biológicas (CIB, CSICMadrid).

En primer lugar se preparon $15 \mathrm{~mL}$ de una disolución tampón de GAB (20 $\mathrm{mM}$ de $\mathrm{NaPi}, 10 \mathrm{mM}$ de $\mathrm{MgCl}_{2}, 1 \mathrm{mM}$ de EGTA, 30\% en volumen de glicerol y agua). A partir de esta disolución se prepararon dos disoluciones máster mix. La primera, $189 \mu \mathrm{L}$ de GDP $1 \mu \mathrm{M}$, sirvió de cero absoluto puesto que el GDP no permite la polimerización de tubulina. Mientras que la segunda, $1.4 \mathrm{~mL}$ de GTP $1 \mu \mathrm{M}$, sirvió tanto de control como para suministrar el GTP necesario para polimerizar la tubulina en las muestras tratadas con los compuestos.

Seguidamente se procedió a la hidratación de la tubulina liofilizada. Se tomaron $10 \mathrm{mg}$ de tubulina liofilizada y se les añadió $500 \mu \mathrm{L}$ de $\mathrm{GAB}$, se dejó 1 minuto en hielo, luego se añadieron $500 \mu \mathrm{L}$ más de GAB y se centrifugó a 
$12000 \mathrm{rpm}$ a $4^{\circ} \mathrm{C}$ durante 5 minutos. Al finalizar, se pasó la disolución de tubulina hidratada a un tubo nuevo desechando los agregados.

Una vez hidratada la tubulina, se midió su concentración mediante un espectrofotómetro de fluorescencia. Para ello se preparó un control consistente en $5 \mu \mathrm{L}$ de GAB en $995 \mu \mathrm{L}$ de una disolución $10 \mathrm{mM}$ de NaPi y al $1 \%$ en SDS y dos muestras de tubulina con $2.5 \mu \mathrm{L}$ de la disolución de tubulina hidratada en $447.5 \mu \mathrm{L}$ de la disolución $10 \mathrm{mM}$ de NaPi y $1 \%$ de SDS. Se realizó un barrido fotométrico entre 240-350 nm y se anotaron los máximos de absorbancia del intervalo. A partir de las absorbancias, conociendo el factor de dilución y aplicando la ley de Lambert-Beer:

$$
c(\mu \mathrm{M})=\frac{A \cdot l}{\varepsilon}
$$

donde $\mathrm{A}$ es la absorbancia medida, I la longitud recorrida por la luz en el medio en $\mathrm{mm}$ y $\varepsilon$ el coeficiente de absorción molar, siendo $1.07 \mathrm{~mm} / \mu \mathrm{M}$ para la tubulina en estas condiciones.

Según este valor, se preparó una disolución de tubulina $50 \mu \mathrm{M}$, diluyéndola con GAB, y en todo caso sobre hielo.

Con las disoluciones de tubulina, máster mix de GDP, máster mix de GTP y GAB ya preparadas se procedió a su desgasificación en hielo y a vacío para el posterior montaje de la placa del ensayo, la cual se realizó de la siguiente forma:

a. A los dos primeros pocillos, cero absoluto, se les añadió 47.25 $\mu \mathrm{L}$ de máster mix GDP y $2.75 \mu \mathrm{L}$ de DMSO.

b. A los dos siguientes, control, se les adicionó $47.25 \mu \mathrm{L}$ de máster mix GTP y $2.75 \mu \mathrm{L}$ de DMSO.

c. Al resto de pocillos se les añadió $47.25 \mu \mathrm{L}$ de máster mix GTP y $2.75 \mu \mathrm{L}$ de la disolución $1 \mathrm{mM}$ de cada compuesto.

d. Finalmente se adicionaron $50 \mu \mathrm{L}$ de la disolución de tubulina 50 $\mu \mathrm{M}$ a todos los pocillos. 
Es decir, todos los pocillos contenían tubulina $25 \mu \mathrm{M}$ y los pocillos con los compuestos una concentración de $27.5 \mu \mathrm{M}$, ligeramente superior a la estequiométrica. A continuación, la placa se incubó a $37^{\circ} \mathrm{C}$ en Multiskan® y la absorbancia a $340 \mathrm{~nm}$ se midió cada 30 segundos durante 2 horas.

\section{4.c. Efecto sobre el ciclo celular}

Los estudios del ciclo celular se realizaron sobre células A-549. Así, $1,5 \cdot 10^{5}$ células se sembraron sobre cada placa de 24 pocillos junto con $300 \mu \mathrm{L}$ de medio de cultivo y se dejaron incubar durante 24 horas. Transcurrido este tiempo se añadió en cada pocillo el compuesto a ensayar a la concentración correspondiente y las células se mantuvieron en incubación durante 16-18 horas en contacto con los compuestos. La progresión del ciclo celular se analizó por determinación de la cantidad de ADN mediante citometría de flujo con yoduro de propidio. Las células A-549 se fijaron, seguidamente se trataron con RNasa y se marcaron con yoduro de propidio siguiendo las instrucciones de BD Cycletest ${ }^{\mathrm{TM}}$ DNA Kit. El análisis se llevó a cabo con el citómetro de flujo BD Accuri ${ }^{\mathrm{TM}} \mathrm{C} 6$.

\section{4.d. Efecto sobre la red de microtúbulos (inmunofluorescencia)}

El ensayo de inmunofluorescencia se realizó sobre células A-549. En este ensayo se sembraron $1,5 \cdot 10^{5}$ células en cubreobjetos redondos y se incubaron con los diferentes derivados durante 12 horas. A continuación, las células se lavaron con PEMP, luego se permeabilizaron con PEM-Triton X-100 al $0.5 \%$, durante 90 segundos a temperatura ambiente y, seguidamente, se fijaron con formaldehido al 3.7\% (en PEM a pH =7.4) durante 30 minutos a temperatura ambiente. La inmunocoloración directa se realizó durante 2.5 horas a $37^{\circ} \mathrm{C}$ en la oscuridad con anticuerpos de anti- $\alpha$-tubulina primarios conjugados con FITC (dilución 1:400 en PBS-BSA 1\% desde una disolución de $1 \mathrm{mg} / \mathrm{mL}$; anticuerpo monoclonal, clon DM1A, Sigma-Aldrich). A continuación, las células se lavaron con PBS y se incubaron durante 30 
minutos a temperatura ambiente, en la oscuridad con Hoescht $2 \mathrm{mM}$ en agua. Más tarde, las células se lavaron con PBS y los cubreobjetos se montaron con $10 \mu \mathrm{L}$ de un tampón glicerina/glicerol. Las imágenes del citoesqueleto se tomaron en microscopio confocal de barrido por láser (CLSM) Leica SP5 con un microscopio invertido Leica, equipado con un objetivo de inmersión en aceite Plan-Apochromat 63x (NA = 1.4). Cada imagen se grabó con el modo espectral del CLSM seleccionando los dominios del espectro de emisión. E fluoróforo FITC se excitó a 488 nm con láser de argón y su emisión fluorescente se midió entre $496 \mathrm{~nm}$ y $535 \mathrm{~nm}$.

\section{4.e. Determinación de la expresión génica de VEGF, hTERT y c-Myc mediante qPCR}

Para determinar la expresión de los genes VEGF, hTERT y c-Myc, se sembraron unas 100000 células HT-29 por pocillo en placas de 6 pocillos y se dejaron incubar 24 horas con $1.5 \mathrm{~mL}$ de medio de cultivo. Luego se cambió el medio de cultivo y se añadió a cada uno de los pocillos los compuestos a ensayar en las concentraciones especificadas en cada caso. A la muestra que correspondía al control se le añadió el mismo volumen de DMSO que el utilizado en los derivados. Las células se incubaron durante 48 horas en presencia de los compuestos. Transcurrido este tiempo, las células se recogieron y el ARN se aisló usando el kit de extracción de ARN Ambion, de acuerdo a sus instrucciones de uso. A continuación, el ARN se retrotranscribió a ADN complementario mediante el empleo de la retrotranscriptasa M-MLV, 1 $21 \mu \mathrm{g}$ de ARN extraído y oligo(dT) 15 siguiendo el protocolo.

La amplificación de los genes mediante la técnica qPCR se efectuó a partir del ADN procedente de cada muestra y mediante el empleo de un termociclador SteoOnePlus ${ }^{\mathrm{TM}}$ y sondas Taqman ${ }^{\circledR}$. Se utilizó TaqMan® Gene Expression Fast Master Mix, que contiene el tampón adecuado para las 
condiciones de amplificación, dNTPs, la enzima ADN polimerasa termoestable y una sonda de referencia pasiva.

Para amplificar cada uno de los genes se utilizaron los cebadores prediseñados y comercializados por Life Technologies TaqMan® Gene Expression Assays.

Todas las medidas se realizaron, como mínimo, por triplicado. 


\section{RESUMEN Y CONCLUSIONES}





\section{RESUMEN Y CONCLUSIONES}

Se ha llevado a cabo la síntesis de tres familias de derivados de combretastatina A-4 a partir de reactivos sencillos comerciales empleando secuencias sintéticas cortas y versátiles que han proporcionado los compuestos deseados con buenos rendimientos.<smiles>[R]C(NC(=O)COc1cc(/C=C\c2cc(OC)c(OC)c(OC)c2)ccc1OC)C(=O)O</smiles><smiles>[R]C(N)C(=O)Nc1cc(/C=C\c2cc(OC)c(OC)c(OC)c2)ccc1OC</smiles><smiles>[R]C(=O)Nc1cc(/C=C\c2cc(OC)c(OC)c(OC)c2)ccc1O</smiles>

Figura 5.1. Familias de compuestos sintetizadas en la presente Tesis.

Sobre los derivados sintetizados se ha estudiado la actividad antiproliferativa, la capacidad antimitótica y la inhibición de la expresión de los genes VEGF, hTERT y c-Myc.

\subsection{Actividad antiproliferativa}

La familia 1 presenta valores de $\mathrm{IC}_{50}$ en el rango micromolar bajo para todas las líneas celulares estudiadas. Los derivados de esta familia que incorporan aminoácidos de la serie D, junto con el derivado 3.18 (L-Met) presentan, en general, los mejores márgenes de seguridad terapéutica, con valores superiores a 1 para HT-29 y MCF-7 y próximos a este valor en la línea A-549.

En la familia 2 la actividad antiproliferativa fluctúa entre valores nanomolares bajos para los derivados de la serie $L$ (excepto los derivados de L-Pro, los cuales presentan $\mathrm{IC}_{50}$ en el rango nanomolar alto) hasta valores 
micromolares bajos para los derivados sintetizados con aminoácidos y aminoésteres de la serie D. En la figura 5.2 se pueden apreciar estas diferencias. En ella se ha representado de forma logarítmica el valor de $\mathrm{IC}_{50}$ en la línea HT-29 de aquellos derivados que fueron sintetizados en sus dos configuraciones ( $L$ y D). Se puede apreciar la diferencia de entre 2 y 4 órdenes de magnitud en su actividad antiproliferativa, diferencia mucho más atenuada en el caso de los derivados de prolina.

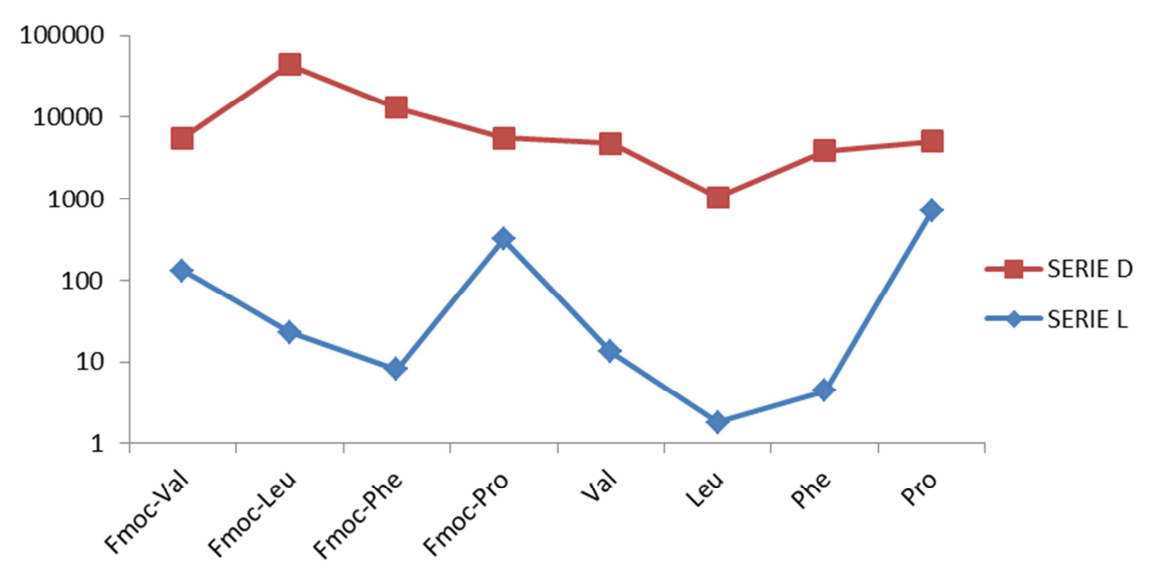

Figura 5.2. $\mathrm{IC}_{50}$ en escala logarítmica en HT-29

Los derivados 3.30 (Fmoc-L-Ala), 3.39 (L-Ala), 3.41 (L-Leu), 3.42 (L-Phe), 3.45 (L-Tyr) y 3.46 (L-Met) son los más activos en las lineas celulares HT-29, MCF-7 y HEK-293, con valores de $\mathrm{IC}_{50}$ inferiores a $5 \mathrm{nM}$. Asimismo, los derivados 3.30 (Fmoc-L-Ala), 3.35 (Fmoc-L-Thr), 3.39 (L-Ala), 3.43 (L-Pro), y 3.44 (L-Thr) y 3.45 (L-Tyr) presentan los mejores IS en la linea HT-29.

Para la linea celular A-549 los derivados de la serie $L$ presentan una menor actividad, con lo que los índices de selectividad son mejores para esta línea celular en el caso de los compuestos de la serie D y los derivados de Pro.

Para la familia 3, los valores de inhibición de la proliferación celular son dependientes de la longitud de la cadena acilada y van desde valores 
nanomolares bajos en los derivados con cadenas de longitud intermedia, a valores micromolares de los derivados con las cadenas más largas (véase la figura 5.3).

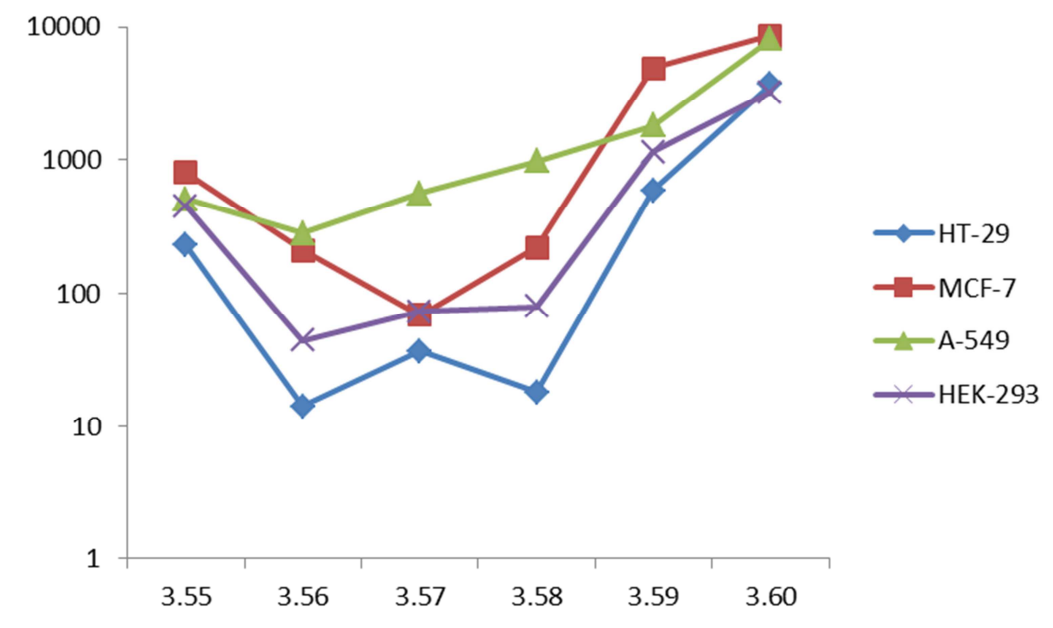

Figura 5.3. Valores de $\mathrm{IC}_{50}$ en escala logarítmica para la familia 3.

Como se puede observar en la figura 5.3, los derivados más activos son 3.56 y 3.57, que contienen cadenas de pentanoílo y hexanoílo, respectivamente. La actividad antiproliferativa disminuye sustancialmente en los derivados con las cadenas acílicas más cortas y con las más largas. Como ocurre en la familia 2, la actividad en A-549 no muestra una variación tan acusada en función de la longitud de la cadena acílica, con lo que los índices de selectividad en esta linea son menores para los derivados 3.56 y 3.57.

El margen de seguridad terapéutico es significativamente bueno en la linea HT-29 para todos los derivados excepto para $\mathbf{3 . 6 0}$, que contiene una cadena de dodecanoílo.

Como conclusión global, los derivados más activos son los de AmCA-4 con aminoácidos de la serie $L o$ con cadenas acílicas de entre 6 y 8 carbonos de longitud. Estos últimos, además, presentan un amplio margen de seguridad terapéutico en la linea celular HT-29. 


\subsection{Actividad antimitótica}

En la familia 1, los derivados con aminoácidos de la serie $D$ no ejercen efecto sobre el ciclo celular, mientras que los que presentan aminoésteres si ejercen cierto efecto antimitótico, acumulando entre un $30-50 \%$ de células en fase G2/M. No obstante, son algunos de los derivados de la serie $L$ los que ejercen un mayor efecto sobre el ciclo celular, llegando incluso a mejorar el efecto de CA-4. Los derivados más activos son los aminoésteres con cadenas polares, 3.7 (L-Thr-OMe) (57\%) y 3.8 (L-Tyr-OMe) (65\%), así como los aminoácidos con cadenas laterales apolares más cortas, 3.11 (L-Val) $(67 \%)$ y 3.12 (L-Leu) (63\%).

Los compuestos de la familia 2 que han sido testados han resultado en general bastante activos y a concentraciones inferiores a las utilizadas en la familia 1. Así, los derivados protegidos con cadenas cortas, 3.29 (Fmoc-Gly) y 3.30 (Fmoc-L-Ala), el derivado desprotegido de alanina, 3.39 (L-Ala), y los que contienen aminoácidos polares o sulfurados (3.44 (L-Thr), 3.45 (L-Tyr) y 3.46 (L-Met)) acumulan más de un $50 \%$ de células en fase G2/M. Además, los compuestos 3.39 (L-Ala), y 3.44 (L-Thr) son inhibidores parciales de la polimerización in vitro de tubulina.

Todos los derivados de la familia 3 presentan cierto efecto sobre el ciclo celular, pero los derivados con cadenas más cortas, 3.55 (But) a 3.58 (Hept), son los que acumulan más células en fase G2/M. A su vez, los derivados 3.553.57 (But-Pent-Hex) son capaces de inhibir totalmente la polimerización in vitro de tubulina, ya que muestran valores de $\mathrm{CrC}$ superiores a 20 , similares a los de CA-4 y AmCA-4. Además, 3.58-3.60 (Hept-Oct-Dod) retrasan el proceso de polimerización, pero con una potencia inhibitoria que disminuye a medida que aumenta la longitud de la cadena. 


\subsection{Efecto sobre la expresión de los genes VEGF, hTERT y c-Myc}

Los derivados de la familia 1 se muestran más activos en general frente a VEGF, siendo 3.25 (D-Leu) particularmente activo, aunque el compuesto más activo de esta familia es $\mathbf{3 . 1 8}$ (L-Met), ya que reduce la expresión de los tres genes estudiados en más del $55 \%$.

En la familia 2, los derivados más activos en VEGF y $c-M y c$ son $\mathbf{3 . 3 0}$ (Fmoc-L-Ala), 3.33 (Fmoc-L-Phe) y 3.44 (L-Thr) ya que reducen la expresión de estos dos genes en más del $60 \%$. Para el conjunto de los tres genes, el derivado más destacable es 3.35 (Fmoc-L-Thr) ya que es capaz de disminuir la expresión de VEGF a un $37 \%$ y a un $56 \%$ para c-Myc y $h T E R T$.

Para la familia 3, el derivado 3.59 (Oct) es el que presenta la mejor inhibición en los tres genes estudiados.

En la siguiente figura 5.4 se muestran los derivados más activos de cada familia en la inhibición de genes.<smiles>COc1ccc(/C=C\c2ccc(OC)c(OCC(=O)N[C@@H](CCSC)C(=O)O)c2)cc1OC</smiles><smiles>C=CNC(C(=O)Nc1cc(/C=C\c2ccc(OC)c(OC)c2)ccc1OC)C(C)O</smiles><smiles>CCCCCCCCC(=O)Nc1cc(/C=C\c2cc(OC)c(OC)c(OC)c2)ccc1OC</smiles>

Figura 5.4 Compuestos más activos de cada familia en la inhibición de genes. 

6. ESPECTROS SELECCIONADOS 


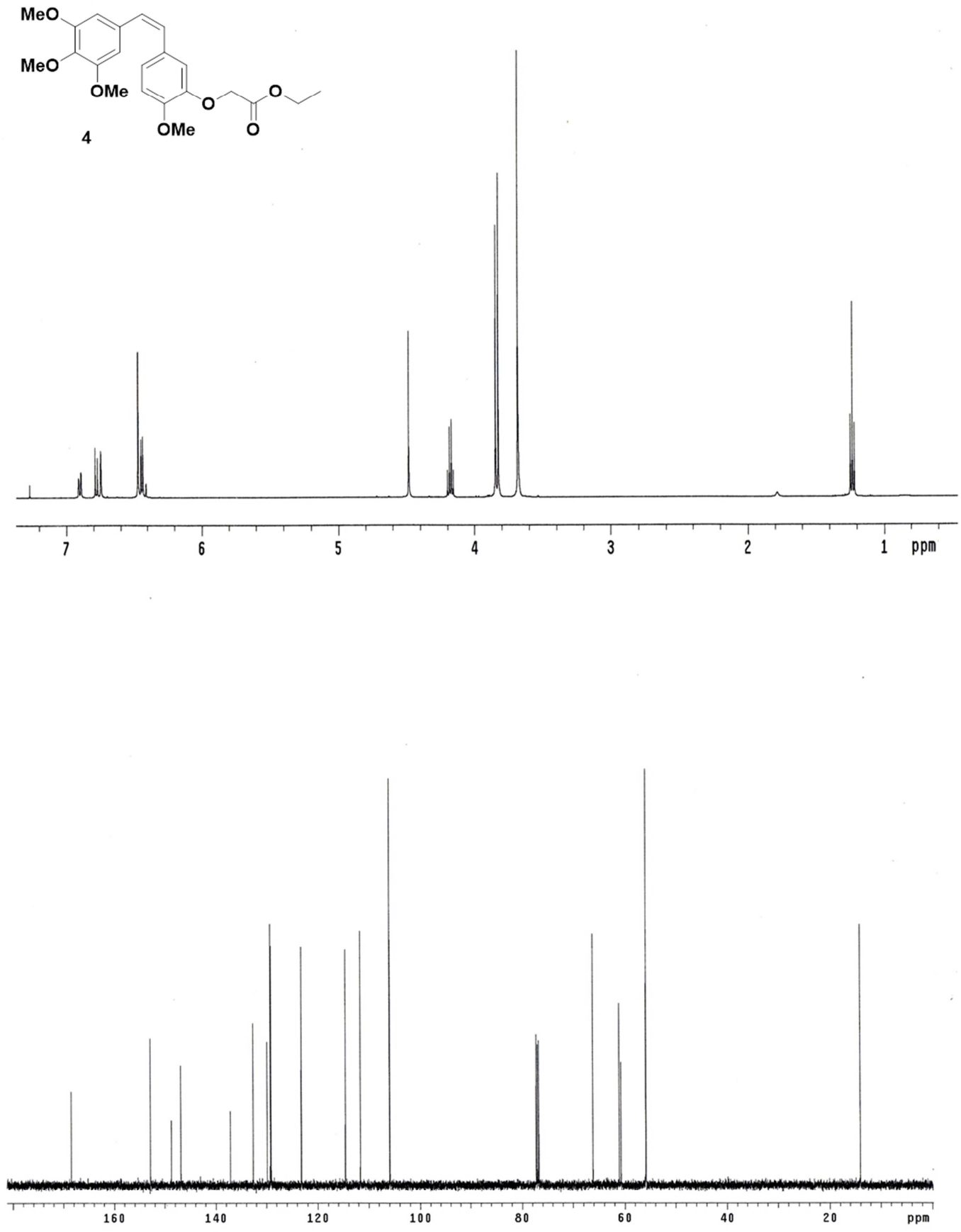
OMe
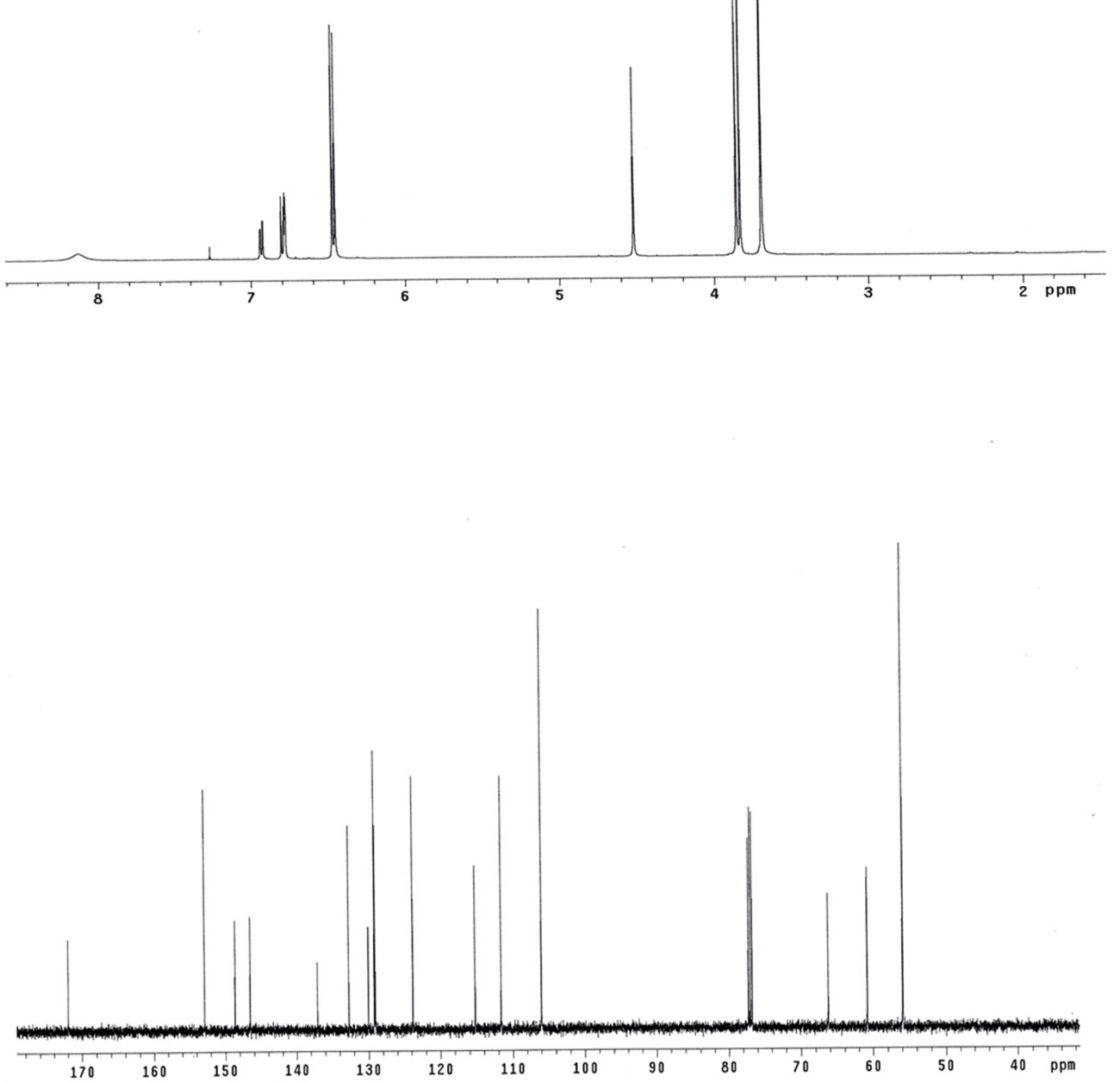

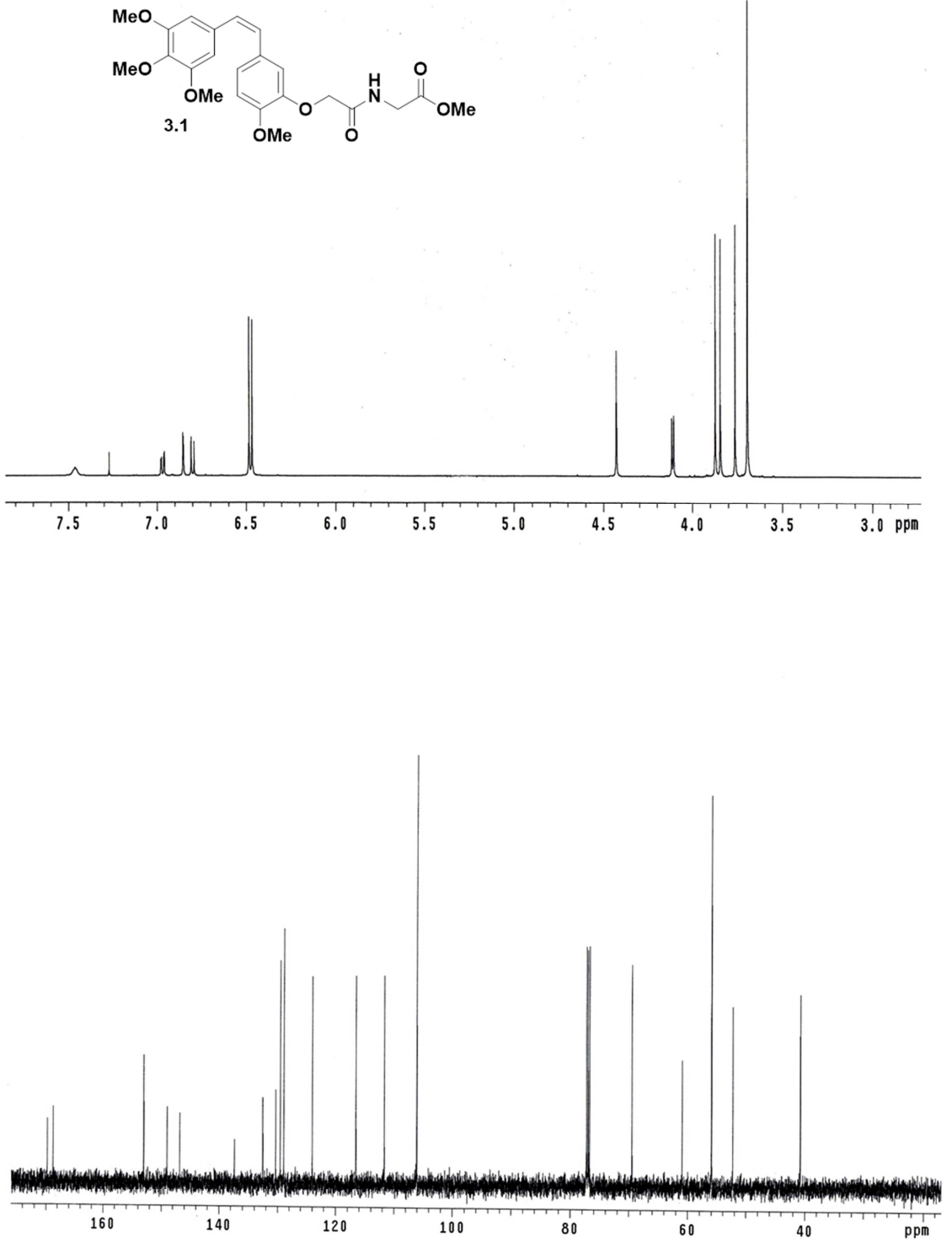

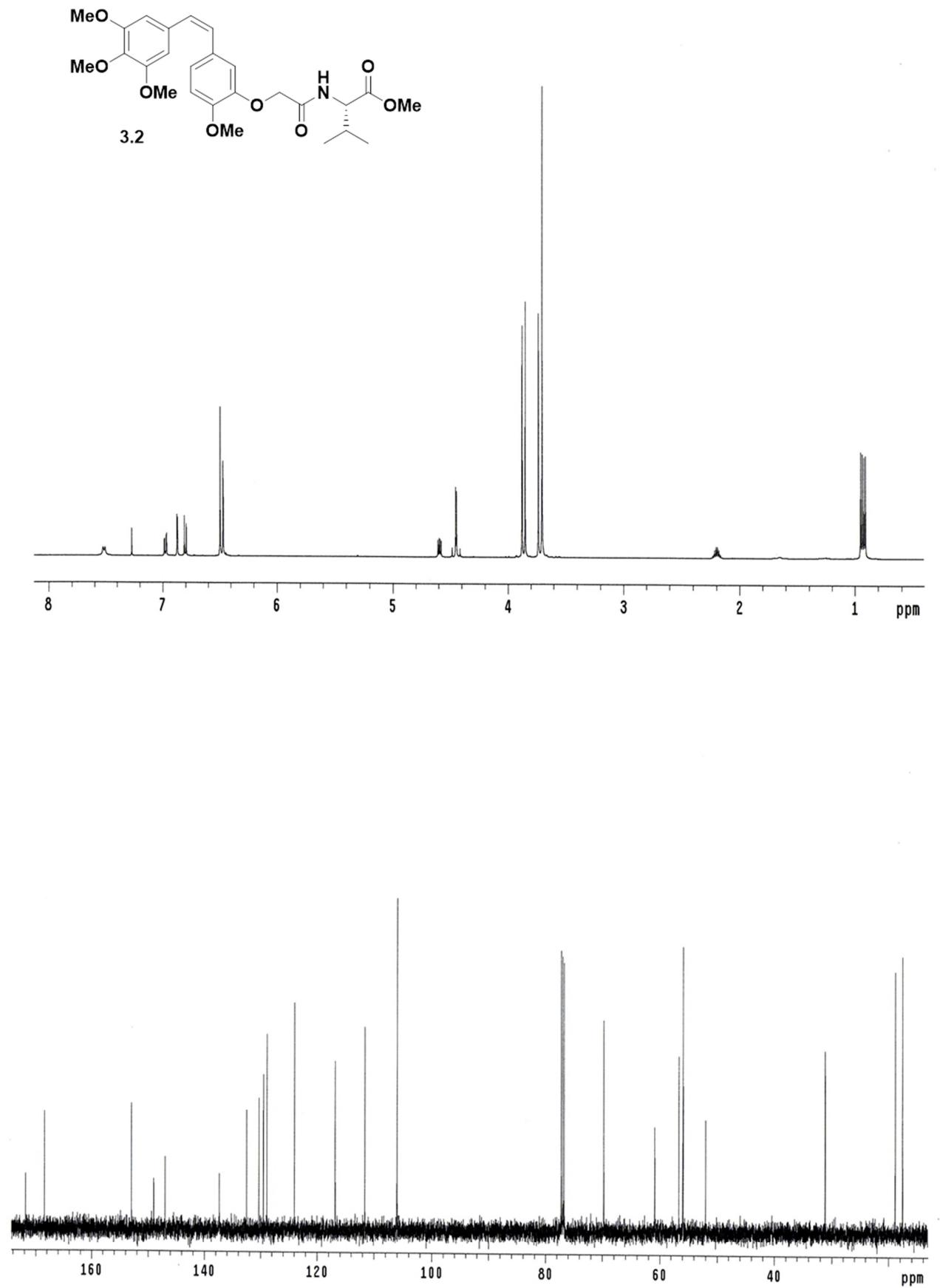
$\mathrm{MeO}$<smiles>CCc1cc(/C=C\c2ccc(OC)c(OCC(=O)N[C@@H](CC(C)C)C(=O)OC)c2)cc(OC)c1OC</smiles>
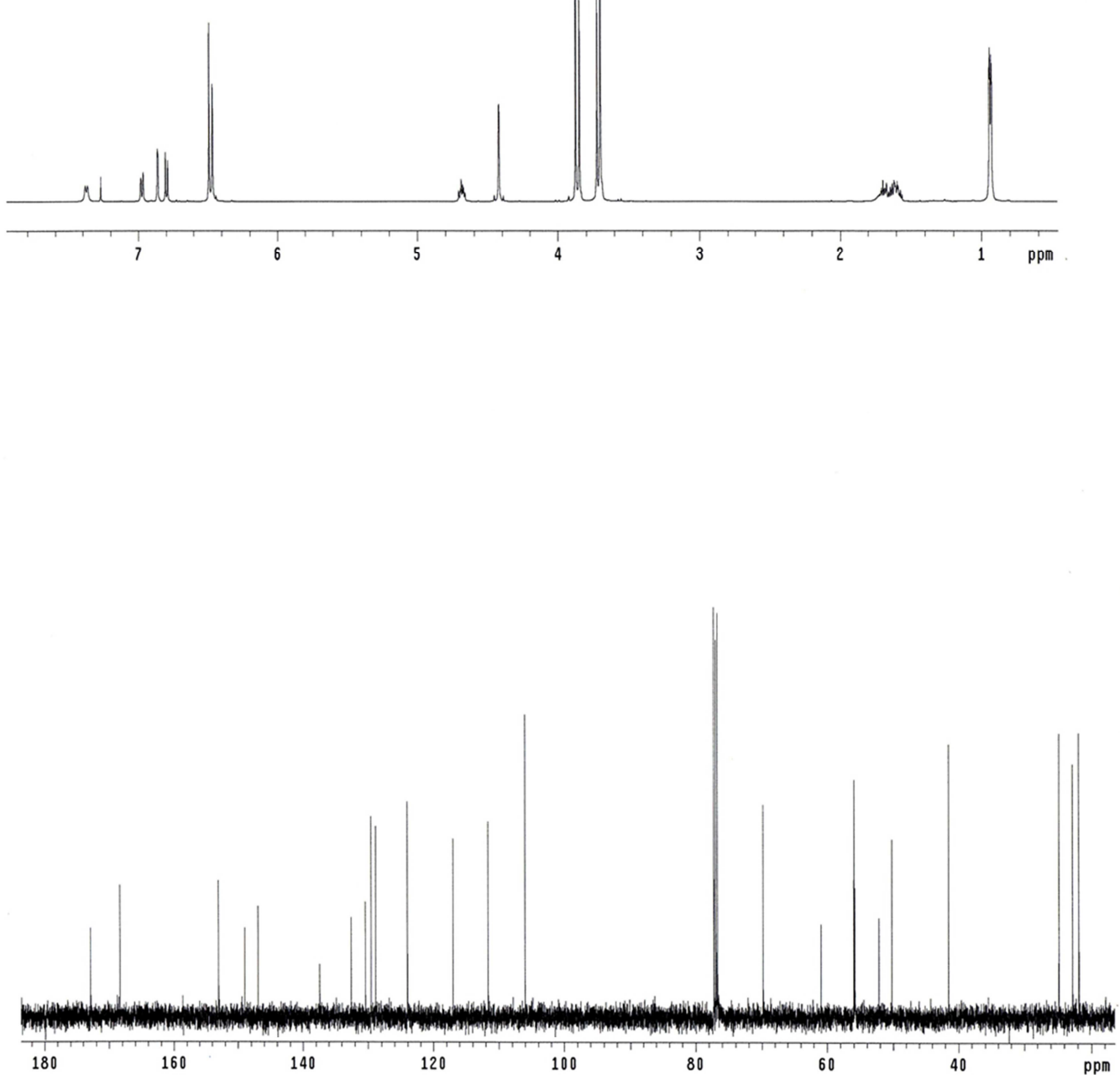

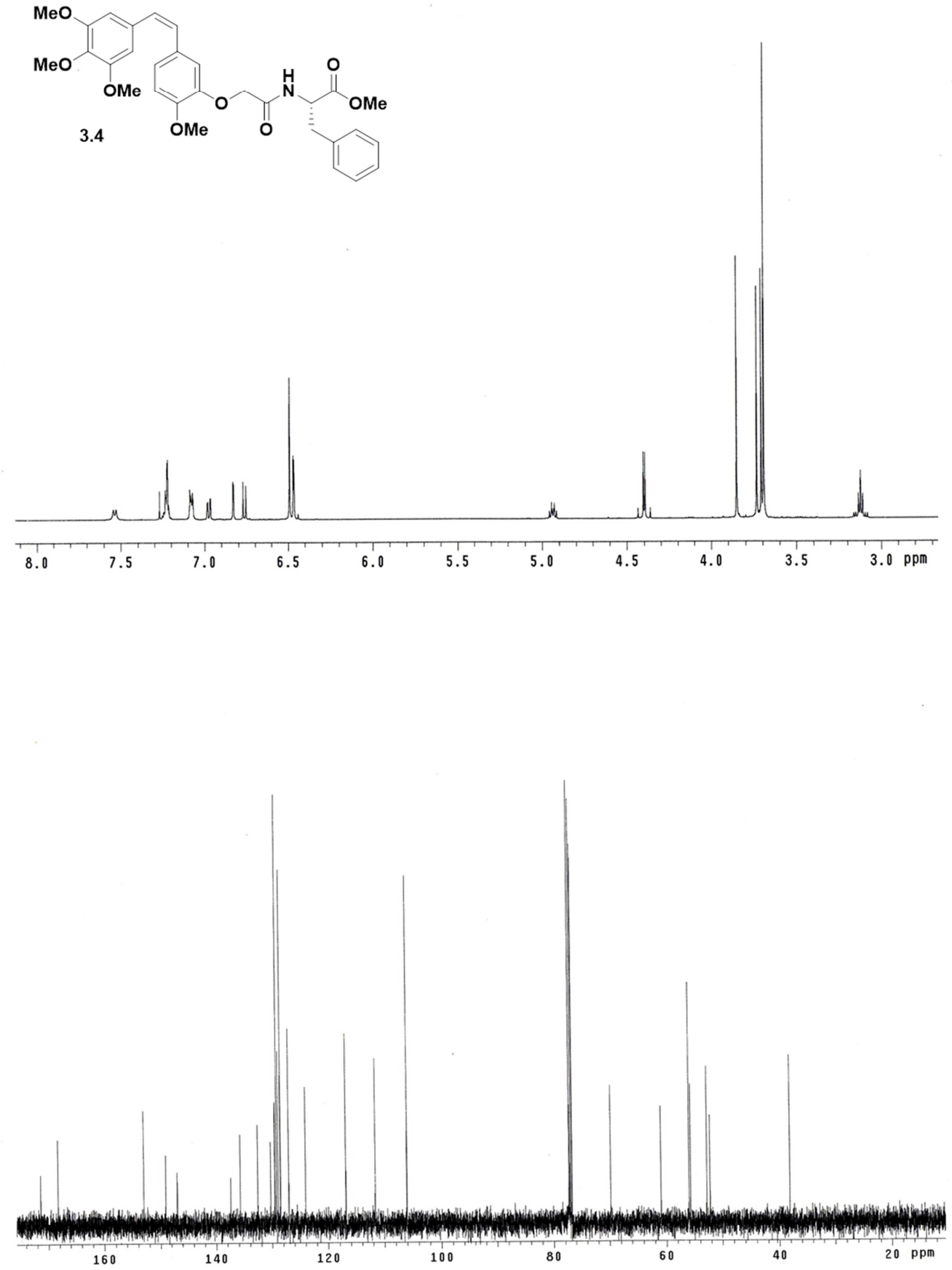

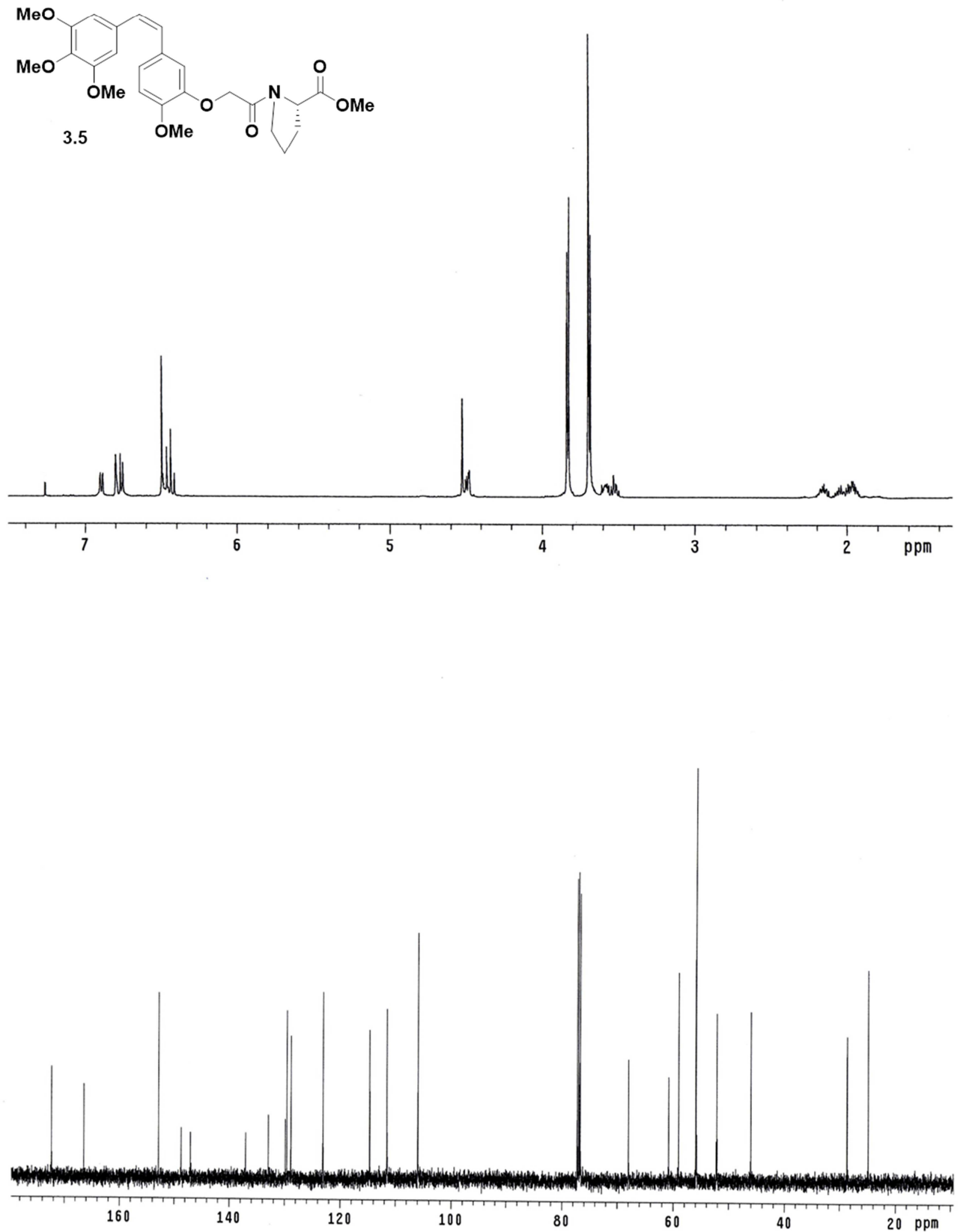

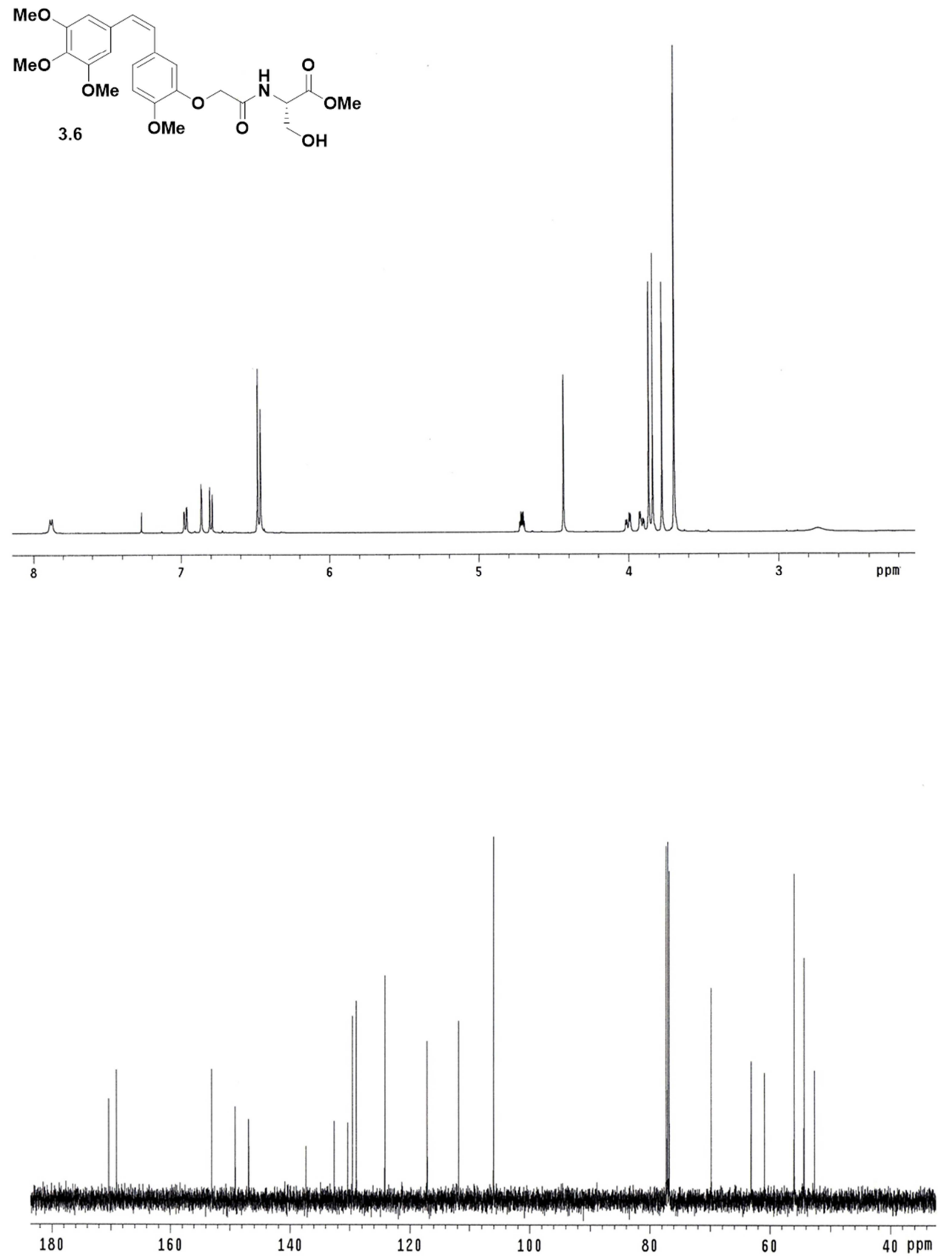

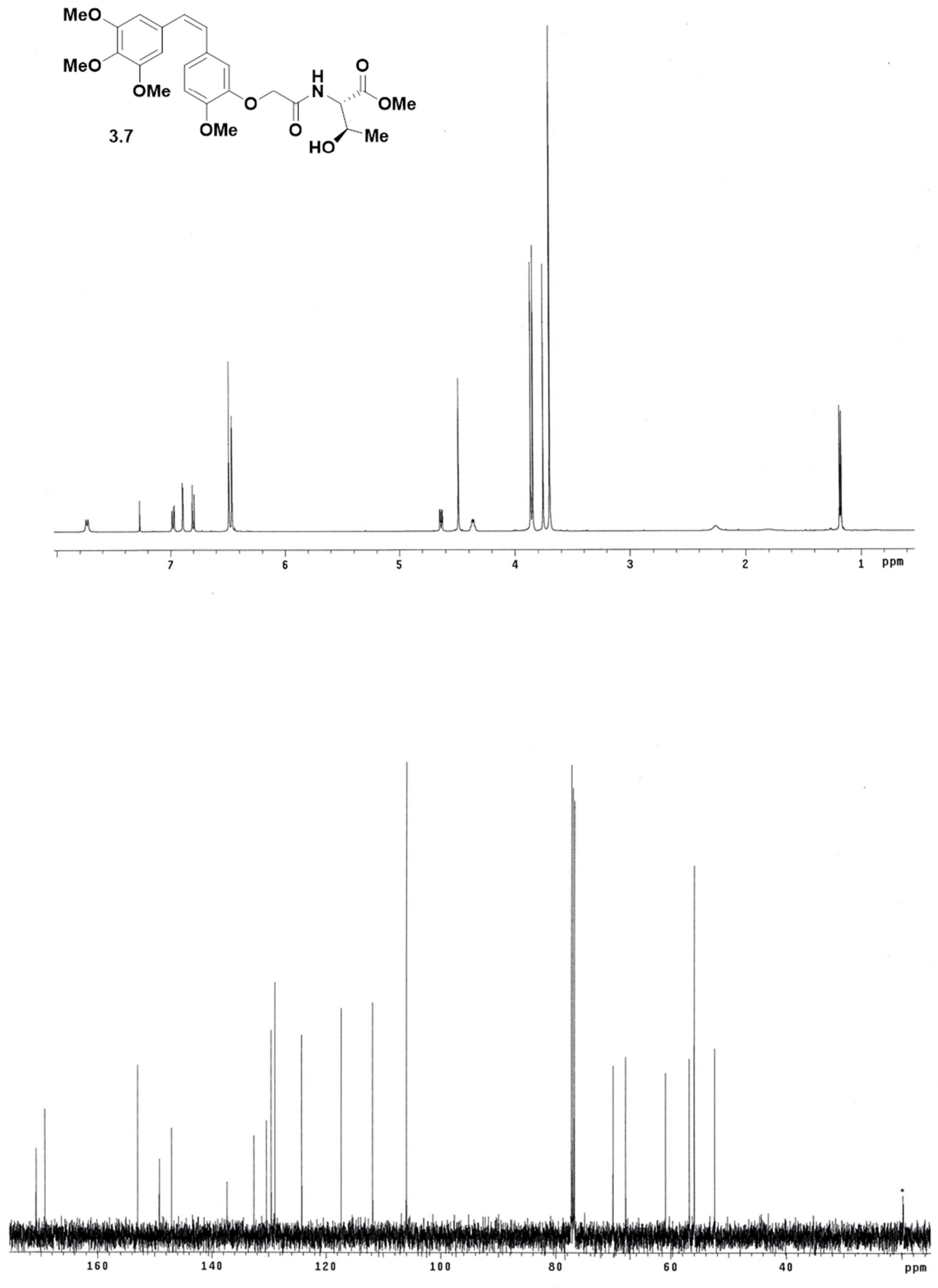

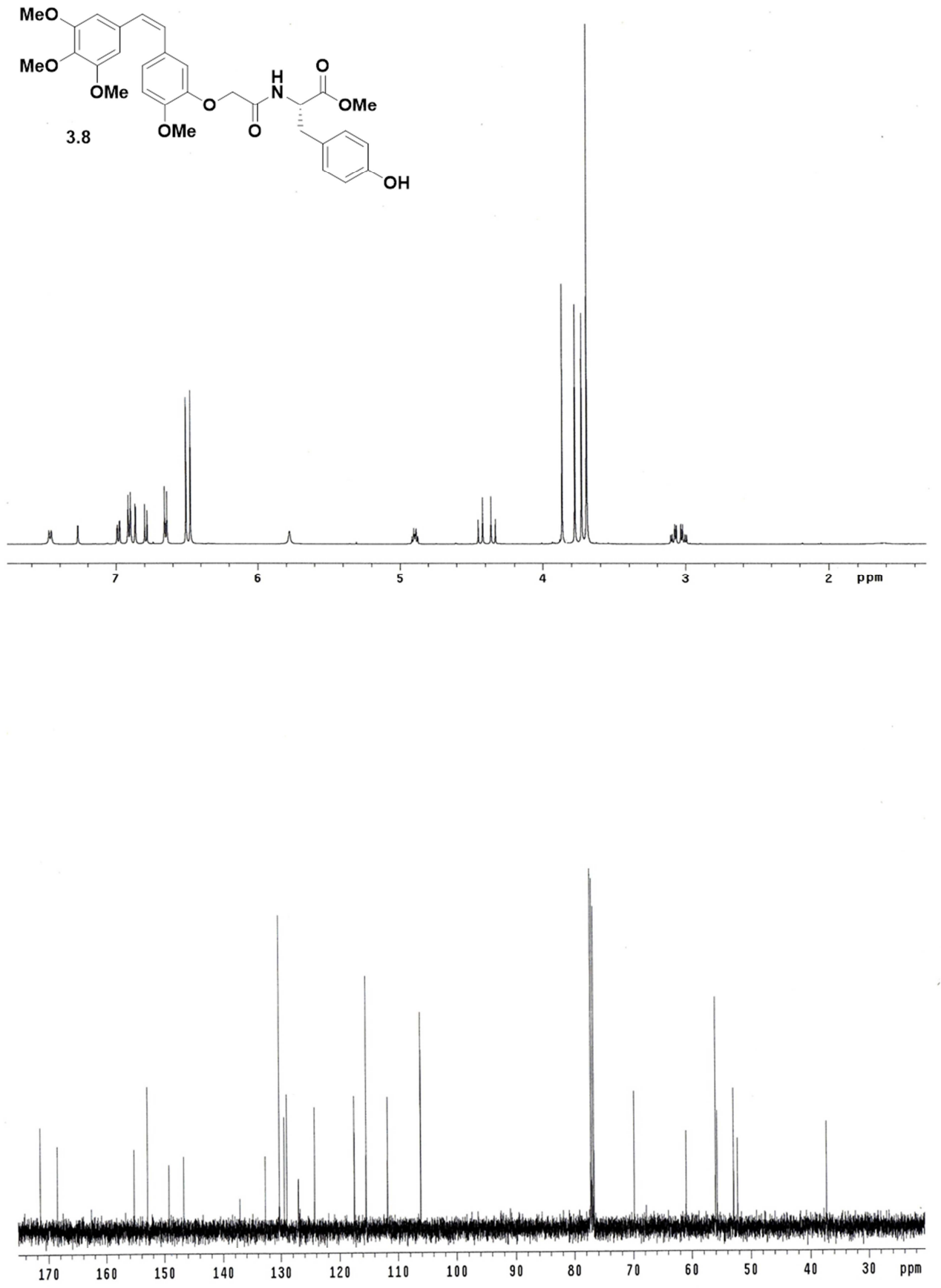

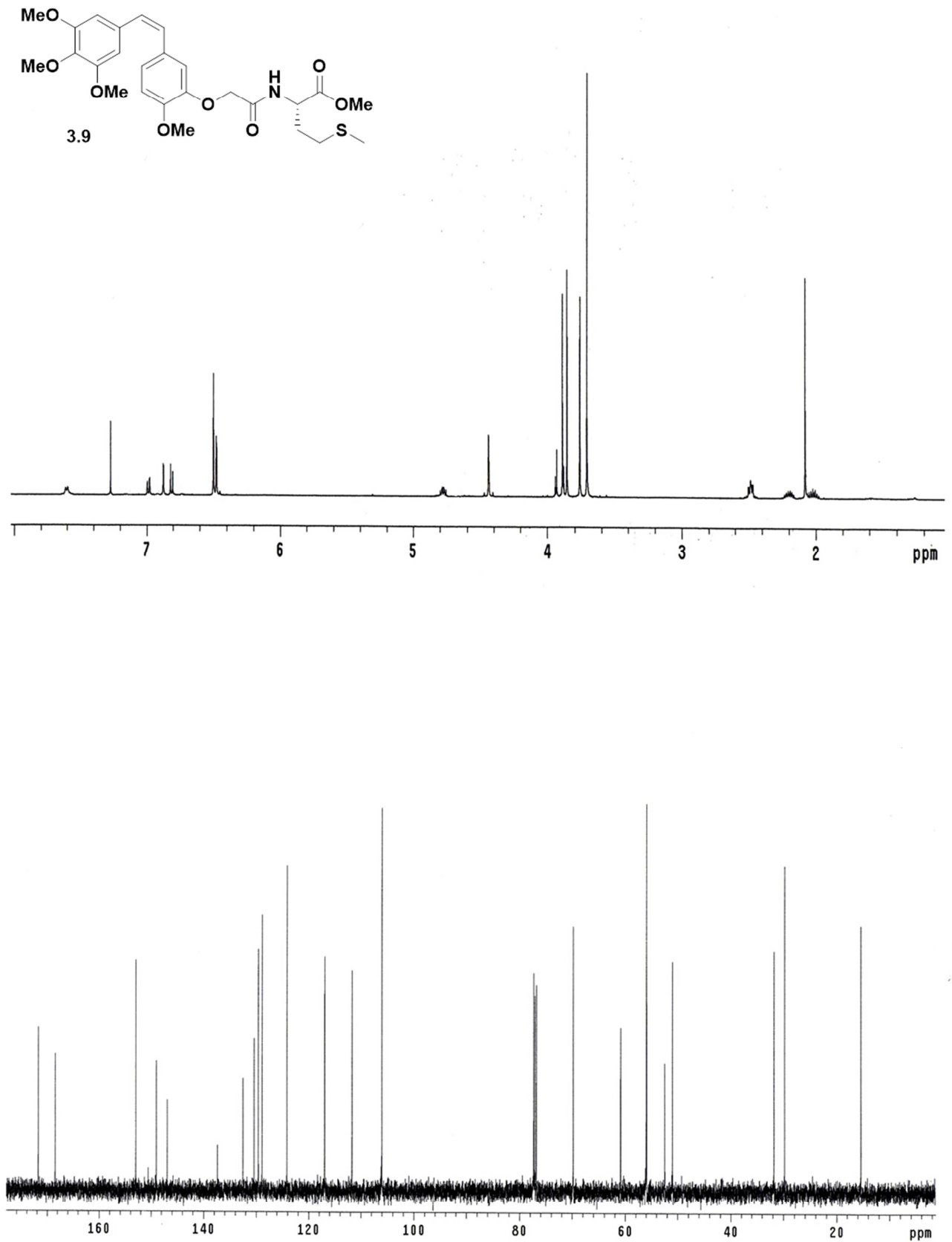

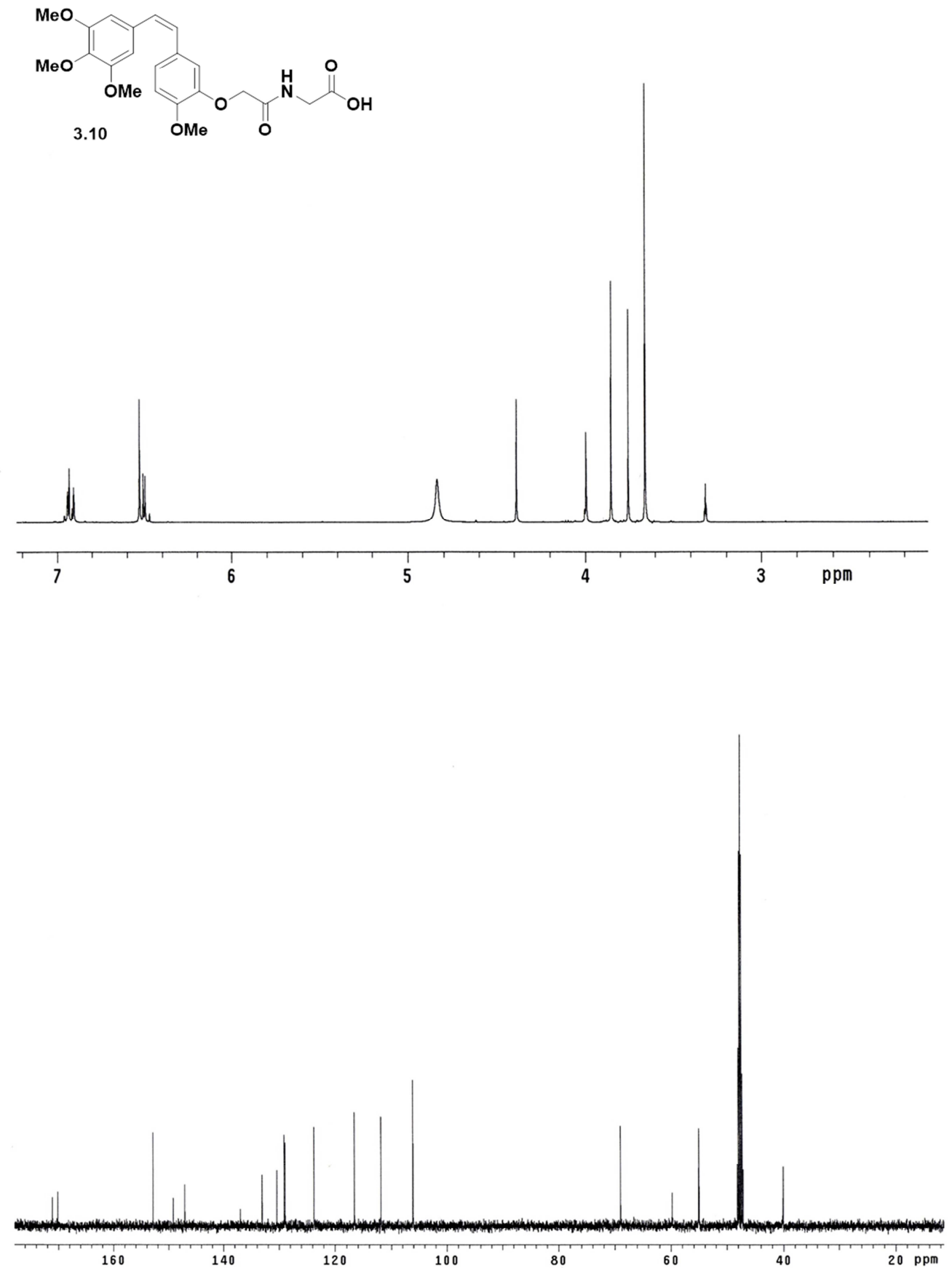

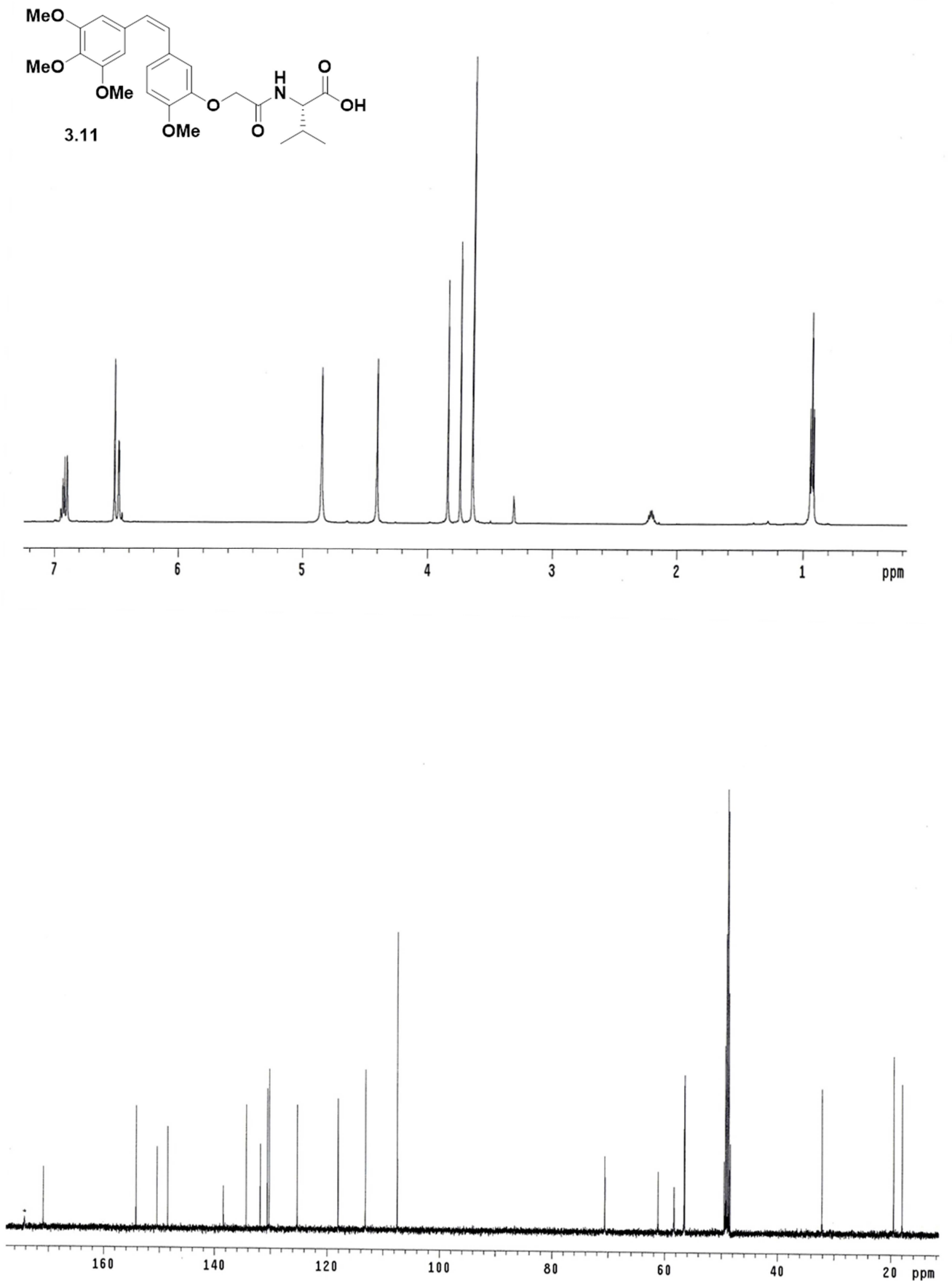

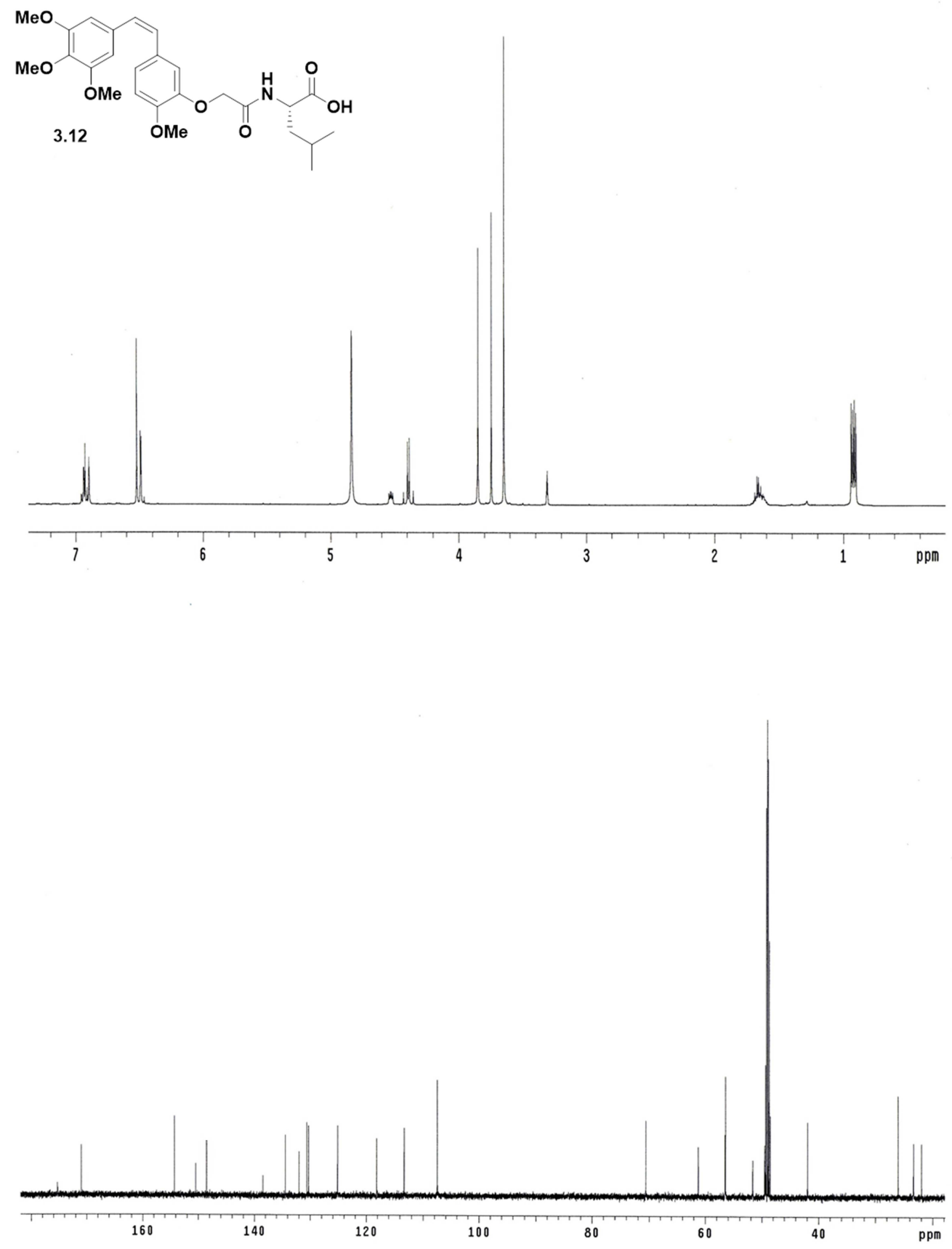

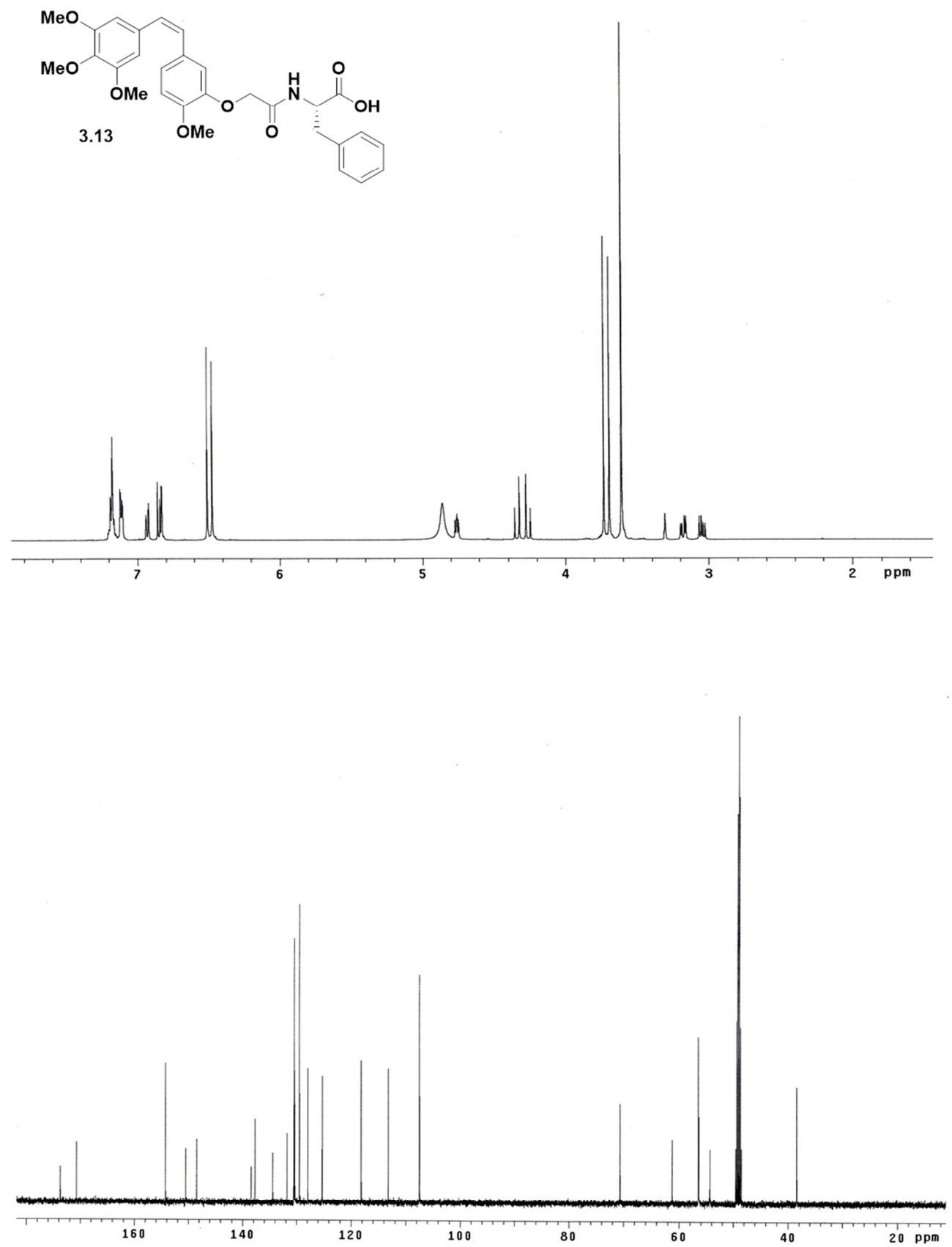

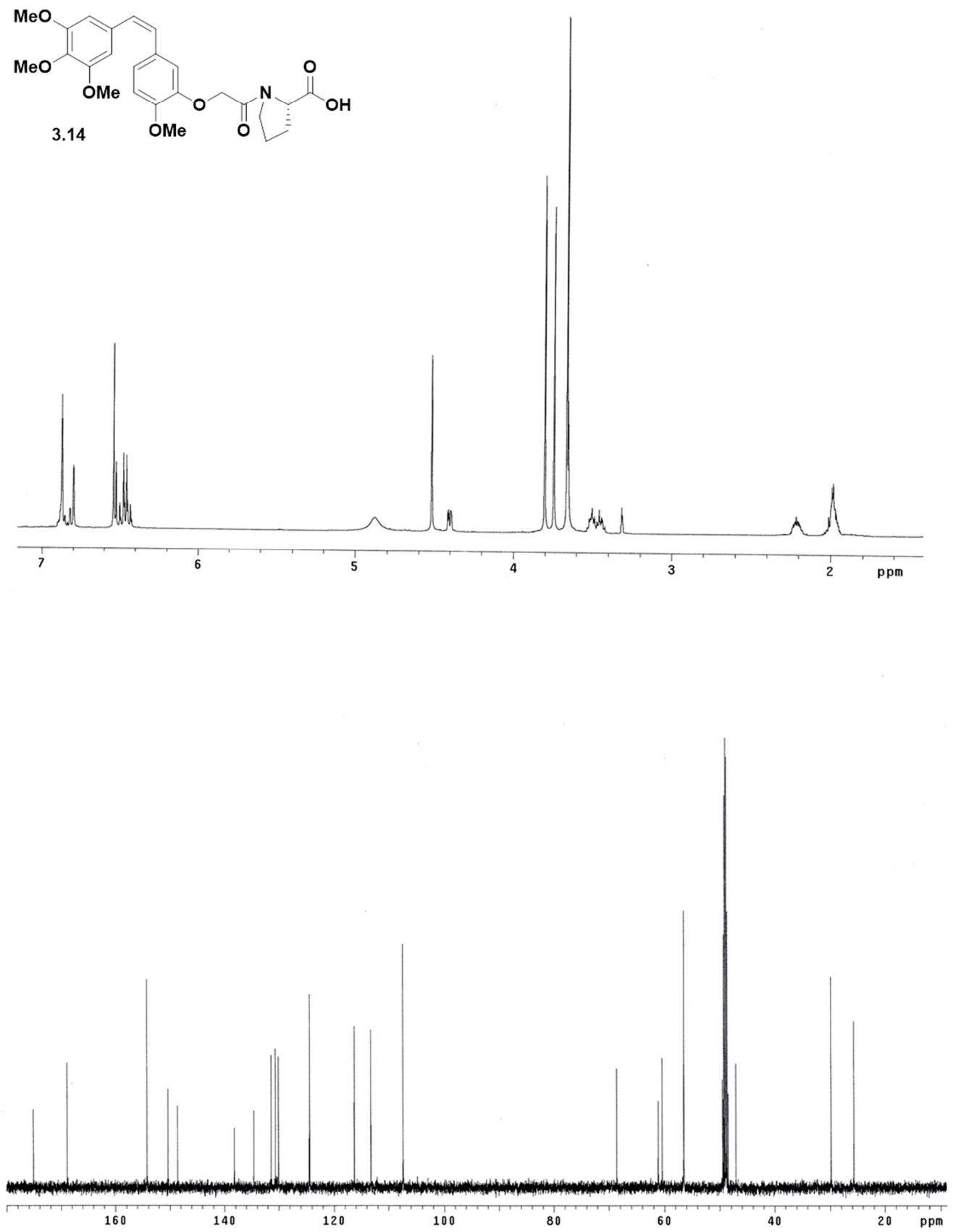

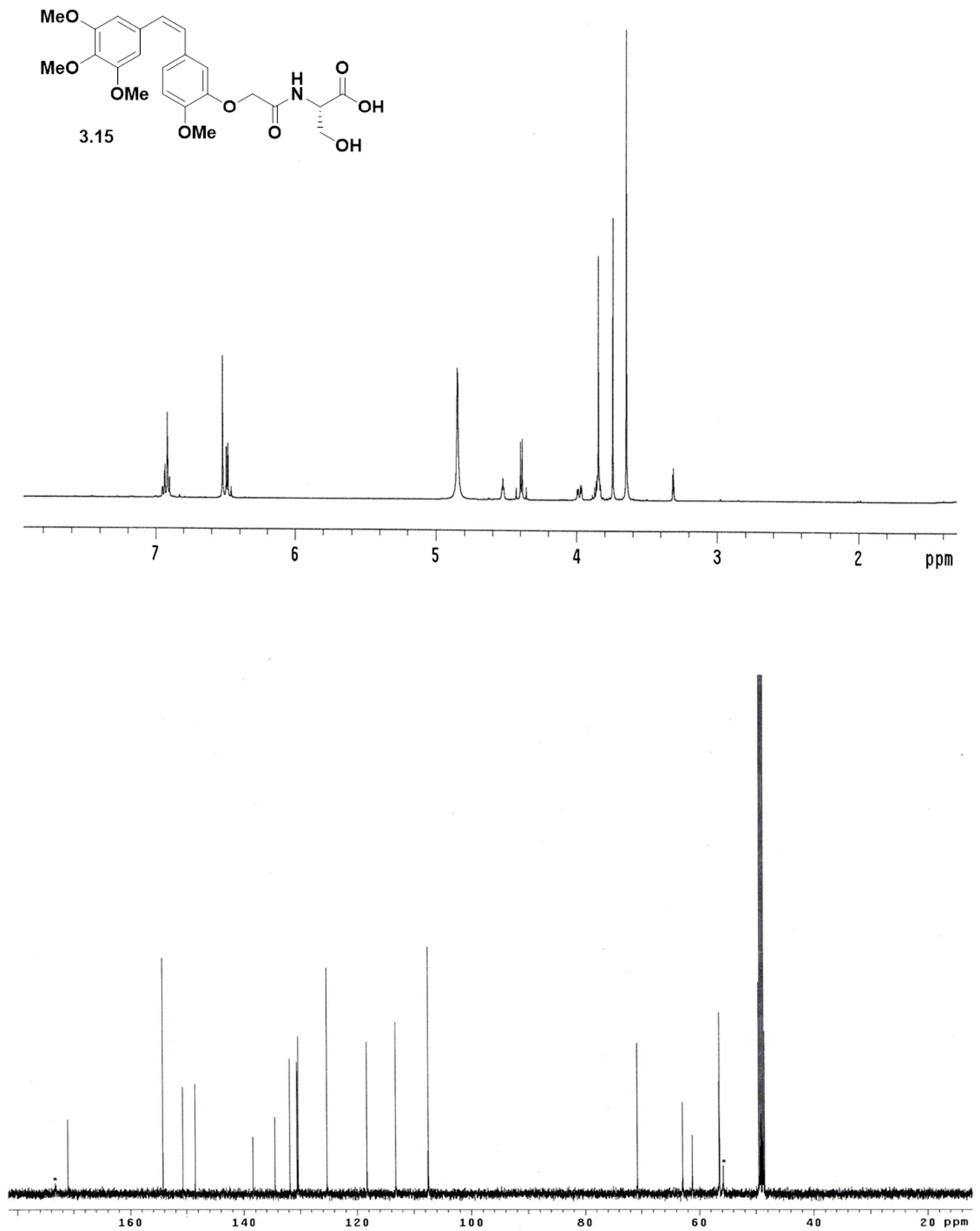

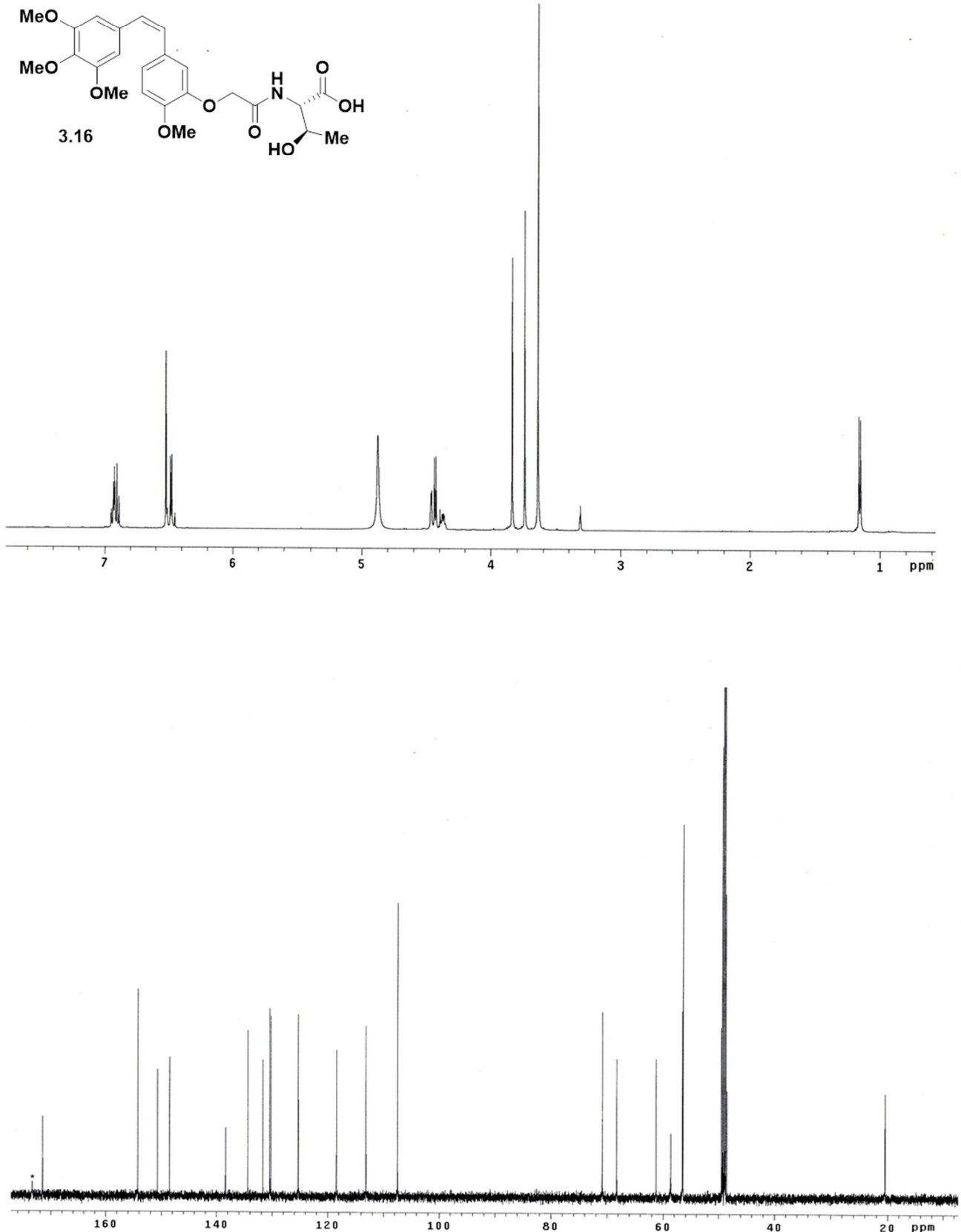

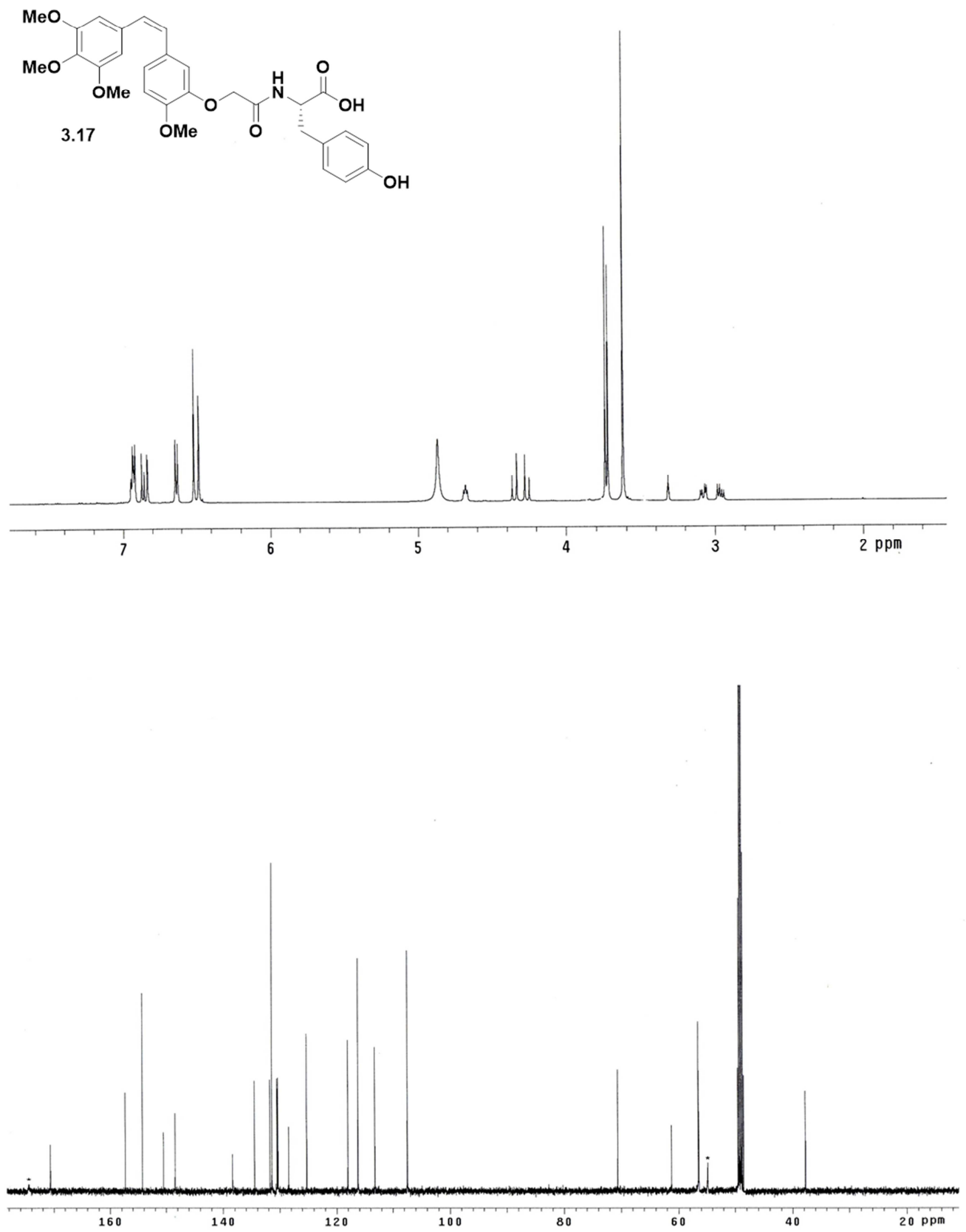

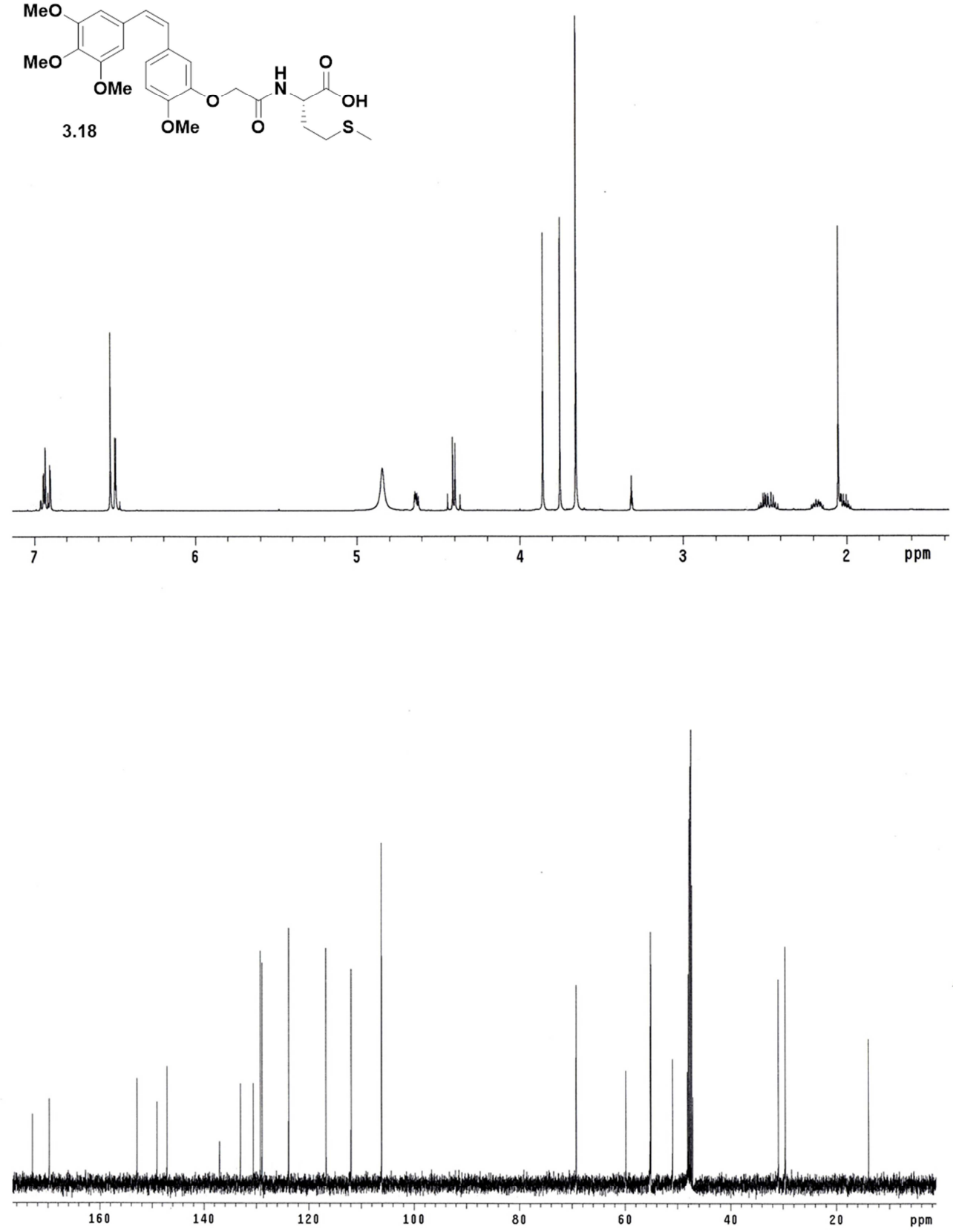

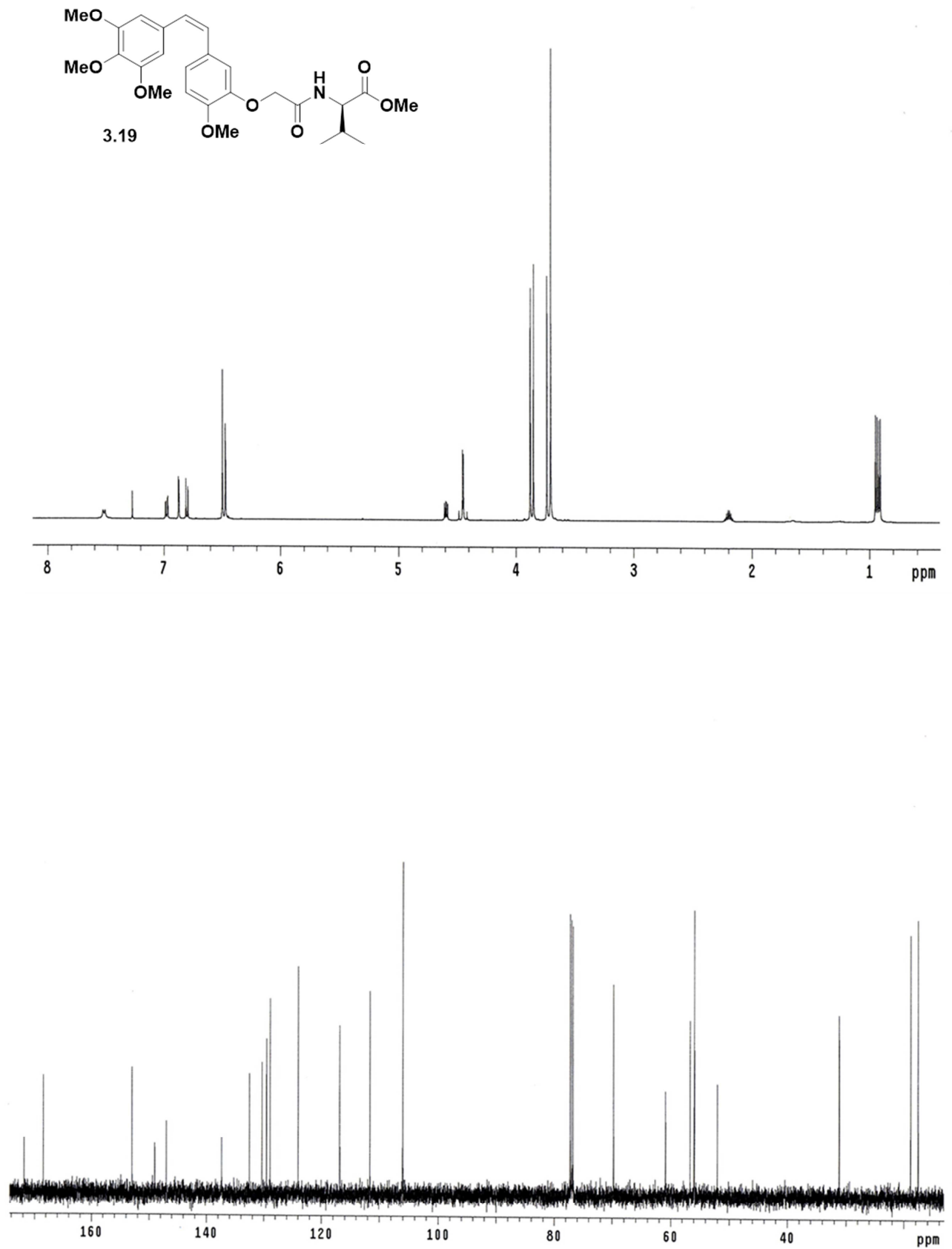

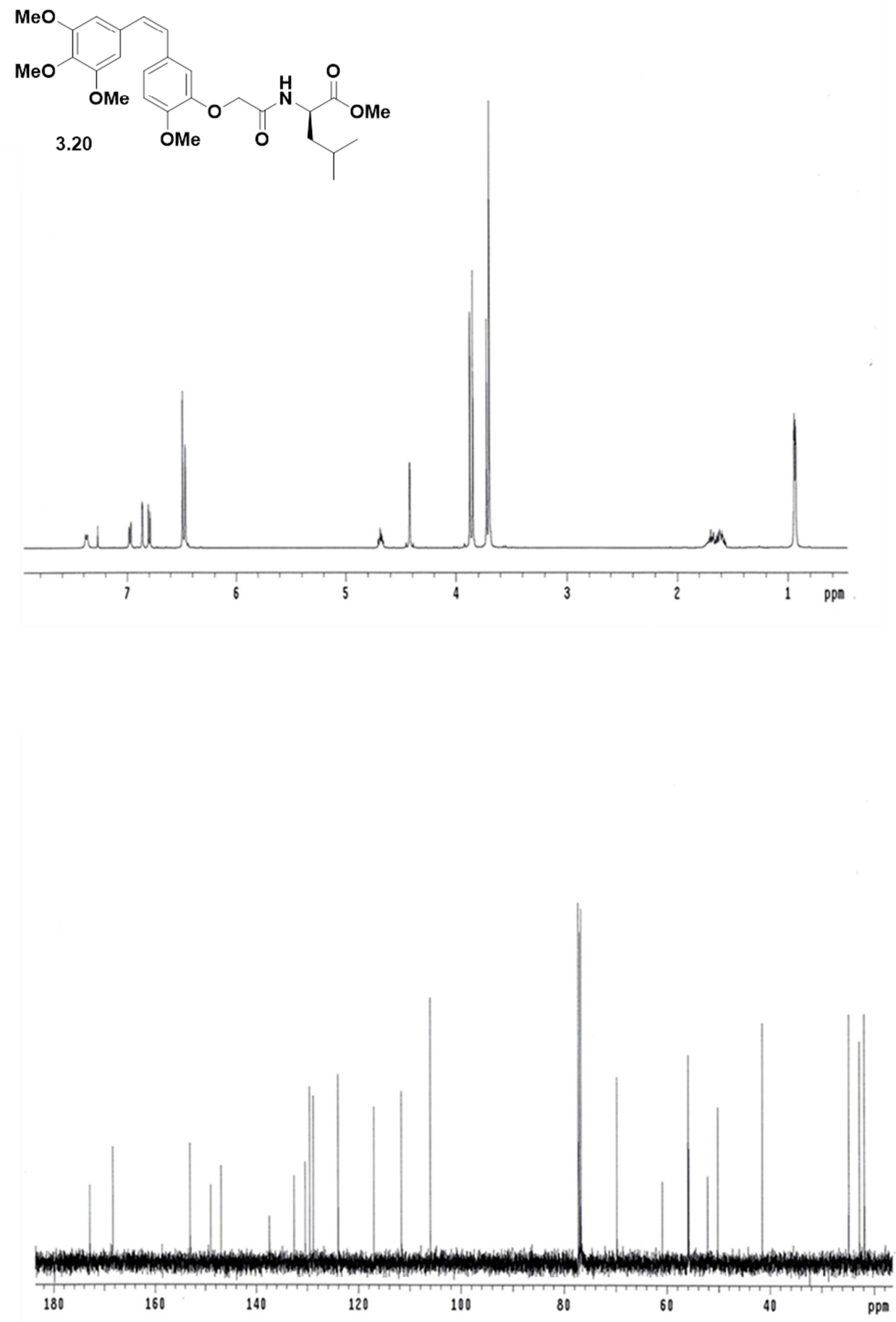

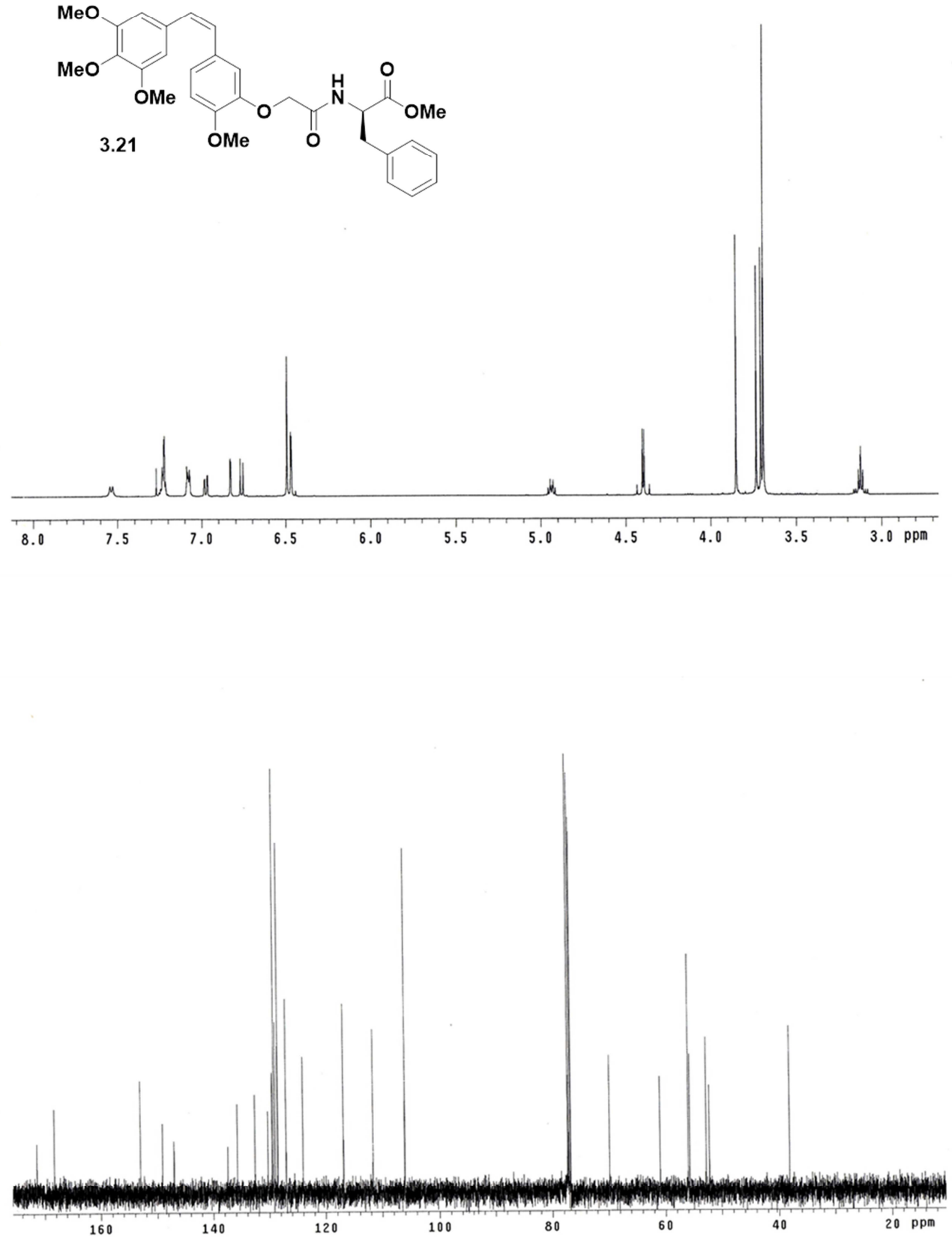

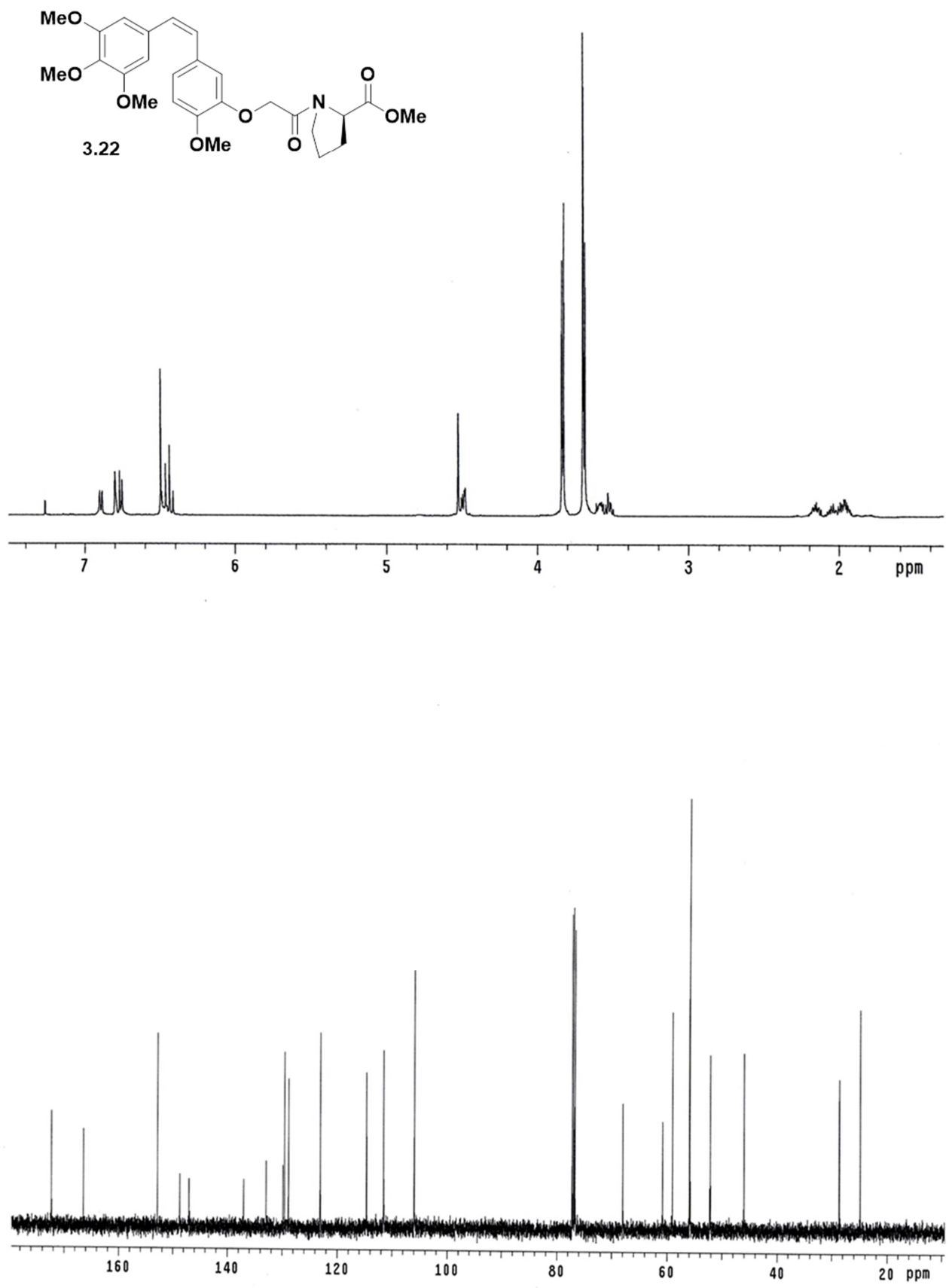

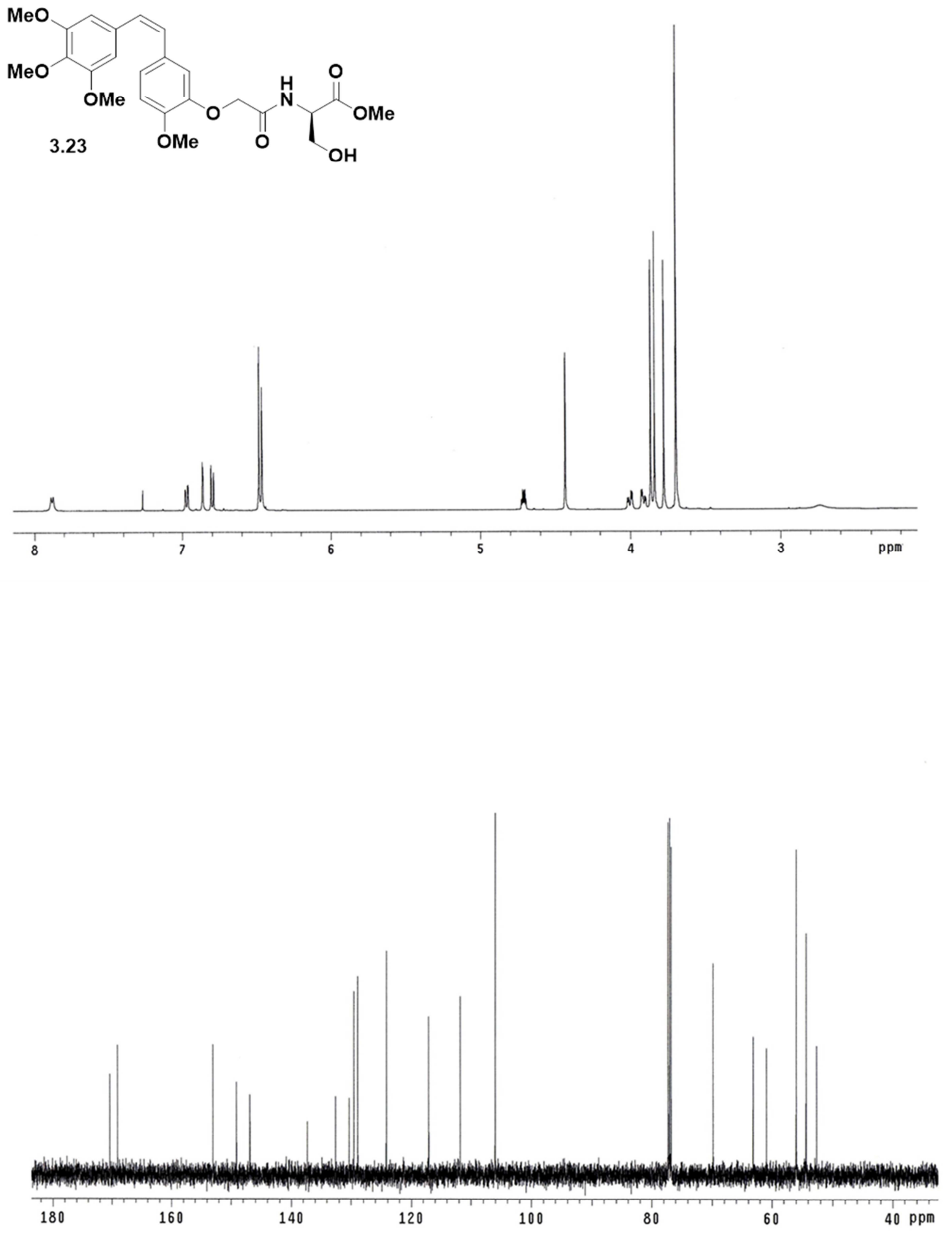

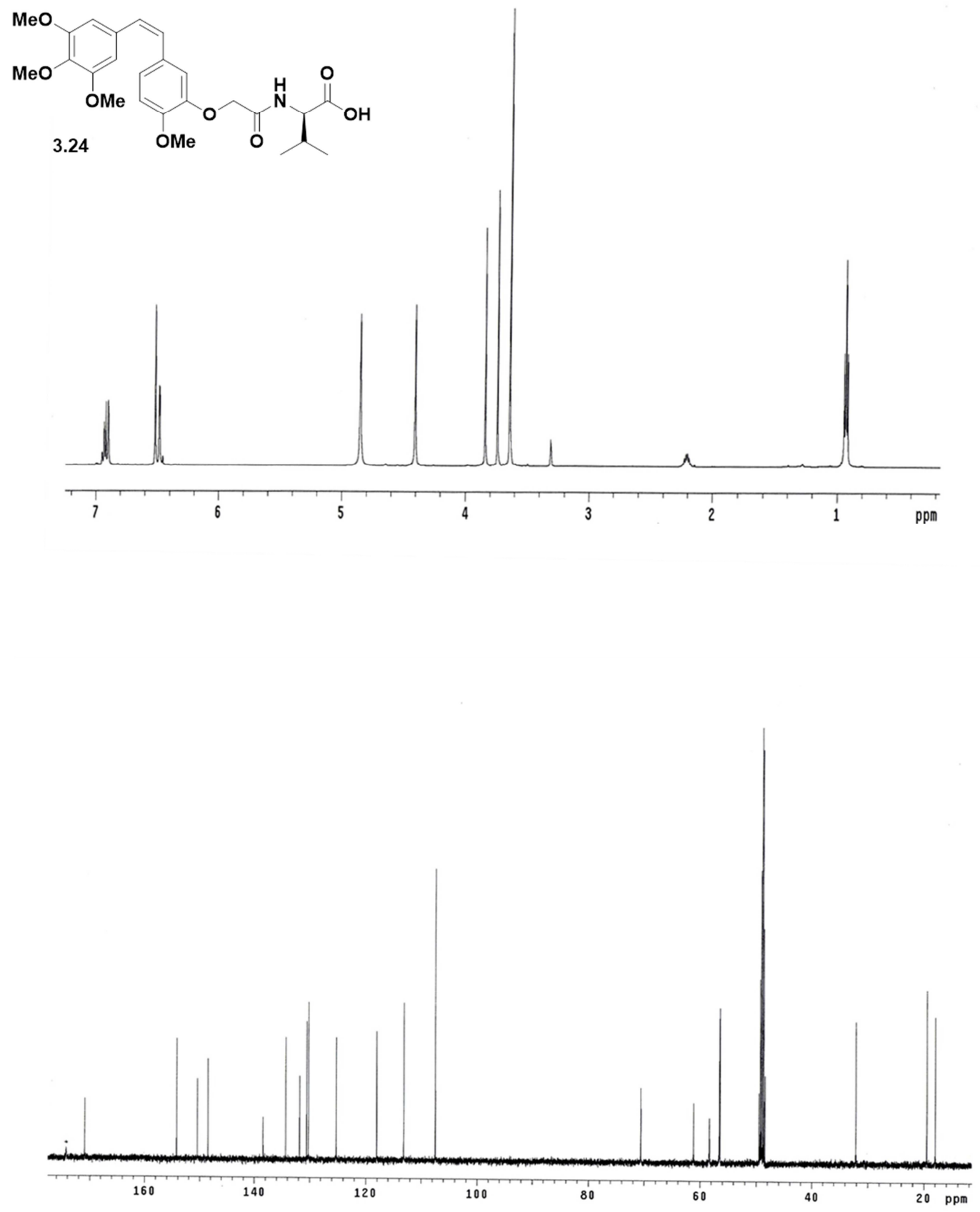

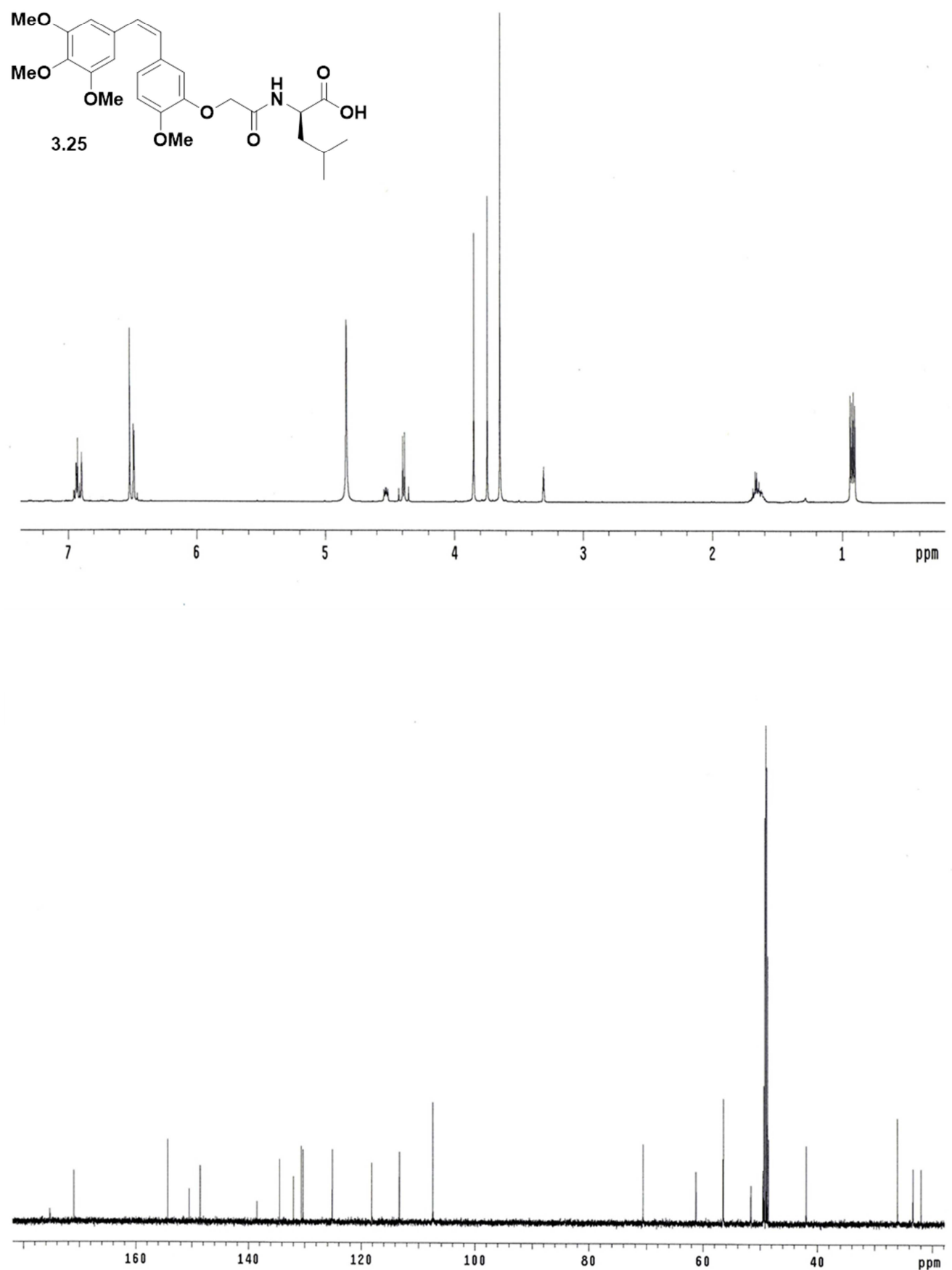

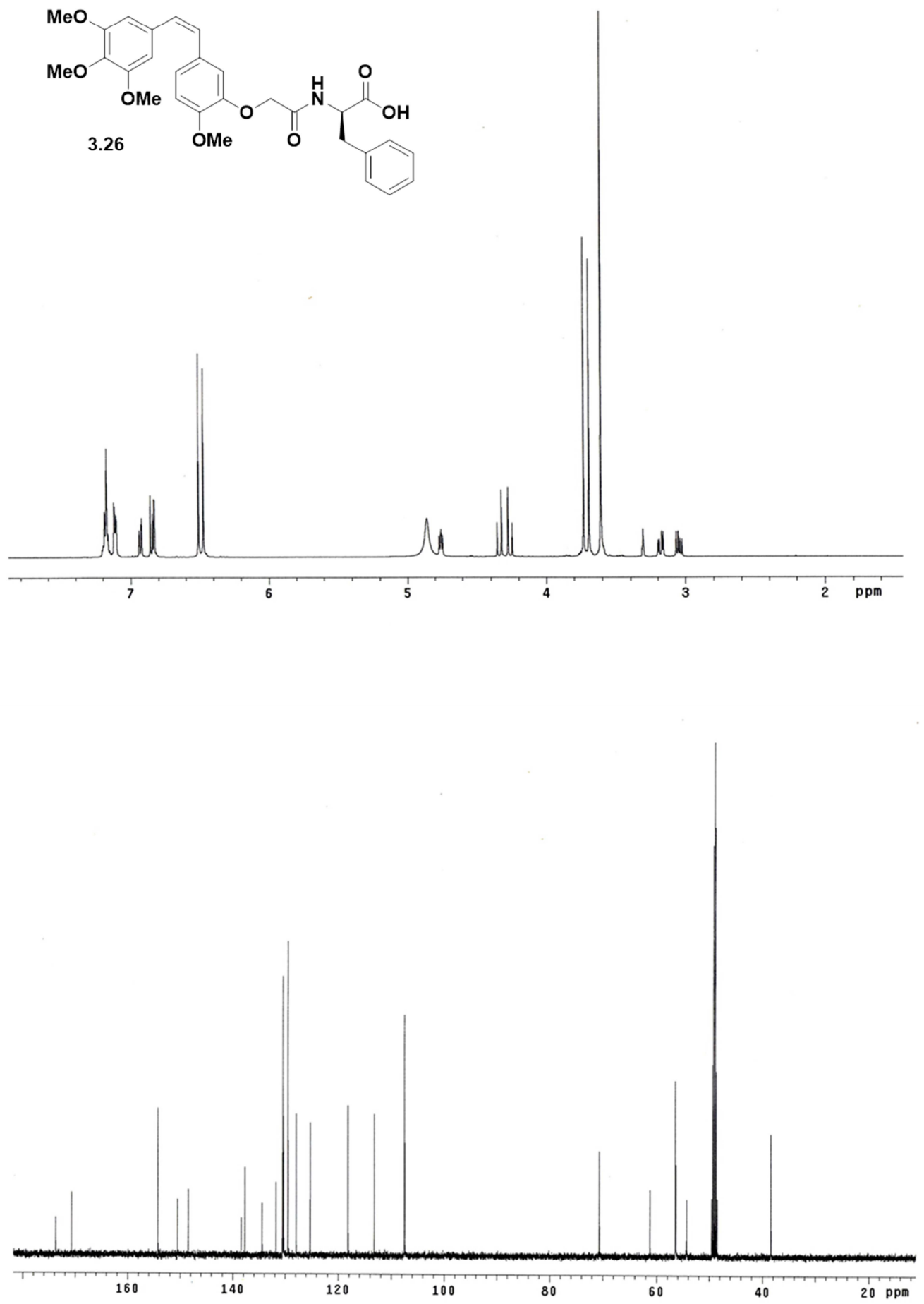

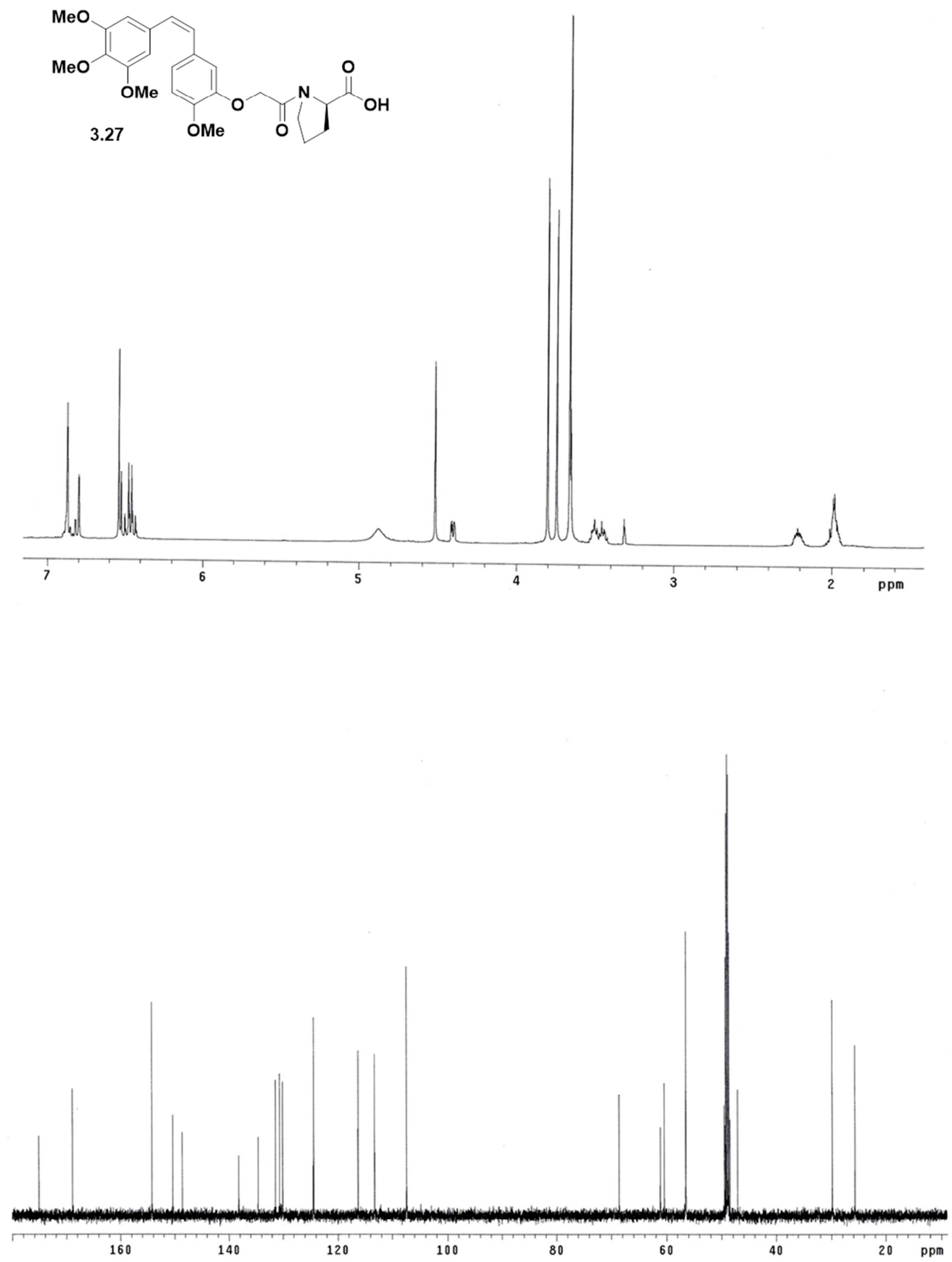

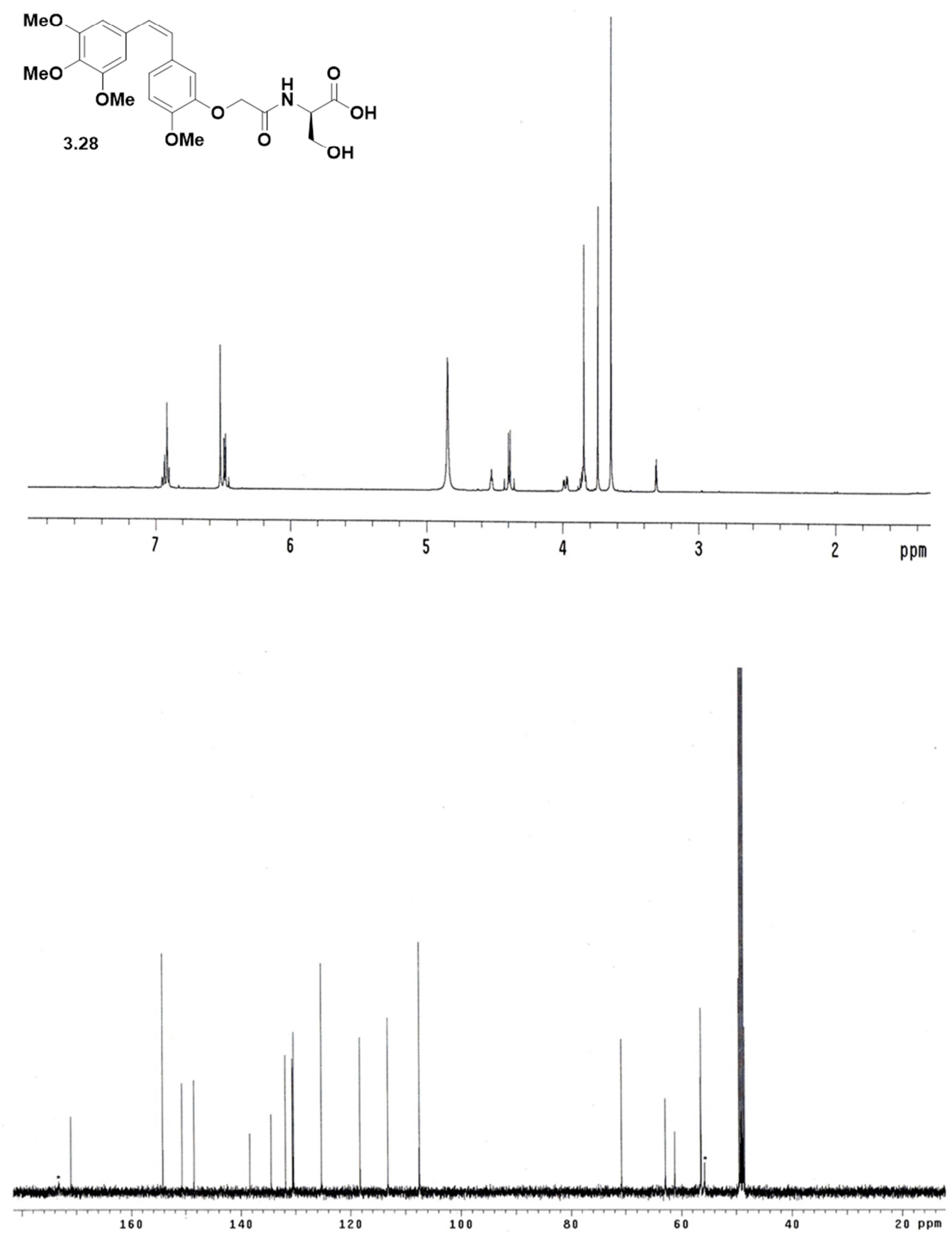

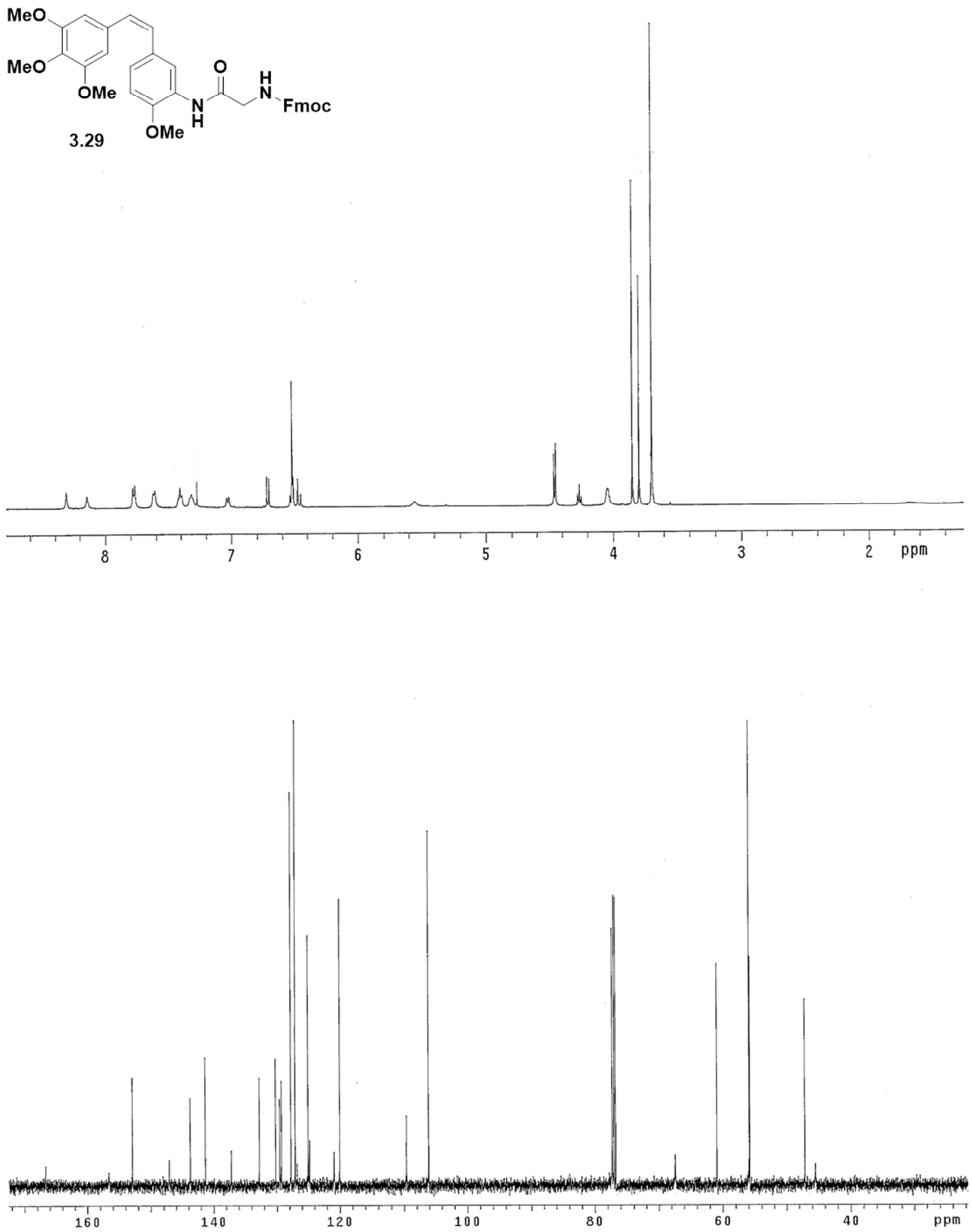
3.30 OMe
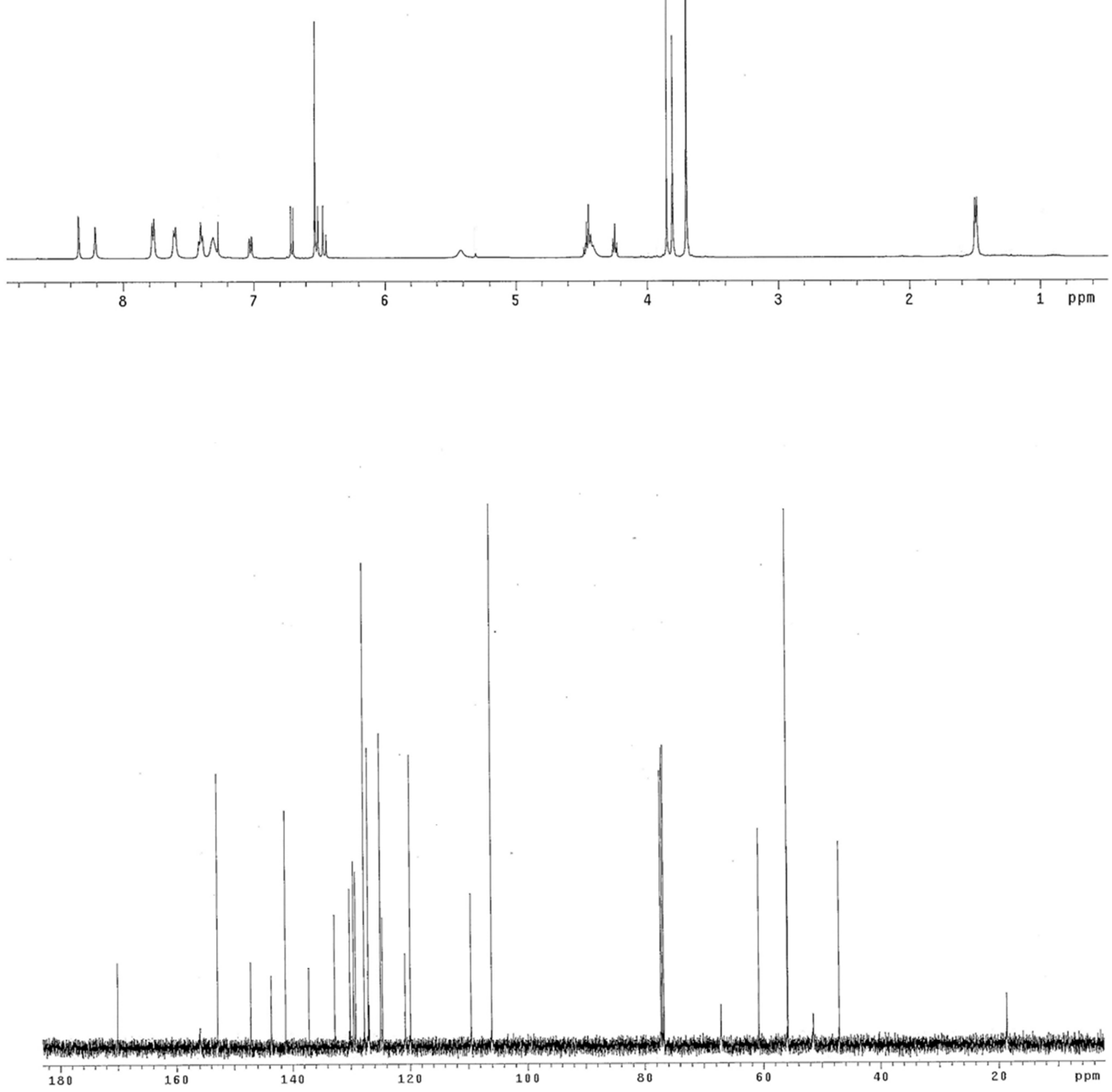

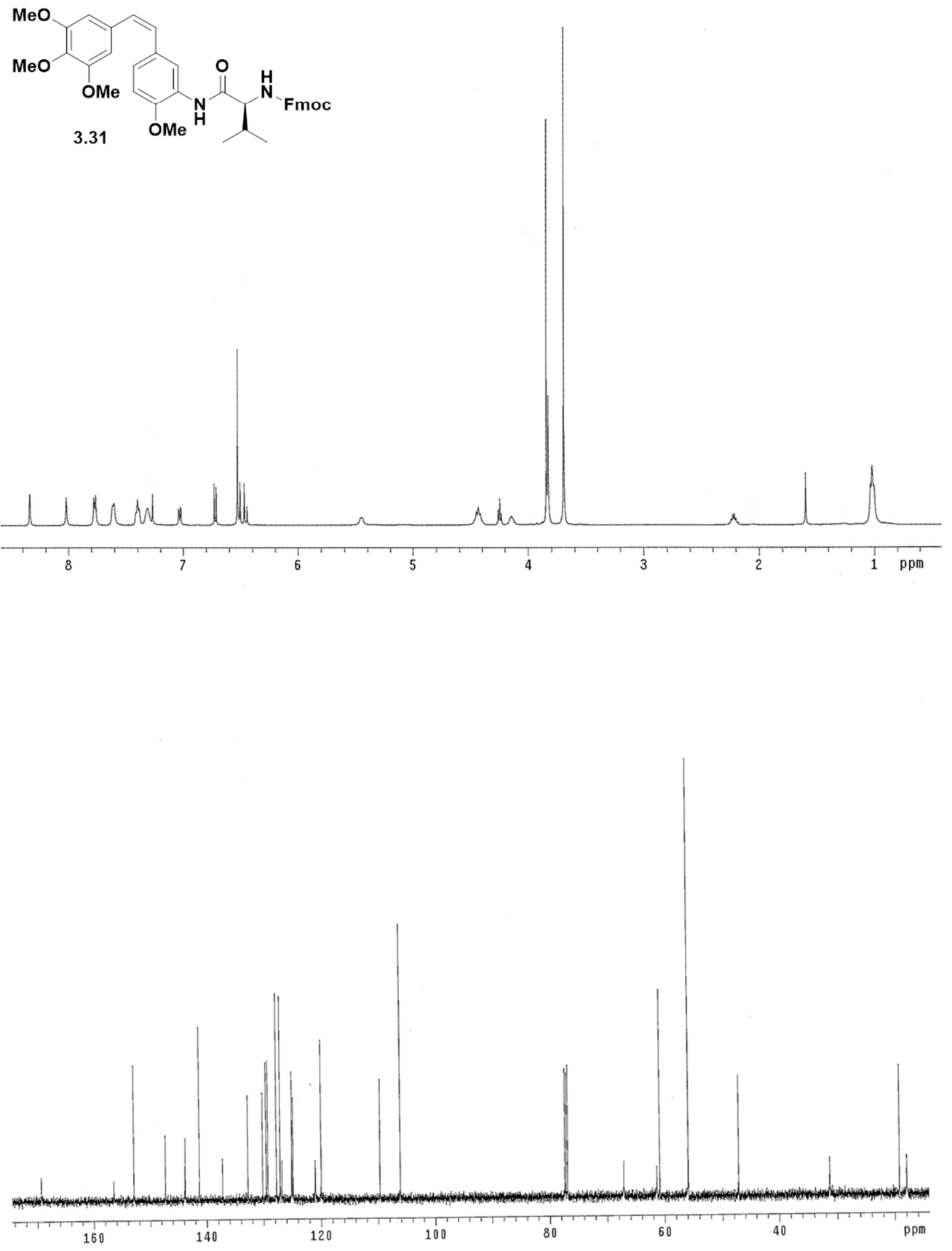

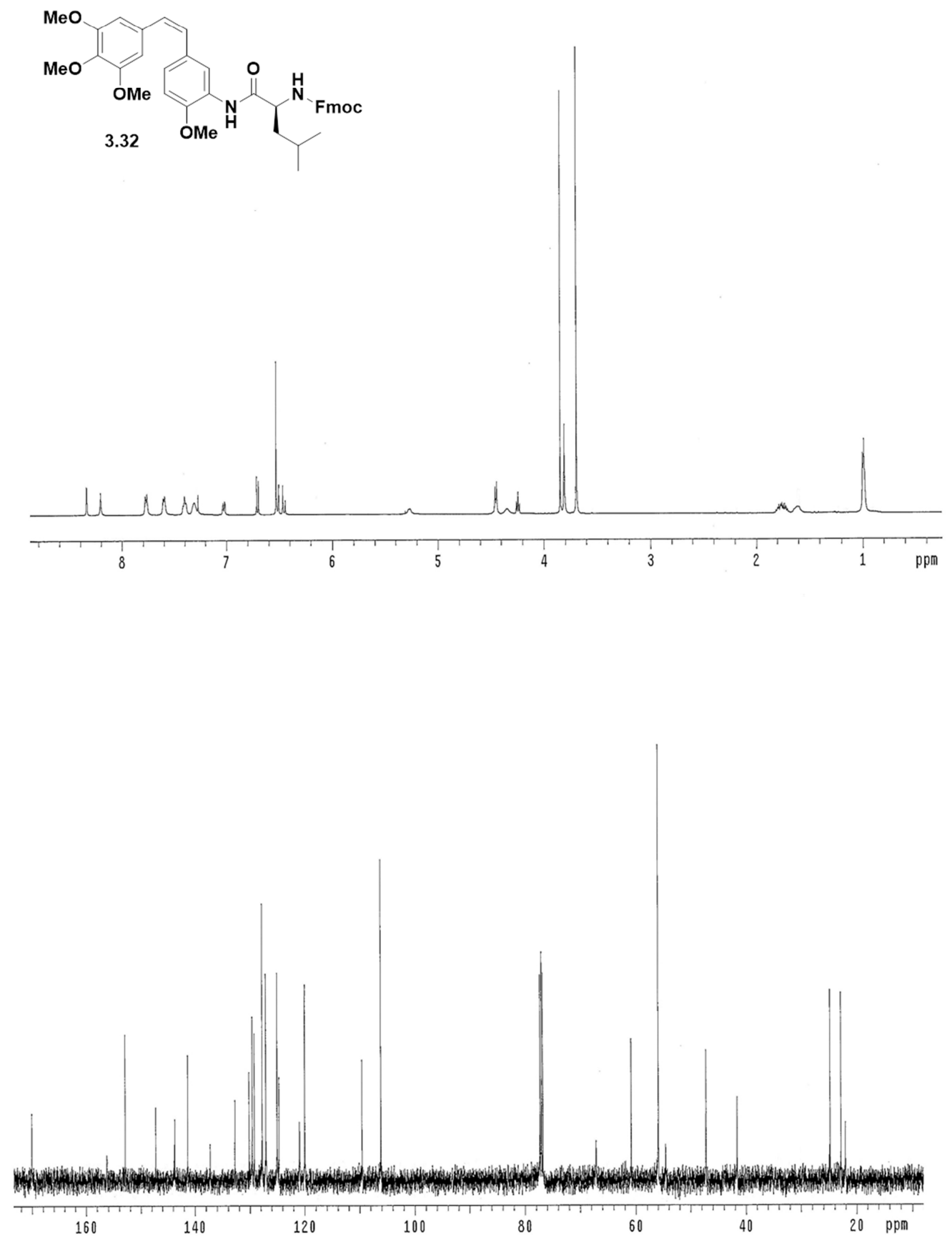

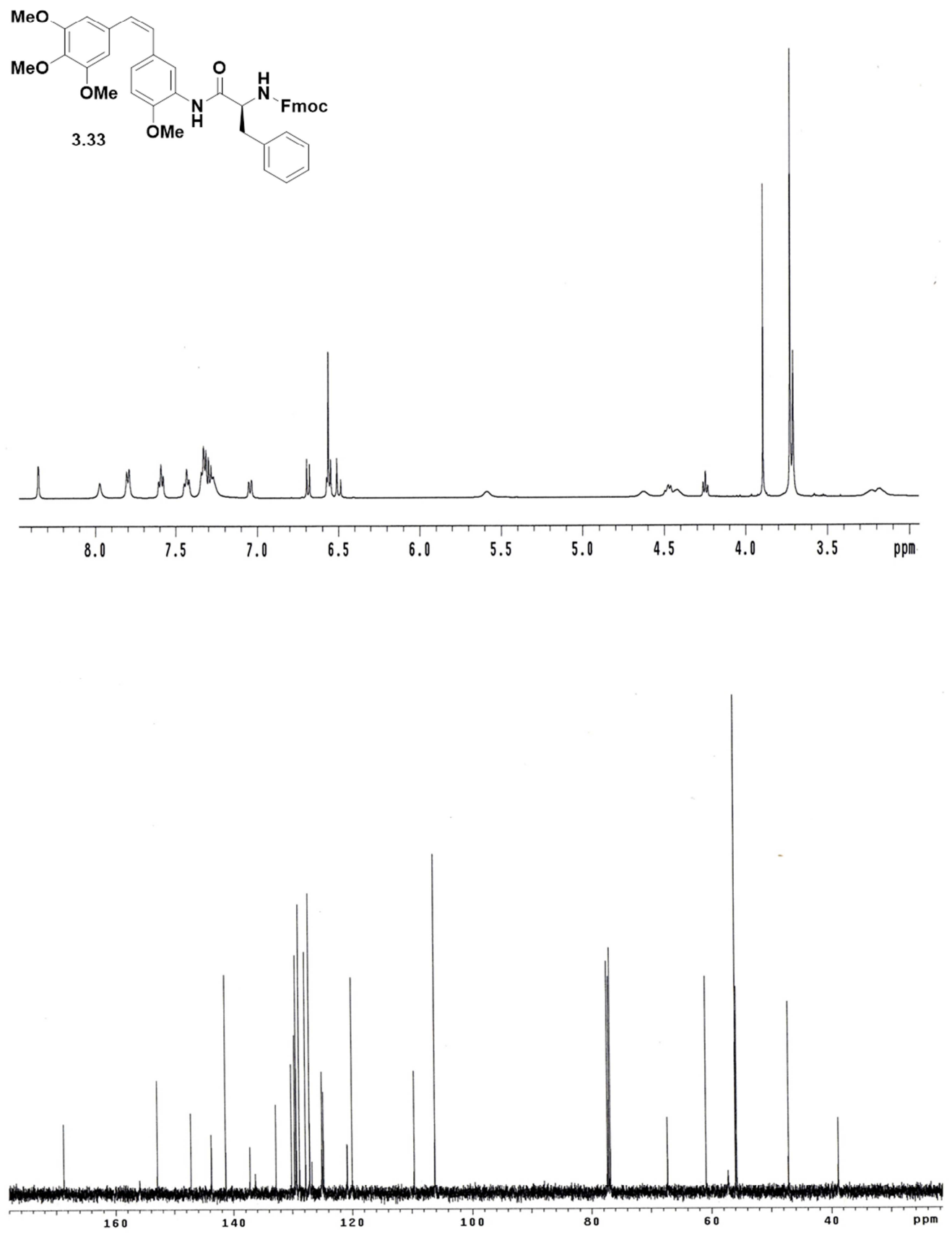

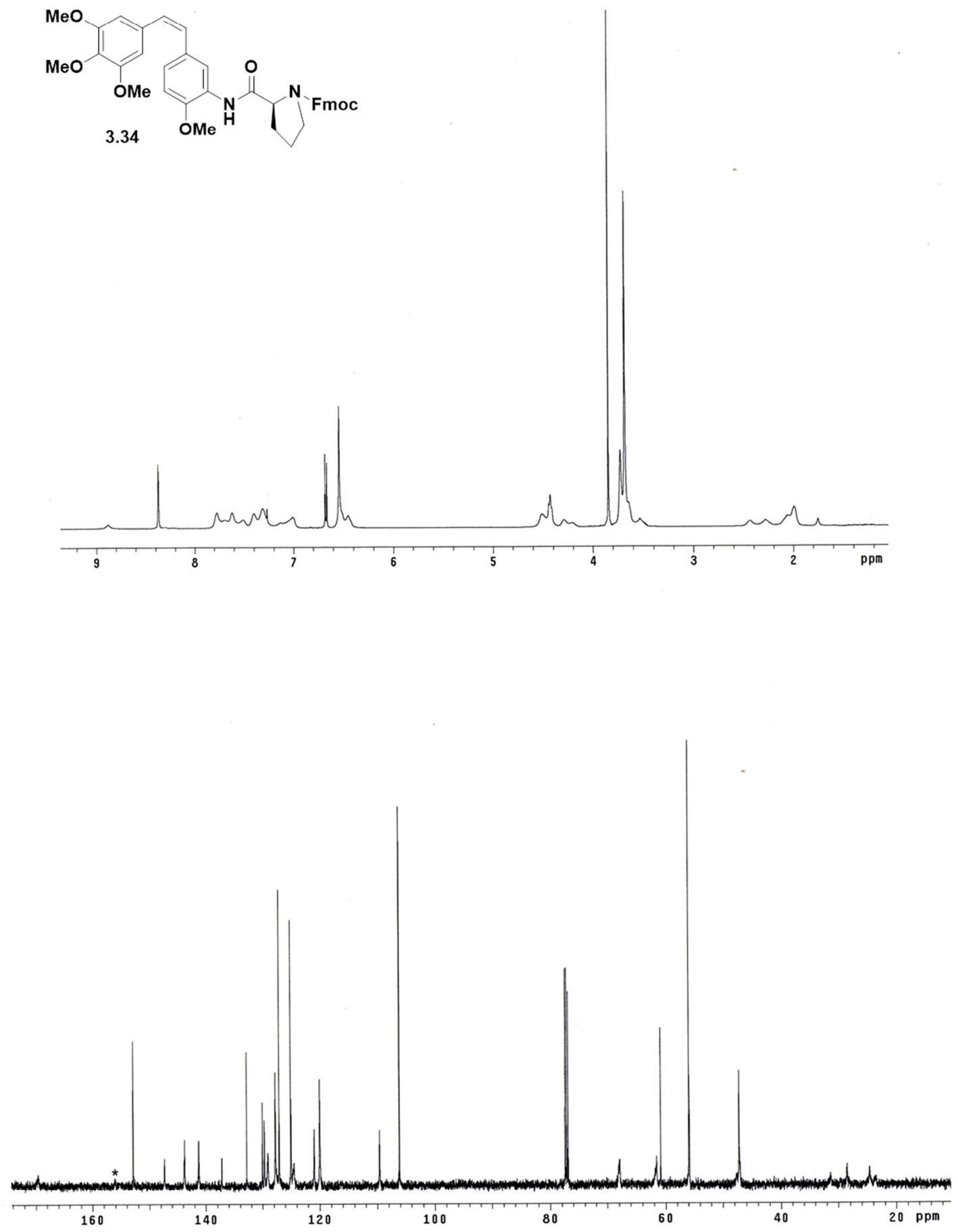

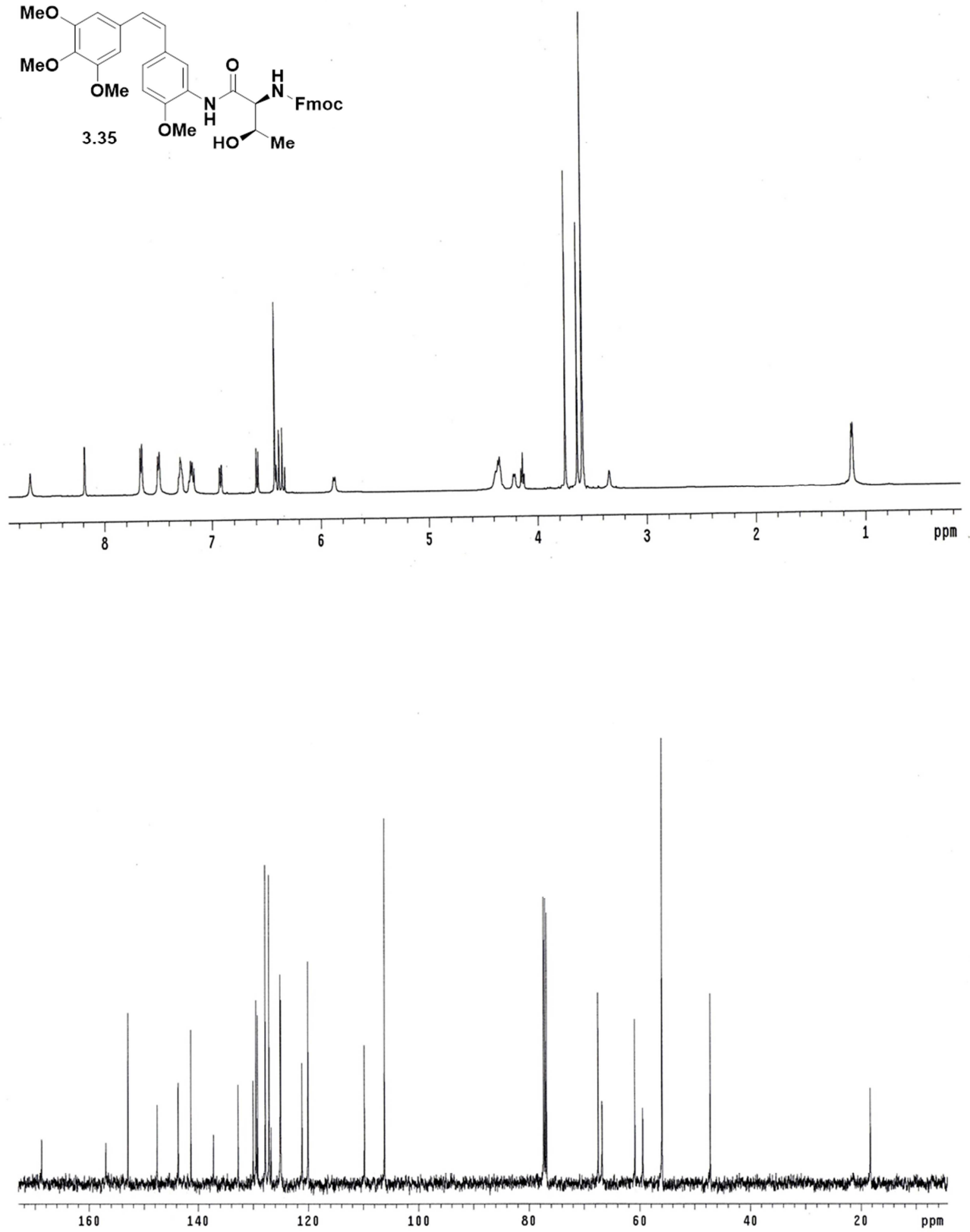

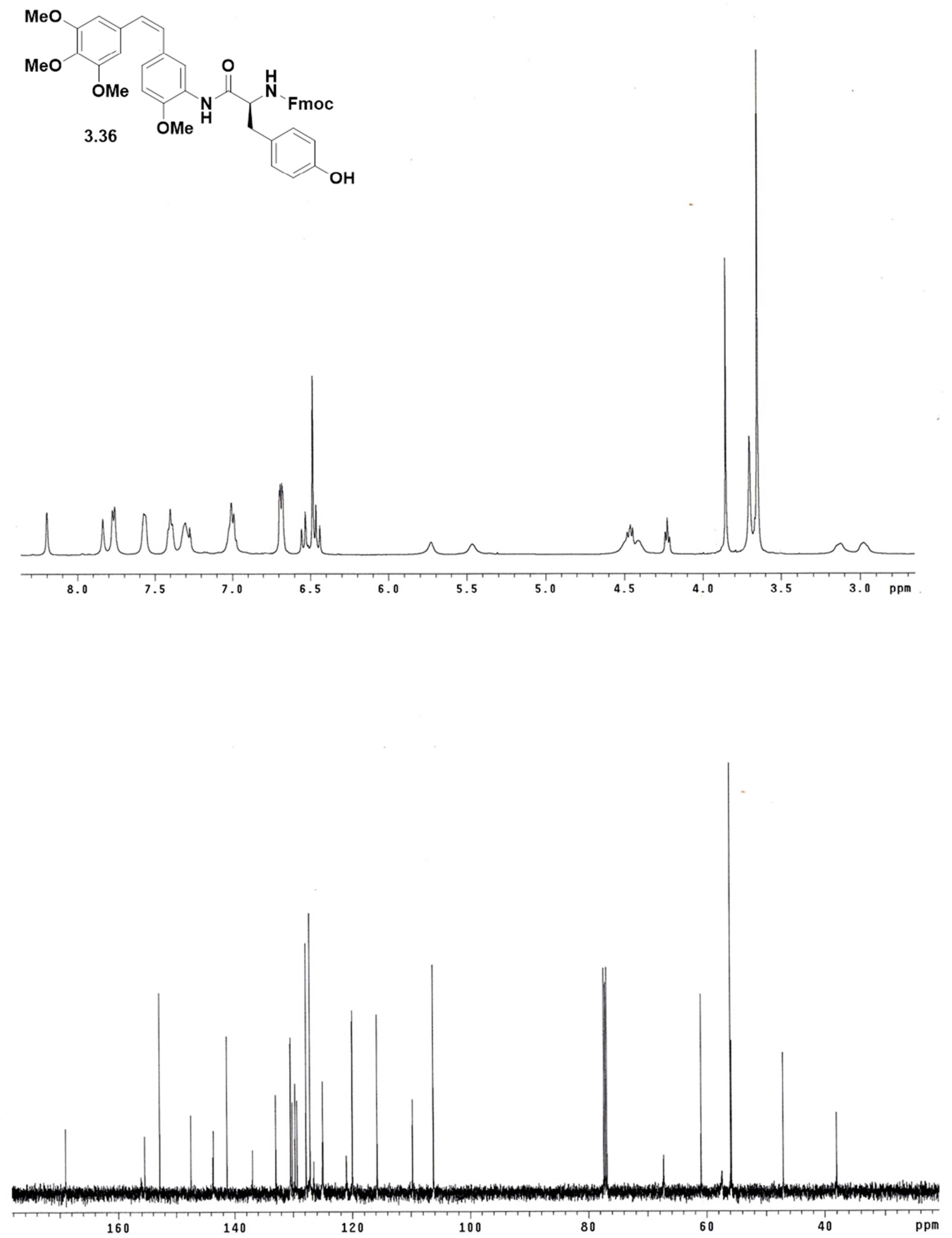

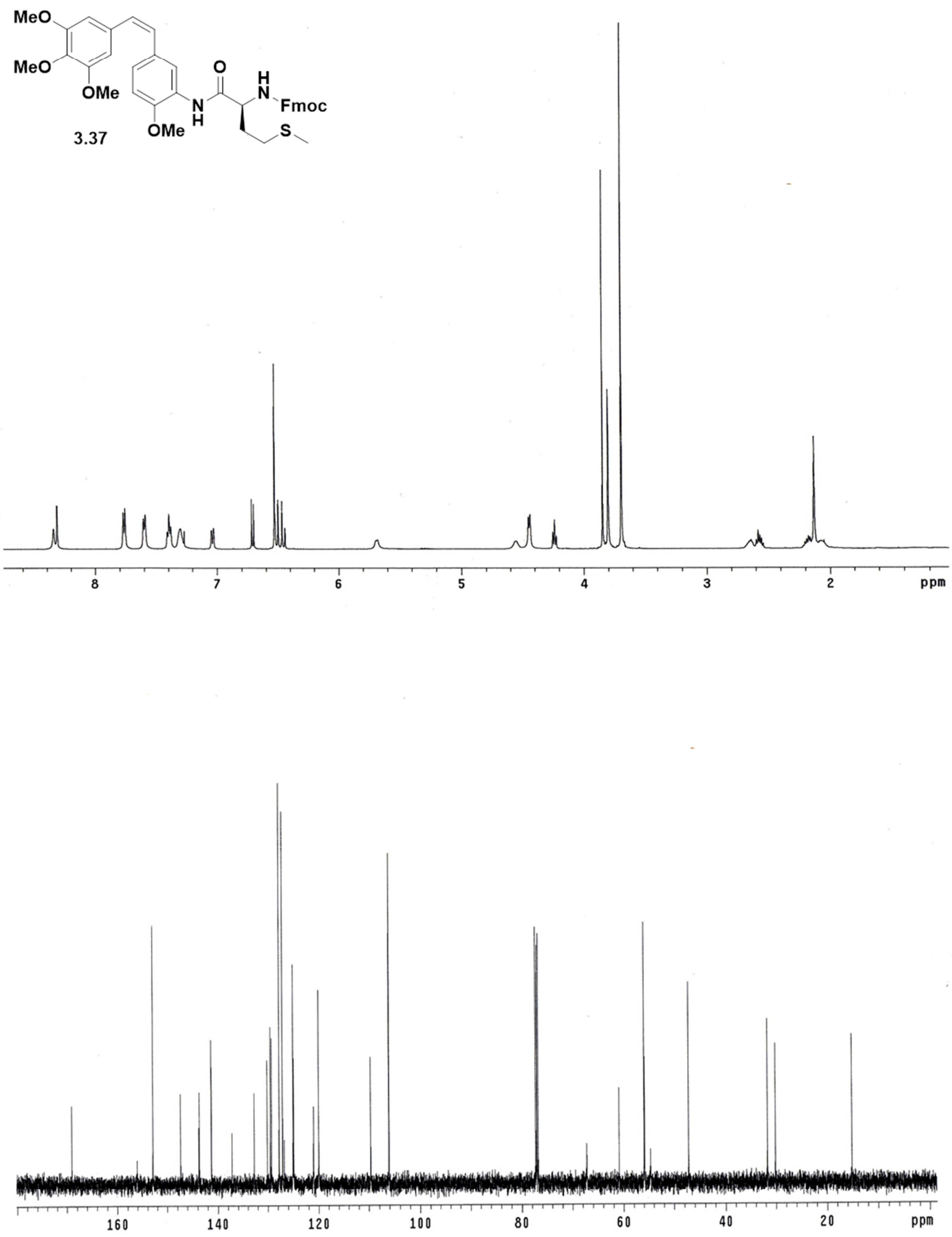

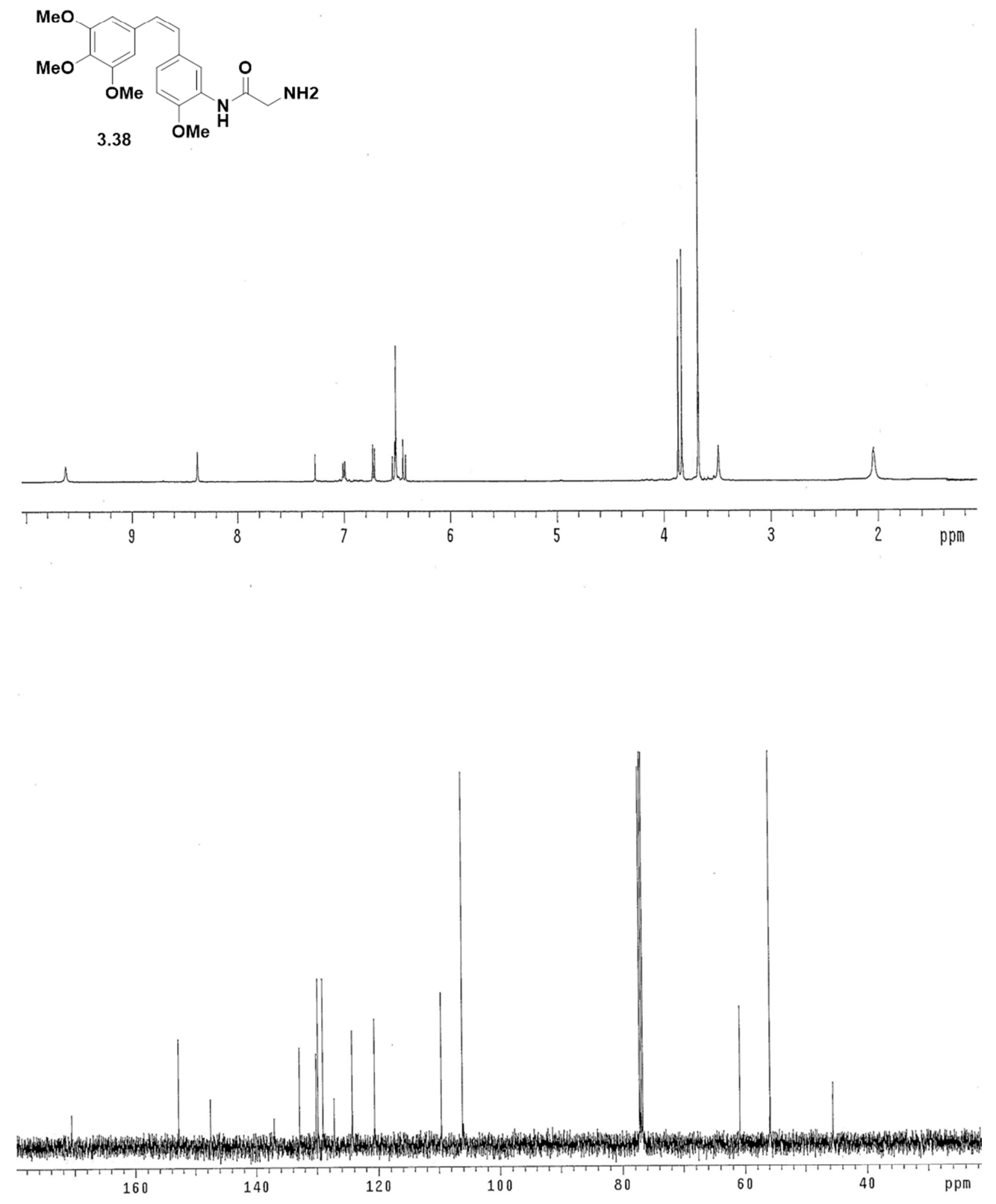

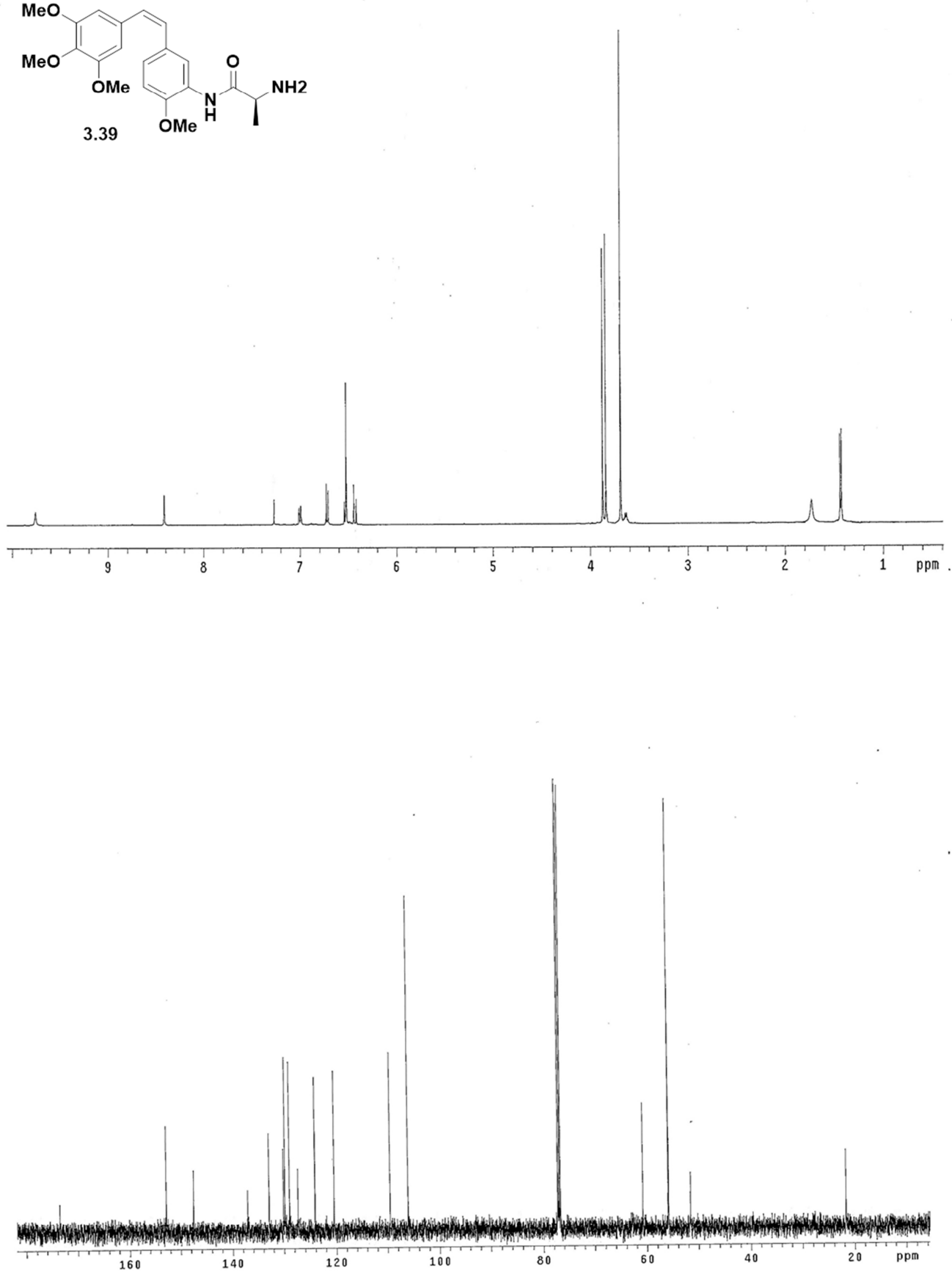

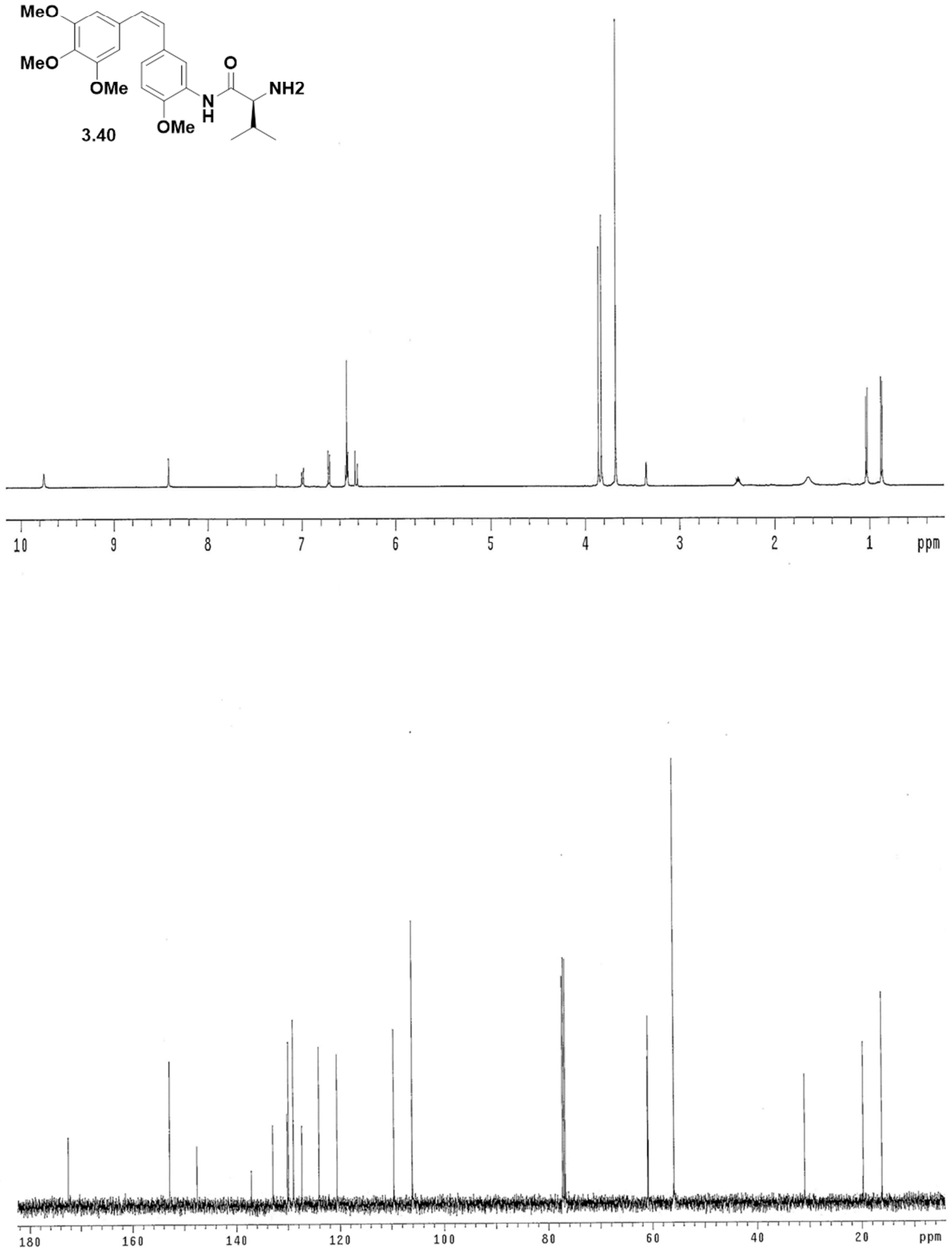

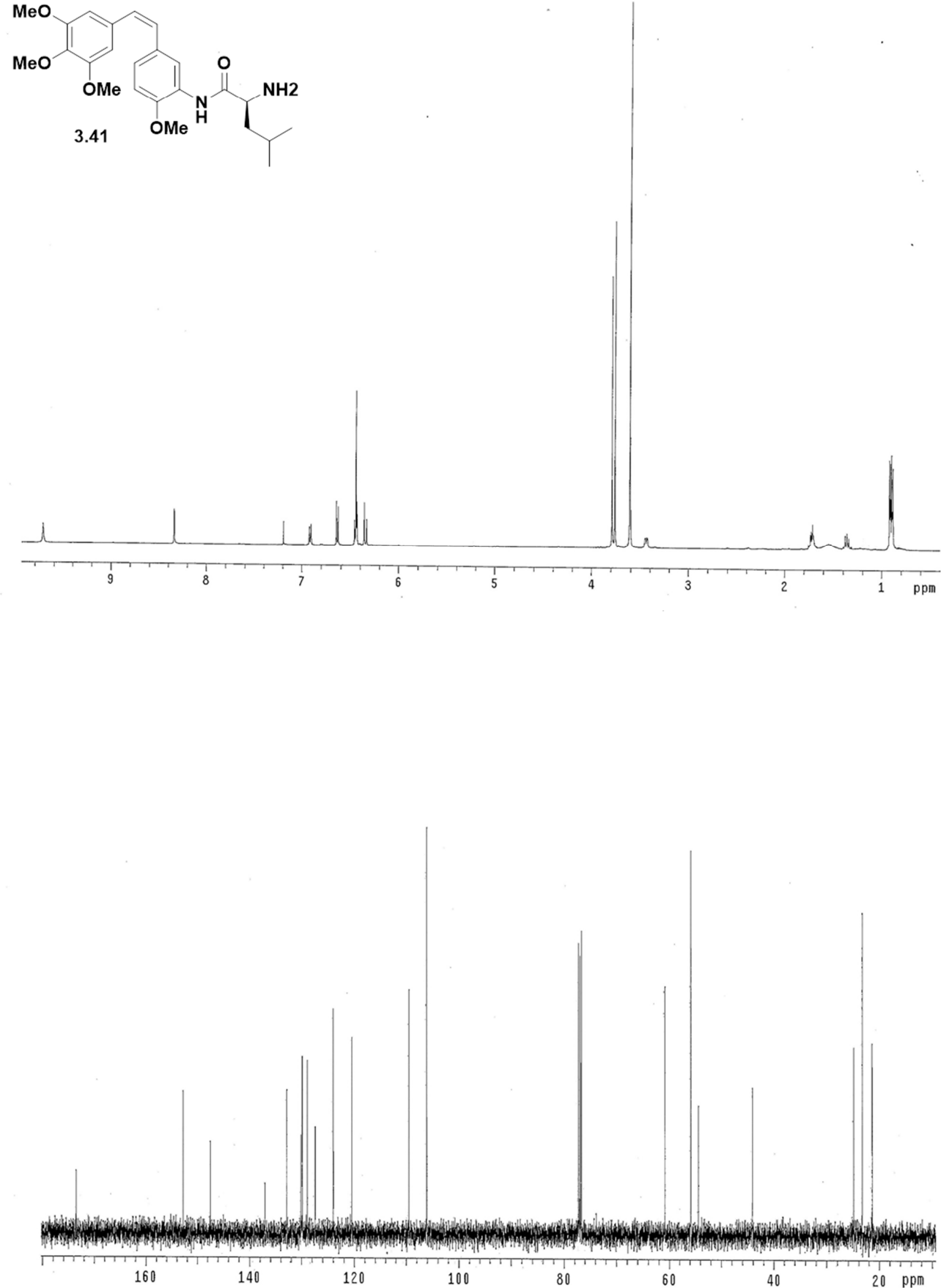

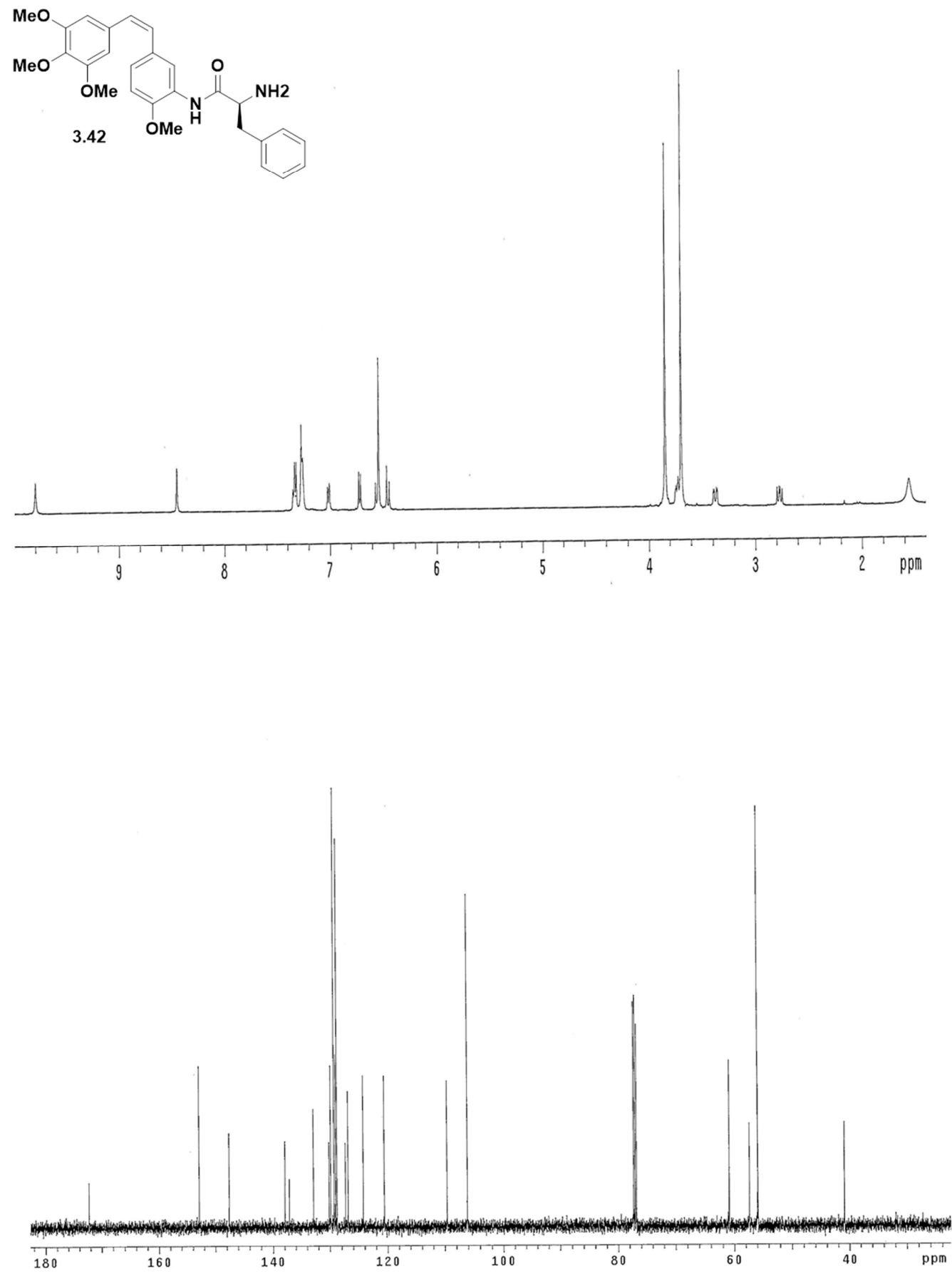

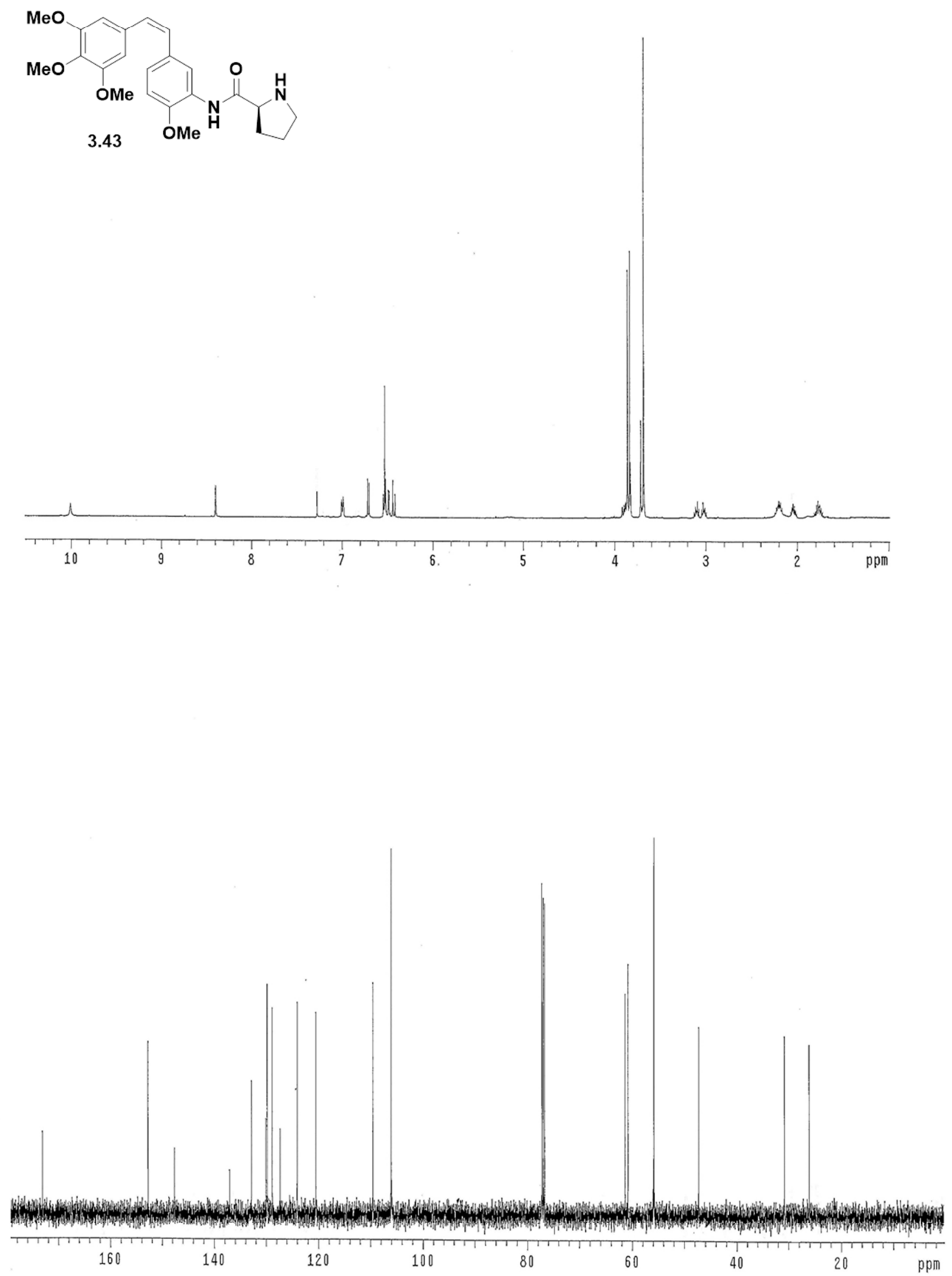

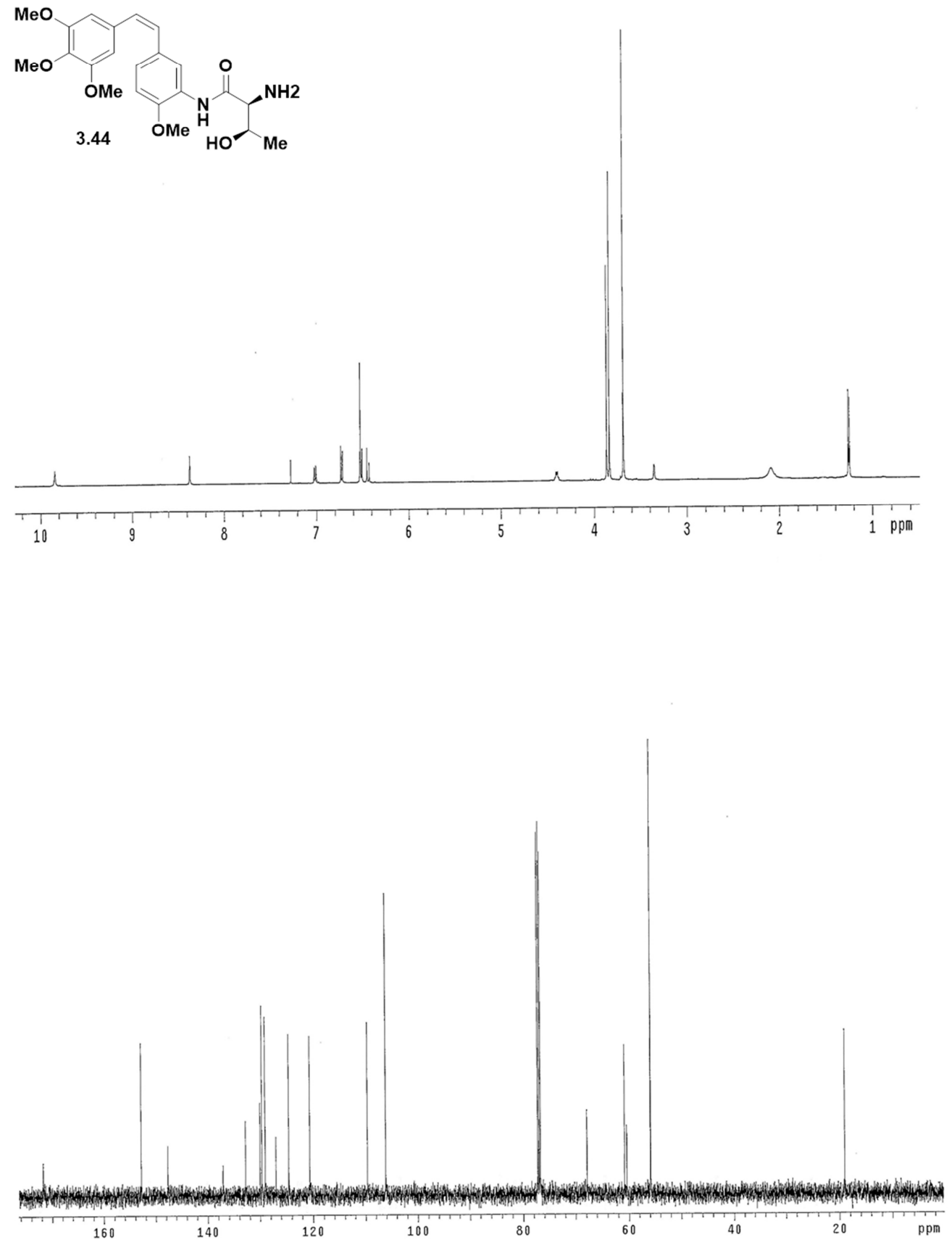

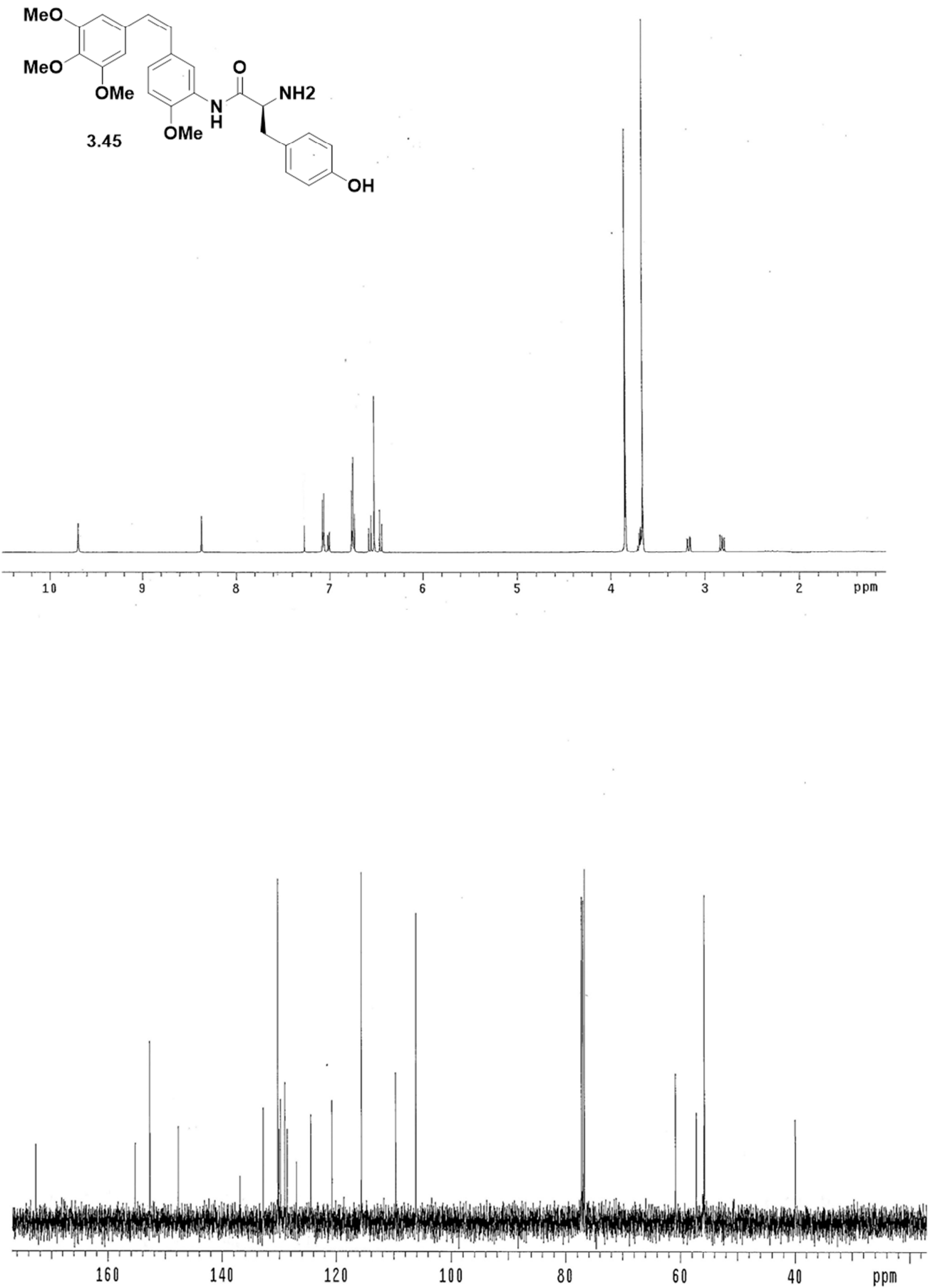

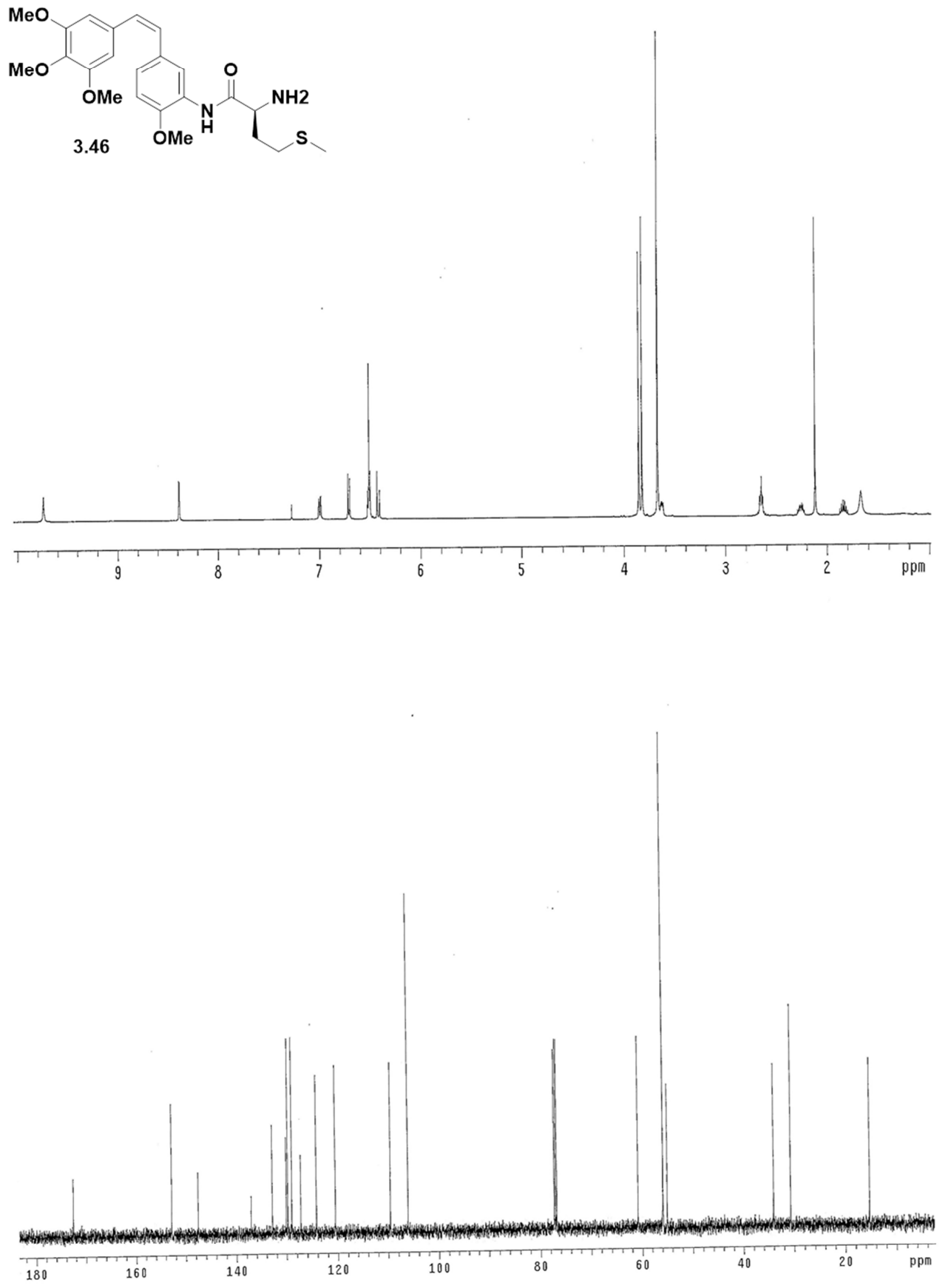

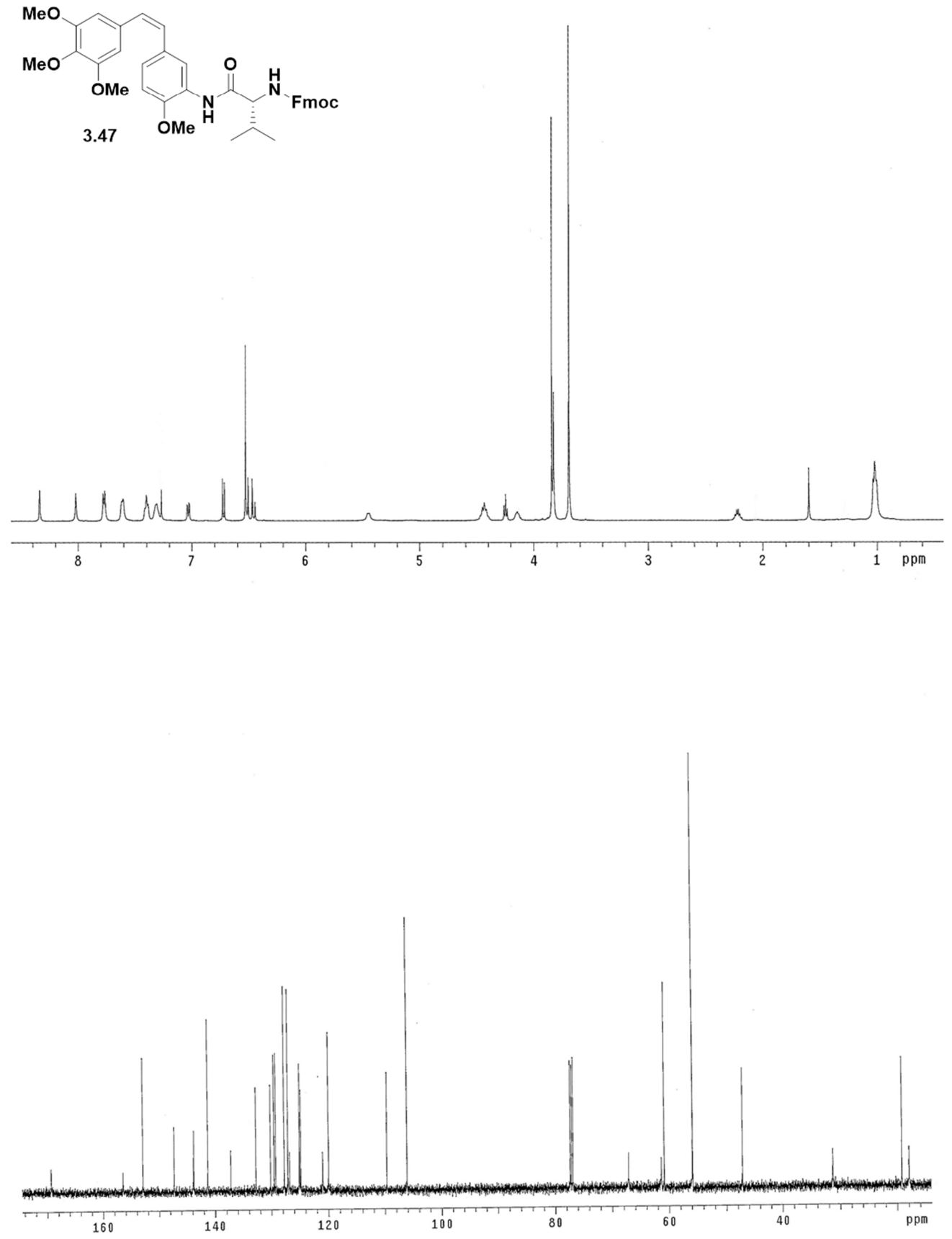

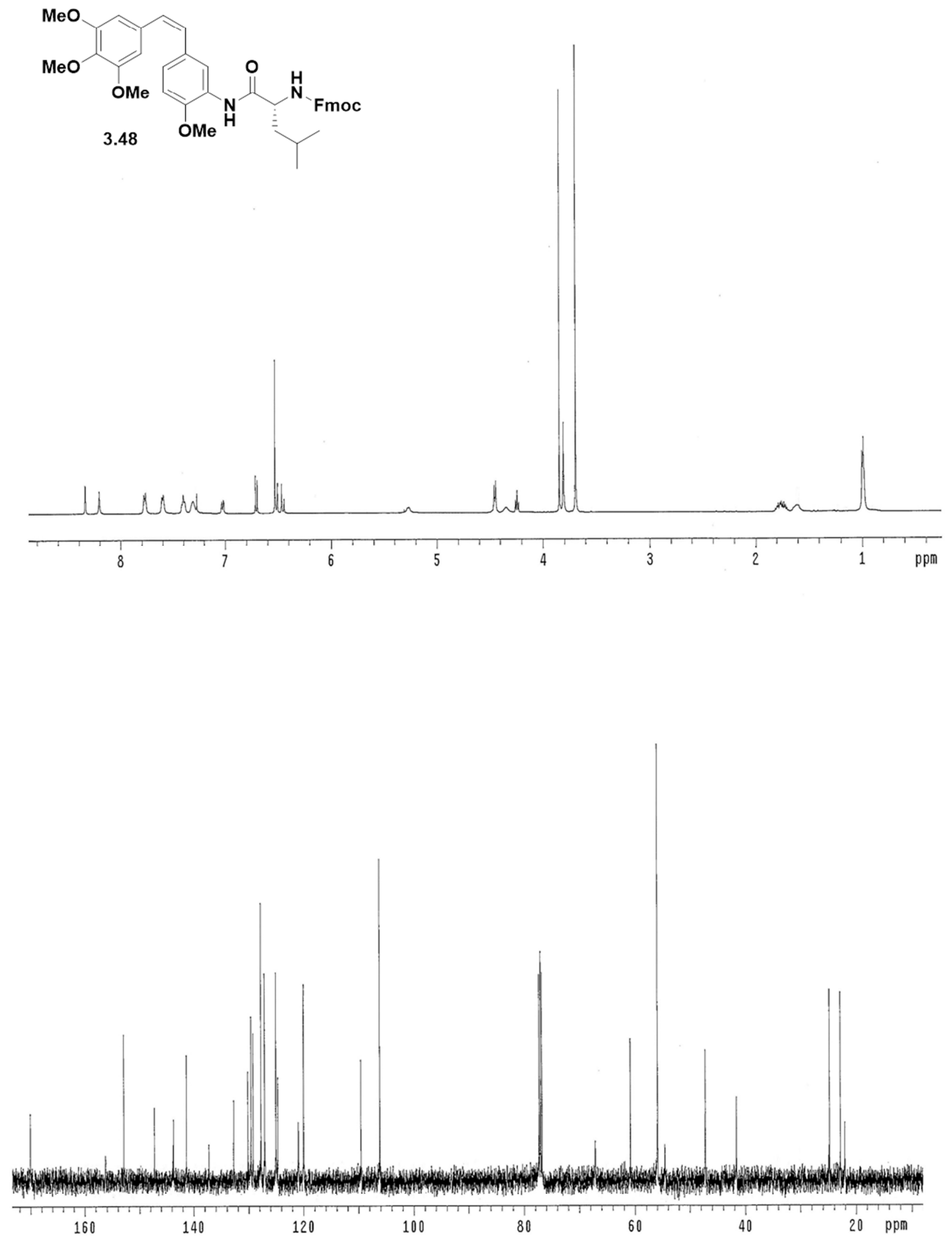

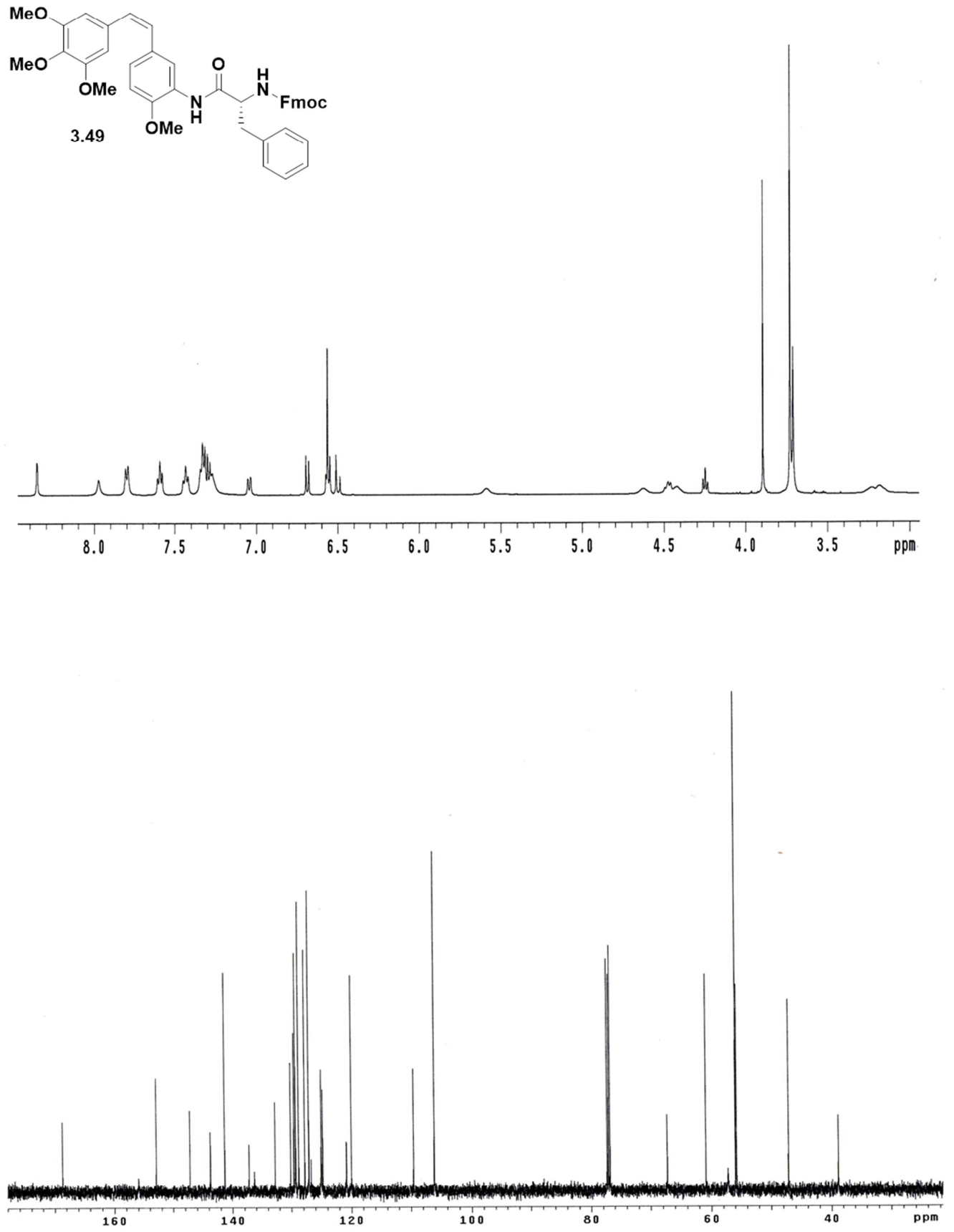

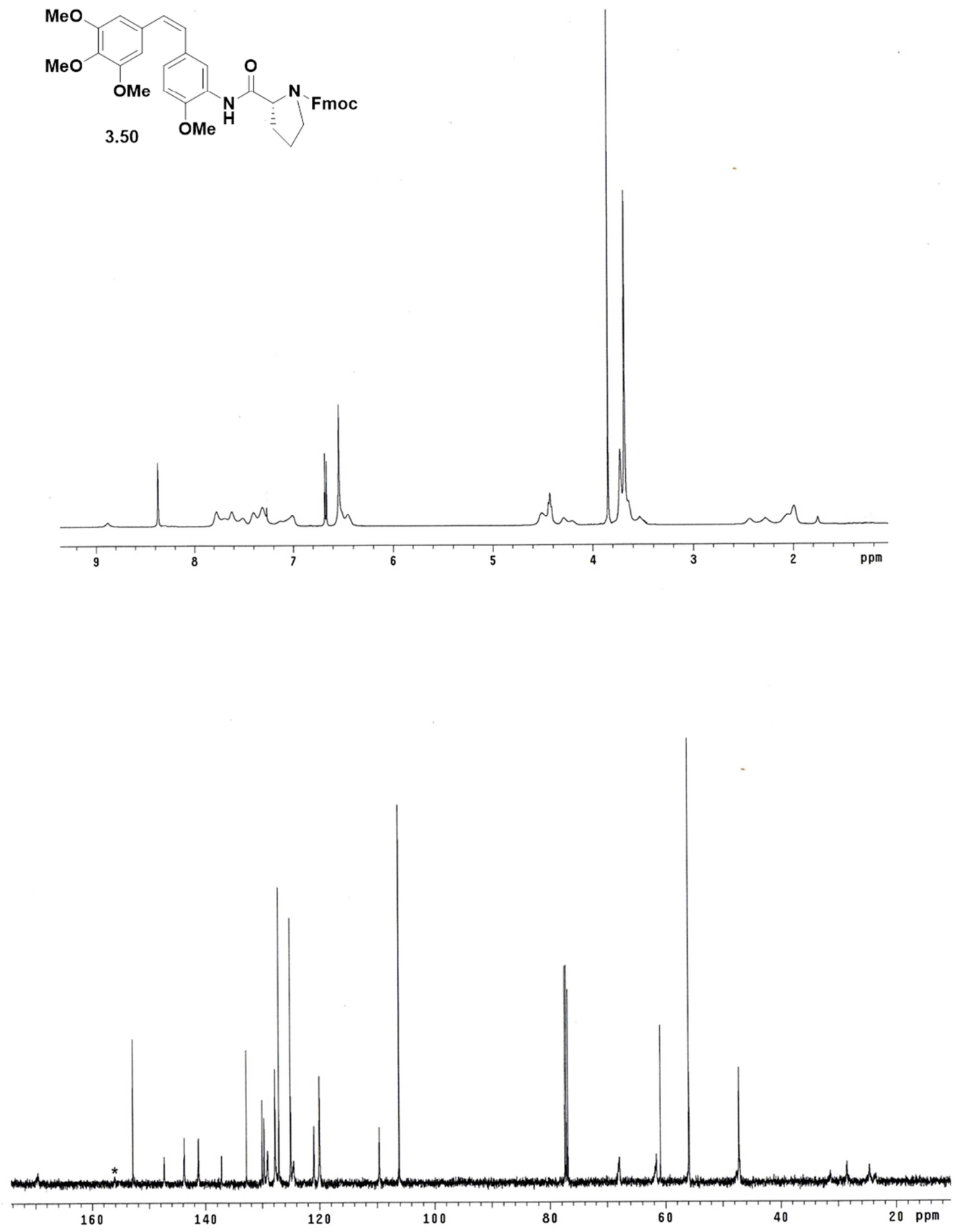
Espectros seleccionados

235
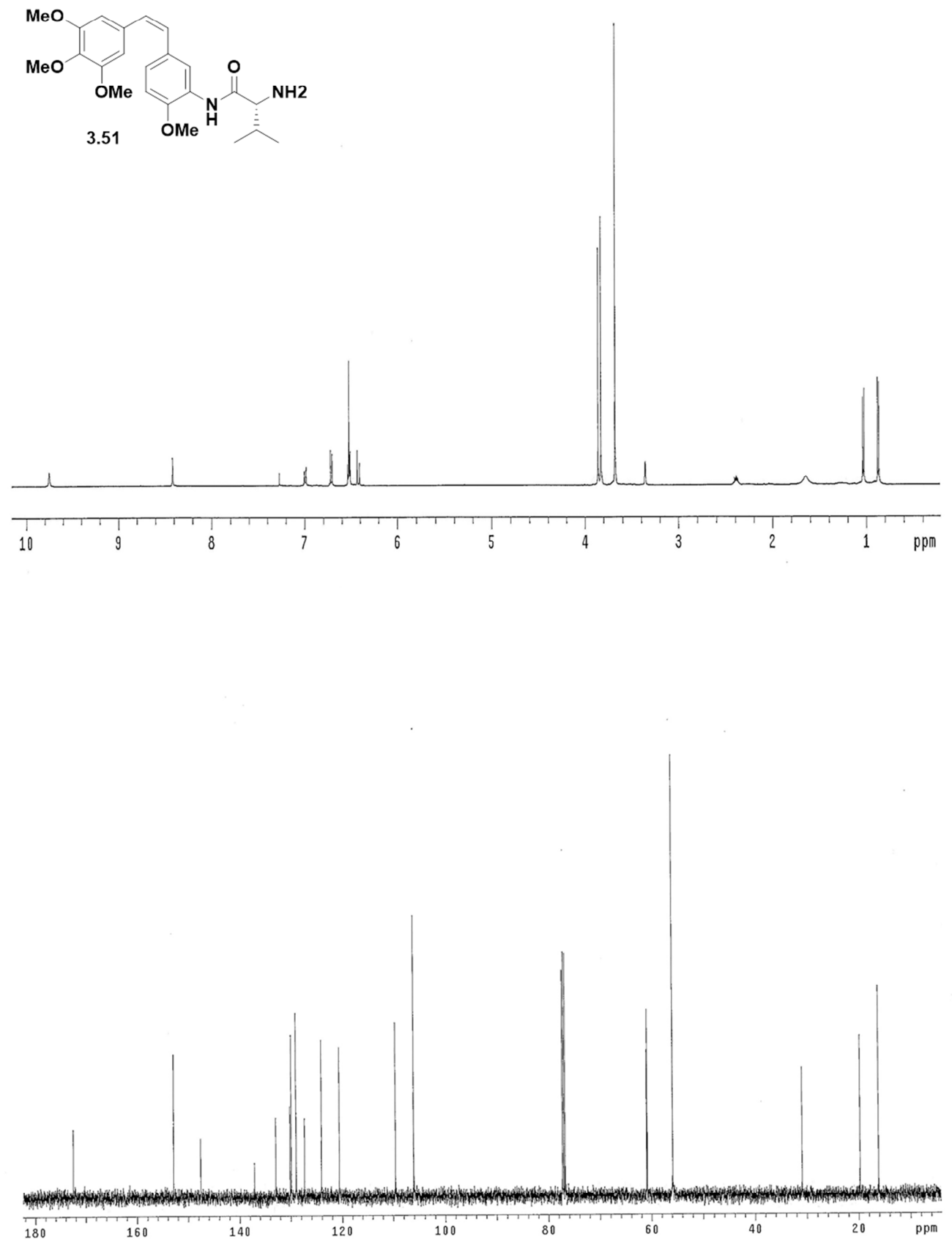

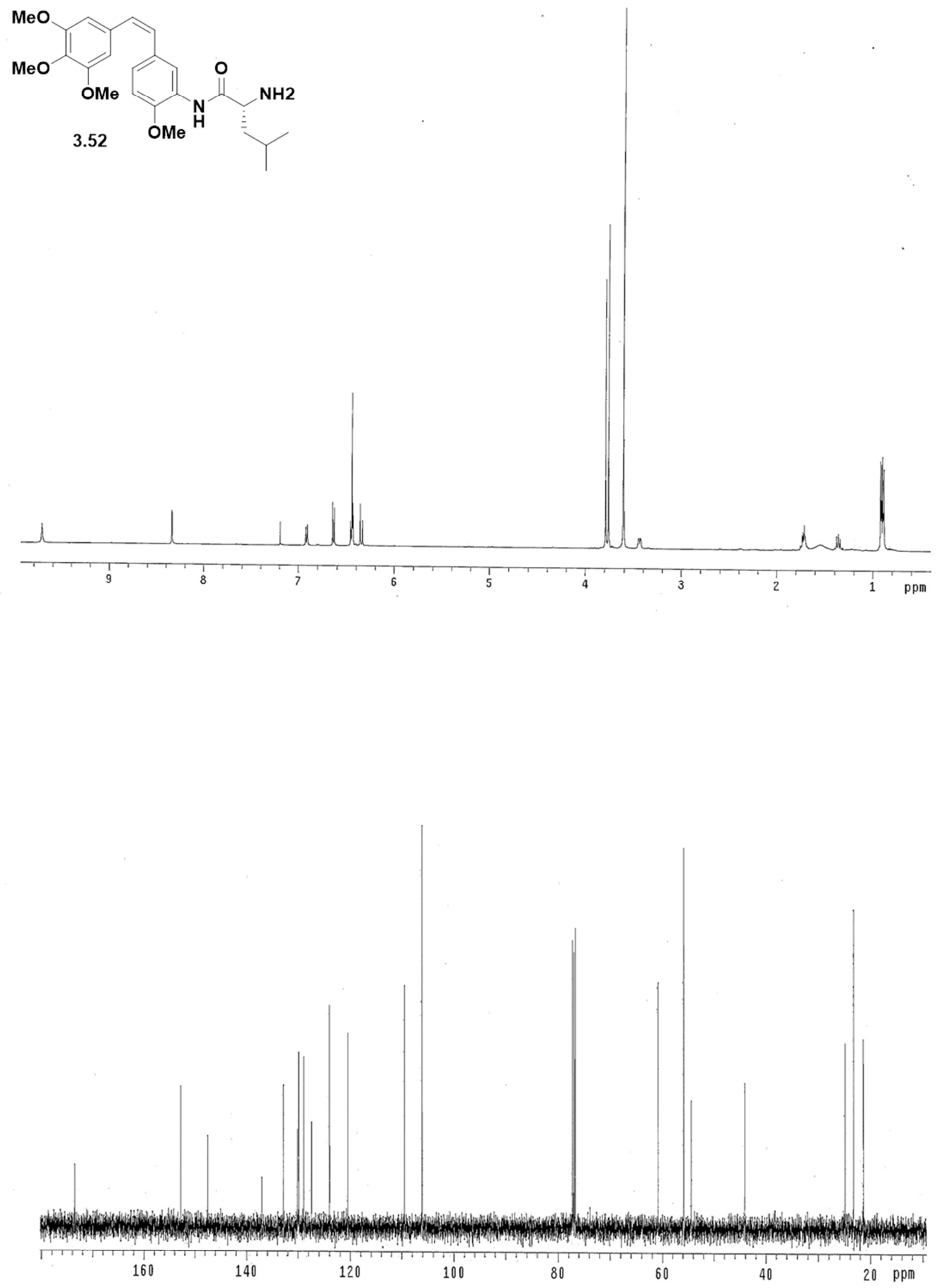

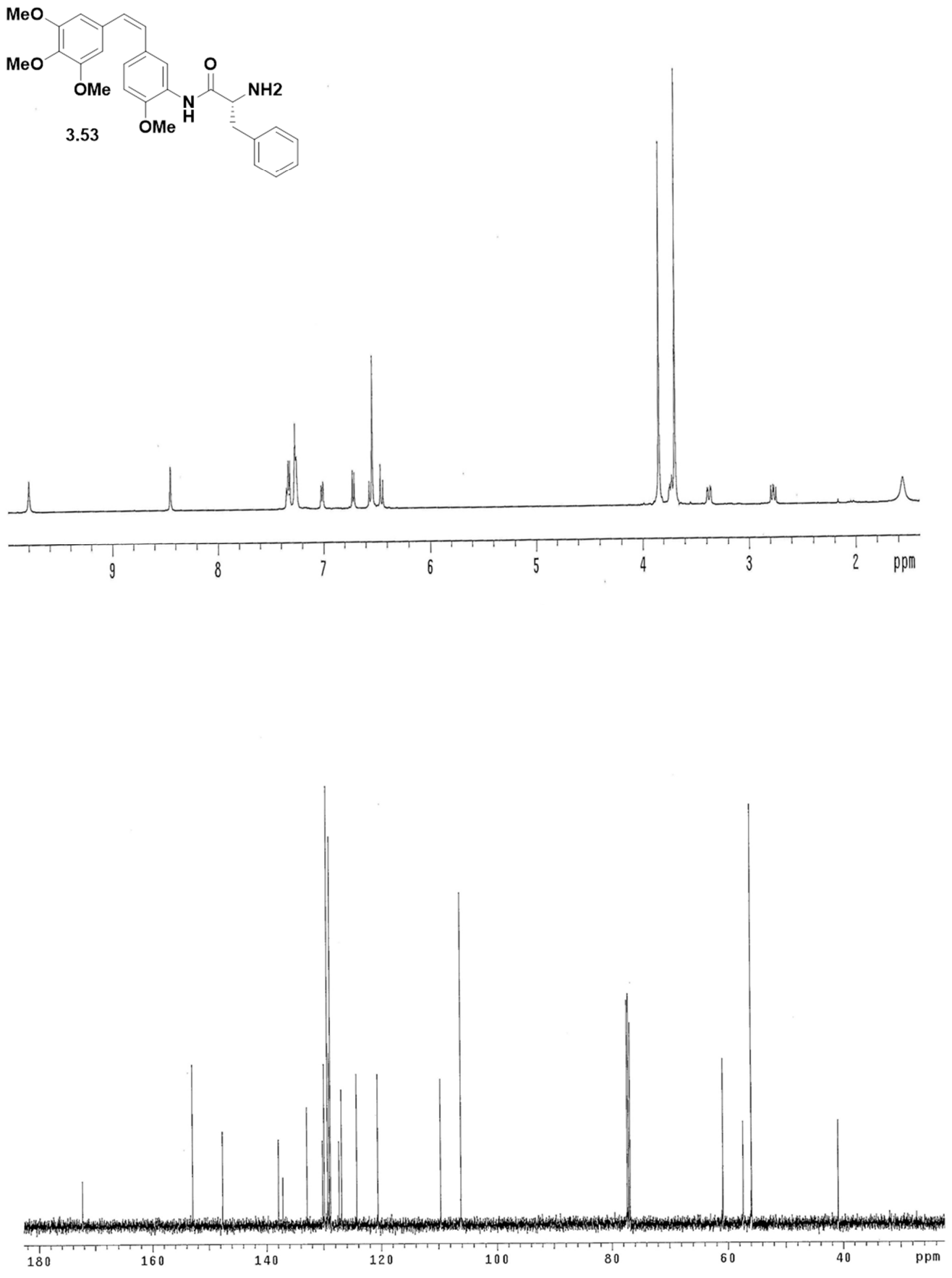

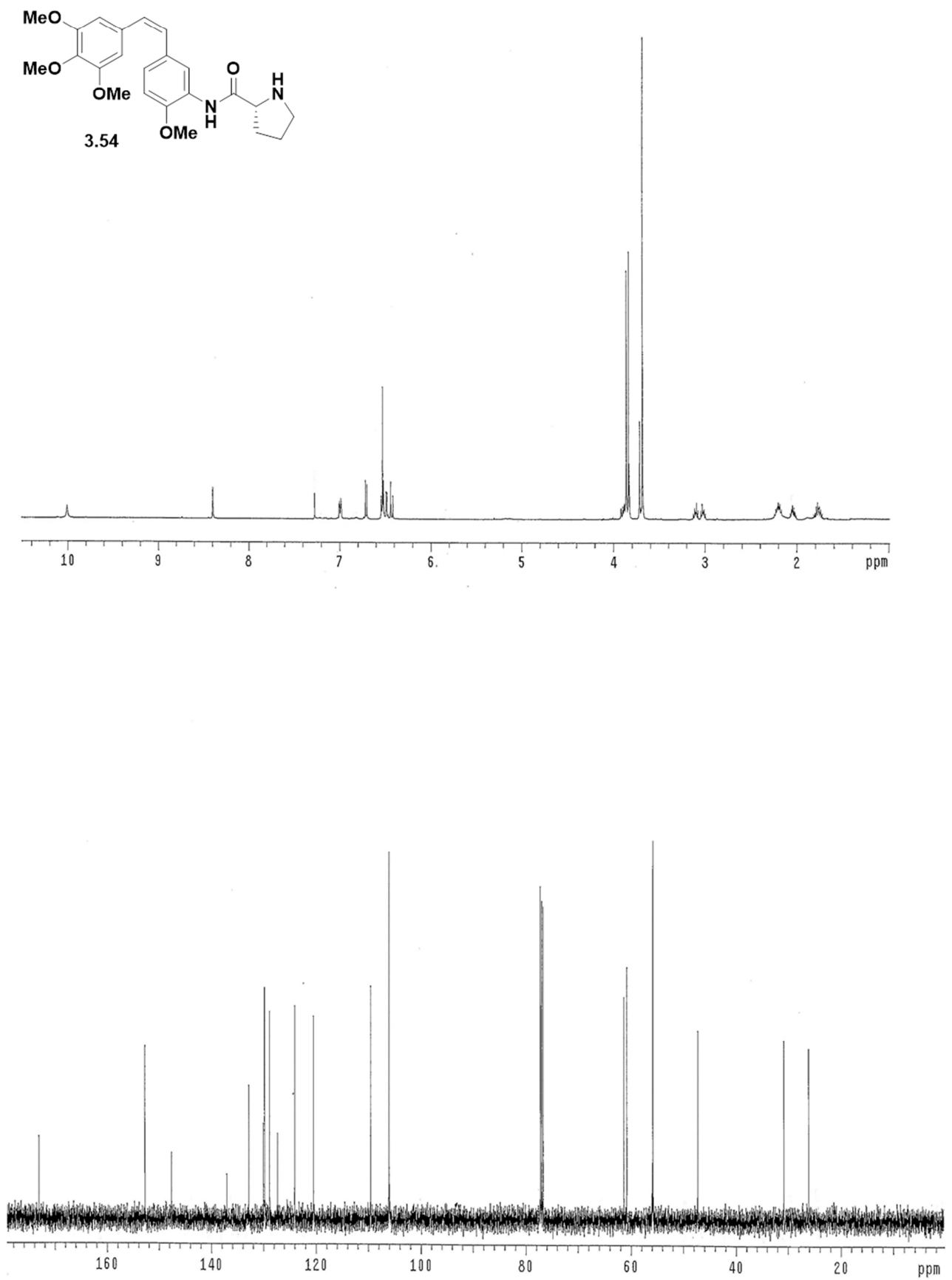

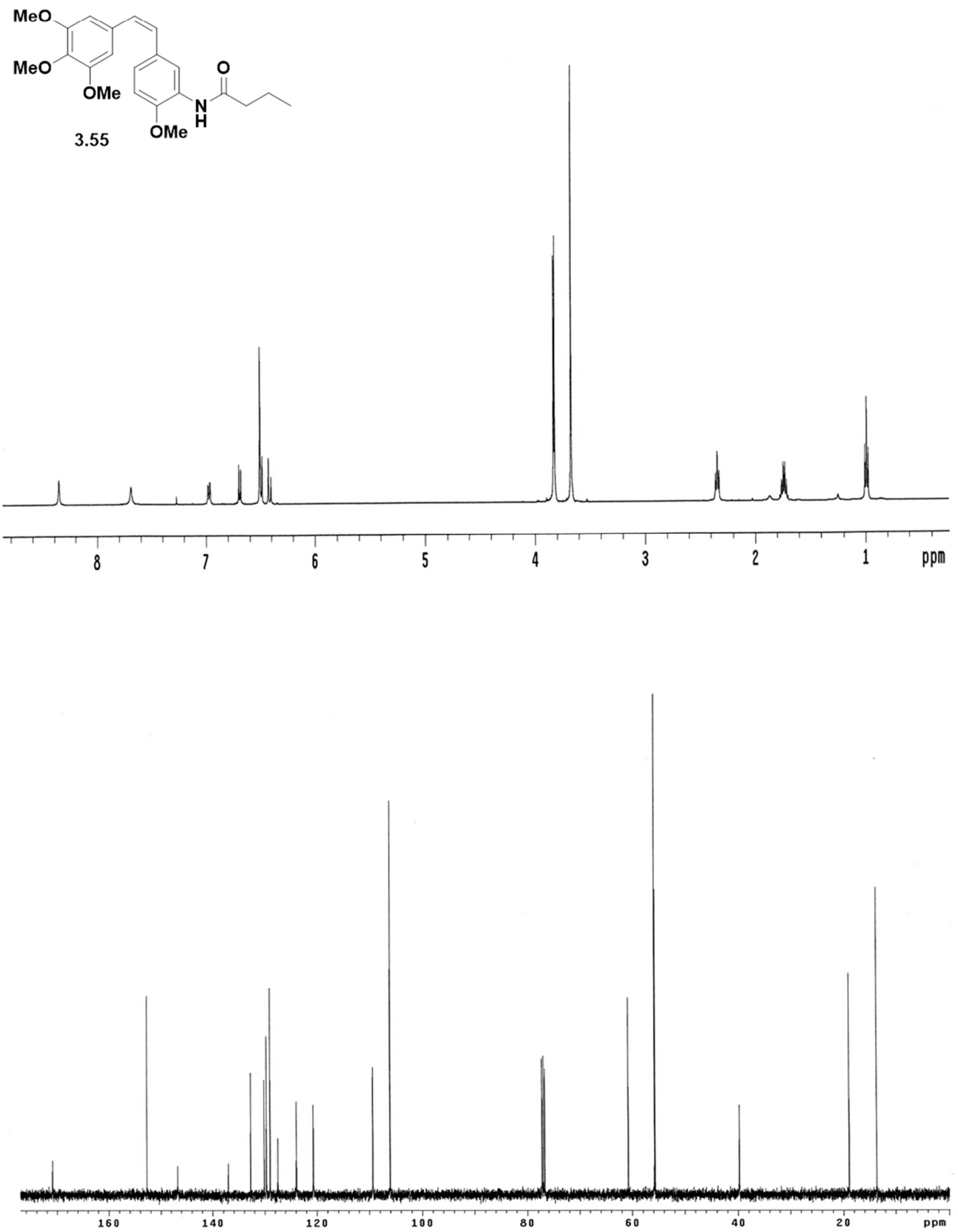

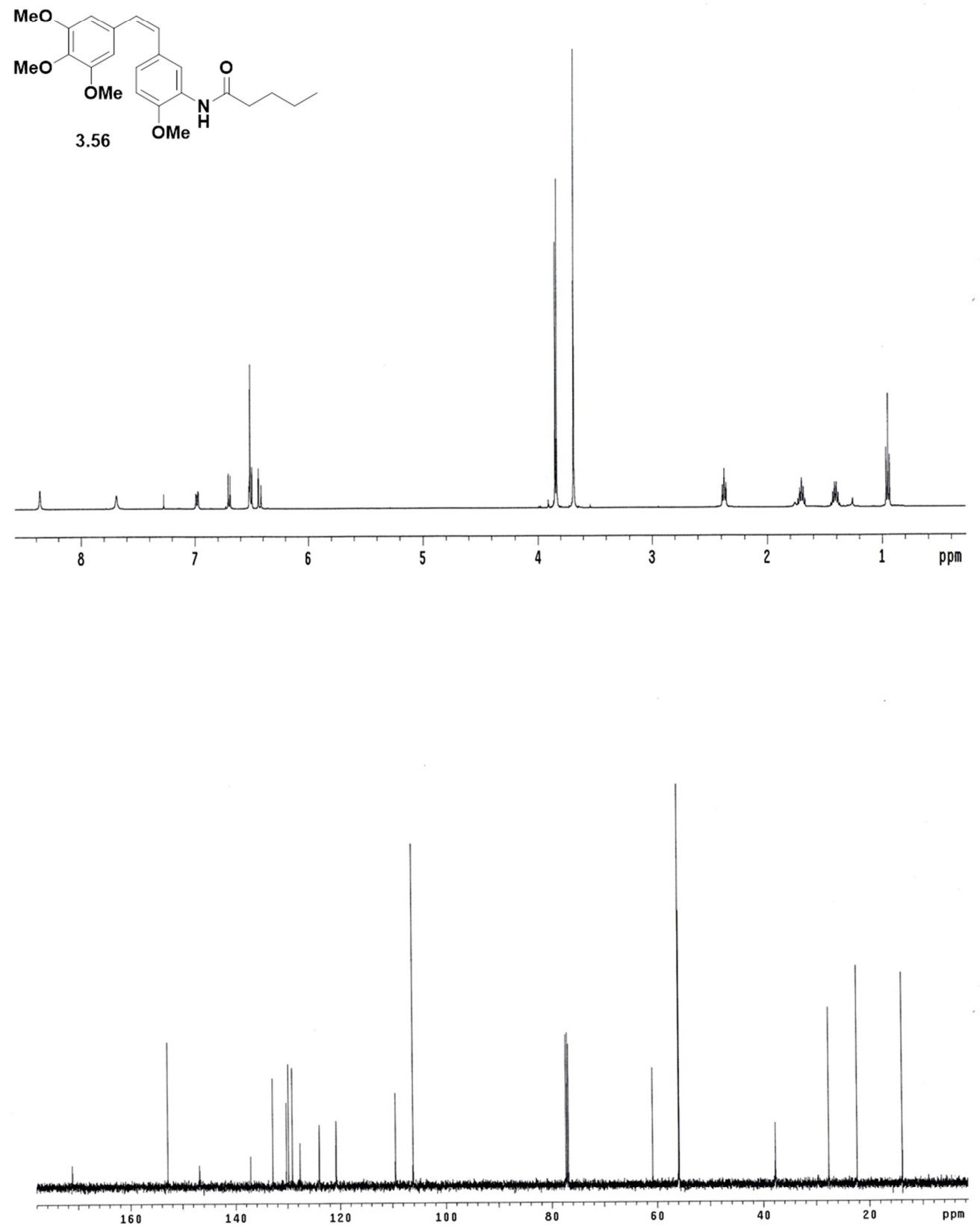

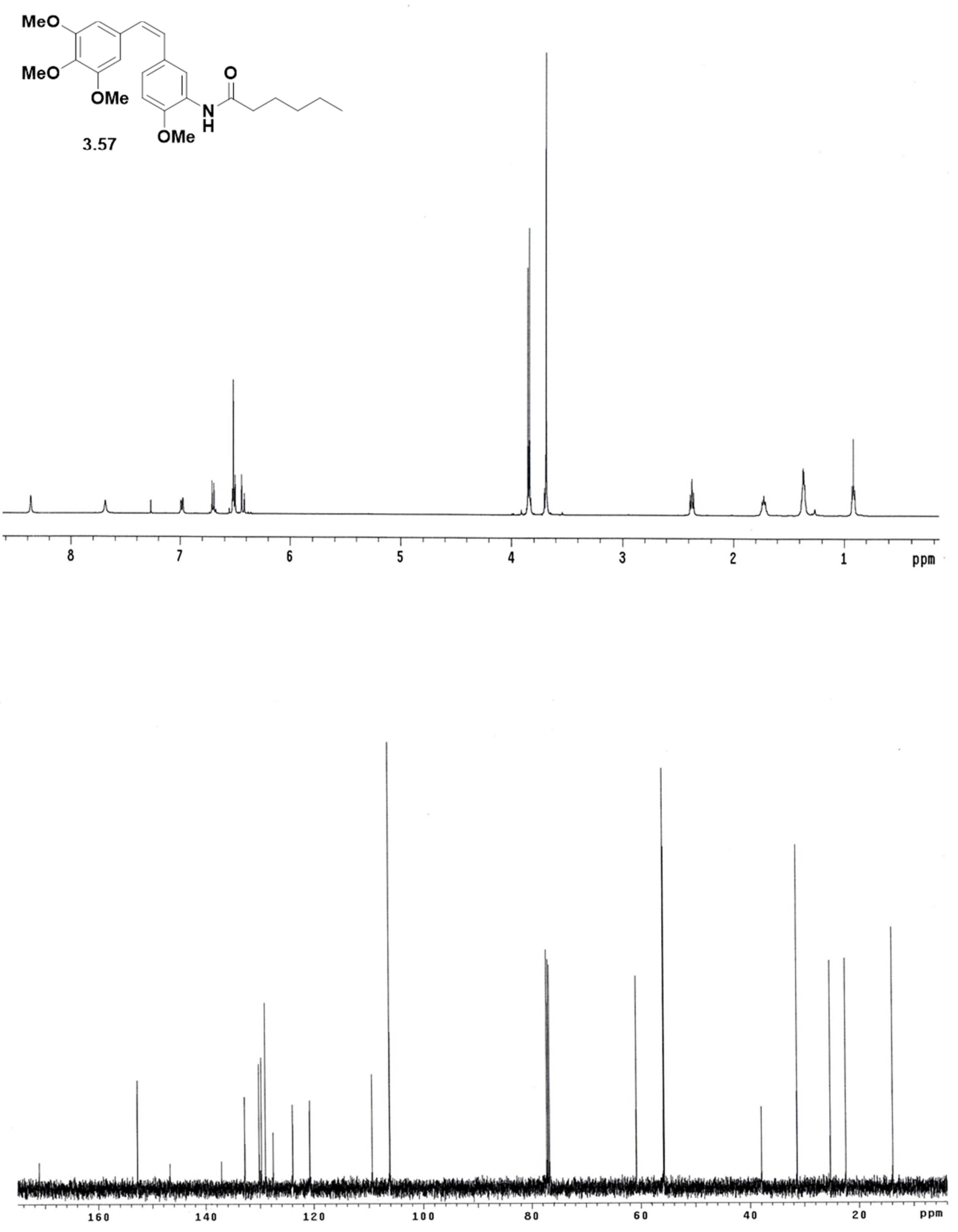

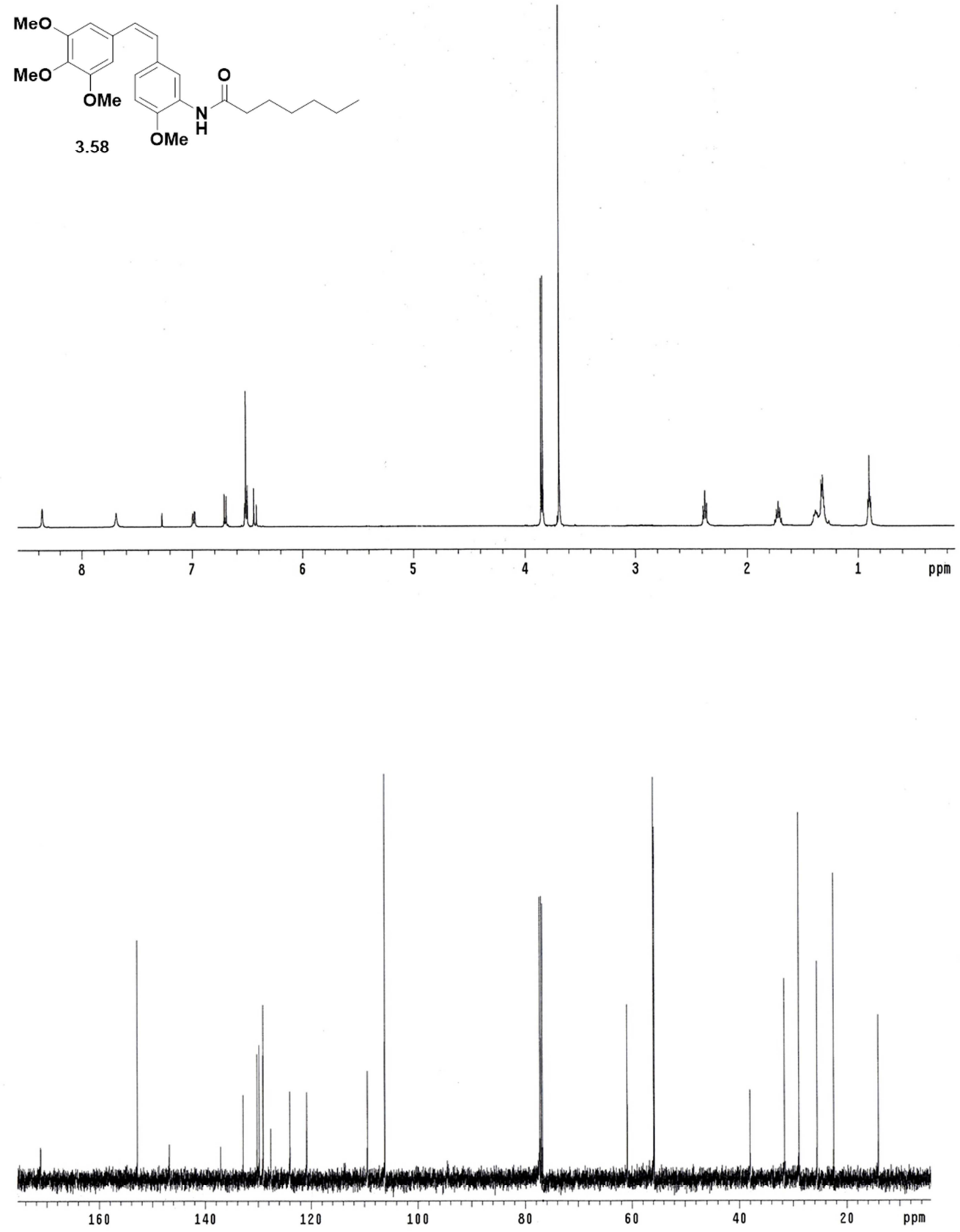

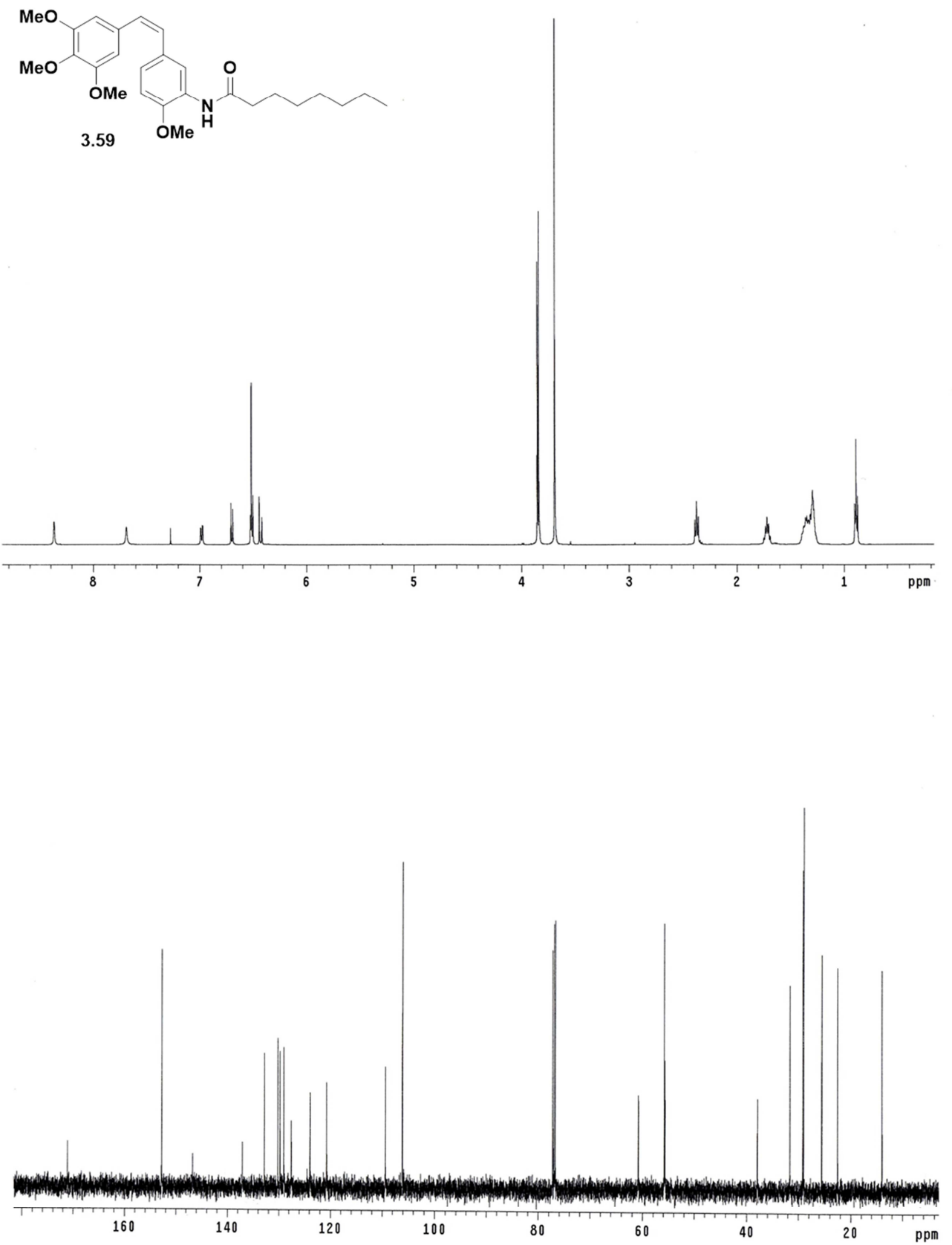

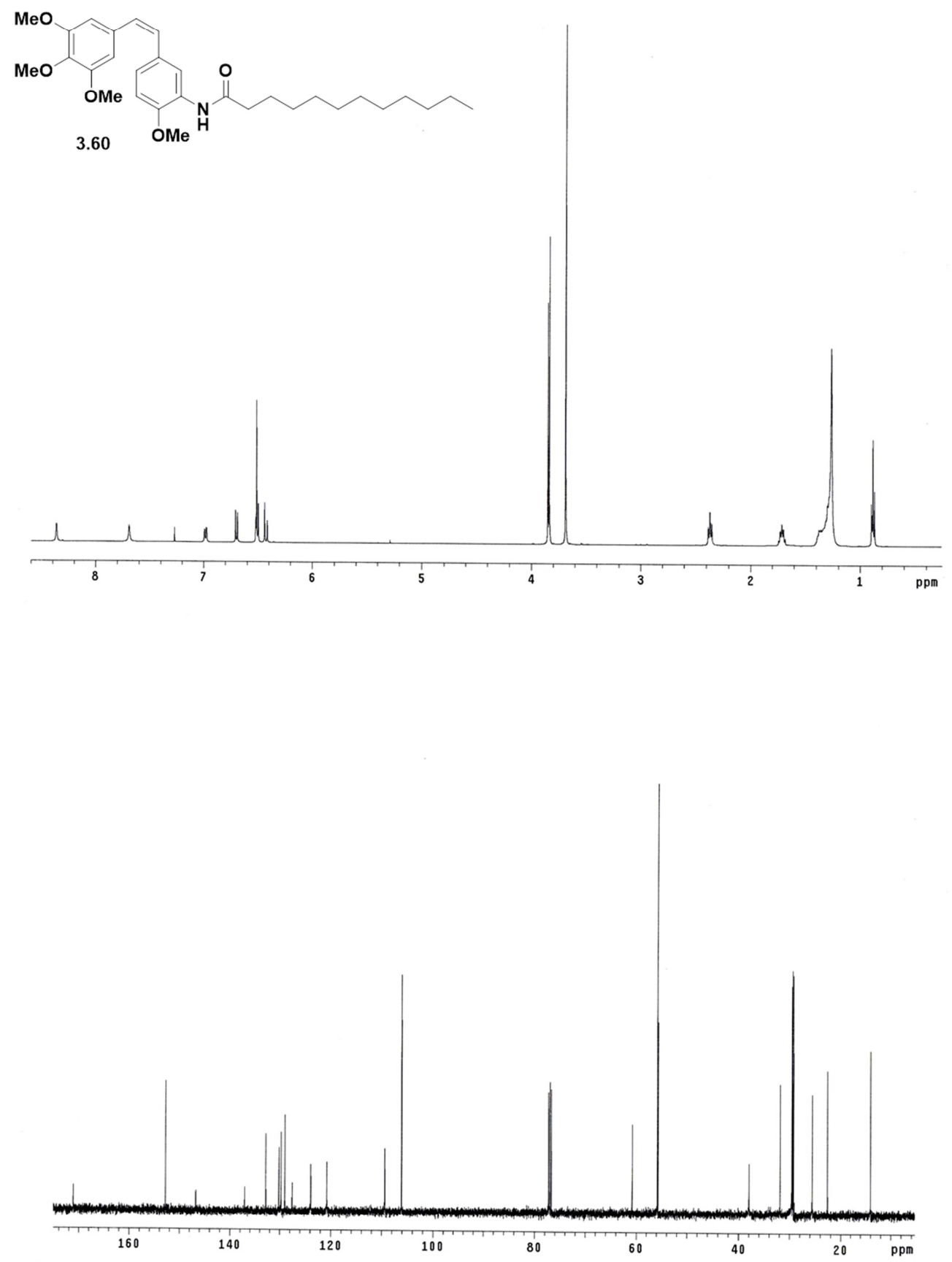
